\title{
Functional hybrid materials for the optical recognition of nitroaromatic explosives involving supramolecular interactions
}

YOLANDA SALINAS SOLER 



\title{
UNIVERSITAT POLITÈCNICA DE VALÈNCIA
}

\author{
DEPARTAMENTO DE QUÍMICA \\ CENTRO DE RECONOCIMIENTO MOLECULAR \\ Y DESARROLLO TECNOLÓGICO
}

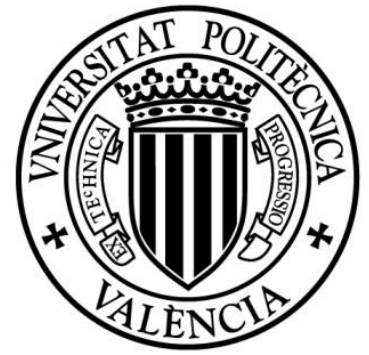

Functional hybrid materials for the optical recognition of nitroaromatic explosives involving supramolecular interactions

\author{
PhD. THESIS \\ Submitted by \\ Yolanda Salinas Soler \\ PhD. Supervisors: \\ Prof. Ramón Martínez Máñez \\ Dr. Félix Sancenón Galarza
}

Valencia, July 2013 
First Edition, 2013

(c) Yolanda Salinas Soler

(C) of the present edition:

Editorial Universitat Politècnica de València www.lalibreria.upv.es

ISBN: 978-84-9048-132-5 (printed version)

Publishing reference: 5661

Any unauthorized copying, distribution, marketing, editing, and in general any other exploitation, for whatever reason, of this piece of work or any part thereof, is strictly prohibited without the authors' expressed and written permission. 

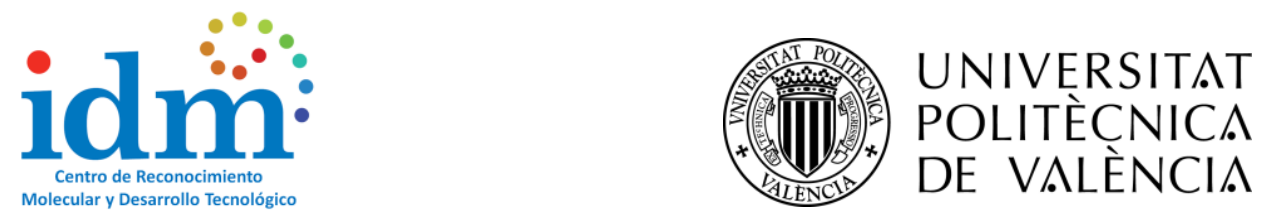

RAMÓN MARTÍNEZ MÁÑEZ, PhD in Chemistry and Professor at the Universitat Politècnica de València, and FÉLIX SANCENÓN GALARZA, PhD in Chemistry and Lecturer at the Universitat Politècnica de València.

\section{CERTIFY:}

That the work "Functional hybrid materials for the optical recognition of nitroaromatic explosives involving supramolecular interactions" has been developed by Yolanda Salinas Soler under their supervision in the Centro de Reconocimiento Molecular y Desarrollo Tecnológico (IDM) of the Universitat Politècnica de València, as a Thesis Project in order to obtain the degree of PhD in Chemistry at the Universitat Politècnica de València.

Valencia, $26^{\text {th }}$ July 2013. 

Dedicada a todos los que me quieren y me han apoyada de corazán durante este larga camina. especialmente a mi familia y a ti Sequnda. 

"Las cosas simples son las más extraordinarias y sólo los sabios consiguen verlas" "fólo una cosa vuelve un suer̃o imposible: el miedo a fracasar" El alquimista de Paulo Coelho 



\section{Acknowledgements}

\section{Agradecimientos}

Tada histaria tiene un final, pera cama camienza es mucha más divertida. Un día de finales de Septiembre del 2008, un anuncia del OSAL me llamá la atencián, y fui a visitar un instituta, en aquel entances llamada $\mathcal{J Q M}$ A, par el pali, dande siempre me perdía. Llegué y Jasé Vicente me entrevistá. Enseguida me presentá a Ramán, directar del Instituta. Ya aún na salía que quería hacer en la vida...pera $\mathcal{H V}$ me dija: iEl lunes empiezas! Y alli me ves can cara de asambra, embarcándame en el munda de la investigacián. En cuanta llegué, me recilieran las chicas can las brazas abiertas. Alli estalean: Elena, Carmen, Andrea, Estela, Cris, Jati, Jnma Candel, Inma Campas, Merche...y cama na, el rey del gallinera Santi. Oi un acenta culana que salia de la pecera...y canací a Hanai., (icuantos pasas de salsa me has de enseñar!). Entances canaci a Félix, y supe que él seria mi directar, junta a Ramán. La vida del lale camenzalea para mí, y aunque na me puse la lata hasta Naviembre (día que marcá expectación), me canacian par la de las "pallas", ya que fue mi primer prayecta aquí.

Las casas empezalean a salir, pera las cursas del DEA me pillaran entre medias, y hacia Barcelana que nas fuimas las Inmas y ya. Fue una experiencia digna de recardar, na sála par la que aprendimas, sina, sabre tada par la cara que se nas quedá al ver a las niñas salir del metra de Barcelana (ite acuerdas Campitas?) y imenuda finde que pasamas!.

La vida en el lale cantinualea y en media de este caas de pallas y langas, llegá la hara de decidir el tema principal de mi tesis: $\mathcal{L O S} E \mathcal{E} \mathcal{L O S} \mathcal{J} V \mathcal{O} S$. Las sensares entralean en mi munda, me empezá a interesar intensamente la nanaciencia y su aplicación (días de llaura inaluidables jeje). Na siempre tada fue radada, hubieran mamentas felices pera también de nervias (sabre tada esperanda la resalucián de las lecas $F \mathcal{F}$ ). Ya en el verana del 2009 empezá par fin mi leca de dactarada que me llevaría a seguir can las investigacianes hasta el día de hay. En el lalearataria cada día la familia ilea crecienda más y más. En Marza de 2009, una nueva adquisicián llegalea can su alegría...mi Mary. La palere se asustá al llegar, na salía dande se 
metía. Pera pranta se diá cuenta que nuestra familia era grande pera a la vez rica en calidad humana. Santi el pabre se fue pronta....decidiá buscarse un nueva hagar en Burjassat, dande conaciá a su amar Andrea Barlea. Qué luena pareja, aunque inimaginable por nadie. Y muchas más auenturas me esperalean...

Par ella, ícama dar gracias par tadas estas añas? Más que un dactarada, he ganada una familia. En primer lugar quiera agradecer de tada carazán a mis directares de Tesis. A Ramán Martínez, mi más sincera agradecimienta par dejarme farmar parte de este gran grupa investigadar, par descubrir en mi vida que la investigación es un campa digna de admirar y explarar, aprendienda cada día, enfrentándame a prablemas, encantranda salucianes y experimentanda técnicas nuevas. Sála un gran jefe hace de su grupa un gran grupa. A Félix Sancenán, cuya experiencia investigadara y capacidad de trabaja es increible. Que mejar maestra que aquel que hace de su enseñanza, su pasián, pera sin aluidar su gran amistad y ayuda incandicianal en cada mamenta. Mamentas inaluidales de risas, dudas, preguntas de química sin resaluer, cacas en el Bacha...par tada ella, na hay manera de agradecerte tadas estas añas de amistad y de cariña. A Jasé Vicente y Jasé Luis, que gran equipa de alimentas hemas farmada eh...haléis sida muy luenas campañeras, y siempre can luenas cansejas que regalarme. Gracias Lales, parque haces de la ciencia de las materiales una ciencia de gran calidad, y tú dulzura cama si fueras nuestra mami, hace de ti una excelente jefa. A Juan, cuanta has de enseñarme de electránica, nadie salee tanta de narices y lenguas...y que luena persana también. $a$ Luis Villaescusa, par esas canciertazas can sála de trampeta en el 2.6, y par su experiencia en resaluer dudas peliagudas. iMUCFAS gRaeJas!

Par supuesta, igracias chicas! Andrea, parque enseguida me integraste en el grupa, y nas hicimas inseparables. Un apaya tanta fuera cama dentra del lab, la hermana mayar que nunca twue. Esteleta, la perla del lab, eres una máquina, y sabre tada estupenda, cuanta me has enseñada...na cambies nunca! Tati, que laca estás! la hippy un paca punk...ja, cuanda te fuiste dejaste un vacia enarme, pera ves, tada llega en la vida, dentra de nada, dactara. Cris Sanfeliu, parque can tu alegría gatuna y luen carazán, siempre me has hecha sanreír, mi pequeña diseñadara. Inma Candel, cama aluidar esas "candeladas", jajajaja, que luena eres, nadie me hace reír tanta, ihasta can chistes malas! Maria, can tu arden y calma nas encandilaste, 
un alma pura y llena de dulzura que nas enamará. Sé que vas a llegar muy alta, parque tú vales mucha mi niña, créeme! Sais mis pequeñanas para siempre, par muy grandes que nas hagamas. Inma Campas, parque tu "me alurra" y las "patas" siempre me recardarán a $t$, par na decir ese viaje a Capenhague y muchas atras awenturas inaluidalles. Merche, sales que sin ti na sabria hacer un filtra de pliegues, y siempre te la recuerda. A mis mamis: Elena, flareta, parque tu saber estar es de admirar y tus grandes cansejas siempre me ayudan a mejarar en tada en la vida, na sála en la química; a Carmen, par tu gran paciencia y experiencia en el lab; y par supuesta a Rasa, par su risa contagiasa y su handad. iGracias amares! A las chicas: a Édgar, el peque de la casa pera can un gran carazán, siempre afrecienda su mana y ayudanda en tada, nadie me saca una sanrisa cama tú; a Santi, parque eres un crack en argánica; a Hanai, par su ritma culana y sabrasura; a Pauel y Carlas, quienes parecian Ramanes y finalmente llegaran a serla....iGracias chicas!

A tadas las nuevas, que ya na sais para nada nuevas, pera que sienda las peques del lab, a las que estáis par aquí y a las que habéis dejada una gran huella, se as quiere cama si hulierais farmada parte de mi vida siempre. Alessandra, par tu gran ayuda en síntesis argánica, eres un máquina! A Núria, María Sapiña, Cris G., Marian, Maria Raga, Cris de la Tarre, Laura, Lluis, Mar, Caral, Rafa, M. Carmen y par supuesta Michele, unestra simpatía y alegría es cantagiasa, y las cenitas na hulieran sida la misma sin vasatras. Esas electránicas Ramán, Jasé Manuel, Raberta y Cristian, gracias par tadas las luenas mamentas y ayuda incandicianal, sabre tada par su paciencia y dedicación en la partada, imuchísimas gracias Jasé, eres estupenda!. También a Nica, cuyas cantas nauideñas alegralean cada camida del grupa. A las niñas nuevas, Cris $\mathcal{M}$., Ángela y Ana, ya sé que llegareis lejas, ánima en esta etapa nueva de unestra vida, de verdad, es muy banita. Luis Enrique, Trishanu y Sameh...que grandes chicas! En vasatras he vista que la amistad cruza tadas las franteras. Y cama na, a mi Patri, íquien nos ilea a decir que ileamas a traleajar juntas en un lalarataria de investigación verdad? Esas días en que na padíamas estar más estresadas can la carrera. El releva del palla la deja en tus manas, jejeje! Quién mejar que tú, amiga meua. La vida nas junta de una manera u atra y ya me alegra un mantán. 
En la planta de alaja también encantré muy luena gente Tania, Jesús, Cristina, Anita, Maria, pera sabre tada Sara y Diana, que han sida un gran descubrimienta en mi vida. Junta a ellas y a "flari" he pasada muchas luenas mamentas de risas y amistad. iSais geniales y nunca as aluidaré! A Dani, Neus, Raúl, Paula, Sergia, Maarthy, Maykel, Mireia, Raherta, Rafa, Herme, David y perdanad si me alvida de alguien, gracias par ayudarme can cada luen canseja, par tadas las luenas mamentas en las camidas y cenas, y par echarme siempre una mana. Fina y Maite, ique grandes profesaras! he aprendida mucha dacencia junta a vasatras, mastrándame siempre unestra enarme calidez cama persanas y educadaras. Teresa, la mejar arganizadara de warkshaps y seminarias, cuanta nas queda par aprender de ti. A Quique, parque las lías de papeleas na serian tan geniales y divertidas sin ti. Y a Inma, Cristina y Chela, gracias par unestra paciencia can tadas mis dudas y prisas en la última etapa de esta tesis. Y cama na, a mis campis y amigas de Burjassat. Tate i Raúl, sau genials, especialmente Andrea, Allerta y Almu parque su desparpaja y cachandea es inigualable, hacienda de cada visita mía una mini fiesta. A las profes Ana, Marga, Bara y Pabla, unestra experiencia y amistad es maravillasa. Gracias par hacerme sentir cama en casa cuanda ilea a weras. I a Pedra Amarás, par su gran experiencia en materiales, de él he aprendida mucha también, quien fue también mi prafe de materiales durante la carrera. Par supuesta, muchas gracias al Instituta Tecnalágica de "La Marañasa” y al Dr. Allerta Pérez de Diega, par facilitarnas sus instalacianes militares, par su enarme experiencia en explasiuas y su gran amabilidad. El viaje a Madrid fue muy interesante y divertida, imuchas gracias Marga!

During my twa $\mathcal{T h D} \mathcal{T}$ hesis stays abraad, $\mathcal{J}$ cauld understand that ewerywhere you ga, if you have an open-mind, you can find awesame calleagues and friends araund the warld. Dr. Jan Oskar Jeppesen, tak for alle, for teaching me your arganic chemistry experience and give me the chance ta join your Danish research graup. Many thanks ta Kent, Karina, Sissel, Relecca, Traels, Mads...during my Odense stay, $\mathfrak{J}$ met wanderful people, pera especialmente mi gran apaya fue Marta, par hacerme sentir cama en casa en un lab extranjera, y parque tu amistad me la demastraste cada día y me la sigues regalanda a día de hay. Esas lailes mañaneras...eres genial amiga mía! Pasita a pasita y dactaras finally! Igne and Egle, hau could $\mathcal{J}$ express my gratitude? Yau shawed me that Lithuanian girls are 
fighter wamen and awesame friends. My stay wauld nat have been the same withaut you bath. Thank you babies! I wauld like ta give my sincerely acknauledgements ta Dr. Tnut Rurack, lecause that amazing oppartunity let me knaw leetter german people and their culture. A part fram great knawledge in chemistry, you showed me your huge science passian, I learnt a lat fram you. Danke schän ta all my calleagues and friends Wei, Mustafa, Tarin, Ashak, Jabias, Daminik, Jeannine, Steffen, Mandy and Delia, wha let me feel as a member of that fabaulaus $\mathcal{B}$ M Ramily. Alsa in Berlin $\mathcal{I}$ faund twa nice friends, Zhenya and Lena, thanks far all that funny maments tagether! $\mathcal{T} \mathscr{H} A \mathcal{N} \mathscr{K} S$ my friends.

Quisiera dedicar esta tesis a tadas las que de alguna manera u atra haléis cantriluida a mi desarralla cama persana. A mis mejares amigas, Jessica y Raquel, sais mi hambra y abriga cuanda nadie más me entiende, y a la vez sais mi alegría, par tadas estas añas que hemas viuida juntas, y par tada la que la amistad significa, gracias par estar ahí siempre, sais el tesara que siempre lusqué. A mi música, parque ella me da paz y serenidad, y en ella pueda inchuir a mis das grandes artistas Ana y M. Jasé, cada ensaya es una auentura que recardad. A M. Carmen, Sara y Fran, esta tesis as la dedica tamlién, grandes amigas cama vasatras san difíciles de encantrar pera impasilles de aluidar.

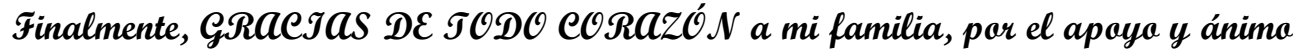
que me han dada para llegar hasta aqui. Parque el cariña de unas padres es impagalele, parque gracias a ellas cumpla cada una de mis sueñas, parque la más grande que tenga en la vida es su amar. Par ellas estay aquí, y a ellas va dedicada tada el esfuerza realizada para llegar a ser la que say hay. A mi hermana Juán y mi cuñada Mara, sé que en la distancia me mandáis siempre fuerzas para seguir adelante can tada, unestras visitas san la mejar del aña. $a$ mis tias M.Carmen y Emilia, par animarme a hacer el dactarada, y a mi prima Vicente, par cada charla sabre temas de investigación. Y finalmente, a Segunda, mi gran amar, cada día que superamas juntas, más fuerte hace nuestra relación. Par esa, y par seguir a mi lada hasta el final de esta etapa, queriéndame y apayándame siempre, iGRaeJaS! iOs quiera mucha!

GRaCJas a $\mathcal{T O D O S}$ par hacer que la investigación ahora farme parte de mi vida. 



\section{Resumen}

La presente tesis doctoral titulada "Materiales funcionales híbridos para el reconocimiento óptico de explosivos nitroaromáticos mediante interacciones supramoleculares" se basa en la combinación de principios de Química Supramolecular y de Ciencia de los Materiales para el diseño y desarrollo de nuevos materiales híbridos orgánico-inorgánicos funcionales capaces de detectar explosivos nitroaromáticos en disolución.

En primer lugar se realizó una búsqueda bibliográfica exhaustiva de todos los sensores ópticos (cromogénicos y fluorogénicos) descritos en la bibliografía y que abarca el período desde 1947 hasta 2011. Los resultados de la búsqueda están reflejados en el capítulo 2 de esta tesis.

El primer material híbrido preparado está basado en la aplicación de la aproximación de los canales iónicos y, para ello, emplea nanopartículas de sílice funcionalizadas con unidades reactivas y unidades coordinantes (ver capítulo 3). Este soporte inorgánico se funcionaliza con tioles (unidad reactiva) y una poliamina lineal (unidad coordinante) y se estudia el transporte de una escuaridina (colorante) a la superficie de la nanopartícula en presencia de diferentes explosivos. En ausencia de explosivos, la escuaridina (color azul y fluorescencia intensa) es capaz de reaccionar con los tioles anclados en la superficie decolorando la disolución. En presencia de explosivos nitroaromáticos se produce la inhibición de la reacción escuaridina-tiol y la suspensión permanece azul. Esta inhibición es debida a la formación de complejos de transferencia de carga entre las poliaminas y los explosivos nitroaromáticos.

En la segunda parte de esta tesis doctoral se han preparado materiales híbridos con cavidades biomiméticas basados en el empleo de MCM-41 como soporte inorgánico mesoporoso (ver capítulo 4). Para ello, se ha procedido al anclaje de tres fluoróforos (pireno, dansilo y fluoresceína) en el interior de los 
poros del soporte inorgánico y, posteriormente, se ha hidrofobado el interior de material mediante la reacción de los silanoles superficiales con 1,1,1,3,3,3hexametildisilazano. Mediante este procedimiento se consiguen cavidades hidrófobas que tienen en su interior los fluoróforos. Estos materiales son fluorescentes cuando se suspenden en acetonitrilo mientras que cuando se añaden explosivos nitroaromáticos a estas suspensiones se observa una desactivación de la emisión muy marcada. Esta desactivación de la emisión es debida a la inclusión de los explosivos nitroaromáticos en la cavidad biomimética y a la interacción de estas moléculas (mediante interacciones de $\pi$-stacking) con el fluoróforo. Una característica importante de estos materiales híbridos sensores es que pueden ser reutilizados después de la extracción del explosivo de las cavidades hidrofóbicas.

En la última parte de esta tesis doctoral se han desarrollado materiales híbridos orgánico-inorgánicos funcionalizados con "puertas moleculares" que han sido empleados también para detectar explosivos nitroaromáticos (ver capítulo 5). Para la preparación de estos materiales también se ha empleado MCM-41 como soporte inorgánico. En primer lugar, los poros del soporte inorgánico se cargan con un colorante/fluoróforo seleccionado. En una segunda etapa, la superficie externa del material cargado se funcionaliza con ciertas moléculas con carácter electrón dador (pireno y ciertos derivados del tetratiafulvaleno). Estas moléculas ricas en electrones forman una monocapa muy densa (debida a las interacciones dipolo-dipolo entre estas especies) alrededor de los poros que inhibe la liberación del colorante. En presencia de explosivos nitroaromáticos se produce la ruptura de la monocapa, debido a interacciones de $\pi$-stacking con las moléculas ricas en electrones, con la consecuencia de una liberación del colorante atrapado en el interior de los poros observándose una respuesta cromo-fluorogénica. 


\section{Resum}

La present tesi doctoral titulada "Materials funcionals híbrids per al reconeixement òptic de explosius nitroaromàtics mediant interaccions supramoleculars" es basa en la combinació dels principis de la Química Supramolecular y de la Ciència del Materials per al disseny y desenvolupament de nous materials híbrids orgànic-inorgànics funcionals capaços de detectar explosius nitroaromàtics en dissolució.

En primer lloc es va realitzar una cerca bibliogràfica exhaustiva de tots els sensors òptics (cromogènics i fluorogènics) descrits en la bibliografia i que abasta el període des de 1947 fins a 2011. Els resultats de la cerca estan reflectits en el capítol 2 d'aquesta tesi.

El primer material híbrid preparat està basat en l'aplicació de l'aproximació dels canals iònics i, per açò, empra nanopartícules de sílice funcionalitzades amb unitats reactives i unitats coordinants (veure capítol 3). Aquest suport inorgànic es funcionalitza amb tiols (unitat reactiva) i una poliamina lineal (unitat coordinant) i s'estudia el transport d'una escuaridina (colorant) a la superfície de la nanopartícula en presència de diferents explosius. En absència d'explosius, la escuaridina (color blau i fluorescència intensa) és capaç de reaccionar amb els tiols ancorats en la superfície descolorint la dissolució. En presència d'explosius nitroaromàtics es produeix la inhibició de la reacció escuaridina-tiol i la suspensió roman blava. Aquesta inhibició és deguda a la formació de complexos de transferència de càrrega entre les poliamines i els explosius nitroaromàtics.

En la segona part d'aquesta tesi doctoral s'han preparat materials híbrids amb cavitats biomimètiques basats en l'ocupació de MCM-41 com a suport inorgànic mesoporós (veure capítol 4). Per a açò s'ha procedit a l'ancoratge de tres fluorófors (piren, dansil i fluoresceïna) a l'interior dels porus del suport inorgànic i, posteriorment, s'hi hidròfoba l'interior de material mitjançant la reacció dels 
silanols superficials amb 1,1,1,3,3,3-hexametildisilazano. Mitjançant aquest procediment s'aconsegueixen cavitats hidròfobes que tenen en el seu interior els fluoròfors. Aquests materials són fluorescents quan se suspenen en acetonitril mentre que quan s'afegeixen explosius nitroaromàtics a aquestes suspensions s'observa una desactivació de l'emissió molt marcada. Aquesta desactivació de l'emissió és deguda a la inclusió dels explosius nitroaromàtics en la cavitat biomimétic i a la interacció d'aquestes molècules (mitjançant interaccions de $\pi$ stacking) amb el fluoròfor. Una característica important d'aquests materials híbrids sensors és que poden ser reutilitzats després de l'extracció de l'explosiu de les cavitats hidrofòbiques.

En l'última part d'aquesta tesi doctoral s'han desenvolupat materials híbrids orgànic-inorgànics funcionalitzats amb "portes moleculars" que han sigut emprats també per a detectar explosius nitroaromàtics (veure capítol 5). Per a la preparació d'aquests materials també s'ha utilitzat MCM-41 com a suport inorgànic. En primer lloc, els porus del suport inorgànic es carreguen amb un colorant/fluoròfor seleccionat. En una segona etapa, la superfície externa del material carregat es funcionalitza amb certes molècules amb caràcter electró dador (piren i certs derivats del tetratiafulvalen). Aquestes molècules riques en electrons formen una monocapa molt densa (deguda a les interacciones dipoldipol entre aquestes espècies) al voltant dels porus que inhibeix l'alliberament del colorant. En presència d'explosius nitroaromàtics es produeix la ruptura de la monocapa, a causa d'interaccions de $\pi$-stacking amb les molècules riques en electrons, amb el conseqüent alliberament del colorant atrapat a l'interior dels porus observant-se una resposta cromo-fluorogènica. 


\section{Abstract}

The present PhD thesis entitled "Functional hybrid materials for the optical recognition of nitroaromatic explosives involving supramolecular interactions" is based in the blending of Supramolecular Chemistry and Material Science principles for the preparation of new functional organic-inorganic hybrid materials with the ability of detecting nitroaromatic explosives in liquid environments.

As a first step a complete and exhaustive search dealing with optical sensors (chromogenic and fluorogenic) explosives described in the literature has been carried out. This search cover examples appeared from 1947 since 2011. The results of this bibliographical search are reflected in chapter 2 of this PhD thesis.

The third chapter deals with the use of the ion-channel sensor approach for the preparation of a hybrid organic-inorganic material for the chromo-fluorogenic sensing of nitroaromatic explosives. At this respect, silica nanoparticles were functionalized with thiols (reactive units) and lineal polyamines (binding units). Then, the transport of a selected dye (squaraine) from the bulky solution to the surface of the silica nanoparticles was studied in the absence and in the presence of selected explosives. In the absence of explosive molecules, squaraine dye (that presented a blue color and an intense emission band) is free to diffuse to the nanoparticle surface. Once in the surface, squaraine reacts with the thiol moieties yielding a colorless non-fluorescent derivative (with the subsequent bleaching of the initial blue solution). When nitroaromatic explosives are present, an inhibition of the squaraine-thiol reaction is produced, and the suspension of the nanoparticles remained blue. This inhibition is ascribed to the formation of charge-transfer complexes between the grafted polyamines and the nitroaromatic explosives.

Hybrid materials equipped with biomimetic cavities based in MCM-41 silica mesoporous support as scaffold have also been prepared (see chapter 4). In order 
to prepare these biomimetic materials, three organic fluorophores (pyrene, dansyl and fluorescein) has been grafted in the inner of the pores of the inorganic support. Then, the inner of the pores were made hydrophobic by the reaction of the silanol moieties (located in the surface) with 1,1,1,3,3,3-hexamethyldisilazane. This two-step procedure yielded hydrophobic cavities containing selected fluorophores. Acetonitrile suspensions of these hydrophobic materials are highly fluorescent whereas addition of nitroaromatic explosives induced marked emission quenching. The observed quenching was ascribed to the inclusion of the nitroaromatic explosives into the biomimetic cavities and subsequent formation of charge transfer complexes (through $\pi$-stacking interactions) with the grafted fluorophore. One important feature of these hybrid sensory materials is their reusability after explosive extraction from the hydrophobic biomimetic cavities.

The last part of this PhD thesis deals with the synthesis and application of hybrid gated organic-inorganic materials for the optical detection of nitroaromatic explosives (see chapter 5). Again, MCM-41 mesoporous silica has been selected as inorganic scaffold. In a first step, the pores of the inorganic scaffold were loaded with a selected dye/fluorophore. Then, in a second step, the external surface of the loaded material was functionalized with selected organic molecules that presented a high electron donor character (such as pyrene and tetrathiafulvalene derivatives). These electron-rich molecules formed a highly dense monolayer (through dipole-dipole interactions) around the pore outlets that inhibit the release of the entrapped dye/fluorophore. Upon addition of nitroaromatic explosives, the monolayer of the electron-rich molecules is disrupted (due to $\pi$ stacking interactions) with the subsequent release of the entrapped dye/fluorophore to the solution. This release induced a chromo-fluorogenic response that indicated the presence of the nitroaromatic explosive. 


\section{Publications}

Results of this PhD Thesis and other contributions have resulted in the following scientific publications:

- Yolanda Salinas, Estela Climent, Ramón Martínez-Máñez, Félix Sancenón, M. Dolores Marcos, Juan Soto, Ana M. Costero, Salvador Gil, Margarita Parra and Alberto Pérez de Diego, "Highly selective and sensitive chromofluorogenic detection of the Tetryl explosive using functional silica nanoparticles", Chem. Commun., 2011, 47, 11885-11887.

- Yolanda Salinas, Ramón Martínez-Máñez, María D. Marcos, Félix Sancenón, Ana M. Costero, Margarita Parra and Salvador Gil, "Optical chemosensors and reagents to detect explosives", Chem. Soc. Rev., 2012, 41, 1261-1296.

- Yolanda Salinas, José V. Ros-Lis, José-L. Vivancos, Ramón MartínezMáñez, M. Dolores Marcos, Susana Aucejo, Nuria Herranz and Inmaculada Lorente, "Monitoring of chicken meat freshness by means of a colorimetric sensor array", Analyst, 2012, 137, 3635-3643.

- Yolanda Salinas, Alessandro Agostini, Édgar Pérez-Esteve, Ramón Martínez-Máñez, Félix Sancenón, M. Dolores Marcos, Juan Soto, Ana M. Costero, Salvador Gil, Margarita Parra and Pedro Amorós, "Fluorogenic detection of Tetryl and TNT explosives using nanoscopic-capped mesoporous hybrid materials", J. Mater. Chem. A., 2013, 1, 3561-3564. 
- Yolanda Salinas, Ramón Martínez-Máñez, Jan O. Jeppesen, Lars H. Petersen, Félix Sancenón, María Dolores Marcos, Juan Soto, Carmen Guillem and Pedro Amorós, "Tetrathiafulvalene-Capped Hybrid Materials for the Optical Detection of Explosives", ACS Appl. Mater. Interfaces, 2013, 5, 1538-1543.

- Krishanu Sarkar, Yolanda Salinas, Inmaculada Campos, Ramón MartínezMáñez, Félix Sancenón and Pedro Amorós; "Organic-inorganic hybrid mesoporous materials as regenerable sensing systems for the recognition of nitroaromatic explosives", Chem.Plus.Chem., 2013, DOI: 10.1002/cplu.201300140.

- Yolanda Salinas, Marta V. Solano, Rebecca E. Sørensen, Karina R. Larsen, Jan O. Jeppesen, Ramón Martínez-Máñez, Félix Sancenón, María Dolores Marcos, Pedro Amorós and Carmen Guillem, "Chromo-fluorogenic detection of nitroaromatic explosives using silica mesoporous supports gated with tetrathiafulvalene derivatives", Chem. Eur. J., 2013, submitted.

- Yolanda Salinas, José V. Ros-Lis, José L. Vivancos, Ramón Martínez-Máñez, M. Dolores Marcos, Susana Aucejo, Nuria Herranz, Inmaculada Lorente and Emilio García; "A novel colorimetric sensor array for monitoring of fresh pork sausages spoilage", Food Control, 2013, accepted.

- Yolanda Salinas, José V. Ros-Lis, José L. Vivancos, Ramón Martínez-Máñez, Susana Aucejo, Nuria Herranz, Inmaculada Lorente and Emilio García; "An optoelectronic nose for boiled marinated turkey freshness monitoring", Sensors and Actuators B, 2013, submitted. 


\section{Abbreviations and Acronyms}

AC

AcAn

$\mathrm{ACrH}^{+}$

$\mathrm{AcrH}_{2}$

$A D P$

APC

ATP

AuNPs

BAm

BET

BJH

$B M I M-P F_{6}$

BP

C1609

C1TPP

$C B P Q T^{4+}$

$C C D$

$C D$

CE

CIAmp

CINB

CTAB

CV

DAN

DCNP

$D C P$

DFP

DFT
Acetyl Chloride

Acetic Anhydride

N-Methylacridinium Fluorophore

10-Methyl-9,10-Dihydroacridine

Adenosine Diphosphate

2,4-Bis-(4-Dialkylaminophenyl)-3-Hydroxy-

4-Alkylsulfanylcyclobut-2-One

Adenosine Triphosphate

Gold Nanoparticles

N-Butylamine

Brunauer, Emmett and Teller model

Barret, Joyner and Halenda model

1-Butyl-3-Methylimidazolium Hexafluorophosphate

Benzoyl Peroxide

5(6)-Carboxyfluorescein-N-Hydroxysuccinimide

Meso-Tri(4-Sulfonatophenyl)Mono(4-Carboxyphenyl) Porphyrin

Cyclobis-(Paraquat-P-Phenylene)

Charge-Couple Device

Cyclodextrine

Capillary Electrophoresis

Chloramphenicol

2-Cloro-Nitrobenzene

Hexadecyltrimethylammonium Bromide

Cyclic Voltammogram

2,3-Diaminonaphthalene

Diethyl Cyanophosphate

Diethyl Chlorophosphate

Diisopropyl fluorophosphate

Density Functional Theory 
DHB

DMF

DMNB

DMSO

DNPD

DS

DTA

1,3-DNB

1,4-DNB

2,4-DCAA

2,4-DNT or DNT

2,6-DNT

EDX

EGDN

EPR

ESIPT

FRET

HEPES

HMDS

HMTD

$H M X$

HPLC

ICS

IMS

lodMet

i- $\mathrm{Pr}_{2} \mathrm{NH}$

$\operatorname{Ir}(p p y)_{3}$

ITO

IUPAC

LD

LDA
2,5-Dihydroxybenzoic Acid

Dimethyl Formamide

2,3-Dimethyl-2,3-Dinitrobutane

Dimethylsulfoxide

1,5-Dioxynaphthalene Derivative

Dimethylsulfate

Dodecyltrimethylammonium Bromide

1,3-Dinitrobenzene

1,4-Dinitrobenzene

2,4-Dichlorophenoxyacetic Acid

2,4-Dinitrotoluene

2,6-Dinitrotoluene

Energy Dispersive X-Ray Spectroscopy

Ethylenglycoldinitrate

Electron Paramagnetic Resonance

Excited-State Intramolecular Proton Transfer

Förster Resonance Energy Transfer

4-(2-Hydroxyethyl)-1-Piperazineethanesulfonic Acid

1,1,1,3,3,3-Hexamethyldisilazane

Hexamethylene Triperoxide Diamine

Octahydro-1,3,5,7-Tetranitro-1,3,5,7-Tetrazocine

High Performance Liquid Chromatography

Ion Channel Sensors

Ion Mobility Spectroscopy

lodomethane

Diisopropylamine

Tris(phenylpyridine)|ridium

Indium Tin Oxide

International Union Of Pure And Applied Chemistry

Laser Diffraction

Lithium Diisopropylamide 
LEDs

$L O D$

LUMO

MB

MCM

MICP

MIP

MLCT

MOF

MPTS

MS-EI

MTO

$\mathrm{MV}^{2+}$

N1TS

N3TS

$\mathrm{NaCNBH}_{3}$

NB

NBD

NE

NG

NM

NMR

NN

NP

NQ

2-NT or NT

3-NT

4-NT

5-NX

NX

PA
Light-Emitting Diodes

Limit Of Detection

Low Unoccupied Molecular Orbital

Methylene Blue

Mobil Composition Of Matter

Molecularly Imprinting Polymers Using Conjugated Polymer

Molecular Imprinting Polymer

Metal-to-Ligand Charge Transfer

Metal-Organic Frameworks

3-Mercaptopropyltrimethoxysilane

Electron Impact Ionization Mass Spectrometry

Methyltrioxorhenium

Methyl Viologen

3-(Aminopropyl)-Triethoxysilane

3-[2-(2-Aminoethylamino)Ethylamino]Propyl-Trimethoxysilane Sodium Cyanoborohydride

Nitrobenzene

Nitrobenzoxadiazole

Nitroethane

Nitroglycerin

Nitromethane

Nuclear Magnetic Resonance

1-Nitronaphthalene

2,4-Dinitrophenol

5-Nitroquinoline

2-Nitrotoluene

3-Nitrotoluene

4-Nitrotoluene

1,3-Dimethyl-5-Nitrobenzene

1,3-Dimethyl-2-Nitrobenzene

Picric Acid 


$\begin{array}{ll}\text { PAMAM } & \text { Poly(Amidoamine) Dendrimers } \\ \text { PCA } & \text { Principal Component Analysis } \\ \left.\text { Pd(PPh }{ }_{3}\right)_{4} & \text { Ethynyltrimethylsilane, Tetrakis(Palladium)Trifenilfosfine } \\ \text { PDDA } & \text { Diallyldimethylammonium Chloride } \\ \text { PDMS } & \text { Poly(Dimethylsiloxane) } \\ \text { PEG } & \text { Poly(Ethyleneglycol) } \\ \text { PET } & \text { Photo-Induced Electron Transfer } \\ \text { PETN } & \text { Pentaerythritol Tetranitrate } \\ \text { PFHI } & \text { Perfluorohexyl lodide } \\ \text { PMMA } & \text { Poly(Methylmetacrylate) } \\ \text { PMOs } & \text { Periodic Mesoporous Organosilicas } \\ \text { PNIPAAm } & \text { N-Isopropylacrylamide Polymer } \\ \text { POD } & \text { Horseradish Peroxidase } \\ \text { PSD } & \text { Pore Size Distributions } \\ \text { PSFF } & \text { Poly(Silafluorene-(9,9-Dimethyl-9H-Fluorene)Divinylene } \\ \text { RDX } & \text { 1,3,5-Trinitro-1,3,5-Triazacyclohexane } \\ \text { RGB } & \text { Red-Green-Blue Coordinates } \\ \text { [Ru(bipy) }{ }_{3}^{2+} & \text { Tris(2,2'bipyridyl)Ruthenium(II) } \\ \text { SAMs } & \text { Self-Assembled Monolayer Surfaces } \\ \text { SBA } & \text { Santa Barbara Amorphous material } \\ \text { SDA } & \text { Structure-Directing Agent } \\ \text { SDS } & \text { Sodium Dodecyl Sulfate } \\ \text { SDTA } & \text { Simultaneous Differential Thermal Analysis } \\ \text { SEM } & \text { Scanning Electron Microscopy } \\ \text { SERS } & \text { Surface Enhanced Raman Spectroscopy } \\ \text { SOMO } & \text { Singlet Singly Occupied Excited Donor Molecular Orbital } \\ \text { SP } & \text { Sodium Perborate } \\ \text { SPE } & \text { Solid Phase Extraction } \\ \text { SQ } & \text { Squaraine Dye } \\ \text { STS } & \text { TAm }\end{array}$


TATP

TBAF

$t-B O C$

$\mathrm{TEAH}_{3}$

TEM

TEOS

Tetryl

TGA

THF

TLCT

TMOS

TNB

TNG

TNT

TTF

UV

UVM

VOC

XRD or PXRD

$\gamma-C D$
Triacetone Triperoxide

Tetra-N-Butylammonium Fluoride

T-Butoxycarbonyl

Triethanolamine

Transmission Electron Microscopy

Tetraethylorthosilica

2,4,6-Trinitrophenylmethylnitramine

Termogravimetric Analysis

Tetrahydrofurane

True Liquid-Crystal Templating

Tetramethylorthosilica

1,3,5-Trinitrobenzene

Trinitroglycerin

2,4,6-Trinitrotoluene

Tetrathiafulvalene

Ultraviolet

Universidad Valencia Material

Volatile Organic Compounds

X-Ray Diffraction

$\mathrm{p}$-Cyclodextrin 



\section{Table of Contents}

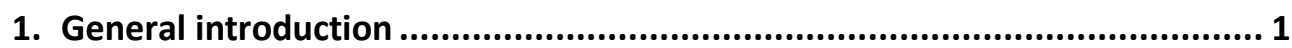

1.1 Supramolecular chemistry. ............................................................... 1

1.2 The chemistry of molecular recognition: molecular chemical sensors. ... 2

1.3 Organic-inorganic hybrid materials...................................................... 6

1.4 Organic-inorganic hybrid materials on 2D surfaces: Effect of pre-

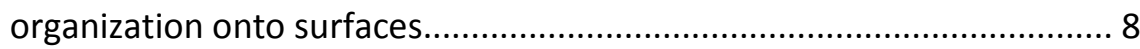

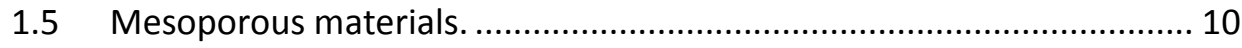

1.5.1 Synthesis of mesoporous materials.................................................... 11

1.5.2 Functionalization of inorganic silica scaffolds: Preparation of organic-inorganic mesoporous hybrid materials............................... 14

1.5.3 Characterization of mesoporous materials. ...................................... 17

1.5.4 Applications of organic-inorganic mesoporous hybrid materials. ...20

1.5.4.1 Molecular Gates.................................................................. 20

- pH-Driven Molecular Gates ...................................................... 22

- Light-Driven Molecular Gates ...................................................... 24

- Redox-Driven Molecular Gates ................................................... 26

- Temperature-Driven Molecular Gates........................................ 27

- Bio (molecules)-Driven Molecular Gates ...................................... 29

2. Optical chemosensors and reagents to detect explosives........................... 31

3. Control Access to silica surfaces. An approximation to ion-channels. .........137

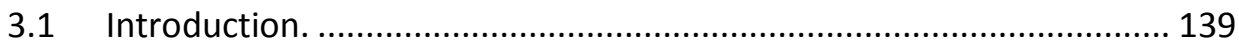

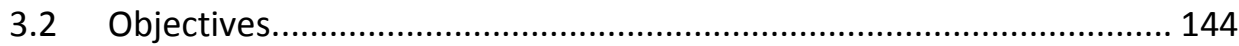

3.3 Highly selective and sensitive chromo-fluorogenic detection of the Tetryl explosive using functional silica nanoparticles.......................... 145

4. Regenerable hybrid materials for the fluorometric detection of explosives 171

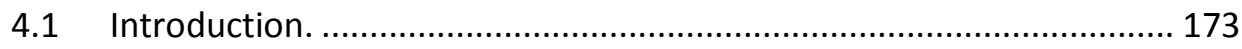

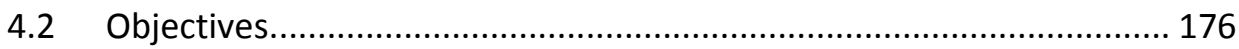


4.3 Organic-inorganic hybrid mesoporous materials as regenerable sensing systems for the recognition of nitroaromatic explosives

5. Gated materials as nitroaromatic explosives probes................................217

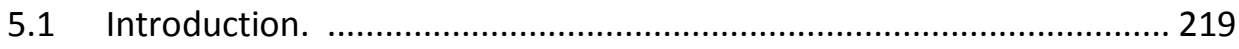

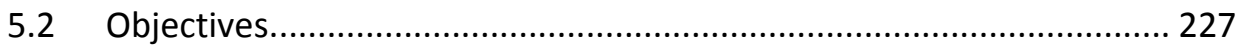

5.3 Fluorogenic detection of Tetryl and TNT explosives using nanoscopiccapped mesoporous hybrid materials ............................................... 229

5.4 Tetrathiafulvalene-capped hybrid materials for the optical detection of explosives ........................................................................................... 261

5.5 Chromo-fluorogenic detection of nitroaromatic explosives using silica mesoporous supports gated with tetrathiafulvalene derivatives ........ 299

6. Conclusions and perspectives 


1. General introduction 



\subsection{Supramolecular chemistry.}

Supramolecular chemistry was defined by Jean-Marie Lehn (Nobel Prize, 1987) as the 'chemistry of molecular assemblies and of the intermolecular bonds'. 'Chemistry beyond the molecule', 'chemistry of non-covalent bond' or 'nonmolecular chemistry' are some of the other expressions used for its definition. ${ }^{1}$

Since the middle of nineteenth century, molecular chemistry, particulary synthetic chemistry, resulted in an increasing development in formation of covalent bonds. A parallel evolution is now being encountered for non covalent intermolecular interactions. Beyond molecular chemistry, based on the covalent bond, lies the field of supramolecular chemistry, the aim of which is to gain control over the intermolecular bond. As stated above, it has been defined as chemistry beyond the molecule, referring to the organized entities of higher complexity that result from association of two or more chemical species held together by intermolecular forces. Moreover, supramolecular chemistry has

\footnotetext{
${ }^{1}$ J. W. Steed, J. L. Atwood, Supramolecular Chemistry, 2009, Wiley.
} 
rapidly expanded at the frontiers of chemical science with physical and biological phenomena. Its roots extend over organic chemistry and the synthetic procedures for molecular construction, coordination chemistry and metal ion ligand complexes, physical chemistry and the experimental and theoretical studies of interactions, biochemistry and the biological process that all start with substrate binding and recognition. ${ }^{2}$

In the 1990s, supramolecular chemistry became even more sophisticated, with researchers such as James Fraser Stoddart developing molecular machinery and highly complex self- assembled structures, and Itamar Willner developing sensors and methods of electronic and biological interfacing. During this period, electrochemical and photochemical motifs became integrated into supramolecular systems in order to increase functionality, research into synthetic self-replicating systems, and work on molecular information processing devices began. The emerging science of nanotechnology also had a strong influence on the subject, with building blocks such as fullerenes, nanoparticles, and dendrimers becoming involved in synthetic systems. ${ }^{3}$

\subsection{The chemistry of molecular recognition: molecular chemical sensors.}

Molecular recognition takes importance around the middle of the last century, when it was noticed that certain molecules may recognize selectively its partner through diverse molecular forces or interactions. In molecular recognition these forces include hydrogen bonding, metal coordination, hydrophobic forces, van der Waals forces, $\pi-\pi$ interactions, etc. Important concepts, which have been emerged from supramolecular chemistry studies, include molecular self-assembly,

\footnotetext{
2 J. L. Atwood, J.-M. Lehn, Comprehensive Supramolecular Chemistry, 1996, Vol 5, Pergamon.

${ }^{3}$ N. S. Dighe, S. R Pattan, D. S. Musmade, S. S. Dengale, R. S. Kalkotwar, V. M. Gaware, M. B. Hole, Res. J. Pharm., Biol. Chem. Sci.., 2010, 1, 291.
} 
folding, molecular recognition, host-guest chemistry, mechanically-interlocked molecular architectures, dynamic covalent chemistry and so on. ${ }^{4}$

Molecular recognition is the specific binding of a guest molecule to a complementary host molecule to form a host-guest complex. Often, the definition of which species is the "host" and which is the "guest" is arbitrary. However, in this area, the receptor or host molecule is usually a large molecule or aggregate, such as an enzyme or synthetic cyclic compound, possessing a sizeable hole or cavity. The guest molecule may be a monoatomic cation, a simple inorganic anion or a more sophisticated molecule, with a geometric size or shape complementarity to the receptor or host. In this concept, based on the lock and key principle, laid the basis for molecular recognition, i.e the discrimination by a host between different guests (See Figure 1.1).

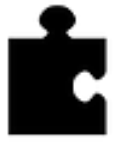

Receptor

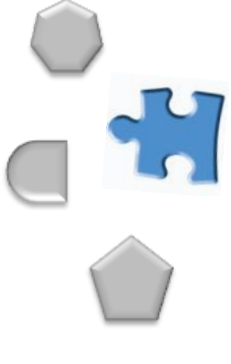

Guests

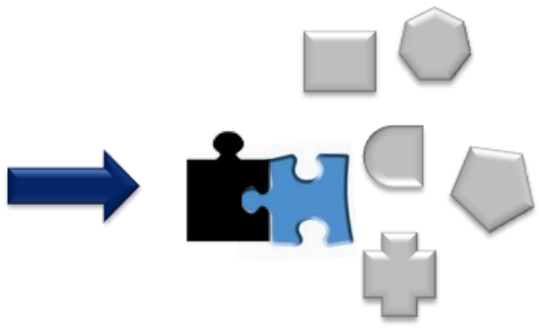

Molecular Recognition

Figure 1.1. Scheme of molecular recognition event by a specific host-guest interaction.

Therefore, molecular recognition is a keyword in supramolecular chemistry, which was related to the early host-guest chemistry of simple crown ether or cryptand-type molecules, yet it has implications on biochemical events which happen upon interaction between a receptor and a substrate. While the lock and key principle offers a simple understanding of molecular recognition, actually

\footnotetext{
${ }^{4}$ G.V. Oshovsky, D. N. Reinhoudt, W. Verboom, Angew. Chem.Int. Ed., 2007, 46, 2366.
} 
occurring binding is much more complicated, which is due to dynamic processes leading to adaptive effects like cooperativity or allosterism. ${ }^{5}$

In the supramolecular chemistry field, receptors specifically designed for sensing purposes are generally called chemosensors. ${ }^{6}$ In general terms, a chemosensor is a molecule that produces a detectable and easy-to measure signal, revealing the presence of the guest, as a result of molecular recognition. Signals widely used to detect the presence of certain guest molecules are changes in color $^{7}$, fluorescence ${ }^{8}$ or modulations in electrochemical properties. ${ }^{9}$ In this sensing process, information at the molecular level, such as the presence or not of a certain guest in solution, is amplified to a macroscopic level; hence, sensing might open the door to the determination (qualitative or quantitative) of certain guests. In this sense, one interesting goal in the development of sensors deals with the synthesis of highly selective systems. ${ }^{10}$ Reversibility and fast response will be also appealing features for an applicable sensor to be taken into account in its design.

A molecular chemical sensor or chemosensor is composed by two units:

- Binding subunit, is the unit responsible of the recognition of the substrate. The process of recognition depends on the host molecule characteristics. The binding subunit is designed in order to achieve a selective coordination via a suitable receptor-guest complementarity.

\footnotetext{
${ }^{5}$ M. Albrecht, Naturwiss, 2007, 94, 951.

${ }^{6}$ Chemosensors for Ion and Molecule Recognition, Ed. J. P. Desvergne, A. W. Czarnik, NATO Asi Series, Series C., 1997, Kluwer Academic Publishers.

${ }^{7}$ a) H.-G. Löhr, F. Vögtle, Acc. Chem. Res., 1985, 18, 65. b) M. Takagi, K. Ueno,Top. Curr. Chem., 1984, $121,39$.

${ }^{8}$ A. W. Czarnik, Acc. Chem. Res., 1994, 27, 302.

${ }^{9}$ a) P. D. Beer, Chem. Commun., 1996, 689. b) P. D. Beer, Coord. Chem. Rev., 2000, 205, 131.

10 a) R. Martínez-Máñez, F. Sancenón, Chem. Rev., 2003, 103, 4419. b) M. Moragues, R. MartínezMáñez, F. Sancenón, Chem. Soc. Rev., 2011, 40, 2593.
} 
- Signalling subunit, acts as a signal transducer and informs of the recognition process that occurs at molecular level through changes in a measurable macroscopic signal.

Among changes that could be observed, modulations in colour and fluorescence are especially appealing. While colorimetric sensors can be used to the naked eye detection of analytes, fluorogenic sensors have in general a high degree of sensitivity.

Chromo-fluorogenic chemosensors are normally constructed by one of following approaches (see Figure 1.2):

a) Binding site-signalling subunit approach: The chemosensor is formed by "binding sites" and "signaling units" that are covalently linked. The coordination of the guest with the binding site changes physical properties of the signaling subunit giving rise to variations either in the color (chromogenic chemosensor) or in its fluorescence behavior (fluorogenic chemosensor). ${ }^{11}$

b) The displacement approach: This approach uses binding sites and signaling subunits forming a coordination complex (molecular ensemble), not covalently linked. This approach relies in a displacement reaction when the target molecule is coordinated with the binding site and the signaling subunit returns to the solution. A suitable signal is observed when the color or emission of the signaling subunit in the sensing ensemble is different than that present when it is free in solution. ${ }^{12}$

${ }^{11}$ R. A. Bissell, P. de Silva, H. Q. N. Gunaratne, P. L.M. Lynch, G. E. M. Maguire, K. R. A. S. Sandanayake, Chem. Soc.Rev., 1992, 21, 187.

12 a) S. L. Wiskur, H. Ait-Haddou, J. J. Lavigne, E. V. Anslyn, Acc. Chem. Res., 2001, 34, 963. b) B. T. Nguyen, E. V. Anslyn, Coord. Chem. Rev., 2006, 250, 3118. 
c) The "chemodosimeter" approach: This is related with the use of specific irreversible reactions involving hosts and guests, which are coupled to a color or emission variations. ${ }^{13}$ If the chemical reaction is irreversible, the use of the term chemosensor cannot strictly be used and we will refer to these systems as chemodosimeters or chemoreactants. ${ }^{14}$

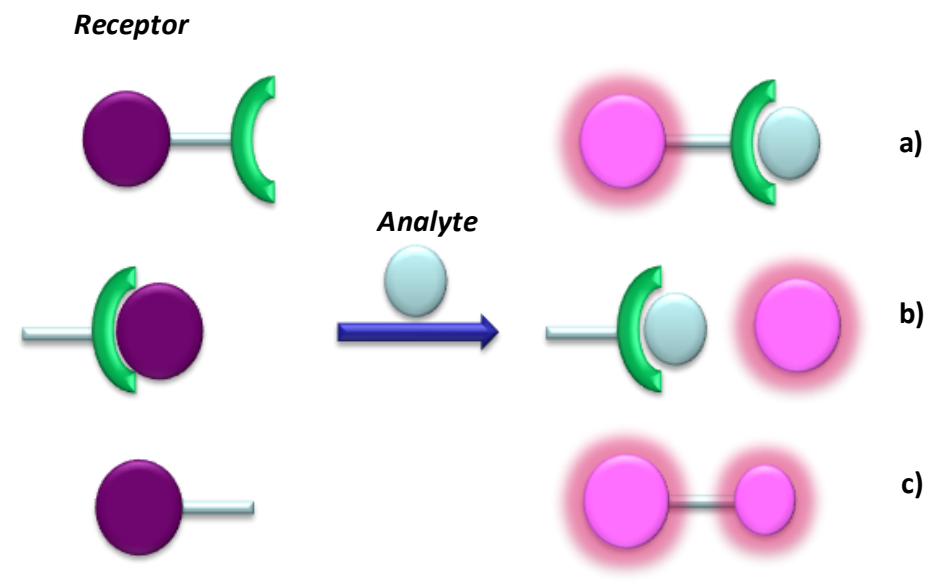

Figure 1.2. Representative scheme of the three main approaches used in the development of optical chemosensors. a) Binding site-signalling subunit; b) Displacement protocol; c) Chemodosimeter approach.

Whereas in the chemodosimeter approach the objective is to find specific reactivity, the goal in both, the binding site-signaling unit and displacement protocols, is to use system displaying a selective coordination.

\subsection{Organic-inorganic hybrid materials.}

Within the area of receptor-guest interactions, the development of materials by assembling organic compounds (receptor) into nanoscopic inorganic materials (support) can lead to hybrid solids with considerably attractive properties

\footnotetext{
13 a) M.-Y. Chae, A. W. Czarnik, J. Am. Chem. Soc., 1992, 114, 9704. b) V. Dujols, F. Ford, A. W. Czarnik, J. Am. Chem. Soc., 1997, 119, 7386.

${ }^{14}$ Z. Xu, X. Chen, H. N. Kim, J. Yoon, Chem. Soc. Rev., 2010, 39, 127.
} 
different, and often better, than those of isolated components. ${ }^{15}$ The main advantages of anchoring receptors by covalent bondings on inorganic supports are the following:

> Receptor units can be organized into the inorganic surfaces in a monolayer (depending of the functionalization degree), improving the recognition process due to the restriction in movement on the solid.

$>$ Modulation of properties of the hybrid material by multifunctionalization in successive steps.

$>$ Reusability of the system. If the coordination processes are reversible, the material could be reused several times, without lossing its chemical recognition properties.

$>$ Avoid leaching processes of receptors.

These heterogenous materials are usually easy to handle. ${ }^{16}$ Furthermore, the possible control of size, shape and surface area, can provide interesting changes on physical and chemical properties of the inorganic surface, improving selectivity and sensitivity. ${ }^{17}$

\footnotetext{
${ }^{15}$ The supramolecular chemistry of organic-inorganic hybrid materials, Ed. K. Rurack, R. MartínezMáñez, 2010, Wiley.

${ }^{16}$ C. Sánchez, J. Mater. Chem., 2005, 15, 3557.

17 a) A. Verma, V. M. Rotello, Chem. Commun., 2005, 3, 303. b) U. Drechsler, B. Erdogan, V. M. Rotello, Chem. Eur. J., 2004, 10, 5570. c) A. B. Descalzo, R. Martínez-Máñez, F. Sancenón, K. Hoffmann, K. Rurack, Angew. Chem. Int. Ed., 2006, 45, 5924. d) F. Mancin, E. Rampazzo, P. Tecilla, U. Tonellato, Chem. Eur. J., 2006, 12, 1844. e) I. Willner, B. Basnar, B. Willner, Adv. Funct. Mater., 2007, $17,702$.
} 


\subsection{Organic-inorganic hybrid materials on 2D surfaces: Effect of pre- organization onto surfaces.}

From a supramolecular point of view, one typical and very remarkable functional effect that is observed upon functionalization of surfaces with specific binding groups is the enhancement of guest recognition. This refers to the fact that pre-organization of the binding sites results in a significant improvement of guest coordination at the surface in terms of binding constants compared to the free receptor in solution (due to the formation of a dense monolayer of binding sites arranged in specific positions). Moreover, in the design of sensing systems, cooperative associate effect may appear with the independent anchoring of binding sites (receptors) and signalling units on surfaces. An example of this cooperative effect appears when binding sites and fluorescent signallig units are both anchored in close proximity on a suitable surface. This bifunctionalization allows the coordination of target species on the binding sites, resulting in a fluorescence change of neighboring anchored dyes (see Figure 1.3).

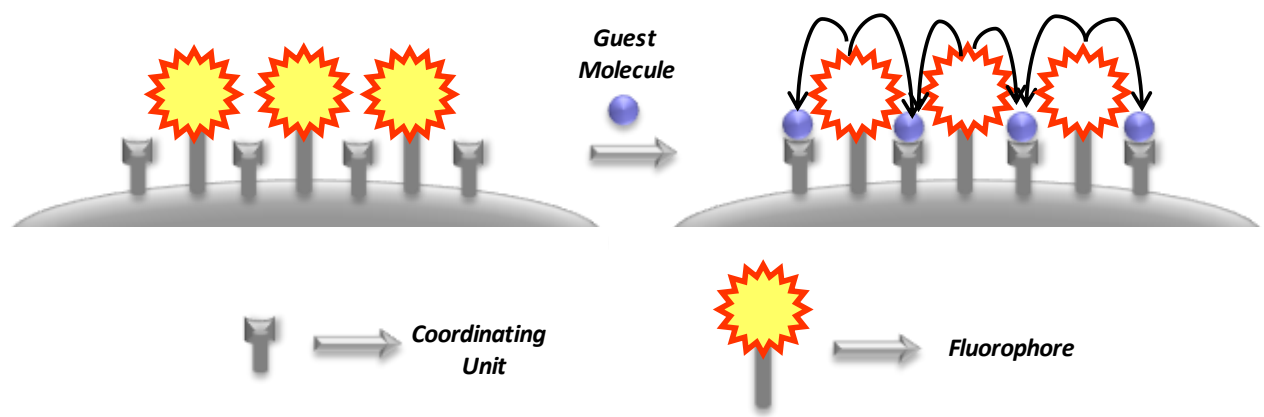

Figure 1.3. Surface bifunctionalized with binding sites and fluorophores. The coordination of a guest molecule with the binding site induced the quenching of the neighboring fluorophore through energy or electron-transfer processes. 
For instance, this approach was explored by Tecilla and Tonellano in the design of a fluorescence nanosensor for $\mathrm{Cu}^{2+}$ based on silica nanoparticles. ${ }^{18}$ The authors prepared silica nanoparticles functionalized with picolinamide subunits (as binding sites) and a dansylamide derivative (as signaling subunit) for cation recognition. DMSO-HEPES ( $\mathrm{pH}$ 7.0) suspensions of the hybrid nanoparticles showed the broad emission band of the dansyl fluorophore centred at $530 \mathrm{~nm}$ (excitation at 340 $\mathrm{nm})$. Of all the cations tested $\left(\mathrm{Cu}^{2+}, \mathrm{Ca}^{2+}, \mathrm{Mg}^{2+}, \mathrm{Zn}^{2+}, \mathrm{Cd}^{2+}, \mathrm{Co}^{2+}, \mathrm{Ni}^{2+}, \mathrm{Fe}^{2+}\right.$ and $\left.\mathrm{Pb}^{2+}\right)$ only addition of $\mathrm{Cu}^{2+}$ induced a remarkable quenching of the emission intensity. Binding of the $\mathrm{Cu}^{2+}$ cation with the picolinamide subunits induced the quenching of the emission of the nearly located dansylamide fluorophore (through an electron-transfer process). The authors demonstrated that binding of a single $\mathrm{Cu}^{2+}$ cation leads to the quenching of up to 10 fluorescent groups, thereby producing an amplification signal effect.

This approach is highly modular because it easily allows selecting between several binding sites (in order to tune selectivity) and between different fluorophores (in order to modulate sensibility of the final material). Additionally, this approach overcomes synthetic problems connected with the conventional preparation of complex receptors and, at the same time, provides a facile method for the use of combinatorial strategies and the selection of commercially available or simple small molecules for probe preparation. Moreover, the functionalization of certain surfaces is straightforward, the final functionalized hybrid materials are easy to handle, are chemically stable and are best suited for real practical applications.

The effect of improved signalling by independent pre-organization of ligands and signalling units is not unique for silica nanoparticles; but, it has also been realized for polymeric nanoparticles, ${ }^{19}$ micellar systems ${ }^{20}$ and in extended surfaces

\footnotetext{
${ }^{18}$ E. Brasola, F. Mancin, E. Rampazzo, P. Tecilla, U. Tonellato, Chem. Commun., 2003, 3026.

${ }^{19}$ R. Méallet-Renault, R. Pansu, S. Amigoni-Gerberier, C-Larpent, Chem. Commun., 2004, 2344.
} 
such as in bi-functionalized, self-assembled monolayers or Langmuir-Blodgett films. $^{21}$

\subsection{Mesoporous materials.}

According to the IUPAC (International Union of Pure and Applied Chemistry) definition, $^{22}$ porous materials are divided into three classes: microporous (pore size $<2 \mathrm{~nm}$ ), mesoporous (pore size in the 2-50 $\mathrm{nm}$ range) and macroporous (pore size $>50 \mathrm{~nm}$ ). Well-known members of the microporous class are zeolites, which provide excellent catalytic properties by virtue of their crystalline aluminosilicate network. However, their applications are somehow limited by the relatively small pore openings. Larger pores are found in mesoporous materials. Member of this family are for instance porous glasses and porous gels. ${ }^{23}$ However, they show disordered pore systems with broad pore-size distributions. Other mesoporous solids can, for instance, be prepared via intercalation of layered materials, such as double hydroxides, metal (titanium, zirconium) phosphates and clays, but they also have very broad mesopore-size distributions, as well as additional micropores. $^{24}$

The first mesoporous solid synthetized, that showed a regulary ordered pore arrangement and a very narrow pore-size distribution, was the MCM-41 material (where MCM stands for Mobil Composition of Matter), discovered in 1992 by the Mobil Oil Company. ${ }^{23}$ In this work, the authors demonstrated that depending on the synthesis conditions (solvent, $\mathrm{pH}$, temperature, concentration...), it was

${ }^{20}$ E. L. Doyle, C. A. Hunter, H. C. Philips, S. J. Webb, N. H. Williams, J. Am. Chem. Soc., 2003, 125, 4593.

${ }^{21}$ Y. Zheng, J. Orbulescu, X. Ji, F. M. Andreopoulos, S. M. Pham, R. M. Leblanc, J. Am. Chem. Soc., 2003, 125, 2680.

${ }^{22}$ K. S. W. Sing, D. H. Everett, R. H. W. Haul, L. Moscou, R. A. Pierotti, J. Rouquerol, T. Siemieniewska, Pure App. Chem., 1985, 57, 603.

${ }^{23}$ C. T. Kresge, M. E. Leonowicz, W. J. Roth, J. C. Vartuli, J. S. Beck, Nature, 1992, 359, 710.

${ }^{24}$ a) A. Corma, Chem. Rev., 1997, 97, 2373. b) G. J. A. A. Soler-Illía, C. Sanchez, B. Lebeau, J. Patarin, Chem. Rev., 2002, 102, 4093. 
possible to obtain different phases (known as M41S phase materials): the silica solid MCM-41 (with a hexagonal arrangement of the mesopores), MCM-48 (with a cubic arrangement of mesopores) and MCM-50 (with a lamellar structure) (see Figure 1.4).

These materials are a new class of solids characterized by large specific surface areas, between 500 and $1000 \mathrm{~m}^{2} \mathrm{~g}^{-1}$, homogeneous pore size, and a high pore volume (in the order of $1 \mathrm{~cm}^{3} \mathrm{~g}^{-1}$ ). Moreover, they are inert and posees high thermal stability. Applications of these materials can be found in the areas of catalysis, sorption, chromatography, the construction of systems for controlled release of active compounds and molecular switches. ${ }^{25}$

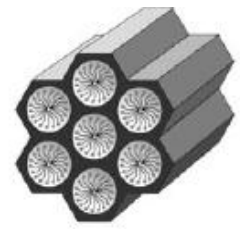

MCM-41

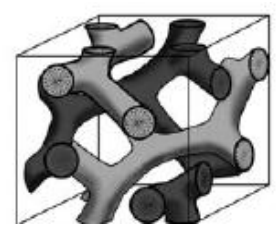

MCM-48

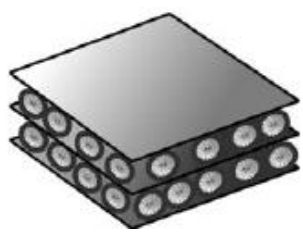

MCM-50

Figure 1.4. Scheme of structures of mesoporous M41S phase materials.(Reprinted with permission from F. Hoffmann et al., Angew. Chem. Int. Ed., 2006, 45, 3216.Copyright $(2006$ Wiley-VCH Verlag $\mathrm{GmbH} \&$ Co. KGaA, Weinheim).

\subsubsection{Synthesis of mesoporous materials.}

The use of supramolecular aggregates of ionic surfactants (long-chain alkyltrimethylammonium halides) as structure-directing agents (SDAs) was groundbreaking in the synthesis of mesoporous materials. These SDAs, in the form of a lyotropic liquid-crystalline phase, lead to the assembly of an ordered mesostructured composite during the condensation of the silica precursors under basic conditions. M41S materials are usually synthesized in alkaline media with the cationic surfactant cetyltrimethylammonium bromide (CTAB) as the structure-

\footnotetext{
${ }^{25}$ F. Hoffmann, M. Cornelius, J. Morell, M. Fröba, Angew. Chem. Int. Ed., 2006, 45, 3216.
} 
directing agent. As explained above, MCM-41 is one of the best known and most widely studied mesoporous support, and its synthesis is schematically represented in Figure 1.5.

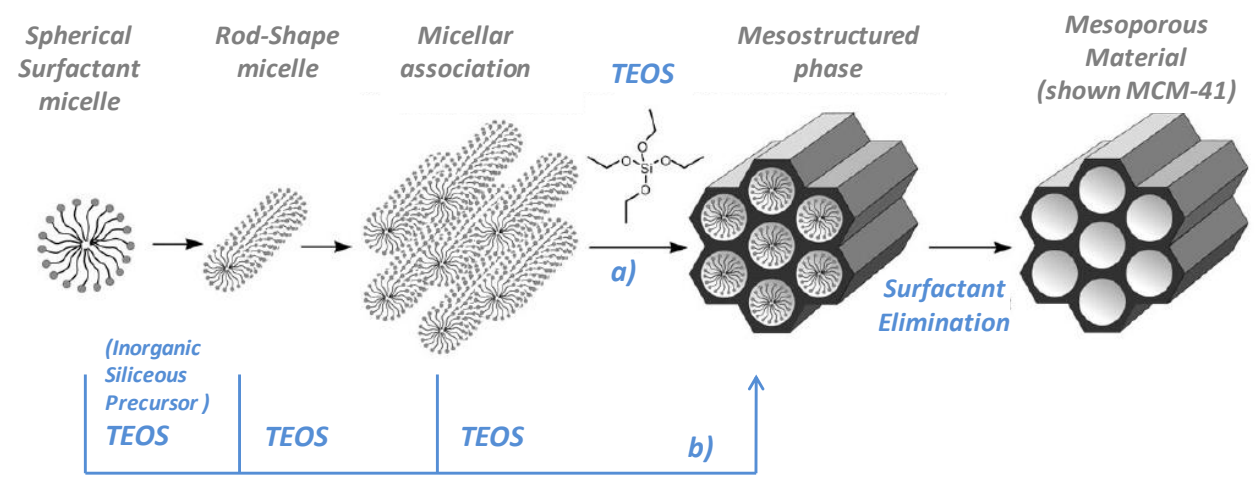

Figure 1.5. Synthesis pathways of MCM-41 by structure-directing agents: a) true liquid-crystal template mechanism and b) cooperative liquid-crystal mechanism. (Reprinted and adapted with permission from F. Hoffmann et al., Angew. Chem. Int. Ed., 2006, 45, 3216.Copyright (C) 2006 WileyVCH Verlag GmbH \& Co. KGaA, Weinheim).

The synthesis starts with the polymerization, in aqueous solution, of the inorganic siliceous precursor tetraethyl orthosilicate around surfactant micelles. Two different mechanisms are involved in the formation of these composite materials. Depending on the CTAB concentration in water, this surfactant forms liquid-crystals, where the CTAB molecules follow a hexagonal cylinder paking. In true liquid-crystal templating (TLCT), the concentration of the surfactant is so high that under the prevailing conditions (temperature, $\mathrm{pH}$ ) a lyotropic liquidcrystalline phase is formed without requiring the presence of precursor inorganic framework materials (normally tetraethyl-(TEOS) or tetramethylorthosilica (TMOS)). ${ }^{26}$ It is also possible that this phase forms even at lower concentrations of surfactant molecules, for example, when there is cooperative self assembly of the SDA and the already added inorganic species, in which case a liquid-crystal phase

${ }^{26}$ G. S. Attard, J. C. Glyde, C. G. GVltner, Nature, 1995, 378, 366. 
with hexagonal arrangement can develop. ${ }^{27}$ Thus, in true liquid-crystal template mechanism (Figure 1.5.a), the liquid crystal phase is intact before the inorganic precursor is added whereas in the cooperative liquid-crystal mechanism (Figure 1.5.b), the inorganic precursor, mediates the ordering of the surfactant micelles. ${ }^{28}$ In both cases silica precursors finally interact with the surface of the surfactant micelles, which cause the surfactant rods to assemble into a hexagonal array. A fundamental condition for this method is that an attractive interaction between the template and the silica precursor is produced to ensure inclusion of the structure director without phase separation taking place.

The mesoporous inorganic scaffold obtained during these synthetic routes, presents cylindrical unidirectional empty channels of approximately $3 \mathrm{~nm}$ of diameter (when CTAB is used as surfactant) arranged in a hexagonal distribution. The mesoporous materials are obtained by subsequent removal of the surfactant by extraction with adequate solvents or by aerobic high temperature calcination $\left(500-600^{\circ} \mathrm{C}\right)$.

Making small changes in the synthesis route, it is possible to modify final important features in the solid. Variying the structure directing agent it is possible to modulate the pore size (from 2 up to $50 \mathrm{~nm}$ ) easily. ${ }^{29}$ In adittion, the particle morphology can also be tuned from micrometric and heterogeneous particles to create thin films, nanoparticles or monoliths. ${ }^{30}$

\footnotetext{
27 A. Monnier, F. SchEth, Q. Huo, D. Kumar, D. Margolese, R. S. Maxwell, G. Stucky,M. Krishnamurty, P. Petroff, A. Firouzi, M.Janicke, B. Chmelka, Science, 1993, 261, 1299.

${ }^{28}$ J. S. Beck, J. C. Vartuli, W. J. Roth, W. J, M. E. Leonowicz, C. T. Kresge, K. D. Schmitt, C. T.-W. Chu, D. H. Olson, E. W. Sheppard, S. B. McCullen, J. B. Higgins, J. L. Schlenker, J. Am. Chem. Soc., 1992, 114, 10834.

${ }^{29}$ S. A. Bagshaw, E. Prouzet, T. J. Pinnavaia, Science, 1995, 269, 1242.

${ }^{30}$ a) H. B. S. Chan, P. M. Budd, T. D. V. Naylor, J. Mater. Chem., 2001, 11, 951. b) Q. Cai, Z.-S. Luo, W.Q. Pang, Y.-W. Fan, X.-H. Chen and F.-Z. Cui, Chem. Mater., 2001, 13, 258. c) S. P. Naik, W. Fan, T. Yokoi, T. Okubo, Langmuir, 2006, 22, 6391. d) J. Kobler, K. Moller, T. Bein, ACS Nano, 2008, 2, 791.
} 
1.5.2 Functionalization of inorganic silica scaffolds: Preparation of organic-inorganic mesoporous hybrid materials.

One important procedure of modifying the physical and chemical properties of mesoporous silicas is the incorporation of organic components, either on the silica surface, as part of the silicate walls, or trapped within the channels. ${ }^{31}$ Organic modification of the silica permits precise control over the surface properties and pore sizes of the mesoporous sieves for specific applications and stabilize the materials towards hydrolysis. Bulk properties can also be affected by mixing inorganic and organic moieties in the mesostructures. The inorganic components can provide mechanical, thermal, or structural stability, whereas organic groups can introduce flexibility into the framework, or change, for example, the optical properties of the solid. Through the development of hybrid inorganic-organic mesoporous solids, much progress has been made in the last few years towards their applications in a variety of fields.

The incorporation of organic functionalities in silica mesoporous materials can be achieved in three ways (see Figure 1.6). By subsequent modification of the pore surface by attachment of organic components onto a pure silica matrix (grafting, postsynthetic functionalization of silica), by simultaneous condensation of inorganic silica species and organosilica precursors (co-condensation, one-pot synthesis), and by the incorporation of organic groups as bridging components directly and specifically into the pore walls using bissilylated organic precursors that lead to periodic mesoporous organosilicas (PMOs).

Post-synthetic functionalization of silicas ("grafting"): Grafting refers to the subsequent modification of the inner surfaces of mesostructured silica phases with organic groups. This process is carried out primarily by reaction of organosilanes of the type $\left(\mathrm{R}^{\prime} \mathrm{O}\right)_{3} \mathrm{SiR}$, or less frequently chlorosilanes $\mathrm{ClSiR}_{3}$

\footnotetext{
${ }^{31}$ K. Moller, T. Bein, Chem. Mater., 1998, 10, 2950. b) G. A. Ozin, E. Chomski, D. Khushalani, M. J. MacLachlan, Curr. Opin. Colloid Interface Sci., 1998, 3, 181.
} 
or silazanes $\mathrm{HN}\left(\mathrm{SiR}_{3}\right)_{3}$, with the free silanol groups of the pore surfaces. By this modification method, the mesostructure of the starting silica phase is usually retained, whereas the lining of the walls is reduced in the porosity of the hybrid material. With very bulky grafting species (extreme cases), this can lead to pore blocking. A superficial modification is usually obtained using this functionalization method. ${ }^{32}$

Direct synthesis functionalization of silicas ("co-condensation"): In this approach, terminal trialkoxyorganosilanes of the type $\left(\mathrm{R}^{\prime} \mathrm{O}\right)_{3} \mathrm{SiR}$ in the presence of structure-directing agents leads to materials with organic residues anchored covalently to the pore walls. Some drawbacks of this method are: a) the degree of mesoscopic order of the products decreases with increasing concentration of $\left(\mathrm{R}^{\prime} \mathrm{O}\right)_{3} \mathrm{SiR}$ in the reaction mixture; $\left.b\right)$ the proportion of terminal organic groups that are incorporated into the porewall network is generally lower than would correspond to the starting concentration of the reaction mixture (homocondensation reactions between silane groups are increased); c) the homogeneous distribution of different organic functionalities in the framework cannot be guaranteed; $d$ ) the incorporated organic groups can lead to a reduction in the pore diameter, pore volume, and specific surface areas. In this method, care must be taken not to destroy the organic functionality during removal of the surfactant, changing the calcination way for an extractive method.

Preparation of Periodic Mesoporous Organosilicas ("PMOs"): Another way to incorporate organic compounds onto mesoporous silicas is by hydrolysis and condensation reactions of bridged organosilica precursors of the type $\left(\mathrm{R}^{\prime} \mathrm{O}\right)_{3} \mathrm{Si}-\mathrm{R}-\mathrm{Si}\left(\mathrm{OR}^{\prime}\right)_{3}{ }^{33}$. By this method, the obtained materials as porous aero- and xerogel have a disordered pore system, can have large inner

\footnotetext{
${ }^{32}$ F. Juan, E. Ruiz-Hitzky, Adv. Mater., 2000, 12, 430.

${ }^{33}$ a) D. A. Loy, K. J. Shea, Chem. Rev., 1995, 95, 1431. b) K. J. Shea, D. A. Loy, Chem. Mater., 2001, 13, 3306.
} 
surface areas (up to $1800 \mathrm{~m}^{2} \mathrm{~g}^{-1}$ ) as well as high thermal stability. ${ }^{34}$ The organic bridges are integral components of the silica network through two covalent bonds and thus distributed homogeneously in the pore walls. The first PMO was synthesized in $1999 .^{35}$

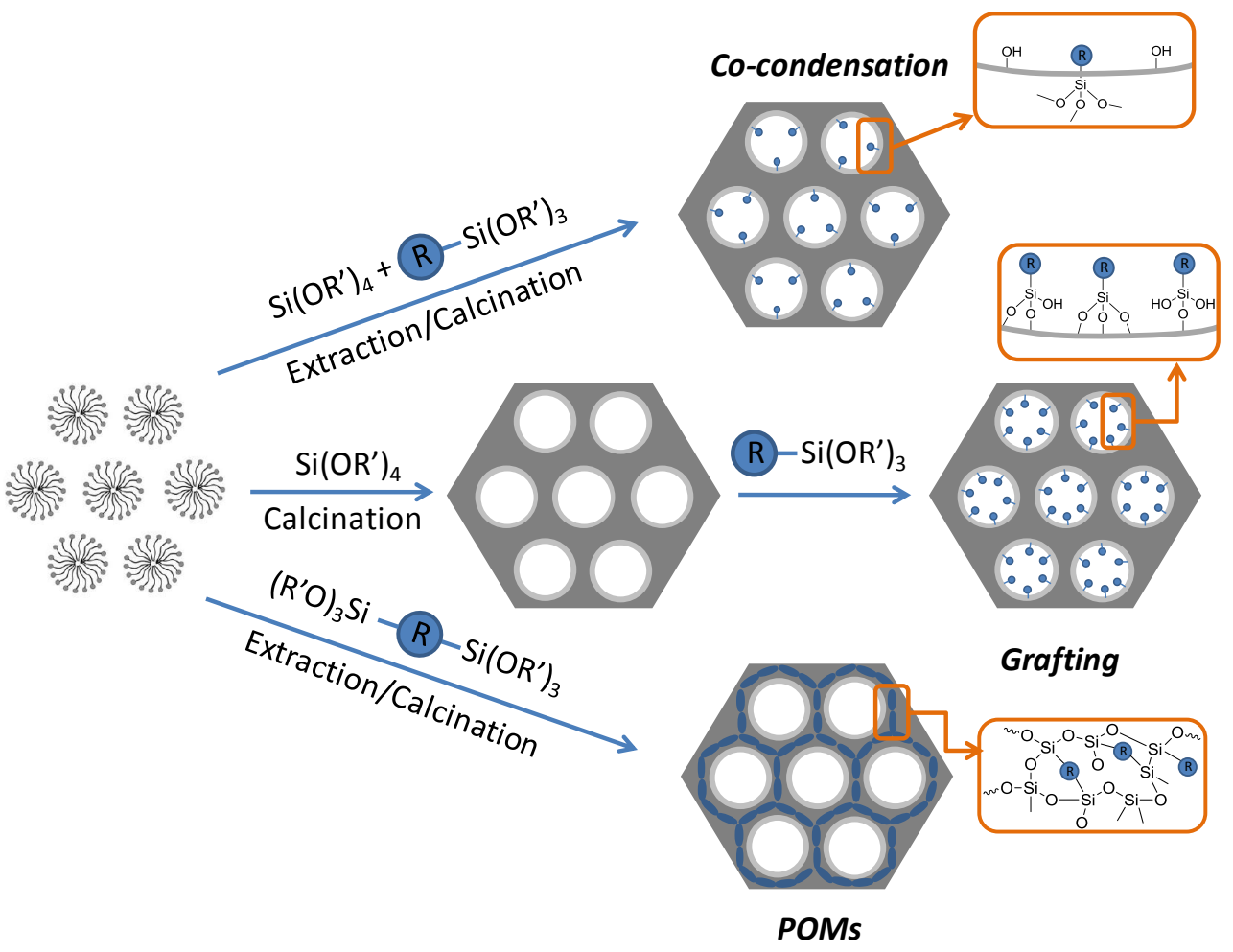

Figure 1.6. A Schematic representation of the functionalization routes of siliceous mesoporous materials.

${ }^{34}$ B. Hatton, K. Landskron, W. Whitnall, D. Perovic, G. A. Ozin, Acc. Chem. Res., 2005, 38, 305.

${ }^{35}$ a) S. Inagaki, S. Guan, Y. Fukushima, T. Ohsuna, O. Terasaki, J. Am. Chem. Soc., 1999, 121, 9611. b) B. J. Melde, B. T. Holland, C. F. Blanford, A. Stein, Chem. Mater., 1999, 11, 3302. c) T. Asefa, M. J. MacLachlan, N. Coombs, G. A. Ozin, Nature, 1999, 402, 867. 


\subsubsection{Characterization of mesoporous materials.}

The inorganic mesoporous support used in this PhD Thesis is the MCM-41 material. It has a honeycomb structure that is the result of an hexagonal packing of unidimensional cylindrical pores. This kind of structure requires basically of four techniques for its characterization: X-Ray diffraction (XRD), transmission electron microscopy (TEM), adsorption analysis and nuclear magnetic resonance spectroscopy (NMR). ${ }^{36}$

The typical MCM-41 XRD pattern shows three to five reflections between $2 \theta=2^{\circ}$ and $5^{\circ}$, corresponding to the ordered hexagonal array of parallel silica tubes and can be indexed assuming a hexagonal unit cell as (100), (110), (200), (210) and (300). No reflections at higher angles are observed since there is not a crystalline phase at atomic level. ${ }^{4}$

TEM is required to elucidate the MCM-41 pore structure. In TEM images of MCM-41 samples, a hexagonal arrangement of uniform pores (size around 2-4 $\mathrm{nm}$ ) is usually observed. Nevertheless, the exact analysis of pore size and thickness of pore walls is difficult without additional studies due to focus problem. Most MCM-41 samples show an ordered regions, lamellar and fingerprint-like structures. ${ }^{37}$ Chenite et al. showed that the equidistant parallel lines observed in the micrographs are related to the hexagonal repeat between tubes. ${ }^{38}$

\footnotetext{
${ }^{36}$ U. Ciesla, M. Grün, T. Isajeva, A. A. Kurganov, A. V. Neimark, P. Ravikovitch, S. Schacht, F. Schüth, K. K. Unger, in T. J. Pinnavaia, M. F. Thorpe (Eds.), Access in Nanoporous Materials, Plenum Press, New York, 1995.

${ }^{37}$ V. Alfredsson, M. Keung, A. Monnier, G. D. Stucky, K. K. Unger, F. Schüth, J. Chem. Soc., Chem. Commun., 1994, 921.

${ }^{38}$ A. Chenite, Y. LePage, A. Sayari, Chem. Mater., 1995, 7, 1015.
} 
Adsorption of probe molecules has been widely used to determine the surface area and to characterize the pore-size distribution of solids. ${ }^{39}$ The typical nitrogen adsorption isotherm for MCM-41 with pores of around $4 \mathrm{~nm}$, which is type IV in the IUPAC classification, ${ }^{40}$ shows a distinct feature: a sharp capillary condensation step at relative pressure of 0.1-0.4 and no hysteresis between the adsorption and desorption branches. This adsorption at low pressure is due to monolayer adsorption of $\mathrm{N}_{2}$ on the walls of the mesopores. ${ }^{41}$ To determine pore-size distributions for this mesopore range the Barrett-Joyner-Halenda (BJH) method is used. ${ }^{42}$ The Brunauer-Emmett-Teller (BET) method is also widely used to calculate the specific surface. ${ }^{43}$

The thickness of the pore wall is calculated by difference between the lattice parameter $\left(a=2 d_{(100)} / \mathrm{V} 3\right)$ determined by X-Ray diffraction, and the pore size obtained from the porosimetry analysis. In the MCM- 41 case, a wall thickness of around $1.0 \mathrm{~nm}$ remains constant into a pore range of 2,5 to $10 \mathrm{~nm}^{36,44}$

${ }^{29} \mathrm{Si}-\mathrm{NMR}$ (and ${ }^{13} \mathrm{C}$ MAS in functional supports), gives us a powerful method to characterize Si or $\mathrm{C}$ and the condensation network grade. The Si groups typically have a tetrahedral coordination; each $\mathrm{Si}$ is surrounded by four oxygens which forms four oxo bridges, yielding a so-called $Q^{4}$ environment. Depending on the

39 a) P. J. Branton, P.G. Hall, K. S. W. Sing, J. Chem. Soc., Chem. Commun., 1993, 1257. b) P. J. Branton, P.G. Hall, K. S. W. Sing, H. Reichert, F. Schüth, K. K. Unger, J. Chem. Soc. Faraday Trans., 1994, 90, 2956. c) O. Franke, G. Schulz-Ekloff, J. Rathousky, J. Starck, A. Zukal, J. Chem. Soc., Chem. Commun., 1993, 724. d) R. Schmidt, M. Stöcker, E. Hansen, D. Akporiaye, O. H. Ellestad, Microporous Mater., 1993, 3, 443.

${ }^{40}$ S. J. Gregg, K. S. W. Sing, Surface Area and Porosity, $2^{\text {nd }}$ edn, Academinc Press, London, 1995.

${ }^{41}$ C. -Y. Chen, H. -X. Li, M. E. Davis, Microporous Mater., 1993, 2, 17.

${ }^{42}$ a) E. P. Barrett, L. G. Joyner, P. P. Halenda. J. Am. Chem. Soc., 1951, 73, 373. b) M. Kruk, M. Jaroniec, Chem. Mater., 2001, 13, 3169.

${ }^{43}$ S. Brunauer, P. H. Emmett, E. Teller, J. Am. Chem. Soc., 1938, 60, 309.

${ }^{44}$ A. Corma, Q. Kan, M. T. Navarro, J. Perez-Pariente, F. Rey, Chem. Mater., 1997, 9, 2123. 
reaction conditions, the oxo bridges may become silanol groups $(\mathrm{OH}$ attached to $\mathrm{Si})$. If oxygen is replaced by one or two $\mathrm{OH}$ group, this yield $\mathrm{Q}^{3}$ or $\mathrm{Q}^{2}$ sites, respectively (see Figure 1.7). In the case of MCM-41 siliceous materials, $Q^{4}$ and $Q^{3}$ environments are in a high proportion because of the hydrolysis and condensation reactions giving a greater number of oxo bridges. During the functionalization process of these siliceous materials, either through cocondensation or anchoring organosilanes groups, new Si environments associated with the functional group $\left[(\mathrm{RO})_{3} \mathrm{SiR}^{\prime}\right]$ appeared. This new $\mathrm{Si}$ environments are called $\mathrm{T}$ type, and as above, there are three different types: $\mathrm{T}^{3}$ ( $\mathrm{Si}$ atom bonded to three other $\mathrm{Si}$ by three oxo groups and one $\mathrm{C}$ from the organic compound), $\mathrm{T}^{2}$ (two oxo groups, a silanol and one carbon from the organic compound) and finally $\mathrm{T}^{1}$ (one oxo group, two silanol and one carbon from the organic group). Uncalcined MCM-41 samples show three peaks assigned to $Q^{2}, Q^{3}$ and $Q^{4}$ silicon species. ${ }^{45} Q^{4}$ environments are formed at the expense $Q^{3}$ and/or $Q^{2}$ after the calcination process.
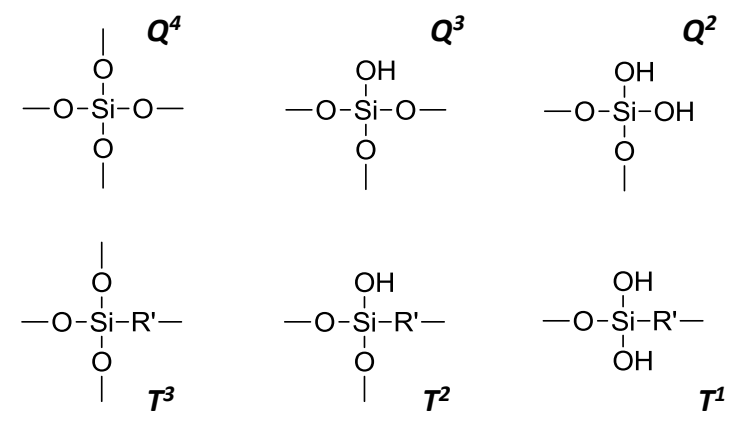

Figure 1.7. Representative scheme showing the $Q^{n}$ and $T^{n}$ sites.

( $n$ is the number of oxygens that belong to an oxo bridge).

\footnotetext{
a) M. T. Janicke, C. C. Landry, S. C. Christiansen, D. Kumar, G. D. Stucky, B. F. Chmelka, J. Am. Chem. Soc. , 1998, 120, 6940-6951. b) S. Huh, J. W. Wiench, J. -C. Yoo, M. Pruski, V. S. -Y. Lin, Chem. Mater., 2003, 15, 4247-4256. c) J. W. Wiench, Y. S. Avadhut, N. Maity, S. Bhaduri, G. K. Lahiri, M. Pruski, S. Ganapathy, J. Phys. Chem. B, 2007, 111, 3877.
} 


\subsubsection{Applications of organic-inorganic mesoporous hybrid materials.}

This family of materials has a huge potential as scaffols, and their application in several research areas (catalysis, controlled release in response to target molecules or certain stimuli, ${ }^{46}$ transport molecules to specific locations, ${ }^{47}$ environmental remediation or design of new probes) is consequence of their properties such as chemical inertness, thermal stability, high surface area, high load capacity, uniform and tuned pores system and biocompatibility. ${ }^{48}$

From all potential applications, a part of this $\mathrm{PhD}$ thesis deals with the design, synthesis and use of organic-inorganic mesoporous materials for sensing of explosives using gated materials.

\subsubsection{Molecular Gates.}

In the last ten years, anchoring organic molecules or supermolecules onto certain inorganic scaffoldings has led to the development of some hybrid materials, which show cooperative functional behaviors which are not found in unanchored molecules or in the un-functionalized solids alone. One appealing concept in this novel research field relates with the development of gated nanodevices for delivery or sensing applications.

One of the most interesting concepts in nature is related with channels than act as gates and are able to control mass transport. Inspired by this example, many researchers have been involved in the preparation of hybrid materials that mimics these channels, developing stimuli-responsive nanoscopic gated systems. ${ }^{18}$

${ }^{46}$ K.K. Cotí, M. E. Belowich, M. Liong, M. W. Ambrogio, Y. A. Lau, H. A. Khatib, J. I. Zink, N. M. Khashab, J. F. Stoddart, Nanoscale, 2009, 1, 16.

${ }^{47}$ a) J. M. Rosenholm, E. Peuhu, L. T. Bate-Eya, J. E. Eriksson, C. Sahlgren, M. Linden, Small, 2010, 6, 1234. b) M. Liong, J. Lu, M. Kovochich, T. Xia, S. G. Ruehm, A. E. Nel, F. Tamanoi, J. I. Zink, ACS Nano, 2008, 2, 889 .

${ }^{48}$ a) M. Vallet-Regi, A. Rámila, R. P. del Real, J. Pérez-Pariente, J. Chem. Mater. 2001, 13, 308. b) B. Muñoz, A. Rámila, J. Pérez-Pariente, I. Díaz, M. Vallet-Regi, Chem. Mater. 2003, 15, 500. 
The first example of molecular gate was described in 2003 by Fujiwara and coworkers. ${ }^{49}$ Since then, number examples of nanoscopic gated systems using mesoporous hybrid scaffoldings have been reported. ${ }^{50}$

A schematic representation of a gated material is shown in Figure 1.8. The scheme represents a mesoporous support loaded with certain guest molecules and with a suitable molecular ensemble anchored in the pore outlets (molecular gate). The application of an extermal stimulus allows the release of the entrapped cargo due to changes in the capping ensemble.
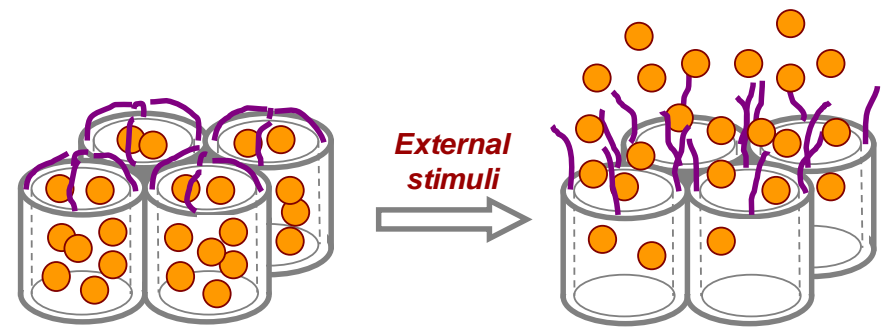

Figure 1.8. Schematic representation of a nanoscopic gated support.

The components of a molecular gate are important and their selection determines the controlled release behaviour of the hybrid support. Mesoporous silicas of different pore sizes and morphologies have been selected and used as inorganic scaffolds in gated ensembles. ${ }^{51}$ In relation to the gate, several molecular and supramolecular systems have been developed which are able to trigger at will the delivery of the entrapped cargo using several external stimuli such as light, ${ }^{52}$

49 a) N. K. Mal, M. Fujiwara, Y. Tanaka, Nature, 2003, 421, 350. b) N. K. Mal, M. Fujiwara, Y. Tanaka, T. Taguchi, M. Matsukata, Chem. Mater. 2003, 15, 3385.

50 a) T. D. Nguyen, H. R. Tseng, P. C. Celestre, A. H. Flood, Y. Liu, J. F. Stoddart, J. I. Zink, Proc. Natl. Acad. Sci. USA, 2005, 102, 10029. b) C.-Y. Lai, B. G. Trewyn, D. M. Jeftinija, K. Jeftinija, S. Xu, S. Jeftinija, V. S.-Y. Lin, J. Am. Chem. Soc., 2003, 125, 4451. c) J. A. Gruenhagen, C. Y. Lai, D. R. Radu, V. S.-Y. Lin, E. S. Yeung, Appl. Spectrosc., 2005, 59, 424. d) S. Giri, B. G. Trewyn, M. P. Stellmaker, V. S.-Y. Lin, Angew. Chem., 2005, 117, 5166.

${ }^{51}$ C. T. Kresge, M. E. Leonowicz, W. J. Roth, J. C. Vartuli, J. S. Beck, Nature, 1992, 359, 710.

52 a) E. Johansson, E. Choi, S. Angelos, M. Liong, J. I. Zink, Sol-Gel Sci. Technol., 2008, 46, 313. b) Q. Lin, Q. Huang, C. Li, C. Bao, Z. Liu, F. Li, L. Zhu, L. J. Am. Chem. Soc., 2010, 132, 10645. 
$\mathrm{pH}^{53}$ changes in redox potential, ${ }^{54}$ temperature ${ }^{55}$ and the presence of certain ions, molecules or biomolecules. ${ }^{56}$ The design of gated mesoporous materials proves to be a promising starting point for applying the versatility of supramolecular ideas to the design of nanoscopic gating solids, and a way of studying the factors that can influence the design of molecular gating functions based on molecular/biomolecular/supramolecular concepts. ${ }^{57}$

Several examples of these solids have been designed in last years. Here we will show some examples of gated materials for controlled release, ordered depending on the type of external stimulus used to induce cargo delivery.

\section{- $\quad$ H-Driven Molecular Gates}

Inclusion of ionizable organic moieties anchored onto the pore outlets of mesoporous supports, which might change in size or shape upon protonation or deprotonation processes is a usual procedure to prepare materials capable of

53 a) Q. Yang, S. Wang, P. Fan, L. Wang, Y. Di, K. Lin, F. -S. Xiao, Chem. Mater., 2005, 17, 5999. b) S. Angelos, Y. -W. Yang, K. Patel, J. F. Stoddart, J. I. Zink, Angew. Chem. Int. Ed., 2008, 47, 2222. c) Y. Klichko, N. M. Khashab, Y. -W. Yang, S. Angelos, J. F. Stoddart, J. I. Zink, Micropor. Mesopor. Mater., 2010, 132, 435. d) J. Liu, X. Du, J. Mat. Chem., 2010, 20, 3642.

${ }^{54}$ a) R. Liu, X. Zhao, T. Wu, P. Feng, J. Am. Chem. Soc., 2008, 130, 14418. b) R. Mortera, J. ViveroEscoto, I. I. Slowing, E. Garrone, B. Onida, V. S.-Y. Lin, Chem. Commun., 2009, 3219.

55 a) C. Liu, J. Guo, W. Yang, J. Hu, C. Wang, S. Fu, J. Mat. Chem., 2009, 19, 4764. b) J. Lai, X. Mu, Y. Xu, X. Wu, C. Wu, C. Li, J. Chen, Y. Zhao, Chem. Commun., 2010, 46, 7370. c) C. R. Thomas, D. P. Ferris, J. -H. Lee, E. Choi, M. H. Cho, E. S. Kim, J. F. Stoddart, J. -S. Shin, J. Cheon, J. I. Zink, J. Am. Chem. Soc., 2010, 132, 10623.

${ }^{56}$ a) C. Coll, R. Casasús, E. Aznar, M. D. Marcos, R. Martínez-Máñez, F. Sancenón, J. Soto, P. Amorós, Chem. Commun., 2007, 1957. b) T. D. Nguyen, K.C.-F. Leung, M. Liong, Y. Liu, J. F. Stoddart, J. I. Zink, Adv. Funct. Mater., 2007, 17, 2101. c) E. Aznar, C. Coll, M. D. Marcos, R. Martínez-Máñez, F. Sancenón, J. Soto, P. Amorós, J. Cano, E. Ruiz, Chem. Eur. J., 2009, 15, 6877. d) Y. Zhao, B. G. Trewyn, I. I. Slowing, V. S.-Y. Lin, J. Am. Chem. Soc., 2009, 131, 8398. e) R. Klajn, J. F. Stoddart, B. A. Grzybowski, Chem. Soc. Rev., 2010, 39, 2203. f) C. Coll, L. Mondragón, R. Martínez-Máñez, F. Sancenón, M. D. Marcos, J. Soto, P. Amorós, E. Pérez-Payá, Angew. Chem. Int. Ed., 2011, 50, 2138.

${ }^{57}$ C. Coll, A. Bernardos, R. Martínez-Máñez, F. Sancenón, Acc. Chem. Res., 2013, 46, 339. 
controlling mass transport by pH modulations. In 2004, R. Casasús, R. Martínez and coworkers reported the first example of nanoscopic molecular gate activated by $\mathrm{pH}$ that worked in water (see Figure 1.9). ${ }^{58}$

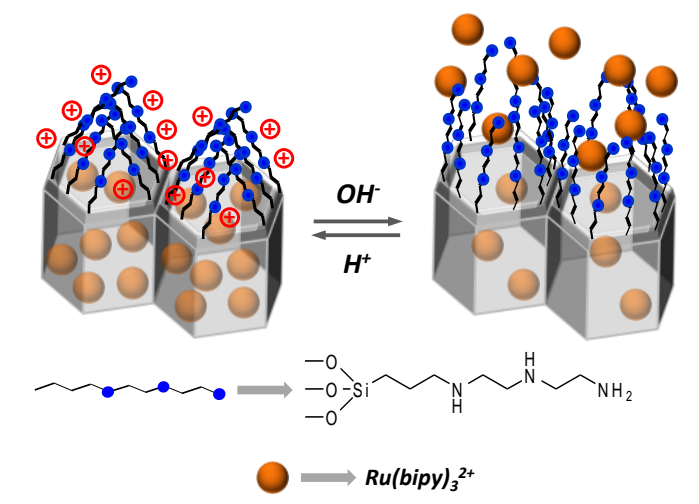

Figure 1.9. Schematic representation of $\mathrm{pH}$-driven nanoscopic molecular gated material. (Reprinted with permission from C. Coll et al., Acc. Chem. Res., 2013, 46, 339. Copyright (C) 2013 American Chemical Society).

The mechanism of that system consisted of protonation/deprotonation processes of polyamines anchored on the external surface. At neutral $\mathrm{pH}$, the polyamines are deprotonated and interacted through hydrogen bonding interactions, inducing pore opening. However, at acidic $\mathrm{pH}$, the amines are protonated and the electrostatic repulsions between them, induced pore closing. In that case, UVM-7 was used as a silica support (a type of MCM-41) that presented a bi-modal pore distribution (intra-nanoparticle and inter-nanoparticle pores). The same authors reported an additional study which demonstrated that the use of different anions at specific pH could additionally control the state of the gate. The system consisted of an ionically controlled gate in which a mesoporous material was loaded with the $\left[\mathrm{Ru}(\mathrm{bipy})_{3}\right]^{2+}$ dye as indicator and functionalized on the external surface with linear polyamines. At pH 7.8, water suspensions of the solid showed an intense yellow color because polyamines were unprotonated, the molecular gate was open, and the ruthenium complex was released into the

\footnotetext{
${ }^{58}$ R. Casasús, M. D. Marcos, R. Martínez-Máñez, J. V. Ros-Lis, J. Soto, L. A. Villaescusa, P. Amorós, D. Beltrán, C. Guillem, J. Latorre, J. Am. Chem. Soc., 2004, 126, 8612.
} 
solution. The influence of different anions in the delivery process was studied. Bulky anions like adenosine triphosphate (ATP) and adenosine diphosphate (ADP) blocked the pores by the formation of strong complexes with tethered polyamines through hydrogen bonding and electrostatic interactions, inhibiting the indicator release. ${ }^{59}$ Finally, the same mechanism was employed to develop a prototype system whose cargo (riboflavin) could be protected from the acid stomach conditions (acid $\mathrm{pH}$, closed gate) and opened just at basic $\mathrm{pH}$ (in the intestine). ${ }^{60}$

\section{- Light-Driven Molecular Gates}

Light is another popular external trigger used for governing mass transport in certain capped hybrid materials. By using light-driven gated systems, one can particularly control cargo release spatially and temporally by finely tuning the area and time of the light stimulus. This field was explored by M. Fujiwara and coworkers in 2003, ${ }^{49}$ reporting the first example of photocontrolled reversible molecular gate. The authors prepared a mesoporous MCM-41 material functionalized with photosensible coumarin derivatives. The intermolecular photodimerization of coumarin by irradiation at $\lambda>310 \mathrm{~nm}$ gave more hindered cyclobutane derivatives blocking the pores, inhibiting cargo release (see Figure 1.10). To check the efficiency of this new hybrid material as a delivery system, the MCM-41 was loaded with cholestane and other steroids. It was observed that irradiating at 250-260 nm, the pores were unblocked, due to the photo-opening of cyclobutane ring and coumarin monomer regeneration, delivering the drugs previously loaded inside the porous material.

\footnotetext{
${ }^{59}$ R. Casasús, E. Aznar, M. D. Marcos, R. Martínez-Máñez, F. Sancenón, J. Soto, P. Amorós, Angew. Chem., Int. Ed., 2006, 45, 6661.

${ }^{60}$ A. Bernardos, E. Aznar, C. Coll, R. Martínez-Máñez, J. M. Barat, M. D. Marcos, F. Sancenón, J. Soto, J. Control. Rel., 2008, 131, 181.
} 


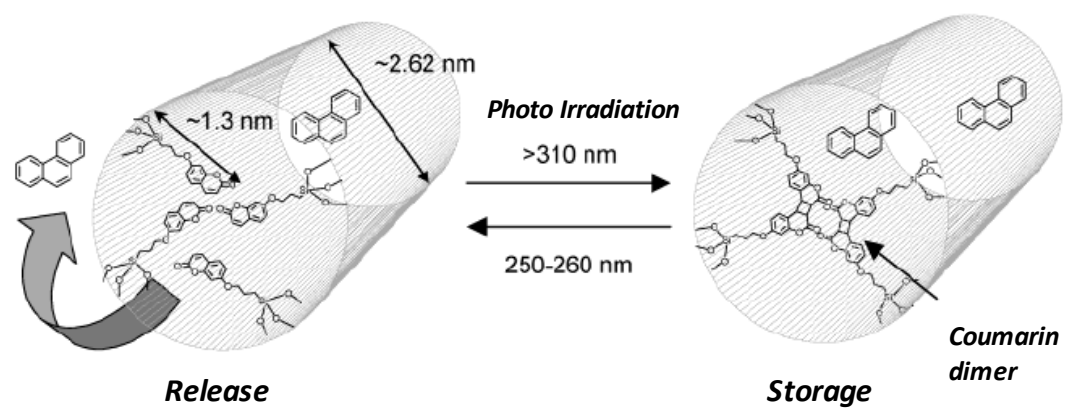

Figure 1.10. Schematic representation of the first light-driven molecular gate material.

(Reprinted with permission from M. Fujiwara et al., Chem. Mater. 2003, 15, 3385.

Copyright (c) 2003 American Chemical Society).

E. Aznar and co-workers prepared a hybrid gated material that can be opened by $\mathrm{pH}$ and light stimuli. In particular, a MCM-41 support was loaded with safranine $O$ and its external surface functionalized with a gluconamide derivative. Gold nanoparticles (AuNPs) of a suitable size were functionalized with 4mercaptophenylboronic acid, and by the formation of boroester bonds with the anchored saccharide were able to cap the nanoscopic pores (see Figure 1.11). ${ }^{61}$

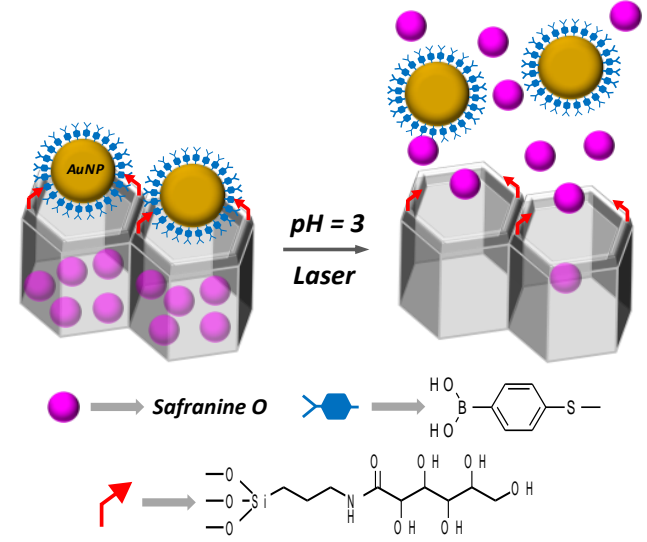

Figure 1.11. Scheme of photo- and $\mathrm{pH}$-switched hybrid gated material. (Reprinted with permission from C. Coll et al., Acc. Chem. Res., 2013, 46, 339.

Copyright (C) 2013 American Chemical Society)

${ }^{61}$ E. Aznar, M. D. Marcos, R. Martínez-Máñez, F. Sancenón, J. Soto, P. Amorós, C. Guillem, J. Am. Chem. Soc., 2009, 131, 6833. 
It was demonstrated that by means of $\mathrm{pH}$-changing cycles, the cargo delivery could be controlled, according to the reversibility of boroester formation. At $\mathrm{pH}$ 5.0 or at a higher $\mathrm{pH}$, no dye delivery is detected due to an effective pore blockage with the AuNPs, whereas a release at pH 3.0 is observed due to the hydrolysis of the boroester bonds, which detaches the AuNPs from the surface. Moreover, application of plasmonic heating by laser irradiation on this hybrid material, leads to thermal cleavage of the boroester bonds, releasing the entrapped cargo.

\section{- Redox-Driven Molecular Gates}

Another stimulus with interesting possibilities is the uncapping of hybrid mesoporous materials by redox reactions. In the last decade, several examples of redox-controlled molecular gated materials have been described. As an example, Stoddart and Zink used [2]pseudorotaxanes, formed by the inclusion of cyclobis(paraquat- $p$-phenylene) $\left(\mathrm{CBPQT}^{4+}\right)$ into a 1,5-dioxynaphthalene derivative (DNPD), as molecular gate (see Figure 1.12). ${ }^{62}$ The anchoring of these [2]pseudorotaxanes derivatives into mesostructured silica films (with the pores loaded with tris(phenylpyridine)iridium $\left.\left(\operatorname{Ir}(\mathrm{ppy})_{3}\right)\right)$ yield the gated material. In the presence of a reducing agent sodium cyanoborohydride $\left(\mathrm{NaCNBH}_{3}\right)$, DNPD groups are reduced with the subsequent dethreading of the $\mathrm{CBPQT}^{4+}$ ring and the delivery of the entrapped complex.

\footnotetext{
${ }^{62}$ R. Hernández, H.-R.Tseng, J. W. Wong, J. F. Stoddart, J. I. Zink, J. Am. Chem. Soc., 2004, 126, 3370.
} 


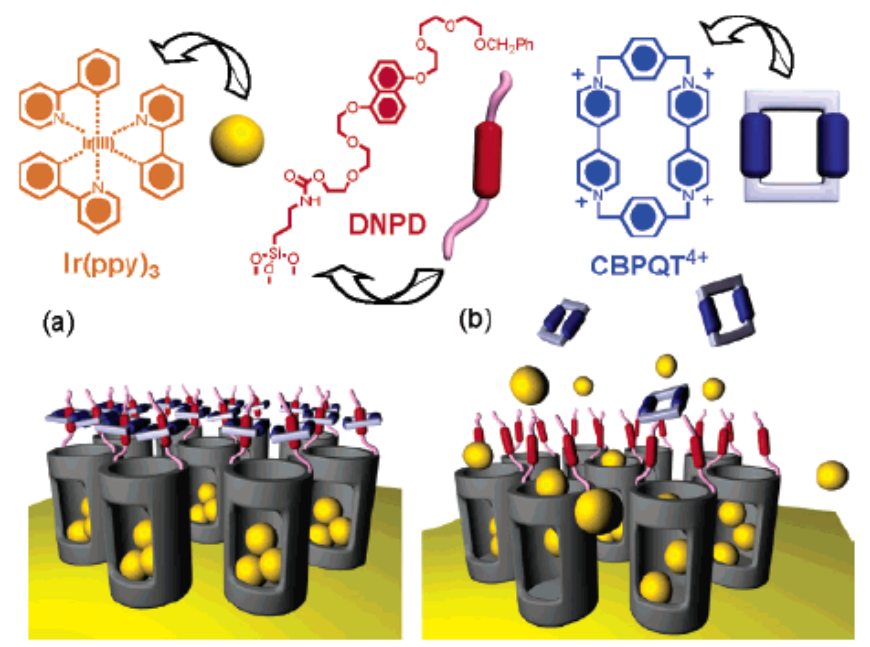

Figure 1.12. Schematic representation of operation of nanovalves. a) the orifices of the nanopores are covered with pseudorotaxanes (formed between DNPD and $C B P Q T^{4+}$ ) which trap the luminescent $\operatorname{Ir}(\text { ppy })_{3}$ molecules inside the nanopores. b) Upon their reduction, the $C B P Q T^{2+}$ bisradical dications are released and so allow the $\operatorname{Ir}(p p y)_{3}$ to escape. (Reprinted with permission from F. Stoddart et al.,

J. Am. Chem. Soc., 2004, 126, 3370. Copyright () 2004 American Chemical Society).

\section{- Temperature-Driven Molecular Gates}

The first example of temperature-controlled nanoscopic gated hybrid material was described in 2003 by G. P. López and co-workers. ${ }^{63}$ In this hybrid support the authors controlled the transport and surface properties of mesoporous silica nanoparticles through surface modification with the temperature sensitive $N$ isopropylacrylamide (PNIPAAm) polymer. At low temperatures, the polymer is hydrated (coil conformation) and extended inhibiting cargo release whereas at higher temperatures (e.g. $50^{\circ} \mathrm{C}$ ) is dehydrated and collapsed (globule state) within the pore network and the cargo is delivered by solute diffusion.

${ }^{63}$ Q. Fu, G. V. R. Rao, L. K. Ista, Y. Wu, B. P. Andrzejewski, L. A. Sklar, T. L. Ward, G. P. López, Adv. Mat., 2003, 15, 1262. 
E. Aznar and co-workers prepared a new tailor made temperature-responsive gated mesoporous materials using paraffins as caps. ${ }^{64}$ These materials were prepared from MCM-41 silica nanoparticles loaded with a suitable guest (safranine 0 ), and with the external surface functionalized with octadecyltrimethoxysilane and paraffins. The alkyl chains molecules, interacting with paraffins, (that can be melted at a defined temperature) are able to close the pores inhibiting guest release. An increase of the temperature above the paraffin melting point resulted in melting of the hydrophobic layer around the silica nanoparticles and the subsequent uncapping of the pores. A schematic representation of the temperature-responsive system is depicted in Figure 1.13. The possibility of selecting a wide range of paraffins with specific melting points over a wide range of temperatures make these solids suitable for applications that demand zero release before stimulus implementation.

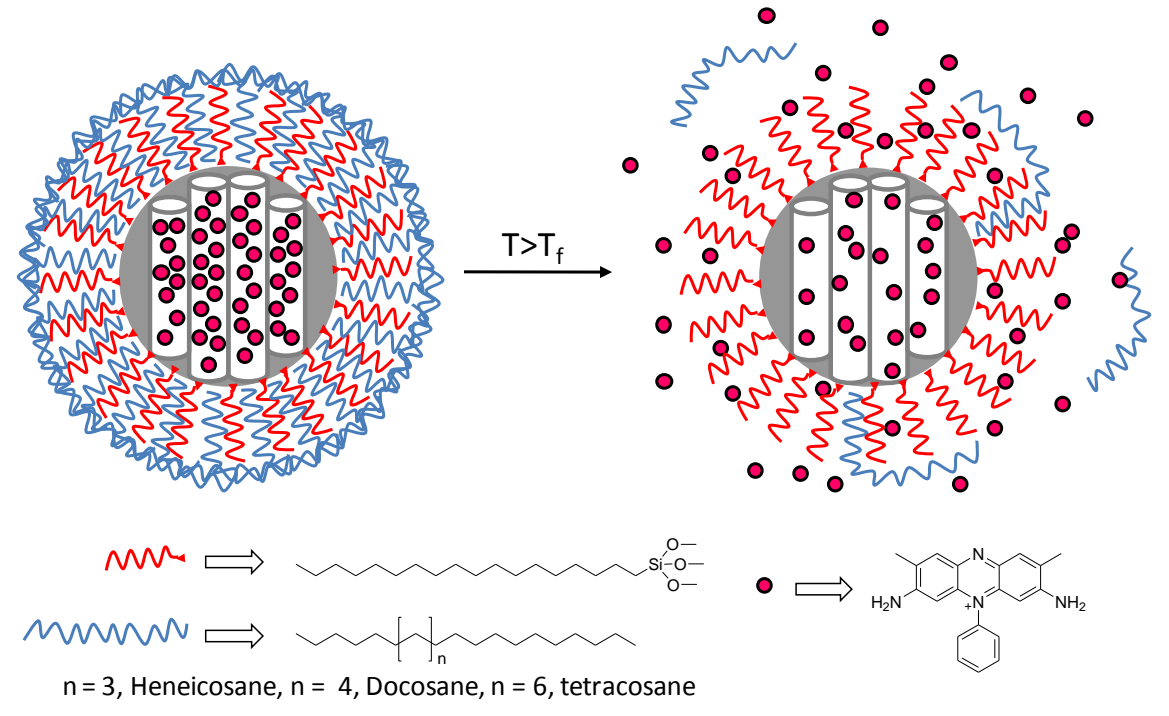

Figure 1.13. Schematic representation of a gated material functionalized with octadecyltrimethoxysilane and capped with paraffins. The delivery of the entrapped guest (safranine $O$ ) is triggered when temperature rises above paraffin melting point. (Reprinted with permission from E. Aznar et al., Angew. Chem. Int. Ed., 2011, 50, 11172.Copyright (C) 2011 WILEY-VCH Verlag GmbH \& Co. KGaA, Weinheim).

\footnotetext{
${ }^{64}$ E. Aznar, L. Mondragón, J. V. Ros-Lis, F. Sancenón, M. D. Marcos, R. Martínez-Máñez, J. Soto, E. Pérez-Payá, P. Amorós, Angew. Chem. Int. Ed., 2011, 50, 11172.
} 


\section{- Biomolecules-Driven Molecular Gates}

The use of biomolecules such enzymes as triggers have also been used in the design of gated materials. The first example using this approach was described by J. F. Stoddart and J. I. Zink in $2008 .^{65}$ The authors loaded a mesoporous support with rodhamine $B$ and the external surface was functionalized with a [2] rotaxane (formed by inclusion of a $\alpha$-cyclodextrin into a polyether) capped with a bulky adamaltyl ester. Upon addition of porcine liver esterase, the fluorescent dye is delivery to the aqueous solution due to the hydrolysis of the ester bond and the subsequent detachment of adamantyl cap. T. Bein and co-workers also described a system using enzyme protease and biotinylated colloidal mesoporous silica. The pores of the inorganic support were loaded with fluoresceine and capped through avidin-biotin complex formation. ${ }^{66}$ Addition of trypsin induced the hydrolysis of the protein avidin with the subsequent release of fluorescein.

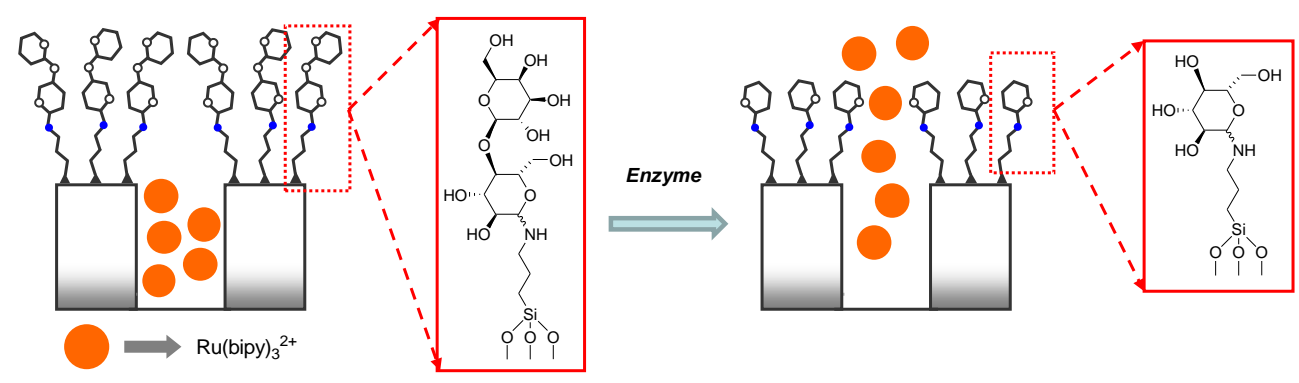

Figure 1.14. Schematic representation of a gated material capped with a trialkoxysilane lactose derivative.

Another example with enzyme-response control was developed by $A$. Bernardos and co-workers. ${ }^{67}$ The system was based on a silica mesoporous support capped with lactose. The formation of a dense network of disaccharides

${ }^{65}$ K. Patel, S. Angelos, W. R. Dichtel, A. Coskun, Y. -W. Yang, J. I. Zink, J. F. Stoddart, J. Am. Chem. Soc., 2008, 130, 2382.

${ }^{66}$ A. Schlossbauer, J. Kecht, T. Bein, Angew. Chem. Int. Ed., 2009, 48, 3092.

${ }^{67}$ A. Bernardos, E. Aznar, M. D. Marcos, R. Martínez-Máñez, F. Sancenón, J. Soto, J. M. Barat, P. Amorós, Angew. Chem. Int. Ed., 2009, 48, 5884. 
linked through hydrogen bonds around the pore outlets inhibits dye release. A selectively uncapping behaviour was found using $\beta$-D-galactosidase due to the rupture of the glycosidic bonds. As a consequence, the steric crowding around the pore outlets is reduced with the subsequent dye release (see Figure 1.14). 


\section{Optical chemosensors and reagents to detect explosives}





\section{Optical chemosensors and reagents to detect explosives}

Yolanda Salinas, ${ }^{a, b, c}$ Ramón Martínez-Máñez, ${ }^{a, b, c *}$ María D. Marcos, ${ }^{a, b, c}$ Félix Sancenón, ${ }^{a, b, c}$ Ana M. Costero, ${ }^{a, d}$ * Margarita Parra ${ }^{a, d}$ and Salvador Gil ${ }^{a, d}$

${ }^{a}$ Centro de Reconocimiento Molecular y Desarrollo Tecnológico, (IDM), Unidad Mixta Universidad Politécnica de Valencia - Universitat de València, Spain.

${ }^{b}$ Departamento de Química. Universidad Politécnica de Valencia. Camino de Vera $s / n$. E-46022, Valencia, Spain.

${ }^{c}$ CIBER de Bioingeniería, Biomateriales y Nanomedicina (CIBER-BBN).

${ }^{d}$ Departamento de Química Orgánica, Facultad de Ciencias Químicas, Universidad de Valencia. Doctor Moliner 50, 46100 Burjassot, Valencia, Spain.

Received: $28^{\text {th }}$ Juny 2011

First published on the web: $22^{\text {nd }}$ September 2011

Chemical Society Reviews, 2012, 41, 1261-1296

(Reproduced with permission of The Royal Society of Chemistry) 

This review is focused on examples reported from 1947 to 2010 related to the design of chromo-fluorogenic chemosensors and reagents for explosives.

\section{Introduction}

In the last few years, the reliable and accurate detection of explosives is an issue of international concern. The detection of chemical explosives is crucial for homeland security, environmental cleaning and military issues. Additionally, given the widespread use of explosive formulations, the analysis of explosives is also of interest in forensic research, land mine detection, and in the study of environmental problems associated with explosive residues. The recent rise in global terrorism has required that the methods followed to detect explosives should be both sensitive and low-cost. With all this in mind, trained canine teams, ${ }^{1}$ gas chromatography coupled with mass spectrometry, ${ }^{2}$ gas chromatography-electron capture detection, ${ }^{3}$ surface-enhanced Raman spectroscopy, ${ }^{4}$ mass spectrometry, ${ }^{5}$ X-ray imaging, ${ }^{6}$ thermal neutron analysis, ${ }^{7}$ electrochemical procedures ${ }^{8}$ and ion mobility spectroscopy (IMS) ${ }^{9}$ have been used or proposed as suitable methods for the detection and quantification of these chemicals. While all the above-mentioned methods offer advantages, none is ideal due to certain features such as lack of portability, susceptibility to false positives owing to environmental contaminants, and false-negative readings due to certain interfering compounds. ${ }^{10}$

Very recently, optical detection techniques based on the design of colorimetric and fluorimetric assays have attracted a great deal of attention. ${ }^{11}$ In particular, the wide variety of fluorescent and dye groups, the simple instrumentation required when using colorimetric probes, and the usually low detection limit reached when 
employing fluorescence probes, all make the optical approach largely appealing. In fact, the development of chromogenic and fluorogenic chemosensors and reagents is an area that is emerging in the supramolecular field, and different protocols have been widely applied to the design of probes for anions, ${ }^{12}$ cations ${ }^{13}$ and, to a lesser extent, to neutral molecules. ${ }^{14}$ Chemosensors are systems that rely on the use of coordinative forces for guest binding. However, we will use the term reactand (or chemodosimeter) when the signalling event uses specific irreversible reactions. ${ }^{15}$ In this context, a relatively large number of signalling chemosensors and reactands has been reported for the optical detection of explosives.

The detection limits of chemosensors and reactants are an important issue in order to asses the future applicability of these sensors for the detection of explosives in real samples. In relation to this subject, nearly in all the published papers detection limits are given in concentrations, particularly in solution phase. However it has to be noted that, from a trace detection point of view, detection limits for explosives in concentration may be misleading because due to the chemical nature of many explosives (very reactive molecules with a high electron acceptor character that usually results in a strong irreversible reaction with the sensing material) the total solution volume plays an important role in the quantification of the explosive. To avoid this problem some references include detection limits in terms of absolute mass, for example in $\mathrm{mg}$ of explosive per $\mathrm{g}$ of sensing material. 
<smiles>O=[N+]([O-])c1cc([N+](=O)[O-])c(O)c([N+](=O)[O-])c1</smiles>

PA<smiles>CN(c1c([N+](=O)[O-])cc([N+](=O)[O-])cc1[N+](=O)[O-])[N+](=O)[O-]</smiles>

Tetryl<smiles>Cc1c([N+](=O)[O-])cc([N+](=O)[O-])cc1[N+](=O)[O-]</smiles>

TNT<smiles>Cc1ccc([N+](=O)[O-])cc1[N+](=O)[O-]</smiles>

2,4-DNT<smiles>Cc1c([N+](=O)[O-])cccc1[N+](=O)[O-]</smiles>

2,6-DNT<smiles>O=[N+]([O-])c1ccccc1</smiles><smiles>O=[N+]([O-])c1cccc([N+](=O)[O-])c1</smiles><smiles>O=[N+]([O-])c1cc([N+](=O)[O-])cc([N+](=O)[O-])c1</smiles><smiles>Cc1ccccc1[N+](=O)[O-]</smiles><smiles>Cc1cccc([N+](=O)[O-])c1</smiles><smiles>Cc1ccc([N+](=O)[O-])cc1</smiles>

NB 1,3-DNB 1,4-DNB

2-NT

3-NT

4-NT<smiles>O=[N+]([O-])c1ccc(O)c([N+](=O)[O-])c1</smiles>

NP<smiles>O=[N+]([O-])c1cccc2ccccc12</smiles>

NN<smiles>Cc1cc(C)cc([N+](=O)[O-])c1</smiles>

5-NX<smiles>Cc1cccc(C)c1[N+](=O)[O-]</smiles>

NX<smiles>O=[N+]([O-])c1cccc2ncccc12</smiles>

NQ<smiles>O=[N+]([O-])c1ccccc1Cl</smiles>

CINB<smiles>NC(C(=O)C(Cl)Cl)C(CO)C(O)c1ccc([N+](=O)[O-])cc1</smiles><smiles>CC(C)([N+](=O)[O-])C(C)(C)[N+](=O)[O-]</smiles>

$\mathrm{CH}_{3}-\mathrm{NO}_{2}$<smiles>CC[N+](=O)[O-]</smiles>

ClAmp

DMNB

NM

NE<smiles>O=[N+]([O-])N1CN([N+](=O)[O-])CN([N+](=O)[O-])C1</smiles>

RDX<smiles>O=[N+]([O-])N1CN([N+](=O)[O-])CN([N+](=O)[O-])CN([N+](=O)[O-])C1</smiles>

HMX<smiles></smiles>

PETN<smiles>O=[N+]([O-])OCC(CONO)O[N+](=O)[O-]</smiles>

TNG<smiles>O=C(OOC(=O)c1ccccc1)c1ccccc1</smiles>

BP<smiles>CC1(C)OOC(C)(C)OOC(C)(C)OO1</smiles>

TATP<smiles>OCN1COOCN(CO)COOC1</smiles>

HMTD

Figure 1. Chemical structures of the explosives cited in this review. 
Explosive compounds, that appeared in this review, are classified mainly into four classes: (i) nitroaromatics and nitroalkanes (ii) nitramines; (iii) nitrate esters; and, finally, (iv) peroxides (see Figure 1 for their chemical structures). ${ }^{16}$ Other class of explosives (such as nitrate salts and metal-based) does not appeared in Figure 1 because, as far as we know, chromogenic and/or fluorogenic sensors and reagents based on supramolecular concepts for their detection have not been described. Nitroaromatic explosives (such as 2,4,6-trinitrotoluene (TNT), 2,4dinitrotoluene (2,4-DNT) and picric acid (PA)) are composed of a benzene ring functionalised with several nitro groups. The detection of this class of explosives is not easy because they have moderate vapour pressures and their reactivity is quite limited. These electron-deficient molecules are able to form $\pi$-stacking complexes with electron-rich fluorophores, and this particular property has been widely used for their detection with chromo-fluorogenic probes. Nitroalkanes, such as 2,3-dimethyl-2,3-dinitrobutane (DMNB), are explosive taggants that present weak binding interactions with electron-rich derivatives, thus making their detection with supramolecular-based interactions extremely difficult. Nitramines (such as 1,3,5-trinitro-1,3,5-triazacyclohexane (RDX)) and nitrate esters (such as pentaerythritol tetranitrate (PETN)) are aliphatic explosives with $\mathrm{N}$ $\mathrm{NO}_{2}$ and $\mathrm{O}-\mathrm{NO}_{2}$ moieties, respectively. Although the lack of aromatic rings in both types makes their optical detection challenging, their unique functional groups allow detection through chemical reactions. Finally, peroxide-based explosives are easily synthesised from commercially available and inexpensive materials. In most cases, the strong oxidant character of these explosives has been used to design fluorogenic and chromogenic probes based on redox reactions coupled by colour/emission changes. 
This review aims to be a comprehensive recompilation of the examples reported in the literature relating to the design of chromogenic and fluorogenic chemosensors and reagents to recognise explosive molecules. The examples provided in this review are related to the application of supramolecularcoordination concepts for the development of optical receptors, and they do not cover optical sensors based on the use of biomolecules. Examples based on irreversible chemical reactions (the chemodosimeter approach) have also been included. This review has been divided into two main sections in relation with the design of (a) fluorescent/luminescent and (b) colorimetric probes. Each section is additionally divided to cover the type of chromo-fluorogenic group used to prepare the final sensing system.

\section{Fluorescence and luminescent sensors for explosives}

\subsection{Fluorescent Conjugated Polymers}

Fluorescent-conjugated polymers have been employed extensively as sensing materials in recent years. ${ }^{17,18}$ One of the features that have boosted the use of fluorescent-conjugated polymers as sensors relates to their ability to produce signal gain in response to an interaction with target analytes. Signal amplification is a direct consequence of the conjugated polymer's ability to serve as a highly efficient transport medium via the migration of excited states (excitons) through the polymer chain by mechanism that involves through space dipolar couplings and/or a strong mixing of electronic states. ${ }^{19,20}$ The first examples of amplifying polymer were developed by the research group of Swager using poly(phenylene ethynylene) with cyclophane receptors integrated in the polymeric backbone for coordination with paraquat (a powerful quencher). ${ }^{21}$ Since this work emerged, 
fluorescence-amplifying polymers have been extensively employed as sensing materials to detect metal cations, anions and neutral molecules. Explosives are included in the large family of neutral chemical species. The fact that many explosives are nitrated organic compounds with a marked electron-deficient character makes them efficient quenchers of fluorescence through photo-induced electron transfer (PET) processes. For these reasons, ever increasing interest has been paid to the development of fluorescent-conjugated amplifying polymers for the detection of explosives.

A number of examples have been reported, most of which are based on the use of poly(phenylene ethynylene)s, poly(phenylene vinylene)s and Si-containing polymers. This section also includes some examples of molecular imprinting polymers (MIPs) for the detection of explosives.

\subsubsection{Poly(phenylene ethynylene)s}

Poly(phenylene ethynylene)s are conjugated polymers that have been widely used as active materials in fluorescence-based chemical sensors because of their high sensitivity to a variety of solution- and vapour-phase analytes. In the specific field of sensing explosives, poly(phenylene ethynylene)s polymers have been widely employed since the pioneering work of T. M. Swager et al. In most cases, polymers are used as films. In this case, the materials' response characteristics depend on a number of parameters, including the strength of the chemical (or physical) interaction between the analyte and the photoactive polymer, and the permeability of the analyte in the polymer. In this sense, Swager et al have additionally shown that the use of the sterically demanding pentiptycene moiety increases the permeability of the fluorescent poly(phenylene ethynylene)s 
polymers films, thus increasing the material's response to vapour-phase explosives. Additionally, the incorporation of the rigid three-dimensional pentiptycene molecule into the polymeric backbone prevents low quantum yields due to $\pi$-stacking, excimer formation and self quenching, which usually show some other fluorescent polymers. A bulky pentiptycene moiety is believed to create molecular-scale channels, which provide pathways for the analyte molecules to diffuse and readily interact with the electron-rich $\pi$-conjugated system in the polymer. This resulting increase in permittivity has been reported to allow nitroaromatics to quench the polymer's fluorescence more rapidly and more efficiently compared to similar polymeric materials lacking the stericallydemanding groups. In all the following examples, the quenching mechanism is similar, and involves an electron transfer process between the corresponding excited polymer and electron acceptor nitroaromatic explosive molecules.

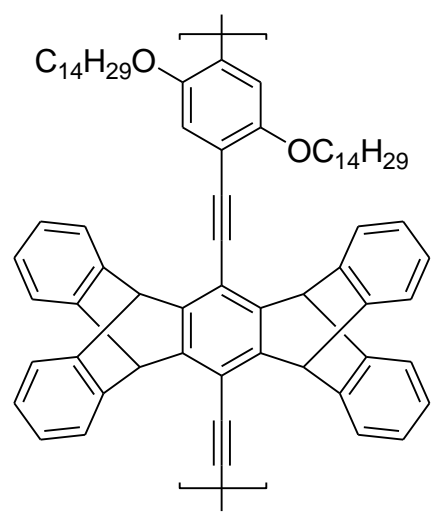

1

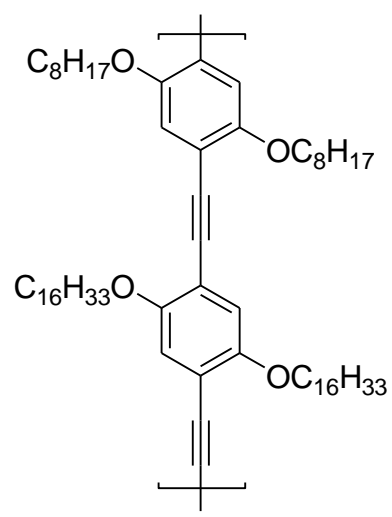

2

Figure 2. Structures of polymers 1 and $2^{22}$

Along these lines, T. M. Swager et al prepared polymers 1 and $\mathbf{2}$ (Figure 2), and showed how they underwent severe fluorescence quenching in the presence of 
TNT and 2,4-DNT vapours. ${ }^{22}$ The intensity of emission quenching was influenced by the exposure time and by thin film thickness. The best results were obtained with films of $25 \AA$ and with exposure times of 60 seconds $(100 \%$ and $75 \%$ quenching with 2,4-DNT and TNT, respectively, for 1-containing films). Also, polymer 1 was incorporated in a man-portable sensor prototype that was used for the detection of landmine signature vapours in air at ultratrace concentration levels (femtograms of TNT / mL of air). ${ }^{17}$

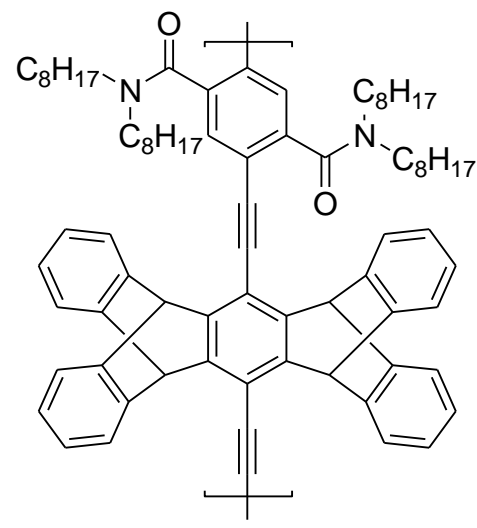

3

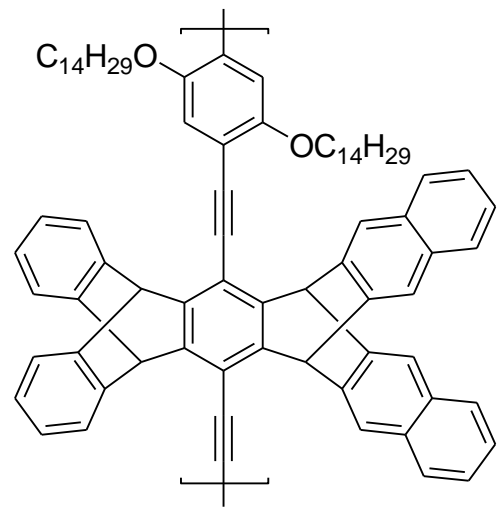

4

Figure 3. Structures of pentiptycene-containing polymers 3 and $4 .^{23}$

In an extended version of their previous work, Yang and Swager synthesised pentiptycene-containing polymers $\mathbf{3}$ and $\mathbf{4}$ (Figure 3) for the vapour-phase sensing of nitroaromatic compounds. ${ }^{23}$ A $200 \AA$ film of polymer 3 showed an emission band at $423 \mathrm{~nm}$, whereas the films of polymer 4 exhibited two emission bands at 463 and $497 \mathrm{~nm}$; the latter was assigned to the formation of an excimer. The fluorescence of the thin films of both polymers was quenched, be it to different extents, in the presence of nitroaromatic derivatives such as TNT, 2,4-DNT and nitrobenzene (NB). Quenching efficiencies were higher for polymer $\mathbf{4}$ than for $\mathbf{3}$ due to the electron-withdrawing character of the amide groups in the structure of 
3. The amide groups make polymer $\mathbf{3}$ less electron donor, when compared with $\mathbf{4}$. Moreover, the interaction with the nitroaromatic compound was weaker, leading to moderate quenching efficiencies.
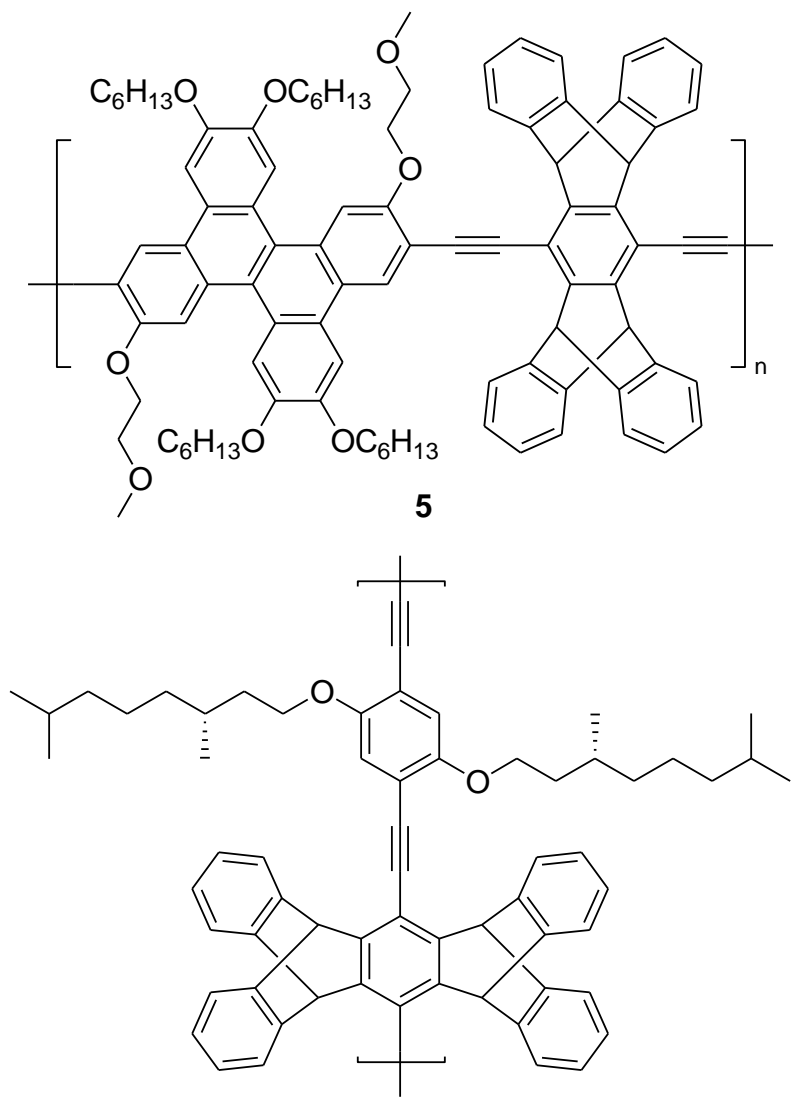

6

Figure 4. Structures of pentiptycene-containing polymers 5 and $6 .^{24,25}$

The related pentiptycene-containing polymers 5 and $\mathbf{6}$ (Figure 4) also displayed sensing ability for TNT. ${ }^{24,25}$ The films of 5 presented an emission band at $474 \mathrm{~nm}$, which was quenched in the presence of TNT vapours. This polymer showed higher sensitivity to TNT than that observed for polymers 1-4. The films of 6 presented an 
intense emission band at $475 \mathrm{~nm}$, which was severely quenched (by about 75\%) upon exposure to $10 \mathrm{ppb}$ of the TNT vapours.

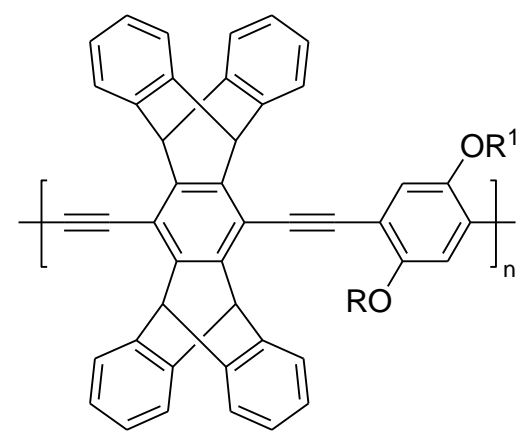

$$
7 \mathrm{R}, \mathrm{R}^{1}=\mathrm{C}_{16} \mathrm{H}_{33}
$$<smiles>[R]CCCC=CCC(O)(C(F)(F)F)C(F)(F)F</smiles><smiles>[R][R]=CCCCC=CCC(O)(C(F)(F)F)C(O)(C(C)(F)F)C(F)(F)F</smiles>

Figure 5. Structures of polyacetylene pentiptycene-containing polymers $\mathbf{7 , 8}$ and $\mathbf{9 .}^{26}$

Swager et al. also reported the design of the polyacetylene pentiptycenecontaining polymers 7-9 (Figure 5) and tested their emission behaviour in the presence of electron deficient molecules. ${ }^{26}$ Polymers 8 and 9 contain pendant hexafluoro-2-propanol groups, therefore displaying a strong hydrogen-bonding donating character. The exposure of polymers 7-9 to the vapours of 2,4-DNT brought about a moderate quenching of the emission intensities (between 16\% and $28 \%$ ). Almost the same response was observed in the presence of the vapours of 2,4-dichloropyrimidine for all three polymers. In addition to the usual $\pi$ stacking interactions between these polymers and analytes, a coordinate interaction via hydrogen-bonding forces between electron-deficient molecules and the hexafluoro-2-propanol moiety also occurred for polymers 8 and $\mathbf{9}$. 


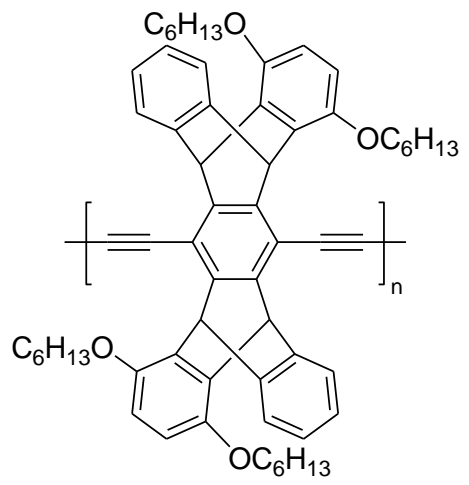

10

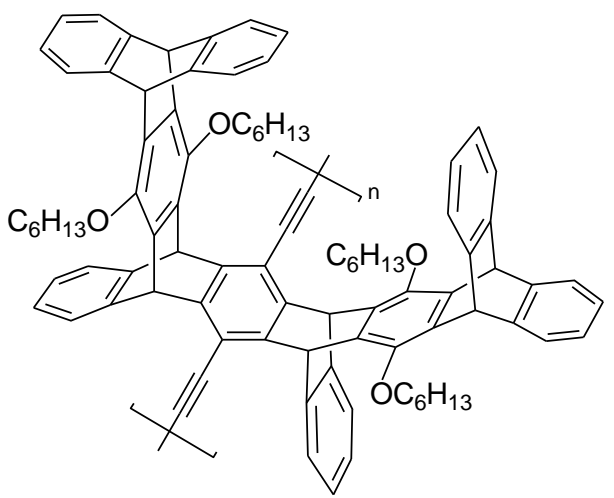

12

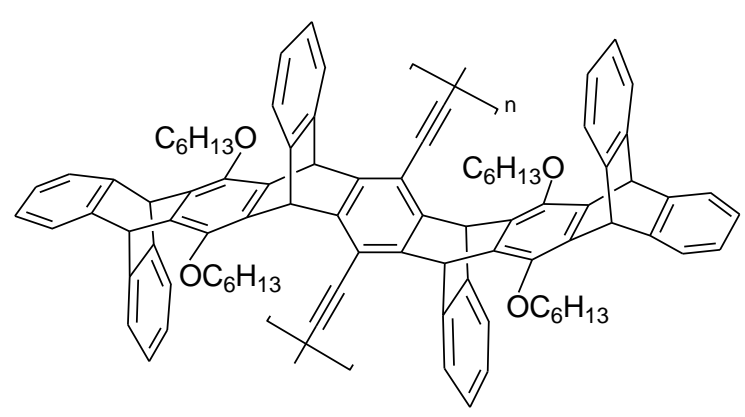

11

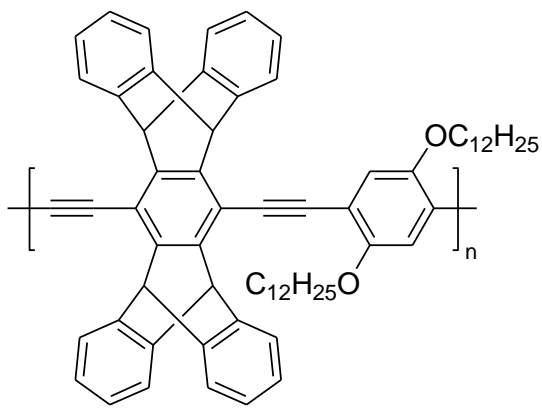

13

Figure 6. Structures of pentiptycene-containing polymers 10, 11, 12 and $13 .^{27}$

Following the use of the pentiptycene-containing polymers to recognise nitroaromatic compounds, Swager's research group recently prepared derivatives 10-13 (Figure 6). ${ }^{27}$ In a chloroform solution, polymers 10-12 showed intense emission bands in the 420-430 nm interval, which were effectively quenched upon addition of TNT, 2,4-DNT and 4-nitrotoluene (4-NT). The most efficient quencher was TNT, while 4-NT was the least effective. Virtually the same response was observed for polymer $\mathbf{1 3}$ in a chloroform solution. Thin films of all four polymers were prepared by spin-casting. The emission of the films of 10-13 was quenched 
upon the addition of TNT and 2,4-DNT (quenching was lower for 10-12 than for 13).
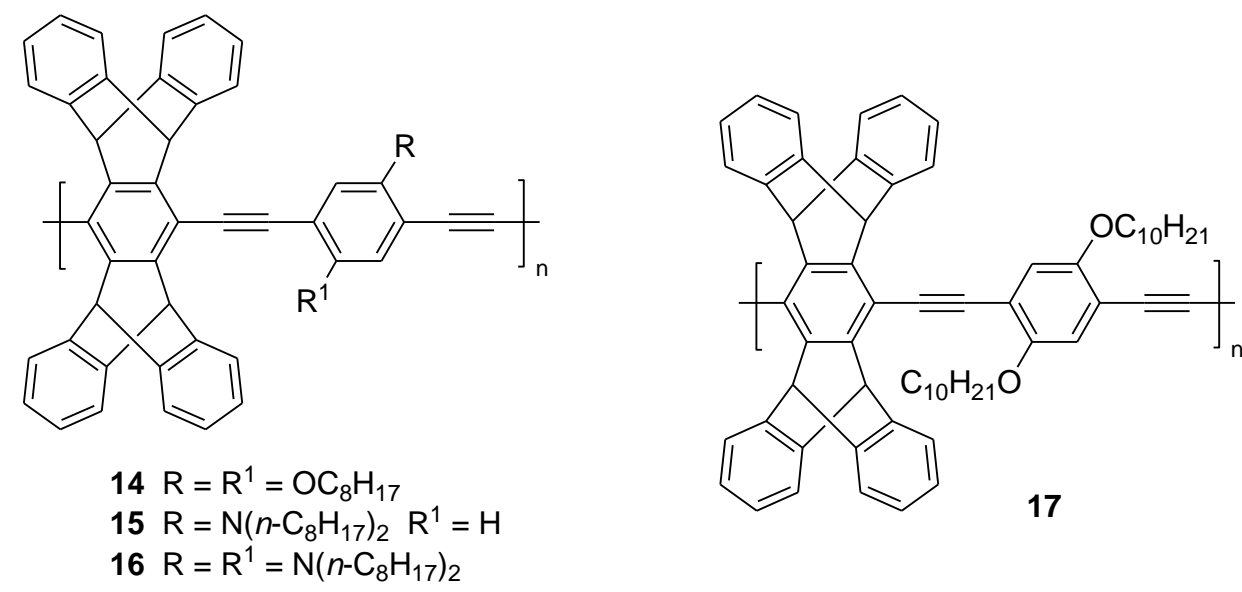

Figure 7. Structures of polymers $14,15,16$ and $17 .^{28,29}$

Polyacetylene pentiptycene-containing polymers 14-16 (Figure 7) have been used for the fluorescent sensing of 2,3-dimethyl-2,3-dinitrobutane (DMNB), which is an additive required in all legally manufactured plastic explosives. ${ }^{28}$ The thin films of poly(phenylene ethynylene) polymers 14-16 showed very weak fluorescent quenching (about 5\% for 15) in the presence of DMNB vapours. The moderate quenching observed with DMNB, when compared with those obtained in the presence of nitroaromatic compounds, was ascribed to the threedimensional shape of this compound, and to the lack of $\pi$-stacking interactions with the polymer chains that induced weak binding.

Polyacetylene-containing polymer 17 exhibited multi-photon excitation and was used for the fluorescent recognition of TNT. ${ }^{29}$ In line with this, the two- or 
three-photon excitation of the solutions of $\mathbf{1 7}$ displayed an emission band at $\mathbf{4 6 0}$ $\mathrm{nm}$, which was quenched in the presence of TNT.

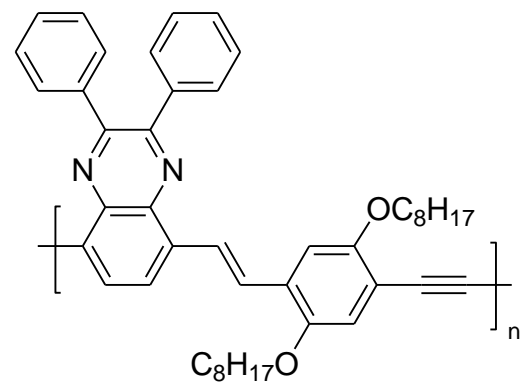

18

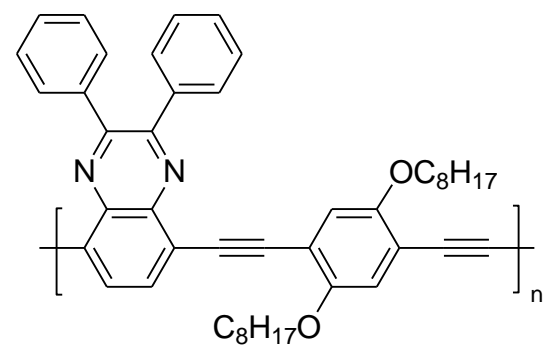

19

Figure 8. Structures of quinoxaline-containing polymers 18 and $19 .^{30}$

Apart from the remarkable work of Swager et al using polyacetylene pentiptycene-containing polymers, polyacetylene derivatives containing quinoxaline and dibenz $[a, h]$ anthracene groups have also been reported for the fluorogenic sensing of nitroaromatic explosives. Zhang et al reported the emission quenching of quinoxaline-containing polymers 18 and 19 (Figure 8) in the presence of TNT. ${ }^{30}$ The chloroform solutions of both polymers displayed intense emission bands at 620 and at $500 \mathrm{~nm}$ for 18 and 19, respectively, which were gradually quenched upon the addition of increasing amounts of TNT. The same quenching effect in the presence of TNT vapour was observed when using the films of 18 and 19. The authors observed a more efficient quenching when using polymer 19. They ascribed this feature to the fact that this polymer has a more planar backbone if compared with polymer 18, which enables easier exciton migration. 


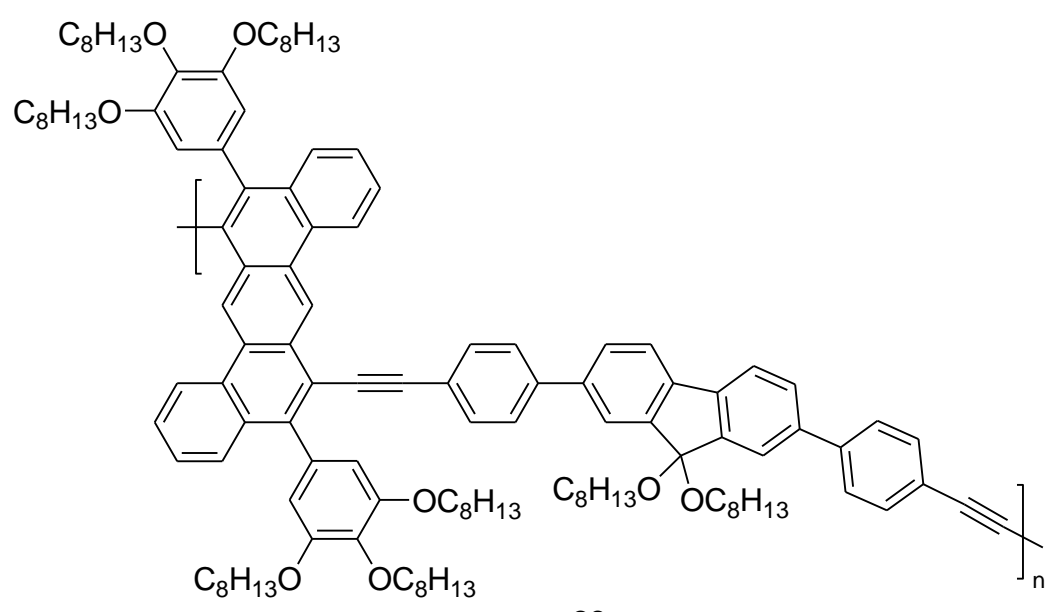

20

Figure 9. Structure of dibenz[a,h]anthracene-containing polymer $20^{31}$

Additionally, Liu et al reported the use of dibenz $[a, h]$ anthracene-containing polymer 20 (Figure 9) for the detection of 2,4-DNT. 20 showed two intense emission bands at 427 and $453 \mathrm{~nm}$ in chloroform, which were significantly quenched in the presence of 2,4-DNT. ${ }^{31}$ As in the aforementioned cases, the quenching effect was due to a PET process favoured by the formation of a complex between the electron-rich polycyclic backbone of $\mathbf{2 0}$ with the electrondeficient 2,4-DNT through $\pi-\pi$ stacking interactions. The films of 20 were prepared by spin-casting or electrospinning using polystyrene as a supporting matrix. Emission of both types of films was quenched upon exposure to 2,4-DNT vapours, but the degree of quenching was greater for the electrospinning film ( $50 \%$ after a 1-h exposure) than for the spin-casting film (about 5\% for the same exposure time). This remarkable difference in sensing performance was ascribed to the formation of a nanofibrous-sensing film with a large surface area and unique porous structure by means of the electrospinning technique. The film's sensitivity was further improved by introducing a secondary porous system into 
the nanofibres through the addition of sodium dodecylsulphate as a porogen agent during the electrospinning process.

\subsubsection{Polyphenylene vinylenes}

Chemosensing applications based on the quenching of light-emitting poly(phenylene vinylene) polymers in the presence of nitroaromatic vapours has also been widely used for the detection of explosive derivatives. For instance, the thin films of polymers $\mathbf{2 1}$ and $\mathbf{2 2}$ (Figure 10) on a cover glass show intense emission bands at 574 and $488 \mathrm{~nm}$, respectively, which were quenched in the presence of TNT vapours. ${ }^{32}$

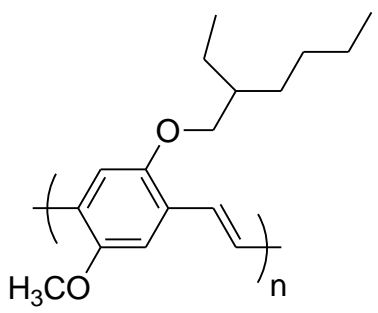

21

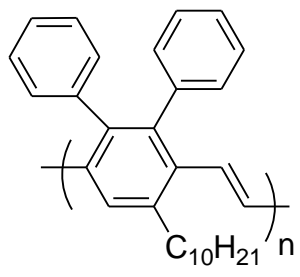

22

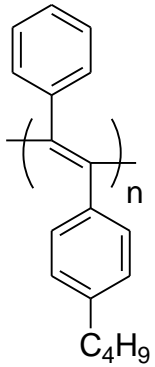

23

Figure 10. Structures of poly(phenylene vinylene) polymers 21, 22 and poly(diphenylacetylene) derivative $\mathbf{2 3}^{32,33}$

The highest quenching efficiency was measured for the thin films of $\mathbf{2 1}$ (90\% after 1000 seconds of exposure) and was ascribed to the strong polar-polar interaction of the donor moieties of $\mathbf{2 1}$ (not present in 22) with the nitroaromatic molecule. Poly(diphenylacetylene) derivative $\mathbf{2 3}$ was also studied. In this case, the emission band at $517 \mathrm{~nm}$ was also quenched in the presence of TNT vapours. Other nitroaromatic compounds, such as 2,4-DNT, 2,6-dinitrotoluene (2,6-DNT) and 4-NT, also led to a quenching of the emission intensity of the three polymers. 
As in other similar cases, emission quenching was ascribed to a PET process between the excited polymer and the nitroaromatic explosive.

The response of $\mathbf{2 1}$ has also been modulated by entrapping the polymer in porous silicon microcavities. ${ }^{33}$ In this situation, the fluorescence spectra of polymers were modulated by a microcavity via a spectral "hole" that matches the resonance peak of microcavity reflectance. With TNT vapours present, a red shift (2-3 nm) of the resonance peak occurred along with fluorescence quenching. The authors indicated that this provided the opportunity for multiple monitoring parameters to help develop an optical sensor array as fluorescence attenuated differently at various wavelengths if compared to the uniform quenching of polymers deposited on a flat substrate.

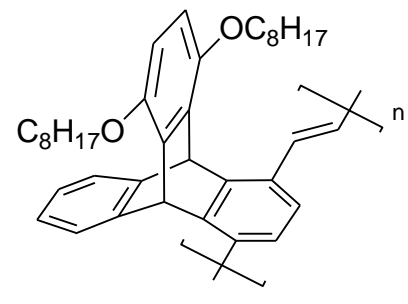

24

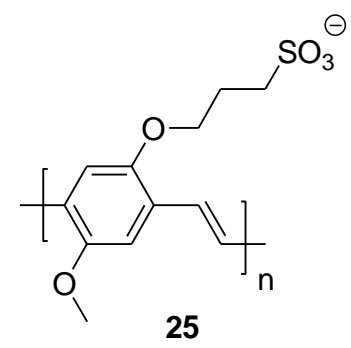

25

Figure 11. Structures of polymers 24 and $25 . .^{29,34}$

Polyphenylene vinylene polymer 24 (Figure 11) presented bulky iptycene moieties in the backbone, which minimised the interaction between chains and prevented self-quenching. ${ }^{29}$ Besides, the presence of iptycene moieties enhanced the permeability of the polymer by increasing the material's response to nitroaromatic explosives. In line with all this, $\mathbf{2 4}$ showed an intense emission band (a quantum yield of 0.76 ) centred at $477 \mathrm{~nm}$, which was quenched in the presence of TNT. 
Water soluble poly(2,5-methoxy-propyloxysulphonate phenylene vinylene) (25) polymers have also been reported to act as optical chemosensors for nitroaromatics. ${ }^{34}$ The aqueous solutions of $\mathbf{2 5}$ presented an intense emission band, which was severely quenched in the presence of methyl viologen $\left(\mathrm{MV}^{2+}\right)$ due to the strong association between the negatively-charged polymer and the positively-charged quencher. Under these conditions, neutral molecules such as TNT and 2,6-DNT presented quenching sensitivities of three orders of magnitude lower than that of $\mathrm{MV}^{2+}$. Quenching behaviour was modulated by the addition of a cationic surfactant (dodecyltrimethylammonium bromide, DTA). In relation to this, DTA was able to neutralise the negative charge of $\mathbf{2 5}$ and to also create a hydrophobic environment around the polymer chains. Under these conditions, quenching in the presence of $\mathrm{MV}^{2+}$ was less effective, whereas quenching by nitroaromatic derivatives was enhanced. Thus, aqueous solutions of $\mathbf{2 5}$ and DTA in a 3:1 ratio provided an intense emission, which was quenched efficiently upon the addition of TNT and 2,6-DNT. Similarly, the thin films of $\mathbf{2 5}$ and a cationic polyelectrolyte (DTA or diallyldimethylammonium chloride (PDDA)) were successfully used for the detection of 2,6-DNT vapours.

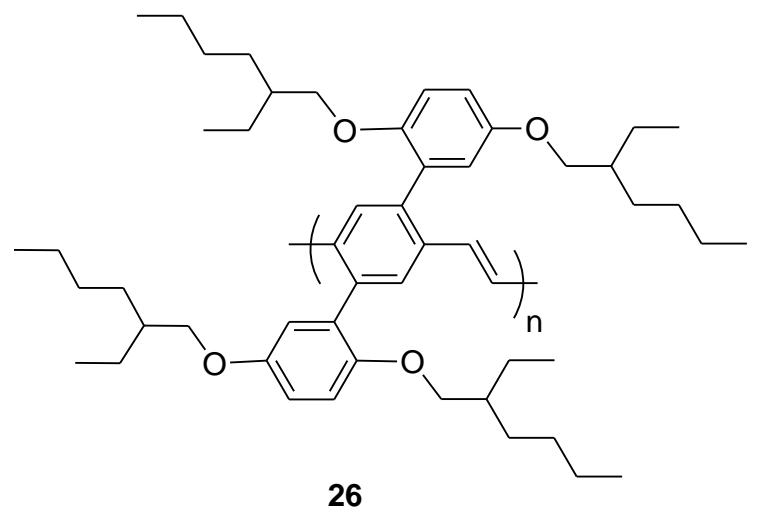

Figure 12. Structure of semiconducting organic polymer $26 .{ }^{35}$ 
Semiconducting organic polymer $\mathbf{2 6}$ (Figure 12) was synthesised and used for the fluorescent sensing of TNT and 2,4-DNT vapours. ${ }^{35}$ The thin films of $\mathbf{2 6}$ gave an intense emission band at $500 \mathrm{~nm}$, which was quenched in the presence of TNT and 2,4-DNT. For the fabrication of solid sensors with amplified signalling, three devices were constructed: (i) the spin-coated films of $\mathbf{2 6}$ on a transparent parylene, forming a two-layer index-matched waveguide on glass; (ii) the spincoated films of $\mathbf{2 6}$ on distributed feedback gratings fabricated from polydimethylsiloxane; and (iii) the dip coating of polymer $\mathbf{2 6}$ on a silica optical fibre. Upon the excitation of these devices with a 4-ns nitrogen laser operating at a frequency of $30 \mathrm{~Hz}$, a multimode lasing action was generated and an intense amplified emission was observed. This emission was quenched in the presence of TNT and 2,4-DNT, whose sensitivity was 30 times greater than that observed with the single polymer. The selectivity of the response was based on the strong binding of analytes to electron-rich polymers. No interference was observed with benzene or naphthalene.

\subsubsection{Si-containing polymers.}

Within the family of Si-containing polymers, silole- and silafluorene-containing polymers have been reported for the fluorogenic detection of organic nitro derivatives. Polysiloles are conjugated polymers with a highly delocalised structure which contain the silacyclopentadiene (silole) group. Siloles proved to be of considerable current interest due to their unusual electronic and optical properties, and because of their possible applications as electron transporting materials in certain devices. ${ }^{36}$ These polymers are highly luminescent and have been used as light-emitting diodes $\left(\right.$ LEDs) ${ }^{37}$ or as chemical sensors. ${ }^{38}$ The characteristic features of polysiloles include a low reduction potential, and a low- 
lying Low Unoccupied Molecular Orbital (LUMO) which leads to visible fluorescence due to $\sigma * \rightarrow \pi *$ conjugation arising from the interaction between the $\sigma^{*}$ orbital of the silicon chain and the $\pi^{*}$ orbital of the butadiene moiety of the five-member ring. The usual high sensitivity of these polymers is related with favourable analyte-polymer hydrophobic interactions. Electron delocalisation in these polysiloles provides amplification because the interaction of an analyte molecule at any position along the polymeric chain quenches an excited state delocalised along the chain.

Silafluorene-containing polymers presented similar electronic features to those of polysiloles, but the presence of a biphenyl framework increased the band gap energy allowing UV-blue emission. Normally, silafluorene moiety was incorporated into $p$-vinylene polymeric backbones, which allows polymer flexibility and thermal stability to increase, while maintaining electronic delocalisation. $^{39}$

The final polysiloles and silafluorene-containing polymers presented high quantum yields and excellent detection limits for explosive materials. The good sensitivity of polysiloles and silafluorene-containing polymers arises from the orbital energy matching between the excited-state ${ }^{1}$ SOMO (singlet singly occupied excited donor molecular orbital) of the polymeric materials and the LUMO of the explosive molecule. Another important factor is the silacycle moiety's (Lewis acid) ability to bind with the oxygen atoms in the nitro groups of explosive molecules. This interaction leads to an efficient PET from the polymer donor to the electronaccepting explosive. 
A comparative study with the organic pentiptycene-containing polymers described in the previous section (see above) indicates that polysiloles and, in general, polymetalloles or metallole-copolymers, exhibit better quenching efficiencies than the former ones in toluene solution. ${ }^{22}$ However, organic pentiptycene-derived polymers offer superior sensitivity as solid-state sensors because of their higher molecular weight and more efficient energy migration in the solid state.

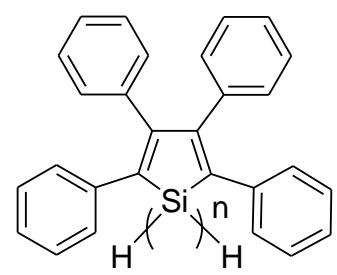

27

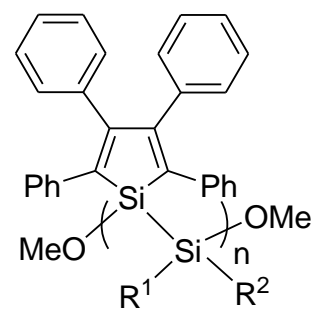

$28 \mathrm{R}^{1}=\mathrm{H} ; \mathrm{R}^{2}=\mathrm{Me}$

$29 \mathrm{R}^{1}=\mathrm{H} ; \mathrm{R}^{2}=\mathrm{Ph}$

$30 \quad \mathrm{R}^{1}=\mathrm{Ph} ; \mathrm{R}^{2}=\mathrm{Me}$

$31 \mathrm{R}^{1}=\mathrm{H} ; \mathrm{R}^{2}=\mathrm{H}$

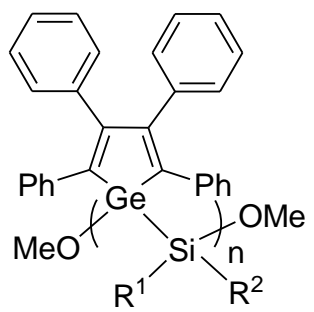

32

33

34

35

Figure 13. Structures of polytetraphenylsilole $\mathbf{2 7}$ and polymers and co-polymers 28-35 containing tetraphenylsilole or tetraphenylgermole. ${ }^{40,41,42}$

Trogler and colleagues reported the use of polytetraphenylsilole 27 (Figure 13) as a suitable sensing polymer for TNT detection by fluorescence quenching. ${ }^{40}$ This inorganic polymer is stable to air, water, acids, common organic solvents and even seawater-containing bioorganisms as the most common interferents. The colloidal nanoparticles of $\mathbf{2 7}$ in tetrahydrofurane (THF)/ $\mathrm{H}_{2} \mathrm{O}$ suspensions were also prepared. ${ }^{41}$ They were obtained by adding water (in different percentages) to the THF solutions of polymer 27 . The volume-fractions between $80-90 \%$ of water induced the precipitation of highly fluorescent nanoparticles with a diameter of ca. $80 \mathrm{~nm}$. Addition of TNT to the suspensions of nanoparticles induced an 
impressive quenching of the emission intensity (quenching efficiencies improved by more than $400 \%$ for nanoparticles in relation to the dissolved oligosilole). Under these conditions, a detection limit below 20 ppb for TNT was obtained.

The same group synthesised polymers and co-polymers 28-35 (see Figure 13) containing tetraphenylsilole or tetraphenylgermole with $\mathrm{Si}-\mathrm{Si}, \mathrm{Ge}-\mathrm{Ge}$ and $\mathrm{Si}-\mathrm{Ge}$ backbones. ${ }^{42}$ Using these systems, detection of nitroaromatic molecules such as NB, 2,4-DNT, TNT and PA were explored. Upon the excitation of the toluene solutions of polymers 28-35 at $340 \mathrm{~nm}$, intense emission bands in the $480-510 \mathrm{~nm}$ range were observed. Addition of NB, 2,4-DNT, TNT and PA to the toluene solutions of polymers brought about different quenching degrees. Quenching efficiency followed the order of PA > TNT > 2,4-DNT > NB, which is clearly related with the electron acceptor character of nitroaromatic molecules. Each polymer's emission quenching was different in the presence of the same nitroaromatic derivative, and the deactivation degree of a given polymer also differed depending on the explosives tested. In addition, these polymers were robust and insensitive to common interferents, such as organic solvents and inorganic acids. Finally, the authors suggested their possible use in sensing arrays to identify nitrated explosives by pattern recognition procedures.

Trogler et al also evaluated the spectroscopic response of polymers 37-39 (Figure 14) in the presence of nitrated explosives. ${ }^{43}$ The toluene solutions of polymers $\mathbf{3 7}$ and $\mathbf{3 8}$ presented two intense absorption bands at ca. $300 \mathrm{~nm}$ and $390 \mathrm{~nm}$, whereas polymer 39 showed only one band at $295 \mathrm{~nm}$. Upon excitation, the toluene solutions of polymers $\mathbf{3 7}$ and $\mathbf{3 8}$ revealed intense emission bands at $493 \mathrm{~nm}$ and $492 \mathrm{~nm}$ for 37 and 38, respectively. For the toluene solutions of polymer 39, an intense emission band at $362 \mathrm{~nm}$ was noted. 


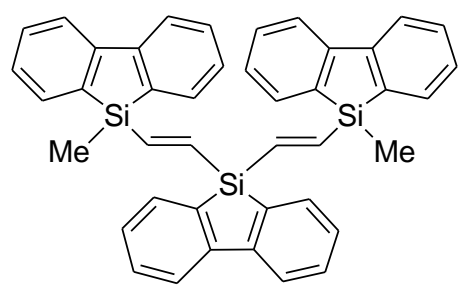

36

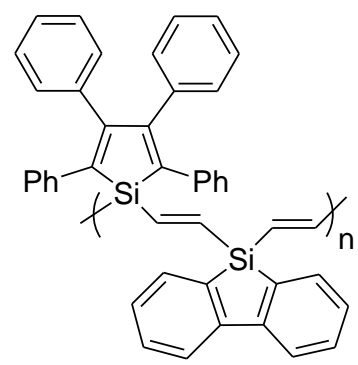

37

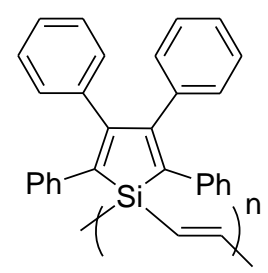

38

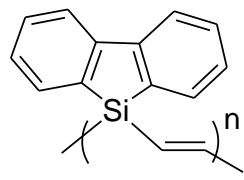

39

Figure 14. Structures of trimer 36 and polymers 37-39. ${ }^{43}$

The emission bands of the three polymers were quenched to different extents upon the addition of nitroaromaric explosives TNT, 2,6-DNT and PA to the toluene solutions containing 37-39, whereas addition of RDX induced negligible changes. Quenching efficiency followed the order of PA > TNT > 2,6-DNT. ${ }^{29} \mathrm{Si}-\mathrm{NMR}$ (nuclear magnetic resonance) measurements of the interaction mode between trimer $\mathbf{3 6}$ (the model compound of polymer 39) and TNT were carried out. They indicated a Lewis acid-base interaction between the nitro groups of the nitroaromatic explosive and the silicon centres which facilitated an electron transfer process, yielding the quenching observed. Finally, and in order to test the possibility of applying these polymers in the detection of solid explosives, the response of the thin films of polymers 37-39 was analysed in the presence of TNT, 2,6-DNT, PA, RDX, octahydro-1,3,5,7-tetranitro-1,3,5,7-tetrazocine (HMX), 2,4,6trinitrophenylmethylnitramine (Tetryl), trinitroglycerin (TNG) and PETN in the 
solid state. Polymers $\mathbf{3 7}$ and $\mathbf{3 8}$ exhibited emission quenching only in the presence of nitroaromatic explosives, whereas the emission of polymer $\mathbf{3 9}$ was quenched in the presence of all the explosives tested (with a remarkable detection limit of 200 pg $\mathrm{cm}^{-2}$ for Tetryl).
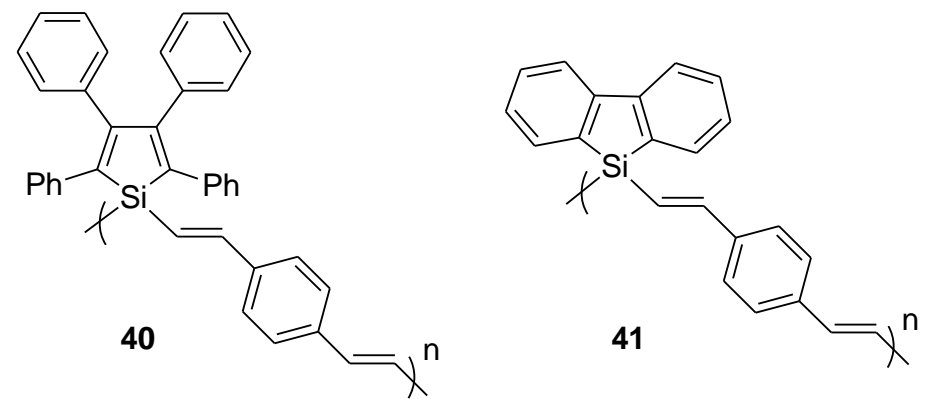

Figure 15. Structures of phenylene-divinylene-conjugated polymers $\mathbf{4 0}$ and $\mathbf{4 1} .^{44}$

In another work, the same authors developed phenylene-divinyleneconjugated polymers $\mathbf{4 0}$ and $\mathbf{4 1}$ (Figure 15) to test the influence of the phenylene aromatic ring in the detection of explosives. ${ }^{44}$ Polymers $\mathbf{4 0}$ and $\mathbf{4 1}$ were used for the fluorescent signalling of TNT, Tetryl, 2,4-DNT, PA, PETN, RDX, TNG and HMX in the solid state. Thin films showed intense emission bands which centred at 478 and $447 \mathrm{~nm}$ for $\mathbf{4 0}$ and $\mathbf{4 1}$, respectively. The emission of the thin films of $\mathbf{4 0}$ was quenched in the presence of the solid particles of nitroaromatic explosives (TNT, Tetryl, 2,4-DNT and PA) located on different surfaces (porcelain and filter paper), whereas the fluorescence of the films containing $\mathbf{4 1}$ was quenched in the presence of all the tested explosives. Neither polymer showed interference when films were exposed to common organic solvents (THF, benzene, toluene, acetonitrile, acetone and methanol), but gave some response in the presence of benzophenone and benzoquinone (oxidising aromatic molecules). 


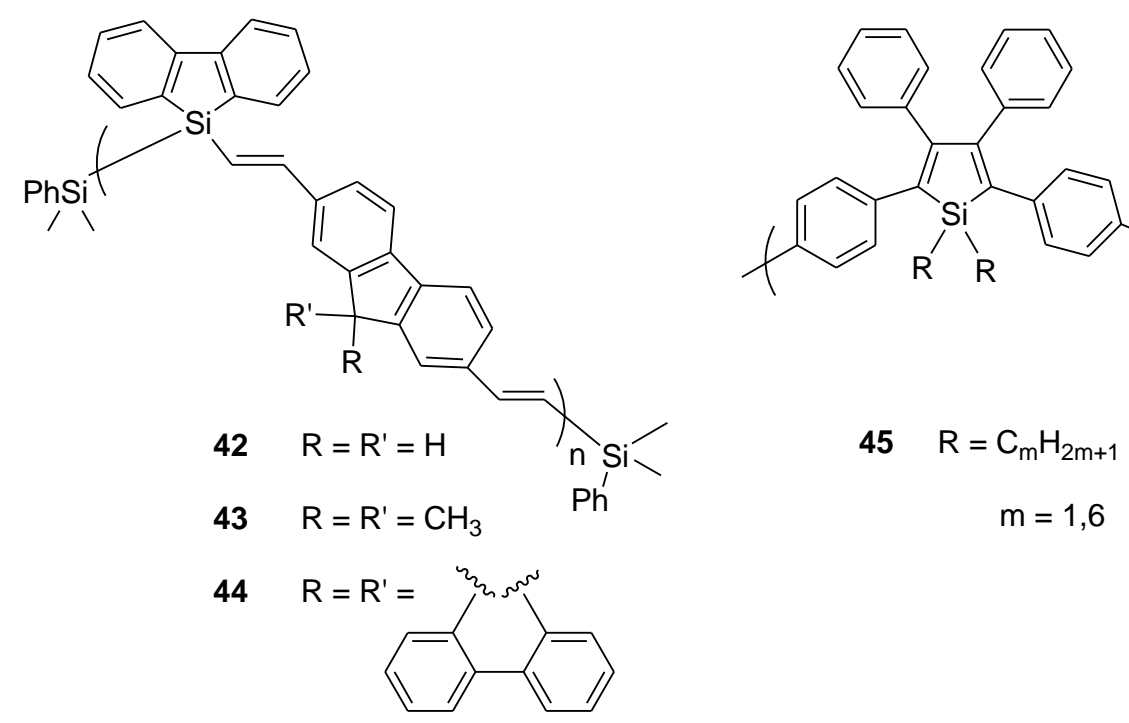

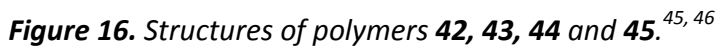

Trogler and Sanchez reported polymers 42-44 (Figure 16) containing fluorenyl units anchored on the silicon centre of the silafluorene moiety via vinylene groups. ${ }^{45}$ Polymers contain trans-only frameworks with molecular weights in the range of 13000-20000. Upon excitation of the toluene solutions of 42-44 at 345 $\mathrm{nm}$, intense emission bands were observed at ca. $\mathbf{3 7 6} \mathrm{nm}$ for $\mathbf{4 2}$ and $\mathbf{4 3}$ and at 392 for 44. The thin films of these polymers were tested for the fluorescent detection of TNT, Tetryl, 2,4-DNT, PA, PETN, RDX, TNG and HMX in the solid state. As observed in other related polymers, the emission of 42-44 was quenched to a different extent in the presence of solid explosives. Lower detection limits were obtained for Tetryl $\left(1 \mathrm{pg} \mathrm{cm}^{-2}\right)$ using the thin films of polymer $\mathbf{4 2}$. Additionally, polymer $\mathbf{4 2}$ produced a turn-on fluorescence mechanism in the presence of PETN. Addition of PETN to the thin films of $\mathbf{4 2}$ induced initial emission quenching, but continued exposure to UV (ultraviolet)-light promoted the photochemical 
oxidation of fluorenyl moieties, which yielded a luminescent green fluorenone copolymer.

Very recently, Tang et al prepared hyperbranched poly(2,5-silole)s, which are closely related with the polymers described above. ${ }^{46}$ The THF solutions of polymer 45 (see Figure 16) produced an absorption band centred at ca. $379 \mathrm{~nm}$, and weak emission bands at 507 and $509 \mathrm{~nm}$ for $\mathrm{m}=1$ and $\mathrm{m}=6$, respectively (excitation at $373 \mathrm{~nm}$ ) due to the presence of active intramolecular rotations of the phenyl rings of the tetraphenylethene units that effectively deactivated the excited state of the polymer through rotational energy relaxation channels. However, addition of water to the THF solutions of $\mathbf{4 5}$ (up to $90 \%$ ) induced the formation of highly fluorescent aggregates. These emission enhancements were ascribed to an inhibition of the free rotation of the phenyl rings upon aggregation. Emission intensity was quenched with the gradual addition of PA to the THF-water 1:9 v/v suspensions of the aggregated nanoparticles. The detection limit of PA using $\mathbf{4 5}$ was $1 \mathrm{ppm}$. The fact that the aggregated polymer presented internal cavities, plus the Lewis acid-base interactions between the silole moieties and the nitro groups of PA, favoured an efficient photo-induced electron transfer accounting for the observed quenching.

Apart from the use of silole- and silafluorene-containing systems, other Sicontaining polymers have been reported for the detection of explosives. For instance, Cheuk et al recently published the hyperbranched poly(silylenevinylene) polymer 46 (Figure 17). ${ }^{47}$ The THF solutions of $\mathbf{4 6}$ presented a weak emission band at $500 \mathrm{~nm}$ which, like the case cited above, was enhanced in the presence of water due to polymer aggregation. The sensing behaviour of polymer 46 resembled that obtained for $\mathbf{4 5}$, and the addition of PA to the THF-water 1:9 v/v 
suspensions of the aggregated nanoparticles of $\mathbf{4 6}$ induced immediate quenching. The detection limit measured for PA was about 1 ppm.

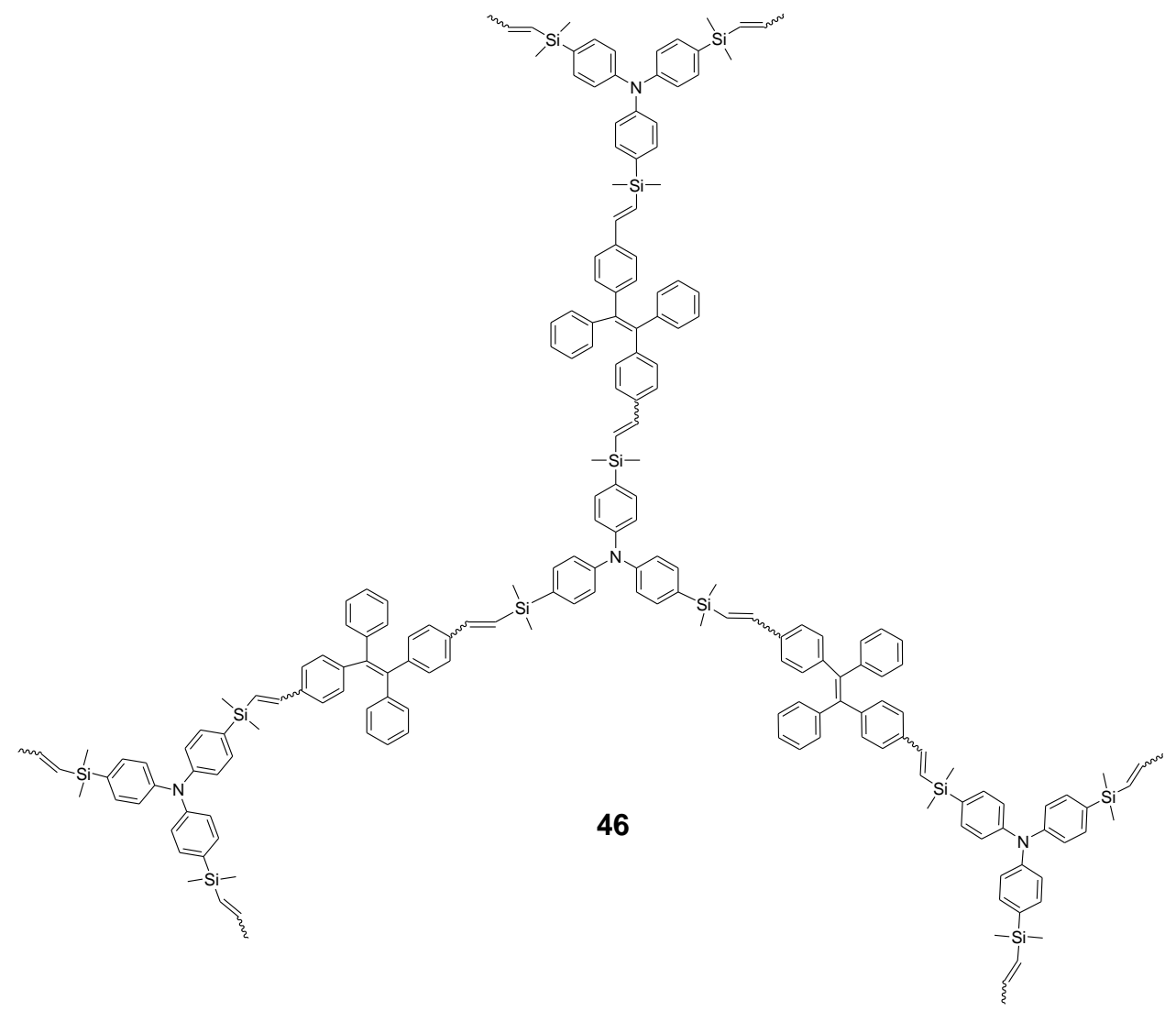

Figure 17. Structure of hyperbranched poly(silylenevinylene) polymer $46{ }^{47}$

Schanze et al prepared fluorescent thin films using polymer poly[1-phenyl-2-(4trimethyl)sililphenyl]ethyne 47 (Figure 18). ${ }^{48}$ This polymer was highly permeable to light gases (i.e., $\mathrm{N}_{2}, \mathrm{O}_{2}, \mathrm{H}_{2}$ ) and hydrocarbon vapours. ${ }^{49}$ This high permeability was ascribed to the polymers' large fractional free volume and to the presence of interconnected channels that allow small molecules to rapidly diffuse within the matrix. These authors observed that the fluorescence of polymer $\mathbf{4 7}$ was strongly quenched by vapours from a variety of nitroaromatic compounds $(1,4-$ 
dinitrobenzene (1,4-DNB), 1,3-dinitrobenzene (1,3-DNB), 2,6-DNT, 2,4-DNT, 4-NT and NB), present at levels ranging from ppm to ppb in air. As with other polymers, quenching is believed to arise from the formation of charge-transfer complexes between electron-poor nitroaromatic quenchers and electron-rich $\mathbf{4 7}$.

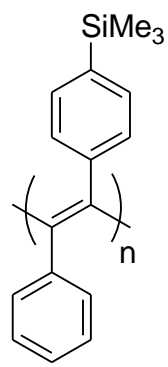

47

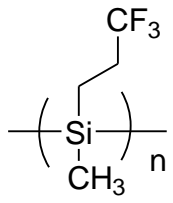

48

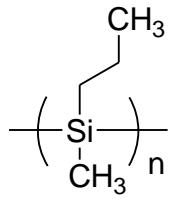

49

Figure 18. Structures of polymers 47,48 and $49 .^{48,49,50}$

Fujiki et al prepared polymers 48 and 49 (see Figure 18) and tested their fluorescent behaviour in the presence of nitroaromatic explosives. ${ }^{50}$ The THF solutions of $\mathbf{4 8}$ showed an intense emission band at $335 \mathrm{~nm}$ which underwent severe quenching in the presence of PA, 1,3,5-trinitrobenzene (TNB), 2,4-DNT and 1,3-DNB. Greater quenching was noted for PA and TNB. In spite of these interesting results, the fluorescence of polymer $\mathbf{4 9}$ remained unchanged in the presence of nitroaromatic explosives. This fact could be ascribed to the electronwithdrawing character of the $-\mathrm{CF}_{3}$ groups in 48 . These groups increase the positive charge on the silicon atom in the backbone facilitating the interaction between this atom and the nitro groups of explosives. This enhanced interaction for $\mathbf{4 8}$, if compared with $\mathbf{4 9}$, enabled an efficient photo-induced electron transfer, which was the main factor of the observed quenching. The thin films of polymer 48 were also used for the signalling of PA and 2,4-DNT in water. One of the 
advantages of the thin films of $\mathbf{4 8}$ was the recovery of the sensory material by rinsing with water or methanol.

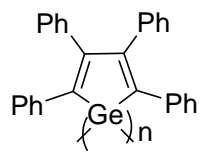

50

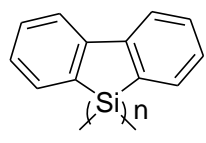

51

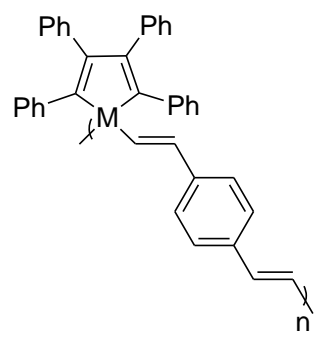

52

Figure 19. Structures of polymers 50,51 and $52 .^{51}$

A visual detection of trace residues of nitroaromatic explosives (TNT, 2,4-DNT and PA) on surfaces using the thin films of photoluminescent metallole-containing polymers $(\mathbf{2 7}, \mathbf{4 0}, \mathbf{4 1}, \mathbf{5 0 - 5 2})$ has been achieved (Figure 19$). .^{51}$ In relation to this, the different polymers showed intense emission bands $(510 \mathrm{~nm}$ for $\mathbf{2 7}, 500 \mathrm{~nm}$ for 50, $495 \mathrm{~nm}$ for 40 and $475 \mathrm{~nm}$ for 52 (M = Ge or Si) and $360 \mathrm{~nm}$ for 51 and 41) upon excitation at $340 \mathrm{~nm}$. Emissions of the different films were quenched to different degrees in the presence of TNT, DNT and PA. These polymeric films were successfully employed for the naked eye detection of TNT, 2,4-DNT and PA on certain surfaces (porcelain and paper).

\subsubsection{Molecularly imprinted polymers (MIPs)}

The molecular imprinting technique allows the formation of specific recognition sites in macromolecules. In this process, functional and cross-linking monomers are copolymerised in the presence of a target analyte (template). Functional monomers form a complex with the imprinting molecule, and the 
functional groups are held in position by highly cross-linked structures in the subsequent polymerisation. Subsequent removal of the template reveals binding sites that are complementary in size and shape to the analyte. Although most MIP applications have been limited to the separation of mixtures, MIP-based sensing systems have also been developed. In the particular case of the detection of explosives, several interesting examples have been reported to date. For instance, S. A. Grant et al. ${ }^{52}$ designed MIP-based sensors that utilised quantum dots as fluorescent antennas for detecting TNT. These authors employed a methacrylic acid-based polymer containing a methyl group and a carboxylic acid moiety as side groups. Using the carboxylic acid functional group, MIPs were labelled with amine-functionalised quantum dots. The templates used for the synthesis of MIPs were 2,4-DNT and TNT. Among the solvents used in the synthesis (acetonitrile, chloroform, toluene and dimethyl formamide (DMF)), chloroform gave rise to the imprinting polymer which decreased the most in fluorescence after treatment with the analyte. Addition of $0.5 \mathrm{mM}$ of 2,4-DNT to the aqueous solutions of the MIP-2,4-DNT sensor induced an immediate drop in fluorescence intensity, with an exponential trend over time. When TNT was used as a template, the addition of this analyte to an aqueous solution containing the MIP sensor gave rise to a similar behaviour to that observed with 2,4-DNT. Detection limits were $30.1 \mu \mathrm{M}$ for 2,4-DNT and $40.7 \mu \mathrm{M}$ for TNT. MIPs' sensing behaviour contrasted with that observed for the non-imprinting polymer, which displayed a poor or negligible response in the presence of these nitroaromatic derivatives. 


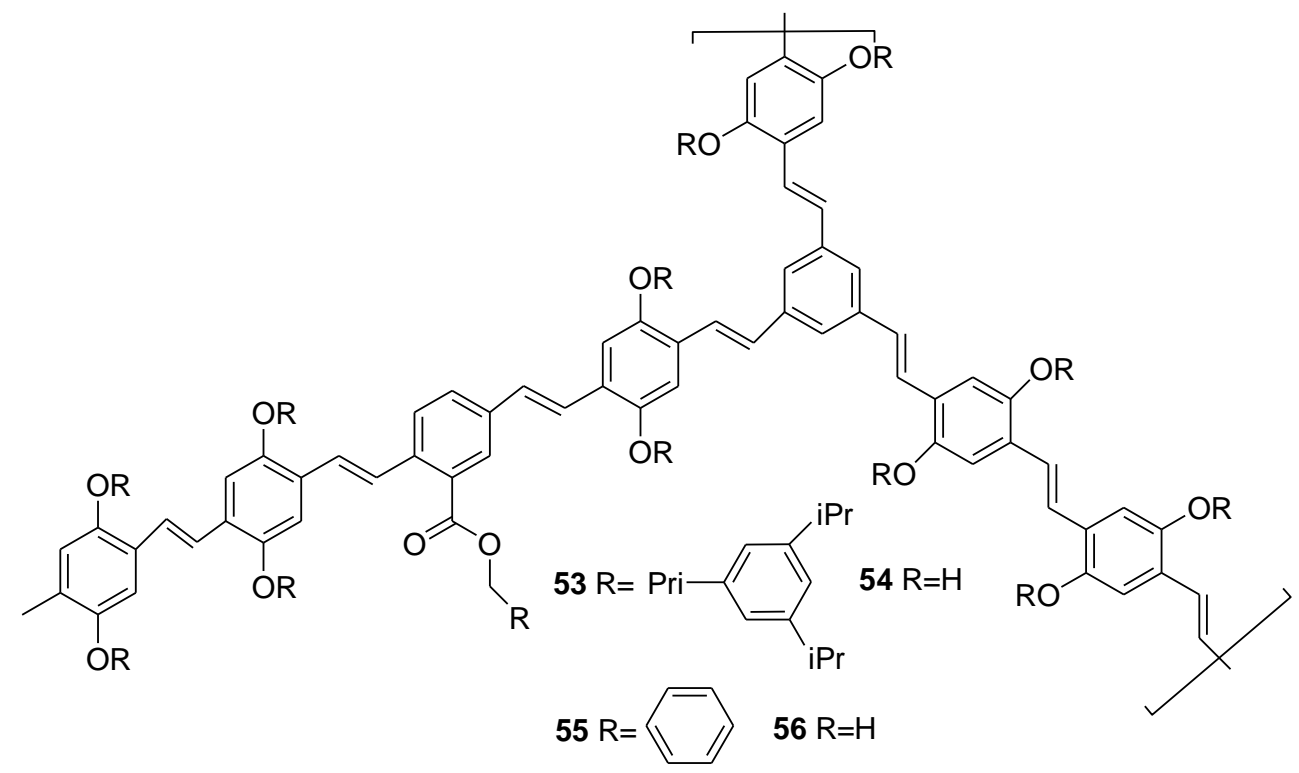

Figure 20. Structures of polymers 53, 54, 55 and 56.

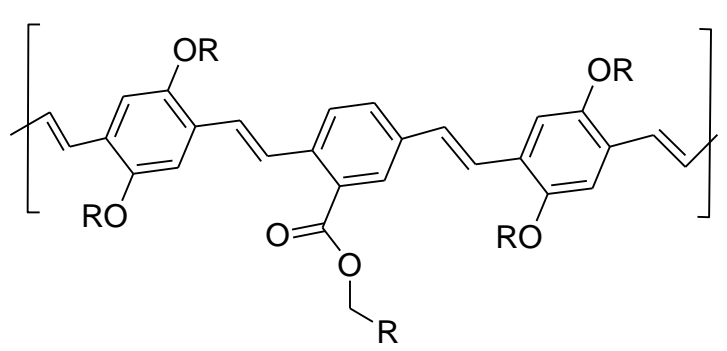<smiles>CC(C)c1cc([Pb]=[Pb])cc(C(C)C)c1</smiles>

$58 \mathrm{R}=\mathrm{H}$

Figure 21. Structure of polymers $\mathbf{5 7}$ and $\mathbf{5 8} .^{53,54}$

As stated in previous sections, conjugated polymers-based sensor devices usually show higher sensitivity than small molecule-based chemosensors due to conjugated polymers' intrinsic ability to provide an amplified response to the analyte-binding event. E. E. Nesterov et al. ${ }^{53}$ described the use of molecularly imprinting polymers using conjugated polymers (MICPs) for the detection of explosives in which the conjugated polymer is used as both imprinting materials and analytical signal transductors. Three-dimensionally cross-linked poly $(p-$ 
phenylene vinylene)s were used as they show some degree of conformational flexibility, required for shaping the imprinting cavity. In addition, poly( $p$ phenylene vinylene)s are highly emissive in the solid state and their fluorescent properties are strongly affected by the presence of quenchers. The imprinting cavity was formed between separate poly( $p$-phenylene vinylene) strands which were held rigidly together by cross-linking units. To avoid problems deriving from the difficulty of template removal, which could give rise to high initial fluorescence quenching, these authors chose 2,4,6-triisopropyltoluene as a nonquenching template to prepare a "TNT imprinting" polymer given the similarity in molecular shape between 2,4,6-triisopropyltoluene and TNT. Following this approach, polymer 53 (Figure 20) was isolated as non-soluble fluorescent spherically shaped micrometer-sized particles. For comparative studies, both polymers 55 (Figure 20) and 57 (Figure 21) were prepared. 57 was a linear polymer prepared in the absence of the crosslinker, and soluble in several organic solvents. On the other hand, polymer $\mathbf{5 5}$ was prepared under the same conditions used for 53, but on this occasion, the template used was toluene. The intention was to know the real effect of the imprinting mechanism. Removal of the template gave rise to polymers $\mathbf{5 4 , 5 6}$ and $\mathbf{5 8}$. The degree of template removal was around $\mathbf{5 0 \%}$ for ligand $\mathbf{5 3}$, and was practically quantitative for ligands $\mathbf{5 5}$ and 57.

Exposure of these polymers to saturated TNT vapours at room temperature resulted in noticeable fluorescence quenching for them all. As expected, polymer 54 showed better sensitivity to TNT than its non-imprinting linear analogue $\mathbf{5 8}$, or template-containing precursors 53, 55 and $\mathbf{5 7}$. Polymer 56 imprinted with the wrong template also displayed lesser sensitivity to TNT. One remarkable and clearly unexpected observation was that exposure of $\mathbf{5 4}$ to the vapours of 2,4-DNT 
caused much stronger fluorescence quenching than TNT. Furthermore, polymer 53 was slightly affected only by 2,4-DNT. Exposure of polymer 54 to 2,4-DNT or TNT vapours for 10 minutes caused a substantial decrease in fluorescence intensity (which was almost complete for 2,4-DNT). In addition, the fluorescence of the samples markedly recovered after maintaining them for 10 minutes in air, and fluorescence recovered completely in $1 \mathrm{~h}$. This exposure to quenchers with the subsequent recovery of fluorescence can be repeatedly done with no noticeable irreversible quenching. In contrast, linear polymer 58 became irreversibly quenched upon exposure to 2,4-DNT or TNT. In addition to fluorescent MIP probes, mass sensitive devices (such as quartz crystal microbalances) coated with MIPs have been suggested to provide promising low-cost detection systems for nitroaromatic explosives in the vapour phase. ${ }^{54}$

\subsubsection{Miscellaneous}

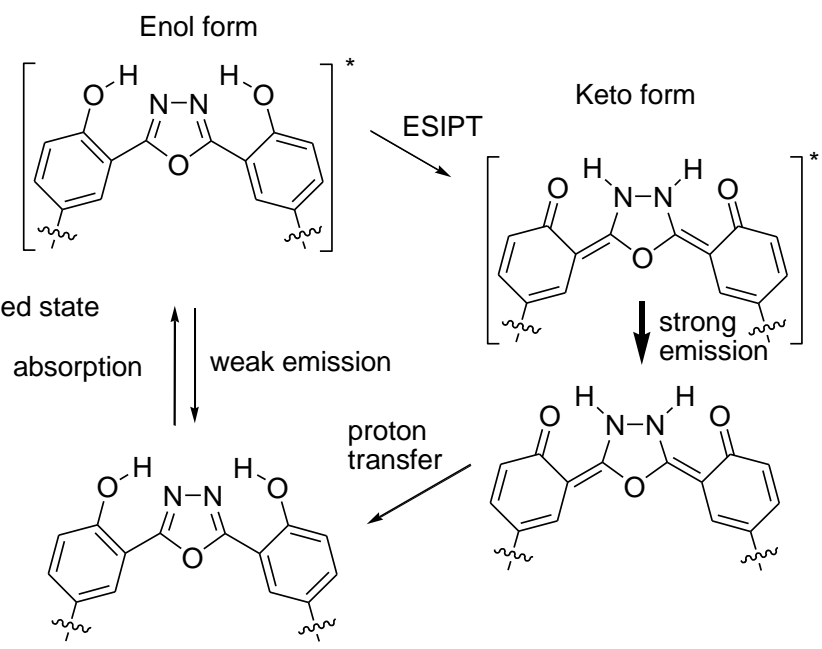

Ground state

Figure 22. Schematic representation of an ESPIT process that is active in oxadiazoles functionalised with o-hydroxyphenyl groups. ${ }^{55}$ 
Organic fluorescent conjugated polymers with nitrogen-containing fused-ring systems have recently received much attention because they usually show high fluorescence. ${ }^{55}$ In particular, oxadiazole-based materials have been reported to display a considerable Stokes shift and can be easily prepared with tailor-made structural modifications. Additionally, it has been established that the incorporation of an o-hydroxyphenyl group into the 2-position of oxadiazole provides an excited-state intramolecular proton transfer (ESIPT) process involving the tautomeric enol and keto forms (Figure 22). ESIPT provides two emission bands from the enol and keto structures; the keto form is responsible for longer wavelength emission.
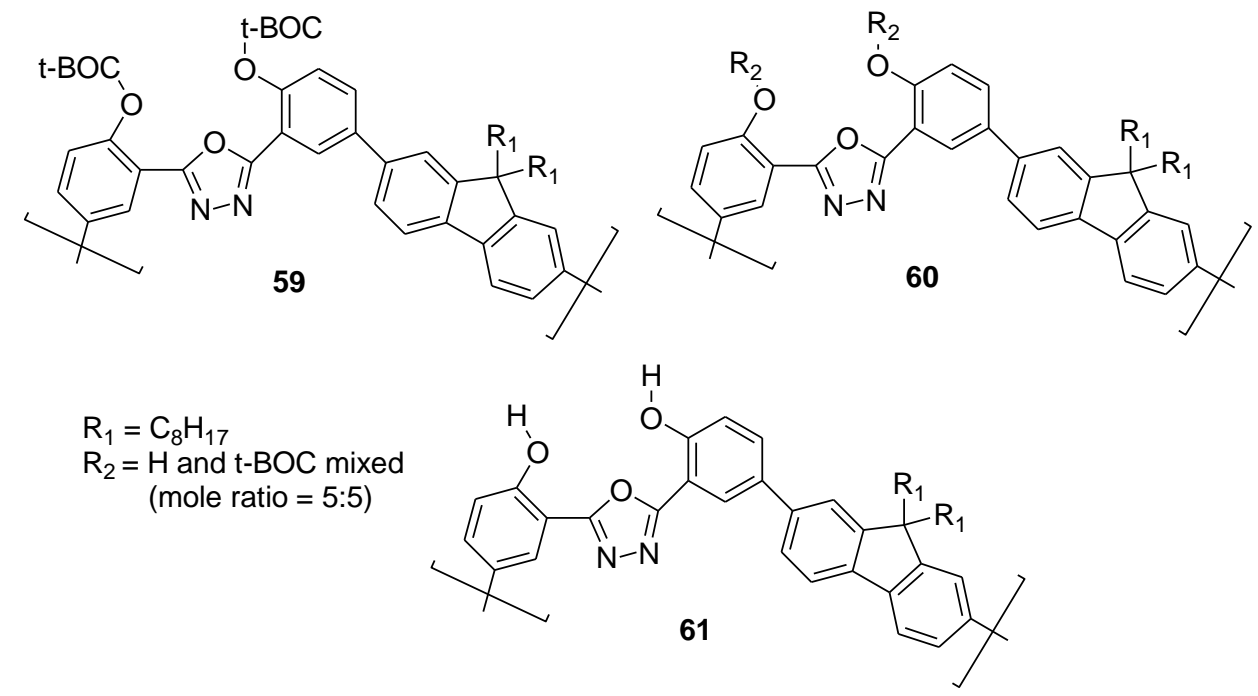

Figure 23. Structures of oxadiazole-based fluorescent conjugated polymers 59,60 and 61.56

Based on these ideas, T. S. Lee et al. prepared oxadiazole-based fluorescent conjugated polymers 59-61 (Figure 23) and investigated their chemosensing properties to electron-deficient nitroaromatic derivatives. ${ }^{56}$ All three polymers presented a low energy absorption band at $330 \mathrm{~nm}$ in chloroform. Additionally, a 
long wavelength emission at $528 \mathrm{~nm}$ was found for $\mathbf{6 0}$ and $\mathbf{6 1}$ which resulted from ESIPT. Polymer 59 did not exhibit the keto form emission because of the effective blocking of proton transfer processes by the t-butoxycarbonyl (t-BOC) group. Apart from the strong emission at $528 \mathrm{~nm}$, a significantly weak emission at a short wavelength of around $410 \mathrm{~nm}$ was also observed in $\mathbf{6 0}$ and $\mathbf{6 1}$, which results from enol form relaxation. The solutions of polymer $\mathbf{6 0}$ in chloroform were titrated with nitroaromatic derivatives such as PA, 2,4-DNT and 1,3-DNB. A dramatic quenching of the emission behaviour of $\mathbf{6 0}$ was noted in these experiments. Concomitantly, absorption of the polymer presented a hyperchromic effect upon exposure to PA and 1,3-DNB without a red shift or a blue shift. This effect is presumably the result of an electron transfer occurring within the electron-deficient nitroaromatic compounds and the bis(hydroxyphenyl)oxadiazole moiety. These studies indicated that PA was the most efficient quencher, followed by 1,3-DNB and 2,4-DNT.

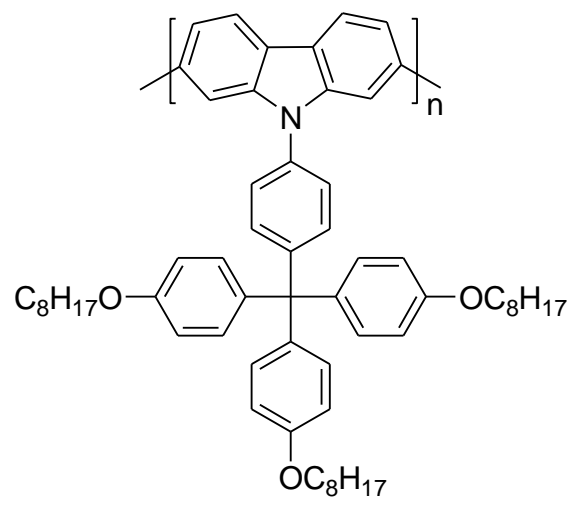

62

Figure 24 Structure of conjugated carbazole polymer $62 .{ }^{57}$

Zhang et al. reported the use of conjugated carbazole polymer 62 (Figure 24) as an efficient sensory material for the detection of TNT and 2,4-DNT traces. ${ }^{57}$ The presence of the bulky side chain in the structure not only prevents the $\pi$-staking 
interaction between polymer chains, which contributes to high fluorescence efficiency, but also generates an efficient pathway and benefits the diffusion of explosives. Furthermore, the moiety of the side chain endows the polymer good solubility and helps form high quality films by spin-coating. The absorption spectrum of the films of $\mathbf{6 2}$ showed two maxima at 270 and $395 \mathrm{~nm}$. In the fluorescence spectrum, 62 showed a blue emission at $417 \mathrm{~nm}$. The timedependent fluorescence intensity of the film of $\mathbf{6 2}(7 \mathrm{~nm})$ upon exposure to TNT vapours revealed a reduction of $57.4 \%$ in $30 \mathrm{~s}$ and of $73.0 \%$ in $60 \mathrm{~s}$. This suitable performance resulted from carbazole's good donor ability and the film's noncompact structure. In addition, $\mathbf{6 2}$ displayed good selectivity to TNT if compared to some potential interfering gases such as $\mathrm{HCl}, \mathrm{NO}_{2}, \mathrm{SO}_{2}, \mathrm{CO}_{2}$ and alcohol. The films of 62 also gave a response to 2,4-DNT vapours, although the response was not as sensitive as it was for TNT. The authors suggested that this might be due to TNT's electron accepting capability, which is higher than that of 2,4-DNT.

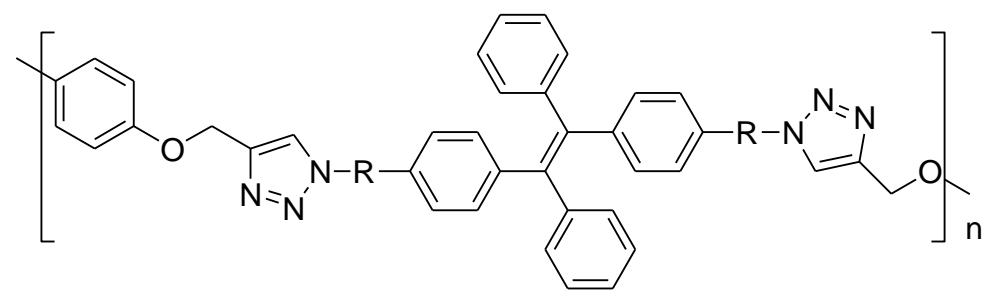

$63 \mathrm{R}=-\mathrm{O}\left(\mathrm{CH}_{2}\right)_{6}^{-}$

$64 \mathrm{R}=-\mathrm{CH}_{2}^{-}$

Figure 25. Structures of polymers 63 and $64 .^{58}$

Tang et al. $^{58}$ reported a family of new tetraphenylethene-containing polytriazoles in which light emission was dramatically enhanced by aggregate formation. For instance, polymers $\mathbf{6 3}$ and $\mathbf{6 4}$ (Figure 25) were not emissive in THF solution, but strong emission bands were observed at around $480 \mathrm{~nm}$ after 
addition of water (>60 vol \% and $10 \mathrm{vol} \%$, respectively). These results confirm that both polymers presented an aggregation-induced emission which is characteristic of tetraphenylethene derivatives. 63 and 64 in the THF/water and DMF/water mixtures were used as probes for the detection of explosives. In these studies, PA was used as a model. Addition of PA to solutions of 63 or $\mathbf{6 4}$ gave rise to fluorescence quenching at concentrations as low as $0.1 \mathrm{ppm}$. A lineal correlation was observed in the $10-30 \mu \mathrm{g} / \mathrm{mL}$ concentration range. The overlap between the bands of PA and the polymers in the wavelength region of 385-485 $\mathrm{nm}$ facilitated the energy transfer from the excited states of polymers to the ground state of $\mathrm{PA}$, resulting in fluorescent quenching. These authors also adsorbed polymers on filter papers and demonstrated their use for the detection of PA in toluene solutions.<smiles>CCCCCCC(C)(O)COCCOC(=O)CCc1c(C)c2ccc(OCC(=O)OC(C)(C)C)c(C)c2oc1=O</smiles>

65<smiles>Cc1c(CCC(=O)NCCC[Si](C)(C)O[Si](C)(C)O[Si](C)(C)C)c(=O)oc2c(C)c(OCC(=O)OC(C)(C)C)ccc12</smiles>

66

Figure 26. Structures of polymers 65 and $66^{59}$

Kumar et al synthesised 65 and 66 (Figure 26), which are co-polymers of 4,8dimethylcoumarins with poly(ethyleneglycol) (PEG) and poly(dimethylsiloxane) (PDMS), respectively. ${ }^{59}$ The chloroform solutions of polymer 65 showed an intense emission at $420 \mathrm{~nm}$, which was assigned to the coumarin fluorophore. The 
emission band was progressively quenched upon the addition of increasing amounts of TNT and 2,4-DNT in chloroform. The thin films of polymer 65 also displayed emission quenching in the presence of TNT and 2,4-DNT vapours (the quenching efficiency order was 2,4-DNT > TNT). Practically the same response was observed for polymer 66 in both solution and vapour studies.

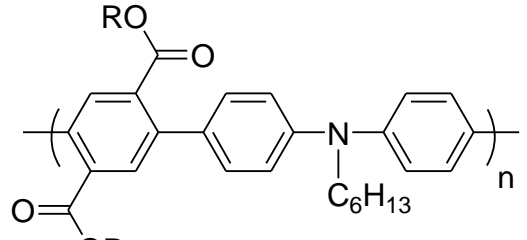

67

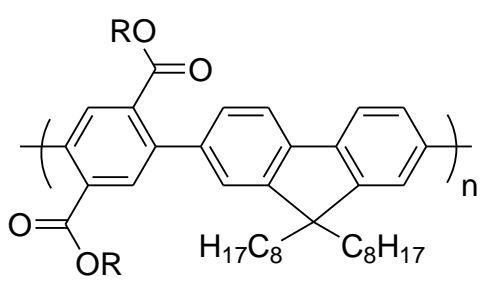

68 a, $\mathrm{R}=-\mathrm{CH}_{3}$

b, $R=$<smiles>CC(C)CCCC1CCC2C3CC=C4CC(C)CCC4(C)C3CCC12C</smiles>

Figure 27. Structures of polymers 67 and $68 .^{60}$

Polymers $67 \mathrm{a}, \mathbf{6 7 b}, \mathbf{6 8 a}$ and $\mathbf{6 8 b}$ (Figure 27 ), coated on a glass substrate, showed intense emission bands at 532, 504, 451 and 438, respectively. Exposure of the four polymers to 2,4-DNT vapours induced different degrees of quenching. The performance of all these polymers mounted on the end tip of an optical fibre was also studied. The best results were obtained with the optical fibre containing polymer $\mathbf{6 8 b}$; quenching of $65 \%$ was observed after $1 \mathrm{~min}$ in the presence of 2,4DNT vapours. ${ }^{60}$ 


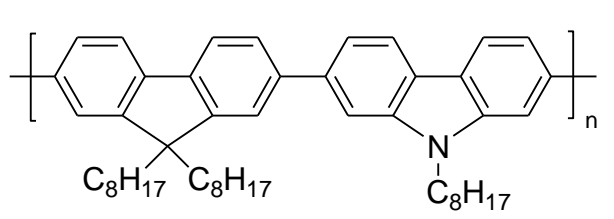

69

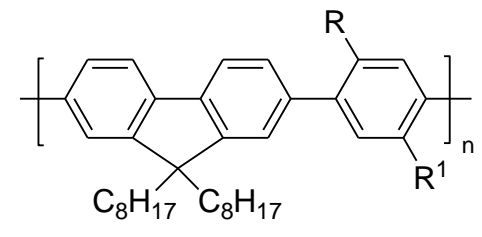

$70 \mathrm{R}=\mathrm{R}^{1}=\mathrm{OC}_{8} \mathrm{H}_{17}$

$71 \mathrm{R}=\mathrm{N}\left(n-\mathrm{C}_{8} \mathrm{H}_{17}\right)_{2} \quad \mathrm{R}^{1}=\mathrm{H}$

$72 \mathrm{R}=\mathrm{R}^{1}=\mathrm{N}\left(\mathrm{n}-\mathrm{C}_{8} \mathrm{H}_{17}\right)_{2}$

Figure 28. Structures of poly(phenylene)s 69-72. ${ }^{28}$

The poly(phenylene)s 69-72 (Figure 28) derivatives bearing fluorene moieties have been reported to display moderate quenching ( $20 \%$ deactivation for 70 ) in the presence of DMNB vapours. This quenching was ascribed to a photo-induced electron transfer process from the excited fluorophore to the DMNB quencher. ${ }^{28}$

\subsection{Hybrid materials}

Different approaches for the development of fluorogenic hybrid systems to detect explosives involving the use of silica microspheres, silica nanoparticles, films, fibres and silicon wafers have been described.

Walt and co-workers ${ }^{61}$ reported an optical microsensor for the high-speed detection of explosives in the vapour phase using the simple porous silica microsphere packing material from High Performance Liquid Chromatography (HPLC) columns (3-5 $\mu \mathrm{m})$ as a support in which a fluorescent dye (red nile) was physisorbed. Differences in the excitation and emission spectra of the physisorbed dye were found with the different functionalisations (amino, cyano, butyl and hydroxyl groups) of the microspheres surface due to different polarity. Each microsphere was attached to the surface of a glass cover slip. Hence, each 
microsensor's individual response was recorded with a fluorescence microscope and a high performance Charge-Couple Device (CCD) camera. In this way, the authors obtained images containing 1000 sensors which can be addressed individually. These authors also used microspheres as individual sensors positioned in the distal wells on the surface of an etched imaging fibre, which was utilised for remote sensing tasks. Vapour exposures to a single element sensor array revealed that the response profiles were highly reproducible from sensor to sensor and that the response profiles resulting for each analyte differed. One important advantage of employing high density sensor arrays is the ability to combine sensor responses in an averaged response, giving rise to signal-to-noise ratio enhancement. Incorporating many identical sensor responses allowed the detection of $23 \mathrm{ppb}$ of 2,4-DNT and $80 \mathrm{ppb}$ of 1,3-DNB.

In a more recent paper, silica particles were also employed as a support for the ultrasensitive detection of TNT in both solution (ethanol/acetonitrile) and the vapour phase. ${ }^{62}$ On this occasion, a Förster Resonance Energy Transfer (FRET)based mechanism was proposed as the signalling paradigm. The surface of nanoparticles was functionalised with both a fluorophore (6-carboxy-rhodamine) and amines. Amines were able to bind TNT molecules, while the TNT-amine Meisenheimer complex formed in close proximity to the fluorophore enhanced quenching of the fluorescence by a FRET mechanism (Figure 29). The authors also used functionalised nanoparticles on a silicon wafer with etched microwells, and found that this format enabled TNT detection as low as $1 \mathrm{nM}$ in solution. A better performance of this assembly was noted when compared with nanoparticles in solution. For the detection of TNT in the vapour phase, a piece of filter containing nanoparticles was used. The response to TNT vapours was higher than for other explosives such as 2,4-DNT, NB or RDX. 


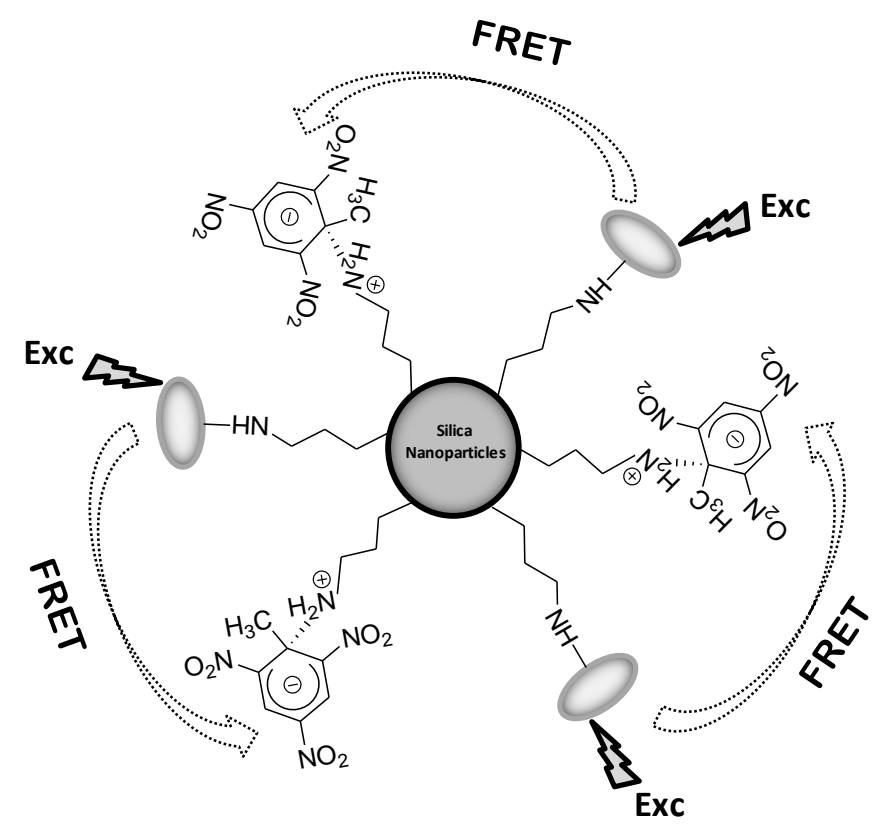

Figure 29. Schematic illustration of FRET-based silica nanoparticle sensors for TNT detection. ${ }^{62}$

A similar approach was used by Zhang et al. who developed a fluorescence chemosensor for the ultrasensitive detection of explosive nitroaromatic vapours by also using a FRET-based quenching mechanism. ${ }^{63}$ In this case, sensing material consisted in an inverted opal silica film containing a hybrid monolayer of amino groups and dye molecules (Figure 30 ). The amino groups selectively captured TNT vapour molecules through the formation of TNT-amino complexes. Fluorescein 5(6)-carboxyfluorescein-N-hydroxysuccinimide ester (C1609 dye) was used as a signalling unit because its emission band completely overlapped the absorption band of the TNT-amino ensemble. The fluorescent response of the C1609-( $\left.\mathrm{NH}_{2}\right)$ silica inverted opal film to saturated nitroaromatic derivatives was NB $>2,4-D N T>$ TNT. However, the quenching percentage for TNT was surprisingly higher than that expected for the relative vapour pressures and diffusion velocity of this analyte. 


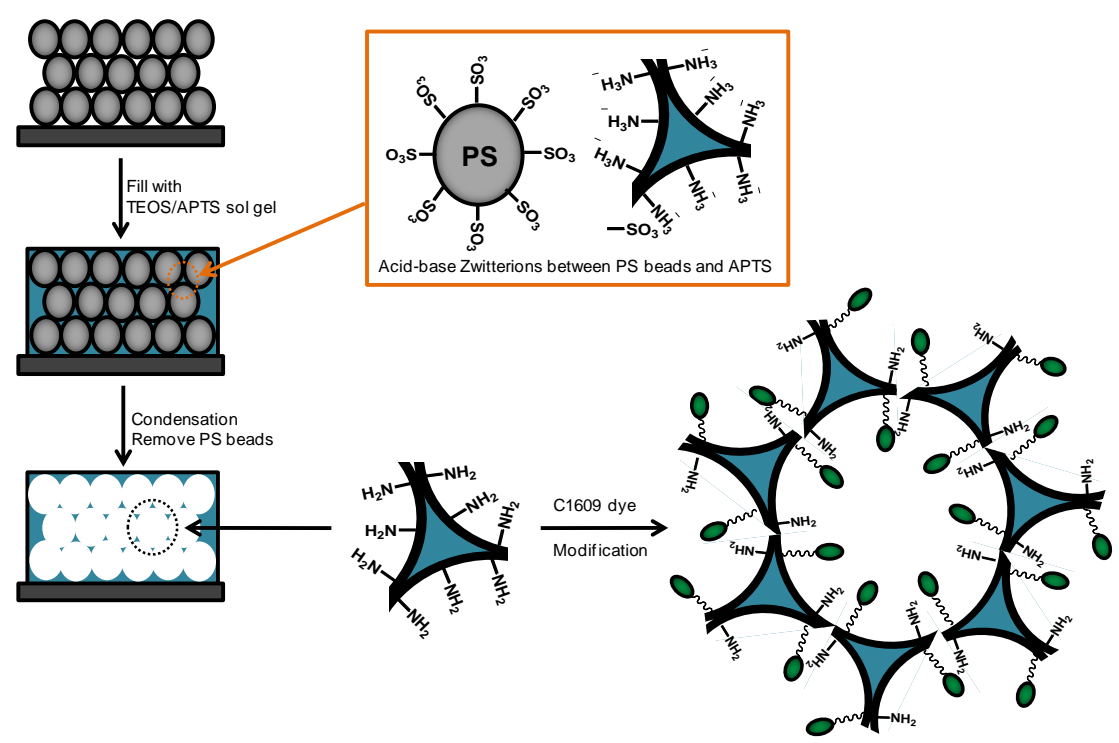

Figure 30. Schematic representation of inverted opal silica film fabrication containing a hybrid monolayer of amino groups and its modification with a dye. ${ }^{63}$

The same group prepared silica nanoparticles functionalised with both free amines as receptors and nitrobenzoxadiazole (NBD) as a signalling unit. ${ }^{64}$ The NBD-( $\left.\mathrm{NH}_{2}\right)$-silica system displayed reversible and controllable emission changes in the presence of protons or TNT. Protons increased fluorescence intensity (fluorescence $\mathrm{ON}$ ) when binding to the nitrogen atoms of the anchored amines. Inhibition of a PET process from the nitrogen to the excited NBD was proposed as the mechanism to explain emission enhancement (Figure 31). However, when TNT binds anchored amines, fluorescence quenching was observed (fluorescence OFF) due to a FRET mechanism based on the strong charge-transfer interaction between the NBD and the Meisenheimer complex formed between TNT and amines. 


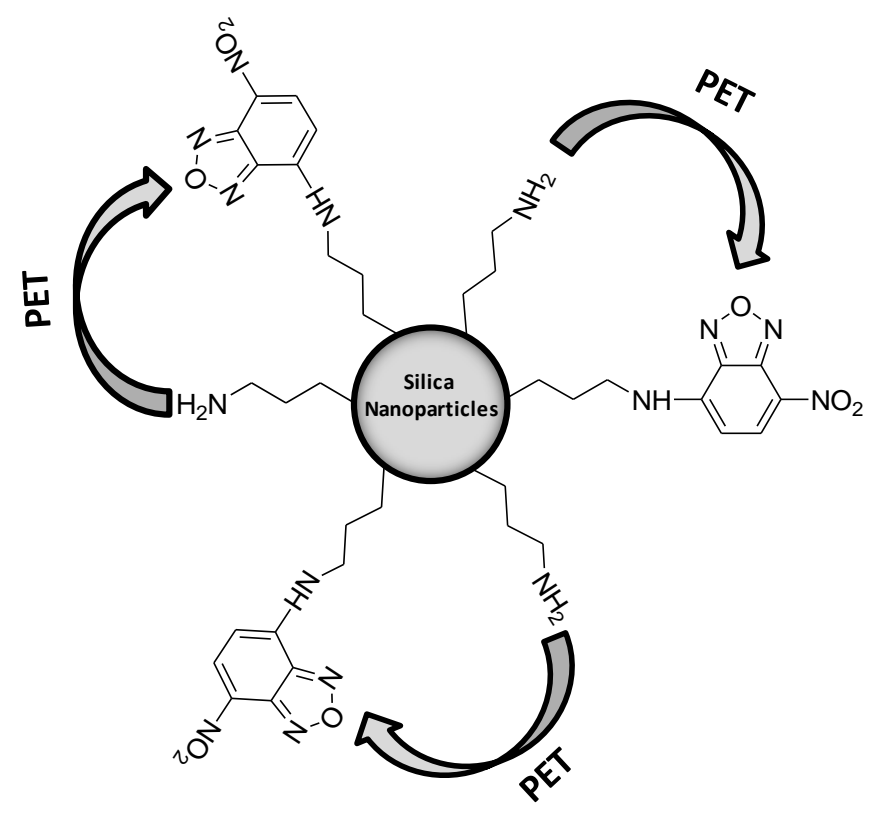

Figure 31. Schematic illustration of $\mathrm{NBD}-\left(\mathrm{NH}_{2}\right)$-silica nanoparticles. ${ }^{64}$

As regards the interaction with protons, fluorescence intensity increased with the addition of successive $\mathrm{HCl}$ aliquots to the system. This enhancement of fluorescence was also applied to determine herbicide 2,4-dichlorophenoxyacetic acid (2,4-DCAA). A detection limit of $10^{-7} \mathrm{~mol} \mathrm{dm}^{-3}$ was determined. As stated above in the interaction with TNT, quenching was observed. The authors developed two inexpensive solid-state chips for the sensitive detection of 2,4DCAA and TNT by the assembly of the NBD- $\left(\mathrm{NH}_{2}\right)$-silica nanoparticles in the etched microwell array of a silicon wafer. 


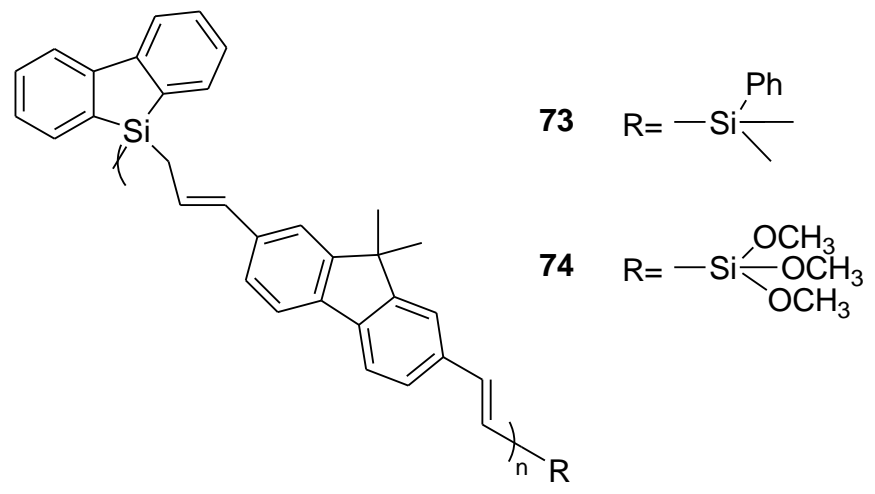

Figure 32. Structures of silafluorene-fluorene polymers $\mathbf{7 3}$ and $\mathbf{7 4} .^{65}$

Trogler et al described the design of a blue emitting silafluorene-fluorene polymer (poly(silafluorene-(9,9-dimethyl-9H-fluorene)divinylene, PSFF) (73-74) (Figure 32) on hollow silica nanoparticles as a sensing system for the detection of TNT and RDX in aqueous solutions. ${ }^{65}$ Fluorescence of the polymer in the solid state was attributed to aggregate-induced emission given the restricted intramolecular rotation. Three different methods were followed to include the PSFF polymer in silica nanoparticles: (a) polymer adsorption on the mesoporous surface (73); (b) covalent bonding of the polymer to the nanoparticles surface (74); and (c) adsorption of the polymer onto octadecyl modified silica nanoparticles (73). The highest quantum yield $(0.13)$ was shown by the material to which PSFF was covalently attached. $K_{s v}$ (Stern-Volmer constant) for TNT detection with this system was 35 times higher with PSFF-coated silica nanoparticles in water than with the toluene solution of the pure polymer. The authors reported detection limits of $200 \mathrm{ppb}$ for TNT and $800 \mathrm{ppb}$ for RDX in aqueous solutions. 


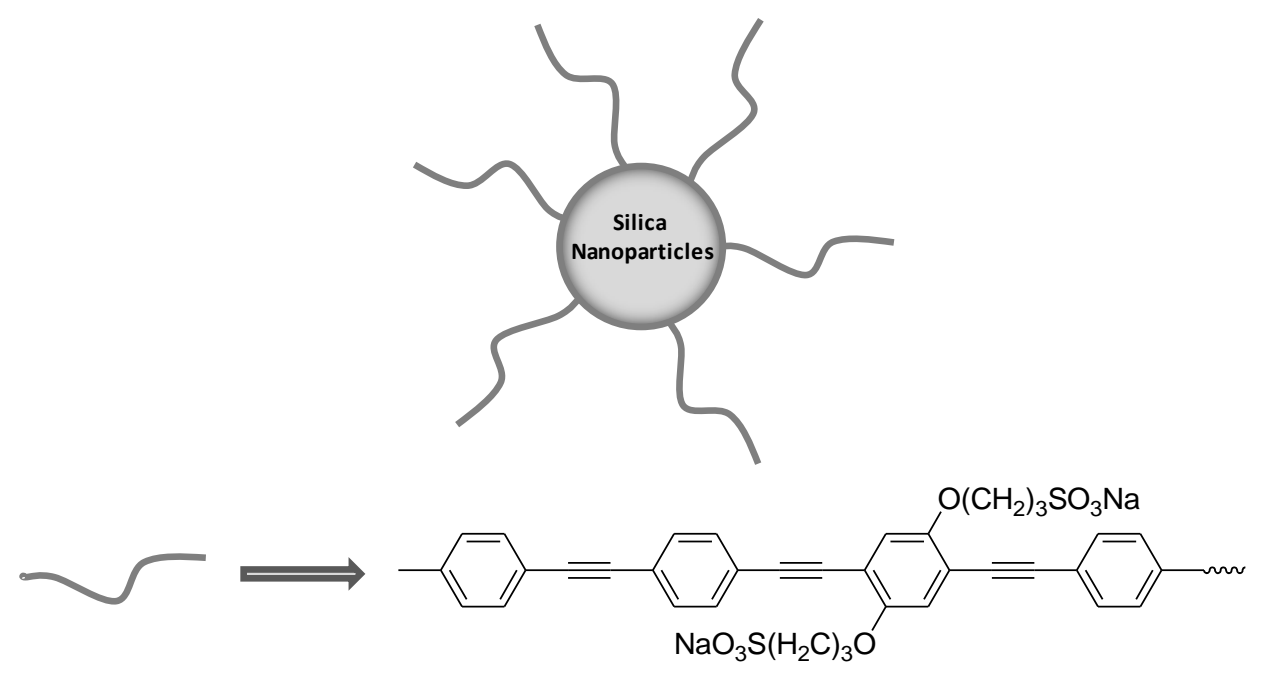

Figure 33. Schematic representation of $\mathrm{SiO}_{2}$ nanoparticles. ${ }^{66}$

Recently, Yang and Li et al prepared different sized silica nanoparticles grafted with a derivative of polyphenyl acetylene. ${ }^{66}$ The response to TNT was examined in various solvents (methanol, dimethylsulfoxide (DMSO)): the $\mathrm{K}_{\mathrm{sv}}$ value increased when the size of the polymer-grafted silica nanoparticles decreased. Particles (Figure 33) exhibited high sensitivity to TNT with a detection limit as low as $1 \mu \mathrm{M}$.

Dye-functionalised silica films used as materials for the detection of explosives have been reported by several authors. In an early work, Li and coworkers developed a hierarchically structured silica nanocomposite consisting of ordered macropores, surrounded by mesostructured walls of porphyrin (75)-functionalised silica as a high-performance chemosensory material (Figure 34) showing considerably enhanced sensing behaviour for the detection of TNT vapours; i.e., sensitivity was nearly twice that observed in conjugated polymer-based TNT sensors. ${ }^{67}$ 


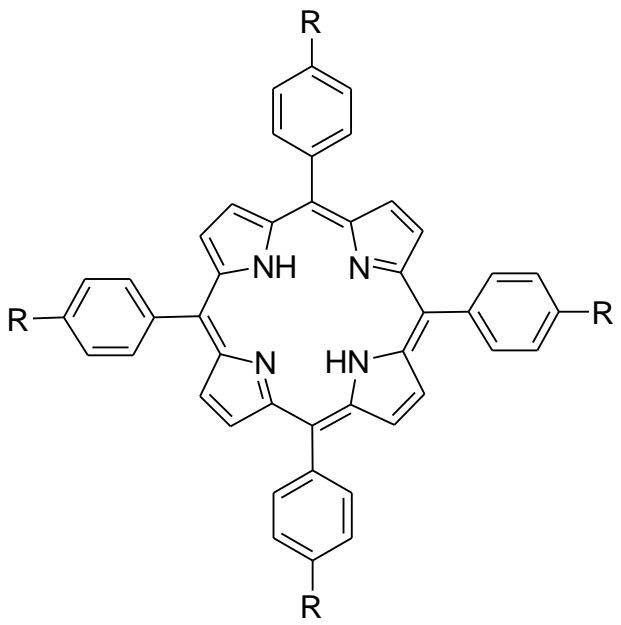<smiles>CCO[SiH2]CCCNC(=O)P</smiles>

75<smiles></smiles>

76

Figure 34. Structures of porphyrins 75 and $76 .^{67,68,69,70,71}$

The interaction of TNT with the material was explained by the well-known tendency of the imino hydrogen of the porphyrin (75) to form hydrogen bonds with the nitro groups of the nitroaromatics and via $\pi$-stacking interactions of porphyrin with TNT. Using the nanocomposite, quenchings of $55 \%$ after a $10 \mathrm{~s}$ exposure to TNT vapours and of $97 \%$ after a $2 \mathrm{~min}$ exposure were observed. Apparently, the unique bimodal porous structure provided the necessary condition for the facile diffusion of analytes, while the large surface area substantially enhanced the interaction between TNT and the sensing elements. In a subsequent study, the same authors reported the successful synthesis of a series of porphyrin- and metalloporphyrin-doped silica films with a bimodal porous structure, which was constructed using polystyrene spheres and a surfactant cetyltrimethylammonium bromide (CTAB) as the structure-directing 
agent. $^{68}$ This new kind of porphyrin-doped silica film displayed excellent fluorescence quenching in the presence of trace TNT vapours (55\% quenching after 10s for $10 \mathrm{ppb}$ of TNT). As in the above case, the hierarchically porous structure provided a necessary condition for the facile diffusion of analytes, while the large surface area considerably enhanced the number of accessible sites.

Using a similar approach, the same authors described the preparation of porphyrin (75) and metalloporphyrin (cobalt and cadmium)-doped mesostructured silica films using small molecular or macromolecular surfactants as structure-directing agents. ${ }^{69}$ Two main key factors were investigated: the appropriate permeation of the analyte through the film and the analyte's affinity with the emissive centres. To study the first factor, a comparison of the timedependent fluorescence quenching of the different silica matrixes upon exposure to nitroaromatic vapour was carried out. The worst response was obtained for amorphous silica films, while the response for mesoporous silica films was seen to be dependent on the surfactant used. In relation to the affinity between analytes and emissive components, the study demonstrated that the signal was better for those films containing metalloprophyrin units than for those containing free-base porphyrin. The cadmium-porphyrin-doped film presented the highest fluorescence quenching (near 56\% after 10 s of exposure). In another work, the same authors obtained similar results when the dip-coating technique was used for film preparation instead of the spin-coating procedure, as described in the example above. Hence, the authors reported the synthesis of porphyrin (75)doped silica films with a mesoporous structure which showed high fluorescence quenching sensitivity to the vapours (10 ppb) of TNT and other explosives. ${ }^{70}$ The mesostructure of the deposited silica film was strongly dependent on the reactants' mole ratio, and two different mesostructured films were prepared: one 
with one-dimensional pore channels oriented in parallel to the substrate; the other with a worm-like mesostructure. The latter film exhibited the highest response: $27 \%$ quenching after 10 s of exposure.

In all the examples used to demonstrate performance as sensors of functionalised silica films, it is quite clear that the porous structure controlled the explosive molecules' accessibility to the signalling centres. Hence, special care has been paid to control film porosity, normally through the use of several different types of templates. However, it is also possible to prepare porous silica films using template-free sol-gel methods. Along this line, Bayindir et al prepared highly porous and transparent organic-modified silica aerogel films with stable fluorescence properties for the detection of gaseous TNT and 2,4-DNT. ${ }^{71}$ Maintenance of a porous network during solvent evaporation under ambient conditions was achieved by using the monomer methyltrimetoxysilane, which also provided the network with hydrophobic behaviour. A porphyrin derivative (76) was used as a fluorescent dopant with no modifications made for covalent linking.

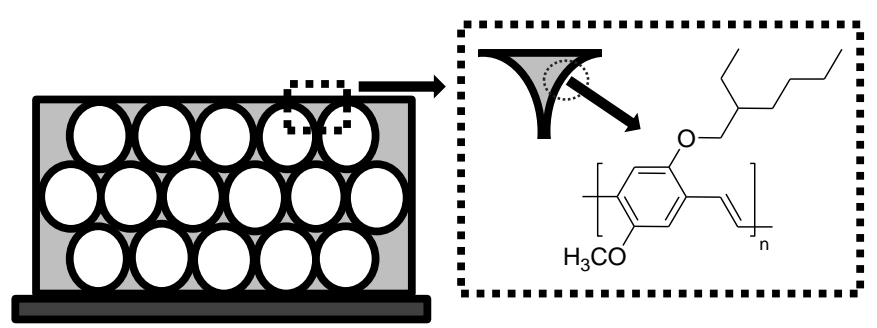

Figure 35. Schematic illustration of inverse opal photonic crystals coated with $\mathbf{2 1}$ on a porous surface for TNT detection. ${ }^{72,73}$

In another interesting work, Wang and co-workers reported the application of the light manipulation property of inverse opal photonic crystals for TNT detection. ${ }^{72}$ In order to obtain information about the porous structure's influence 
on fluorescence amplification, these authors prepared inverse opal photonic crystals in a range of macropore diameters that went from 225 to $520 \mathrm{~nm}$ (Figure 35). The fluorescence intensities of all the photonic crystal-based sensors were obviously higher than those of the control sample (a porous non-periodic material). Those with the lesser increased fluorescence (18.6-fold enhancement) were photonic crystal whose stopband was far away from the absorption band of the deposited fluorophore (poly-[2-methoxy-5-(2-ethylhexyloxy)- $p$ phenylenevinylene], 21). The films with the greatest enhancement (39.4-fold and 60.6-fold) were those whose stopband overlapped the emission spectrum of 21. The film's sensing behaviour with the highest fluorescent amplification was tested in the presence of TNT-saturated vapour, and a quenching efficiency of ca. $80 \%$ was found.

Li et al. also used 75 (see Figure 34 ) to prepare porphyrin-doped silica nanoafibres to detect TNT. Fibres were generated by electrospinning silica precursor sols. The authors demonstrated that doped nanofibres were efficient sensing materials for the detection of trace vapours $(10 \mathrm{ppb})$ of TNT. $^{73}$ Incorporation of a small portion of organic components into silica gel can considerably improve fibre formability, and allowed the preparation of a nonwoven mesh of functionalised silica fibres, which can be handled like tissue paper. Membranes showed enough mechanical strength and flexibility, which are crucial for most applications. The nanofibres in fluorescence-based sensing materials with smaller diameters presented higher sensitivity, which was probably due to a larger amount of porphyrin molecules on the surface. 


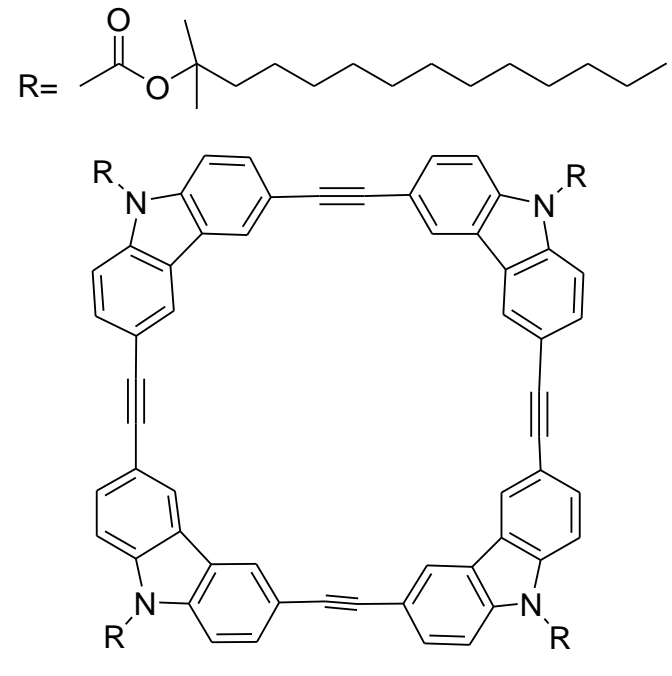

77

Figure 36. Structure of arylene-ethynylene macrocycle $77 .^{74,75}$

In relation to the above functionalised silica films, a different type of fluorescence sensory material, with no silica support, was prepared using an arylene-ethynylene macrocycle (77) (Figure 36). By means of the surface casting method, the authors prepared films of different thicknesses based on the micrometric nanofibres of the macrocycle. ${ }^{74}$ These films presented very effective fluorescence quenching upon exposure to the saturated vapour of 2,4-DNT and TNT. Quenching displayed little dependence on film thickness due to macrocycle's porous morphology and extended one-dimensional $\pi-\pi$ staking, which facilitated quencher molecules' access to excited states. Film fluorescence was slowly recovered by exposure to air or was quickly recovered by exposure to hydrazine vapour. The film showed great stability against photobleaching and a similar efficient quenching response was obtained with repeated use. 
A different approach to the detection of nitroaromatics (TNT, 2,4-DNT, and NB) reported by Trogler, Sailor et al was based on the photoluminiscence decrease of porous silicon materials in the presence of these compounds. ${ }^{75}$ Porous silicon is a high surface area network of $\mathrm{Si}$ nanocrystallites, and is produced by an electrochemical etching of single crystal Si wafers. These nanocrystals exhibit quantum confinement effects and emit photoluminiscence. Photoluminiscence intensity depends on the presence of surface adsorbates and can also be quenched by charge acceptors and/or corrosive molecules. Nitroaromatic molecules have two of these features which can be applied to their detection: first, they are good electron acceptors ("direct detection") and, second, nitrocompounds can be catalytically oxidised to $\mathrm{CO}_{2}, \mathrm{H}_{2} \mathrm{O}$ and $\mathrm{NO}_{2}$ at temperatures lower than those needed to oxidise almost all other potential organic interferents. The authors found that using photoluminiscence measurements on porous silicon discrimination between the nitroaromatic derivatives and several common atmospheric interferents such as benzene, hexane, toluene, isooctane and isoprene could be achieved. The detection limits for 2,4-DNT and TNT using this system were $2 \mathrm{ppb}$ and $1 \mathrm{ppb}$, respectively.

Covalent attachment of different fluorophores to glass plate surfaces was a strategy applied by the group of Lü and Fang to accomplish sensing films for nitroaromatics (Figure 37). One of the reported works was devoted to the study of a glass slide covalently functionalised with the small dansyl fluorophore via a relatively long, flexible spacer. ${ }^{76}$ 


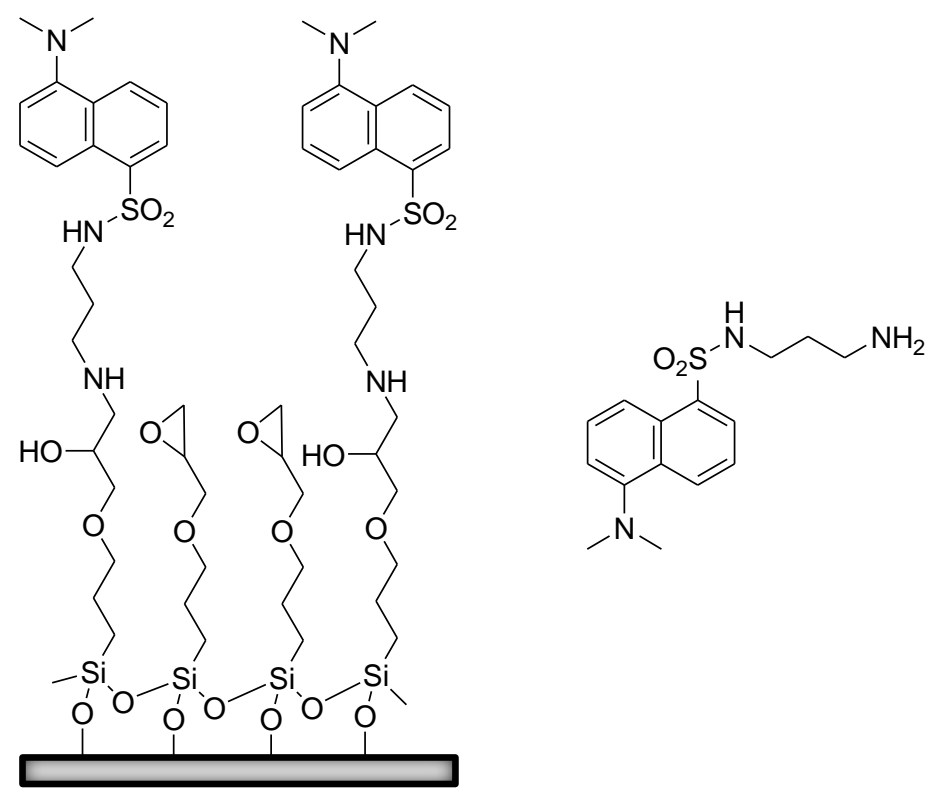

Figure 37. Schematic representation of the covalent immovilisation of dansyl on a glass slide surface. ${ }^{76}$

By means of fluorescence quenching studies, the authors demonstrated how the system was not only selective to nitroaromatics in the aqueous phase, but was also quite sensitive as the detection limit of the film for TNT was as low as $10^{-6}$ $\mathrm{mol}^{-1}$. The authors also found that nitroaromatics exhibited much greater quenching efficiencies in the emission of films than those observed for aromatics with no electron-withdrawing groups. They also observed that the higher the number of nitro-groups in the nitroaromatic derivative, the greater the quenching efficiency. 


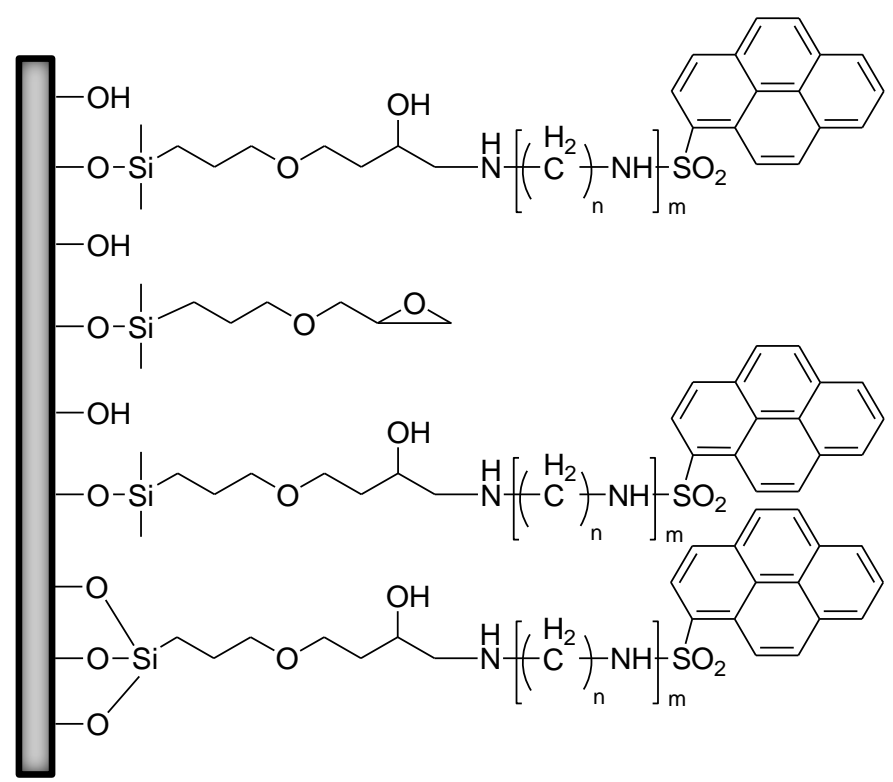

Figure 38. Schematic representation of pyrene functionalised fluorescent film. ${ }^{77}$

The same group also reported a different functionalisation, employed to investigate the effect of some typical nitroaromatics in the vapour phase on a series of pyrene-anchored functionalised films with different densities and/or different spacer lengths (Figure 38). ${ }^{77}$ The authors found that the greater the loading density, the higher the excimer/monomer intensity ratio of the pyrene. Fluorescence quenching was observed in the presence of NB, 2,4-DNT and TNT. The authors also observed that the response rate of films followed an order of NB $>$ 2,4-DNT > TNT, which is in accordance with the saturated vapour pressure order. In relation to the spacer effect, the intermediate length system (diamino propane subunit) proved the most sensitive to the presence of TNT and NB. On the other hand, better performance was seen with the lower loaded film as this consumes less quencher molecules to achieve similar quenching efficiency. The response of films was reversible and their performance was not affected by 
common interferents such as vapours of organic solvents, benzene, toluene, ethanol, perfume and smoke.

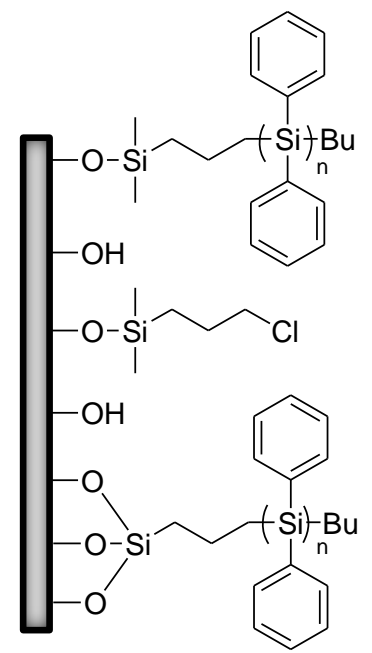

Figure 39. Schematic representation of poly(dipheny/silane)s grafted onto a glass plate surface. ${ }^{78}$

The same authors reported the detection of nitroaromatic compounds in the vapour phase by means of a fluorescence film sensor prepared by the chemical assembly of oligo(diphenylsilane)s on a glass plate surface (Figure 39 ). ${ }^{78}$ For TNT, $55 \%$ reduction of fluorescence emission after 10 s of exposure was reported. By comparing the quenching results from static measurements with those of fluorescence lifetime measurements, the authors concluded that quenching was mainly caused by formation of a non-fluorescent donor-acceptor complex between conjugated polymers and nitroaromatic derivatives. 


\subsection{Single fluorophores}

\subsubsection{Polycyclic aromatic hydrocarbons}

Polycyclic aromatic hydrocarbons are organic molecules that consist in fused aromatic rings without the presence of heteroatoms. Their fairly well-known photo-physical properties, relatively high quantum yields and the fact that there are a large number of commercially available derivatives, make them a clear choice for the preparation of fluorescent receptors to detect neutral and charged species. One remarkable feature of polycyclic aromatic hydrocarbons is their electron donor nature due to their electron-rich structure, which allows the formation of charge transfer complexes with electron acceptor molecules. For this reason, polycyclic aromatic hydrocarbons (such as pyrene, perylene, anthracene, binaphtyl and fluorene) have been employed as receptors for nitrated explosives by means of a signalling event based on the latter's ability to quench the excited state of the former. This simple approach has been explored by McGuffin et al who reported the separation of complex explosive mixtures (also containing their degradation products) with capillary liquid chromatography and the individual detection of nitrated aromatic derivatives by measuring pyrene emission quenching by laser-induced fluorescence. ${ }^{79}$ The interaction mechanism relies on the formation of charge-transfer complexes between the electron-rich pyrene and the electron withdrawing nitrated explosives. For nitroaromatic explosives, these authors found that the Stern-Volmer quenching constants increased with the number of nitro groups (TNT > 2,4-DNT > 2-NT), whereas the effectiveness of quenching did not follow this trend for non-aromatic nitrated explosives. The method showed certain interferences and other species such as organic amines, nitriles, halides and inorganic anions also induced a partial quenching of pyrene 
emission. This method was successfully applied to determine RDX, HMX, TNT, nitromethane (NM) and ammonium nitrate in various commercial explosive samples.

Anslyn et al used simple fluorescent polycyclic aromatic hydrocarbons (pyrene, perylene and diphenylanthracene) located inside micelles to develop a differential array for the detection and identification of TNT, Tetryl, RDX and HMX explosives. ${ }^{80}$ These authors studied pyrene emission quenching efficiency by nitrated explosives in aqueous solutions containing Tween 80. Under these conditions, the monomer emission of pyrene was quenched to different extents upon the addition of TNT, Tetryl, RDX and HMX. However, the emission modulation observed was insufficient for accurate differentiation. It was observed that the excimer emission of the pyrene in aqueous solutions containing Tween 80 was also quenched upon the addition of TNT and RDX. TNT and RDX could be differentiated by using the ratio between monomer and excimer emission. The authors also studied the quenching of pyrene and perylene fluorophores codissolved in Tween 80 in the presence of nitrated explosives. In this system, excitation of pyrene resulted in some relaxation via the emission of the pyrene monomer along with some FRET to excite perylene, which then relaxes through its own emission. Addition of increasing quantities of TNT and RDX induced the gradual quenching of both emission bands. Finally, diphenylanthracene was also included in the Tween 80 micelles, and the changes in emission in the presence of nitrated derivatives were studied. In this case, addition of RDX and HMX induced negligible changes in the emission profile of the fluorophore, whereas the addition of TNT resulted in quenching due to a simple absorption of excitation light by TNT. The authors designed a sensory array consisting in several solutions of the above-cited fluorophores in Tween 80. Examination of the array's 
fluorescence response in the presence of nitrated explosives using linear discriminant analysis resulted in a "fingerprint" for each analyte.<smiles>[R][Y]([H])([H])Cc1ccc2ccc3cccc4ccc1c2c34</smiles>

$78 \mathrm{n}=0, \mathrm{R}=\mathrm{Ph}$

$79 \mathrm{n}=1, \mathrm{R}=\mathrm{Ph}$

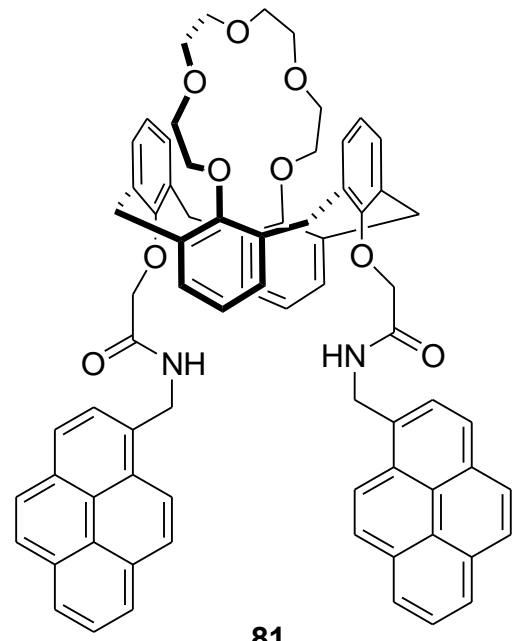

$80 \mathrm{n}=1, \mathrm{R}=\mathrm{p}-\mathrm{PhOMe}$
a $X=S$
b $\mathrm{X}=\mathrm{S}(\mathrm{O})$
c $\mathrm{X}=\mathrm{SO}_{2}$

Figure 40. Structures of pyrene derivatives $78-80$ and dipyrenylamidocalix[4]arene-[15]crown-5 receptor $\mathbf{8 1} .81,82,83,84$

Pyrene derivatives containing sulfoxide moieties (78b, 79b and $\mathbf{8 0 b}$ ) (Figure 40) were used for the indirect fluorescence detection of Triacetone triperoxide (TATP) in dichloromethane. ${ }^{81}$ The authors demonstrated how the UV irradiation of TATP and methyltrioxorhenium (MTO) in dichloromethane solutions of $\mathbf{8 0 b}$ induced photolysis of TATP, mediated by MTO, to yield $\mathrm{H}_{2} \mathrm{O}_{2}$, which induced the oxidation of sulfoxide $80 \mathrm{~b}$ to yield the highly emissive sulfone $80 \mathrm{c}$. A maximum 50 -fold increase in the emission intensity at $400 \mathrm{~nm}$ after a 90 minute reaction was observed. Almost the same response was obtained with $\mathbf{7 8 b}$ and $\mathbf{7 9 b}$. By using 
this indirect method, TATP concentrations as low as $100 \mathrm{nmol}$ were detected. The selectivity of the method proved remarkable because other oxidants such as $t$ $\mathrm{BuOOH}, \mathrm{NaOCl}, \mathrm{LiClO}_{4}, \mathrm{~K}_{2} \mathrm{Cr}_{2} \mathrm{O}_{7}$, or air, were unable to oxidise sulfoxides to the corresponding emissive sulfones, whereas $\mathrm{KMnO}_{4}$ was a clear interferent (it was able to induce the sulfoxide-sulfone reaction).

Scaiano et al. also employed pyrene as an electron-rich molecule to detect nitro explosives by emission quenching. ${ }^{82}$ In this case, ethanolic solutions of pyrene excited at $355 \mathrm{~nm}$ showed two distinct emission bands: one finely structured band below $400 \mathrm{~nm}$ corresponding to the emission from the singlet excited state monomer; one broad band at $470 \mathrm{~nm}$ due to the formation of excimers. Both emission bands were quenched upon the addition of electrondeficient nitro derivatives such as NB, 1,4-DNB, 5-NX (1,3-dimethyl-5nitrobenzene), 1,3-DNB, NM and nitroethane (NE), whereas electron-rich derivatives such as $N, N$-dimethylaniline, trioctylamine and $N, N$-dimethyl-2,6diisopropylaniline did not significantly quench the pyrene emission. From an analytical point of view, the ratio between monomer intensity and excimer emission $\left(F_{M} / F_{E}\right)$ as a function of the quencher concentration allowed the discrimination of different nitro derivatives.

The dipyrenylamidocalix[4]arene-[15]crown-5 (81) receptor was used for the colorimetric and fluorimetric detection of nitrated explosives. ${ }^{83}$ Acetonitrile solutions of receptor $\mathbf{8 1}$ presented two emission bands at 375 (monomer) and $450 \mathrm{~nm}$ (excimer), when excited at $343 \mathrm{~nm}$. Addition of TNB and TNT to acetonitrile solutions of $\mathbf{8 1}$ induced a significant quenching of both emission bands, whereas addition of 2,6-DNT, 1,3-DNB and NB resulted in only moderate quenching. With receptor $\mathbf{8 1}$, TNT could be detected at concentrations as low as 1 
ppb. Receptor $\mathbf{8 1}$ could also be used for the colorimetric detection of TNT and TNB. Thus, chloroform solutions of receptor $\mathbf{8 1}$ showed the typical intense absorption bands of pyrene in the 320-360 nm interval. With the addition of TNT, the initial colourless solution turned yellow, whereas it turned reddish-orange when TNB was added.

Seitz et al. prepared cellulose triacetate membranes which were plasticised with isodecyl diphenylphosphate, containing pyrenebutyric acid as a fluorophore for the detection of TNT, 2,4-DNT and RDX in water. ${ }^{84}$ The membrane was able to extract nitrated derivatives from water to induce the quenching of the emission band of pyreneburyric acid centred at $412 \mathrm{~nm}$ (excitation at $354 \mathrm{~nm}$ ). The detection limits obtained with this membrane were $2 \mathrm{ppm}$ of TNT and 2,4-DNT and $10 \mathrm{ppm}$ of RDX. Membrane sensitivity (TNT > 2,4-DNT > RDX) correlated well with the octanol-water partition coefficients of nitrated derivatives.

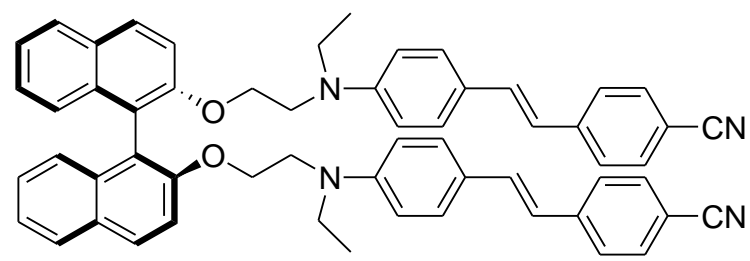

82

Figure 41. Structure of binaphtyl derivative $82 .{ }^{85}$

Binaphtyl derivative 82 (Figure 41), functionalised with donor-acceptor substituted trans-stilbenes, was used for the detection of 2,4-DNT and TNT. ${ }^{85}$ The films of $\mathbf{8 2}$, drop-casted from 1:3 v/v chloroform-toluene mixtures, showed an intense emission band at $510 \mathrm{~nm}$ which was quenched in the presence of 2,4-DNT (91\% quenching after a 10-minute exposure to saturated vapours) and TNT (72\% 
quenching after a 10-minute exposure to saturated vapours). The different quenching degree clearly related with the higher vapour pressure of 2,4-DNT when compared to that of TNT. The observed quenching was ascribed to a photoinduced electron transfer process from $\mathbf{8 2}$ to nitroaromatic quenchers.

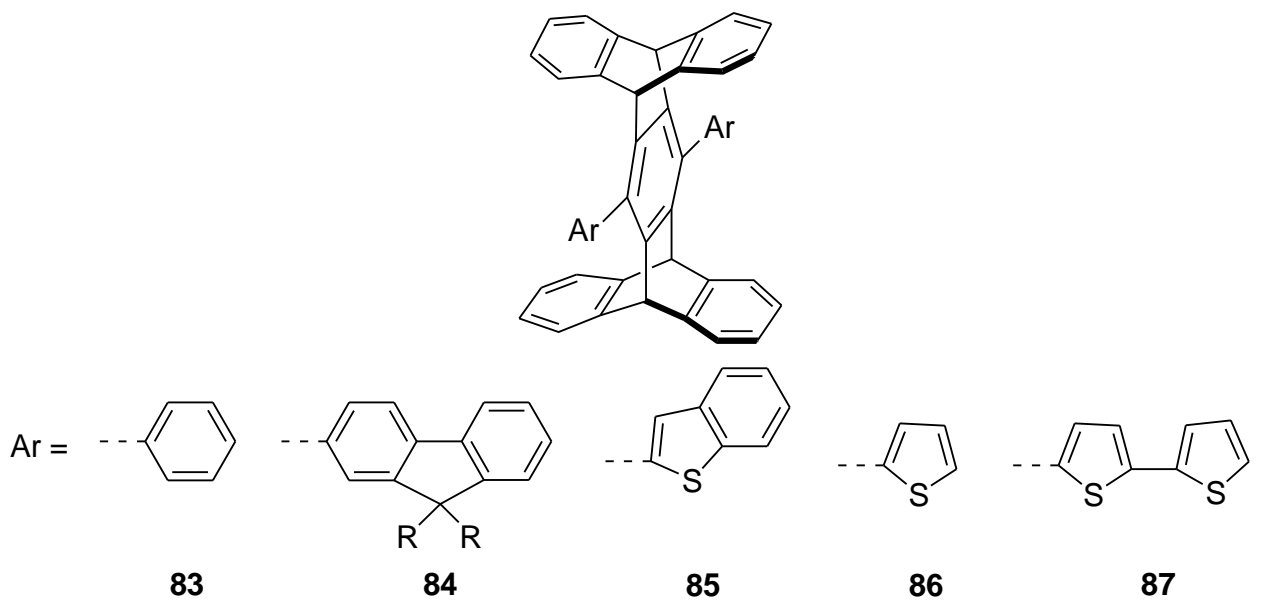

Figure 42. Structures of 1,4-diarylpentiptycenes $83-87^{86}$

Anzenbacher Jr. et al reported a series of 1,4-diarylpentiptycenes 83-87 (Figure 42) for the fluorescence detection of nitroaromatic derivatives. ${ }^{86}$ The dichloromethane solutions of receptor 87 showed an emission band at $450 \mathrm{~nm}$, which was gradually quenched upon the addition of increasing quantities of NB, 2,4-DNT, TNT, 1-nitronaphthalene (NN), DMNB. Virtually the same results were obtained with the dichloromethane solutions of 83-86 receptors. The authors also embedded receptors $\mathbf{8 6}$ and $\mathbf{8 7}$ in polyurethane films and demonstrated that emission was quenched upon exposure to 2,4-DNT and TNT vapours. Moreover, the fluorescence of the films was restored upon washing with a stream of clean air. 


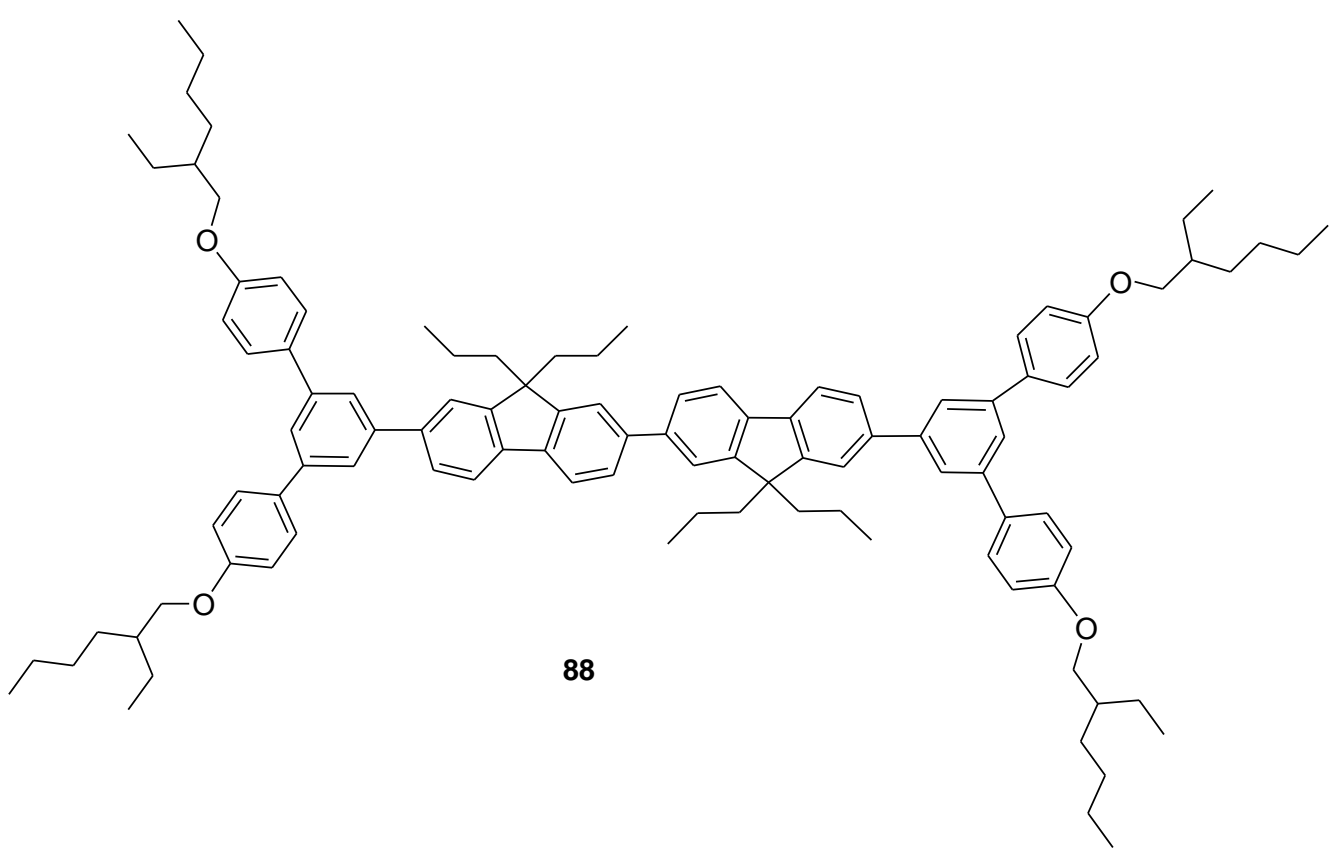

Figure 43. Structure of bifluorene-containing dendrimer $88{ }^{87}$

Fluorescent dendrimers have been suggested as an alternative to organic polymers in the development of sensory materials for nitrated explosives. Although less accessible, they offer the advantage of being monodisperse and their structure can be modulated to control their response. Recently, a study into the photophysical properties of the bifluorene-containing dendrimers $\mathbf{8 8}$ (Figure 43) and 89 (Figure 44) as fluorescent materials to detect explosives, has been published. ${ }^{87}$ 


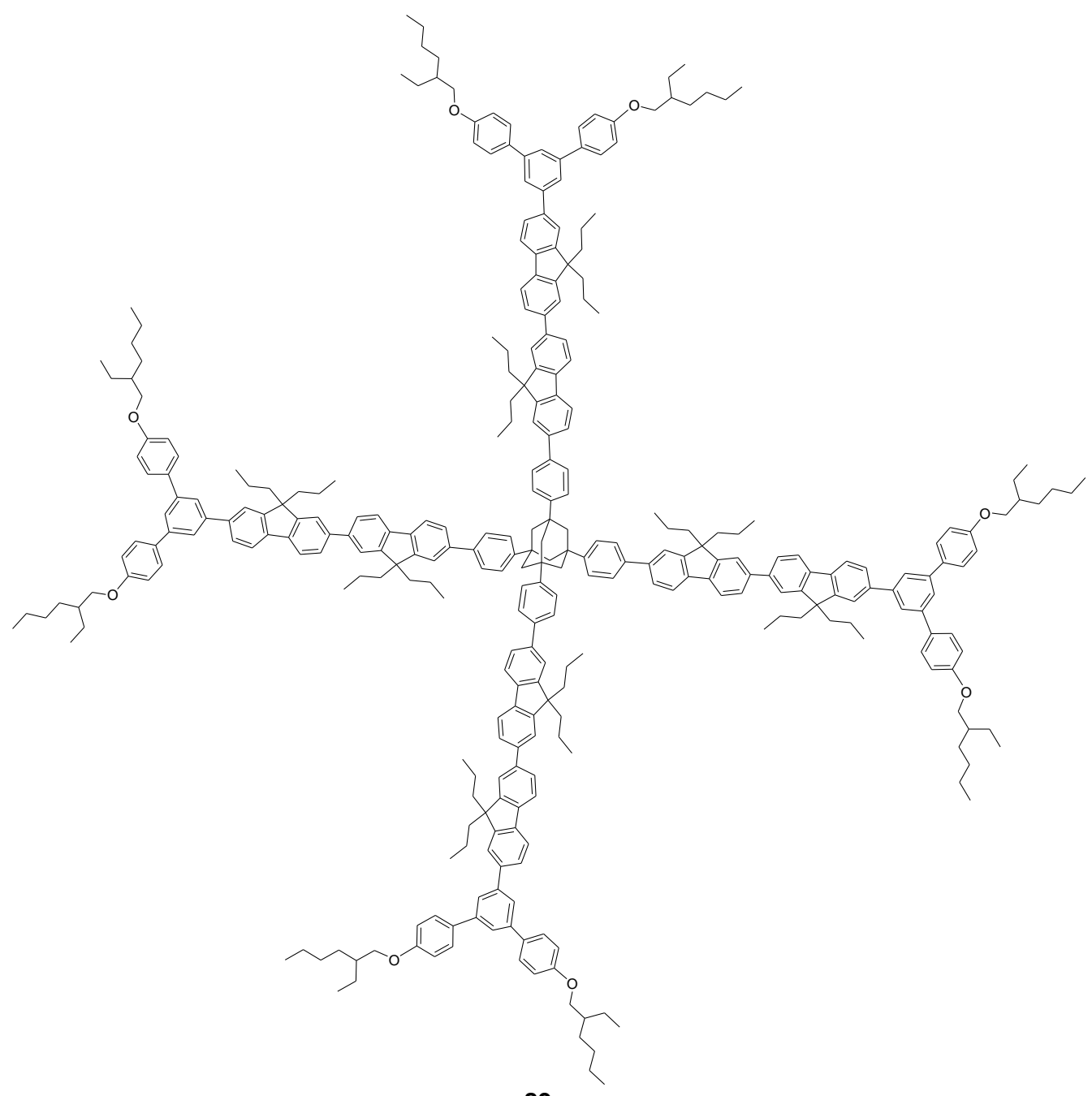

89

Figure 44. Structure of bifluorene-containing dendrimer $89 .{ }^{87}$

The spectroscopic behaviour of both dendrimers $\mathbf{8 8 - 8 9}$ was identical and the THF solutions of both derivatives showed an intense emission band at $393 \mathrm{~nm}$ with quantum yields of $90 \%$. The emission of the THF solutions of $\mathbf{8 8}$ and $\mathbf{8 9}$ was quenched upon the addition of 1,4-DNB, 2,4-DNT and 4-NT. Moreover, quenching efficiency was greater for the 3-dimensional dendrimer $\mathbf{8 9}$ than it was for $\mathbf{8 8}$. This 
enhanced quenching efficiency was ascribed to an amplification effect in 89, which has multiple identical chromophores that can all be quenched by a single analyte molecule. Emission quenching was ascribed to an efficient photo-induced electron transfer from excited bifluorene moieties to nitroaromatic explosives.

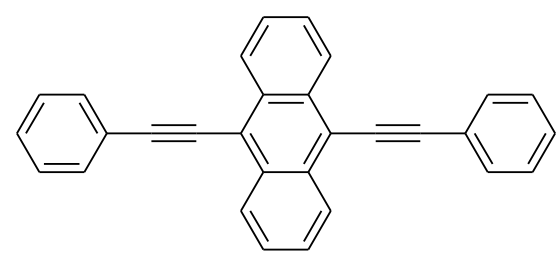

90

Figure 45. Structure of 9,10-bis(phenylethynyl)anthracene $90 .{ }^{88}$

The formation of inclusion complexes by $\gamma$-cyclodextrin $(\gamma-C D)$ was used by the same authors for the fluorescence recognition of nitroaromatic explosives. ${ }^{88}$ Water-THF 95:5 v/v solutions of 9,10-bis(phenylethynyl)anthracene (90) (Figure 45) presented an intense emission band upon excitation at $495 \mathrm{~nm}$, which was moderately quenched upon the addition of increasing quantities of $\gamma$-CD. This emission quenching was ascribed to the formation of an inclusion complex between 90 and $\gamma$-CD. Upon the addition of nitroaromatic explosives, TNT and Tetryl, to solutions of the $\mathbf{9 0} \cdot(\gamma-C D)$ complex, the quenching of the fluorophore emission intensity was seen to become further intense. This quenching was ascribed to the formation of a charge transfer complex between the nitroaromatic explosive and $\mathbf{9 0}$ in the cavity of the $\mathrm{\gamma}-\mathrm{CD}$. The same complex was formed in the absence of $\gamma-C D$, but the observed emission quenching was poorer. Addition of RDX, HMX and PETN to the solutions of $\mathbf{9 0}(\gamma-C D)$ complex induced negligible changes in emission intensity. 


\subsubsection{Heterocycles}

Heterocycles containing more than one fused cycle (carbazoles, siloles, thiophenes, benzothiophenes and porphyrins) have been used as fluorophores in the design of receptors for the detection of explosive molecules.

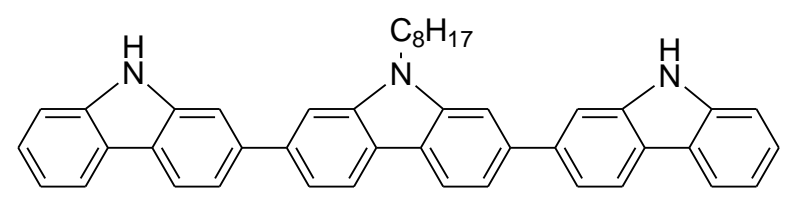

91

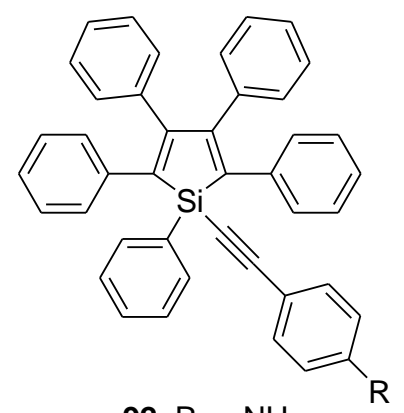

92, $\mathrm{R}=-\mathrm{NH}_{2}$

93, $\mathrm{R}=-\mathrm{OH}$

Figure 46. Structures of linear 2,7-linked carbazole trimer 91 and silole derivatives $92-93$. $^{89,90}$

The linear 2,7-linked carbazole trimer (91) (Figure 46) was used to prepare fluorescent nanofibrils (ca. $30 \mathrm{~nm}$ and lengths of several microns) which formed nanoporous films consisting of entangled fibril networks. ${ }^{89}$ The nanofibrils of 91 exhibited strong blue fluorescence at $438 \mathrm{~nm}$ upon excitation with UV light. These systems possess long-range exciton diffusion due to the extended intermolecular $\pi-\pi$ electronic interaction, tunable porosity and the large surface area:volume 
ratio, which is intrinsic to the nanofibril film. Films displayed potential applications in sensor devices for on-site explosives monitoring. Thus, efficient fluorescent quenching in the presence of TNT (70\% quenching after 60 seconds) and 2,4-DNT (50\% quenching after 10 seconds) vapours was observed. The same sensing films containing 91 were also used for the fluorescent detection of nitromethane. In all cases, the sensing mechanism relies on the photo-induced electron transfer between the carbazole trimer and explosives. Finally, fluorescence of nanofibrils can be recovered by heating films at $50^{\circ} \mathrm{C}$ in vacuum for 10 minutes.

As described above, siloles are a class of organometallic molecules which possess a unique silacyclopentadiene core structure and exhibit a number of interesting properties. One characteristic of silole derivatives is their aggregationinduced emission phenomenon; i.e., non-emissive molecules are induced to emit efficiently by aggregate formation, a totally opposite effect to that typically observed in common luminophores. Silole derivatives 92 and 93 (see Figure 46) were prepared by employing the terminal alkyne 1-ethynylpentaphenylsilole via a palladium catalysed cross-coupling reaction with aryl halide derivatives. ${ }^{90}$ The THF-water 1:9 v/v solutions of 92 showed an intense emission band at $500 \mathrm{~nm}$ upon excitation at $370 \mathrm{~nm}$ due to the formation of highly luminescent aggregates. This emission band was quenched upon the addition of increasing quantities of PA. Nearly the same emission quenching with PA was obtained with receptor 93. The response of both receptors was quite selective to PA and addition of 2,4-DNT to THF-water 1:9 v/v solutions only induced moderate quenching. Moreover, the detection limits obtained for both receptors were ca. $0.1 \mathrm{ppm}$ of PA. The observed emission quenching was ascribed to the rupture of the aggregates of $\mathbf{9 2}$ and 93 upon coordination with PA. 


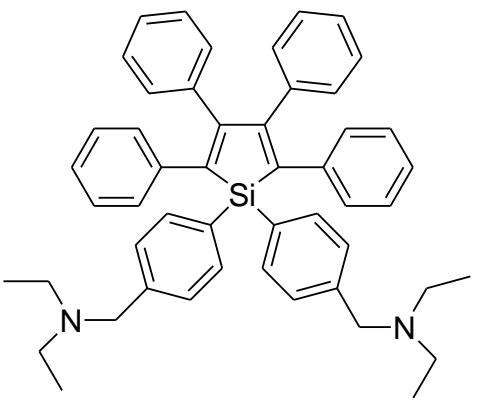

94

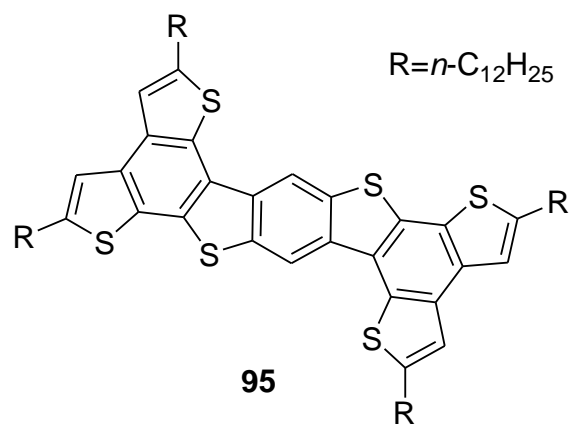

Figure 47. Structure of silole derivative 94 and planar benzothiophene compound 95 . $^{91,92}$

The aggregation-induced emission phenomenon was also observed for silole derivative 94 (Figure 47). ${ }^{91}$ The THF-water 1:100 v/v solutions of receptor 94 showed an intense emission band centred at ca. $500 \mathrm{~nm}$ due to the formation of highly dispersed nano-sized aggregates. Addition of increasing quantities of PA to the solutions of receptor 94 induced a progressive quenching of the emission band and complete quenching was observed upon the addition of $5 \mu \mathrm{g} / \mathrm{mL}$ of PA. As in the previous example, the observed emission quenching was ascribed to the rupture of the aggregates of $\mathbf{9 4}$ upon coordination with PA.

Planar benzothiophene compound 95 (see Figure 47) was used for the preparation of 1D microbelts and 3D flower-shaped supernanostructures through $\pi-\pi$ stacking and van der Waals interactions. ${ }^{92} 1 \mathrm{D}$ microbelts were self-assembled from 95 in 1,4-dioxane after the solution was drop-casted onto a glass substrate and the solvent was evaporated. By replacing the 1,4-dioxane with THF and $n$ decane, and after drop-casting onto glass substrates, two 3D flower-shaped supernanostructures ( $A$ and $B$, respectively) were obtained. Upon excitation of the films of these nanostructures, intense emission bands in the 450-480 nm interval were observed. Exposure of the films of flower A and flower B to 2,4-DNT vapours 
(ca. $100 \mathrm{ppb}$ ) induced a quenching of emission intensity to half the original intensity after 330 and 30 seconds for flower A and flower B, respectively. However for the 1D microbelts, a half emission quenching was achieved after 22000 seconds. These high response speeds observed for flowers $A$ and $B$, when compared with those obtained with 1D microbelts, were ascribed to the large surface area and the more porous morphology of the former. Practically the same quenching effects, but at lower speeds, were obtained for the three nanomaterials in the presence of TNT vapour (ca. $5 \mathrm{ppb}$ ). The detection mechanism was attributed to an electron transfer process from the electron-rich organic materials to electron-deficient nitroaromatic compounds. This is a good example of how morphology control through self-assembly provides an interesting platform to develop organic crystalline microstructures to design chemosensors in which differences in film morphologies lead to dramatic changes in explosive detection speed.

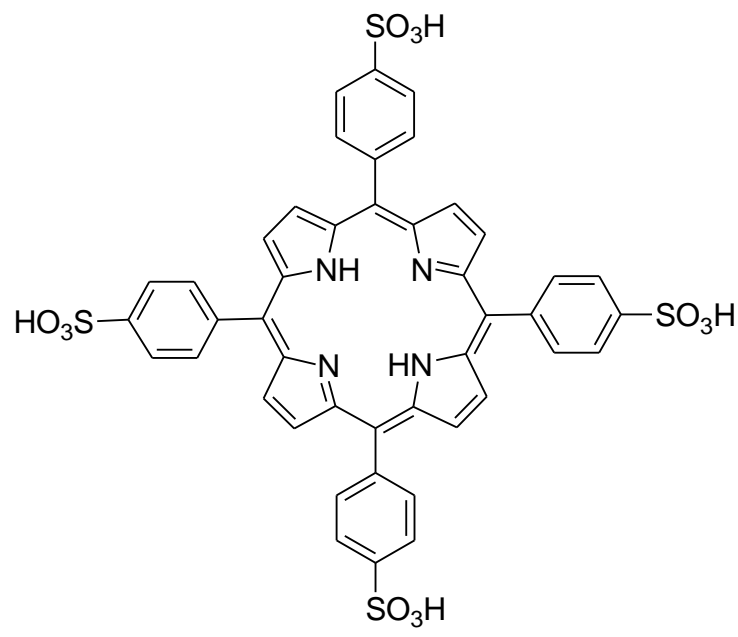

96

Figure 48. Structure of Meso-tetra(4-sulfonatophenyl)porphyrin $96{ }^{93}$ 
Meso-tetra(4-sulfonatophenyl)porphyrin (96) (Figure 48) was prepared and used for the fluorescence detection of TNT in water. ${ }^{93}$ Aqueous solutions of 96 buffered at $\mathrm{pH} 7.0$ showed two emission bands at 645 and $702 \mathrm{~nm}$ upon excitation at $413 \mathrm{~nm}$. Addition of increasing quantities of TNT resulted in the formation of a non-emissive 96-TNT complex. By taking emission quenching measurements, the authors reported a detection limit of $200 \mathrm{ppb}$ for TNT. Harmon et al also used meso-tri(4-sulfonatophenyl)mono(4-carboxyphenyl) porphyrin ( $C_{1}$ TPP) for the fluorogenic detection of TNT in water. ${ }^{94}$ At this respect water solutions at $\mathrm{pH} 7.0$ of $\mathrm{C}_{1}$ TPP presented an intense absorption band in the Soret region at $413 \mathrm{~nm}$. Addition of increasing quantities of TNT induced a reduction of the extinction coefficient of the band centred at $413 \mathrm{~nm}$ together with the apparition of a broad shoulder centred at $424 \mathrm{~nm}$. By excitation of the water solutions of $C_{1}$ TPP at $413 \mathrm{~nm}$ two emission bands centred at 636 and 706 $\mathrm{nm}$ appeared. The addition of increasing quantities of TNT induced a moderate quenching of both emission bands. The visible and emission changes were ascribed to the formation of a co-planar complex between the porphyrin and the TNT molecules. The formation of hydrogen bonds between one of the nitro groups of TNT and the $\mathrm{N}-\mathrm{H}$ moieties of the pyrrole rings is the main force that drives the formation of the co-planar complex. 
<smiles>COc1ccc(-c2ccc(-c3ccc(OC)cc3)s2)cc1</smiles>

97<smiles>COc1ccc(-c2ccc(-c3ccc(-c4ccc(C)cc4)s3)s2)cc1</smiles>

98 $\mathrm{R}=$<smiles>CCCCC(CC)CC</smiles><smiles></smiles>

99

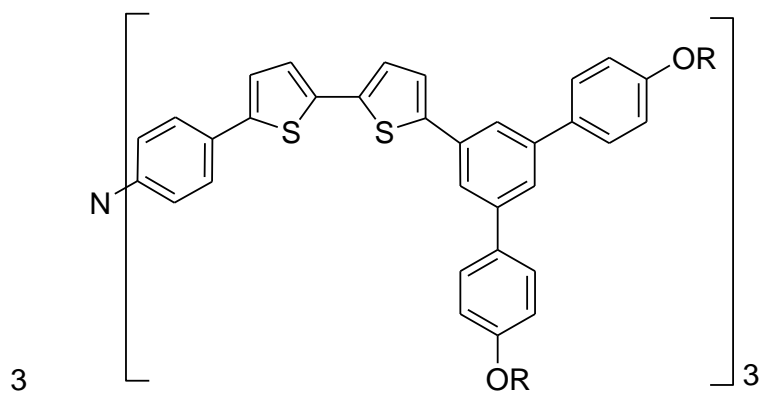

100

Figure 49. Structures of branched fluorescent receptors $97-100 .^{95}$

Branched fluorescent receptors containing thiophene units in the arms and triphenylamine centres, 97-100 (Figure 49), were prepared and used for the detection of nitrated compounds such as 2,4-DNT, 1,4-DNB, plastic explosive DMNB and 4-NT. ${ }^{95}$ The THF solutions of 97-100 exhibited intense emission bands in the 450-650 $\mathrm{nm}$ range upon excitation at $400 \mathrm{~nm}$. Addition of increasing quantities of 2,4-DNT, 1,4-DNB, 4-NT and DMNB induced different degrees of quenching (more intensity for the thiophene-containing $\mathbf{9 7}$ and 99 dendrimers) due to an efficient photo-induced electron transfer involving electron-rich dendrimers and nitro derivatives. The greatest quenching was observed for 1,4DNB followed by 2,4-DNT, 4-NT and DMNB, the observed trend clearly relating 
with the reduction potential of nitrated compounds. Time-resolved measurements demonstrated that, in contrast to conjugated polymers, quenching is dominated by collisional interactions between the dendrimers and the nitro derivatives.

\subsubsection{Metal complexes}

Fluorophores containing metal complexes have also been used for the detection of nitrated explosives by emission quenching. One of the first examples used poly(amidoamine) dendrimers (PAMAM) functionalised with pendant $\left[\mathrm{Ru}(\mathrm{bpy})_{3}\right]^{2+}$ fluorophores of G0-to-G4 generations, which were employed for the detection of TNT and 2,4-DNT. ${ }^{96}$ Ethanol-water 3:7 v/v solutions of dendrimers showed the typical emission band of the $\left[\mathrm{Ru}(\mathrm{bpy})_{3}\right]^{2+}$ complex in the $575-640 \mathrm{~nm}$ range. Addition of increasing quantities of TNT and DNT induced the quenching of the emission intensity of dendrimers, whereas addition of NT induced negligible changes. The most intense quenching was observed for TNT. Additionally, the greatest quenching efficiency was noted for dendrimer G2, which was the dendrimer with a more "open" structure, thereby exhibiting fine accessibility to the pendant $\left[\mathrm{Ru}(\mathrm{bpy})_{3}\right]^{2+}$ fluorophores. 

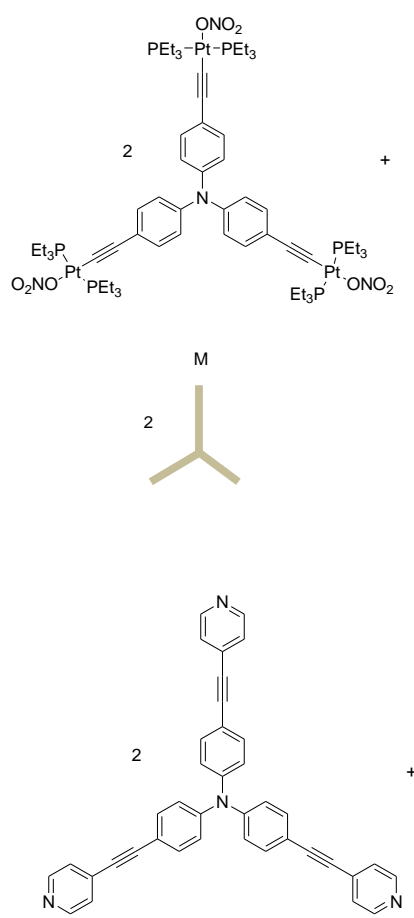

$M_{b}$
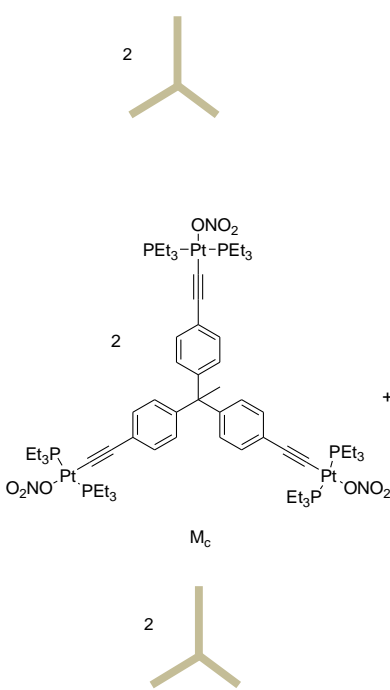
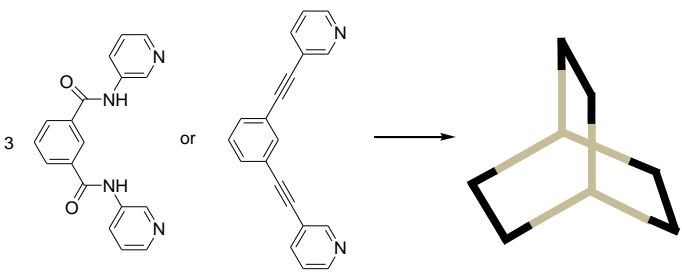

$\mathrm{L}_{\mathrm{a}}$
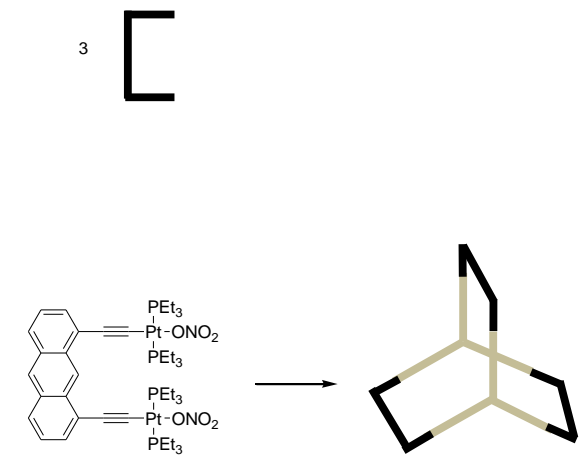

$101 b$
3
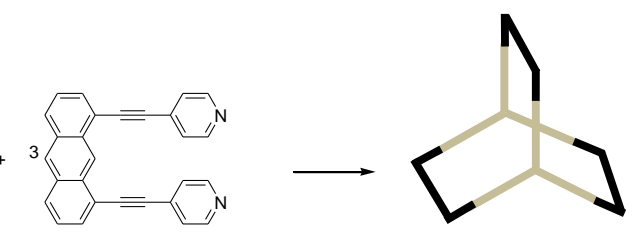

$L_{c}$

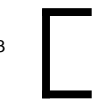

Figure 50. Schematic representation of the formation of 101, 101a, 101b and 101c from $M$ and $L$ respectively. ${ }^{97,98}$ 
Mukherjee et al reported some $\mathrm{Pd}$ and $\mathrm{Pt}$ complexes for the detection of nitroaromatic explosives. In a first report, they designed and synthesised a nanoscopic trigonal prismatic cage $M_{2} L_{3}(\mathbf{1 0 1})$ obtained by the self-assembly of the organometallic $\mathrm{Pt}_{3}$ tritopic planar acceptor 4,4',4"-tris[ethynyl-trans$\operatorname{Pt}\left(\mathrm{PEt}_{3}\right)_{2}\left(\mathrm{NO}_{3}\right)$ ]triphenylamine $(\mathrm{M})$ with a clip-type amide containing the ligand 1,3-bis(3-pyridyl)isophthalic amide (L) (Figure 50). ${ }^{97}$ Ethynyl functionality was introduced to make the linker rigid and planar, and to make it particularly fluorescent since it has been found that coordination complexes containing this functional group frequently show fluorescent behaviour. Complex 101 in $\mathrm{CH}_{2} \mathrm{Cl}_{2}$ DMF 4:1 v/v solution showed two absorption bands at $275 \mathrm{~nm}$ (related with a $\pi$ $\pi^{*}$ transition) and $368 \mathrm{~nm}$ (attributed to a metal-to-ligand charge transfer). Upon excitation at $400 \mathrm{~nm}$, a broad emission band at $546 \mathrm{~nm}$ was observed. This emission was gradually quenched upon the addition of increasing quantities of TNT. The quenching of the emission intensity of 101 was ascribed to a photoinduced electron transfer from the excited state of the complex to the nitroaromatic compound.

In another work, the same authors reported the synthesis of a new trigonal prism 101a from $\mathbf{M}$ using the ethynyl-containing donor clip 1,3-bis(3pyridylethynyl)benzene) (La). A complementary approach was also followed to prepare not only $\mathbf{1 0 1 b}$ from the organic tritopic planar donor $4,4^{\prime}, 4^{\prime \prime}$-tris(4pyridylethynyl)triphenylamine ( $\mathbf{M b})$ in combination with an organometallic $\mathrm{Pt}_{2}-$ clip containing an anthracene with ethynyl functionality (Lb), but also 101c from 4,4', 4'"-tris[ethynyl-trans-Pt $\left(\mathrm{PEt}_{3}\right)_{2}\left(\mathrm{NO}_{3}\right)$ ]triphenylethane $(\mathrm{Mc})$ upon the reaction with [1,8-bis(4-pyridylethynyl)anthracene] (LC). ${ }^{98}$ The conjugated ethynyl bridges in 101a, 101b and 101c make these assemblies $\pi$-electron-rich and possible hosts for electron-deficient nitroaromatic compounds. DMF solutions of complexes 
101a, 101b and 101c showed broad intense emission bands in the $420-700 \mathrm{~nm}$ range when excited at $400 \mathrm{~nm}$. The fluorescence of the DMF solutions of $\mathbf{1 0 1 b}$ and 101c was quenched upon the gradual addition of TNT. The quenching mechanism was ascribed to the formation of a charge transfer complex between the $\pi$-electron-rich cages and the electron-deficient TNT. The formation of these complexes favours a photo-induced electron transfer process from the excited states of cages to the ground state of TNT. The authors also studied the performance of spin-cast films prepared by the spin-coating of DMF solutions of 101c over quartz, and they observed a fluorescent quenching on exposure to TNT vapours.

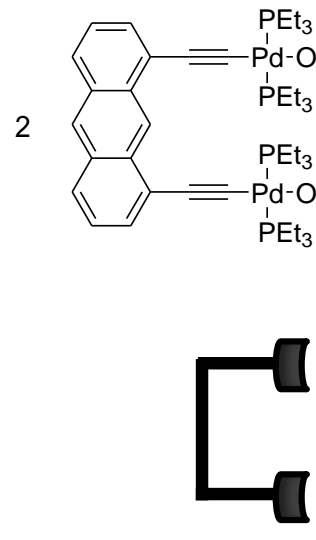

$\mathrm{Lb}$
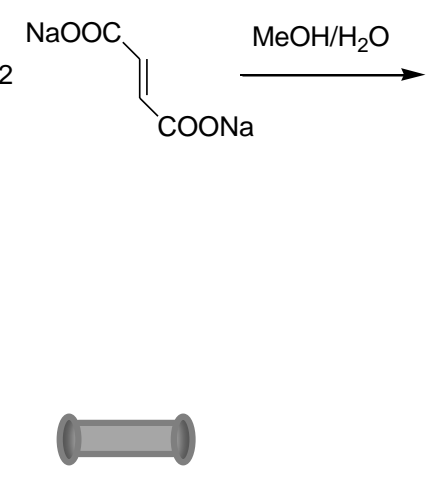

Fumarate

Figure 51. Schematic representation of the formation of 102 from $\mathbf{L b}$ and Fumarate. ${ }^{99}$

The same group also reported the synthesis of the molecular rectangle 102 through the $[2+2]$ self-assembly of a $\mathrm{Pd}_{2}^{\prime \prime}$ shape selective organometallic molecular "clip" (Lb) with the linear dicarboxylate donor fumarate (Figure 51). ${ }^{99}$ Chloroform solutions of rectangle $\mathbf{1 0 2}$ showed an intense emission band at $\mathbf{4 4 0}$ 
$\mathrm{nm}$, which was efficiently quenched upon the addition of increasing quantities of TNT with a detection limit of $1.0 \times 10^{-5} \mathrm{~mol} \mathrm{dm}^{-3}$.

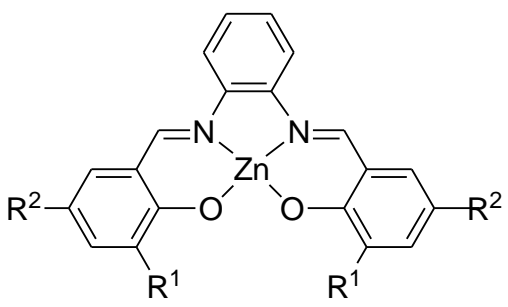

$103 \mathrm{R}^{1}=\mathrm{tBu}, \mathrm{R}^{2}=\mathrm{tBu}$

$104 \mathrm{R}^{1}=\mathrm{DMA}, \mathrm{R}^{2}=\mathrm{tBu}$

$105 \mathrm{R}^{1}=\mathrm{H}, \mathrm{R}^{2}=\mathrm{tBu}$

$106 \mathrm{R}^{1}=\mathrm{H}, \mathrm{R}^{2}=\mathrm{Cl}$

$107 \mathrm{R}^{1}=\mathrm{H}, \mathrm{R}^{2}=\mathrm{NO}_{2}$

$108 \mathrm{R}^{1}=\mathrm{H}, \mathrm{R}^{2}=\mathrm{H}$

$109 R^{1}=H, R^{2}=\mathrm{OMe}$

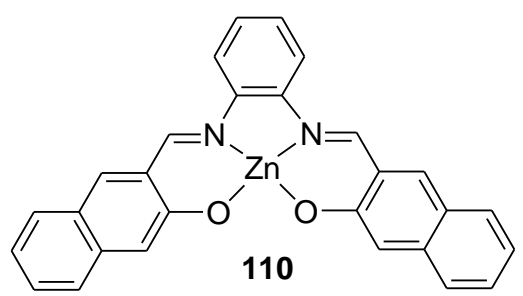

DMA = Dimethylamine

Figure 52. Structures of Zn-salophen complex 103 and a family of Zn(salicylaldimine)

derivatives 104-110. ${ }^{100,101,102}$

Knapp et al prepared $\mathrm{Zn}$-salophen complex 103 (Figure 52) and studied the fluorescent behaviour in the presence of nitroaromatic compounds and DMNB. ${ }^{100}$ The authors reported that addition of increasing quantities of DMNB, 1,3dimethyl-2-nitrobenzene (NX), NT, NB and 5-nitroquinoline (NQ) induced different quenching degrees of the emission band at $538 \mathrm{~nm}$ of the acetonitrile solutions of complex 103. Stern-Volmer plots indicated a dynamic quenching process in which nitro derivatives accepted an electron from the excited state of 103. In an additional work, the same authors prepared a family of $\mathrm{Zn}$ (salicylaldimine) derivatives (104-110). They were organised in a sensory array which was able to display differential responses to closely related nitroaromatics. ${ }^{101}$ The authors found that the emission of the $\mathrm{Zn}$ complexes was quenched to different extents upon the addition of nitro derivatives such as NX, 4-NT, NB, 2-chloro-1nitrobenzene (CINB), 2,4-DNT, 1,3-DNB, chloramphenicol (CIAmp), NQ and PA. In 
the score plot, the mononitroaromatic compounds were separated from not only dinitroaromatics, but also from ClAmp and PA. The emission quenching mechanism of complexes 104-110 by nitroaromatic derivatives was studied by means of emission lifetime measurements, electron paramagnetic resonance (EPR) and density functional theory (DFT) calculations. ${ }^{102}$

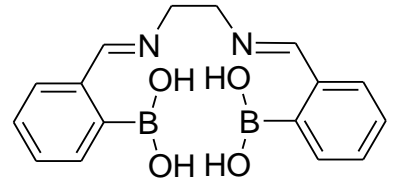

111a

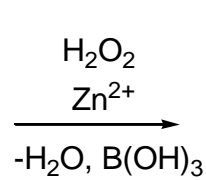

$-\mathrm{H}_{2} \mathrm{O}, \mathrm{B}(\mathrm{OH})_{3}$

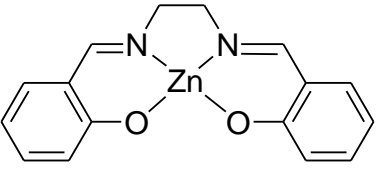

111

Figure 53. Oxidative deboronation of the receptor 111a to obtain fluorescent $111 .^{103}$

The same group reported a highly sensitive system based on a turn-on fluorescence approach to detect low levels of $\mathrm{H}_{2} \mathrm{O}_{2}$ and benzoyl peroxide (BP). ${ }^{103}$ The signalling protocol relied on an oxidative deboronation of a boronic acid derivative (111a) (Figure 53), resulting in the formation of $\mathrm{H}_{2}$ Salen which is able to complex $\mathrm{Zn}^{2+}$ to form the corresponding $\mathrm{Zn}($ Salen) fluorophore (111). Oxidative deboronation (see Figure 53) is chemically selective for peroxides and involved the conversion of a C-B bond into a $\mathrm{C}-\mathrm{O}$ bond by $\mathrm{H}_{2} \mathrm{O}_{2}$ and $\mathrm{BP}$. The authors demonstrated that the methanolic solutions of 111a containing $\mathrm{Zn}(\mathrm{OAc})_{2}$ showed negligible fluorescence at $440 \mathrm{~nm}$, whereas the addition of increasing quantities of $\mathrm{H}_{2} \mathrm{O}_{2}$ induced the appearance of an intense emission band at $440 \mathrm{~nm}$ due to the formation of the highly emissive complex 111. The same response was observed in the presence of BP. In a parallel experiment, TATP was pre-incubated with acetic acid for 5 minutes and then added to 111a- $\mathrm{Zn}(\mathrm{OAc})_{2}$, the mixture resulting in an 80-fold increase of the emission intensity at $440 \mathrm{~nm}$. This emission enhancement was ascribed to the acid-promoted TATP decomposition that led to 
the formation of $\mathrm{H}_{2} \mathrm{O}_{2}$. The detection limits for $\mathrm{H}_{2} \mathrm{O}_{2}, B P$ and TATP using this methodology were ca. $10 \mathrm{nM}$.

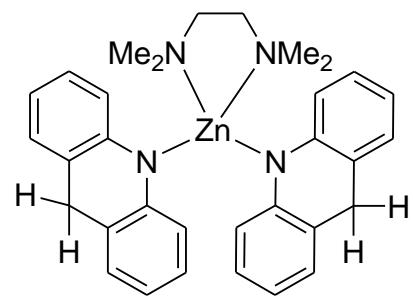

112

Figure 54. Structure of Zn complex $112 .{ }^{104}$

A molecular fluorescence-based chemosensor for the direct detection of RDX and PETN was reported using the $\mathrm{Zn}$ complex 112 (Figure 54). ${ }^{104}$ Acetonitrile solutions of $\mathbf{1 1 2}$ were weakly emissive, whereas the addition of RDX or PETN after a 30-second irradiation at $313 \mathrm{~nm}$ induced the appearance of an intense emission band at $480 \mathrm{~nm}$ (80- and 25-fold fluorescence enhancement at $480 \mathrm{~nm}$ for RDX and PETN, respectively). This emission was ascribed to the formation of an $\mathrm{N}$ methylacridinium fluorophore $\left(\mathrm{AcrH}^{+}\right)$. The mechanism involved in the $\mathrm{RDX}$ and PETN photoreduction was extensively studied with analogue receptor 10-methyl9,10-dihydroacridine $\left(\mathrm{AcrH}_{2}\right)$. The authors observed that RDX and PETN were able to oxidise $\mathrm{AcrH}_{2}$ by a photo-induced electron transfer mechanism, in which the photo-excited acridine $\left(\mathrm{AcrH}_{2}{ }^{*}\right)$ transferred one electron to RDX, followed by hydride ion transfer to form the emissive $\mathrm{AcrH}^{+}$along with the decomposition products from RDX and PETN. Using complex 112, amounts as low as $7.0 \times 10^{-5}$ and $1.3 \times 10^{-4} \mathrm{~mol} \mathrm{dm}^{-3}$ of RDX and PETN, respectively, were detected. 


\subsubsection{Chemical reactions}

The formation of fluorescent products by chemical reactions has been applied to the detection of peroxide-based explosives. For instance, Karst el al developed a reverse-phase HPLC with post-column UV irradiation and fluorescence detection for the determination of TATP and hexamethylene triperoxide diamine (HMTD). ${ }^{105}$ After separation, analytes were degraded photochemically to hydrogen peroxide with UV light of $254 \mathrm{~nm}$. The hydrogen peroxide formed was determined through the formation of fluorescent dimer 114 (Figure 55) (emission band at $405 \mathrm{~nm}$ ), which was obtained by the peroxidase-catalysed oxidation of $p$ hydroxyphenylacetic acid (113) (See Figure 55).

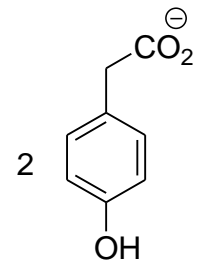

113

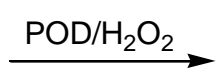<smiles>O=C([O-])Cc1ccc(O)c(-c2cc(CC(=O)[O-])ccc2O)c1</smiles>

114

Figure 55. Formation of 114 by a peroxidase-catalysed oxidation of $113 .^{105}$

The detection limits for both the peroxide-based explosives was $2.0 \times 10^{-6} \mathrm{~mol}$ $\mathrm{dm}^{-3}$. The authors indicated that this method sufficed for the analysis of real samples, the analysis of an explosion site or to detect the remains of these two explosives, including illegal manufacturing sites. 


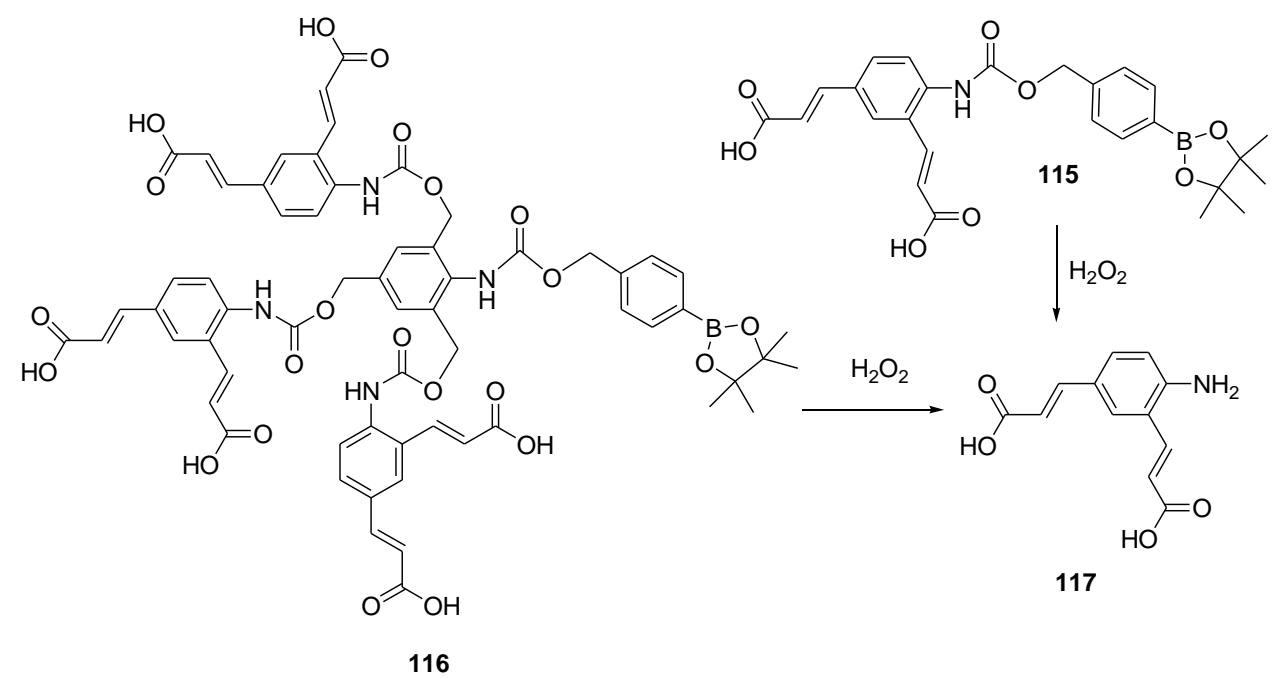

Figure 56. TATP dendritic sensor 116 and its monomeric counterpart 115, where the reaction with hydrogen peroxide (from TATP decomposition) induced the release of fluorescent amine $117 .{ }^{106}$

Shabat et al reported a new molecular probe for the sensitive, direct detection of TATP in microgram amounts in aqueous buffer solutions with no acid pretreatment. It is based on a self-immolative dendritic platform that can amplify a single cleavage event generated by hydrogen peroxide into a multiple release of fluorogenic end-groups. ${ }^{106}$ For this purpose, probes 115 and 116 (Figure 56) were prepared and tested. Both derivatives contained strongly fluorescent amine 117, connected to an aryl borate ester through carbamate linkages. Final probes $\mathbf{1 1 5}$ and 116 showed an intense emission band centred at $450 \mathrm{~nm}$ upon excitation at $270 \mathrm{~nm}$ in water containing $\mathrm{NaHCO}_{3}$ at pH 8.3. After a 90-min incubation, addition of hydrogen peroxide to the solutions of both probes led to the appearance of a new emission band at $510 \mathrm{~nm}$, which was assigned to free 117. The release of 117 from the aqueous solutions of $\mathbf{1 1 5}$ and $\mathbf{1 1 6}$ was a direct consequence of the mechanism shown in Figure 56. Hydrogen peroxide was easily detected at a concentration of $1.0 \times 10^{-6} \mathrm{~mol} \mathrm{dm}^{-3}$. As expected, the intensity of the fluorescence generated by dendritic probe $\mathbf{1 1 6}$ in the presence of hydrogen 
peroxide was 3-fold higher than that obtained for $\mathbf{1 1 5}$. The same response was observed after a 120-min incubation of both probes in the presence of TATP.

$$
\begin{aligned}
& \mathrm{R}-\mathrm{ONO}_{2}^{\ominus} \underset{\text { Reagent B }}{\stackrel{\mathrm{OH}^{-} / \Delta}{\longrightarrow}} \mathrm{NO}_{2}^{\ominus}+\text { Organics } \\
& \underset{\text { Reagent } \mathrm{C}}{\mathrm{NO}_{2}^{\ominus}} \mathrm{HNO}_{2}+
\end{aligned}
$$

Figure 57. Reaction scheme for steps 1 and 2 of the two-step detection procedure that yield $119 .{ }^{107}$

Trogler et al developed a protocol for the detection of TNT, RDX, HMX, PETN, Tetryl, and TNG in the solid state. ${ }^{107}$ These authors prepared three reactives: reactive $A$, containing a polysilole polymer dissolved in acetone; reactive $B$, formed by 2,3-diaminonaphthalene (DAN) and potassium hydroxide; and finally reactive $\mathrm{C}$, a mixture of ethanol and phosphoric acid. Nitramine and nitrate esters were detected by a two-step procedure using reactives B and C (Figure 57). Thus, when applying reactive $B$ to a filter paper containing solid explosives, the base contained in the mixture deprotonated either the nitramine or the nitrate esters in the alpha position to $\mathrm{N}$ or $\mathrm{O}$, respectively. This deprotonation induced the release of a nitrite anion. In the second step, upon application of reactive $C$, the nitrite anion was converted into nitrous acid which induced the transformation of 118 into the highly fluorescent $1-[\mathrm{H}]$-naphthotriazole 119. With this two-step protocol, TNT gave no response, but nitramine and nitrate esters were detected at quantities as low as $2 \mathrm{ng}$. Additionally, the authors incorporated reactive A, which was able to detect TNT via the quenching of the polysilole polymer. 


\subsubsection{Miscellaneous}

Detection of target nitrated compounds (NM, NB, 4-NT and 2,6-DNT) by using common fluorophores purpurin (120), malachite green (121), and phenol red (122) (Figure 58) has been studied. ${ }^{108}$<smiles>O=C1c2ccccc2C(=O)c2c(O)c(O)cc(O)c21</smiles>

120<smiles>CCN(CC)c1ccc(C(=C2C=CC(=NC)C=C2)c2ccccc2)cc1</smiles>

121<smiles>O=C1C=CC(=C(c2ccc(O)cc2)c2ccccc2S(=O)(=O)O)C=C1</smiles>

122

Figure 58. Structures of fluorophores 120-122. ${ }^{108}$

Addition of all the nitrated derivatives to ethanolic solutions of the three fluorophores induced different degrees of emission quenching. For the three fluorophores, the Stern-Volmer constants measured for nitroaromatic derivatives were higher than those determined for the nitroaliphatic counterparts. Of the three fluorophores, purpurin showed the greatest quenching constants. As in similar cases, the emission quenching of the three fluorophores was ascribed to a photo-induced electron transfer from the excited state of fluorophores to the ground state of nitro derivatives.

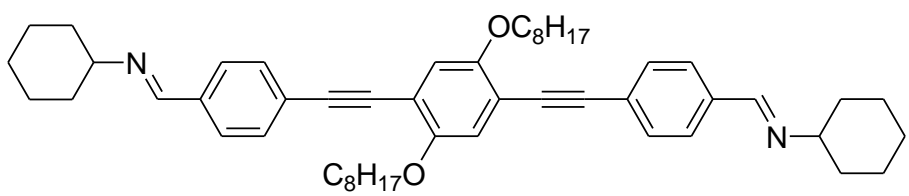

123<smiles>[R]c1ccc(Cc2cc(C)ccc2C)cc1</smiles>

$$
\begin{aligned}
& 124 \mathrm{R}=-\mathrm{H} \\
& 125 \mathrm{R}=-\mathrm{CH}_{3} \\
& 126 \mathrm{R}=-\mathrm{OC}(\mathrm{O}) \mathrm{CH}_{3} \\
& 127 \mathrm{R}=-\mathrm{OCH} \mathrm{H}_{3} \\
& 128 \mathrm{R}=-\mathrm{OH}
\end{aligned}
$$

Figure 59. Structures of $\pi$-conjugated phenylene-ethylene diimine 123 and 2,5-dimethylphenyl-(4substituted-phenyl)methanes $124-128 .{ }^{109,} 110$ 
Montméat et al described a portable, low-cost and reliable detection device based on a thin film of the fluorescent $\pi$-conjugated phenylene-ethylene diimine 123 (Figure 59). The film was deposited on a glass substrate, then acted as a wave-guide, and was used for the ultra-trace detection of TNT or 2,4-DNT in ambient air or on objects tainted with these explosives. ${ }^{109}$ This material exhibited excellent fluorescence properties and the high electron density of the diimine conferred it a strong affinity to electron-deficient compounds such as nitroaromatics. The film's fluorescence (greenish-blue fluorescence with a maximum at $480 \mathrm{~nm}$ ) diminished in the presence of either TNT ( $40 \%$ of quenching after 10 minutes) or 2,4-DNT ( $80 \%$ of quenching after 10 minutes). The film of $\mathbf{1 2 3}$ presented detection thresholds of $0.75 \mathrm{ppbv}$ and $9 \mathrm{ppbv}$ for TNT and 2,4-DNT, respectively, with no loss of performance in the presence of humidity or interfering compounds.

2,5-dimethylphenyl-(4-substituted-phenyl)methanes (124-128) (see Figure 59) were synthesised by Cartmill et al and their ability to recognise nitroaromatic compounds in solution was tested. ${ }^{110}$ The hexane-ethyl acetate $91: 9 \mathrm{v} / \mathrm{v}$ solutions of receptors 124-128 showed emission bands in the 400-440 nm interval, which were quenched upon the addition of 2,4-DNT, 4-NT and NB. Emission quenching was assigned to an efficient photo-induced electron transfer between the excited receptor and the nitroaromatic derivative upon the formation of 1:1 complexes. The larger quenching was observed for receptor 124 in the presence of 2,4-DNT. 


\section{Colorimetric sensors and reagents for explosives.}

\subsection{Colour changes induced by coordination.}

Mao et al developed a simple yet sensitive method based on the colour change of cysteamine-functionalised gold nanoparticles (AuNPs), which went from red wine (dispersion state) to violet blue (aggregation state) induced by the donoracceptor (D-A) interaction between TNT and primary amines (Figure 60). ${ }^{111}$

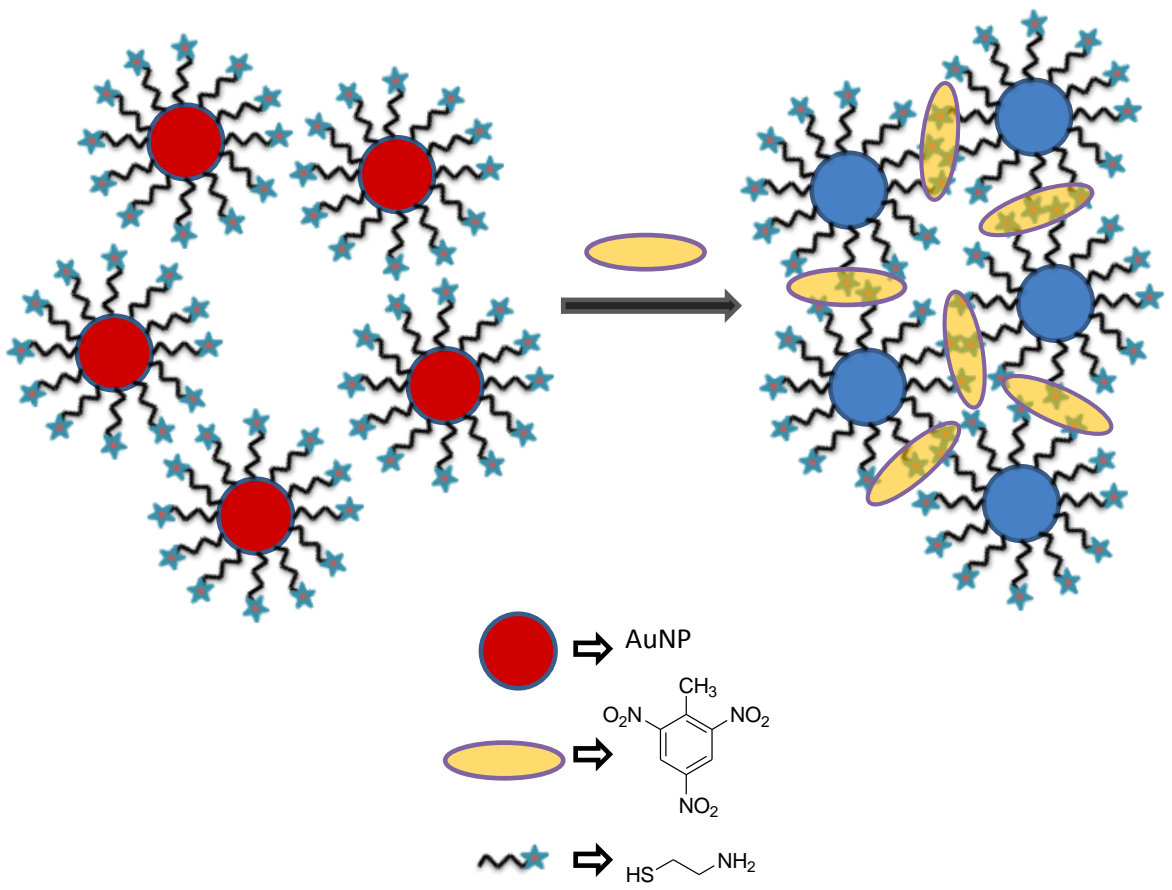

Figure 60. Scheme of the colorimetric sensing of TNT based on the aggregation of functionalisedgold nanoparticles. ${ }^{111}$

The detection limit achieved was lower than picomolar, and the authors reported a gradual change in colour at different TNT concentrations ranging from $5 \cdot 10^{-13} \mathrm{M}$ to $5 \cdot 10^{-9} \mathrm{M}$ in aqueous environments. The presence of other explosives 
and derivates such as 2,4-dinitrotoluene, nitrobenzene or toluene did not induce changes in either colour or the absorbance spectrum of the AuNPs suspension.

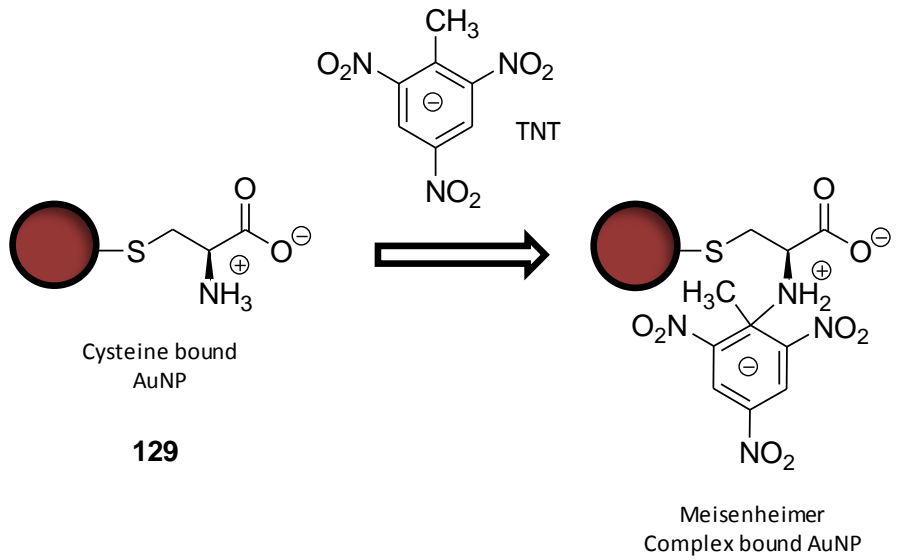

Figure 61. Schematic illustration of the formation of the Meisenheimer complex between TNT and cysteine-conjugated AuNPs. ${ }^{112}$

A highly selective and ultrasensitive cysteine-modified gold nanoparticle labelfree surface enhanced Raman spectroscopy (SERS) probe for TNT recognition at the pico molar (pM) level in aqueous solution was reported by Ray et al. ${ }^{112}$ Due to the formation of the Meisenheimer complex between TNT and cysteineconjugated AuNPs (129), a substantial shift in plasmon band energy to a longer wavelength and a red-to-blue colour change were observed (Figure 61). As a result of this aggregation process, the intensity of the Raman signals significantly enhanced and attributed to the plasmonic coupling between nanoparticles in close proximity, resulting in large local electromagnetic field enhancements in the confined junctions. By this method, TNT can be detected quickly (in less than 10 min) and accurately without any dye tagging at the pM level with excellent discrimination against other nitro compounds such as 2,4-DNT, 2,4-dinitrophenol (NP), NB and heavy metals. 


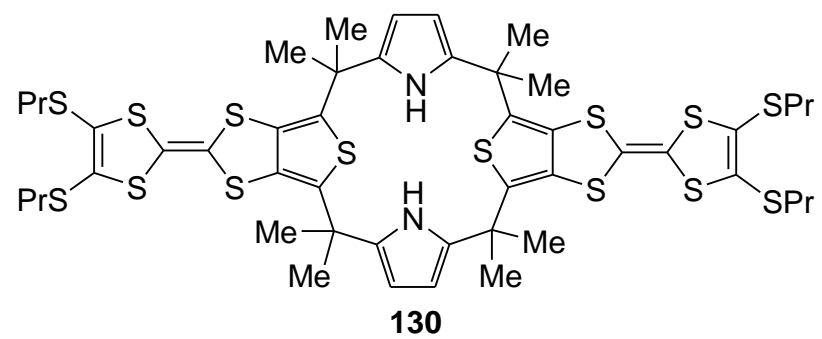

Figure 62. Structure of bis-tetrathiafluvalene-calix[2] thiophene[2]pyrrole derivative $130{ }^{113}$

A colorimetric chemosensor based on bis-tetrathiafluvalenecalix[2]thiophene[2] pyrrole derivative 130 (Figure 62) was synthesised and its chromogenic behaviour against several nitroaromatic explosives (TNT, PA and TNB) was tested. ${ }^{113}$ The chloroform solutions of $\mathbf{1 3 0}$ showed an intense absorption band at $450 \mathrm{~nm}$. Addition of TNB to the chloroform solutions of $\mathbf{1 3 0}$ resulted in the appearance of a small band at $649 \mathrm{~nm}$ with a clear colour change from yellow to green, whereas addition of PA led to another absorption at $746 \mathrm{~nm}$ (colour change from yellow to dark green). In contrast, addition of TNT induced negligible changes in the UV-visible spectra of $\mathbf{1 3 0}$. The colour changes observed in the presence of TNB and PA were ascribed to the formation of charge-transfer complexes between 130 and nitroaromatic molecules. In these complexes, nitroaromatic molecules were located between both tetrathiafulvalene (TTF) subunits in a sandwich-like fashion with $\pi-\pi$ donor-acceptor interactions. Hydrogen bonding interactions between the pyrrolic $\mathrm{N}-\mathrm{H}$ protons of $\mathbf{1 3 0}$ and the oxygen atoms of the nitro groups (and the hydroxyl group in the case of PA) were also present. Finally, the authors demonstrated that addition of the chloroform solutions of receptor $\mathbf{1 3 0}$ to silica gel containing TNB, PA and TNT also led to a chromogenic response. 


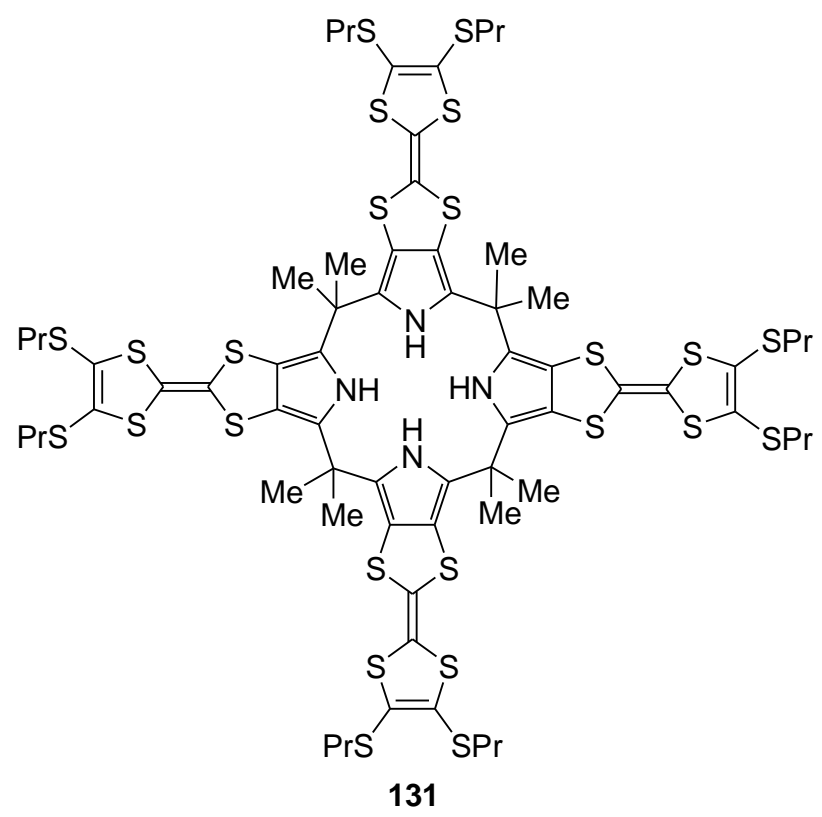

Figure 63. Structure of calix-[4]pyrrole derivative with four appended TTF units $131 .^{114}$

The same authors designed a calix-[4]pyrrole derivative by incorporating four appended TTF units (131) (Figure 63) which acted as a sandwich-like host for the electron-deficient guests in its 1,3-alternate conformation via charge transfer interactions. ${ }^{114}$ Receptor 131 acted as an effective receptor for molecules, such as TNB, tetrafluoro- $p$-benzoquinone, tetrachloro- $p$-benzoquinone and $p$ benzoquinone, in $\mathrm{CH}_{2} \mathrm{Cl}_{2}$ solutions. Receptor 131 showed a yellow colouration in dichloromethane, which changed to green with the addition of 2 equivalents of TNB given the appearance of a band at $677 \mathrm{~nm}$ resulting from the formation of the 131·(TNB $)_{2}$ complex, in which TNB molecules were sandwiched between each pair of TTF arms. Addition of chloride anions to the dichloromethane solutions of the 131·(TNB) 2 complex brought about a colour change from green to yellow due to the binding of this anion with receptor 131 , which adopted cone conformation. Finally, the same colour change was obtained upon the addition of tetrafluoro- $p$ - 
benzoquinone, tetrachloro-p-benzoquinone and $p$-benzoquinone to the dicholomethane solutions of 131.
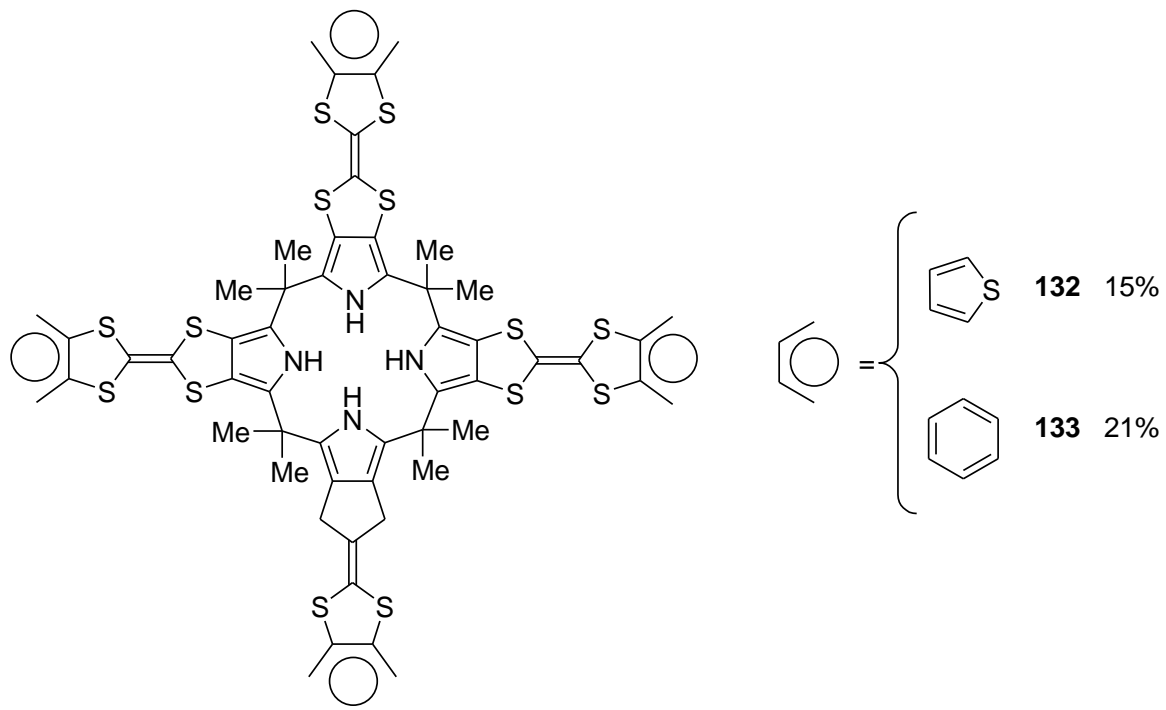

Figure 64. Structures of tetrathiafulvalene (TTF)-calix[4]pyrroles 132 and $133 .^{115}$

In another work Jeppesen, Sessler et al reported selective colorimetric sensing probes for nitroaromatic guests (TNB, TNT and PA) based on the use of modified tetrathiafulvalene (TTF)-calix[4]pyrroles $(131,132,133)$ (Figure 64) frameworks. ${ }^{115}$ As cited above, the chromogenic behaviour of receptor 131 in the presence of TNB was similar to that observed in the presence of TNT and PA in the chloroform solutions of this compound (colour modulations from yellow to green). In contrast, receptor 131 was characterised by modest binding affinities to TNB, TNT and PA in organic solvents, and was also found to require relatively high concentrations to produce a detectable colorimetric response to the naked eye. Almost the same results, but with better sensitivities, were obtained with receptors 132 and 133 upon binding with TNB, TNT and PA. For instance, the yellow chloroform solutions of receptors 132 and 133 changed to dark green when TNB was added, and to green upon the addition of TNT and PA. Changes in 
colour were ascribed to the formation of charge-transfer complexes between the receptors in the 1,3-alternate conformation and nitroaromatic molecules. In all cases, 1:2 receptor-nitroaromatic complexes were observed in which explosives were located in the TTF subunits on the opposite sides of the central calix[4]pyrrole core. The greatest affinity was observed for PA (PA > TNB > TNT). The detection limits observed were; TNB: 0.44, 0.30, $1.56 \mu \mathrm{gmL}^{-1}$; PA: 0.77, 0.64, $2.68 \mu \mathrm{gmL}^{-1}$; TNT: 3.04, 2.72, $15.3 \mu \mathrm{gmL}^{-1}$, for receptors 133, 132, and 131, respectively.

The reaction between cymantrene (cyclopentadienylmanganesetricarbonyl) and nitroaromatics upon UV irradiation (330-350 nm) to yield a blue colour derivative (absorption band at $680 \mathrm{~nm}$ ) was used to detect explosives. ${ }^{116}$ The thin films of divinyl-styrene copolymer were embedded with cymantrene (10-40\%) and used for the colorimetric detection and quantification of 2,4-DNT, 1,3-DNB and 2nitrotoluene (2-NT) (a volatile taggant of TNT). The response obtained in the presence of 2,4-DNT, 1,3-DNB and 2-NT was nearly the same with detection limits of $0.2 \mathrm{ng}$ for nitroaromatic derivatives.

Dyes 134 and 135 (Figure 65), included in polymeric thin films and spin-coated on glass slides, were used for the colorimetric detection of 2,4-DNT. ${ }^{117}$ For instance, the thin films of poly(methylmetacrylate) (PMMA) containing 134 showed an absorption band at $630 \mathrm{~nm}$, which underwent a red shift and a reduction in absorbance upon exposure (24 hours) to air saturated with 2,4-DNT at $65{ }^{\circ} \mathrm{C}$. This was reflected by a change in colour from dark blue to light purple. A similar trend was observed when exposing the thin films of amorphous polycarbonate containing 135 to 2,4-DNT vapours at $65^{\circ} \mathrm{C}$. Optical changes were ascribed to the formation of a charge-transfer complex between 134, 135 and the 
nitroaromatic molecules. Apart from changes in colour, exposure of chromophore-containing films to 2,4-DNT vapours induced important changes in the refraction index of polymers. Finally, chromophore-containing polymers were used for the construction of microring resonators, which allowed the detection of 2,4-DNT at the ppb level.

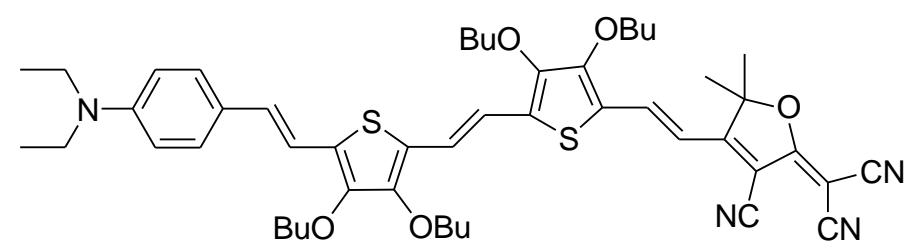

134

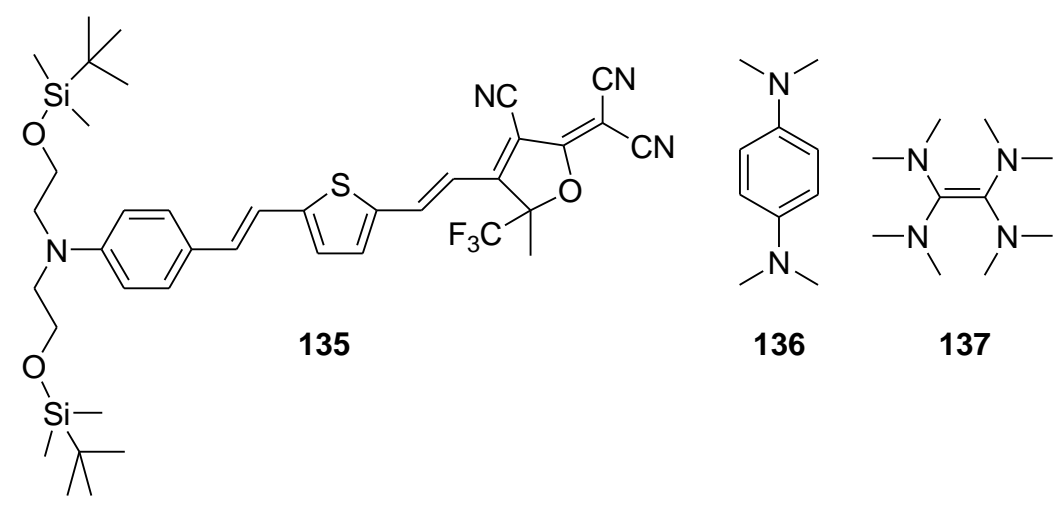

Figure 65. Structures of dyes 134-135, $N, N, N^{\prime}, N^{\prime}$-tetramethyl-p-phenylenediamine (136) and tetrakis(dimethylamino) ethylene (137). ${ }^{116,117,118}$

A novel and simple method for the colorimetric detection and differentiation of nitro explosives by specific colour reactions using host-guest and chargetransfer acceptor/donor complexes has been developed. ${ }^{118}$ Different colours were observed when several charge-transfer complexes were formed using nitrated explosives (TNT, Tetryl, RDX and HMX) as electron acceptors and electron donor molecules; for example, $N, N, N^{\prime}, N^{\prime}$-tetramethyl-p-phenylenediamine (136) and 
tetrakis(dimethylamino) ethylene (137) in the presence or absence of $\gamma$-CD. For instance, 136 and TNT formed a charge-transfer complex in acetonitrile (absorption band at $504 \mathrm{~nm}$ ). When changing to a more competitive solvent, such as acetonitrile-water 95:5 v/v, the band at $504 \mathrm{~nm}$ disappeared and two new absorptions emerged at 560 and $610 \mathrm{~nm}$ (the solution became violet). This colour change was attributed to the rupture of the charge-transfer complex and to the formation of radicals $\mathrm{TNT}^{\circ-}$ and $136^{\circ+}$. When the same experiments were carried out in the presence of $\gamma-C D$ (acetonitrile-water 95:5 v/v), the charge-transfer complex between 136 and TNT again formed in the inner hydrophobic cavity of the macrocycle. Almost the same response in acetonitrile was observed by changing TNT to RDX, but in this case, the formed complex showed a very weak absorbance at $504 \mathrm{~nm}$. Once again, addition of water induced the formation of the corresponding radicals. However in this case, that is, in the presence of $\gamma-C D$, the charge-transfer complexes did not form. This different chromogenic behaviour of TNT and RDX in the presence of $\gamma-C D$ was the basis of a pattern colorimetric recognition of nitrated explosives via a sensor array design. Electron donor 137 was also used for the development of a sensing array with 136 without the use of $\mathrm{Y}$-CD. Similar discrimination features were observed.

\subsection{Colour changes induced by chemical reactions.}

The use of chemical reactions which induced the formation of coloured or fluorescent compounds to recognise nitroaromatic explosives has been extensively employed. In fact, the first examples had already been described in the last decade of the $19^{\text {th }}$ century. In line with this, Janowski's reaction (reaction of 1,3-dinitrobenzene with an alcoholic solution of alkali) provided an adequate test for dinitro and trinitro aromatic compounds by means of the characteristic 
colour developed in alkaline acetone. ${ }^{119}$ In 1948, English described enhanced results in sensitivity terms using 50/50 acetone-ethanol mixtures and potassium hydroxide as a base. ${ }^{120}$ Some years later, Amas and Yallop proposed the use of different organic bases, such as tetramethylammonium hydroxide, diethylene triamine and tetraethylene pentamine, to induce the colorimetric reactions in the presence of 2,4-DNT and TNT at low concentrations. ${ }^{121}$ For instance, addition of tetramethylammonium hydroxide to acetone-ethanol solutions of 2,4-DNT resulted in the formation of a blue colour (detection limit of $2 \mu \mathrm{g}$ ), whereas a red colour was observed with TNT (detection limit of $1 \mu \mathrm{g}$ ). Furthermore, a slightly yellow colour developed with TNG. The same authors described a specific test for RDX based on the appearance of a red colour achieved in the presence of thymol and nitrogen-free sulphuric acid. However, this colour was also induced by other compounds like sugars and aldehydes. ${ }^{122}$ Three years later, the same authors improved the colorimetric method to eliminate interferences. ${ }^{123}$

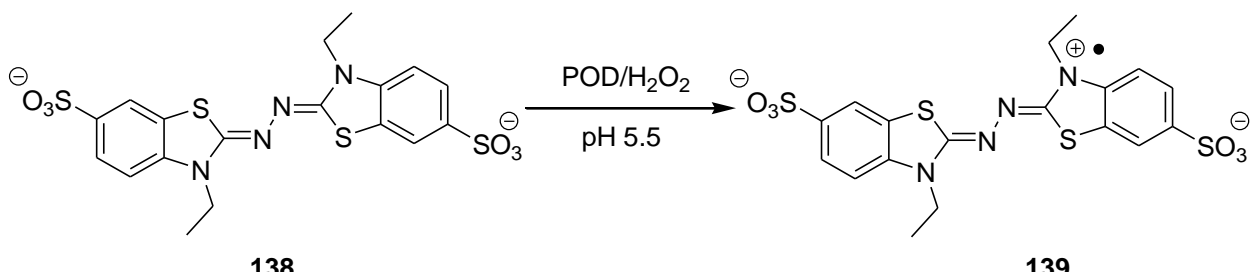

Figure 66. Enzymatic reaction between POD and 138 that yields the green-coloured radical cation $139 .^{124}$

The recent literature contains examples of using the chemodosimeter approach to design colorimetric probes, which have been reported mainly for the detection of peroxide-based explosives. For instance, Karst et al reported the development of a new rapid, simple field test for the chromogenic detection of peroxide-based explosives such as TATP and HMTD. ${ }^{124}$ The proposed method uses 
decomposition of peroxide-based explosives via UV irradiation ( $254 \mathrm{~nm}$ ) to yield hydrogen peroxide, which is further determined by an enzymatic reaction between horseradish peroxidase (POD) and substrate 138 (2,2'-azino-bis(3ethylbenzothiazoline)-6-sulphonate), which yields the green-coloured radical cation 139 in acetonitrile-water 1:10 v/v mixtures (Figure 66). Detection limits of $8.0 \times 10^{-6} \mathrm{~mol} \mathrm{dm}^{-3}$ and $8.0 \times 10^{-7} \mathrm{~mol} \mathrm{dm}^{-3}$ were determined for TATP and HMTD, respectively. In order to obtain lower detection limits, the same enzymatic assay was carried out with 113 ( $p$-hydroxyphenylacetic acid), which dimerises to form the highly fluorescent compound $\mathbf{1 1 4}$ (emission band at $405 \mathrm{~nm}$ upon excitation at $320 \mathrm{~nm}$ ). Using this fluorescence-based test, limits of detection of $8.0 \times 10^{-7} \mathrm{~mol}$ $\mathrm{dm}^{-3}$ were obtained for both TATP and HMTD.

Apak et al described a procedure for the on-site colorimetric signalling of TATP and HMTD based on the detection of $\mathrm{H}_{2} \mathrm{O}_{2}$ formed upon hydrolysis via the reaction of hydrogen peroxide with the chromogenic reactive $\mathrm{Cu}(\mathrm{II})$-neocuproine, resulting in light absorption at $454 \mathrm{~nm} .{ }^{125}$ The hydrolysis reaction of TATP and HMTD was carried out in water-acetone 20:1 v/v mixtures. Using this simple procedure, the limit of detection was $0.2 \mathrm{mg} \mathrm{L}^{-1}$ for both TATP and HMTD. The method was successfully applied for the detection of TATP and HMTD without any interference by complex samples containing nitroexplosives, such as TNT, RDX and PETN, or by household detergents containing sodium percarbonate and perborate-based bleaching powder constituents. The procedure was also unaffected by the common ions present in soil extracts. Finally, and in order to enhance the applicability of the chromogenic method, the $\mathrm{Cu}(I I)$-neocuproine complex was implemented in a polymeric nafion membrane to be used to accurately detect TATP and HMTD in the liquid phase. 
Very recently, Suslick et al, developed a simple, yet highly sensitive colorimetric sensor array based on several redox sensitive dyes to detect TATP in the gas phase. ${ }^{126}$ The authors pretreated a gas stream containing TATP vapours with Amberlyst-15 (an acid catalyst) with a view to inducing the decomposition of the peroxidic explosive to $\mathrm{H}_{2} \mathrm{O}_{2}$. Then the gas stream was passed through an array containing redox active dyes, which changed colour upon the reaction with hydrogen peroxide. Finally, the Red-Green-Blue (RGB) coordinates of the developed colours were measured and colour difference maps were generated. By applying principal component analysis (PCA) to the data obtained from the array, TATP could be distinguished and determined (limit of detection of $2 \mathrm{ppb}$ ) from hydrogen peroxide, bleach, $t$-butylhydroperoxide and peracetic acid.

A hybrid electrochemical-colorimetric sensor for the selective detection of nitroaromatic explosives in the gas phase has been recently published. ${ }^{127}$ The hybrid sensor is composed of a microcontroller-based potentiostat, a typical webcam, a transparent substrate of indium tin oxide (ITO)-printed electrodes, and a thin layer of 1-butyl-3-methylimidazolium hexafluorophosphate (BMIM-PF $)$ covering it. Upon the exposure of the sensor to the vapours of nitroaromatic explosives (PA, TNT, 2,4-DNT and 2-NT), an adsorption process in the BMIM-PF 6

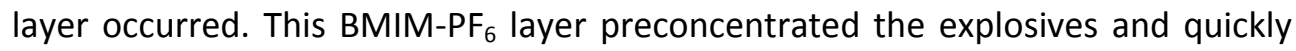
transported these analytes to electrodes. Application of a -2.0 v potential lasting 2.5 minutes induced the reduction of the nitroaromatic explosives to the corresponding azo and azoxy derivatives (red colour with absorbances at ca. 450 $\mathrm{nm})$. Changes in the RGB coordinates upon reduction of the nitroaromatic explosives were used for identification and quantification purposes. With this hybrid sensor, limits of detection of ppb in the vapour phase were achieved. 


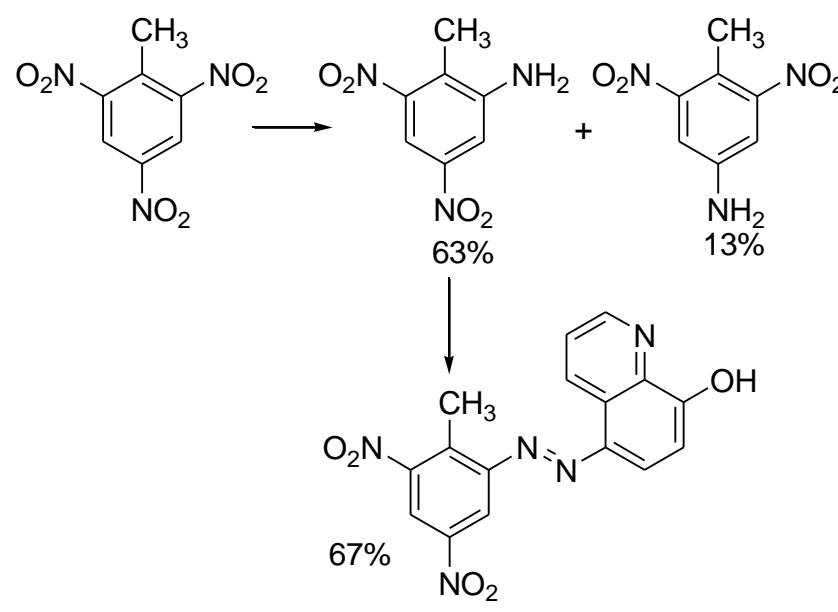

140

Figure 67. Colorimetric recognition of TNT through the formation of an azoic dye $140{ }^{128}$

TNT was chemically modified to form an azo dye to be then easily detected by surface-enhanced resonance Raman scattering. ${ }^{128}$ In this technique, an analyte containing a chromophore was adsorbed onto a roughened metal (usually silver or gold), and the enhanced Raman scattering from the surface was recorded. For this purpose, TNT was reduced to a mixture of 2-amino-4,6-dinitrotoluene (63 \%) and 4-amino-2,6-dinitrotoluene (13\%) by using iron in acetic acid. Then, 2-amino4,6-dinitrotoluene was diazotised with 8-hydroxyquinoline to confer the coloured derivative 140 (Figure 67). An aqueous solution of 140 at pH 8.0 showed an intense absorption band at $523 \mathrm{~nm}$ which could be used for the colorimetric recognition of TNT. Additionally, the SERRS spectrum of $\mathbf{1 4 0}$ was measured and detection limit as low as $1.0 \times 10^{-9} \mathrm{~mol} \mathrm{dm}^{-3}$ was obtained.

Microchip capillary electrophoresis (CE) coupled with solid phase extraction (SPE) was used for the colorimetric detection of TNT, Tetryl and TNB in complex explosive mixtures containing TNT, Tetryl, TNB, 2-NT, 3-nitrotoluene (3-NT), 4-NT, 
NB, 1,3-DNB, 2,4-DNT, 2,6-DNT, 2-amino-4,6-DNT, HMX and RDX. ${ }^{129}$ Measurements were taken in acetonitrile-water 87.5-12.5 v/v mixtures containing $\mathrm{NaOH}(2.5 \mathrm{mM})$ and a surfactant (CTAB or sodium dodecyl sulfate (SDS) at the 0.25-1.5 mM concentrations). Of all the explosives tested, only TNT, Tetryl and TNB were able to undergo the deprotonation process with bases leading to the formation of coloured products with bands in the $400-700 \mathrm{~nm}$ interval (TNT gave a purple colour, whereas Tetryl and TNB gave yellowish-brown solutions). In line with this, SPE was used to preconcentrate explosives from an aqueous sample into the mixture of organic solvents containing the base. Then, TNT, Tetryl and TNB formed the coloured deprotonated products, separated by CE. With this technique, trinitroaromatic explosives were detected at levels as low as 0.19-0.34 $\mu \mathrm{g} \mathrm{L}^{-1}$ in water.

A sensitive, specific and simple colour test for the improvised explosive urea nitrate was described. It was based on the formation of a coloured pigment upon the reaction between urea nitrate and $p$-dimethylaminocinnamaldehyde (141) (Figure 68) under neutral conditions. ${ }^{130}$<smiles>NC(N)=[OH+]</smiles>

Urea Nitrate<smiles>CCCCCCCCC=O</smiles>

141
142

Figure 68. Reaction between urea nitrate and 141 to yield the coloured derivative $142 .{ }^{130}$

The procedure involved the addition of urea nitrate (dissolved in water or in the solid form) to the ethanolic solutions of 141, resulting in the appearance of a red colour $\left(\lambda_{\max } 514 \mathrm{~nm}\right.$ ) due to the formation of compound 142 . The detection 
limit on paper was about $100 \mu \mathrm{g} / \mathrm{cm}^{2}$. When dealing with possible interferences, urea itself does not react with $\mathbf{1 4 1}$ under the same conditions. Other potential sources of false-positive responses, such as acidic salts, with a $\mathrm{pH}$ lower than 4, brought about the formation of a light pink colour. The authors suggested that this reagent in neutral solution would provide a diagnostic test in trace amounts for the improvised explosive urea nitrate that could be used in the field, on hands of suspects, on door handles or in packaging devices, and with other suspected materials.

\section{Conclusions and future perspectives}

In the last few decades, inspiration from several signalling paradigms has led to the development of chromo-fluorogenic probes for explosives with both enhanced functional behaviour and suitable selectivity and sensitivity. This review, focused on examples reported from 1947 to 2010, has been divided into two parts: one deals with fluorogenic systems, while the other relates to the use of chromogenic probes. Fluorogenic chemosensors have been more widely employed than chromogenic ones. Most reported examples using fluorescent signals have been reported for the detection of nitro explosives. In most cases, fluorogenic systems rely on a suitable interaction between electron-deficient nitro derivatives and electron-rich aromatic compounds. The latter are also highly fluorescent, whereas the former are efficient fluorescence quenchers through photo-induced electron transfer mechanisms. As a result of this design, a quenching process was observed as a signalling event in most of the systems reported for the detection of nitro explosives. As presented in Section 2.1, fluorescent-conjugated polymers have been employed extensively in recent years as sensing materials to detect explosives. One special feature of these systems is 
their ability to produce signal amplification in response to interactions with target analytes. Examples involving the use of poly(phenylene ethynylene)s, polyphenylene vinylenes and Si-containing polymers have been shown. Section 2.1 also includes a few examples that combine the appealing characteristics of imprinted polymers and the use of fluorescent signalling reporters, such as quantum dots or fluorescent-conjugated polymers which, at the same time, acted as a framework of the imprinted system and as a signalling reporter via quenching interactions. Coupling fluorescent functional chemical systems with inorganic supports to design hybrid signalling supports is a particularly fascinating area of research. This approach is relatively new; thus, it is not surprising that, despite the interesting examples reported in Section 2.2, the potential of hybrid signalling systems remains to be fully explored. Section 2.3 explores the use of single fluorophores as reporters. Polycyclic aromatic hydrocarbon and other fluorophores based on heterocycles have been fundamentally used to detect nitroaromatic explosives, whereas most of the examples following a chemodosimeter approach using irreversible chemical reactions have been designed to detect peroxide-based explosives. Finally, aggregation-induced colour changes, coordination interactions and the use of chemodosimeters have been used to develop chromogenic probes for nitro- and peroxide-based explosives. Yet despite these interesting examples, there are a low number of chromogenic probes for the selective and sensitive detection of target explosives, and this is still an unexplored area. In summary, the chemistry of chromo-fluorogenic probes for explosives is currently timely research within the field of sensing chemistry. In fact, during the first semester of 2011, several new examples dealing with this issue has been published. These new examples are mainly based in fluorescent polymers, ${ }^{131-132}$ organic and metal-containing fluorophores ${ }^{133-135}$ and sensory materials. ${ }^{136-141}$ Upcoming studies will probably involve the investigation of new 
signalling paradigms; for instance, using nano-hybrid systems, probes showing enhanced fluorescence instead of quenching upon interaction with explosives, coupling of probes with sophisticated instrumentation, and more in-depth research into the design of chromogenic chemosensors. A number of new results in this field are envisioned.

\section{Acknowledgments}

Financial support from the Spanish Government (project MAT2009-14564-C04) and the Generalitat Valencia (project PROMETEO/2009/016) is gratefully acknowledged.

\section{References}

1. K. G. Furton, L. J. Myers, Talanta, 2001, 54, 487-500.

2. K. Hakansson, R. V. Coorey, R. A. Zubarev, V. L. Talrose, P. Hakansson, J. Mass Spectrom., 2000, 35, 337-346.

3. M. E. Walsh, Talanta, 2001, 54, 427-438.

4. J. M. Sylvia, J. A. Janni, J. D. Klein, K. M. Spencer, Anal. Chem., 2000, 72, 5834-5840.

5. a) J. Yinon, Mass Spectrom. Rev., 1982, 1, 257-307. b) J. C. Mathurin, T. Faye, A. Brunot, J. C. Tabet, Anal. Chem., 2000, 72, 5055-5062.

6. S. F. Hallowell, Talanta, 2001, 54, 447-458.

7. C. Vourvopoulos, P. C. Womble, Talanta, 2001, 54, 459-468.

8. M. Krausa, K. Schorb, J. Electroanal. Chem., 1999, 461, 10-13.

9. a) E. Wallis, T. M. Griffin, N. Popkie Jr., M. A. Eagan, R, F. McAtee, D. Vrazel, J. McKinly, Proc. SPIE-Int. Soc. Opt. Eng., 2005, 5795, 54-64. (b) G. A. Eiceman, J. A. Stone, Anal. Chem., 2004, 76, 390A-397A.

10. a) J. L. Steinfeld, J. Wormhoudt, J. Annu. Rev. Phys. Chem., 1998, 49, 203-232. b) D. S. Moore, Rev. Sci. Instrum., 2004, 75, 2499-2512.

11. R. Martínez-Máñez, F. Sancenón, M. Hecht, M. Biyical, K. Rurack, Anal. Bioanal. Chem., 2011, 399, 55-74.

12. a) M. E. Moragues, R. Martínez-Máñez, F. Sancenón, Chem. Soc. Rev., 2011, 40, 2593-2643. b) R. Martínez-Máñez, F. Sancenón, J. Fluoresc., 2005, 15, 267-285. c) Z. Xu, X. Chen, H. N. Kim, J. Yoon, Chem. Soc. Rev., 2010, 39, 127-137. 
13. a) E. M. Nolan, S. J. Lippard, Chem. Rev., 2008, 108, 3443-3480. b) P. Pallavicini, Y. A. DíazFernández, L. Pasotti, Coord. Chem. Rev., 2009, 253, 2226-2240. c) E. L. Que, C. J. Chang, Chem. Soc. Rev., 2010, 39, 51-60.

14. G. J. Mohr, Anal. Chim. Acta, 2004, 508, 233-237.

15. R. Martínez-Máñez, F. Sancenón, Chem. Rev., 2003, 103, 4419-4476.

16. J. P. Agrawal, R. D. Hodgson, Organic Chemistry of Explosives, John Wiley \& Sons, Chichester, 2007, ISBN-13 978-0-470-02967-1 (HB).

17. C. J. Cumming, C. Aker, M. Fisher, M. Fox, M. J. la Grone, D. Reust, M. G. Rockley, T. M. Swager, E. Towers, V. Williams, IEEE Transactions on Geoscience and Remote Sensing, 2001, 39, 11191128.

18. S. J. Toal, W. C. Trogler, J. Mater. Chem., 2006, 16, 2871-2883.

19. D.T. McQuade, A.E. Pullen, T.M. Swager, Chem. Rev. 2000, 100, 2537-2574.

20. D.T. McQuade, A.E. Pullen, T.M. Swager, Chem. Rev. 2000, 100, 2537-2574.

21. Q. Zhou, T. M: Swager, J. Am. Chem. Soc., 1995, 117, 7017-7018.

22. J. -S. Yang, T. M. Swager, J. Am. Chem. Soc., 1998, 120, 5321-5322.

23. J. -S. Yang, T. M. Swager, J. Am. Chem. Soc., 1998, 120, 11864-11873.

24. S. Yamaguchi, T. M. Swager, J. Am. Chem. Soc., 2001, 123, 12087-12088.

25. S. Zahn, T. M. Swager, Angew. Chem. Int. Ed., 2002, 41, 4226-4230.

26. J. P. Amara, T. M. Swager, Macromolecules, 2005, 38, 9091-9094.

27. D. Zhao, T. M. Swager, Macromolecules, 2005, 38, 9377-9384.

28. S. W. Thomas III, J. P. Amara, R. E. Bjork, T. M. Swager, Chem. Commun., 2005, 4572-4574.

29. A. Narayanan, O. P. Varnavsky, T. M. Swager, T. Goodson III, J. Phys. Chem. C, 2008, 112, 881884.

30. S. Chen, Q. Zhang, J. Zhang, J. Gu, L. Zhang, Sensors Act. B, 2010, 149, 155-160.

31. Y. Long, H. Chen, Y. Yang, H. Wang, Y. Yang, N. Li, K. LI, J. Pei, F. Liu, Macromolecules, 2009, 42, 6501-6509.

32. C. -P. Chang, C. -Y. Chao, J. H. Huang, A. -K. Li, C. -S. Hsu, M. -S. Lin, B. R. Hsieh, A. -C. Su, Synth. Met., 2004, 144, 297-301.

33. I.A. Levitsky, W.B. Euler, N. Tokranova, A. Rose, Appl. Phys. Lett., 2007, 90, 041904.

34. L. Chem, D. McBranch, R. Wang, D. Whitten, Chem. Phys. Lett., 2000, 330, 27-33.

35. A. Rose, Z. Zhu, C.F. Madigan, T.M. Swager, V. Bulovic, Nature, 2005, 434, 876-879.

36. K. Tamao, M. Uchida, T. Izumizawa, K. Furukawa, S. Yamaguchi, J. Am. Chem. Soc., 1996, 118, 11974-11975.

37. H. Sohn, R. R. Huddleston, D. R. Powell, R. West, J. Am. Chem. Soc., 1999, 121, 2935-2936.

38. H. Sohn, R. M. Calhoun, M. J. Sailor, W. C. Trogler, Angew. Chem. Int. Ed., 2001, 40, 2104-2105.

39. J. Ohshita, A. Kunai, Acta Polym., 1998, 49, 379-403.

40. H. Sohn, R. M. Calhoun, M. J. Sailor, W. C. Trogler, Angew. Chem. Int. Ed., 2001, 40, 2104-2105.

41. S. J. Toal, D. Magde, W. C. Trogler, Chem. Commun., 2005, 5465-5467. 
42. H. Sohn, M. J. Sailor, D. Magde, W. C. Trogler, J. Am. Chem. Soc., 2003, 125, 3821-3830.

43. J. C. Sanchez. A. G. DiPascuale, A. L. Rheingold, W. C. Trogler, Chem. Mater., 2007, 19, 64596470.

44. J. C. Sanchez, S. A. Urbas, S. J. Toal A. G. DiPascuale, A. L. Rheingold, W. C. Trogler, Macromolecules, 2008, 41, 1237-1245.

45. J. C. Sanchez, W. C. Trogler, J. Mater. Chem., 2008, 18, 3143-3156.

46. J. Liu, Y. Zhong, J. W. Y. Lam, P. Lu, Y. Hong, Y. Yu, Y. Yue, M. Faisal, H. H. Y. Sung, I. D. Williams, K. S. Wong, B. Z. Tang, Macromolecules, 2010, 43, 4921-4936.

47. P. Lu, J. W. Y. Lam, J. Liu, C. K. W. Jim, W. Yuan, N. Xie, Y. Zhong, Q. Hu, K. S. Wong, K. K. L. Cheuk, B. Z. Tang, Macromol. Rapid Commun., 2010, 31, 834-839.

48. Y. Liu, R. C. Mills, J. M. Boncella, K. S. Schanze, Langmuir, 2001, 17, 7452-7455.

49. L. G. Toy, K. Nagai, B. D. Freeman, I. Pinnau, T. Masuda, M. Teraguchi, Y. P. Yampolskii, Macromolecules, 2000, 33, 2516-2524.

50. a) A. Saxena, M. Fujiki, R. Rai, G. Kwak, Chem. Mater., 2005, 17, 2181-2185. b) A. Saxena, R. Rai, S.-Y. Kim, M. Fujiki, M. Naito, K. Okoshi, G. Kwak, J. Polymer Sci.: Part A: Polymer Chem., 2006, 5060-5075.

51. S. J. Toal, J. C. Sanchez, R. E. Dugan, W. C. Trogler, J. Forensic Sci., 2007, 52, 79-83.

52. R. C. Stringer, S. Gangopadhyay, S. A. Grant, Anal Chem, 2010, 82, 4015-4019.

53. J. Lin, C. E. Kending, E. E. Nesterov, J. Am. Chem Soc. 2007, 129, 15911-15918.

54. G. Bunte, J. Hürttlen, H. Pontius, K. Hartlieb, H. Krause, Anal. Chim. Acta, 2007, 591, 49-56.

55. a) X. Zhang, S. A. Jenekhe, Macromolecules, 2000, 33, 2069-2082. b) S. Hou, M. Ding, L. Gao, Macromolecules, 2003, 36, 3826-3832.

56. T. H. Kin, H. J. Kim, C. G. Kwak, W. H. Park, T. S. Lee, J. Polym. Sci., Part A: Polym. Chem. 2006, 2059-2068.

57. H. Nie, Y. Zhao, M. Zhang, Y. Ma, M. Baumgarten, K. Müllen, Chem. Commun, 2011, 47, 12341236.

58. A. Qin, J. W. Y. Lam, L. Tang, C. K. W. Jim, H. Zhao, J. Sun, B. Z. Tang, Macromolecules, 2009, 42, 1421-1424.

59. A. Kumar, M. K. Pandey, R. Anandakathir, R. Mosurkal, V. S. Parmar, A. C. Watterson, J. Kumar, Sensors and Actuators B, 2010, 147, 105-110.

60. H.H. Nguyen, X. Li, N. Wang, Z.Y. Wang, J. Ma, W.J. Bock, D. Ma, Macromolecules, 2009, 42, 921-926.

61. K. J. Albert, D. R. Walt, Anal.Chem. 2000, 72, 1947-1955.

62. D, Gao, Z. Wang, B. Liu, L. Ni, M. Wu, Z. Zhang, Anal. Chem. 2008, 80, 8545-8553.

63. Q. Fang, J. Geng, B. Liu, D. Gao, F. Li, Z. Wang, G. Guan, Z. Zhang, Chem. Eur. J., 2009, 15, 1150711514.

64. J. Geng, P. Liu, B. Liu, G. Guan, Z. Zhang, M.-Y. Han, Chem. Eur. J., 2010, 16, 3720-3727.

65. J. Yang, S. Aschemeyer, H. P. Martínez, W. C. Trogler, Chem. Commun., 2010, 46, 6804-6806. 
66. J. Feng, Y. Li, M. Yang, Sensors \& Actuators, B, 2010, 145, 438-443.

67. S. Tao, Z. Shi, G. Li, P. Li, ChemPhysChem., 2006, 7, 1902-1905.

68. S. Tao, J. Yin, G. Li, J. Mat.Chem., 2008, 18, $4872-4878$.

69. S. Tao, G. Li, H. Zhu, J. Mat. Chem., 2006, 16, 4521-4528.

70. S. Tao, G. Li, Colloid Polym. Sci. 2007, 285, 721-728.

71. A. Yildirim, H. Budunoglu, H. Deniz, M. O. Guler, M. Bayindir, Appl. Mater. Interfaces, 2010, 2, 2892-2897.

72. H. Li, J. Wang, Z. Pan, L. Cui, L. Xu, R. Wang, Y. Song, L. Jiang, J. Mater. Chem., 2011, 21, 17301735.

73. Z. Tao, G. Li, J. Yin, J. Mater.Chem., 2007, 17, 2730-2736.

74. T. Naddo, Y. Che, W. Zhang, K. Balakrishnan, X. Yang, M. Yen, J. Zhao, J. S. Moore, L. Zang, J. Am. Chem. Soc., 2007, 129, 6978-6979.

75. S. Content, W. C. Trogler, M. J. Sailor, Chem. Eur. J., 2000, 6, 2205-2213.

76. J. Kang, L. Ding, F. Lü, S. Zhang, Y. Fang, J.Physics D: Appl. Phys., 2006, 39, 5097-5102.

77. S. Zhang, F. Lü, L. Gao, L. Ding, Y. Fang, Langmuir, 2007, 23, 1584-1590.

78. G. He, G. Zhang, F. Lü, Y. Fang, Chem.Mater., 2009, 21, 1494-1499.

79. J. V. Goodpaster, V. L. McGuffin, Anal. Chem. 2001, 73, 2004-2011.

80. A. D. Hughes, I. C. Glenn, A. D. Patrick, A. Ellington, E. V. Anslyn, Chem. Eur. J. 2008, 14, 18221827.

81. S. Malashikhin, N. S. Finney, J. Am. Chem. Soc., 2008, 130, 12846-12847.

82. K.-S. Focsaneanu, J. C. Scaiano, Photochem. Photobiol. Sci., 2005, 4, 817-821.

83. Y. H. Lee, H. Liu, J. Y. Lee, S. H. Kim, S. K. Kim, J. L. Sessler, Y. Kim, J. S. Kim, Chem. Eur. J., 2010, 16, 5895-5901.

84. C. Jian, W. R. Seitz, Analytica Chimica Acta, 1990, 237, 265-271.

85. C. Vijayakumar, G. Tobin, W. Schmitt, M. Kima, M. Takeuchi, Chem. Commun., 2010, 46, 874876.

86. G. V. Zyryanov, M. A. Palacios, P. Anzenbacher Jr, Org. Lett, 2008, 10, 3681-3684.

87. H.Cavaye, P.E. Shaw, X. Wand, P.L. Burn, S-C Lo, P. Meredith, Macromolecules, 2010, 43, 1025310261.

88. A. Ponnu, E. V. Anslyn, Supramol. Chem., 2010, 22, 65-71.

89. C. Zhang, Y. Che, X. Yang, B. R. Bunes, L. Zang, Chem. Commun., 2010, 46, 5560-5562.

90. Z. Li, Y. Q. Dong, J. W. Y. Lam, J. Sun, A. Qin, M. Haüßler, Y. P. Dong, H. H. Y. Sung, I. D. Williams, H. Sing Kwok, B. Z. Tang, Adv. Funct. Mater. 2009, 19, 905-917.

91. Y. Dong, J.W.Y. Lam, A. Qin, Z. Li, J. Liu, J. Sun, Y. Dong, B. Z. Tang, Chem. Phys. Lett., 2007, 446, 124-127.

92. L. Wang, Y. Zhou, J. Yan, J. Wang, J. Pei, Y. Cao., Langmuir, 2009, 25, 1306-1310.

93. M. Rahman, H. J. Harmon, Spectrochim. Acta Part A, 2006, 65, 901-906.

94. W. M. Hikal, H. J. Harmon, J. Hazard. Mater., 2008, 154, 826-831. 
95. D. A. Olley, E. J. Wren, G. Vamvounis, M. J. Fernee, X. Wang, P. L. Burn, P. Meredith, P. E. Shaw, Chem. Mater. 2011, 23, 789-794.

96. S. Glazier, J.A. Barron, N. Morales, A. M. Ruschak, P. L. Houston, H. D. Abruña. Macromolecules, 2003, 36, 1272-1278.

97. S. Ghosh, P. S. Mukherjee, Organometallics, 2008, 27, 316-319.

98. S. Ghosh, B. Gole, A. K. Bar, P. S. Mukherjee, Organometallics, 2009, 28, 4288-4296.

99. A. Kumar Bar, B. Gole, S. Ghosh, P. Sarathi Mukherjee, Dalton Trans., 2009, 6701-6704.

100. M. E. Germain, T. R. Vargo, P. G. Khalifah, M. J. Knapp, Inorg. Chem. 2007, 46, 4422-4429.

101. M. E. Germain, M. J. Knapp, J. Am. Chem. Soc., 2008, 130, 5422-5423.

102. M. E. Germain, T. R. Vargo, B. A. McClure, J. J. Rack, P. G. Van Patten, M. Odoi, M. J. Knapp, Inorg. Chem. 2008, 47, 6203-6211.

103. M. E. Germain, M. J. Knapp, Inorg. Chem., 2008, 47, 9748-9750.

104. T. L. Andrew, T. M. Swager, J. Am. Chem. Soc., 2007, 129, 7254-7255.

105. R. Schulte-Ladbeck, P. Kolla, U. Karst, Anal. Chem., 2003, 75, 731-735.

106. E. Sella, D. Shabat, Chem. Commun., 2008, 5701-570.

107. J. C. Sanchez, S. J. Toal, Z. Wang, R. E. Dugan, W. C. Trogler, J. Forensic Sci., 2007, 52, 13081312.

108. M. S. Meaney, V. L. McGuffin, Anal. Chim. Acta, 2008, 610, 57-67.

109. T. Caron, M. Guillemot, P. Montméat, F. Veignal, F. Perraut, P. Prené, F. Serein-Spirau, Talanta, 2010, 81, 543-548.

110. L. Cartmill, V. B. Rajpara, G. A. Sereda, J. Undergrad. Chem. Res., 2007, 6, 95-97.

111. Y. Jiang, H. Zhao, N. Zhu, Y. Lin, P. Yu and L. Mao, Angew. Chem. Int. Ed., 2008, 47, 8601-8604.

112. S. S. R. Dasary, A. Kumar Singh, D. Senapati, H. Yu, P. C. Ray , J. Am. Chem. Soc., 2009, 131, 13806-13812.

113. D. S. Kim, V. M. Lynch, K. A. Nielsen, C. Johnsen, J. O. Jeppesen, J. L. Sessler, Anal. Bioanal. Chem., 2009, 395-400.

114. K. A. Nielsen,W-S. Cho, J. O. Jeppesen, V. M. Lynch, J. Becher, J. L. Sessler, J. Am. Chem. Soc., 2004, 126, 16296-16297.

115. J. Su Park, F. Le Derf, C. M. Bejger, V. M. Lynch, J. L. Sessler, K. A. Nielsen, C. Johnsen, J. O. Jeppesen, Chem. Eur. J., 2010, 16, 848-854.

116. L. M. Dorozhkin, V. A. Nefedov, A. G. Sabelnikov, V. G. Sevastjanov, Sensors Act. B, 2004, 99, 568-570.

117. A. Chen, H. Sun, A. Pyayt, X. Zhang, J. Luo, A. Jen, P. A. Sullivan, S. Elangovan, L. R. Dalton, R. Dinu, D. Jin, D. Huang, J. Phys. Chem. C, 2008, 112, 8072-8078.

118. A. Ponnu, N. Y. Edwards, E. V. Anslyn, New J. Chem., 2008, 32, 848-855.

119. J. V. Janowski, Ber., 1886, 19, 2155.

120. F. L. English, Anal. Chem., 1948, 20, 745-746.

121. S. A. H. Amas, H. J. Yallop, Analyst, 1966, 91, 336-337. 
122. S. A. H. Amas, H. J. Yallop, J. Forens. Sci. Soc., 1966, 6, 185-188.

123. S. A. H. Amas, H. J. Yallop, Analyst, 1969, 94, 828.

124. R. Schulte-Ladbeck, P. Kolla, U. Karst, Analyst, 2002, 127, 1152-1154.

125. Ş. Eren, A. Üzer, Z. Can, T. Kapudan, E. Erçağ, R. Apak. Analyst, 2010, 135, 2085-2091.

126. H. Lin, K. S. Suslick, J. Am. Chem. Soc, 2010, 132, 15519-15521.

127. E. S. Forzani, D. Lu, M. J. Leright, A. Diaz Aguilar, F. Tsow, R. A. Iglesias, Q. Zhang, J. Lu, J. Li, N. Tao, J. Am. Chem. Soc., 2009, 131, 1390-1391.

128. C. J. McHugh, R. Keir, D. Graham, W. E. Smith, Chem. Commun., 2002, 580-581.

129. Q. Lua, G. E. Collins, M. Smith, J. Wang, Anal. Chim. Acta, 2002, 469, 253-260.

130. J. Almog, A. Klein, T. Tamiri, Y. Shloosh, S. Abramovich-Bar, J. Forensic Sci., 2005, 50, 582-586.

131. H. Nie, Y. Zhao, M. Zhang, Y. Ma, M. Baumgarten, K. Müllen, Chem. Commun., 2011, 47, 12341236.

132. J. Wang, J. Mei, W. Yuan, P. Lu, A. Qin, J. Sun, Y. Ma, B. Z. Tang, J. Mater. Chem., 2011, 21, 4056-4059.

133. D. A. Olley, E. J. Wren, G. Vamvounis, M. J. Fernee, X. Wang, P. L. Burn, P. Meredith, P. E. Shaw, Chem. Mater. 2011, 23, 789-794.

134. V. Vajpayee, H. Kim, A. Mishra, P. S. Mukherjee, P. J. Stang, M. H. Lee, H. K. Kim, K-W. Chi, Dalton Trans., 2011, 40, 3112-3115.

135. T. L. Andrew, T. M. Swager, J. Org. Chem., 2011, 76, 2976-2993.

136. H. Xu, F. Liu, Y. Cui, B. Chen, G. Qian, Chem. Commun., 2011, 47, 3153-3155.

137. S. Pramanik, C. Zheng, X. Zhang, T. J. Emge, J. Li, J. Am. Chem. Soc., 2011, 133, 4153-4155.

138. W. -G. Qu, B. Deng, S. -L. Zhong, H. -Y. Shi, S. -S. Wang, A. -W. Xu, Chem. Commun., 2011, 47, 1237-1239.

139. H. Li, J. Wang, Z. Pan, L. Cui, L. Xu, R. Wang, Y. Song, L. Jianga, J. Mater. Chem., 2011, 21, 17301735.

140. D. Wang, A. Chen, S. -H. Jang, H. -L. Yip, A. K. -Y. Jen, J. Mater. Chem., 2011, 21, 7269-7273.

141. M. -Y. Liao, C. -C. Huang, M. -C. Chang, S. -F. Lin, T. -Y. Liu, C. -H. Su, C. -S. Yeh, H. -P. Lin, J. Mater. Chem., 2011, 21, 7974-7981. 

3. Control Access to silica surfaces. An approximation to ion-channels 



\subsection{Introduction.}

Ion channels are very general systems in biological activities. For instance, the unique feature of ion channels in biological cell membranes deals with a selective recognition of substrates and the following amplification of this information by channel switchings: the selective binding of substrates with receptors triggers the opening of an ion-specific channel which allows the permeation of a great amount of ions across the membrane following an electrochemical potential gradient. Therefore, it seemed natural that different authors have taken advantage of this principle as a new approach in the developmment of chemical sensors. ${ }^{1}$

Umezawa and co-workers developed ion channel sensors (ICS) using LangmuirBlodgett monolayers on solid electrodes. These sensors had a function of channel switching by the following sequence. (i) In the absence of a stimulus or analyte (S), the channel is closed and, therefore, marker ions (monitoring ions, $\mathrm{m}$ ) cannot permeate through the membrane (Figure 3.1a). (ii) With the analyte present, the

\footnotetext{
${ }^{1}$ a) M. Sugawara, K. Kojima, H. Sazawa, Y. Umezawa, Anal. Chem., 1987, 59, 2842. b) L. M. Goldenberg, M. R. Bryce, M. C. Petty, J. Mater. Chem., 1999, 9, 1957. c) Y. Umezawa, H. Aoki, Anal. Chem., 2004, 76, 320A.
} 
channel is opened, and a large amount of marker ions are allowed to permeate through the membrane, which are immediately detected electrochemically at an underlying electrode. The amount of marker ions thus detected is a direct but much amplified measure of the amount of analyte (Figure 3.1b). (iii) With elimination of the analyte, by addition of quenching reagent $(Q)$, the channel is again closed reversibly (Figure 3.1c). In order to open the channel with the analyte, some specific interaction of the analyte with the membrane assemblies is required to change their permeability for marker ions. In order to guarantee the amplification, it is necessary by definition that permeated amounts of marker ions through channels should be greater than that of the stimulus (analyte) bound to receptor sites at the membrane surface where the opening of ion channels occurs. ${ }^{2}$ Several illustrative examples are presented to discuss the potential of this sensing approach.

a)
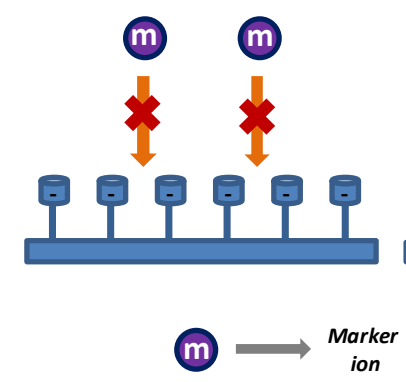

b)

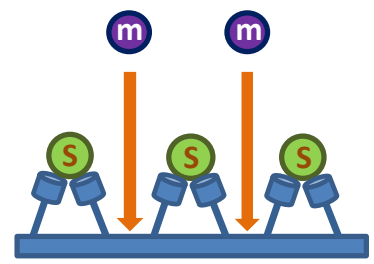

(S) $\longrightarrow$ Stimulus c)

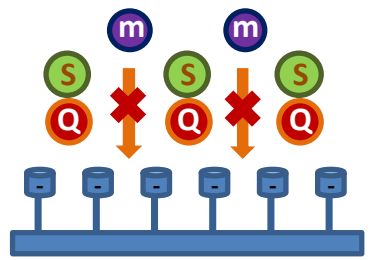

Q Quenching
reagent

Figure 3.1. Scheme of ICSs mechanism. a) channel closed, b) channel opened, c) reversible channel closing by a quencher.

Ion channel sensors have been usefully applied to the recognition and quantification of polyions such as protamine (a polycation with an average charge of +20 ) and heparine (a polyanion with an average charge of -70 ). Heparin is extensively employed as anticoagulant whereas protamine is used to neutralize

2 P. Bühlmann, H. Aoki, K. P. Xiao, S. Amemiya, K. Tohda, Y. Umezawa, Electroanalysis, 1998, 10, 1149. 
the anticoagulant activity of heparine. For their determination, gold electrodes were modified by the formation of Self-Assembled Monolayer surfaces (SAMs) of thioctic acid. ${ }^{3}$ Upon deprotonation of the anchored thioctic acid molecules, a negatively charged layer on the electrode is generated that induces protamine adsorption through electrostatic forces (Figure 3.2, top). These sensors could detect protamine levels as low as $0.11 \mu \mathrm{M}$ when $\left[\mathrm{Ru}\left(\mathrm{NH}_{3}\right)_{6}\right]^{3+}$ was used as the redox marker. The development of ICSs sensors for heparin was closely related to that prepared for the detection of protamine. ${ }^{4}$ Again, SAMs of thioctic acid were prepared on the surface of an electrode. Subsequent treatment with protamine created a positively charged layer able to interact with the negatively charged heparin (Figure 3.2, bottom). This interaction provided the electrode surface with an excess of negative charges thereby repelling the marker ions, $\left[\mathrm{Fe}(\mathrm{CN})_{6}\right]^{3-}$ and $\left[\mathrm{Mo}(\mathrm{CN})_{8}\right]^{4-}$, from the electrode surface. In a solution containing inorganic species at physicological blood concentrations as a background, heparin could be detected, using this method, in a linear concentration range of $3.3 \mathrm{nM}-0.1 \mu \mathrm{M}$.

${ }^{3}$ V. P. Y. Gadzekpo, K. P. Xiao, H. Aoki, P. Bühlmann, Y. Umezawa, Anal. Chem., 1999, 71, 5109.

${ }^{4}$ V. P. Y. Gadzekpo, P. Bühlmann, K. P. Xiao, H. Aoki, Y. Umezawa, Anal. Chim. Acta, 2000, 411, 163. 


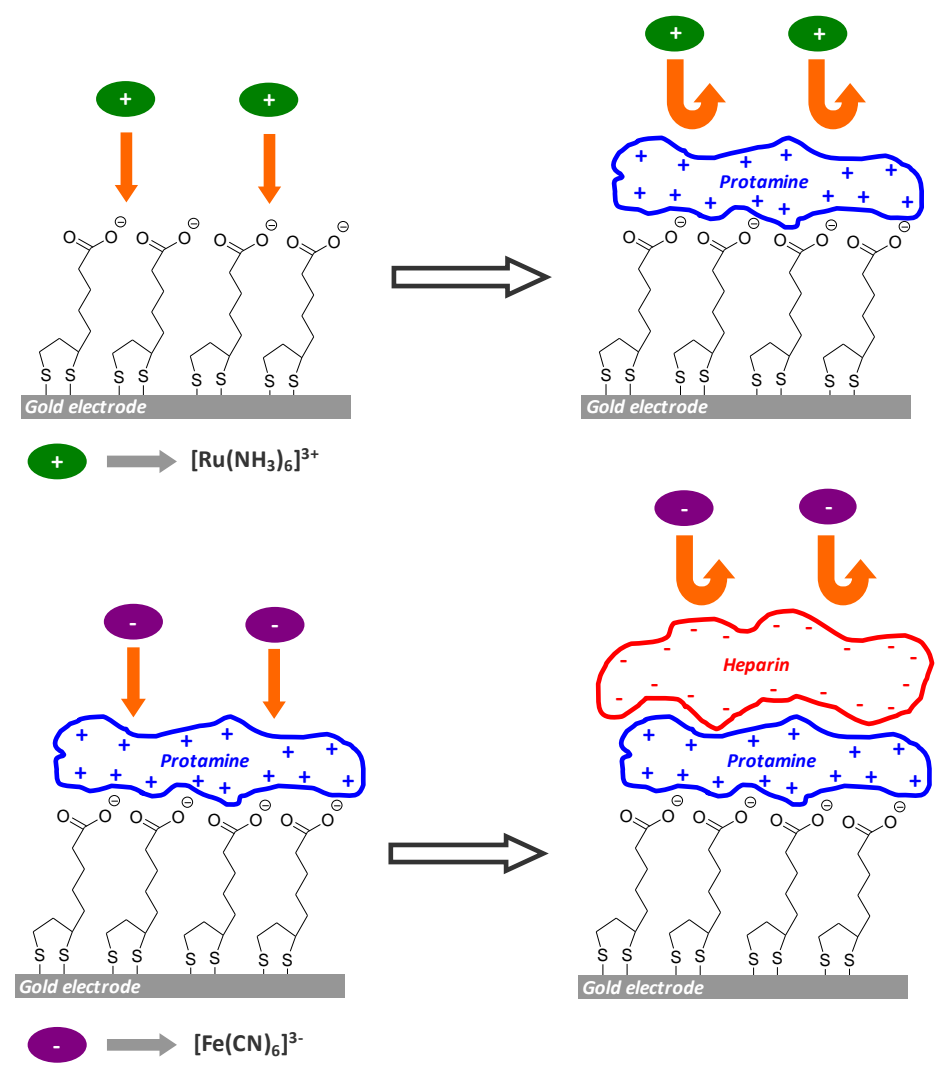

Figure 3.2. Top: Scheme for protamine detection with a gold electrode modified with a SAM of thioctic acid and $\left[\mathrm{Ru}\left(\mathrm{NH}_{3}\right)_{6}\right]^{3+}$ as probe. Bottom: Scheme for heparin detection with the protaminethioctic acid-gold electrode and $\left[\mathrm{Fe}(\mathrm{CN})_{6}\right]^{3-}$ as probe.

Very recently, this ion-channel sensing approach has been used for the development of colorimetric and fluorimetric sensing hybrid materials (see Figure 3.3). In these systems an inorganic surface is functionalized with reactive $(R)$ and coordinating/host $(\mathrm{H})$ sites. The role of the reactive units is to interact with a dye (D) inducing color or fluorescence changes, whereas the coordinating moieties are able to bind with the selected analyte. When the analyte is present, their interaction with the coordinating units inhibits the access of the dye to the reactive moiety grafted onto the surface. However, in the absence of analyte, the reaction between the dye and the reactive moiety is allowed with the subsequent 
change in colour or fluorescence. This sensing systems approach allows detecting several chemical species with a simple change in the receptor-indicator pair. By using that paradigm, E. Climent and co-workers, have prepared different chromofluorogenic assays employing silica fumed and silica nanoparticles as inorganic supports for detection of pyrophosphate, ${ }^{5}$ heparin ${ }^{6}$ and surfactants. ${ }^{7}$

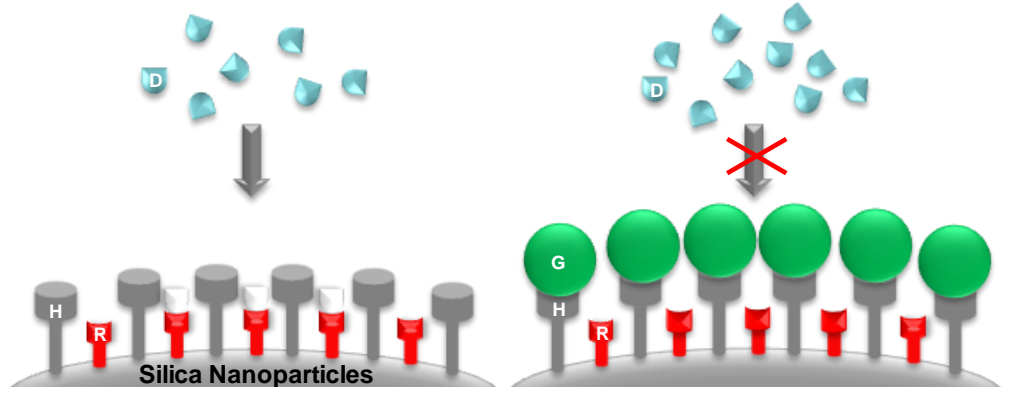

Figure 3.3. Colorimetric protocol using the ICS concept for the detection of guest.

An illustrative example of this approach was described by E. Climent and coworkers, who prepared a hybrid material for the chromogenic sensing of nerve agent mimics by using silica nanoparticles that were functionalized with hydroxyl $(\mathrm{OH})$ and thiol moieties $(\mathrm{SH}) .{ }^{8}$ The analytes are nerve agent mimins (diethyl cyanophosphate (DCNP), diisopropyl fluorophosphate (DFP) and diethyl chlorophosphate (DCP)) that are able to react with the hydroxyl groups of the reactive units yielding bulky phosphate derivatives (see Figure 3.3). In the absence of nerve agents mimics, squaraine dye (blue) is able to react with the reactive unit (thiol) resulting in the formation of a colourless specie. In the presence of nerve

\footnotetext{
${ }^{5}$ a) E. Climent, R. Casasús, M. D. Marcos, R. Martínez-Máñez, F. Sancenón, J. Soto, Chem. Commun., 2008, 6531. b) E. Climent, R. Casasús, M. D. Marcos, R. Martínez-Máñez, F. Sancenón, J. Soto, Dalton Trans., 2009, 4806.

${ }^{6}$ E. Climent, P. Calero, M. D. Marcos, R. Martínez-Máñez, F. Sancenón, J. Soto, Chem. Eur. J., 2009, 15, 1816.

${ }^{7}$ E. Climent, C. Giménez, M. D. Marcos, R. Martínez-Máñez, F. Sancenón, J. Soto, Chem. Commun., 2011, 6873.

${ }^{8}$ E. Climent, A. Martí, S. Royo, R. Martínez-Máñez, M. D. Marcos, F. Sancenón, J. Soto, A. M. Costero, S. Gil, M. Parra, Angew. Chem. Int. Ed., 2010, 49, 5945.
} 
agent stimulants, the formation of bulky phosphate derivatives with the grafted hydroxyl groups, inhibit the reaction of the dye with the thiol reactive centers, resulting in a colorimetric response. Improved recognition is observed due to entropic factors of preorganization of coordination units into the support that reduces the flexibility of the receptors and increases effective concentration on the surface.

\subsection{Objectives.}

In this chapter we focus on the possibility of designing a hybrid material based on the ICS paradigm described above for the selective colorimetric detection of the explosive Tetryl. Particulary, our aim was:

- To prepare bi-functionalized silica nanoparticles for the chromofluorogenic sensing of nitroaromatic explosives, using the well-established ICS protocol.

- To characterize the prepared hybrid sensing systems.

- To evaluate the response of the prepared hybrid material in the presence or absence of different explosives. 
3.3 Highly selective and sensitive chromofluorogenic detection of the Tetryl explosive using functional silica nanoparticles. 



\section{Highly selective and sensitive chromo- fluorogenic detection of the Tetryl explosive using functional silica nanoparticles}

Yolanda Salinas, ${ }^{a, b, c}$ Estela Climent, ${ }^{a, b, c}$ Ramón MartínezMáñez, ${ }^{* a, b, c}$ Félix Sancenón, ${ }^{a, b, c}$ M. Dolores Marcos, ${ }^{a, b, c}$ Juan Soto, ${ }^{a, b}$ Ana M. Costero, ${ }^{* a, d}$ Salvador Gil, ${ }^{a, d}$ Margarita Parra ${ }^{a, d}$ and Alberto Pérez de Diego ${ }^{e}$

${ }^{a}$ Centro de Reconocimiento Molecular y Desarrollo Tecnológico (IDM), Unidad Mixta Universidad Politécnica de Valencia-Universidad de Valencia, Spain.

${ }^{b}$ Departamento de Química, Universidad Politécnica de Valencia, Camino de Vera s/n, 46022, Valencia, Spain.

${ }^{c}$ CIBER de Bioingeniería, Biomateriales y Nanomedicina (CIBER-BBN).

${ }^{d}$ Departamento de Química Orgánica, Facultad de Ciencias Químicas, Universitat de Valencia, 46100 Burjassot, Valencia, Spain.

e Instituto Tecnológico "La Marañosa". Carretera de San Martín de la Vega, E-28330, San Martín de la Vega, Madrid, Spain.

Received: $7^{\text {th }}$ August 2011

First published on the web: $10^{\text {th }}$ October 2011

Chemical Communication, 2011, 47, 11885-11887 



\section{Silica nanoparticles containing polyamines and thiol groups have been used as probes for the selective detection of Tetryl.}

International concern about terrorist attacks with explosives has increased in recent years, and the development of reliable and easy-to-use detection systems for these chemicals has been extensively explored. ${ }^{1}$ Additionally, due to the widespread use of explosive formulations, analyzing explosives is also of interest in forensic research, land mine detection and in the study of environmental problems associated with explosive residues. Among the chemical compounds used as explosives, nitrated derivatives such as 2,4,6-trinitrotoluene (TNT) and 2,4,6-trinitrophenylmethylnitramine (Tetryl) are of particular importance. Current methods to detect nitrated explosives are based on enzymatic assays, ${ }^{2}$ gas and liquid chromatography, ${ }^{3}$ mass spectrometry, ${ }^{4}$ ion-mobility spectroscopy, ${ }^{5}$ electrochemical procedures ${ }^{6}$ and optodes. ${ }^{7}$ However, some of these protocols usually have limitations, such as low selectivity, poor portability and a certain complexity in terms of their use. As an alternative to these classical instrumental methods, the use of fluorescent polymers and several chromogenic and fluorogenic probes and reagents has recently emerged. ${ }^{8}$ In relation to our interest in the design of hybrid organic-inorganic materials as sensing systems, ${ }^{9}$ we herein show the preparation of bi-functionalized silica nanoparticles for the chromofluorogenic sensing of nitrated explosives. Among the different silica supports available, we decided to use nanoparticles given their easy preparation, straightforward surface functionalization and good stability in both water and organic solvents. Additionally, sensory material employs the well-established ionchannel paradigm introduced by Umezawa some years ago for electrochemical sensors. ${ }^{10}$ In our analogous optical version, nanoparticles were functionalized with two groups: polyamines as binding sites to nitro explosives and thiols as reactive units. The optical response arises via the reaction of reactive units (R) and a squaraine dye (SQ). 
In the absence of a nitrated compound, the reaction of thiols with the central electron-deficient ring of squaraine led to loss of aromaticity and a bleaching of the blue squaraine solution. ${ }^{11}$ The formation of a charge-transfer complex, ${ }^{12}$ between the nitrogen atoms of the polyamine $(\mathrm{H})$ and electron-deficient nitrated explosives inhibits the reaction between thiol groups and the dye. Consequently, the suspension remains blue (see Scheme 1).
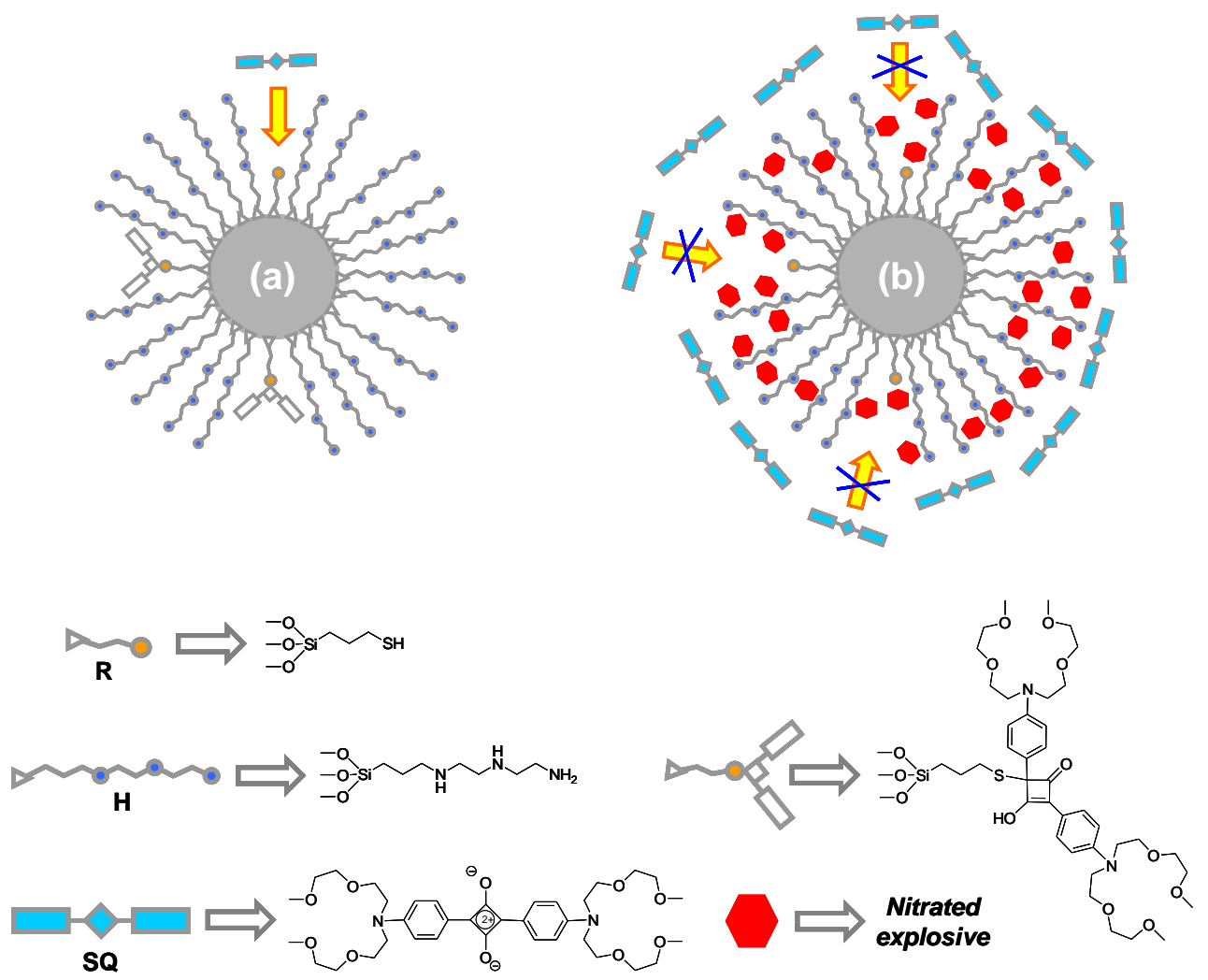

SQ

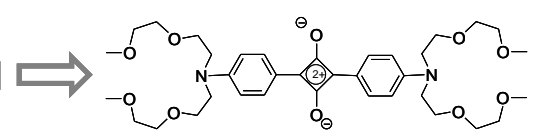

Nitrated explosive

Scheme 1. Colorimetric protocol for nitrated explosives detection. (a): The thiol groups $(R)$ in the bifunctionalized nanoparticles $\mathbf{N} \mathbf{1}$ are able to react with squaraine (SQ) in the absence of nitrated explosives. (b) Formation of charge-transfer complexes between nitrated explosives and the nitrogen atoms of amines $(H)$ inhibits the thiol-squaraine reaction. 
Coated silica nanoparticles $\mathbf{N} \mathbf{1}$ were prepared using the commercially available trialcoxysilane derivatives 3-mercaptopropyltrimethoxysilane (MPTS) and 3-[2-(2aminoethylamino)ethylamino]propyl-trimethoxysilane (N3TS) following the procedures recently reported by Montalti and coworkers. ${ }^{13}$ In this synthetic protocol, silica nanoparticles were heated at $80{ }^{\circ} \mathrm{C}$ in a water:ethanol:acetic acid (1:2:1) mixture in the presence of coating subunits. To prepare $\mathbf{N} 1$ nanoparticles, a N3TS/MPTS molar ratio of 10 was set. This molar ratio was selected to obtain a dense monolayer of polyamines on the final surface of the nanoparticles with a small number of thiol groups. On the other hand, and by the same procedure, solid $\mathbf{N}-\mathbf{S H}$ functionalised only with thiol moieties was synthesized as model.

Solid N1 was characterized using standard procedures. Amine and thiol contents were determined by elemental analysis and thermogravimetric measurements and amounted to 0.271 and $0.039 \mathrm{mmol} / \mathrm{g} \mathrm{SiO}_{2}$, respectively. The thiol content in solid $\mathbf{N}-\mathrm{SH}$ amounts to $0.26 \mathrm{mmol} / \mathrm{g} \mathrm{SiO}_{2}$.

N1 shows a very homogeneous particle size of $18.0 \pm 2.6 \mathrm{~nm}$ (see Supporting Information). By considering the contents and value of the silica nanoparticle support's specific surface $\left(200 \mathrm{~m}^{2} \mathrm{~g}^{-1}\right)$, the average coverage of the surface of solid $\mathbf{N} 1$ by polyamine and thiol groups was ca. 0.93 molecules $/ \mathrm{nm}^{2}$, resulting in an average distance between anchored molecules of ca. 10.34 Á.

One of the more important advantages of using silica nanoparticles lies in the possibility of preparing dispersible stable suspensions. This is especially appealing when using silica supports in sensing protocols because color changes can be easily monitored. The N1-SQ system's colorimetric response in the presence of the nitrated explosives 2,4,6-trinitrophenylmethylnitramine (Tetryl), 2,4,6trinitrotoluene (TNT), 2,4-dinitrotoluene (DNT), 1,3,5-trinitrobenzene (TNB), hexahydro-1,3,5-trinitro-1,3,5-triazine (RDX), octahydro-1,3,5,7-tetranitro-1,3,5,7tetrazocine $(\mathrm{HMX})$, pentaerythritol tetranitrate (PETN), nitroglycerin (NG) or ethylenglycoldinitrate (EGDN) was studied (see Scheme 2). In a typical 
experiment, $10 \mathrm{mg}$ of $\mathbf{N 1}$ nanoparticles were suspended in $13.5 \mathrm{ml}$ of water and $1.5 \mathrm{ml}$ of acetonitrile or acetonitrile containing the target nitrated explosive, while the $\mathrm{pH}$ of the suspension was adjusted to 7. Then, $1.35 \mathrm{~mL}$ of these suspensions were mixed with $50 \mu \mathrm{L}$ of an acetonitrile squaraine dye solution $\left(1.0 \times 10^{-4} \mathrm{~mol} \mathrm{~L}^{-1}\right)$ and the final mixture was stirred for 3 minutes. Finally, the absorbance of the squaraine dye at $642 \mathrm{~nm}$ was measured (see Figure 1).<smiles>CN(c1c([N+](=O)[O-])cc([N+](=O)[O-])cc1[N+](=O)[O-])[N+](=O)[O-]</smiles>

Tetryl<smiles>Cc1c([N+](=O)[O-])cc([N+](=O)[O-])cc1[N+](=O)[O-]</smiles>

TNT<smiles>Cc1ccc([N+](=O)[O-])cc1[N+](=O)[O-]</smiles>

DNT<smiles>O=[N+]([O-])c1cc([N+](=O)[O-])cc([N+](=O)[O-])c1</smiles>

TNB<smiles>O=[N+]([O-])N1CN([N+](=O)[O-])CN([N+](=O)[O-])C1</smiles>

RDX<smiles>O=[N+]([O-])N1CN([N+](=O)[O-])CN([N+](=O)[O-])CN([N+](=O)[O-])C1</smiles>

HMX<smiles>O=[N+]([O-])OCC(CO[N+](=O)[O-])(CO[N+](=O)[O-])CO[N+](=O)[O-]</smiles>

PETN<smiles></smiles>

NG<smiles>O=[N+]([O-])OCCO[N+](=O)[O-]</smiles>

EGDN

Scheme 2. Chemical structure of nitrated explosives used in this communication.

As Figure 1 depicts, the N1-squaraine system's response to Tetryl is highly selective and only this explosive was able to inhibit the reaction between the squaraine and thiols grafted on the surface of $\mathbf{N 1}$ with the subsequent chromogenic response (the solution remained blue, see inset in Figure 1). Figure 1 illustrates the N1-SQ system's response to explosives at a concentration of $2.3 \mathrm{x}$ $10^{-4} \mathrm{~mol} \mathrm{~L}^{-1}$. Nevertheless, a very similar chromogenic response was observed upon addition of nitrated explosives at a concentration of $1.0 \times 10^{-3} \mathrm{~mol} \mathrm{~L}^{-1}$ (see Supporting Information). 


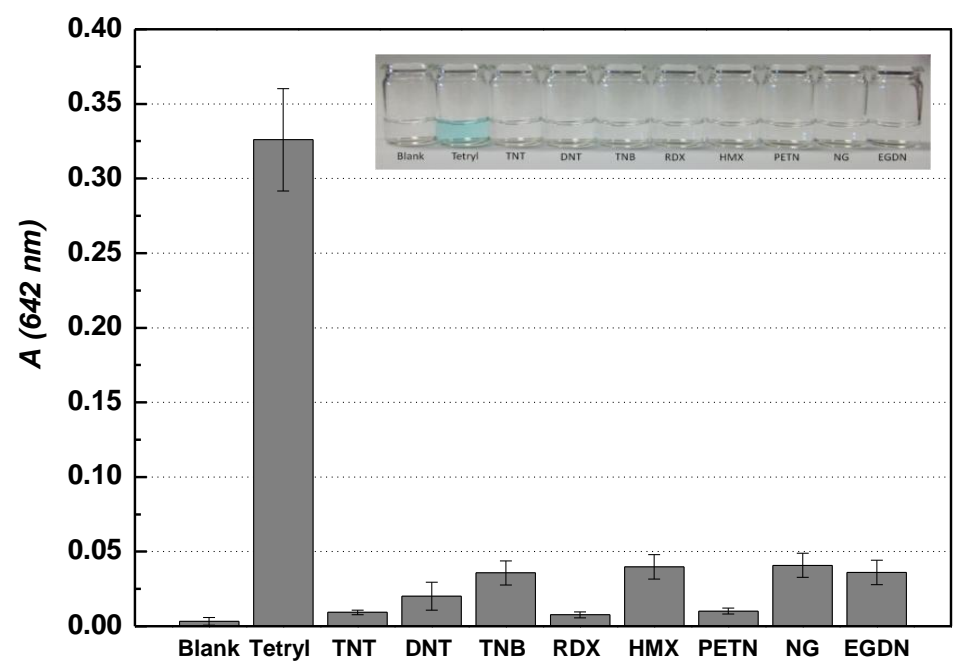

Figure 1. Absorbance at $642 \mathrm{~nm}$ (squaraine band) for water-acetonitrile 90:10 v/v at pH 7.2, suspensions containing $\mathbf{N} 1$, SQ and Tetryl, TNT, DNT, TNB, RDX, HMX, PETN, NG and EGDN at $2.3 x$ $10^{-4} \mathrm{~mol} \mathrm{~L}^{-1}$ after 3 minutes. Three independent experiments were performed and the data are reported as mean \pm s. Inset: photograph showing $\mathbf{N} \mathbf{1}$ suspensions in the absence (blank) and the presence of selected nitrated explosives

A fluorogenic response was also observed. For instance, Figure 2 shows the emission of the squaraine dye at $666 \mathrm{~nm}\left(\lambda_{\mathrm{ex}}=642 \mathrm{~nm}\right)$ versus the time for wateracetonitrile 90:10 v/v at pH 7.2 suspensions containing N1 and SQ in the absence and the presence of Tetryl. A detection limit of $0.17 \mathrm{ppm}$ of Tetryl was determined in the mixed aqueous solution using this simple method (see the inset in Figure 2).

Additionally, sensing material N1's shelf life was determined at one month in air and more than four months when the solid was stored under Ar. The fact that Tetryl was the only explosive able to modulate SQ-thiol reactivity could be assigned to this nitrated derivative's stronger electron acceptor character due to the presence of four electron-withdrawing nitro groups if compared with similar derivatives such as TNT, TNB and DNT. Other nitrated derivatives, for instance RDX, HMX, PETN, NG and EGDN, were also unable to inhibit the thiol-squaraine reaction. We also confirmed that the presence of other aromatic derivatives such 
as toluene, nitrobenzene and $\mathrm{N}$-methylaniline induced negligible changes in the kinetics of the thiol-squaraine reaction, and did not inhibit the bleaching of the solution. Other possible interferents such as amines (triethylamine, $n$-butylamine at $2.0 \times 10^{-4} \mathrm{~mol} \mathrm{~L}^{-1}$ ), acylating agents (acetic anhydride, acetyl chloride at $2.0 \times 10^{-}$ ${ }^{4} \mathrm{~mol} \mathrm{~L}^{-1}$ ), alkylating agents (dimethylsulfate, iodomethane at $1.0 \times 10^{-5} \mathrm{~mol} \mathrm{~L}^{-1}$ ), oxidants (hydrogen peroxide, sodium perborate, sodium thiosulfate, copper(II) chloride at $5.0 \times 10^{-5} \mathrm{~mol} \mathrm{~L}^{-1}$ ) and anions (chloride, sulfate, phosphate, nitrate at $5.0 \times 10^{-3} \mathrm{~mol} \mathrm{~L}^{-1}$ ) were tested. None was able to inhibit the thiol-squaraine reaction (see Supporting Information for details).

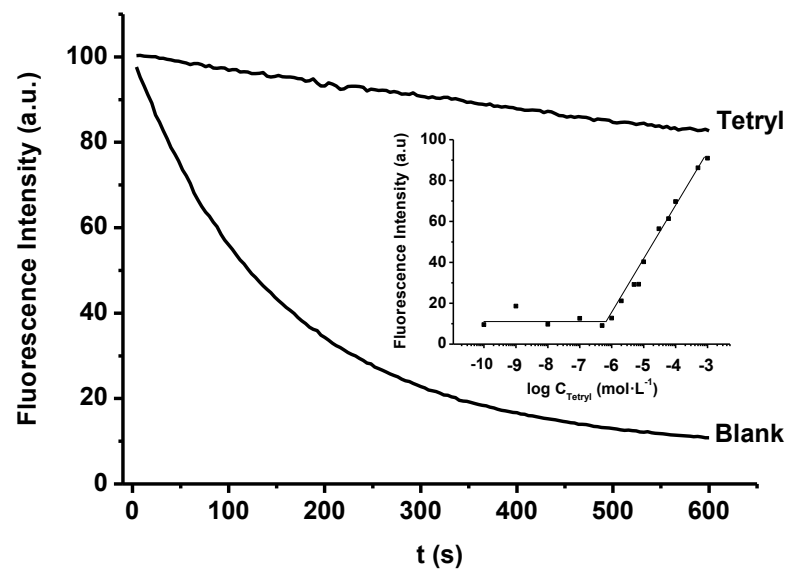

Figure 2. Fluorescence intensity at $666 \mathrm{~nm}$ (squaraine band, $\lambda_{e x}=642 \mathrm{~nm}$ ) versus the time for wateracetonitrile 90:10 v/v suspensions of $\mathbf{N} 1$ and SQ (Blank) and in the presence of Tetryl ( $C=2.3 \times 10^{-4}$ $\mathrm{mol}^{-1}$ ) at $p H$ 7.2. Inset: calibration curve for Tetryl using the N1-SQ ensemble in water-acetonitrile 90:10 v/v mixtures at $\mathrm{pH} 7.2$.

Based on this promising proof-of-principle, and after studying the detection of Tetryl in solution, we broadened our interest to the possible use of $\mathbf{N} 1$ material for Tetryl detection in soil samples. It is well-established that the disposal of obsolete explosives and munitions has not always been carried out in an environmentally acceptable manner, and that the analysis of trace levels of explosive contaminants in complex environmental matrices still requires the development of new sensing methods. The signaling protocol relies on a simple 
extraction of the Tetryl explosive with acetonitrile from soil and further addition of nanoparticles suspended in water and the SQ dye (see Supporting Information). Figure 3 depicts the N1-SQ system's fluorescence response in terms of Tetryl concentration in soil samples after extraction and preconcentration with acetonitrile. As seen, low amounts of Tetryl in soil can be detected using this procedure and conventional fluorimetric methods.

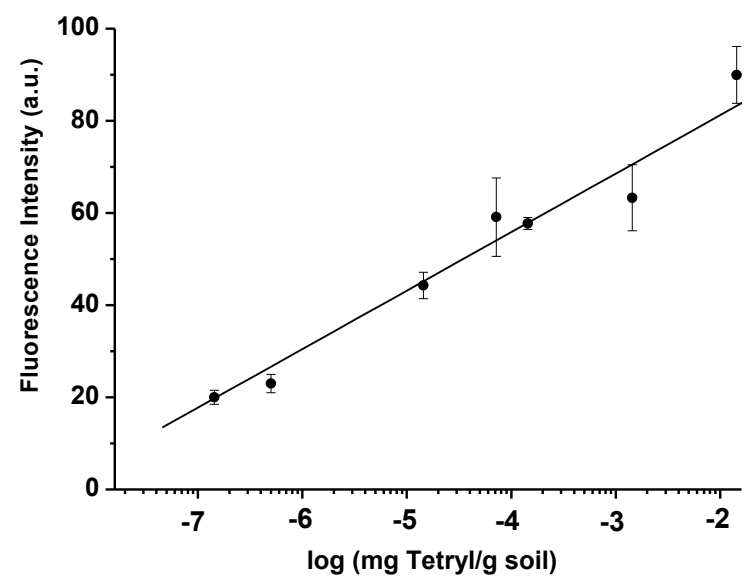

Figure 3. Fluorescence intensity at $666 \mathrm{~nm}$ (squaraine band, $\lambda_{\text {exc }}=642 \mathrm{~nm}$ ) in water-acetonitrile $90: 10 \mathrm{v} / \mathrm{v}$ at $\mathrm{pH} 7.2$ suspensions containing $\mathbf{N} 1$ and SQ for solutions obtained from soil samples containing increasing concentrations of Tetryl after $5 \mathrm{~min}$. Three independent experiments were performed and the data are reported as mean $\pm s$.

Finally, we were concerned with the possibility that the observed chromofluorogenic response was not due to the formation of amine-Tetryl complexes but by a certain interaction between the explosive and thiol groups. To elucidate the response mechanism the reactivity of the $\mathrm{N}$-SH-SQ-Tetryl $\left(1.0 \times 10^{-3} \mathrm{~mol} \mathrm{~L}^{-1}\right)$ system was evaluated. In this case a very rapid bleaching of the SQ was observed in the absence and in the presence of explosive (see Supporting Information). This result strongly points to the amine-Tetryl interaction as the main force that controls the chromogenic response observed in Figure 1. 
In short, we prepared bi-functionalized silica nanoparticles via the independent anchoring of binding sites (amines) and signaling units (thiols) to use them as a simple probe for the chromo-fluorogenic detection of Tetryl. In the absence of Tetryl, the thiol located on the surface of the nanoparticles reacts with a squaraine dye, inducing the bleaching of the solution. In the presence of Tetryl, the formation of charge-transfer complexes between the explosive and amines grafted on the surface inhibits the thiol-squaraine reaction. The probe is simple to prepare, easy to use, and allows a highly selective and sensitive detection of Tetryl in aqueous solution and soils. Selectivity of similar hybrid nanoparticles towards other nitrated explosives may be designed by changing the electron donor nature of the binding site (for instance using pyrene or anthracene). Further efforts into this direction are actually carried out in our research group.

Financial support from the Spanish Government (project MAT2009-14564-C0401) and Generalitat Valencia (project PROMETEO/2009/016) is gratefully acknowledged. Y.S. is grateful to the Spanish Ministry of Science and Innovation for a grant.

\section{References}

1. a) S. Singh, J. Haz. Mat., 2007, 144, 15. b) R. Schulte-Ladbeck, M. Vogel, U. Karst, Anal. Bioanal. Chem., 2006, 386, 559.

2. R. G. Smith, N. D'Souza, S. Nicklin, Analyst, 2008, 133, 571.

3. D. S. Moore, Rev. Sci. Instrum., 2004, 75, 2499.

4. K. Hakansson, R. V. Coorey, R. A. Zubarev, V. L. Talrose P. Hakansson, J. Mass Spectrom., 2000, 35, 337.

5. E. Wallis, T. M. Griffin, N. Popkie, Jr., M. A. Eagan, R. F. McAtee, D. Vrazel, J. McKinly, Proc. SPIE-Int. Soc.Opt. Eng., 2005, 5795, 54.

6. E. S. Forzani, D. Lu, M. J. Leright, A. D. Aguilar, F. Tsow, R. A. Iglesias, Q. Zhang, J. Lu, J. Li, N. Tao, J. Am. Chem. Soc., 2009, 131, 1390-1391.

7. a) S. W. Thomas III, G. D. Joly, T. M. Swager, Chem. Rev., 2007, 107, 1339. b) M. E. Germain, M. J. Knapp, Chem. Soc. Rev., 2009, 38, 2543.

8. a) J. S. Park, F. Le Derf, C. M. Bejger, V. M. Lynch, J. L. Sessler, K. A. Nielsen, C. Johnsen, J. O. Jeppesen, Chem. Eur. J., 2010, 16, 848. (b) S. Malashikhin, N. S. Finney, J. Am. Chem. Soc., 2008, 130, 12846. 
9. a) E. Climent, M. D. Marcos, R. Martínez-Máñez, F. Sancenón, J. Soto, K. Rurack, P. Amorós, Angew. Chem. Int. Ed., 2009, 48, 8519. b) E. Climent, A. Bernardos, R. Martínez-Máñez, A. Maquieira, M. D. Marcos, N. Pastor-Navarro, R. Puchades, F. Sancenón, J. Soto, P. Amorós, J. Am. Chem. Soc., 2009, 131, 14075.

10. M. Sugawara, K. Kojima, H. Sazawa, Y. Umezawa, Anal. Chem., 1987, 59, 2842.

11. a) E. Climent, P. Calero, M. D. Marcos, R. Martínez-Máñez, F. Sancenón, J. Soto, Chem. Eur. J., 2009, 15, 1816. b) E. Climent, A. Martí, S. Royo, R. Martínez-Máñez, M. D. Marcos, F. Sancenón, J. Soto, A. M. Costero, S. Gil, M. Parra, Angew. Chem. Int. Ed., 2010, 49, 5945.

12. A. Ponnu, N. Y. Edwards, E. V. Anslyn, New J. Chem., 2008, 32, 848.

13. M. Montalti, L. Prodi, N. Zacheronni, G. Falini, J. Am. Chem. Soc., 2002, 124, 13540. 



\title{
SUPPORTING INFORMATION
}

\section{Highly selective and sensitive chromo-fluorogenic detection of Tetryl explosive using functionalized silica nanoparticles}

\author{
Yolanda Salinas, Estela Climent, Ramón Martínez-Máñez, * \\ M. Dolores Marcos, Félix Sancenón, Juan Soto, Ana Costero, ${ }^{*}$ \\ Salvador Gil, Margarita Parra and Alberto Pérez de Diego
}

\section{Experimental procedures}

A $30 \%$ suspension of Ludox silica nanoparticles AS-30 Colloidal Silica were purchased from Sigma-Aldrich and nanoparticles were used with no further purification. Solvents were of absolute grade and were purchased from Scharlab. The $3 \%$ solution in acetonitrile of the subsequently nitrated explosives 2,4,6trinitrophenylmethylnitramine (Tetryl), 2,4,6-trinitrotoluene (TNT), 1,3,5trinitrobenzene (TNB), hexahydro-1,3,5-trinitro-1,3,5-triazine (RDX), pentaerythritol tetranitrate (PETN), were purchased from SelectLab Chemicals. 2,4-Dinitrotoluene (DNT) was acquired from Aldrich Chemistry. The authors thank the "La Marañosa" Technology Institute of the Spanish Ministry of Defence for preparing octahydro-1,3,5,7-tetranitro-1,3,5,7-tetrazocine (HMX), nitroglycerin (NG) and ethylenglycoldinitrate (EGDN). Dimethylsulfate (DS), iodomethane (lodMet), acetic anhydride (AcAn), acetyl chloride (AC), n-butylamine (BAm), sodium sulfate, sodium thiosulfate (STS) and copper(II) chloride were purchased from Sigma-Aldrich. Sodium chloride, sodium nitrate, hydrogen peroxide and sodium perborate (SP) were purchased from Scharlau. Triethyl amine (TAm) was purchased from J.T. Baker. Finally, sodium hydrogen phosphate was obtained from Acros Organics. 
Thermogravimetric analyses were carried out on TGA/SQTA 851e Mettler Toledo equipment using an oxidant atmosphere (Air, $80 \mathrm{~mL} / \mathrm{min}$ ) with a heating program consisting in a heating ramp of $10{ }^{\circ} \mathrm{C}$ per minute from $20^{\circ} \mathrm{C}$ to $1000{ }^{\circ} \mathrm{C}$, and an isothermal heating step at this temperature for 30 minutes. Transmission Electron Microscopy (TEM) images of particles were obtained with a Philips CM10, operating at $20 \mathrm{KeV}$. TEM samples were prepared by spreading a drop of nanoparticles solution in decane onto standard carbon-coated copper grids (200 mesh). Fluorescence spectroscopy was carried out in a Felix 32 Analysis Version 1.2 (Build 56) PTI (Photon Technology International), and UV-visible spectroscopy was carried out with a Lambda 35 UV/Vis Spectrometer (Perkin Elmer Instruments).

\section{Preparation of coated silica nanoparticles}

Coated silica nanoparticles (N1, N2, N3 and $\mathbf{N}-\mathbf{S H}$ ) were prepared from Ludox silica nanoparticles using the corresponding trialcoxysilyl derivatives following the procedures reported by Montalti and coworkers. ${ }^{1}$ Nanoparticles N1 and N2 were prepared using Ludox silica nanoparticles AS-30 and the trialcoxysilyl derivatives 3-[2-(2-aminoethylamino)ethylamino]propyl-trimethoxysilane (N3TS) and mercaptopropyltrimethoxysilane (MPTS) in two different amine-thiol ratios (10:1 and 5:1 for N1 and N2 respectively). Also, hybrid nanoparticles using 3(aminopropyl)-triethoxysilane (N1TS) and MPTS were prepared (N3) in order to test the selective response of the material upon changing the chemical nature of the binding site. Finally, as a model, and in order to test the role played by the binding site in the chromo-fluorogenic response observed, hybrid nanoparticles $\mathbf{N}$ SH were prepared using only MPTS. As an example, the preparation of N1 nanoparticles is described below in more detail. 
Preparation of coated silica nanoparticles $\mathbf{N} \mathbf{1}$

Ludox silica nanoparticles AS-30, with an average diameter of $18 \mathrm{~nm},(12 \mathrm{~mL})$, were added to a solution containing acetic acid $(60 \mathrm{~mL})$, water $(60 \mathrm{~mL})$ and ethanol $(100 \mathrm{~mL})$. Then a mixture of mercaptopropyltriethoxysilane (MPTS, $0.1636 \mathrm{mmol})$ and 3-[2-(2-aminoethylamino)ethylamino]propyl-trimethoxysilane (N3TS, $1.6363 \mathrm{mmol}$ ) was added to the nanoparticle suspension. The crude reaction was heated at $80{ }^{\circ} \mathrm{C}$ for 48 hours, ethanol was evaporated, then the acetic acid solution was neutralized with a saturated solution of ammonium acetate. Functionalized nanoparticles (N1) were precipitated and isolated by filtration, washed with water and acetone and dried at $40{ }^{\circ} \mathrm{C}$. This method obtained a uniform distribution of both the functional groups on the silica surface. This synthetic procedure allows the preparation of silica nanoparticles in which the functional groups were expected to be uniformly distributed into the surface forming a compact monolayer. The only expected differences between the solids would derive from the initial concentrations of amine and thiol derivatives. The values of organic content in mmol of MPTS and N3TS or N1TS per gram of $\mathrm{SiO}_{2}$ for solids N1, N2, N3 and N-SH were determined by elemental and thermogravimetric analysis, and the results are shown in Table SI-1.

Table SI-1. Total mmols of N3TS, N1TS and MPTS per gram of $\mathrm{SiO}_{2}$, average coverage and interdistance between anchored groups for the functionalised nanoparticles N1, N2, N3 and $\mathbf{N}-\mathrm{SH}$.

\begin{tabular}{cccccccc}
\hline Solid & $\begin{array}{c}\text { Ratio } \\
\text { amino/thiol } \\
(\mathrm{mmol} / \mathrm{mmol})\end{array}$ & $\begin{array}{c}\alpha_{\text {total }} \\
(\mathrm{mmol} / \mathrm{g}\end{array}$ & $\begin{array}{c}\alpha_{\mathrm{N} \text { TS }} \\
(\mathrm{mmol} / \mathrm{g}\end{array}$ & $\begin{array}{c}\alpha_{\text {N1TS }} \\
(\mathrm{mmol} / \mathrm{g}\end{array}$ & $\begin{array}{c}\alpha_{\text {MPTS }} \\
(\mathrm{mmol} / \mathrm{g}\end{array}$ & $\begin{array}{c}\beta_{\text {total }} \\
(\mathrm{molecules})\end{array}$ & $\begin{array}{c}\text { Distance } \\
(\AA)\end{array}$ \\
\hline $\mathbf{N 1}$ & $10 / 1$ & 0.3103 & 0.2707 & - & 0.039 & 0.97 & 10.34 \\
$\mathbf{N 2}$ & $5 / 1$ & 0.2906 & 0.2244 & - & 0.066 & 0.94 & 10.69 \\
$\mathbf{N 3}$ & $10 / 1$ & 0.3491 & - & 0.3406 & 0.008 & 1.05 & 9.75 \\
$\mathbf{N}-$ SH & - & 0.2593 & - & - & 0.259 & 0.88 & 11.31 \\
\hline
\end{tabular}


Thermogravimetric analyses were carried out under an air flow and with a heating rate of $10{ }^{\circ} \mathrm{C}$ per minute in the $20-1000^{\circ} \mathrm{C}$ intervals. As an example typical thermograms for $\mathbf{N} \mathbf{1}$ are described below. Three clearly defined zones were observed for $\mathrm{N} 1$; (i) from $30{ }^{\circ} \mathrm{C}$ to $200{ }^{\circ} \mathrm{C}$, which was assigned to loss of water and organic solvents (3.03\%), (ii) from $150{ }^{\circ} \mathrm{C}$ to $800{ }^{\circ} \mathrm{C}$, which was assigned to the organic matter attached to the nanoparticle surface (8.05\%), and (iii) from $800{ }^{\circ} \mathrm{C}$ to $1000^{\circ} \mathrm{C}$, a third step assigned to the condensation of silanol groups $(0.41 \%)$. The silica residue amounted to $88.51 \%$. Amine and thiol contents were determined by elemental analysis and thermogravimetric measurements, amounting to 0.271 and $0.039 \mathrm{mmol} / \mathrm{g} \mathrm{SiO}_{2}$, respectively. The diameter of the $\mathbf{N 1}$ nanoparticles was determined by TEM. TEM images for all the prepared nanoparticles show a very homogenous particle size of $18.0 \pm 2.6 \mathrm{~nm}$ (see Figure SI-1 as an example for $\mathbf{N 1}$ ).

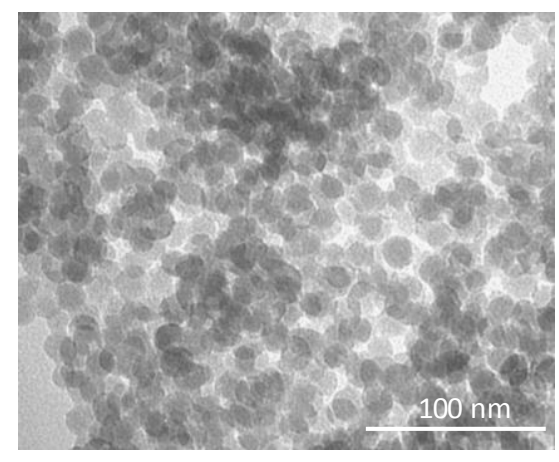

Figure SI-1. TEM images of functionalized nanoparticles N1, average diameter $=18.0 \pm 2.6 \mathrm{~nm}$.

\section{Experimental signaling procedure for the detection of explosives}

\section{Solution studies}

In a first step the reactivity of the squaraine (I) with the surface thiols in all the studied materials was tested. At this respect, addition of squaraine to suspensions of N1, N2 and N3 nanoparticles in water-acetonitrile 90:10 v/v induced a marked bleaching of the solution due to the reaction of the grafted thiol moieties with the 
dye. Then, the response of water-acetonitrile 90:10 v/v suspensions of N1, N2 and N3 nanoparticles in the presence of nitrated explosives was tested. The best results were obtained with suspensions of $\mathbf{N} \mathbf{1}$ nanoparticles because, of all the nitrated explosives tested, Tetryl was able to inhibit the thiol-squaraine reaction giving rise to a clear selective chromo-fluorogenic response.

In a typical assay, $10 \mathrm{mg}$ of $\mathbf{N} \mathbf{1}$ nanoparticles were suspended in $15 \mathrm{~mL}$ of water-acetonitrile $90: 10 \mathrm{v} / \mathrm{v}$ solutions (blank sample). At the same time, $10 \mathrm{mg}$ of N1 nanoparticles were suspended in $15 \mathrm{~mL}$ of water-acetonitrile 90:10 v/v containing the corresponding nitrated explosive. Then samples were sonicated for 15 minutes and $\mathrm{pH}$ was adjusted to 7-7.2 (this $\mathrm{pH}$ was selected because amines are partly protonated and the formation of the charge-transfer complex is partially inhibited at acid $\mathrm{pH}$ ). Then, $1.35 \mathrm{ml}$ of the corresponding suspensions were mixed with $50 \mu \mathrm{L}$ of an acetonitrile solution of the squaraine dye $(C=1.0 \mathrm{x}$ $\left.10^{-4} \mathrm{~mol} \mathrm{~L}^{-1}\right)$. After 3 minutes, an aliquot was filtered ( $0.2 \mu \mathrm{m}$ Teflon filters) and the absorbance of the SQ dye at $642 \mathrm{~nm}$ was measured. Also kinetic measurements, monitoring the changes of the squaraine absorption band centered at $642 \mathrm{~nm}$, in the presence and in the absence of nitrated explosives were carried out. For the fluorescence kinetic measurements, $1.35 \mathrm{~mL}$ of the initial suspension were mixed with $15 \mu \mathrm{L}$ of an acetonitrile solution of the squaraine dye $\left(C=1.0 \times 10^{-4} \mathrm{~mol} \mathrm{~L}^{-1}\right)$ in the fluorescence tray, and the fluorescence changes occurring with time were monitored at $666 \mathrm{~nm}$ (excitation at $642 \mathrm{~nm}$ ). 


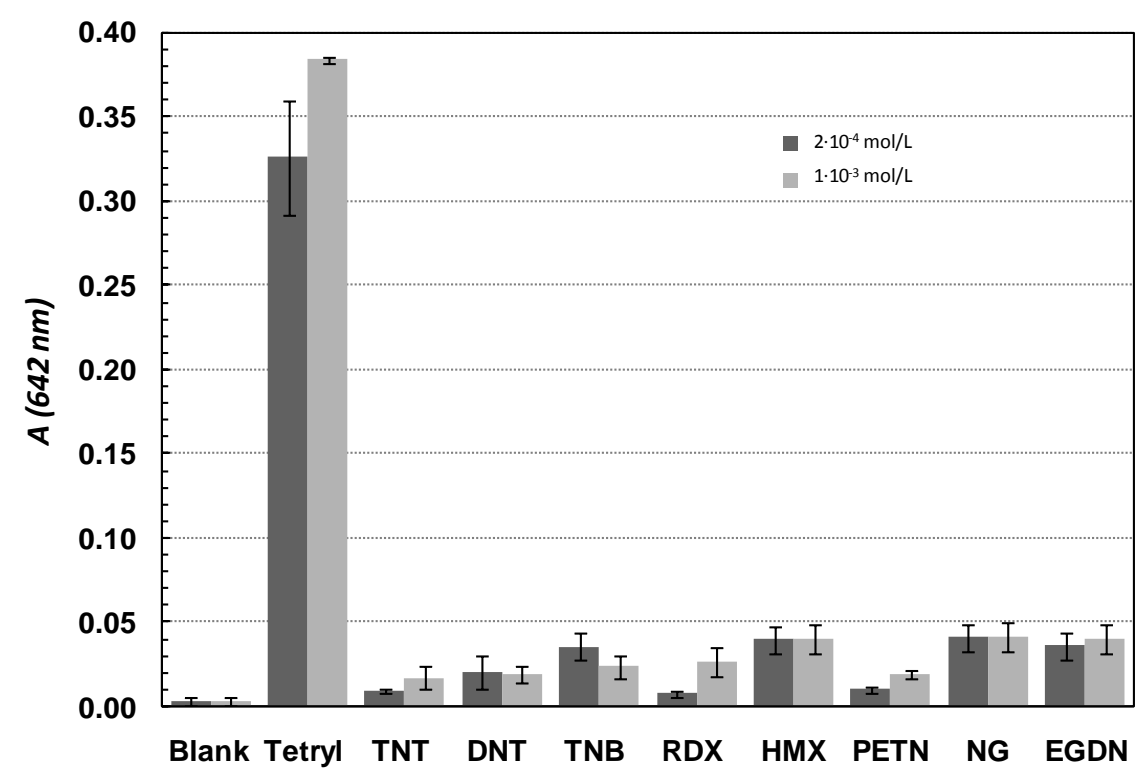

Figure SI-2. Absorbance at $642 \mathrm{~nm}$ (squaraine band) for water-acetonitrile 90:10 v/v at pH 7.2, suspensions containing N1, SQ and Tetryl, TNT, DNT, TNB, RDX, HMX, PETN, NG and EGDN at $2 \times 10^{-4}$ $\mathrm{mol}^{-1}$ and $1.0 \times 10^{-3} \mathrm{~mol} \mathrm{~L}^{-1}$ after 3 minutes. Three independent experiments were done and the data are reported as mean $\pm s$.

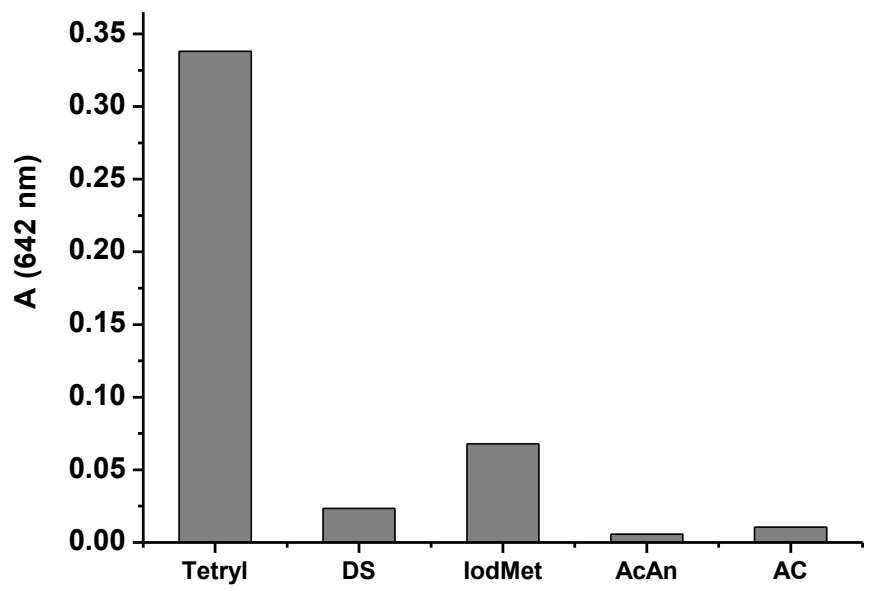

Figure SI-3. Absorbance at $642 \mathrm{~nm}$ (squaraine band) for water-acetonitrile 90:10 v/v at pH 7.2, suspensions containing N1, SQ and Tetryl, dimethyl sulfate (DS), iodomethane (lodMet), acetic anhydride (AcAn) and acetyl chloride (AC) after 3 minutes (DS and lodMet at $1.0 \times 10^{-5} \mathrm{~mol} \mathrm{~L}^{-1}, A c A c$ and $A C$ at $\left.2.0 \times 10^{-4} \mathrm{~mol} \mathrm{~L}^{-1}\right)$. 


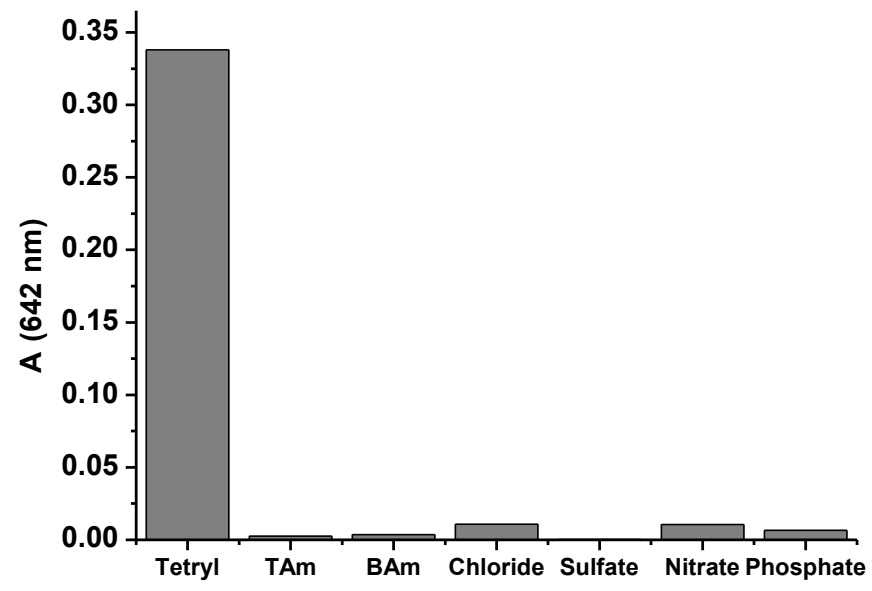

Figure SI-4. Absorbance at $642 \mathrm{~nm}$ (squaraine band) for water-acetonitrile 90:10 v/v at pH 7.2, suspensions containing N1, SQ and Tetryl, triethylamine (TAm), n-butylamine (Bam), chloride, sulfate, nitrate and phosphate after 3 minutes (anions at $5.0 \times 10^{-3} \mathrm{~mol} \mathrm{~L}^{-1}$; TAm and BAm at $2.0 \times 10^{-4} \mathrm{~mol} \mathrm{~L}^{-1}$ ).

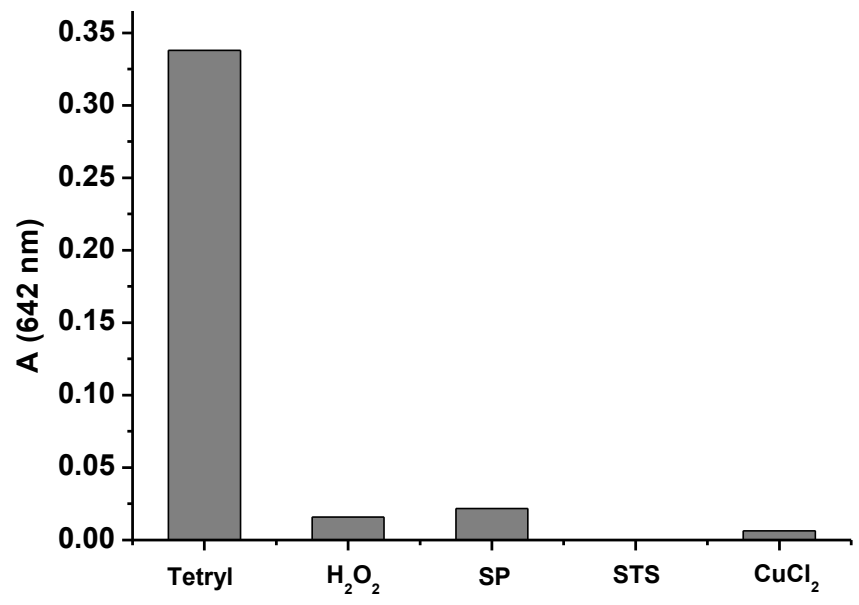

Figure SI-5. Absorbance at $642 \mathrm{~nm}$ (squaraine band) for water-acetonitrile 90:10 v/v at pH 7.2, suspensions containing $\mathbf{N} \mathbf{1}, S Q$ and Tetryl, hydrogen peroxide, sodium perborate (SP), sodium thiosulfate (STS) and copper(II) chloride after 3 minutes (hydrogen peroxide, SP, STS and copper(II) chloride at $\left.5.0 \times 10^{-5} \mathrm{~mol} \mathrm{~L}^{-1}\right)$. 
Figure SI-2 shows the N1-SQ system's chromogenic response in the presence of two different concentrations of nitrated explosives. As shown, only Tetryl was able to inhibit the reaction on the surface of $\mathbf{N} 1$ between the thiol groups and the squaraine dye. Figures SI-3, SI-4 and SI-5 depict the N1-SQ ensemble's response in the presence of potential interferents such as amines (triethylamine, $n$ butylamine), acylating agents (acetic anhydride, acetyl chloride), alkylating agents (dimethylsulfate, iodomethane), oxidants (hydrogen peroxide, sodium perborate, sodium thiosulfate, copper(II) chloride) and anions (chloride, sulfate, phosphate, nitrate). As observed, despite some partial inhibition noted in the presence of iodomethane, the remaining species were unable to significantly modify the reaction between squaraine and thiols on $\mathbf{N 1}$. We also observed how the presence of larger amounts of alkylating or acylating agents could easily be removed by using a basic water-acetonitrile 90:10 v/v. Then, the $\mathrm{pH}$ of the mixture was adjusted to $\mathrm{pH}$ 7-7.2, and nanoparticles $\mathbf{N} \mathbf{1}$ and the acetonitrile solution of the squaraine dye were added as explained above to detect Tetryl. With this previous basic treatment, the alkylating or acylating agents hydrolyze and their potential interference is then eliminated.

In order to determine the detection limit for Tetryl, fluorescence measurements with the N1-SQ systems in the presence of this explosive at different concentrations were made. Figure SI-6 illustrates the changes in the emission band at $666 \mathrm{~nm}$ in the presence of different concentrations of Tetryl in water-acetonitrile $90: 10 \mathrm{v} / \mathrm{v}$ at $\mathrm{pH} 7.2$, suspensions containing nanoparticles $\mathbf{N} 1$ with further addition of SQ. A detection limit of $0.14 \mathrm{ppm}$ Tetryl in the mixed aqueous solution was established. 


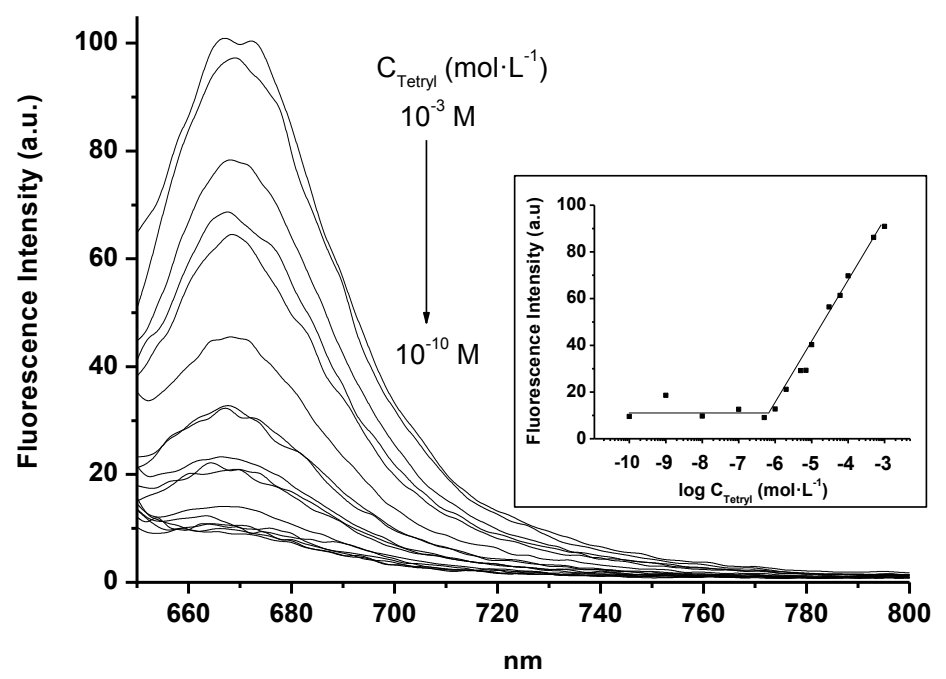

Figure SI-6. Fluorescence spectra of SQ (excitation at $642 \mathrm{~nm}$ ) in the presence of different Tetryl concentrations in water-acetonitrile $90: 10 \mathrm{v} / \mathrm{v}$ at pH 7.2, suspensions containing nanoparticles $\mathbf{N 1}$ with further addition of SQ. The inset shows the calibration curve for Tetryl using the N1-SQ ensemble in water-acetonitrile 90:10 v/v mixtures at $\mathrm{pH}$ 7.2.

The response observed with water-acetonitrile $90: 10 \mathrm{v} / \mathrm{v}$ suspensions of $\mathbf{N 2}$ nanoparticles was different from the obtained for N1 suspensions; i.e. the difference between the absorbance at $644 \mathrm{~nm}$ ( $\mathrm{SQ}$ band) in the absence and in the presence of Tetryl, for a certain time, was lower for nanoparticles $\mathbf{N} 2$ than that observed in the same conditions for N1. This different response should be related with the different polyamine-thiol ratio in both nanoparticles. In the same line nanoparticles N3 displayed a poorer response to Tetryl when compared to N1 both in terms if selectivity and sensitivity.

The optimal $\mathrm{pH}$ range for the optical detection of Tetryl with the N1-SQ system was determined to be 7-9. At acidic pH the amines are partly (or totally) protonated and the formation of charge-transfer complexes between the 
electron-rich nitrogen atoms and the electron-deficient Tetryl was observed to be highly inhibited (Figure SI-7), whereas more basic pH values were avoided in order to prevent degradation of the silica support.

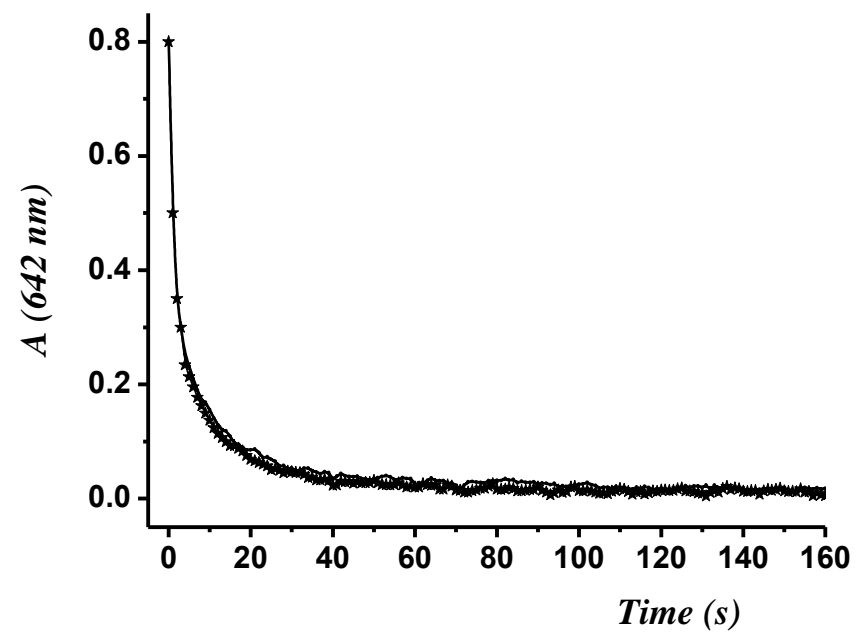

Figure SI-7. Absorbance at $642 \mathrm{~nm}$ (squaraine band) as a function of time for water-acetonitrile 90:10 v/v suspensions containing $\mathbf{N}$-SH and SQ in the absence and in the presence of Tetryl $\left(1 \times 10^{-3} \mathrm{~mol} \mathrm{~L}^{-1}\right)$ at acidic $\mathrm{pH}$.

Finally, and in order to check the role played by the polyamine binding site in the chromo-fluorogenic response, the behavior of water-acetonitrile 90:10 v/v suspensions of $\mathbf{N}-\mathbf{S H}$ was tested in the absence and in the presence of Tetryl. Exactly the same response was obtained in both cases, i.e. the bleaching of the solution due to the free access of the SQ to the surface grafted with thiols (see Figure SI-7). This fact strongly suggests that there is not interaction between the thiol groups and Tetryl and points out the critical role played by the formation of amine-explosive interactions in the observed response. 
Soil extraction studies

The extraction of Tetryl from soil samples was carried out by means of a simple method in which soil was grinded and sifted to obtain a homogeneous soil sample. Then $30 \mathrm{~g}$ of soil sample was doped with a certain amount of Tetryl. The sample was stirred for $15 \mathrm{~min}$ with $25 \mathrm{~mL}$ of acetonitrile to extract the explosive traces to be then filtered. The extract obtained was concentrated, in a rotary evaporator until the solvent was eliminated. The crude extract was dissolved in $1.5 \mathrm{~mL}$ of a water-acetonitrile $90: 10 \mathrm{v} / \mathrm{v}$ mixture $(\mathrm{pH} \mathrm{7.2)}$ to which $10 \mathrm{mg}$ of $\mathbf{N 1}$ were added. The resultant crude was sonicated for 15 minutes to obtain an adequate suspension of nanoparticles. Next, this suspension was mixed with 15 $\mu \mathrm{L}$ of an acetonitrile solution of the squaraine dye $\left(C=1.0 \times 10^{-4} \mathrm{~mol} \mathrm{~L}^{-1}\right)$, and the fluorescence emission at $666 \mathrm{~nm}$ (excitation at $642 \mathrm{~nm}$ ) was measured after 5 minutes. The experimental procedure was repeated for different samples containing differing amounts of Tetryl. Figure SI-9 shows the fluorescence emission spectra of the squaraine dye in final solutions for selected Tetryl concentrations.

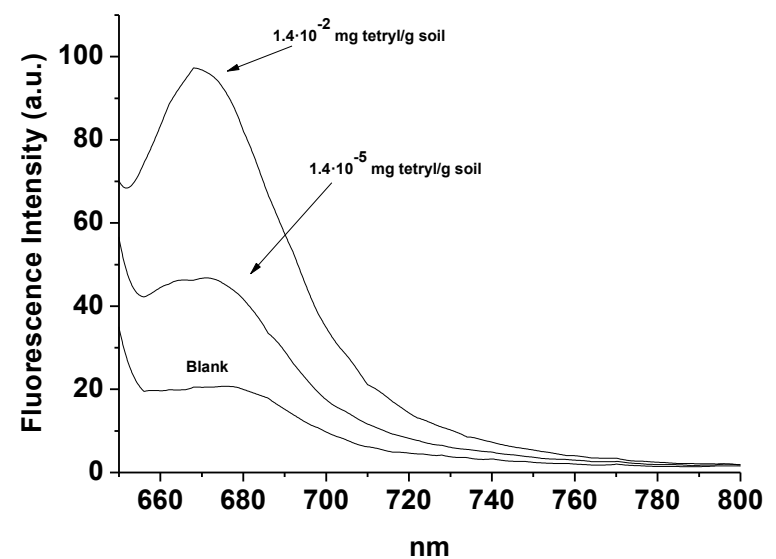

Figure SI-9. Changes in the SQ emission band centred at $666 \mathrm{~nm}$ (excitation at $642 \mathrm{~nm}$ ) in the absence and presence of Tetryl after soil extraction with acetonitrile. 


\section{References}

1. M. Montalti, L. Prodi, N. Zacheronni, G. Falini, J. Am. Chem. Soc., 2002, 124, 13540. 


\section{Regenerable hybrid materials for the fluorometric detection of explosives}





\subsection{Introduction.}

Billions of years of evolution have produced extremely efficient natural materials, which are increasingly becoming a source of inspiration for engineers. In fact, as researchers strive to develop better and better materials and devices, there is a lot to learn from nature. Biomimetics (the science of imitating nature) is a growing multidisciplinary field which is now leading to the fabrication of novel materials with remarkable properties. ${ }^{1}$ Nature can therefore inspire alternative approaches to solving design problems. Moreover, natural materials possess qualities, which would be highly beneficial to duplicate in their man-made counterparts, such as miniaturization, adaptability, and multifunctionality. ${ }^{2}$

The aim in this chapter is the application of nanoscopic preorganized mesoporous materials for the fluorogenic detection of certain nitroaromatic

\footnotetext{
${ }^{1}$ a) Y. Bar- Cohen, Bioinsp. Biomim., 2006, 1, P1. b) J. F. V. Vicent, O. A. Bogatyreva, N. R. Bogatyrev, A. Bowyer, A. -K. Pahl, J. R. Soc. Interface, 2006, 3, 471.

${ }^{2}$ F. Barthela, Phil. Trans. R. Soc. A, 2007, 365, 2907.
} 
explosives. These materials are prepared by the inclusion of specific binding/signaling units (namely selected fluorophores) inside cavities of mesoporous materials having additional groups on the walls that modulate the polarity (see Figure 4.1). This functionalization creates hydrophobic (or hydrophilic) binding pockets which are expected to be adequate in size and shape for nitroaromatic explosives inclusion and signaling.

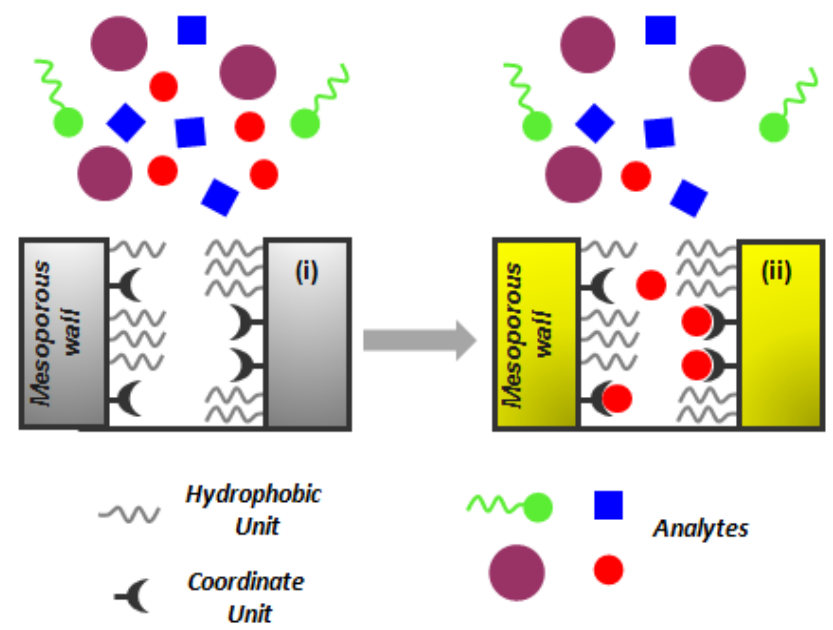

Figure 4.1. Scheme of hydrophobic "Binding Pockets" in mesoporous materials (i), and fluorescence signaling after host-guest recognition (ii).

One recent example of this paradigm based in the use of binding pockets was presented by A. B. Descalzo et al. and consisted in a mesoporous inorganic scaffold with hydrophobic cavities containing a urea-phenoxazinone derivative (as binding and signaling unit). ${ }^{3}$ The hybrid material was prepared in two step by anchoring first the urea-phenoxazinone derivative in a low proportion and then, in a second step, by the reaction of the remaining silanol groups of the inner pore walls with 1,1,1,3,3,3-hexamethyldisilazane (HMDS, that changes the $-\mathrm{OH}$ moieties into hydrophobic $-\mathrm{O}-\mathrm{Si}\left(\mathrm{CH}_{3}\right)_{3}$ groups). Addition of non-polar long-chain carboxylates to water suspensions of this hybrid material induced a change in

\footnotetext{
${ }^{3}$ A. B. Descalzo, K. Rurack, H. Weisshoff, R. Martínez-Máñez, M. D. Marcos, P. Amorós, K. Hoffmann, J. Soto, J. Am. Chem. Soc., 2005, 127, 184.
} 
colour and in fluorescence due to their inclusion in the hydrophobic environment of the pores and their subsequent coordination with the phenoxazinone derivative (through the formation of hydrogen bonds with the urea moiety). Small-chain carboxylates were unable to enter in the hydrophobic pores of the material and induced no chromo-fluorogenic response. The observed selectivity was clearly related with the inclusion of the urea-phenoxazinone derivative into the hydrophobic binding pocket because the same compound in solution yielded chromo-fluorogenic response with polar (small and medium chain) and non-polar (long chain) carboxylates.

Another example was reported by $\mathrm{M}$. Comes et al. The sensing system consisted of a MCM-41 support functionalized with a pyrylium derivative (able to give color changes from pink to yellow in the presence of primary amines) and with disilazane moieties to make the material hydrophobic (see Figure 4.2). ${ }^{4}$ In solution, the reaction of amines with pyrylium salts is unselective. However, the selectivity increased after the inclusion of the pyrylium derivative into the hydrophobic pores. The authors observed that the solid gave a cromogenic response with lineal aliphatic amines of medium size (such as n-octilamine) in water, whereas, long chain amines ( $n$-dodecilamine) or short chain amines (such as $\mathrm{n}$-propilamine) were unable to induce any response.
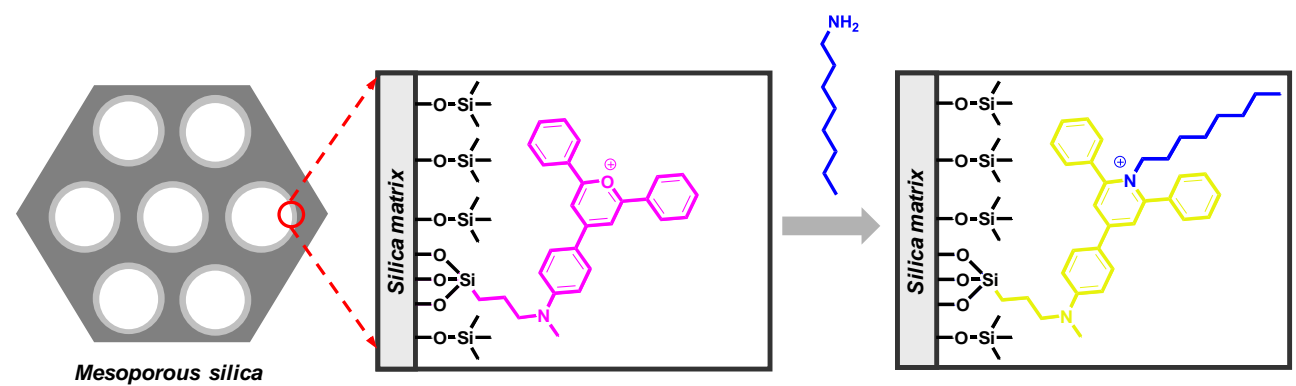

Figure 4.2. Scheme of a biomimetic material for amine detection. The color change is due to the reaction between the pyrylium ring and amines.

\footnotetext{
${ }^{4}$ M. Comes, M. D. Marcos, R. Martínez Máñez, F. Sancenón, J. Soto, L. A. Villaescusa, P. Amorós, D. Beltrán, Adv. Mater., 2004, 16, 1783.
} 
In 2007, A. B. Descalzo et al., designed a VOC (Volatile Organic Compounds) optical hybrid sensor, by using a mesoporous support functionalized with a phenoxazinone derivative. The mechanism of this sensor is based on the solvatocromic properties of this fluorescent dye. ${ }^{5}$ As in other probes explained above, the mesoporous material was first functionalized with the dye, and then, with disilazane moieties in order to obtain a hydrophobic material, which was used for the chromo-fluorogenic sensing of VOCs with a fast response, reversible behavior and with a low interference of humidity.

\subsection{Objectives.}

In this chapter we focus on the possibility of preparing different hybrid materials for the chromo- and fluorogenic detection of explosives using different fluorescent aromatic recognition groups (pyrene, dansyl and fluorescein). The polarity of the support was additionaly modulated by the introduction of a second functionality that generates "hydrophobic pockets" by reaction with $1,1,1,3,3,3$ hexamethyldisilazane moieties.

Particulary, our aim was:

- To prepare functionalised mesoporous materials with three different fluorophores (pyrene, dansyl and fluorescein) located in hydrophilic or hydrophobic environments.

- To characterize these new prepared hybrid systems.

- To study the fluorescence response of these materials with selected explosives.

- To study the potencial reusability of the sensing materials with no loss of their recognition ability.

\footnotetext{
${ }^{5}$ A. B. Descalzo, M. D. Marcos, C. Monte, R. Martínez-Máñez, K. Rurack, J. Mat. Chem., 2007, 17, 4716.
} 
4.3 Organic-inorganic hybrid mesoporous materials as regenerable sensing systems

for the recognition of nitroaromatic explosives. 



\title{
Organic-inorganic hybrid mesoporous materials as regenerable sensing systems for the recognition of nitroaromatic explosives
}

\author{
Krishanu Sarkar, ${ }^{a, 1}$ Yolanda Salinas, ${ }^{a, b, 1}$ \\ Inmaculada Campos, ${ }^{a, b}$ Ramón Martínez-Máñez, *a,b \\ María. D. Marcos, ${ }^{a, b}$ Félix Sancenón ${ }^{a, b}$ and Pedro Amorós ${ }^{c}$ \\ ${ }^{a}$ Centro de Reconocimiento Molecular y Desarrollo Tecnológico, (IDM), Unidad \\ Mixta Universidad Politécnica de Valencia - Universitat de València, Spain. \\ Departamento de Química. Universidad Politécnica de Valencia. Camino de Vera \\ $s / n$. E-46022, Valencia, Spain. \\ ${ }^{b}$ CIBER de Bioingeniería, Biomateriales y Nanomedicina (CIBER-BBN). \\ ${ }^{c}$ Institut de Ciència del Materials (ICMUV) Universitat de València P.O. Box 2085, \\ E-46071Valencia, Spain. \\ ${ }^{1}$ Both authors contributed equally to the work.
}

Received: $19^{\text {th }}$ April 2013

First published on the web: $31^{\text {st }}$ May 2013

ChemPlusChem Journal, 2013,

DOI: 10.1002/cplu.201300140.

(Reproduced with permission of Wiley-VCH Verlag GmbH \& Co. KGaA, Weinheim) 



\section{Abstract}

Fluorescent organic-inorganic mesoporous hybrid materials have been prepared and characterised, and their behaviour against nitroaromatic explosives have been tested. MCM-41 silica was used as inorganic scaffold and pyrene (P derivative containing trialkoxysilane moieties), dansyl and fluorescein ( $\mathbf{D}$ and $\mathbf{F}$ derivatives also containing trialkoxysilane groups, respectively) fluorophores have been anchored on hybrid materials by a co-condensation method to obtain a homogenous distribution of dyes into the pores of the support. Six sensing materials have been prepared, of which SP, SD, SF were hydrophilic and SPh, SDh, SFh were hydrophobic. Template-free hydrophilic materials (SP, SD, SF) were obtained after repeated $\mathrm{NH}_{4} \mathrm{NO}_{3}$ /ethanol extractions under temperature from assynthesised (MP, MD and MF supports, respectively) solids. Hydrophobic materials (SPh, SDh, SFh) were prepared by reacting excess 1,1,1,3,3,3hexamethyldisilazane with template-free hydrophilic (SP, SD and SF) materials. The six final materials displayed the typical emission bands of the grafted fluorophores. In particular, SP and SPh showed the typical pyrene monomer (370$420 \mathrm{~nm})$ and excimer (430-600 nm) emissions. SD and SDh exhibited the broad dansyl fluorescence band in the 450-600 $\mathrm{nm}$ range, whereas solids SF and SFh presented sharp fluorescein emission centred at $525 \mathrm{~nm}$. The fluorescent behaviour of the six final materials was tested in the presence of explosives (pentaerythritol tetranitrate (PETN), hexahydro-1,3,5-trinitro-1,3,5-triazine (RDX), nitrobenzene (NB), 1,3,5-trinitrobenzene (TNB), 2,4,6-trinitrotoluene (TNT), 2,4dinitrotoluene (DNT), 2,4,6-trinitrophenylmethylnitramine (Tetryl) and picric acid (PA)). Only nitroaromatics were able to induce emission quenching. As a general trend, the quenching degree depended on the nature of the final material. The best response was obtained with explosives PA and Tetryl, which were able to significantly quench the emission of the sensing supports. The observed quenching was ascribed to the $\pi-\pi$ stacking interactions between the electron donor fluorophores and the electron withdrawing nitroaromatic explosives. When using SPh for Tetryl and PA, the limits of detection were 8.5 and 1.4 ppm, 
respectively, whereas they were 14.4 and $1.2 \mathrm{ppm}$ for SDh. PCA algorithms were applied to the fluorescence measurements taken with the six hybrid materials and the seven explosives. The obtained score plot showed well-defined clusters for the seven explosives tested. Finally, solid SDh was applied to detect trace amounts of Tetryl in soil samples with good results.

\section{Introduction}

The detection of explosives and explosive-related illicit materials is crucial for preventing terrorist activities, homeland security, environmental cleaning, etc. ${ }^{1}$ In this field, the development of quick, reliable methods to detect these chemicals is a particularly interesting issue. Among the various chemical explosives available, nitroaromatics are perhaps the most commonly used. ${ }^{2}$ Current methods to detect nitrated explosives are based on enzymatic assays, ${ }^{3}$ gas and liquid chromatography, ${ }^{4}$ mass spectrometry, ${ }^{5}$ ion-mobility spectroscopy, ${ }^{6}$ electrochemical procedures, ${ }^{7}$ optodes, ${ }^{8}$ etc. Although each method offers advantages, none is ideal. Principal deficiencies include lack of portability or susceptibility to false-positive results due to environmental contaminants, or false-negative results as a result of interfering compounds. As an alternative to these instrumental procedures, optical probes have been extensively researched for signalling applications given their potential for high sensitivity, selectivity, portability, and cost-effectiveness. ${ }^{9}$ Optical detection techniques have focused on either colorimetric or fluorescence assays. ${ }^{10}$ In particular, fluorescence is a highly sensitive technique when compared with other light-based methods.

For all the above reasons, the preparation of optical probes to detect nitrated explosives based on fluorimetric measurements has attracted much attention in recent years. ${ }^{11}$ As a general trend, the designed probes make full use of the electron-deficient character of nitrated explosives that induces them to form charge-transfer complexes with electron-rich molecules, such as polycyclic aromatic hydrocarbons, dansyl derivatives or tetrathiafulvalenes. ${ }^{12}$ The formation 
of these stacked ensembles usually results in the quenching of the signalling fluorophore through electron and energy transfer processes. ${ }^{13}$ By making full use of this concept, molecular fluorescent receptors used to detect nitrated explosives have been explored in the last few years. ${ }^{14}$ In spite of this, one of the most important drawbacks of employing molecular fluorophores to sense nitrated explosives is lack of selectivity; i.e., the stronger the electron withdrawing character of the nitrated explosive, the greater the quenching of the fluorophore emission. In order to overcome this lack of selectivity, researchers have incorporated molecular fluorophores into organic polymeric matrices ${ }^{15}$ or into inorganic supports. ${ }^{16}$ The underlying idea relies on the fact that the physical and chemical properties of the support can be tuned as a way to control selectivity towards a certain nitrated explosive.

Bearing in mind the importance of mesoporous materials in several scientific and technological fields, ${ }^{17}$ our previous experience in preparing hybrid organicinorganic materials for their application in recognition protocols ${ }^{18}$ and our recent interest in designing probes for explosives, ${ }^{19}$ we report herein the synthesis, characterisation and recognition behaviour towards nitrated explosives of six solids functionalised with three different fluorophores (pyrene, dansyl and fluorescein) located in hydrophilic or hydrophobic environments. Studies on the fluorescent response of these materials with selected explosives are reported.

\section{Results and discussion}

Design and synthesis of the hybrid sensing materials

The proposed sensing protocol is schematically shown in Scheme 1. As inorganic support, a mesoporous MCM-41 phase was selected for its high load capacity (derived from the presence of a dense pore network) and its easy chemical functionalisation. ${ }^{20}$ The inorganic support was functionalised with three fluorophores (pyrene, dansyl and fluorescein) by a co-condensation procedure. This yielded hydrophilic materials SP, SD and SF. In a second step, the hydrophilic 
materials were made hydrophobic and solids SPh, SDh and SFh were obtained (see Scheme 1). This synthetic procedure allows to obtain a family of highly emissive hybrid solids in which the polarity of the inner pores was also controlled. As the scheme 1 explains, the signalling protocol relies on the existence of fluorophore-nitroaromatic explosive interactions, which is expected to result in a quenching of the emission of the grafted fluorophores. Moreover, a modulation of the reponse was expected to occur bearing in mind both the presence of a given fluorophore with a certain electron-donor character and the polarity of the pores. As a first step to prepare the different solids, the selected fluorophores (pyrene, dansyl and fluorescein) should be properly derivatised with trialkoxysilane moieties in order to anchor them on the MCM-41 inorganic support (see Scheme 2). For this purpose, 1-pyrenemethylamine (1) was reacted with (3-isocyanatopropyl)triethoxysilane (2) to yield ethoxysilane derivative $\mathbf{P}$. The ${ }^{1} \mathrm{H}$ NMR spectra of compound $\mathbf{P}$ showed the typical $\mathrm{N}-\mathrm{H}$ protons of the urea moiety as broad triplets centred at $5.98 \mathrm{ppm}$ and $6.47 \mathrm{ppm}$. Other significant signals were aromatic pyrene protons, which appeared in the 8.1-8.4 ppm interval and the doublet centred at $4.95 \mathrm{ppm}$, which was adscribable to the methylene protons linked directy with the pyrene and urea moieties.
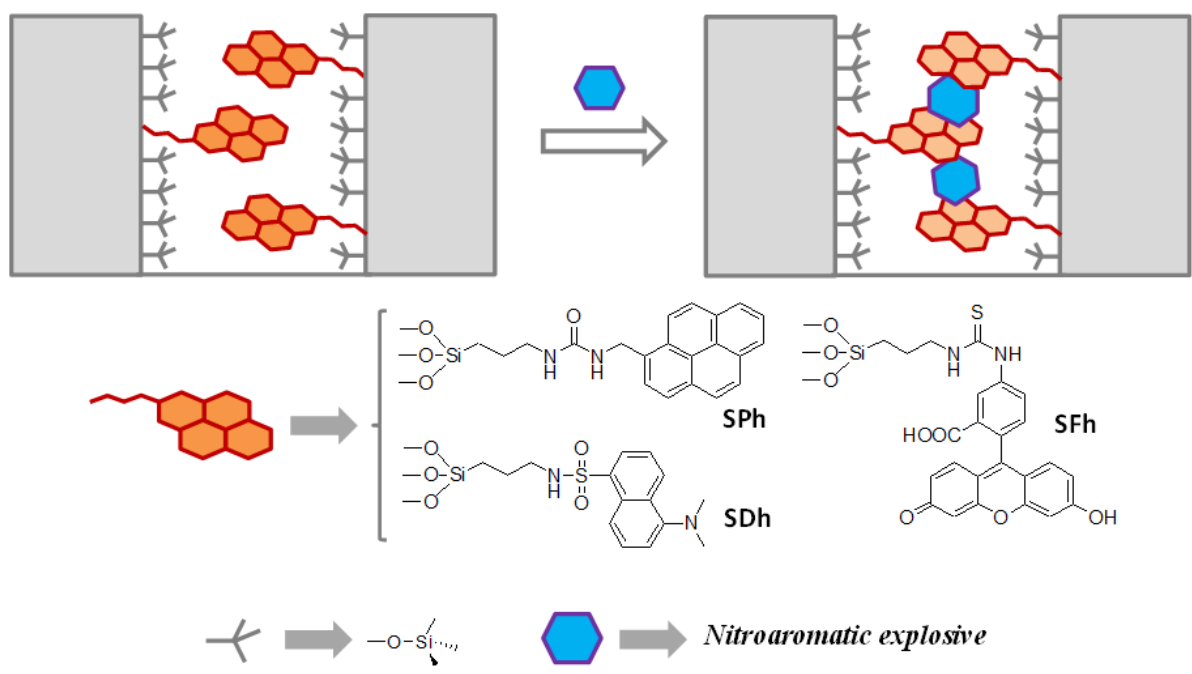

Scheme 1. Schematic representation of the sensing protocol using the hydrophobic materials SPh, SDh and SFh. 

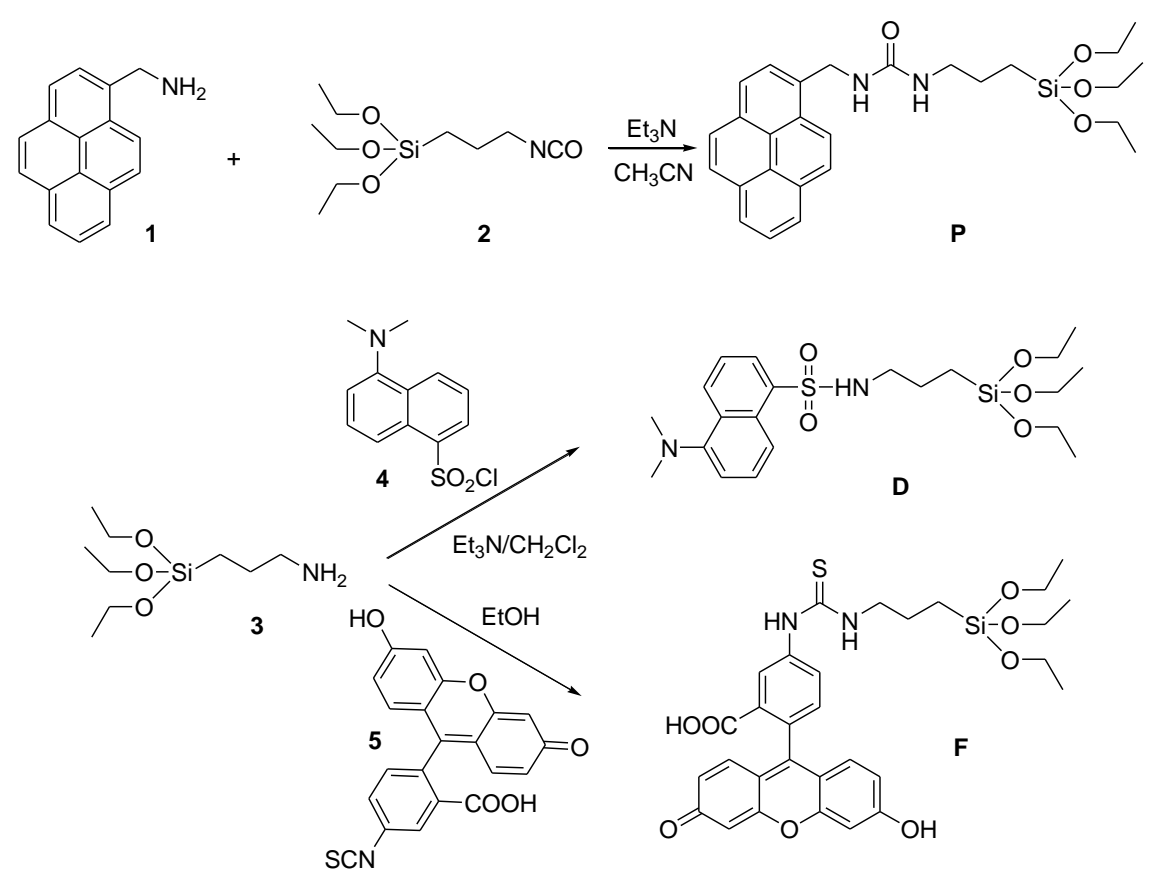

Scheme 2. Synthetic procedures for the preparation of alkoxysilane derivatives $\boldsymbol{P}, \boldsymbol{D}$ and $\boldsymbol{F}$.

Moreover, the synthesis of derivatives $\mathbf{D}$ and $\mathbf{F}$ is straighforward and has been published elsewhere. ${ }^{21}$ In particular, the reaction of (3aminopropyl)triethoxysilane (3) with dansyl chloride (4) yielded product D, whereas $\mathbf{F}$ was obtained through the reaction of $\mathbf{3}$ with fluoresceinisothiocyanate (5). The NMR data of $\mathbf{D}$ and $\mathbf{F}$ were in full agreement with those described in the literature.

The functionalised hybrid MCM-41 materials were prepared using a mixture of TEOS and the corresponding derivatised fluorophore ( $\mathbf{P}, \mathbf{D}$ and $\mathbf{F})$ in a 99:1 TEOSderivatised fluorophore ratio. The molar ratio of the reagents in the mother liquour was fixed to the $3.5 \mathrm{TEAH}_{3}: 1$ silica source (TEOS-derivatised fluorophore 99:1): 0.26 CTAB: $0.25 \mathrm{NaOH}: 4.45 \mathrm{H}_{2} \mathrm{O}$. With this procedure, the "as made" materials containing pyrene (MP), dansyl (MD) and fluorescein (MF) attached in the inner porous network were obtained. Then, the structure directing agent (CTAB) was removed using ethanolic solutions of ammonium nitrate. This 
extraction procedure was repeated 4 times to yield the final hydrophilic solids SP, SD and SF. In another step, these template-free hybrid solids were used to prepare the hydrophobic materials through a reaction with $1,1,1,3,3,3-$ hexamethyldisilazane, which transformed the remaining silanol groups into the solids in the corresponding trimethylsilyl moieties. With this procedure, hybrid solids SPh, SDh and SFh were obtained (see the Experimental section for details).

\section{Materials characterisation}

All the prepared solids were characterised using standard procedures. For the organic-inorganic hybrid materials, one key point associated with their characterisation was the determination of the degree of functionalisation. The contents of the functionalised groups (i.e., fluorophore and trimethylsilane) in the MCM-41 supports were determined from the thermogravimetric and elemental analyses (see Table 1).

Table 1. Organic content in solids SP, SD, SF, SPh, SDh and SFh.

\begin{tabular}{ccccc}
\hline Solid & $\begin{array}{c}\alpha_{\mathrm{P}} \\
\left(\mathrm{mmol}_{\mathrm{g} \mathrm{SiO}}\right)\end{array}$ & $\begin{array}{c}\alpha_{\mathrm{D}} \\
\left(\mathrm{mmol}_{\mathrm{g} \mathrm{SiO}}\right)\end{array}$ & $\begin{array}{c}\alpha_{\mathrm{F}} \\
\left(\mathrm{mmol}_{\mathrm{g} \mathrm{SiO}}\right)\end{array}$ & $\begin{array}{c}\alpha_{\mathrm{SiMe} 3} \\
\left(\mathrm{mmol}_{\mathrm{g} \mathrm{SiO}}\right)\end{array}$ \\
\hline SP & 0.32 & - & - & - \\
SPh & 0.32 & - & - & 0.56 \\
SD & - & 0.48 & - & - \\
SDh & - & 0.48 & - & 0.09 \\
SF & - & - & 0.19 & - \\
SFh & - & - & 0.19 & 0.16 \\
\hline
\end{tabular}

Despite the presence of similar amounts of the functionalised $\mathbf{D}, \mathbf{P}$ and $\mathbf{F}$ derivatives in the mother liquour during hybrid solids preparation, the contents of each fluorophore in the final solids was somewhat different. This may be due to the different reactivity of the derivatives which is apparently related with fluorophore size; i.e. the larger the size $(\mathbf{F}>\mathbf{P}>\mathbf{D})$, the smaller the final amount anchored onto the inorganic support. Moreover, the polarity of the grafted 
fluorophore has a clear effect on the further functionalisation with hexamethyldisilazane. In paticular, the lesser the polarity of the fluorophore ( $\mathbf{P}$ > D $>$ F), the larger the final amount of the $-\mathrm{O}-\mathrm{Si}\left(\mathrm{CH}_{3}\right)_{3}$ groups linked to the inner area of the pores.

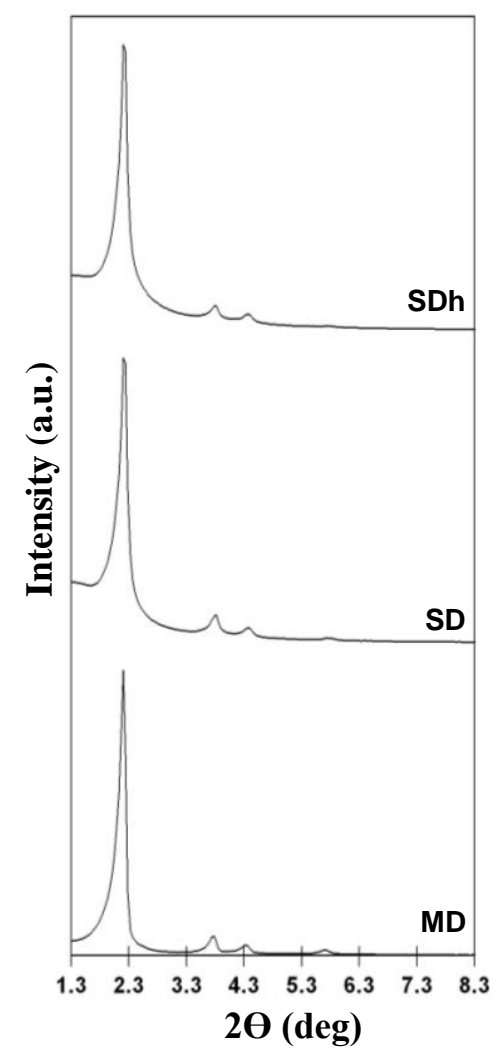

Figure 1. Small-angle powder XRD patterns of as-synthesised (MD), extracted (SD) and hydrophobic (SDh) solids.

The powder X-ray diffraction patterns (PXRD) of solids MD, SD and SDh are shown in Figure 1, whereas the PXRD for the remaining solids can be found in the Supporting Information. The PXRD pattern of the siliceous MCM-41-type assynthesised materials (i.e., MP, MD and MF) presented four low-angle reflections, which are typical of the hexagonal-ordered array that can be indexed as (100), (110), (200) and (210) Bragg peaks. The slight shift of the (100) reflection and the 
broadening of the (110) and (200) peaks in the diffraction pattern of the extracted and hydrophobic samples are clearly seen. This broadening of the (110) and (200) reflections is related with a more marked reduction in contrast (see the Supporting Information). Nonetheless, the clear presence of the (100) reflexion in all the PXRD patterns of the final solids suggests that the functionalisation with the fluorophore and the subsequent reaction with 1,1,1,3,3,3hexamethyldisilazane did not substantially modify the mesoporous MCM-41 scaffold.

The presence of the mesoporous structure in the functionalised solids was also confirmed by the TEM analysis, in which the typical MCM-41 type matrix structure was found. By way of example, Figure 2 shows the TEM images of the SF and SFh materials (for the TEM images of the other materials, see the Supporting Information).
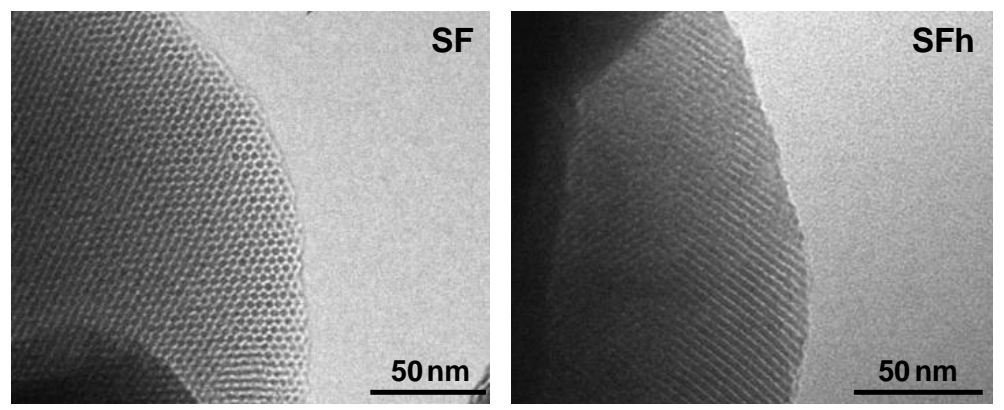

Figure 2. TEM images of solids SF and SFh showing the typical hexagonal porosity of the MCM-41 matrix.

The $\mathrm{N}_{2}$ adsorption/desorption isotherms of the extracted (SP) and hydrophobic material (SPh) are displayed in Figure 3 (see the Supporting Information for the $\mathrm{N}_{2}$ adsorption/desorption isotherms of SD, SF, SDh and $\mathbf{S F h}$ ). The obtained isotherms can be classified as type IV, which are characteristic of mesoporous supports. Moreover, the sharp increase in $\mathrm{N}_{2}$ uptake observed at partial pressure $\mathrm{P} / \mathrm{P}_{0}$ of 0.28-0.4 clearly indicates that mesopores were uniform in size. The pore size distributions (PSD) of these samples were calculated by following the Barret- 
Joyner-Halenda (BJH) method (see Table 2). ${ }^{22}$ The estimated pore diameters were basically in agreement with those found from the TEM images. In addition, the specific surface areas of the sensory materials were calculated from the adsorption data in the low-pressure range using the Brunauer-Emmett-Teller (BET) model. ${ }^{23}$ The specific surface areas, pore volumes, pore sizes, cell parameter and wall thickness for the final solids are shown in Table 2. This table clearly reveals that the specific BET surface areas of the extracted materials (SP, SD, SF) were larger than those corresponding to the hydrophobic counterparts (SPh, SDh, SFh), which is in agreement with further functionalisation with the bulky trimethylsilane moieties in the latter. Moreover, the pore size for SP-SPh gradually decreased (from 2.51 to $2.11 \mathrm{~nm}$ ), SD-SDh (from 2.84 to $2.53 \mathrm{~nm}$ ) and SF-SFh (from 2.76 to $2.57 \mathrm{~nm}$ ) also indicated the effective functionalisation in the hydrophobed supports. Another remarkable correlation observed was related with the areas of the solids containing different fluorophores. Thus, despite the degree of functionalisation (vide Table 1), Dansyl was the smallest fluorophore and materials SD and SDh showed the largest specific surface, whereas materials SF and SFh, containing the bulky fluorescein fluorophore, presented the smallest specific areas.

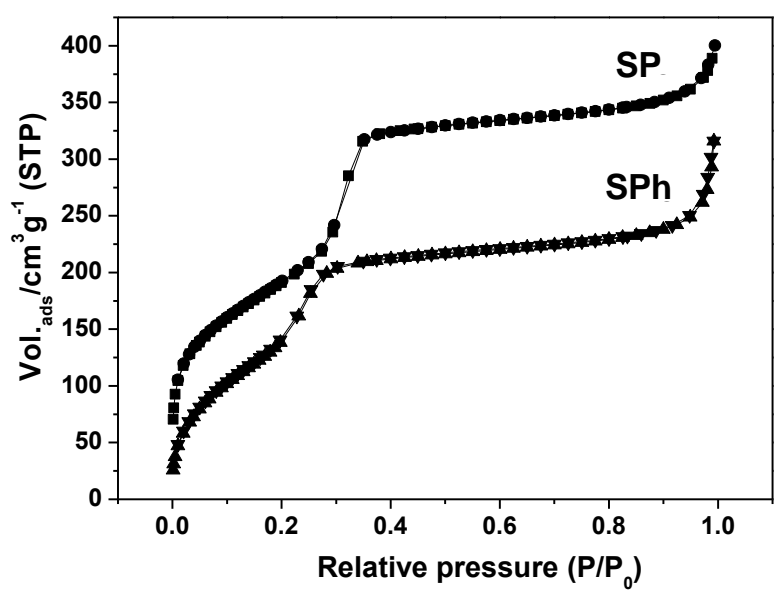

Figure 3. The nitrogen adsorption-desorption isotherms for solids SP and SPh. 
Table 2. The BET-specific surface areas, pore volumes, pore sizes (calculated from the $\mathrm{N}_{2}$ adsorption/desorption isotherms), cell parameter and wall thickness (calculated by X-ray diffraction patterns) for the sensing materials.

\begin{tabular}{c|ccccc}
\hline & $\begin{array}{c}S_{\text {BET }} \\
\left(\mathrm{m}^{2} \mathrm{~g}^{-1}\right)\end{array}$ & $\begin{array}{c}\text { Pore Volume }^{a} \\
\left(\mathrm{~cm}^{3} \mathrm{~g}^{-1}\right)\end{array}$ & $\begin{array}{c}\text { Pore size }^{a} \\
(\mathrm{~nm})\end{array}$ & $\begin{array}{c}\mathrm{a}_{0} \\
(\mathrm{~nm})\end{array}$ & $\begin{array}{c}\text { Wall thickness } \\
(\mathrm{nm})\end{array}$ \\
\hline SP & 696.6 & 0.63 & 2.51 & 4.98 & 2.47 \\
SPh & 538.4 & 0.44 & 2.11 & 4.98 & 2.87 \\
SD & 1012.6 & 0.92 & 2.84 & 4.62 & 1.78 \\
SDh & 773.2 & 0.62 & 2.53 & 4.62 & 2.09 \\
SF & 436.5 & 0.37 & 2.76 & 4.88 & 1.86 \\
SFh & 360.4 & 0.22 & 2.57 & 4.88 & 2.31 \\
\hline \multicolumn{5}{c}{${ }^{a}$ Volume (V) and diameter (D) of the mesopores. }
\end{tabular}

${ }^{\mathrm{a}}$ Volume (V) and diameter (D) of the mesopores.

\section{Fluorescence studies}

The emission responses of the six prepared materials were tested in acetonitrile in the absence and presence of Tetryl, which was selected in this first study as a characteristic nitrated explosive. In a typical experiment, $1 \mathrm{mg}$ of the corresponding hybrid material was suspended in $3 \mathrm{ml}$ of acetonitrile or in $3 \mathrm{ml}$ of a Tetryl solution $\left(2.0 \times 10^{-3} \mathrm{~mol} \mathrm{dm}^{-3}\right)$ in the same solvent. In all cases, the partial quenching of emission was observed in the presence of Tetryl. As an example of this behaviour, Figure 4 shows the emission profile of the hydrophobic solids in acetonitrile in the presence of Tetryl.

In particular, upon excitation at $341 \mathrm{~nm}$, the acetonitrile suspensions of SPh showed the typical structured pyrene monomer emission band in the $370-420 \mathrm{~nm}$ interval together with a broad unstructured band at $476 \mathrm{~nm}$, which was ascribed to the excimer pyrene emission. ${ }^{24}$ The presence of the latter red-shifted emission indicates that the pyrene groups come close enough in the SPh solid to yield the excimer complex. Moreover, the hydrophobic environment in the inner of the pores also favours the interaction between excited pyrenes and their counterparts in the ground state. Addition of Tetryl induced a 5-fold quenching of both monomer and excimer emissions. The acetonitrile suspensions of SDh show 
the typical broad emission band of the dansyl fluorophore centred at $516 \mathrm{~nm}$ upon excitation at $347 \mathrm{~nm}$. In this particular case, addition of Tetryl also induced a 6-fold quenching of the emission band. Finally, the suspensions of SFh exhibited the narrow emission band of fluorescein at $525 \mathrm{~nm}$ upon excitation at $493 \mathrm{~nm}$. In this case however, addition of Tetryl induced a relatively low 1.4-fold quenching of the fluorescein emission band. Addition of Tetryl to acetonitrile suspensions of the hydrophilic materials (SP, SD and SF) also induced a quenching of the emission intensity of the three fluorophores, but this quenching was lesser if compared with that observed for hydrophobic solids. This was most likely the result of the polarity environment around the fluorophores. Tetryl is a nitroaromatic explosive with a medium/low polarity that prefers hydrophobic environments (in fact, its solubility in water is very low). The presence of highly hydrophobic cavities in the SPh, SDh and SFh materials would account for the stronger interactions of Tetryl with the corresponding fluorophore when compared with the hydrophilic materials, which resulted in greater quenching efficiency. The quenching observed upon addition of Tetryl was ascribed to $\pi-\pi$ interactions between the electron donor-grafted fluorophores and the electron acceptor nitroaromatic explosive. ${ }^{12}$

Bearing in mind that the larger quenching results were obtained with hydrophobic solids SPh and SDh, a complete study of fluorescent behaviour in the presence of other explosives for both materials is detailed herein. The experiments were performed using $1 \mathrm{mg}$ of the selected solid, which was suspended in $3 \mathrm{~mL}$ of acetonitrile or in $3 \mathrm{~mL}$ of acetonitrile containing explosives pentaerythritol tetranitrate (PETN), hexahydro-1,3,5-trinitro-1,3,5-triazine (RDX), 1,3,5-trinitrobenzene (TNB), nitrobenzene (NB), 2,4,6-trinitrotoluene (TNT), 2,4dinitrotoluene (DNT), 2,4,6-trinitrophenylmethylnitramine (Tetryl) or picric acid (PA) $\left(2.0 \times 10^{-3} \mathrm{~mol} \mathrm{dm}^{-3}\right)$. The emission intensity of the suspensions (at 476 and $516 \mathrm{~nm}$ for SPh and SDh, respectively) was measured after $1 \mathrm{~min}$. The obtained results are shown in Figure 5. 

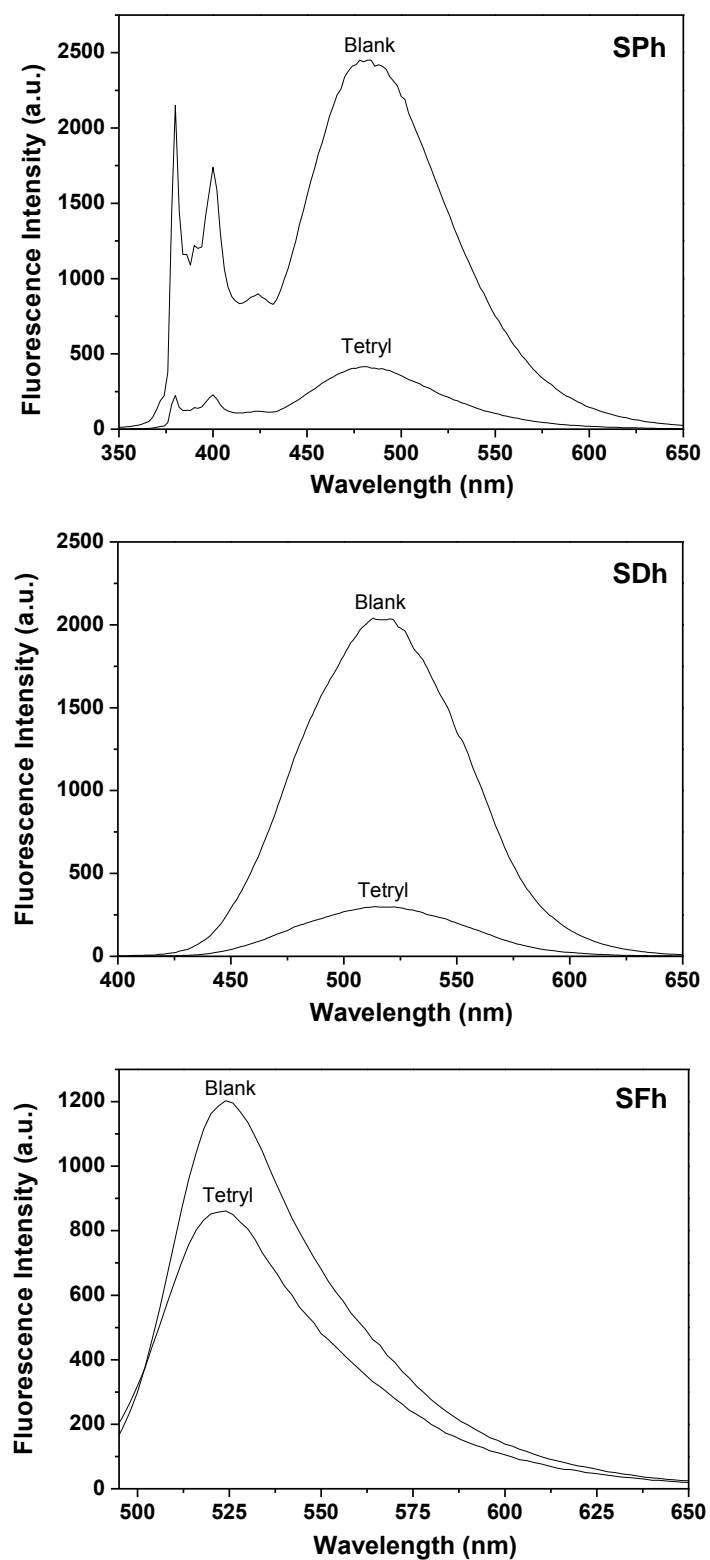

Figure 4. The fluorescence spectra of hydrophobised solids SPh, SDh and SFh alone and after the reaction with Tetryl $\left(2.0 \times 10^{-3} \mathrm{~mol} \mathrm{dm}^{-3}\right)$. 

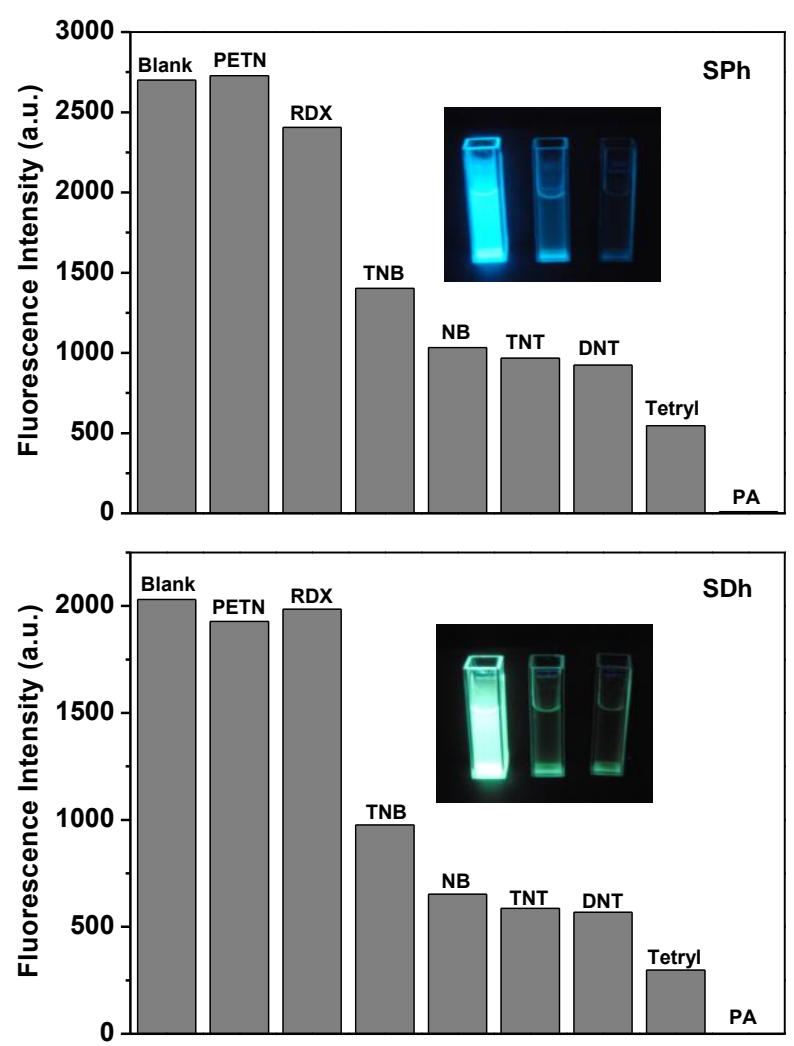

Figure 5. Fluorescent emission representation of the solid suspensions of $\boldsymbol{S P h}\left(\lambda_{e x}=341 \mathrm{~nm}, \lambda_{e m}=476\right.$ $\mathrm{nm})$ and $\mathbf{S D h}\left(\lambda_{e x}=347 \mathrm{~nm}, \lambda_{e m}=516 \mathrm{~nm}\right)$ in the presence of different nitroaromatic explosives $(2.0 \mathrm{x}$ $\left.10^{-3} \mathrm{~mol} \mathrm{dm}^{-3}\right)$. The inset presents photographs of the suspensions of solids alone (left) and in the presence of Tetryl (middle) and PA (right).

As this figure depicts, addition of PA and Tetryl induced stronger quenching among all the nitrated explosives tested. Moderate quenching was observed upon the addition of TNT, TNB, DNT and NB, whereas negligible changes were measured for RDX and PETN. Almost the same selectivity trend was found for both the SPh and SDh sensing materials. The negligible quenching found upon the addition of RDX and PETN is clearly the result of the chemical nature of these explosives. RDX is a nitramine, whereas PETN is a nitrate ester, and both are nonaromatic. This non-aromatic character precludes the interaction with grafted fluorophores and a poor fluorescent response was therefore observed. The other nitroaromatic compunds tested induced several quenching degrees, which clearly 
relate with their electron withdrawing character. As a general trend, the more the nitro groups in their structure, the greater the quenching measured. Moreover, the selectivity and sensitivity observed for SPh and SDh could additionally be originated from a highly cooperative association of PA and Tetryl with the grafted electron rich fluorophores. The incorporation of these fluorophores into the mesoporous matrix induced the formation of hydrophobic pre-organized cavities with sizes that matches well with those of PA and Tetryl. These cooperative adsorption processes have been recently used for the selective sensing and separation of certain species. ${ }^{25}$

One interesting feature of both the SPh and SDh solids was the greater quenching observed with PA, when compared with that observed for TNT. When comparing this result with the literature, it is apparent that most of the described chromogenic and fluorogenic methods were unable to distinguish between PA and TNT due to their extremely similar structure and chemical properties. ${ }^{26}$ In our case, both hybrid materials SPh and SDh displayed a differentiable response towards these nitroaromatic explosives and may allow the selective detection of PA. In fact the sensing systems for PA are greatly demanded for homeland security needs (PA has a strong explosion ability when compared with TNT, and is capable of exploding with no trigger). ${ }^{27}$

Having established the response of SPh and SDh with several explosives, the limit of detection (LOD) was calculated for explosives PA and Tetryl, which displayed a more marked response. For these studies, $1 \mathrm{mg}$ of the corresponding solid was suspended in $3 \mathrm{~mL}$ of acetonitrile solutions containing different concentrations of PA or Tetryl and, after $1 \mathrm{~min}$, the intensity of the emission band was measured (at 476 and $516 \mathrm{~nm}$ for SPh and SDh, respectively). As a representative result, the fluorescence calibration curve for the SDh-PA system is shown in Figure 6 (see the Supporting information for the other calibration curves). The LODs for PA and Tetryl were calculated to be $1.4 \mathrm{ppm}$ and $8.5 \mathrm{ppm}$ using solid SPh, whereas they were $1.2 \mathrm{ppm}$ and $14.4 \mathrm{ppm}$ for SDh. 


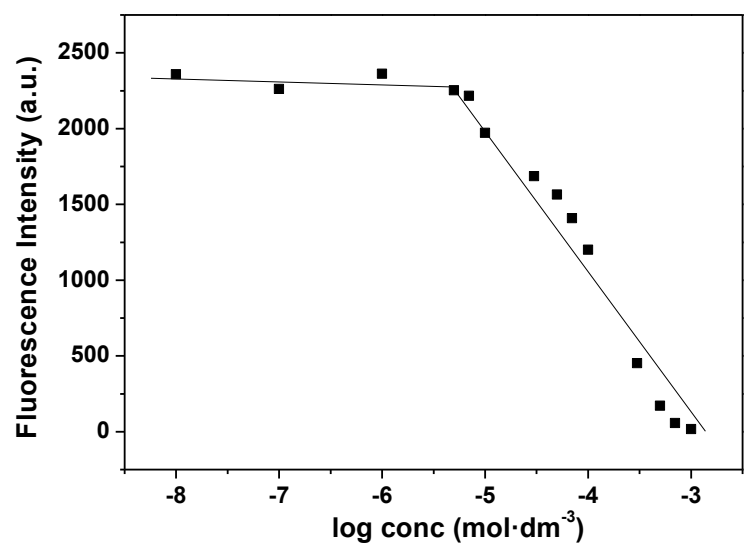

Figure 6. Calibration curve of acetonitrile suspensions of solid SDh upon the addition of increasing quantities of PA.

Complementary studies on explosive desorption from the SPh material and its potential reusability was investigated. The SPh solid, which was in contact with an acetonitrile solution of PA $\left(2.0 \times 10^{-3} \mathrm{~mol} \mathrm{dm}^{-3}\right)$, was filtered and the solid material was washed with THF (150 mL), NaOH $\left(50 \mathrm{~mL}, 0.08 \mathrm{~mol} \mathrm{dm}^{-3}\right)$ and acetone $(10 \mathrm{~mL})$ and dried. $^{28}$ The solid was then suspended again and the PA adsorption/desorption cycle was repeated 5 times (Figure 7).

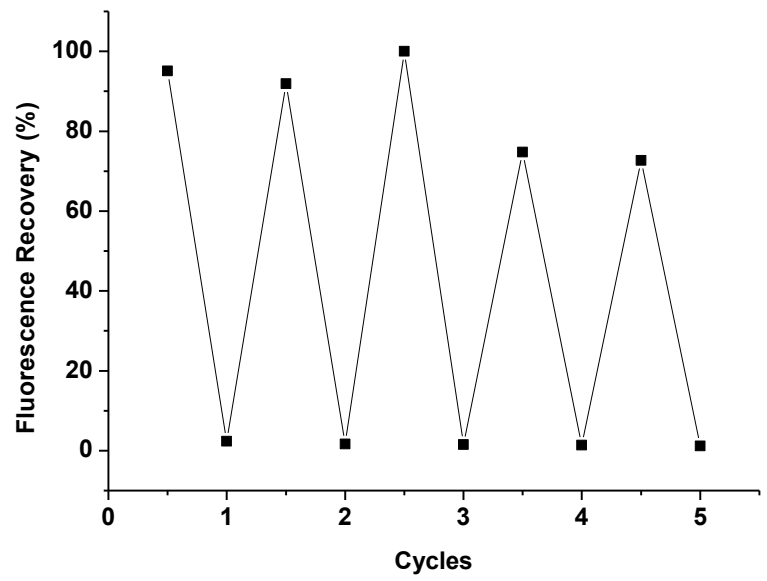

Figure 7. Fluorescence emission recovery for the SPh material upon addition of Tetryl $\left(2.0 \times 10^{-3} \mathrm{~mol}\right.$ $\mathrm{dm}^{-3}$ ) and subsequent nitroaromatic explosive removal upon washing with THF and $\mathrm{NaOH}\left(0.08 \mathrm{~mol} \mathrm{dm}^{-3}\right)$. 
The recovery results provided in Figure 7 indicates that the SPh material can be reused at least for 5 cycles with no significative loss of its recognition ability. The unique observed effect was the reduced fluorescence of the free material after several cycles (ca. $70 \%$ of the initial emission), which is most likely due to a partial hydrolysis of the grafted pyrene moiety upon $\mathrm{NaOH}$ washings.

\section{Stern-Volmer costants calculations}

In order to quantify the interaction of explosives PA and Tetryl with the grafted pyrene and dansyl fluorophores in solids SPh and SDh, the corresponding SternVolmer quenching constants were determined. Figures 8 and 9 depict the emission quenching of solids SPh and SDh upon the addition of increasing quantities of PA and Tetryl. As seen in the inset, the changes in emission intensity upon the addition of Tetryl are linear, whereas they are exponential for PA. In the latter case, the Stern-Volmer constants were calculated within the linear range.

Stern and Volmer considered the quenching process to be a bimolecular reaction which competes with the radiative process and all other molecular processes. Accordingly, an equation which can be expressed as $F_{0} / F=1+K_{d}[Q]$ (Eq. 1) can be derived. ${ }^{29}$ In the equation, $F_{0}$ and $F$ are the fluorescence intensities in the absence and the presence of a quencher at concentration (Q), and $K_{d}$ is the socalled quenching constant. Following this procedure, the Stern-Volmer quenching constants for SPh and SDh with Tetryl and PA were calculated and they are included in Table 3. The values of the obtained Stern-Volmer quenching constants indicate that PA was able to provide the strongest interaction with the pyrene or dansyl fluorophores grafted in solids SPh and SDh. This is in agreement with the more electron-deficient character of PA when compared with Tetryl. It is also noteworthy that the quenching constants measured for both solids were of the same order of magnitude as those reported for polymeric materials or molecularbased fluorescence probes in the presence of nitroaromatic explosives. ${ }^{30}$ 
Table 3. Quenching constants for solids SPh and SDh with Tetryl and PA.

\begin{tabular}{c|cccc}
\hline \multirow{3}{*}{ SPh } & Explosive & $K_{d}\left(\mathrm{M}^{-1}\right)^{a}$ & $b^{b}$ & $\mathrm{R}^{2 \mathrm{c}}$ \\
\hline \multirow{3}{*}{ SDh } & Tetryl & 1028 & 1.02 & 0.94 \\
& PA & 14189 & 1.16 & 0.95 \\
& Tetryl & 1425 & 0.99 & 0.95 \\
& PA & 14110 & 0.92 & 0.98
\end{tabular}

${ }^{a} K_{d}$, the Stern-Volmer quenching constant from Eq. $1 .{ }^{b} b$, the intercept from Eq. $1 .{ }^{c} R^{2}$, the correlation coefficient from Eq. 1.
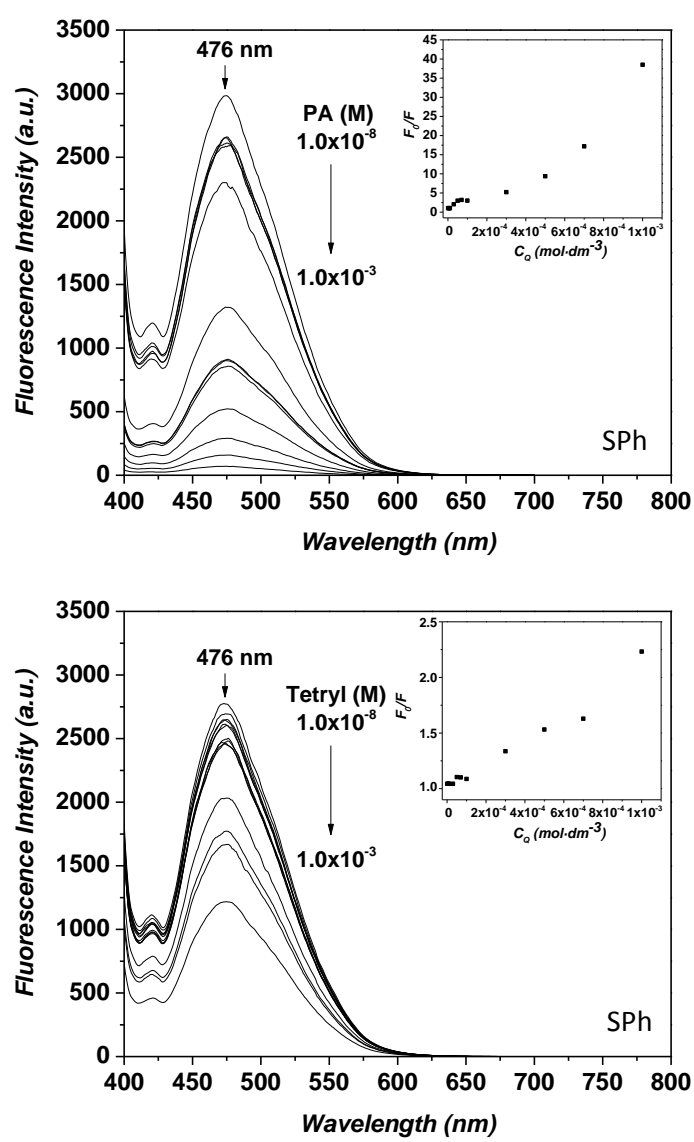

Figure 8. Emission changes of the hybrid SPh solid suspended in acetonitrile upon the addition of increasing quantities of PA and Tetryl. The inset provides a plot of $F_{0} / F$ versus $C_{Q}$, a Stern-Volmer quenching representation. 

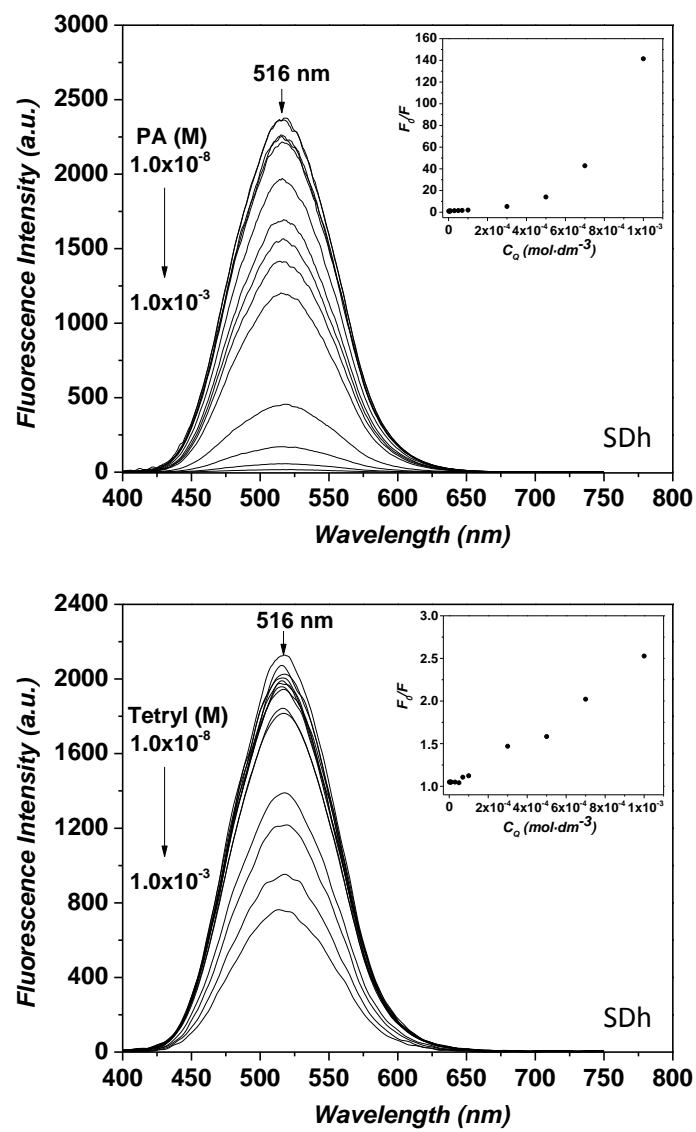

Figure 9. Emission changes of the hybrid SDh solid suspended in acetonitrile upon the addition of increasing quantities of PA and Tetryl. The inset provides a plot of $F_{0} / F$ versus $C_{Q}$, a Stern-Volmer quenching representation.

\section{PCA Studies}

The response of the six sensory materials (SP, SD, SF, SPh, SDh and SFh) toward the seven nitrated explosives tested were unselective and different quenching degrees were obtained depending on the solid and explosive used. The response of a given solid in the presence of a certain explosive therefore depends on the intrinsic chemical nature of the binding site (the fluorophore), the shape, 
size and electron-acceptor character of the explosive, the presence or not of trimethylsilyl groups, etc.

These subtle differences were reflected in the specific final quenching observed. This differential response of the solids was a well-suited prerequisite for pattern recognition. In this approach the response of solids SP, SD, SF, SPh, SDh and SFh with the set of explosives can be combined in order to search for selective pattern recognition fingerprints. This can be carried out, for instance, when the data matrix is analysed by principal component analysis (PCA) algorithms. ${ }^{31}$ The PCA score plot of the results for solids SP, SD, SF, SPh, SDh and SFh in the presence of the nitrated explosives studied was shown in Figure 10 for three different trials.

Separately of the response of the explosives a blank sample (in the absence of analite) was also included. A total of 144 measurements (i.e. 8 sampling data $\times 3$ replicates $x 6$ sensory materials) were used to generate de PCA score plot. The first principal component contained only $60.92 \%$ of the variance of the data, whereas the first three components used in the representation (see Figure 10) accounted for $80.12 \%$ of total variance. Recognition patterns can be identified clearly for all the explosives studied, even for explosives that gave a fairly small response. Moreover, a detailed look at the PCA plot suggests that there is some correlation between the position of the explosive clusters on the PC1 axis and their electron-acceptor ability. Thus, TNB, PETN, RDX, DNT and TNT appear at positive values of PC1, whereas the Tetryl and PA are placed at negative PC1 values. Additionally, when PC2 and PC3 were also taken into account a remarkable clustering of all the samples can be observed. From all the explosives studies PA was the one showing a larger distance in the score plot from the blank sample. 


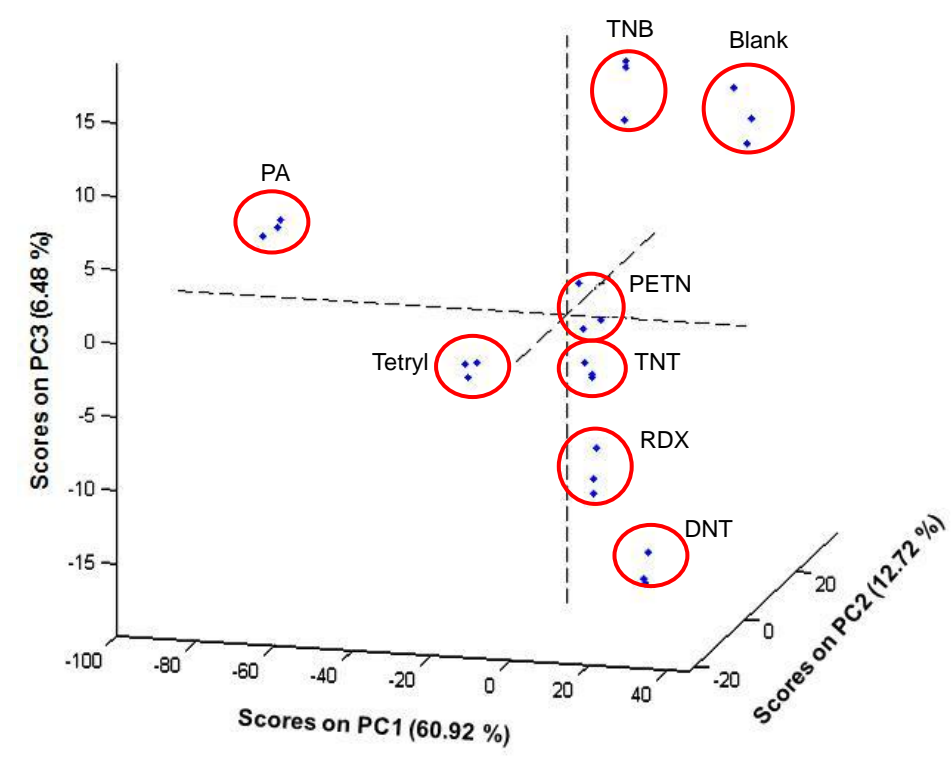

Figure 10. Principal component analysis (PCA) score plot using the data set obtained from the response of solids SP, SD, SF, SPh, SDh and SFh and diverse nitrated explosives $\left(2.0 \times 10^{-5} \mathrm{~mol} \mathrm{dm}^{-3}\right)$. Data shown from three different trials.

Signalling applications. Sensing explosives in soil samples

After studying the response of the different solids to nitrated explosives in solution, we extended our interest to the possible use of these materials to detect explosives in soil samples. It is known that the removal of obsolete explosives and munitions has not always been performed in an environmentally satisfactory manner, and even today, the analysis of trace levels of explosive contaminants in complex environmental matrices such as soils still requires the development of new easy-to-use sensing protocols. ${ }^{9}$ For this study, solid SDh as support and Tetryl as a representative explosive were selected. Based on the research described above, the detection of an explosive can be achieved by simply extracting the explosive from a contaminated soil sample with acetonitrile, by the addition of 
the SDh sensing support and by taking additional emission intensity measurements. In one particular experiment, $10 \mathrm{~g}$ of soil were spiked with a known amount of Tetryl (28.71 ppm) and the dopant was extracted simply with acetonitrile $(3 \times 15 \mathrm{~mL})$. Then the obtained extract was dried in a rotary evaporator, the crude was dissolved in $10 \mathrm{~mL}$ of acetonitrile and the SDh sensing material was added. After 1 min., emission was measured upon exciting at 347 $\mathrm{nm}$. Further addition of Tetryl allowed the detection of Tetryl in the soil sample following a standard addition method. The results obtained are shown in Figure 11, which depicts the fluorescence response of the SDh-Tetryl system in terms of Tetryl concentration after extraction with acetonitrile. This simple procedure determined a concentration of Tetryl of 23.58 ppm ( $82 \%$ of recovery).

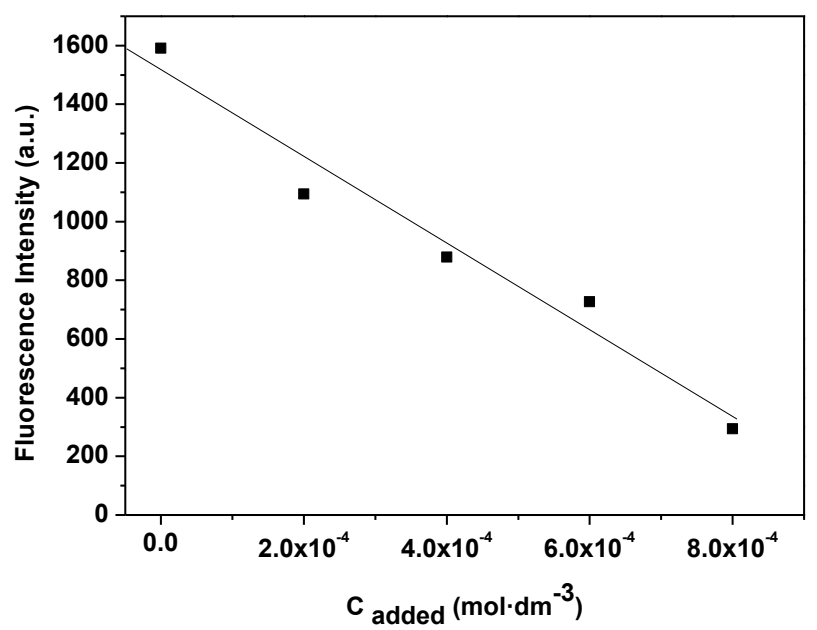

Figure 11. Fluorescence intensity at $516 \mathrm{~nm}\left(\lambda_{\text {exc }}=347 \mathrm{~nm}\right)$ in acetonitrile suspensions containing SDh and Tetryl for a solution obtained from a soil sample. Increasing concentrations of Tetryl were added to the former solution in order to detect the Tetryl concentration in soil following an addition standard procedure.

\section{Conclusions}

Six new fluorescent organic-inorganic hybrid MCM-41-type materials were prepared, characterised and used for the detection of nitroaromatic explosives. 
The grafted fluorophores employed were pyrene, dansyl and fluorescein. Moreover, the polarity of inner pores was modulated through the formation of silyl ether moieties. Of the six materials, three were hydrophilic (SP, SD and SF) and the rest were hydrophobic (SPh, SDh and SFh). Addition of nitroaromatic explosives induced several degrees of quenching, and the most remarkable were those obtained with the hydrophobic SPh and SDh materials. The quenching observed clearly related with the electron acceptor character of the nitroaromatic explosives, with the most important emission change obtained upon addition of PA and Tetryl. These emission modulations were ascribed to the $\pi-\pi$ stacking interaction between the electron-rich fluorophores and the electron-deficient nitroaromatic explosives. Materials SPh and SDh presented fairly good sensitivities to PA and Tetryl with limits of detection of $1.4 \mathrm{ppm}$ and $8.5 \mathrm{ppm}$ (for SPh) and of $1.2 \mathrm{ppm}$ and $14.4 \mathrm{ppm}$ (for SDh), respectively. It is demonstrated that solid SPh can be reused for at least 5 cycles with no significant loss of its recognition ability. The sensing performances (selectivity, limits of detection and quenching constans) of the hydrophobic SPh and SDh solids are similar to those measured for other fluorescent materials (see comparative table in Supporting Information). Moreover, solid SDh was used to detect trace amounts of Tetryl explosives from contaminated soil, which might open up the way for promising applications in detection and remediation in real samples.

\section{Experimental}

\section{Methods}

Powder XRD, Thermogravimetric analyses (TGA), TEM images and $\mathrm{N}_{2}$ adsorption/desorption studies were employed to characterise synthesised materials. Fluorescence spectroscopy was used for kinetic and quenching studies of the materials after interactions with different explosives. Powder X-ray diffraction measurements were taken in a Bruker D8 Advance diffractometer using $\mathrm{Cu} \mathrm{K}_{\alpha}$ radiation. The thermo-gravimetric analyses were carried out on a 
TGA/SDTA 851e Mettler Toledo balance using an oxidant atmosphere (air, 80 $\mathrm{mL} / \mathrm{min}$ ) with a heating programme consisting of a ramp of $10^{\circ} \mathrm{C} / \mathrm{min}$ from $20^{\circ} \mathrm{C}$ to $1000{ }^{\circ} \mathrm{C}$, and an isothermal heating step at this temperature for $30 \mathrm{~min} . \mathrm{N}_{2}$ adsorption/desorption isotherms were recorded with a Micromeritics ASAP2010 automated sorption analyser. Samples were degassed at $120{ }^{\circ} \mathrm{C}$ in vacuum overnight. Specific surface areas were calculated from the adsorption data in the low pressures range using the BET model. Pore size was determined following the BJH method. Fluorescence spectroscopy was carried out with a JASCO FP-8500 spectrofluorometer. TEM images were obtained with a 100 kV Philips CM10 microscope. ${ }^{1} \mathrm{H}$ nuclear magnetic resonance (NMR) was acquired with a Varian 300 spectrometer (Sunnyvale, CA, USA).

\section{Chemicals}

Chemicals 1-pyrenemethylamine hydrochloride $(\mathbf{1} \cdot \mathrm{HCl})$, isocyanatopropyl)triethoxysilane (2), (3-aminopropyl)triethoxysilane (3), dansyl chloride (4), fluorescein isothiocyanate (5), tetraethylorthosilicate (TEOS), $n$ cetyltrimethylammonium bromide (CTAB), sodium hydroxide, triethanolamine $\left(\mathrm{TEAH}_{3}\right)$, triethylamine, sodium sulphate, ammonium nitrate, 1,1,1,3,3,3hexamethyldisilazane (HMDS), 2,4-dinitrotoluene (DNT), nitrobenzene (NB) and picric acid (PA) were provided by Sigma-Aldrich and used as received. The $3 \%$ solution in acetonitrile of the subsequently nitrated explosives 2,4,6trinitrophenylmethylnitramine (Tetryl), 2,4,6-trinitrotoluene (TNT), hexahydro1,3,5-trinitro-1,3,5-triazine (RDX), pentaerythritol tetranitrate (PETN) and 1,3,5trinitrobenzene (TNB) were purchased from SelectLab Chemicals. Analytical-grade solvents were acquired from Scharlab (Barcelona, Spain). All the reagents were used as received. Caution! Explosives should be used with extreme caution and handled only in small quantities. 
Extraction of 1-pyrenemethylamine (1)

1-pyrenemethylamine hydrochloride $(\mathbf{1} \cdot \mathrm{HCl}, 500 \mathrm{mg}, 1.86 \mathrm{mmol})$ was dissolved in basic water $(\mathrm{pH}>10)$ and then extracted with diethyl ether. The ether layer was then dried with $\mathrm{Na}_{2} \mathrm{SO}_{4}$ and filtered. The solvent was removed by rotary evaporation and finally dried under vacuum. The final compound was obtained as a yellow solid.

Synthesis of $\boldsymbol{P}$

$1(500 \mathrm{mg}, 2.16 \mathrm{mmol})$ and $2(536 \mu \mathrm{L}, 2.16 \mathrm{mmol})$ were reacted in anhydrous acetonitrile $(60 \mathrm{~mL})$ at room temperature in an inert atmosphere for $24 \mathrm{~h}$. Triethylamine ( 3 drops) was used to catalyse the reaction. The final yellow solid $(\mathbf{P}, 806 \mathrm{mg}, 1.68 \mathrm{mmol}, 77 \%)$ was obtained by evaporating the solvent and then drying with a vacuum pump for $1 \mathrm{~h} .{ }^{1} \mathrm{H}$ NMR (400 Mhz, DMSO): $\delta=0.53(\mathrm{t}, 2 \mathrm{H}, J=$ $7.0 \mathrm{~Hz}, \mathrm{Si}-\mathrm{CH}_{2}-\mathrm{CH}_{2}$ ), 1.09 (t, 9H, J=7.0 Hz, $\mathrm{CH}_{3}-\mathrm{CH}_{2}-\mathrm{O}$ ), 1.44 (q, $2 \mathrm{H}, J=7.0 \mathrm{~Hz}$, Si$\mathrm{CH}_{2}-\mathrm{CH}_{2}$ ), $3.03\left(\mathrm{~m}, 2 \mathrm{H}, \mathrm{CH}_{2}-\mathrm{NH}-\mathrm{CO}\right), 3.72$ (q, $\left.6 \mathrm{H}, \mathrm{J}=7.0 \mathrm{~Hz}, \mathrm{CH}_{3}-\mathrm{CH}_{2}-\mathrm{O}\right), 4.95$ (d, $2 \mathrm{H}$, $\left.J=5.5 \mathrm{~Hz}, \mathrm{Pyr}-\mathrm{CH}_{2}-\mathrm{N}\right), 5.98(\mathrm{t}, 1 \mathrm{H}, J=5.5 \mathrm{~Hz}, \mathrm{NH}-\mathrm{CO}-\mathrm{NH}), 6.47(\mathrm{t}, 1 \mathrm{H}, J=5.5 \mathrm{~Hz}$, NH-CO-NH), 8.10-8.40 ppm (m, 9H, Pyr). HRMS (ESI): $m / z$ for $\mathrm{C}_{27} \mathrm{H}_{34} \mathrm{~N}_{2} \mathrm{O}_{4} \mathrm{Si}$; calcd 478.2288, found $479.2343\left[\mathrm{M}^{+} \mathrm{H}^{+}\right]$.

Synthesis of $\boldsymbol{D}$

$3(575 \mu \mathrm{L}, 2.45 \mathrm{mmol}), 4(1 \mathrm{~g}, 3.71 \mathrm{mmol})$, and triethylamine $(516 \mu \mathrm{L}, 3.69$ $\mathrm{mmol})$ were refluxed for $2 \mathrm{~h}$ in dry dichloromethane under inert atmosphere. After the reaction was completed, the solvent was evaporated by rotary evaporation and then dried with a vacuum pump. The final product (D, $1.25 \mathrm{~g}$, $2.83 \mathrm{mmol}, 77 \%$ ) was obtained as an orange oil. ${ }^{1} \mathrm{H}$ and ${ }^{13} \mathrm{C}$ NMR data are fully coincident with those reported in the literature. ${ }^{21 a}$ 
Synthesis of $\boldsymbol{F}$

5 (500 mg, $1.28 \mathrm{mmol}$ ) and $3(299 \mu \mathrm{L}, 1.28 \mathrm{mmol})$ were reacted in anhydrous ethanol under dark conditions for $4 \mathrm{~h}$. An orange yellow product $(\mathbf{F}, 801 \mathrm{mg}, 1.31$ mmol, $98 \%$ ) was obtained after evaporating the solvent and with subsequent drying under vacuum. ${ }^{1} \mathrm{H}$ and ${ }^{13} \mathrm{C}$ NMR data are fully coincident with those reported in the literature. ${ }^{21 b}$

Synthesis of $\mathbf{S P}$

The synthetic strategy for preparing hybrid MCM41-type materials was an application of the "atrane" route with a minor experimental modification. Here TEOS and $\mathbf{P}$ were used (99:1 TEOS-P ratio) instead of only TEOS. The molar ratio of the reagents in the mother liquour was fixed at 3.5 TEAH $\mathrm{TH}_{3}: 1$ silica source (TEOS-P 99:1): 0.26 CTAB: $0.25 \mathrm{NaOH}: 4.45 \mathrm{H}_{2} \mathrm{O}$. In a typical synthesis, CTAB (4.67 g, 12.81 mmol) was added at $118{ }^{\circ} \mathrm{C}$ to a $\mathrm{TEAH}_{3}$ solution ( $25.76 \mathrm{~g}, 173 \mathrm{mmol}$ ) containing $\mathrm{NaOH}(0.48 \mathrm{~g}, 12 \mathrm{mmol})$ and a silatrane derivative $(10.89 \mathrm{~mL}, 48.77 \mathrm{mmol}$ of TEOS and $0.24 \mathrm{~g}, 0.5 \mathrm{mmol}$ of $\mathbf{P}$ ) was added to $\mathrm{TEAH}_{3}$ at $70{ }^{\circ} \mathrm{C}$; e.g., in the form of $\mathrm{Si}(\mathrm{TEA})\left(\mathrm{TEAH}_{2}\right)$, where TEA was the fully deprotonated ligand. Then deionised water $\left(80 \mathrm{~mL}\right.$ ) was added with vigorous stirring at $70^{\circ} \mathrm{C}$. After some minutes, a yellowish suspension was obtained. This mixture was aged at room temperature for $2 \mathrm{~h}$ and was finally autoclaved at $100{ }^{\circ} \mathrm{C}$ for $36 \mathrm{~h}$. The resulting as-made powder (MP) was collected by filtration and repeatedly washed with water until the filtrate reached $\mathrm{pH} \mathrm{6-7,} \mathrm{and} \mathrm{the} \mathrm{solid} \mathrm{was} \mathrm{dried} \mathrm{at} 70^{\circ} \mathrm{C}$. Then the structure directing agent (CTAB) was removed using ethanolic solutions of ammonium nitrate. Typically, MP (1 g) was exchanged by stirring with $\mathrm{NH}_{4} \mathrm{NO}_{3}(0.3 \mathrm{~g})$ in ethanol $(150 \mathrm{~mL})$ at $60^{\circ} \mathrm{C}$ for $15 \mathrm{~min}$. Then it was filtered and repeatedly washed with cold ethanol and finally dried in an oven at $40^{\circ} \mathrm{C}$ for $12 \mathrm{~h}$. Finally, solid SP was obtained by repeating this exchange procedure 4 times. 
Syntheis of SD

The synthetic procedure was the same used for the preparation of solid SP. The only difference relies with the use of $\mathbf{D}$ as silica source. SD was obtained after the removal of surfactant from the as-synthesised material (MD) following the same procedure used for SP.

\section{Synthesis of SF}

The synthetic procedure was the same as that used to prepare solid SP. The only difference lies in using $\mathbf{F}$ as a silica source. SF was obtained after removing the surfactant from the as-synthesised material (MF) following the same procedure used for SP.

\section{Synthesis of SPh, SDh and SFh}

Template-free hybrid material (SP, SD, SF, $0.6 \mathrm{~g}$ ) was suspended in anhydrous toluene $(30 \mathrm{~mL})$ and heated at $110^{\circ} \mathrm{C}$ in a Dean-Stark apparatus to remove the adsorbed water by azeotropic distillation in an inert atmosphere. After collecting $10 \mathrm{~mL}$ of the azeotropic mixture, excess 1,1,1,3,3,3-hexamethyldisilazane (2.62 $\mathrm{mL}, 12.4 \mathrm{mmol}$ ) was added and the mixture was stirred at room temperature for $24 \mathrm{~h}$. Finally, hydrophobic solids (0.61 g) (SPh, SDh and SFh) were obtained after filtration, and washing was repeated with toluene, acetone to be then dried with a vacuum pump.

\section{Fluorescence quenching studies}

In a typical experiment, $1 \mathrm{mg}$ of the corresponding solid was added to $3 \mathrm{~mL}$ of acetonitrile. The solution was stirred for $1 \mathrm{~min}$ and the fluorescence of the mixture was measured. For the explosives, the same procedure was followed, but using $3 \mathrm{~mL}$ of the acetonitrile solutions of the different explosives at a 
concentration of $2.0 \times 10^{-3} \mathrm{~mol} \mathrm{dm}^{-3}$. In this quenching study, the excitation and emission maxima of SP and $\mathbf{S P h}\left(\lambda_{\mathrm{ex}}=341 \mathrm{~nm}, \lambda_{\mathrm{em}}=476 \mathrm{~nm}\right), \mathbf{S D}$ and $\mathbf{S D h}\left(\lambda_{\mathrm{ex}}=347\right.$ $\left.\mathrm{nm}, \lambda_{\mathrm{em}}=516 \mathrm{~nm}\right)$, and $\mathbf{S F}$ and $\mathbf{S F h}\left(\lambda_{\mathrm{ex}}=493 \mathrm{~nm}, \lambda_{\mathrm{em}}=525 \mathrm{~nm}\right)$ were measured in the dispersed state.

\section{Soil extraction experiment}

$10 \mathrm{~g}$ of finely ground homogeneous soil sample was doped with a known concentration of Tetryl $\left(10 \mathrm{~mL}\right.$ of concentration $\left.1.0 \times 10^{-4} \mathrm{~mol} \cdot \mathrm{dm}^{-3}\right)$. After $3 \mathrm{~h}$ of stirring, this dopant was extracted with acetonitrile $(3 \times 15 \mathrm{~mL})$. Then the obtained extract was dried in a rotary evaporator until the solvent was eliminated. The crude extract was dissolved in $10 \mathrm{~mL}$ of acetonitrile. Five different samples $(2 \mathrm{~mL}$ of crude extract) were prepared, increasing volumes of standard Tetryl solution $\left(0,1,2,3\right.$ and $4 \mathrm{~mL}$ of conc. $2.0 \times 10^{-4} \mathrm{~mol} \cdot \mathrm{L}^{-1}$ throughout) with acetonitrile were added in five different samples, and the final volume of each sample was adjusted to $10 \mathrm{~mL}$ by adding acetonitrile. Finally, $3 \mathrm{~mL}$ of each sample solution were added to $1 \mathrm{mg}$ of SDh, stirred for $1 \mathrm{~min}$, and the fluorescent emission was measured by exciting at $347 \mathrm{~nm}$.

\section{Acknowledgements}

Financial support from the Spanish Government (Project MAT2012-38429-C0401) and the Generalitat Valencia (Project PROMETEO/2009/016) is gratefully acknowledged. Y.S. is grateful to the Spanish Ministry of Science and Innovation for her grant. I.C is also grateful to the Universidad Politécnica de Valencia for her grant.

Keywords: Fluorogenic recognition · fluorophores · hybrid materials · mesoporous materials $\cdot$ nitroaromatic explosives. 


\section{References}

1. a) S. Singh, J. Hazard. Mater. 2007, 144, 15-28; b) D. S. Moore, Rev. Sci. Instrum. 2004, 75, 24992512.

2. a) J. S. Yang, T. M. Swager, J. Am. Chem. Soc. 1998, 120, 11864-11873; b) T. F. Jenkins, D. C. Leggett, P. H. Miyares, M. E. Walsh, T. A. Ranney, J. H. Cragin, V. George, Talanta 2001, 54, 501513.

3. a) J. M. V. Emon, V. López-Avila, Anal. Chem. 1992, 64, 78A-88A; b) M. Alstein, A. Bronshtein, B. Glattstein, A. Zeichner, T. Tamiri, J. Almong, Anal. Chem. 2001, 73, 2461-2467; c) D. R. Shankaran, K. Matsumoto, K. Toko, N. Miura, Sens. Actuators B 2004, 100, 450-454.

4. M. E. Walsh, Talanta 2001, 54, 427-438.

5. K. Hakansson, R. V. Coorey, R. A. Zubarev, V. L. Talrose, P. Hakansson, J. Mass. Spectrom. 2000, 35, 337-346.

6. a) E. Walis, T, M, Griffin, N. Popkie Jr., M. A. Eagan, R. F. McAtee, D. Vrazel, J. McKinly, Proc. SPIE-Int. Soc. Opt. Eng. 2005, 5795, 54-64; b) G. A. Eiceman, J. A. Stone, Anal. Chem. 2004, 76, 390A-397A.

7. M. Krausa, K. Schrob, J. Electroanal. Chem. 1999, 461, 10-13.

8. a) K. J. Albert, D. R. Walt, Anal. Chem. 2000, 72, 1947-1955; b) J. M. Conder, T. W. P. La, G. R. Lotufo, J. A. Steevens, Environ. Sci. Technol. 2003, 37, 1625-1632.

9. M. E. Germain, M. J. Knapp, Chem. Soc. Rev. 2009, 38, 2543-2555.

10. a) M. E. Moragues, R. Martínez-Máñez, F. Sancenón, Chem. Soc. Rev., 2011, 40, 2593-2643; b) Z. Xu, X. Chen, H. N. Kim, J. Yoon, Chem. Soc. Rev., 2010, 39, 127-137; c) R. Martínez-Máñez, F. Sancenón, M. Hecht, M. Biyical, K. Rurack, Anal. Bioanal. Chem., 2011, 399, 55-74.

11. Y. Salinas, R. Martínez-Máñez, M. D. Marcos, F. Sancenón, A. M. Costero, M. Parra, S. Gil, Chem. Soc. Rev., 2012, 41, 1261-1296.

12. a) J. S. Park, F. Le Derf, C. M: Bejger, V. M. Lynch, J. L. Sessler, K. A. Nielsen, C. Johnsen, J. O. Jeppesen, Chem. Eur. J., 2010, 16, 848-854; b) M. S. Meaney, V. L. McGuffin, Anal. Chim. Acta., 2008, 610, 57-67; c) A. D. Hughes, I. C. Glenn, A. D. Patrick, A. Ellington, E. V. Ansyln, Chem. Eur. J., 2008, 14, 1822-1827.

13. S. J. Toal, W. C. Trogler, J. Mater. Chem., 2006, 16, 2871-2883.

14. a) M. E. Germain, T. R. Vargo, P. G. Khalifah, M. J. Knapp, Inorg. Chem., 2007, 46, 4422-4429; b) T. L. Andrew, T. M. Swager, J. Am. Chem. Soc., 2007, 129, 7254-7255.

15. S. W. Thomas III, G. D. Joly, T. M. Swager, Chem. Rev., 2007, 107, 1339-1386.

16. a) A. Lan, K. Li, H. Wu, D. H. Olson, T. J. Emge, W. Ki, M. Hong, J. Li, Angew. Chem. Int. Ed., 2009, 48, 2334-2338; b) J. Yang, S. Aschemeyer, H. P. Martinez, W. C. Trogler, Chem. Commun., 2010, 46, 6804-6806; c) J. Geng, P. Liu, B. Liu, G. Guan, Z. Zhang, M. -Y. Han, Chem. Eur. J., 2010, 16, 3720-3727; d) L. Feng, H. Li, Y. Qu, C. Lü, Chem. Commun., 2012, 48, 4633-4635. 
17. a) C. Coll, A. Bernardos, R. Martínez-Máñez, F. Sancenón, Acc. Chem. Res., 2013, 46, 339-349, b) Z. Li, J. C. Barnes, A. Bosoy, J. F. Stoddart, J. I. Zink, Chem. Soc. Rev., 2012, 41, 2590-2605; c) F. Tang, L. Li, D. Chen, Adv. Mater., 2012, 24, 1504-1534; d) K. Ariga, A. Vinu, Y. Yamauchi, Q. Ji, J. P. Hill, Bull. Chem. Soc. Jpn., 2012, 85, 1-32.

18. a) E. Climent, M. D. Marcos, R. Martínez-Máñez, F. Sancenón, J. Soto, K. Rurack, P. Amorós, Angew. Chem. Int. Ed., 2009, 48, 8519-8522; b) R. Casasus, E. Aznar, M. D. Marcos, R. MartínezMáñez, F. Sancenón, J. Soto, P. Amorós, Angew. Chem. Int. Ed., 2006, 45, 6661-6664; c) C. Coll, E. Aznar, R. Martínez-Máñez, M. D. Marcos, F. Sancenón, J. Soto, P. Amorós, J. Cano, E. Ruiz, Chem. Eur. J., 2010, 16, 10048-10061; d) E. Aznar, C. Coll, M. D. Marcos, R. Martínez-Máñez, F. Sancenón, J. Soto, P. Amorós, J. Cano, E. Ruiz, Chem. Eur. J. 2009, 15, 6877-6888; e) I. Candel, A. Bernardos, E. Climent, M. D. Marcos, R. Martínez-Máñez, F. Sancenón, J. Soto, A. M. Costero, S. Gil, M. Parra, Chem. Commun., 2011, 47, 8313-8315.

19. a) Y. Salinas, E. Climent, R. Martínez-Máñez, F. Sancenón, M. D. Marcos, J. Soto, A. M. Costero, S. Gil, M. Parra, A. Pérez de Diego, Chem. Commun., 2011, 47, 11885-11887; b) Y. Salinas, A. Agostini, E. Pérez-Esteve, R. Martínez-Máñez, F. Sancenón, M. D. Marcos, J. Soto, A. M. Costero, S. Gil, M. Parra, P. Amorós, J. Mater. Chem. A, 2013, 1, 3561-3564; c) Y. Salinas, R. MartínezMáñez, J. O. Jeppesen, L. H. Petersen, F. Sancenón, M. D. Marcos, J. Soto, C. Guillem, P. Amorós, ACS Appl. Mater. Interfaces, 2013, 5, 1538-1543.

20. a) A. P. Wight, M. E. Davis, Chem. Rev., 2002, 102, 3589-3614; b) G. Kickelbick, Angew. Chem. Int. Ed., 2004, 43, 3102-3104.

21. a) M. Montalti, L. Prodi, N. Zaccheroni, G. Falini, J. Am. Chem. Soc., 2012, 124, 13540-13546; b) M. Liong, J. Lu, M. Kovochich, T. Xia, S. G. Ruehm, A. E. Nel, F. Tamanoi, J. I. Zink, ACS Nano, 2008, 2, 889-896.

22. E. P. Barret, L. G. Joyner, P. P. Halenda, J. Am. Chem. Soc., 1951, 73, 373-380.

23. S. Brunauer, P. H. Emmet, E. Teller, J. Am. Chem. Soc., 1938, 60, 309-319.

24. A. P. de Silva, H. Q. N. Gunaratne, T. Gunnlaugsson, A. J. M. Huxley, C. P. McCoy, J. T. Rademacher, T. E. Rice, Chem. Rev. 1997, 97, 1515-1566.

25. a) K. Ariga, A. Vinu, M. Miyahara, J. P. Hill, T. Mori, J. Am. Chem. Soc., 2007, 129, 11022-11023;

b) K. Ariga, A. Vinu, Q. Ji, O. Ohmori, J. P. Hill, S. Acharya, J. Koike, S. Shiratori, Angew. Chem. Int. Ed., 2008, 47, 7254-7257; c) A.B. Descalzo, D.Jimenez, M.D. Marcos, R. Martínez-Máñez, J. Soto, J. El Haskouri, C. Guillem, D. Beltrán, P. Amorós, M.V. Borrachero. Adv. Mater, 2002, 14, 966-969; d) M. Comes, M.D. Marcos, R. Martínez-Máñez, P. Amorós, D. Beltrán, Adv. Mater., 2004, 16, 1783-1786; e) A.B. Descalzo, K. Rurack, H. Weisshoff, R. Martínez-Máñez, M.D. Marcos, P. Amorós, K. Hoffmann, J. Soto, J. Am. Chem. Soc., 2005, 127, 184-200.

26. a) J. C. Sanchez, W. C. Trogler, J. Mater. Chem., 2008, 18, 3143-3156; b) H. Sohn, R. M. Calhoun, M. J. Sailor, W. C. Trogler, Angew. Chem. Int. Ed., 2001, 40, 2104-2105; c) N. Venkatramaiah, S. Kumar, S. Patil, Chem. Commun., 2012, 48, 5007-5009; d) V. Bhalla, H. Aroa, H. Singh, M. Kumar, Dalton Trans. 2013, 42, 969-974. 
27. a) J. Akhavan, The Chemistry of explosives, Royal Society of Chemistry, Cambridge, UK, 2004; b) Y. Peng, A. -J. Zhang, M. Dong, Y. -W. Wang, Chem. Commun. 2011, 47, 4505-4507; c) V. Bhalla, A. Gupta, M. Kumar, D. S. Shankar Rao, S. Krishna Prasad, ACS Appl. Mater. Interfaces, 2013, 5, 672-679.

28. D. Li, J. Liu, R. T. K. Kwok, Z. Liang, B. Z. Tang, J. Yu, Chem. Commun., 2012, 48, 7167-7169.

29. J. Lackowicz, Principles of fluorescence spectroscopy, Plenum Press, New York, 1983.

30. a) K. -S. Focsaneanu, J. C. Scaiano, Photochem. Photobiol. Sci., 2005, 4, 817-821; b) Y. Wang, A. La, C. Brückner, Y. Lei, Chem. Commun., 2012, 48, 9903-9905; c) N. Venkatramaiah, S. Kumar, S. Patil, Chem. Eur. J., 2012, 18, 14745-14751; d) P. Anzenbacher Jr., L. Mosca, M. A. Palacios, G. V. Zyryanov, P. Koutnik, Chem. Eur. J., 2012, 18, 12712-12718.

31. J. T. Jolliffe, Principal Component Analysis, Springer, New York, 2002. 


\section{SUPPORTING INFORMATION}

\section{Organic-inorganic hybrid mesoporous materials as regenerable sensing systems for the recognition of nitroaromatic explosives}

Krishanu Sarkar ${ }^{1}$, Yolanda Salinas ${ }^{1}$, Inmaculada Campos, Ramón MartínezMáñez,* María D. Marcos, Félix Sancenón and Pedro Amorós.

${ }^{1}$ Both authors contributed equally to the work

Materials characterization
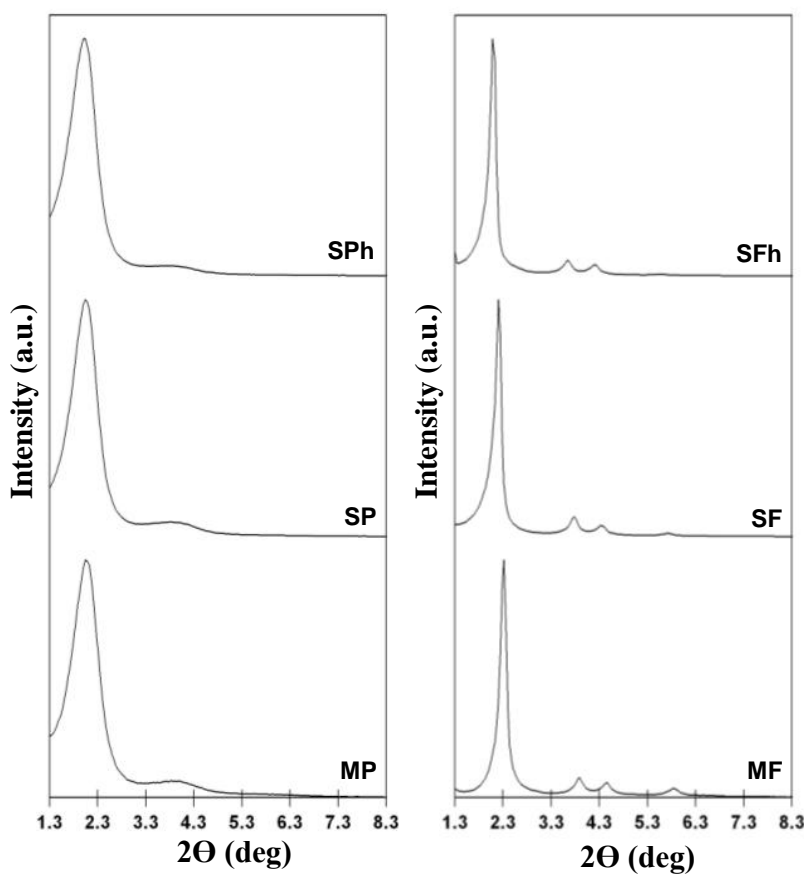

Figure SI-1. Small-angle powder XRD patterns of as synthesized (MP, MF), extracted (SP, SF) and hydrophobic (SPh, SFh) solids. 

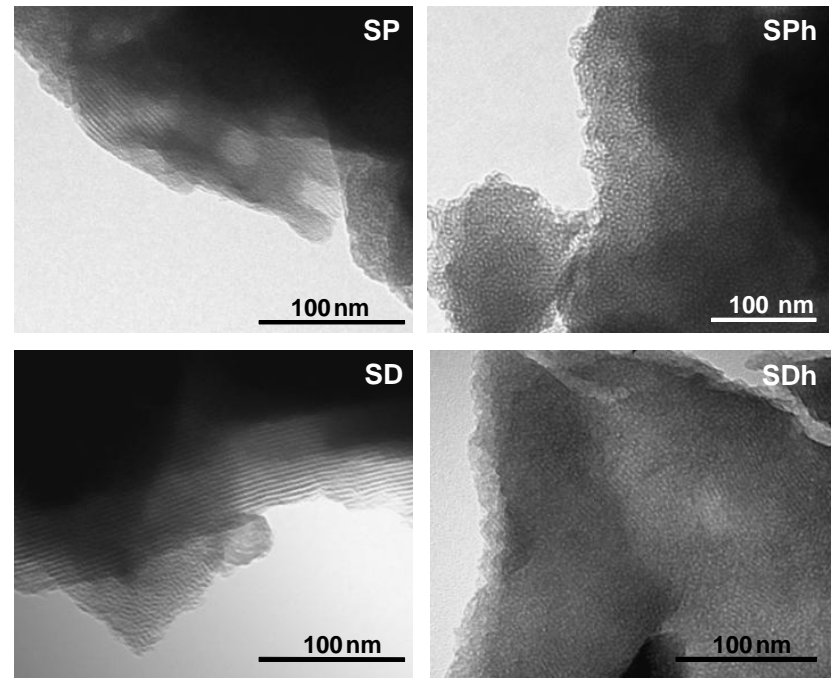

Figure SI-2. TEM images of solids SP, SD, SPh and SDh showing the typical hexagonal porosity of the MCM-41 matrix.
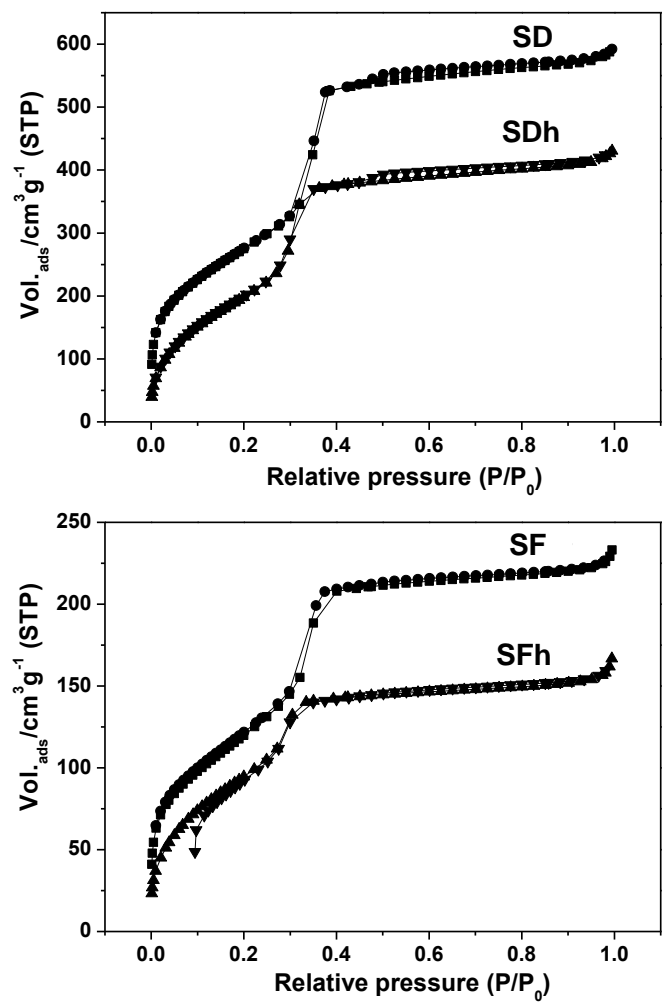

Figure SI-3. Nitrogen adsorption-desorption isotherms for solids SD, SDh, SF and SFh. 


\section{Fluorescence measurements}
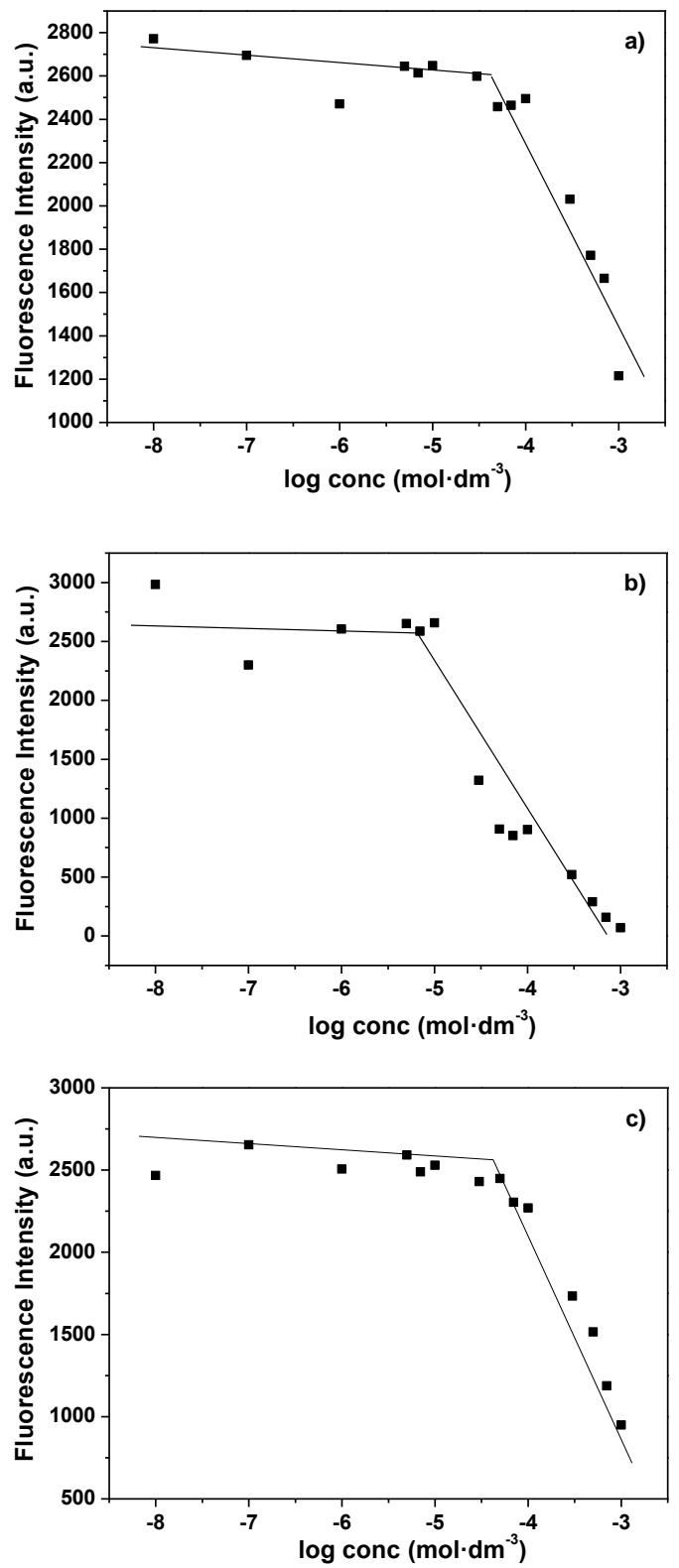

Figure SI-4. Calibration curves of acetonitrile suspensions of SPh and SDh upon addition of increasing quantities of Tetryl and PA. (a) Tetryl calibration curve for SPh, (b) PA calibration curve for SPh and (c) Tetryl calibration curve for SDh. 
Table SI-1. Hybrid materials for the fluorogenic recognition of nitrated explosives

\begin{tabular}{|c|c|c|c|c|}
\hline Sensing system & Selectivity & LOD & $\mathrm{K}_{\mathrm{sv}}\left(\mathrm{M}^{-1}\right)$ & Reference \\
\hline $\begin{array}{c}\text { Mesoporous } \\
\text { materials } \\
\text { functionalized with } \\
\text { fluorophores }\end{array}$ & $\begin{array}{c}P A \text { and Tetryl vs. } \\
D N T, T N T, N B, \\
T N B, R D X \text { and } \\
\text { PETN }\end{array}$ & $\begin{array}{c}1 \mathrm{ppm} / 4 \mu \mathrm{M} \\
(P A) \\
8 \mathrm{ppm} / 28 \mu \mathrm{M} \\
\text { (Tetryl) }\end{array}$ & $\begin{array}{c}1000 \text { (Tetryl) } \\
14000(P A)\end{array}$ & This paper \\
\hline Microporous MOF & $\begin{array}{l}\text { n.r. (studies with } \\
\text { DNT and DMNB) }\end{array}$ & n.r. & n.r. & $\begin{array}{c}\text { Angew. Chem. } \\
\text { Int. Ed., 2009, 48, } \\
2334\end{array}$ \\
\hline $\begin{array}{l}\text { Silafluorene- } \\
\text { fluorene polymer } \\
\text { attached onto } \\
\text { hollow silica } \\
\text { nanoparticles }\end{array}$ & $\begin{array}{l}\text { n.r. (studies with } \\
\text { TNT and RDX) }\end{array}$ & $\begin{array}{c}1 \text { ppm TNT } \\
0.8 \text { ppm RDX }\end{array}$ & $\begin{array}{l}2.1 \times 10^{6}(\mathrm{TNT}) \\
4.7 \times 10^{6}(\mathrm{RDX})\end{array}$ & $\begin{array}{c}\text { Chem. Commun., } \\
\text { 2010, 46, } 6804\end{array}$ \\
\hline $\begin{array}{l}\text { Silica nanoparticles } \\
\text { functionalized with } \\
\text { NBD and amines }\end{array}$ & $\begin{array}{c}\text { TNT vs. DNT and } \\
\text { NB }\end{array}$ & $1 \mu \mathrm{M}$ & n.r. & $\begin{array}{l}\text { Chem. Eur. J., } \\
\text { 2010, 16, } 3720\end{array}$ \\
\hline $\begin{array}{l}\text { Mesoporous silica } \\
\text { nanoparticles } \\
\text { functionalized with } \\
\text { amines and poly ( } p \text { - } \\
\text { phenylenevinylene) }\end{array}$ & TNT vs. DNT & $0.6 \mu \mathrm{M}$ & 74200 (TNT) & $\begin{array}{c}\text { Chem. Commun., } \\
\text { 2012, 48, } 4633\end{array}$ \\
\hline $\begin{array}{l}\text { Amine-capped } \\
{\mathrm{ZnS}-\mathrm{Mn}^{2+}}^{\text {nanocrystals }}\end{array}$ & $\begin{array}{c}\text { PA vs. TNT, DNT, } \\
\text { NB, RDX }\end{array}$ & $0.2 \mathrm{ppb}$ & $35000(\mathrm{PA})$ & $\begin{array}{l}\text { Anal. Chem., } \\
\text { 2008, } 80,3458\end{array}$ \\
\hline $\begin{array}{l}\text { Silica nanoparticles } \\
\text { functionalized with } \\
\text { amine and } \\
\text { fluorophores } \\
\text { (fluorescein and } \\
\text { rhodamine) }\end{array}$ & $\begin{array}{l}\text { TNT vs. DNT, NB } \\
\text { and RDX }\end{array}$ & $1 \mathrm{nM}$ & $\begin{array}{l}4200 \text { (TNT- } \\
\text { Rhodamine) } \\
9000 \text { (TNT- } \\
\text { Fluorescein) }\end{array}$ & $\begin{array}{c}\text { Anal. Chem., } \\
\text { 2008, 80, } 8545\end{array}$ \\
\hline Porous silicon & $\begin{array}{c}\text { n.r. (studies with } \\
\text { TNT, DNT and NB) }\end{array}$ & $1 \mathrm{ppb}$ & n.r. & $\begin{array}{l}\text { Chem. Eur. J., } \\
\text { 2000, 6, 2205 }\end{array}$ \\
\hline $\begin{array}{c}\text { Amine and dye } \\
\text { (C1609) } \\
\text { functionalized silica } \\
\text { Inverted opal }\end{array}$ & $\begin{array}{c}\text { NB vs. DNT and } \\
\text { TNT }\end{array}$ & Several ppb & n.r. & $\begin{array}{l}\text { Chem. Eur. J., } \\
\text { 2009, 15, } 11507\end{array}$ \\
\hline $\begin{array}{c}\text { CdSe quantum } \\
\text { dots }\end{array}$ & TNT, DNT, NB, NT & $0.1-1 \mu \mathrm{M}$ & n.r. & $\begin{array}{c}\text { Spectrochim. } \\
\text { Acta A, 2008, 70, } \\
247\end{array}$ \\
\hline $\begin{array}{c}\text { Ru nanoparticles } \\
\text { functionalized with } \\
\text { pyrene }\end{array}$ & TNT, DNT, NB & $\mathrm{nM}$ range & $230-64000$ & $\begin{array}{l}\text { Anal. Chem., } \\
\text { 2010, 82, } 461\end{array}$ \\
\hline
\end{tabular}




\begin{tabular}{|c|c|c|c|c|}
\hline Sensing system & Selectivity & LOD & $K_{s v}\left(M^{-1}\right)$ & Reference \\
\hline Microporous MOF & TNT, DNT, NB & n.r. & n.r. & $\begin{array}{c}\text { Chem. Commun., } \\
\text { 2011, 47, } 3153\end{array}$ \\
\hline Microporous MOF & TNT, NP, DNT, NB & n.r. & n.r. & $\begin{array}{l}\text { Chem. Commun., } \\
\text { 2011, } 47,12137\end{array}$ \\
\hline $\begin{array}{c}\text { SBA-15 } \\
\text { functionalized with } \\
\text { amines and TPE }\end{array}$ & $\begin{array}{l}\text { Only studies with } \\
\text { PA }\end{array}$ & $0.4 \mathrm{ppm}$ & 200000 & $\begin{array}{c}\text { Chem. Commun., } \\
\text { 2012, 48, } 7167\end{array}$ \\
\hline Microporous MOF & PA vs. DNT & n.r. & n.r. & $\begin{array}{l}\text { Dalton Trans., } \\
\text { 2013, 42, } 5508\end{array}$ \\
\hline $\begin{array}{c}\text { organic-inorganic } \\
\text { hybrid } \\
\text { polyphosphazene } \\
\text { microspheres }\end{array}$ & $\begin{array}{c}\text { PA vs. TNT and } \\
\text { DNT }\end{array}$ & $0.05 \mu \mathrm{g} / \mathrm{mL}$ & 38000 & $\begin{array}{c}\text { RSC Adv., 2012, } \\
\text { 2, } 3765\end{array}$ \\
\hline Microporous MOF & $\begin{array}{c}\text { NB vs. NT, DNT } \\
\text { and DMNB }\end{array}$ & n.r. & n.r. & $\begin{array}{l}\text { J. Am. Chem. } \\
\text { Soc., 2011, 133, } \\
4153\end{array}$ \\
\hline $\begin{array}{c}\text { CdTe quantum } \\
\text { dots grafted onto } \\
\text { silica nanoparticles }\end{array}$ & $\begin{array}{c}\text { TNT vs. DNT, NB } \\
\text { and RDX }\end{array}$ & $1 \mu \mathrm{M}$ & n.r. & $\begin{array}{l}\text { J. Am. Chem. } \\
\text { Soc., 2011, 133, } \\
8424\end{array}$ \\
\hline
\end{tabular}



5. Gated materials as nitroaromatic explosives probes 



\subsection{Introduction.}

As we have reported above in the general introduction, a number of mesoporous gated materials able to respond to stimuli such as light, $\mathrm{pH}$, temperature or redox reactions have been reported. In contrast, few examples of capped materials able to induce a control release in response to small molecules (anions, cations or neutral species) have been described. However, the design of such systems may be interesting for the development of new recognition protocols, and for the development of highly selective and sensitive probe systems.

The concept of using molecular gatelike hybrid ensembles for guest-sensing purposes is outlined in Figure 5.1 and involves molecular-recognition events coupled with the control of dye transport. It entails the use of solids with nanoscopic 3D organized surfaces (e.g., MCM-41 type mesoporous materials) that have been functionalized at the outer surface with certain binding sites (labeled $C$ in Figure 5.1). Additionally, the pores have been loaded with a suitable dye (depicted as yellow dots in Figure 5.1). 


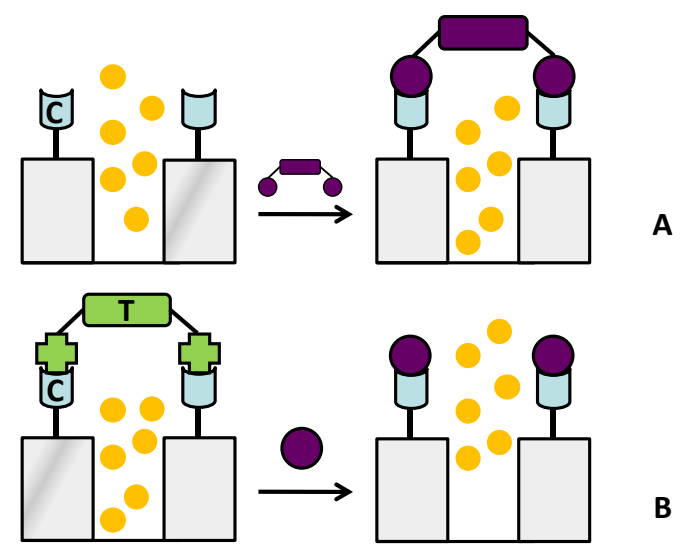

Figure 5.1. Guest recognition and signalling by using molecular gates through: A) opened-to-closed; B) closed-to-opened guest-induced protocols.

Using this functionalized hybrid system, two basic approaches can be considered: In the first case (A) there is an open gatelike system that is able to deliver the enclosed dye to the solution. The addition of a target guest, capable of forming a suitable complex with the binding site C, might "close the gate", which would lead to recognition and signaling of the target by the inhibition of the mass delivery process. In the second case (B), the binding sites are blocked with a large polydentate molecule ( $\mathrm{T})$. The interaction of $\mathrm{T}$ with $\mathrm{C}$ has to be strong enough to avoid release of the dye but not be very selective. The addition of a suitable guest able to form strong complexes with $\mathrm{C}$ (or with $\mathrm{T}$ ) will lead to the displacement of $\mathrm{T}$, the delivery of the dye to the bulk solution, and the signaling of the guest. These two situations (A and B), based on nanoscopic mass control, are reminiscent of the fluorescence enhancement/quenching or color development/bleaching observed in classical fluorogenic or chromogenic sensors. ${ }^{1}$

\footnotetext{
${ }^{1}$ a) M. E. Moragues, R. Martínez-Máñez, F. Sancenón, Chem. Soc. Rev., 2011, 40, 2593. b) L. E. Santos-Figueroa, M. E. Moragues, E. Climent, A. Agostini, R. Martínez-Máñez, F. Sancenón, Chem. Soc. Rev., 2013, 42, 3489.
} 
These new sensory materials, prepared by one of both approaches cited above, would have an important impact in new analytical applications. Of the innovative properties presented by these hybrid sensory materials, the amplification features is perhaps the most valuable. In particular, few molecules of target analyte may modulate the release/inhibition of high amounts of dye entrapped in the inner of the porous network. This would allow the preparation of sensing materials with enhanced sensitivities, when compared with the classical molecular based chromo-fluorogenic receptors (based on supramolecular concepts). Moreover, this approach has a high modular character and a large number of mesoporous supports, pore, reactive/coordination sites and loaded dyes can be selected. This variability is unconceivable in classical molecular receptors. $^{2}$

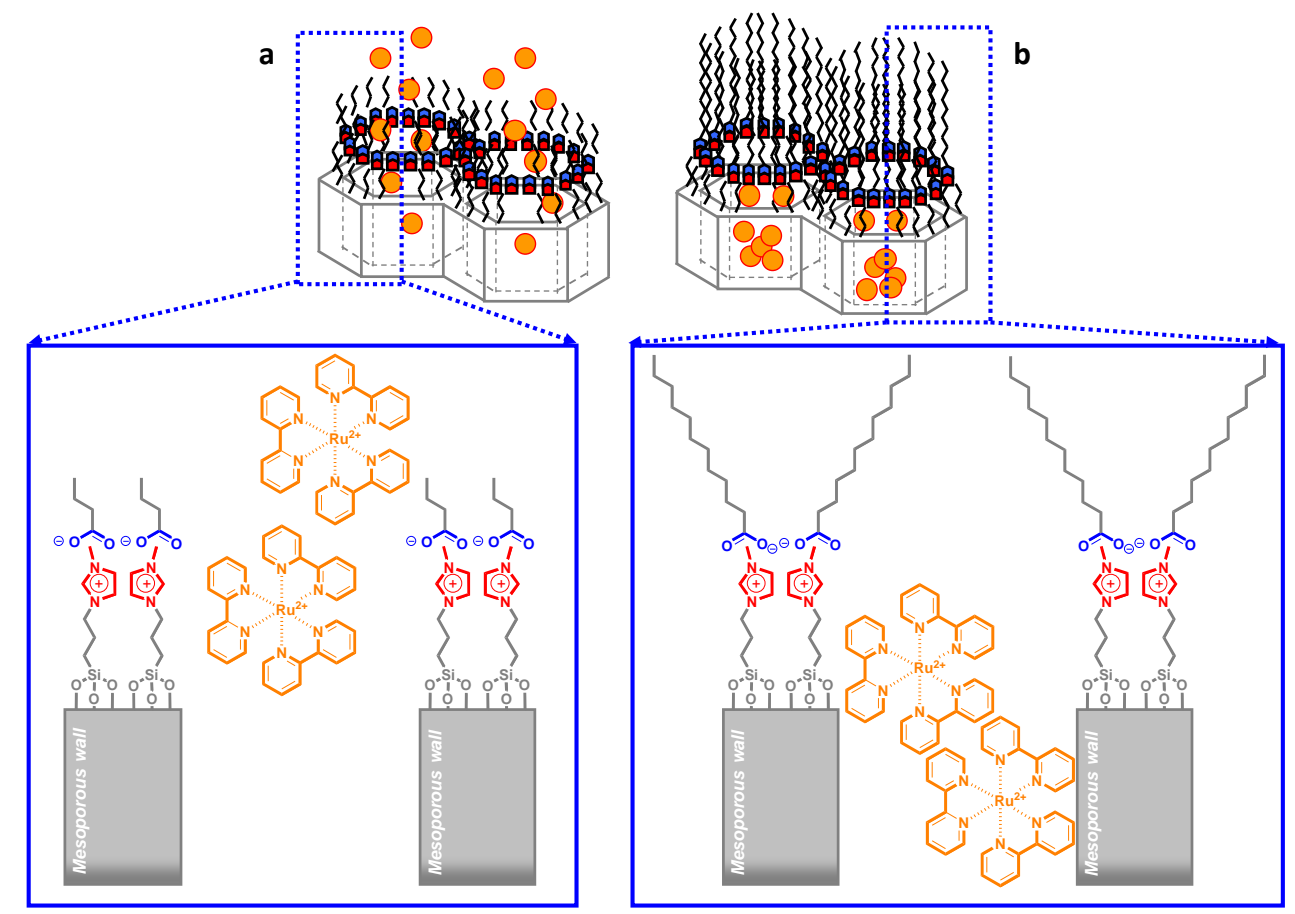

Figure 5.2. Scheme of sensing hybrid material for carboxylates detection. a) butanoate (open gate) and b) dodecanoate (closed gate).

${ }^{2}$ C. Coll, A. Bernardos, R. Martínez-Máñez, F. Sancenón, Acc. Chem. Res., 2013, 46, 339. 
Following the pore-blockage paradigm, C. Coll and coworkers designed new sensing solids for carboxylate recognition in aqueous media at neutral $\mathrm{pH}$ (see Figure 5.2). ${ }^{3}$ A mesoporous MCM-41 solid functionalized on the pores surfaces with imidazolium groups (able to form complexes with carboxylates) and loaded with a dye is used. Whereas short carboxylates (acetate, butanoate, hexanoate, and octanoate) are unable to block the pores, large-chain carboxylates (decanoate and dodecanoate) form a dense hydrophobic monolayer and hamper dye release.

A second example was design by E. Aznar and coworkers. The solid consists of a mesoporous support loaded with $\left[\mathrm{Ru}(\mathrm{bipy})_{3}\right]^{+2}$ and functionalized on the external surface with the saccharide derivative $\mathrm{N}$-(3-triethoxysilylpropyl)gluconamide. ${ }^{4}$ Dye release is observed for the aqueous suspensions of this solid (at neutral $\mathrm{pH}$ ), while an inhibited dye delivery is noted in the presence of borate anion. This inhibition is clearly related with the formation of boroester bonds with the hydroxyl moieties of the grafted saccharide (see Figure 5.3). The chromo-fluorogenic system is selective for borate detection and other tested anions (i.e., carbonate, chloride, bromide, nitrate, sulfate and phosphate) are unable to induce pore blockage. Following this approach, a detection limit as low as 70 ppb of boron can be achieved.

3 a) C. Coll, E. Aznar, R. Martínez-Máñez, M. D. Marcos, F. Sancenón, J. Soto, P. Amorós, J. Cano, E. Ruiz, Chem. Eur. J., 2010, 16, 10048. b) C. Coll, R. Casasús, E. Aznar, M. D. Marcos, R. MartínezMáñez, F. Sancenón, J. Soto, P. Amorós, Chem. Commun., 2007, 1957.

${ }^{4}$ E. Aznar, C. Coll, M. D. Marcos, R. Martínez-Máñez, F. Sancenón, J. Soto, P. Amorós, J. Cano, E. Ruíz, Chem. Eur. J., 2009, 15, 6877. 


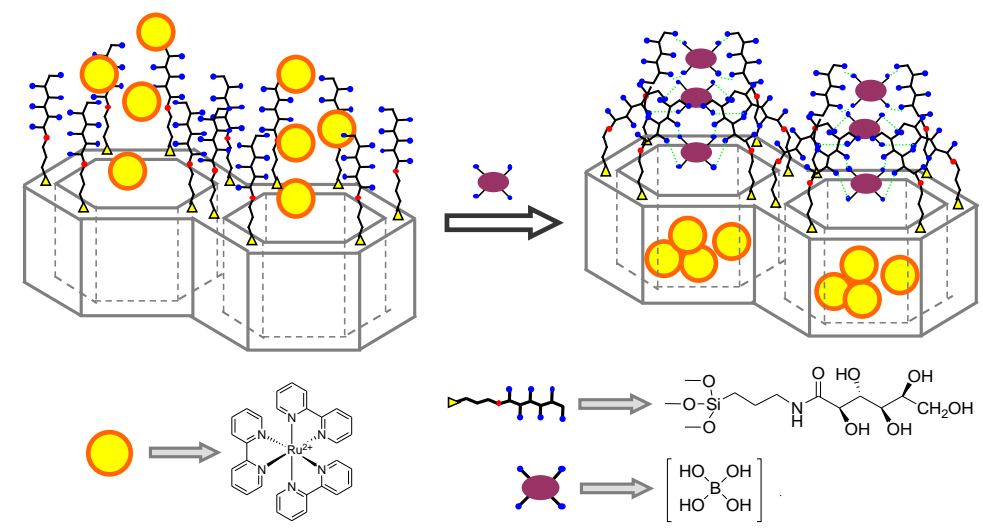

Figure 5.3. Scheme of borate control of mass transport using a nanoscopic supramolecular gate. (Reprinted and adapted with permission from E. Aznar et al., Chem. Eur. J., 2009, 15, 6877. Copyright (C) 2009 Wiley-VCH Verlag GmbH \& Co. KGaA, Weinheim).

The next example follows approach B (Figure 5.1.) and was designed for the selective detection of $\mathrm{CH}_{3} \mathrm{Hg}^{+}$. In this case, a mesoporous support is loaded with safranin $O$ dye and capped with 2,4-bis-(4-dialkylaminophenyl)-3-hydroxy-4alkylsulfanylcyclobut-2-one (APC) groups formed by the reaction of a squaraine dye with surface-grafted thiols (see Figure 5.4). ${ }^{5}$ Acetonitrile-toluene $4: 1 \mathrm{v} / \mathrm{v}$ suspensions of the hybrid material showed negligible dye release due to the fact that the pores are closed with the bulky APC groups. However, addition of $\mathrm{CH}_{3} \mathrm{Hg}^{+}$ induces the uncapping of pores with the subsequent release of entrapped safranine $\mathrm{O}$. This uncapping process derives from the reaction of $\mathrm{CH}_{3} \mathrm{Hg}^{+}$with the thiol group on APC moieties, resulting in the coordination of the cation to thiols and in the release of the squaraine chromophore. An inherent feature of such capped systems is the potential achievement of signal amplification. In this particular system, the reaction of one equivalent of $\mathrm{CH}_{3} \mathrm{Hg}^{+}$with the APC groups leads to the delivery of one squaraine and of around 200 safranine $O$ molecules.

\footnotetext{
${ }^{5}$ E. Climent, M. D. Marcos, R. Martínez-Máñez, F. Sancenón, J. Soto, K. Rurack, P. Amorós. Angew. Chem., Int. Ed., 2009, 48, 8519.
} 


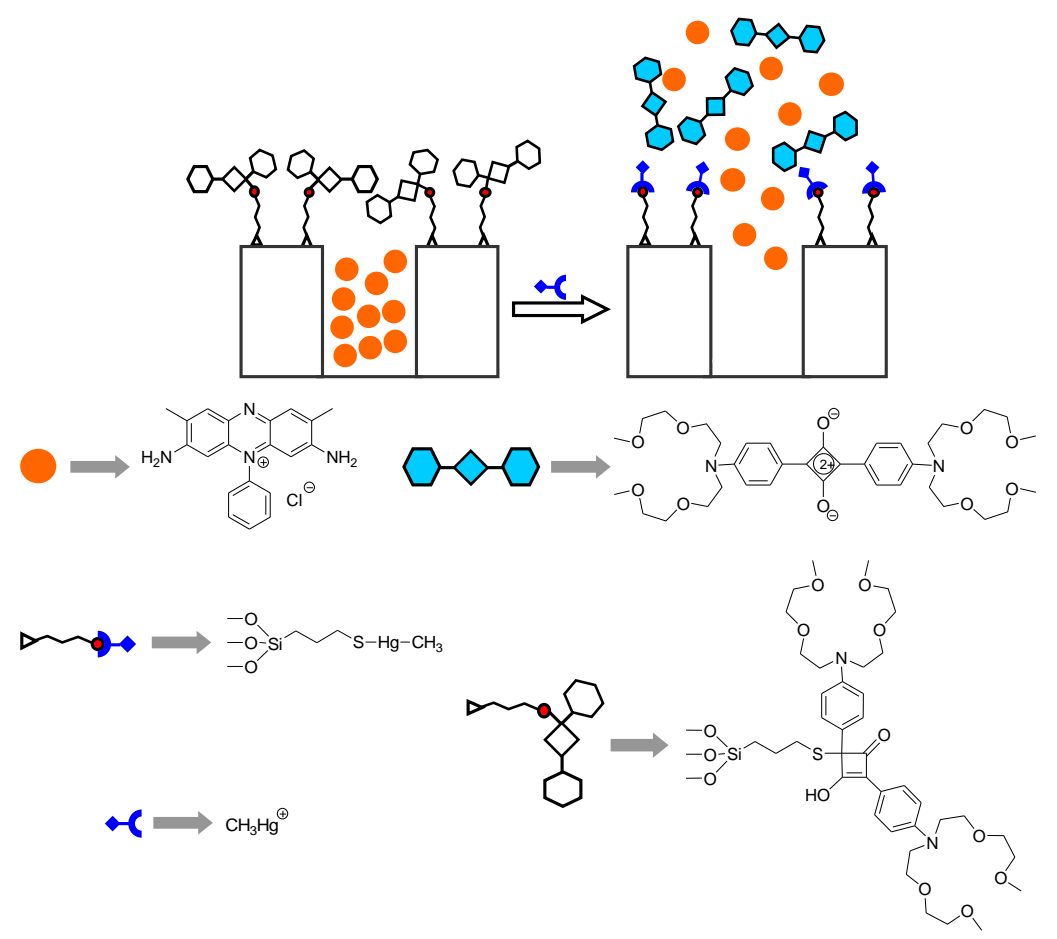

Figure 5.4. Scheme of the chromo-fluorogenic sensing of methylmercury using an uncapping protocol. (Reprinted and adapted with permission from E.Climent et al., Angew. Chem., Int. Ed., 2009, 48, 8519. Copyright (C) 2009 Wiley-VCH Verlag GmbH \& Co. KGaA, Weinheim)

In another example, E. Climent and coworkers reported a sensing material designed to detect oligonucleotides using a biomolecule as a cap. In this case, the sensing material was prepared with mesoporous nanoparticles loaded with fluorescein, functionalized on the outer surface with (3aminopropyl)triethoxysilane, and capped with the oligonucleotide sequence $5^{\prime}$ AATGCTAGCTAATCAATCGGG-3', which remains attached to the nanoparticle surface via electrostatic interactions with the partially protonated amines (see Figure 5.5). ${ }^{6}$ At pH 7.5, aqueous suspensions of the nanoparticles were opened selectively in the presence of the complementary single strand due to the

\footnotetext{
${ }^{6}$ E. Climent, R. Martínez-Máñez, F. Sancenón, M. D. Marcos, J. Soto, A. Maquieira, P. Amorós. Angew. Chem., Int. Ed., 2010, 49, 7281.
} 
hybridization of both single oligonucleotide sequences with the concomitant cargo release.

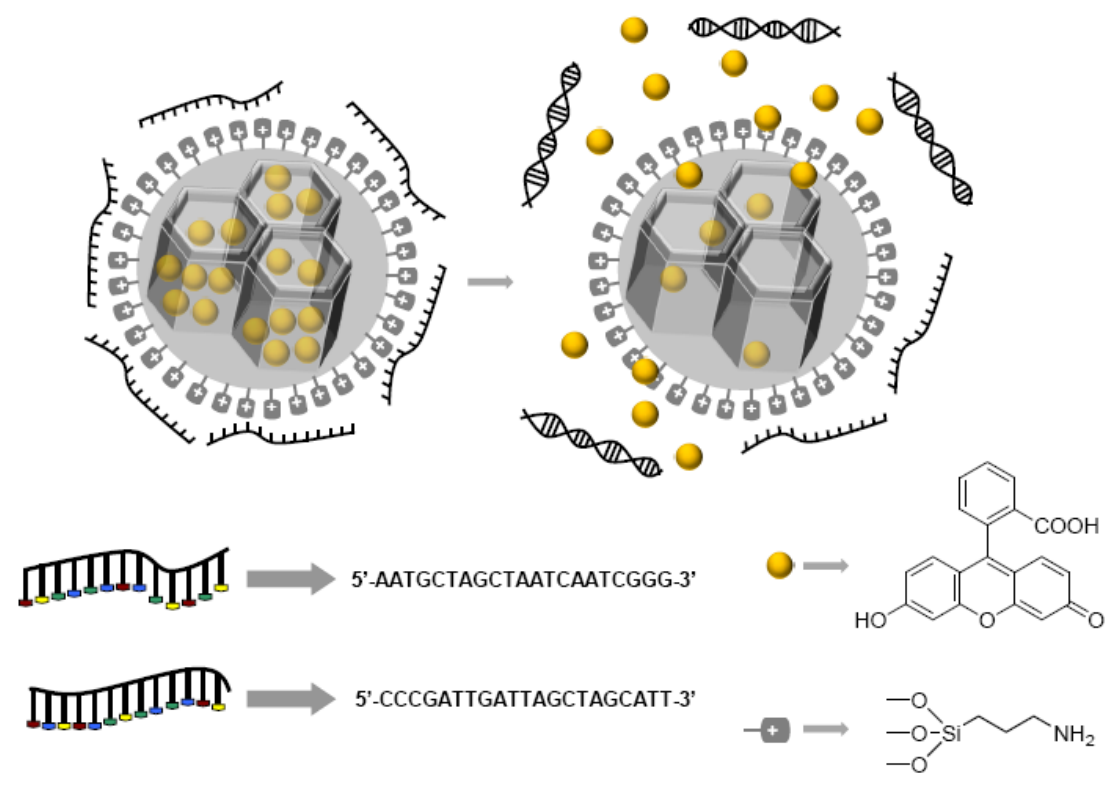

Figure 5.5. Scheme of a gated material functionalized with 3-aminopropy/triethoxysilane and capped with a single-stranded oligonucleotide. Dye delivery in the presence of the complementary oligonucleotide is produced. (Reprinted and adapted with permission from C. Coll et al., Acc. Chem. Res., 2013, 46, 339. Copyright (c) 2013 American Chemical Society).

In another example of an uncapping protocol, the pores of the mesoporous silica support are loaded with $\left[\mathrm{Ru}(\text { bipy })_{3}\right]^{2+}$, the hapten 4-(4-aminobenzenesulfonylamino)-benzoic acid derivative is anchored onto the outer surface and the pores are capped finally with a polyclonal antibody for sulfathiazole. Addition of sulfathiazole to suspensions of the capped solid in water induced the uncapping of the pores (by the selective coordination with the antibody) and release of the entrapped dye. Dye delivery is proportional to the added sulfathiazole and a remarkably low limit of detection of 100 ppb was determined. ${ }^{7}$

\footnotetext{
${ }^{7}$ E. Climent, A. Bernardos, R. Martínez-Máñez, A. Maquieira, M. D. Marcos, N. Pastor-Navarro, R. Puchades, F. Sancenón, J. Soto, P. Amorós. J. Am. Chem. Soc., 2009, 131, 14075.
} 


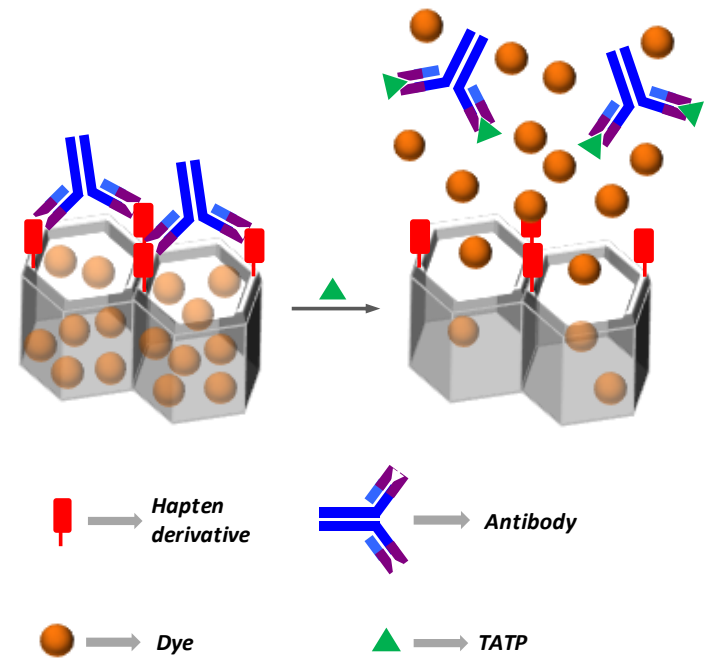

Figure 5.6. General scheme of antibody capping system for sensing of small molecules. (Reprinted and adapted with permission from C. Coll et al., Acc. Chem. Res., 2013, 46, 339. Copyright $@ 2013$ American Chemical Society).

Finally, we report an antibody capped hybrid material which was designed to detect triacetone triperoxide (TATP). ${ }^{8}$ TATP is the prototype of a small-molecule analyte which is difficult to target with supramolecular recognition chemistry because it lacks functional groups for classical noncovalent binding and is neither particularly polar nor apolar. The sensing material is prepared from mesoporous silica nanoparticles loaded with the brightly fluorescent dye sulforhodamine $B$ and functionalized on the outer surface with a suitable hapten. The approach relies on the use of a TATP-selective polyclonal antibody as cap. In the presence of TATP, the noncovalent antibody-antigen interactions dislocate the stoppers and opened the pores releasing the entrapped dye (see Figure 5.6). The solid was implemented in test-strip assays, obtaining a highly selective and sensitive response while guaranteeing fast response times.

\footnotetext{
${ }^{8}$ E. Climent, D. Groninger, M. Hecht, M. A. Walter, R. Martínez-Máñez, M. G. Weller, F. Sancenón, P. Amorós, K. Rurack. Chem. Eur. J., 2013, 19, 4117.
} 


\subsection{Objectives.}

The main goal of this chapter is the design and preparation of new capped mesoporous gated materials to the chromo-fluorogenic detection of nitroaromatic explosives.

Specifically, our aim was:

- To synthetize electron-rich molecules, such as pyrene or tetrathiafulvalene derivatives, able to interact with electron-deficient nitroaromatic explosives TNT and Tetryl, through donor-acceptor interactions.

- To anchor these electron rich molecules onto the external surface of the inorganic support (MCM-41).

- To characterize these new hybrid systems.

- To study the chromo-fluorogenic response of these materials with selected explosives.

- To use the final solids for explosive detection in soil samples. 


\subsection{Fluorogenic detection of Tetryl and TNT explosives using nanoscopic-capped mesoporous hybrid materials.}





\section{Fluorogenic detection of Tetryl and TNT}

\section{explosives using nanoscopic-capped mesoporous hybrid materials}

Yolanda Salinas, ${ }^{a, b, c}$ Alessandro Agostini, ${ }^{a, b, c}$ Édgar PérezEsteve, ${ }^{a, d}$ Ramón Martínez-Máñez, ${ }^{* a, b, c}$ Félix Sancenón, ${ }^{a, b, c}$ M. Dolores Marcos, ${ }^{a, b, c}$ Juan Soto, ${ }^{a, b}$ Ana M. Costero, *a,e Salvador Gil ${ }^{a, e}$ Margarita Parra, ${ }^{a, e}$ and Pedro Amorós ${ }^{f}$

${ }^{a}$ Centro de Reconocimiento Molecular y Desarrollo Tecnológico (IDM), Unidad Mixta Universidad Politécnica de Valencia-Universidad de Valencia, Spain.

${ }^{b}$ Departamento de Química, Universidad Politécnica de Valencia, Camino de Vera $s / n, 46022$, Valencia, Spain.

${ }^{c}$ CIBER de Bioingeniería, Biomateriales y Nanomedicina (CIBER-BBN).

${ }^{d}$ Grupo de Investigación e Innovación Alimentaria, Departamento de Tecnología de Alimentos, Universitat Politècnica de València, Camino de Vera s/n., 46022 Valencia, Spain.

e Departamento de Química Orgánica, Facultad de Ciencias Químicas, Universitat de Valencia, 46100 Burjassot, Valencia, Spain.

${ }^{f}$ Institut de Ciència del Materials (ICMUV) Universitat de València P.O. Box 2085, E-46071 Valencia, Spain.

Received: $10^{\text {th }}$ December 2012

First published on the web: $23^{\text {rd }}$ January 2013

Journal of Materials Chemistry A, 2013, 1, 3561-3564

(Reproduced with permission of The Royal Society of Chemistry) 

A hybrid capped mesoporous material, which was selectively opened in the presence of Tetryl and TNT, has been synthesised and used for the fluorogenic recognition of these nitroaromatic explosives.

Current international public awareness on terrorist attacks using explosives means that the development of quick, reliable methods to detect these chemicals is a particularly interesting issue. ${ }^{1}$ Additionally, given the widespread use of explosive formulations, the analysis of explosives is also of interest in forensic research, landmine detection, and to study environmental problems associated with explosive residues. Among the different chemical explosives, nitroaromatics are perhaps the most commonly used. Current methodologies employed for the detection of nitroaromatic explosives are enzymatic assays, ${ }^{2}$ gas and liquid chromatography, ${ }^{3}$ mass spectrometry, ${ }^{4}$ ion-mobility spectroscopy, ${ }^{5}$ optodes ${ }^{6}$ and electrochemical procedures. ${ }^{7}$ One alternative to these methods, which has recently attracted a great deal of attention, are optical detection probes based on the design of fluorimetric assays. In most cases, the designed probes are based on the electron-deficient character of nitroaromatic explosives that induces them to form charge-transfer complexes with electron donor molecules (such as polycyclic aromatic hydrocarbons, dansyl derivatives or tetrathiafulvalenes). ${ }^{8}$ Based on this concept, fluorescent polymers, ${ }^{9}$ fluorescent silica-based materials ${ }^{10}$ and single fluorophores ${ }^{11}$ such as probes for the detection of nitroaromatic explosives have been explored.

However in many cases, one common drawback in these systems is that fluorescence quenching, involving an electron transfer process between the corresponding excited fluorophore and electron acceptor nitroaromatic explosive molecules, is observed. Nevertheless, reagents which exhibit a turn-on behaviour, rather than the turn-off response, are preferred for designing efficient probes for practical applications. Moreover in the literature, reports on fluorescence-based probes with a turn-on response for nitroaromatic explosives are very limited. ${ }^{12}$ 
By making full use of the good properties of electron-rich fluorophores, such as pyrene to form complexes with nitroaromatic explosives, and by attempting to design probes showing enhanced fluorescence upon interaction with target nitroaromatics at the same time, we report herein the use of a capped mesoporous material that is selectively uncapped in the presence of nitroaromatic explosives, resulting in the delivery of a selected fluorophore. Despite some examples reported by us, the use of capped materials to selectively detect target analytes is a barely explored approach. ${ }^{13}$

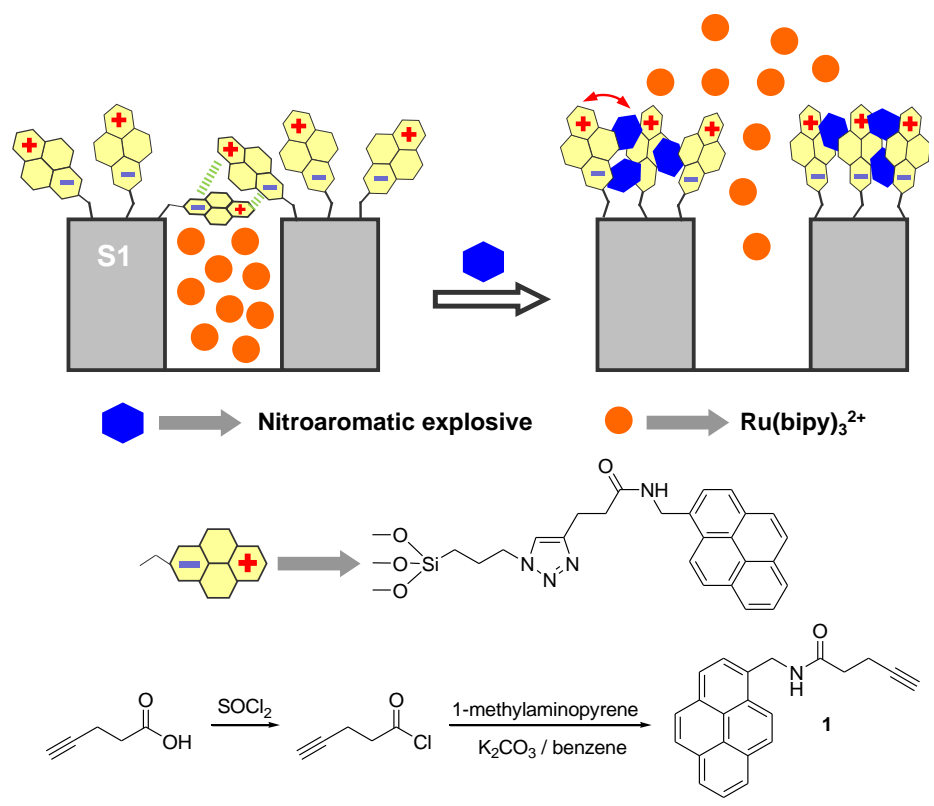

Scheme 1. Schematic representation of the sensing mechanism of solid $\mathbf{S 1}$ in the presence of explosives and synthesis of pyrene derivative 1.

An illustration of the signalling paradigm is shown in Scheme 1. As an inorganic support, a mesoporous MCM-41 phase was selected given its high loading capacity and easy surface functionalisation. The mesoporous support was first loaded with the dye tris(2,2'-bipyridyl)ruthenium(II) chloride $\left(\left[\mathrm{Ru}(\text { bipy })_{3}\right] \mathrm{Cl}_{2}\right)$ and was then functionalised with 3-(azidopropyl)triethoxysilane. Finally, the support was capped, through a click chemistry reaction, using pyrene derivative $\mathbf{1}$ (see Supporting Information for details). The presence of a dense network of bulky 
pyrene moieties around the pores was expected to inhibit the delivery of the dye. The signalling protocol relies on pyrene-nitroaromatic complexes formation, which would push apart the bulky pyrene from the pore outlets (to unlock the gate) and the delivery of the dye.

The MCM-41 mesoporous support was prepared by using tetraethyl orthosilicate (TEOS) as a hydrolytic inorganic precursor and the surfactant hexadecyl-trimethylammonium bromide (CTAB) as a porogen species. ${ }^{14}$ After the surfactant was removed by calcination, the MCM-41 solid was obtained. The MCM-41 structure of the starting material was confirmed by X-Ray diffraction and transmission electron microscopy (TEM), see Supporting Information. The $\mathrm{N}_{2}$ adsorption-desorption isotherms of the prepared phase show a typical type IVcurve (see Figure 1) with a specific surface area of $1415 \mathrm{~m}^{2} \mathrm{~g}^{-1}$, a narrow pore size distribution and an average pore diameter of $2.3 \mathrm{~nm}$. The inorganic support was then loaded with $\left[\mathrm{Ru}(\text { bipy })_{3}\right]^{2+}$ as a suitable fluorophore and the outer surface was functionalised with 3-(azidopropyl)triethoxisylane groups. In a second step, pyrene derivative 1 was attached to the solid support by a copper (I)-catalysed Huisgen azide/alkyne 1,3-dipolar cycloaddition "click" reaction. ${ }^{15}$ This led to the formation of a 1,2,3-triazole heterocycle and yielded the final hybrid material S1. The solid was filtered, intensively washed with acetonitrile and dried overnight at $36^{\circ} \mathrm{C}$.

S1 displays the expected features of the MCM-41 phase, indicating that the mesoporous structure was preserved throughout the filling process with the dye and the anchoring of the pyrene derivative at the pore outlets (see Supporting Information). Moreover, TEM images of the MCM-41 support and of the final hybrid material S1 showed the typical porosity associated with the inorganic support (see Supporting Information). The $\mathrm{N}_{2}$ adsorption-desorption isotherm of S1 (see Figure 1) was typical of gated mesoporous systems with partially filled mesopores, and a significant decrease in the $\mathrm{N}_{2}$ volume adsorbed was observed when compared with the starting MCM-41 material. The organic content in S1 
was determined by thermogravimetric analysis; this solid contained $0.061 \mathrm{mmol}$ of the ruthenium complex/g $\mathrm{SiO}_{2}$ and $0.104 \mathrm{mmol}$ of pyrene derivative/g $\mathrm{SiO}_{2}$ (see Supporting Information). LD (Laser Diffraction) studies in acetonitrile showed microparticles with a mean diameter of $30.2 \mu \mathrm{m}$ (see Supporting Information).

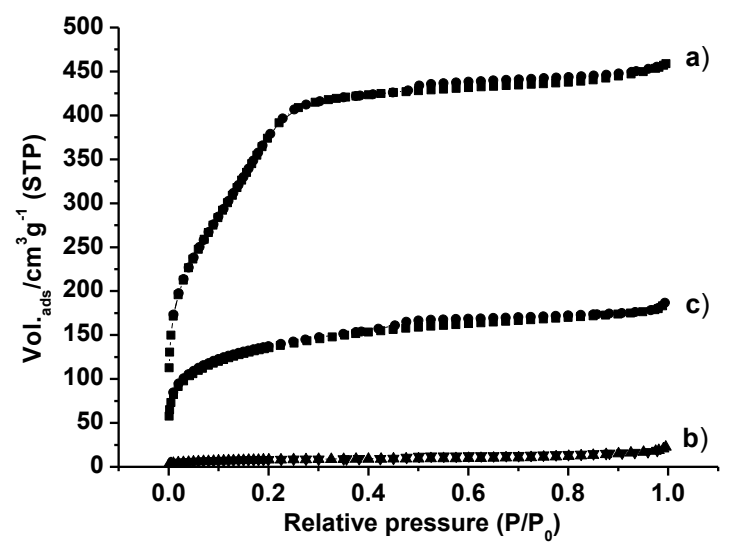

Figure 1. $N_{2}$ adsorption-desorption isotherms of (a) calcined MCM-41 (b) MCM-41 loaded with $\left[R u(b i p y)_{3}\right]^{2+}$ and functionalized with azide and (c) solid $\mathbf{S 1}$.

The studies into the explosive-induced uncapping paradigm were carried out in acetonitrile. In this solvent, a remarkably rather tight pore closure was observed and, at the same time, both the ruthenium dye and the selected explosives showed suitable solubility (see Supporting Information). In a typical assay, $4 \mathrm{mg}$ of S1 were suspended in $10 \mathrm{~mL}$ of acetonitrile in the presence of different explosives at $25^{\circ} \mathrm{C}$. Delivery of the dye to the bulk solution was easily detected by monitoring the spin allowed $d-\pi$ metal-to-ligand charge transfer (MLCT) transition band of the $\left[\mathrm{Ru}(\text { bipy })_{3}\right]^{2+}$ complex centred at $453 \mathrm{~nm}$, or through its luminescence centred at $625 \mathrm{~nm}\left(\lambda_{\mathrm{ex}}=453 \mathrm{~nm}\right) \cdot{ }^{16}$ Figure 2 shows the release kinetics of the ruthenium dye from S1 in the presence of explosives Tetryl and TNT at $2.0 \times 10^{-3} \mathrm{~mol} \mathrm{dm}^{-3}$. In the presence of both explosives, a clear dye delivery took place, reaching a maximum release at ca. 15 minutes. 


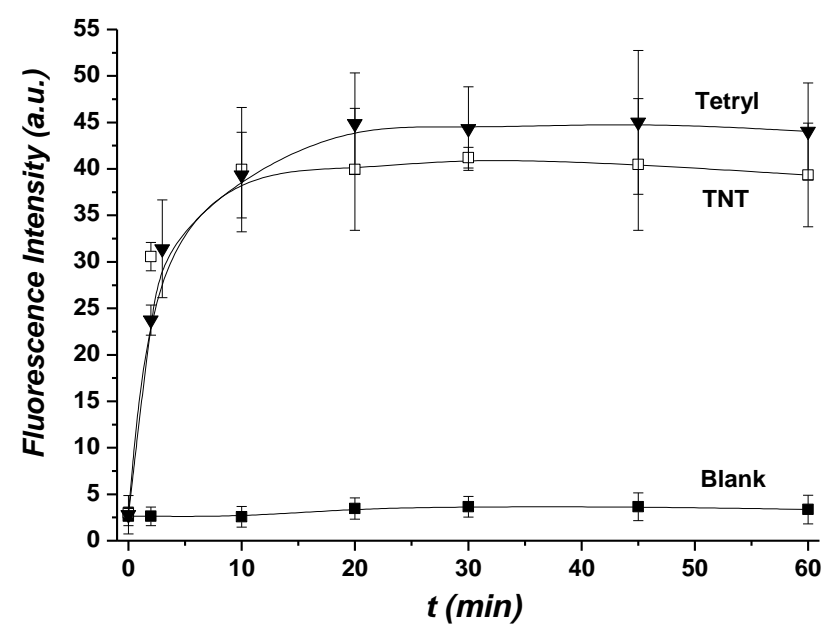

Figure 2. Kinetics of the release of the $\left[\mathrm{Ru}(\text { bipy })_{3}\right]^{2+}$ dye from solid $\mathbf{S 1}$ (at $25^{\circ} \mathrm{C}$ ) in the absence (blank) and the presence of nitroaromatic explosives $\left(2.0 \times 10^{-3} \mathrm{~mol} \mathrm{dm}^{-3}\right)$ in acetonitrile $\left(\lambda_{e x}=453 \mathrm{~nm}, \lambda_{e m}=625 \mathrm{~nm}\right)$.

In order to prove the proposed sensing mechanism (see Scheme 1), the interaction of Tetryl and TNT with the anchored pyrene groups was explored by the former's ability to quench the latter's excited state. The acetonitrile suspensions of $\mathbf{S 1}$ (at $25^{\circ} \mathrm{C}$ ) displayed the typical structured emission of the pyrene monomer in the $380-430 \mathrm{~nm}$ range (see Supporting Information). Addition of Tetryl and TNT to the acetonitrile suspensions of $\mathbf{S 1}$ induced a quenching of the monomer emission (89\% and $93 \%$ of the quenching for TNT and Tetryl, respectively, for an explosive concentration of $2.0 \times 10^{-3} \mathrm{~mol} \mathrm{dm}^{-3}$ ), indicative of the formation of complexes between the electron donor pyrene ring and the electron-withdrawing nitroaromatic explosives. In addition, these Tetryl- and TNTpyrene interactions were responsible for the dye delivery and the enhanced turnon luminescence signal observed.

Besides, both facts, i.e., the appearance of the $\left[\mathrm{Ru}(\text { bipy })_{3}\right]^{2+}$ luminescence and the pyrene emission quenching upon addition of TNT and Tetryl, would allow the ratiometric detection of both nitroaromatic explosives (see Supporting 
Information). In the absence of the nitroaromatic explosives the bulky pyrene inhibited dye delivery due to a partial pore blocking. This blocking may probably arise from strong dipole-dipole interactions between the anchored pyrene derivatives. In fact the gating molecule (containing an electron donor pyrene moiety and a 1,2,3-triazole heterocycle group with an electron acceptor character) has a strong dipole moment of ca. 3.2 D (see Supporting Information). Bearing in mind this value and the use of acetonitrile as solvent, dipole-dipole interactions between the anchored molecules would impose some rigidity and would induce the interaction between gating molecules in the pore voids. This may be favored by the relatively short distance between anchored pyrenes groups (ca. $0.78 \mathrm{~nm}$ ) and the presence of about ten fluorophores surrounding each pore as average (see Supporting Information for details). As the experimental results suggested, Tetryl and TNT interacted with the pyrene group disrupting pyrenepyrene interactions and inducing dye delivery.

Moreover, in order to discard a simple possible nitroaromatic-induced displacement of the ruthenium complex additional experiments were carried out. In particular, the chromogenic response in the presence of Tetryl and TNT of a hybrid solid that contains the ruthenium complex in the pores and azide moieties, in the external surface, was tested. $4 \mathrm{mg}$ of solid were suspended in $10 \mathrm{~mL}$ of acetonitrile or in acetonitrile containing Tetryl or TNT. The suspensions were stirred and then filtered. In these experiments the same absorbance and emission intensity in the bulk solution for the solid alone and for the solid in the presence of Tetryl and TNT was obtained indicating that there is no a preferential displacement of the ruthenium complex by the nitroaromatic explosives.

Further studies were carried out and titration curves in the presence of Tetryl and TNT were obtained. The increasing intensity in the emission band of the $\left[\mathrm{Ru}(\mathrm{bipy})_{3}\right]^{2+}$ dye was found to be proportional to the concentration of the explosives, which is in agreement with the above-described assisted uncapping protocol. A simple fluorogenic titration allowed us to calculate detection limits of 
1.4 and $11.4 \mathrm{ppm}$ for the detection of Tetryl and TNT, respectively. The detection limits were also calculated from the nitroaromatic-induced quenching of the pyrene emission. Using this procedure, detection limits of 8.6 and $9.1 \mathrm{ppm}$ for Tetryl and TNT were calculated.

Finally, in order to check the selectivity of S1 to Tetryl and TNT, the response of the hybrid material in the presence of other aromatic derivatives (i.e., 2,4dinitrotoluene (2,4-DNT), N-methylaniline (NM), 2-nitrotoluene (NT) and nitrobenzene (NB)), non-aromatic explosives (i.e., hexahydro-1,3,5-trinitro-1,3,5triazine (RDX) and pentaerythritol tetranitrate (PETN)), methylene blue (MB) and naphthalene (NP) were studied. As seen in Figure 3, only 2,4-DNT was also able to induce a partial release of the ruthenium complex, but to a much lesser extent, whereas no delivery from $\mathbf{S 1}$ alone and $\mathbf{S} 1$ in the presence of other tested products was noted. The observed selectivity was related with the strong electron acceptor character of TNT (with 3 nitro groups) and Tetryl (4 nitro groups) when compared with the other nitro compounds tested. Addition of TNT and Tetryl induced the formation of charge-transfer complexes with the grafted pyrene allowing dye release.

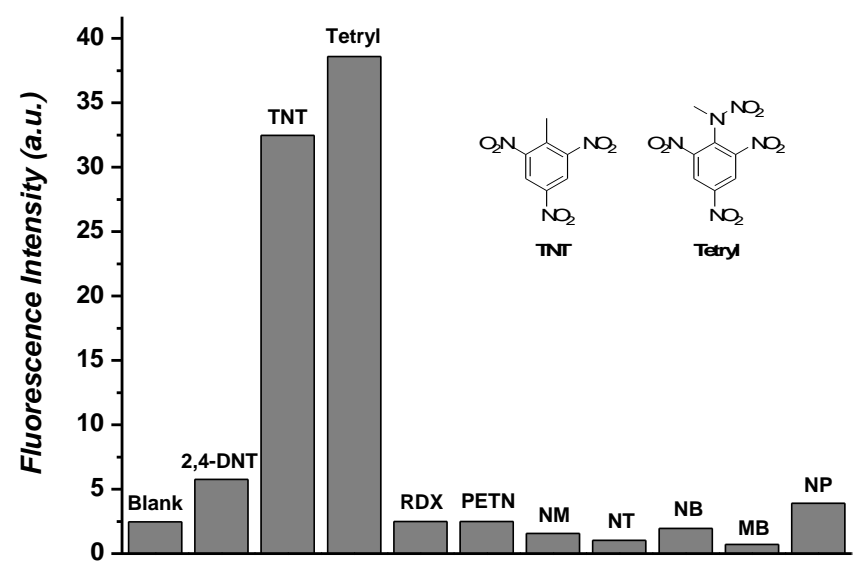

Figure 3. Emission intensity at $625 \mathrm{~nm}$ of acetonitrile suspensions of $\mathbf{S 1}$ (at $25^{\circ} \mathrm{C}$ ) in the presence of different nitroaromatic $\left(2 \times 10^{-3} \mathrm{~mol} \mathrm{dm}^{-3}\right)$ and non-aromatic $\left(2 \times 10^{-3} \mathrm{~mol} \mathrm{dm}^{-3}\right)$ derivatives. 
In summary, a novel approach for the fluorimetric sensing of nitroaromatic explosives using silica gated mesoporous hybrid materials has been reported. The presence of explosives Tetryl and TNT in the acetonitrile suspensions of the hybrid material induced a pore opening with the subsequent release of an entrapped dye. By using this simple procedure, fluorescence in the presence of nitroaromatic explosives was observed. In fact, as far as we know, this is one of the very few examples showing an off-on fluorescence in the presence of nitro explosives. Despite the relatively high limit of detection obtained, in the ppm range, one advantage of our hybrid material, when compared with molecular receptors, is its modular character. In particular, the possible functionalisation of the external surface of mesoporous materials with other gating electron-deficient groups (to enhance or tune selectivity) and the possible use of different fluorophores make this approach appealing for the future development of materials with tailor-made sensing properties showing a turn-on chromo-fluorogenic behaviour for the easy detection of explosives and current efforts into this direction are being carried out in our research group.

\section{Acknowledgments}

Financial support from the Spanish Government (project MAT2012-38429-C0401) and the Generalitat Valencia (project PROMETEO/2009/016) is gratefully acknowledged. Y.S. and E.P. are grateful to the Spanish Ministry of Science and Innovation for their grants. A. A. also thanks the Generalitat Valenciana for his Santiago Grisolia fellowship.

\section{References}

1. a) S. Singh, J. Haz. Mat., 2007, 144, 15. b) R. Schulte-Ladbeck, M. Vogel, U. Karst, Anal. Bioanal. Chem., 2006, 386, 559.

2. R. G. Smith, N. D'Souza, S. Nicklin, Analyst, 2008, 133, 571.

3. D. S. Moore, Rev. Sci. Instrum., 2004, 75, 2499. 
4. K. Hakansson, R. V. Coorey, R. A. Zubarev, V. L. Talrose P. Hakansson, J. Mass Spectrom., 2000, 35, 337.

5. E. Wallis, T. M. Griffin, N. Popkie, Jr., M. A. Eagan, R. F. McAtee, D. Vrazel, J. McKinly, Proc. SPIE-Int. Soc.Opt. Eng., 2005, 5795, 54.

6. M. E. Germain, M. J. Knapp, Chem. Soc. Rev., 2009, 38, 2543.

7. E. S. Forzani, D. Lu, M. J. Leright, A. D. Aguilar, F. Tsow, R. A. Iglesias, Q. Zhang, J. Lu, J. Li, N. Tao, J. Am. Chem. Soc., 2009, 131, 1390.

8. Y. Salinas, R. Martínez-Máñez, M. D. Marcos, F. Sancenón, A. M. Costero, M. Parra, S. Gil, Chem. Soc. Rev., 2012, 41, 1261.

9. S. W. Thomas III, G. D. Joly, T. M. Swager, Chem. Rev., 2007, 107, 1339.

10. See for example: a) D. Gao, Z. Wang, B. Liu, L. Ni, M. Wu, Z. Zhang, Anal. Chem., 2008, 80, 8545. b) S, Zhang, F. Lu, L. Gao, L. Ding, Y. Fang, Langmuir, 2007, 23, 1584.

11. See for example: a) A. D. Hughes, I. C. Glenn, A. D. Patrick, A. Ellington, E. V. Anslyn, Chem. Eur. J., 2008, 14, 1822. b) C. Vijayakumar, G. Tobin, W. SchmittM. Kima, M. Takeuchi, Chem. Commun., 2010, 46, 874.

12. Y. Salinas, E. Climent, R. Martínez-Máñez, F. Sancenón, M. D. Marcos, J. Soto, A. M. Costero, S. Gil, M. Parra, A. Pérez de Diego, Chem. Commun., 2011, 47, 11885.

13. a) E. Climent, R. Martínez-Mañez, F. Sancenón, M. D. Marcos, J. Soto, A. Maquieira, P. Amorós, Angew. Chem. Int. Ed.., 2010, 49, 7281. b) E. Climent, M. D. Marcos, R. Martínez-Máñez, F. Sancenón, J. Soto, K. Rurack, P. Amorós, Angew. Chem. Int. Ed., 2009, 48, 8519. c) E. Climent, A. Bernardos, R. Martínez-Máñez, A. Maquieira, M. D. Marcos, N. Pastor-Navarro, R. Puchades, F. Sancenón, J. Soto, P. Amorós, J. Am. Chem. Soc., 2009, 131, 14075.

14. S. Cabrera, J. El Haskouri, C. Guillem, J. Latorre, A. Beltrán, D. Beltrán, M. D. Marcos, P. Amorós, Solid State Sci., 2000, 2, 405.

15. H. C. Kolb, M. G. Finn, K. B. Sharpless, Angew. Chem. Int. Ed., 2001, 40, 2004.

16. a) F. Felix, J. Ferguson, H. U. Gudel, A. Ludi, J. Am. Chem. Soc., 1980, 102, 4096. b) F. E. Lytle, D. M. Hercules, J. Am. Chem. Soc., 1969, 91, 253. 



\section{SUPPORTING INFORMATION}

\section{Fluorogenic detection of Tetryl and TNT explosives using nanoscopic-capped mesoporous hybrid materials}

Yolanda Salinas, Alessandro Agostini, Édgar Pérez-Esteve, Ramón MartínezMáñez, Félix Sancenón, M. Dolores Marcos, Juan Soto, Ana M. Costero, Salvador Gil, Margarita Parra and Pedro Amorós

\section{Chemicals}

The chemicals tetraethylorthosilicate (TEOS) (98\%), $n$ cetyltrimethylammonium bromide (CTAB) ( $\geq 99 \%)$, sodium hydroxide $(\geq 98 \%)$, triethanolamine $\left(\mathrm{TEAH}_{3}\right) \quad(\geq 99 \%), \quad$ tris(2,2'-bipyridyl)dichlororuthenium(II) hexahydrate $\left(\left[\mathrm{Ru}(\mathrm{bipy})_{3}\right] \mathrm{Cl}_{2} \cdot 6 \mathrm{H}_{2} \mathrm{O}\right)(100 \%), 2,4$-dinitrotoluene $(2,4-\mathrm{DNT}), \mathrm{N}$ methylaniline (98\%) (NM), 2-nitrotoluene (NT), nitrobenzene (99\%) (NB), thionyl chloride, 1-pyrenemethylamine hydrochloride, 4-pentynoic, 3(azidopropyl)triethoxysilane, methylene blue and naphthalene were provided by Sigma-Aldrich and used as received. The $3 \%$ solution in acetonitrile of the subsequently nitrated explosives 2,4,6-trinitrophenylmethylnitramine (Tetryl), 2,4,6-trinitrotoluene (TNT), hexahydro-1,3,5-trinitro-1,3,5-triazine (RDX) and pentaerythritol tetranitrate (PETN) were purchased from SelectLab Chemicals. LAscorbic sodium salt (99\%), potassium carbonate, sodium sulfate and copper (II) sulfate pentahydrate $\left(\mathrm{CuSO}_{4} \cdot 5 \mathrm{H}_{2} \mathrm{O}\right)$ were acquired from Scharlab (Barcelona, Spain). Analytical-grade solvents were purchased from Scharlab (Barcelona, Spain). All the reagents were used as received.

\section{General Techniques}

Powder XRD, TG analysis and $\mathrm{N}_{2}$ adsorption-desorption techniques were employed to characterise the prepared materials. Fluorescence spectroscopy was 
used for studying the controlled release behaviour of the synthesised materials. The fluorescence measurements were carried out at $25^{\circ} \mathrm{C}$. Powder X-ray diffraction measurements were taken in a Philips D8 Advance diffractometer using $\mathrm{Cu} \mathrm{K}_{\alpha}$ radiation. Thermo-gravimetric analyses were carried out on a TGA/SDTA 851e Mettler Toledo balance, using an oxidant atmosphere (air, 80 $\mathrm{mL} / \mathrm{min}$ ) with a heating program consisting in a heating ramp of $10^{\circ} \mathrm{C}$ per minute from $293 \mathrm{~K}$ to $1273 \mathrm{~K}$ and an isothermal heating step at this temperature for 30 minutes. $\mathrm{N}_{2}$ adsorption-desorption isotherms were recorded with a Micromeritics ASAP2010 automated sorption analyser. Samples were degassed at $120{ }^{\circ} \mathrm{C}$ in vacuum overnight. Specific surface areas were calculated from the adsorption data in the low pressures range using the BET model. Pore size was determined following the BJH method. The size distribution of particle dispersions was measured with a Malvern Masterisizer 2000 (Malvern, UK) using acetonitrile as dispersant. For data evaluation, an optical model based on the Mie theory was created using the instrumental software assuming 1.45 as the real and 0.001 as the imaginary part of the refractive index of the particles. Results given are the mean of 5 successive measurements. Fluorescence spectroscopy was carried out with a Felix 32 Analysis Version 1.2 (Build 56) PTI (Photon Technology International). TEM images were obtained with a $100 \mathrm{kV}$ Philips CM10 microscope. ${ }^{1} \mathrm{H}$ and ${ }^{13} \mathrm{C}$ nuclear magnetic resonance (NMR) were acquired with a Varian 300 spectrometer (Sunnyvale, CA, USA) and the Mass spectrometry analysis was performed employing a MALDI TOF/TOF 4700 Proteomics Analyser from Applied Biosystems.

\section{Synthesis}

Synthesis of 4-pentynoyl chloride

Thionyl chloride $(410 \mu \mathrm{L}, 5.6 \mathrm{mmol})$ was added to a solution of 4-pentynoic acid (500 mg, $5.1 \mathrm{mmol}$ ) in benzene $(5 \mathrm{~mL}$ ) in an argon atmosphere. The reaction was stirred at room temperature for 4 hours and for 1 additional hour at reflux. The benzene and the excess of thionyl chloride were eliminated in a rotary 
evaporator. Finally, 4-pentynolyl chloride was taken up in THF $(5 \mathrm{~mL})$ and the solution used in the next step of the synthetic sequence.

\section{Synthesis of compound 1}

1-Pyrenemethylamine hydrochloride $(500 \mathrm{mg})$ was dissolved in basic water and then extracted with diethyl ether in order to obtain the free base 1pyrenemethylamine. The ether layer was then dried $\left(\mathrm{Na}_{2} \mathrm{SO}_{4}\right)$, filtered and the solvent removed by rotary evaporation. The resulting yellow solid was used to prepare pyrene derivative 1. Next, 1-pyrenemethylamine (200 mg, $0.75 \mathrm{mmol}$ ) was dissolved in benzene $(25 \mathrm{~mL})$ and then an excess of dry $\mathrm{K}_{2} \mathrm{CO}_{3}$ was added. The 4-pentynoyl chloride solution $(2.5 \mathrm{~mL})$ was added to the suspension and the resulting yellow crude was stirred overnight at room temperature (see Figure SI1). The benzene and THF in the crude reaction were removed by rotary evaporation and the crude was suspended in ethyl acetate $(20 \mathrm{~mL})$. The organic phase was washed with basic water (in order to hydrolise unreacted thionyl chloride and 4-pentynoyl chloride), with distilled water, and finally, with acidic water until a neutral $\mathrm{pH}$ was obtained. The organic layer was then dried $\left(\mathrm{Na}_{2} \mathrm{SO}_{4}\right)$, filtered and the solvent was removed by rotary evaporation. Final product 1 was obtained as a yellow solid (187 mg, $0.60 \mathrm{mmol}, 80.5 \%$ yield). The final structure of 1 was confirmed by ${ }^{1} \mathrm{H}-\mathrm{NMR},{ }^{13} \mathrm{C}-\mathrm{NMR}$ and mass spectra measurements.
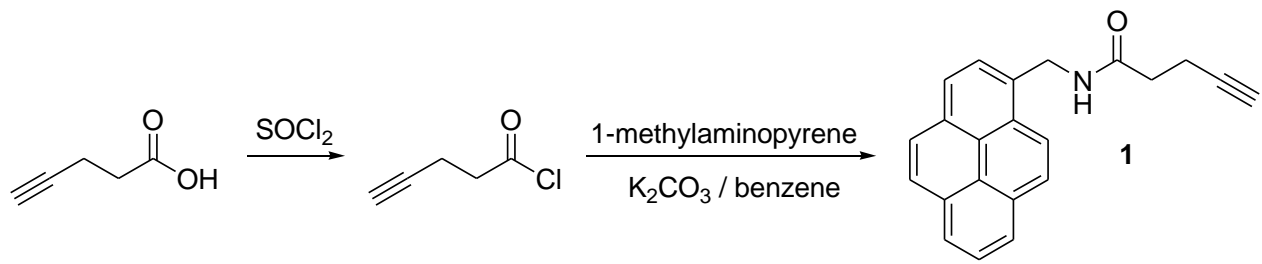

Figure SI-1. Synthesis of compound 1.

${ }^{1} \mathrm{H}-\mathrm{NMR}\left(300 \mathrm{Mhz}, \mathrm{CDCl}_{3}\right.$ ) $\delta: 1.91(\mathrm{~s}, 1 \mathrm{H}, \mathrm{C} \equiv \mathrm{C}-\mathrm{H}), 2.43\left(\mathrm{t}, 2 \mathrm{H}, \mathrm{CH}_{2}-\mathrm{C} \equiv \mathrm{C}-\mathrm{H}\right)$, $2.57\left(\mathrm{t}, 2 \mathrm{H}, \mathrm{CH}_{2}-\mathrm{CH}_{2}-\mathrm{C} \equiv \mathrm{C}-\mathrm{H}\right), 5.16\left(\mathrm{~s}, 2 \mathrm{H}, \mathrm{Pyr}-\mathrm{CH}_{2}-\mathrm{N}\right), 5.92(\mathrm{~s}, 1 \mathrm{H}, \mathrm{CO}-\mathrm{NH}), 7.96-$ 8.26 (m, 9H, Pyr) ppm. ${ }^{13} \mathrm{C}-\mathrm{NMR}\left(75 \mathrm{Mhz}, \mathrm{CDCl}_{3}\right) \delta: 15.0,35.5,42.1,69.4,82.9$, 
$122.8,124.8,125.1,125.4,126.1,127.2,127.3,127.6,128.3,129.1,130.8,130.9$, 131.1, 170.5. HRMS-El $\mathrm{m} / \mathrm{z}$ calculated for $\mathrm{C}_{22} \mathrm{H}_{17} \mathrm{NO} 311.1310$, measured for $\mathrm{MH}^{+}$ 312.1338 .

Synthesis of the mesoporous silica support

The molar ratio of the reagents in the mother liquor was fixed to $7 \mathrm{TEAH}_{3}: 2$ TEOS: 0.52 CTAB: $0.5 \mathrm{NaOH}: 8.89 \mathrm{H}_{2} \mathrm{O}$. In a typical synthesis leading to the MCM41 pure silica, CTAB (4.67 g) was added at $118{ }^{\circ} \mathrm{C}$ to a $\mathrm{TEAH}_{3}$ solution ( $25.76 \mathrm{~g}$ ) containing $\mathrm{NaOH}(0.012 \mathrm{~mol})$ and a silatrane derivative (e.g., $0.049 \mathrm{~mol}, 11 \mathrm{~mL}$ of TEOS) was added at $70{ }^{\circ} \mathrm{C}$ to TEAH $H_{3}$, e.g., in the form of Si(TEA) $\left(\mathrm{TEAH}_{2}\right)$, where TEA was the fully deprotonated ligand). Then deionised water $(80 \mathrm{~mL})$ was added with vigorous stirring at $70{ }^{\circ} \mathrm{C}$. After some minutes, a white suspension was obtained. This mixture was aged at room temperature overnight. The resulting powder was collected by filtration and washed with water until pH 6-7. Finally the solid was dried at $70{ }^{\circ} \mathrm{C}$ (MCM-41 as synthesised). To prepare the final porous material (MCM-41), the as-synthesised solid was calcined at $550{ }^{\circ} \mathrm{C}$ for $5 \mathrm{~h}$ to remove the template.

\section{Synthesis of solid $\mathbf{S 1}$}

In a typical synthesis, template-free MCM-41 $(3 \mathrm{~g})$ and $\left[\mathrm{Ru}(\text { bipy })_{3}\right] \mathrm{Cl}_{2} \cdot 6 \mathrm{H}_{2} \mathrm{O}(1.8$ $\mathrm{g}, 2.4 \mathrm{mmol}$ ) were suspended in acetonitrile $(120 \mathrm{~mL})$ in a round-bottomed flask. To remove the adsorbed water, $40 \mathrm{~mL}$ of acetonitrile were distilled using a DeanStark set-up. Then, the mixture was stirred for 24 hours at room temperature for the purpose of achieving maximum loading in the pores of the MCM-41 scaffolding. Afterwards an excess of 3-(azidopropyl)triethoxysilane $(1.48 \mathrm{~mL}, 6$ mmol) was added, and the suspension was stirred for $5.5 \mathrm{~h}$. Finally, the orangeyellow solid was filtered off. In a second step, the mixture of azide-functionalised microparticles $(3 \mathrm{~g})$ and pyrene derivative 1 (303.23 $\mathrm{mg}, 0.975 \mathrm{mmol}$ ) was suspended in 50:50 v/v DMSO-water $(100 \mathrm{~mL})$ in the presence of an excess of the 
ruthenium (II) dye (1.8 g, $2.4 \mathrm{mmol})$ in order to avoid the delivery of the dye from the pores to the bulk solution during the synthesis of this solid. Then, a solution of $\mathrm{CuSO}_{4} \cdot 5 \mathrm{H}_{2} \mathrm{O} 1.0 \times 10^{-3} \mathrm{~mol} \mathrm{dm}^{-3}(9.75 \mathrm{~mL})$ and sodium ascorbate $(19.32 \mathrm{mg}, 0.097$ mmol) was added. The reaction mixture was stirred at room temperature for 3 days. Microparticles were filtered off and washed with $\mathrm{CH}_{2} \mathrm{Cl}_{2}(100 \mathrm{~mL}), \mathrm{H}_{2} \mathrm{O}(100$ $\mathrm{mL})$, acetonitrile $(100 \mathrm{~mL}), \operatorname{THF}(250 \mathrm{~mL})$ and dried at $70^{\circ} \mathrm{C}$ for $12 \mathrm{~h}$.

\section{Material Characterisation}

MCM-41 as-synthesised, calcined MCM-41 and S1 materials were characterised by standard techniques. Figure SI-2 shows the powder X-ray patterns of the solid MCM-41 as-synthesised (without calcination), calcined MCM41 and S1. The powder XRD of siliceous MCM-41 as-synthesised shows four lowangle reflections that are typical of the hexagonal-ordered array which can be indexed as (100), (110), (200), and (210) Bragg peaks. A significant shift of the (100) reflection and a remarkable broadening of the (110) and (200) peaks in the XRD powder of the MCM-41 calcined sample are clearly seen. This scenario corresponds to an approximate cell contraction of ca. 6-8 A during the calcination step. Despite this clear partial order loss, the fact that the overlapped (100) and (200) reflections are observed indicates that a certain relative mesopore symmetry is preserved after calcination. Figure $\mathrm{SI}-2$ also shows the curve that corresponds to S1. For this solid, reflection (200) was lost, most probably relating to a reduced contrast because of the pore voids filling with the ruthenium complex. Nevertheless, the clear presence of the (100) peak in this pattern suggests that the loading process with the $\left[\mathrm{Ru}(\mathrm{bipy})_{3}\right]^{2+}$ complex, and the additional functionalisation with 3-(azidopropyl)triethoxysilane and pyrene derivative 1 , have not substantially modified the mesoporous MCM-41 support. 


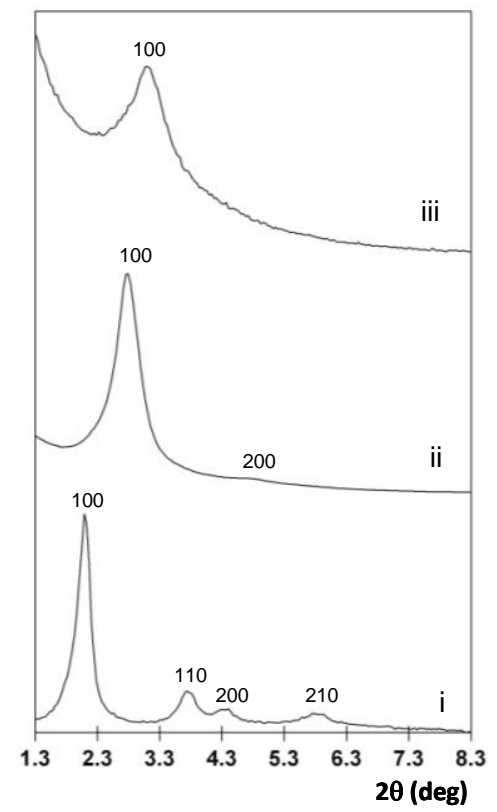

Figure SI-2. Powder X-Ray diffractograms showing the X-Ray patterns of the MCM-41 scaffolding as synthesized (i), MCM-41 after the calcination process (ii) and final solid S1 (iii).

The presence of the mesoporous structure in the final functionalised solid (S1) was also confirmed by the TEM analysis, in which the typical channels of the MCM-41 matrix were visualised as alternate black and white stripes (see Figure S1-3 for solid S1). The figure also shows that the prepared S1 was obtained as microparticles. The TEM images also indicate that the loading and grafting procedures did not modify the mesoporous structure of the starting material.
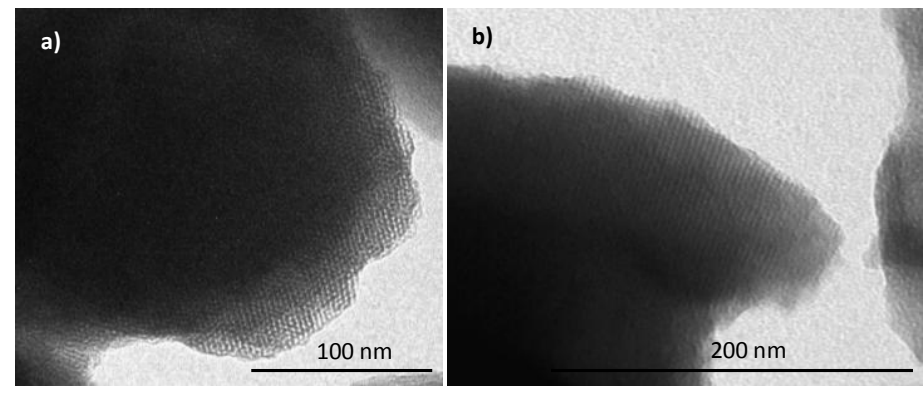

Figure SI-3. TEM image of a) the MCM-41 solid support and b) solid S1, showing the typical hexagonal porosity of the MCM-41 matrix. 
LD (Laser Diffraction) studies showed S1 microparticles with a mean diameter of $30.2 \mu \mathrm{m}$ (see Figure SI-4). The studies also shown that the size of the microparticles was not modified throughout the loading and functionalization processes.

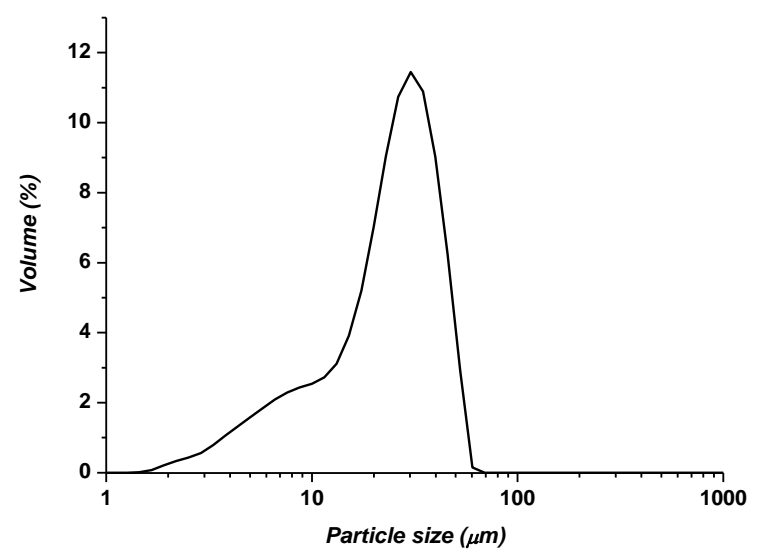

Figure SI-4. Statistical representation of particle size obtained by LD (Laser Diffraction) studies. The average size of $\mathbf{S 1}$ microparticles was found to be $30.2 \mu \mathrm{m}$.

The $\mathrm{N}_{2}$ adsorption-desorption isotherms of the MCM-41 calcined material show a typical curve for these mesoporous solids; i.e., an adsorption step at the intermediate $P / P_{0}$ value (0.2-0.4). This curve corresponds to a type IV isotherm, in which the observed step may be related to the nitrogen condensation inside the mesopores by capillarity (see Figure SI-5). The application of the BET model resulted in a total specific surface value of $1415 \mathrm{~m}^{2} / \mathrm{g}$. From the XRD, porosimetry and TEM studies, the $\mathrm{a}_{0}$ cell parameter $(3.64 \mathrm{~nm})$, the pore diameter $(2.29 \mathrm{~nm})$ and a value for the wall thickness of $1.35 \mathrm{~nm}$ can be calculated. The $\mathrm{N}_{2}$ adsorption-desorption isotherms of $\mathbf{S 1}$ (see Figure SI-5) are typical of mesoporous systems with filled mesopores, and a significant decrease in the $\mathrm{N}_{2}$ volume adsorbed is observed. In fact, these solids present flat curves when compared (on the same scale) to those of the MCM-41 parent material, indicating significant pore blocking and the subsequent absence of appreciable porosity. 

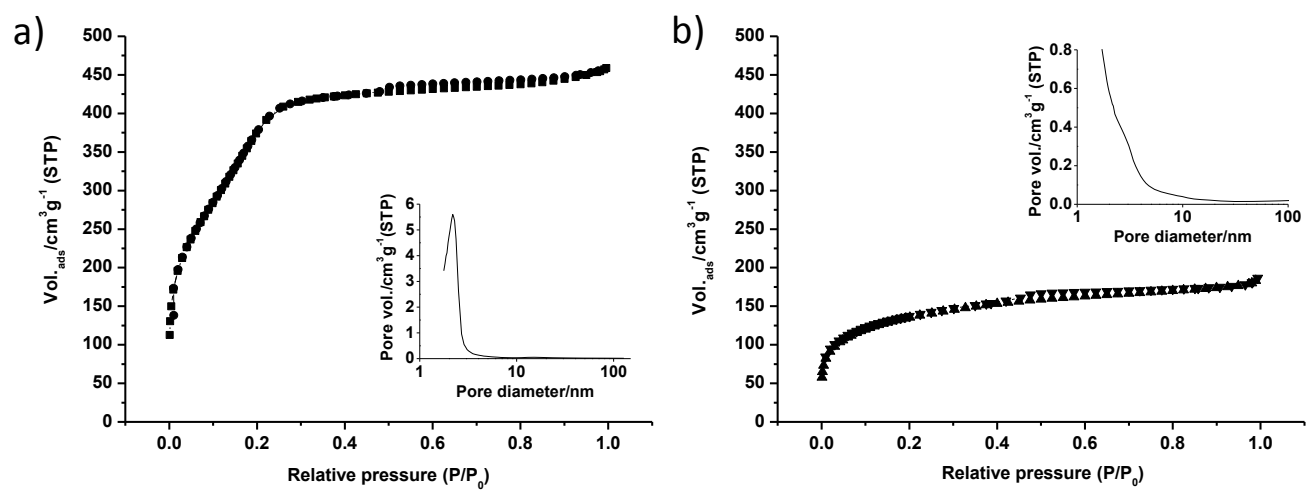

Figure SI-5. The nitrogen adsorption-desorption isotherms for (a) the MCM-41 mesoporous material (b) S1.

This is an expected result if we bear in mind that these solids have a high content of dye filling pores. The specific surface values, pore volumes and pore sizes for MCM-41 and $\mathbf{S 1}$ are presented in Table SI-1.

Table SI-1. The BET-specific surface values, pore volumes and pore sizes calculated from the $\mathrm{N}_{2}$ adsorption-desorption isotherms for selected materials.

\begin{tabular}{c|ccc}
\hline & $\begin{array}{c}S_{\text {BET }} \\
\left(\mathrm{m}^{2} \mathrm{~g}^{-1}\right)\end{array}$ & $\begin{array}{c}\text { Pore Volume }^{a} \\
\left(\mathrm{~cm}^{3} \mathrm{~g}^{-1}\right)\end{array}$ & $\begin{array}{c}\text { Pore size }^{a} \\
(\mathrm{~nm})\end{array}$ \\
\hline MCM-41 & 1415 & 0.88 & 2.29 \\
S1 & 484.3 & 0.21 & - \\
\hline \multicolumn{2}{c}{ a Volume (V) and diameter (D) of the mesopores. }
\end{tabular}

${ }^{\mathrm{a}}$ Volume (V) and diameter (D) of the mesopores.

The content of the $\left[\mathrm{Ru}(\mathrm{bipy})_{3}\right]^{2+}$ complex and the pyrene derivative in the prepared solid S1 were determined by thermogravimetric measurements, and amount to $0.061 \mathrm{mmol} / \mathrm{g} \mathrm{SiO}_{2}$ and $0.104 \mathrm{mmol} / \mathrm{g} \mathrm{SiO}_{2}$, respectively. The heating ramp used to perform the thermogravimetric analyses consisted in a heating ramp of $10^{\circ} \mathrm{C}$ per minute, from $20^{\circ} \mathrm{C}$ to $1000{ }^{\circ} \mathrm{C}$, and an isothermal step at this temperature for 30 minutes. Examination of the thermogravimetric curve and its first derivative shows four weight loss steps: a first weight loss of $11.50 \%$ 
corresponding to solvents elimination $\left(T<200^{\circ} \mathrm{C}\right)$; a second weight loss of $9.73 \%$ due to the decomposition of the organic groups anchored on the siliceous surface $\left(200<\mathrm{T}<360^{\circ} \mathrm{C}\right)$; a third weight loss of $2.47 \%$ assigned to the decomposition of the ruthenium complex $\left(360<\mathrm{T}<800^{\circ} \mathrm{C}\right)$; finally, a weight loss of $0.87 \%$ owing to the condensation of the silanols on the siliceous surface $\left(\mathrm{T}>800^{\circ} \mathrm{C}\right)$.

The higher amount of pyrene $\left(0.104 \mathrm{mmol} / \mathrm{g} \mathrm{SiO}_{2}\right)$, when compared with the ruthenium dye $\left(0.061 \mathrm{mmol} / \mathrm{g} \mathrm{SiO}_{2}\right)$, is a direct consequence of the low yield (about $40 \%$ ) of the click reaction used for the grafting of the fluorophore. Bearing this in mind, there are pores without a sufficient amount of pyrene groups in their surroundings that are unable to retain the ruthenium complex. After the click reaction solid S1 was exhaustively washed with dichloromethane, water, acetonitrile and tetrahydrofuran in order to remove the adsorbed matter and the ruthenium dye from the non-closed pores (with the aim to achieve a "zero release" material). This fact accounts for the specific surface presented by S1 $\left(484.3 \mathrm{~m} \mathrm{~g}^{2} \mathrm{~g}^{-1}\right)$ and also for the apparent contradiction that there are more pyrene anchored in the outer surface than ruthenium complex in the inner of the pores.

\section{Solvent selection}

The studies into the explosive-induced uncapping paradigm were carried out in acetonitrile. In this solvent, a remarkably rather tight pore closure was observed and, at the same time, both the ruthenium dye and the selected explosives showed suitable solubility. Protic solvents (such as methanol and ethanol) are avoided because could give certain charge-transfer interactions with the electron deficient nitroaromatic compounds. Moreover water-acetonitrile mixtures were also tested but unfortunately in this media no sensing features were observed when using $\mathbf{S 1 .}$ 


\section{Fluorescence quenching studies}

To confirm the fact that the observed response of solid $\mathbf{S 1}$ arises from the interaction between the anchored pyrene and nitroaromatic explosives TNT and Tetryl, further fluorescence measurements were taken (at $25^{\circ} \mathrm{C}$ ). Indeed, $1 \mathrm{mg}$ of S1 was suspended in $3 \mathrm{~mL}$ of the acetonitrile solutions of TNT and Tetryl $\left(2.0 \times 10^{-3}\right.$ mol dm${ }^{-3}$ ), while the emission of pyrene (excitation at $341 \mathrm{~nm}$ ) was measured in the presence of increasing quantities of the nitroaromatic explosives. As seen in Figure $\mathrm{SI}-6$, the monomer emission of the appended pyrene was quenched upon addition of nitroaromatic explosives.

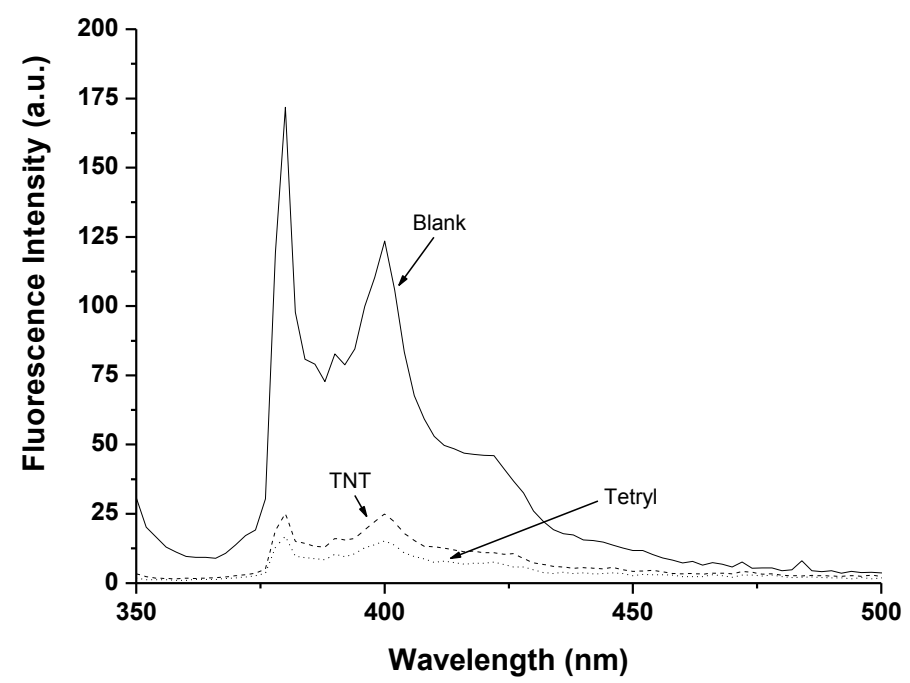

Figure SI-6. The fluorescence spectrum of the acetonitrile suspensions of $\mathbf{S 1}$ (at $25^{\circ} \mathrm{C}$ ) in the presence of TNT and Tetryl $\left(2.0 \times 10^{-3} \mathrm{~mol} \mathrm{dm}^{-3}\right)$.

Sterm and Volmer considered the quenching process to be a bimolecular reaction which competes with the radiative process and all other molecular processes. Following this, we measured the quenching constants of the grafted pyrene with Tetryl and TNT. The procedure followed is analogous to that described in the dye release studies. Briefly, $4 \mathrm{mg}$ of $\mathbf{S 1}$ were suspended in $10 \mathrm{~mL}$ of an acetonitrile containing explosives TNT or Tetryl. Different aliquots ( $3 \mathrm{~mL}$ ) were taken after $1 \mathrm{~min}$ of reaction, and the emission of the appended pyrene was 
measured. The Stern-Volmer plots of relative fluorescence intensity $\left(F_{0} / F\right)$ of $\mathbf{S 1}$ versus Tetryl and TNT concentration are shown in Figure SI-7 in which $\mathrm{F}_{0}$ and $\mathrm{F}$ are the fluorescence intensity of the hybrid material before and after adding explosive, respectively. It is notable that the $F_{0} / F$ versus [explosive] plots bends upwards instead of being linear, which may be due to the pyrene emission is quenched by a static quenching or with the participation of a dynamic quenching. The Stern-Volmer curves of $\mathbf{S 1}$ in acetonitrile can be well fitted to the exponential equations $F_{0} / F=1.13 e^{1617[T e t r y l]}$ and $F_{0} / F=1.14 e^{1166[T N T]}$ with quenching constants (in the low concentration range) of about $3044 \mathrm{M}^{-1}$ and $1050 \mathrm{M}^{-1}$ for Tetryl and TNT, respectively.

The values of the Stern-Volmer quenching constants clearly indicate that Tetryl is able to provide the strongest interactions with the pyrene grafted on the surface of the $\mathbf{S 1}$ material. This is most likely related to the more electrondeficient character of Tetryl when compared with TNT. The Stern-Volmer quenching constants measured for $\mathbf{S 1}$ were of the same order of magnitude as those measured for either polymeric materials or molecular fluorophores in the presence of nitroaromatic molecules.

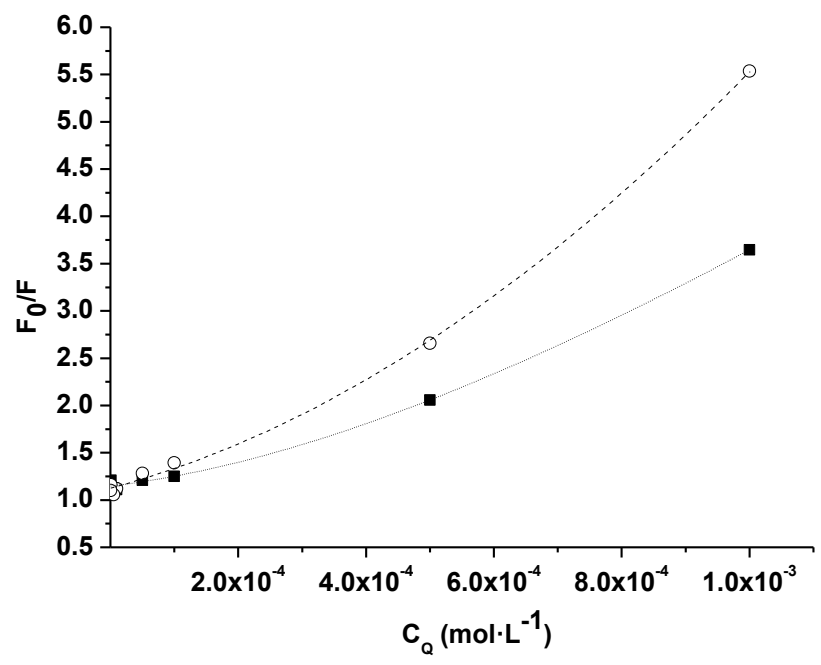

Figure SI-7. A Stern-Volmer quenching representation for acetronitrile suspensions of S1 upon addition of Tetryl (o) and TNT ( $\boldsymbol{\bullet})$. 


\section{Dye release studies}

For the dye release studies (carried out at $25^{\circ} \mathrm{C}$ ), $4 \mathrm{mg}$ of $\mathbf{S 1}$ were suspended in $10 \mathrm{~mL}$ of acetonitrile solution $\left(2.0 \times 10^{-3} \mathrm{~mol} \mathrm{dm}^{-3}\right)$ of the following compounds: 2,4-DNT, TNT, Tetryl, hexahydro-1,3,5-trinitro-1,3,5-triazine (RDX), pentaerythritol tetranitrate (PETN), N-methylaniline (NM), 2-nitrotoluene (NT), nitrobenzene $(\mathrm{NB})$, methylene blue (MB) and naphthalenene (NP). Different aliquots $(2 \mathrm{~mL})$ were separated and filtered after 10 minutes. The delivery of the dye from the pore voids to the solution was monitored by the emission band of the $\left[\mathrm{Ru}(\text { bipy) })_{3}\right]^{2+}$ complex centred at $625 \mathrm{~nm}$. The results are observed in Figure 3 (see the manuscript). Of all the nitroaromatic derivatives tested, only Tetryl and TNT were able to uncap the pores with the subsequent release of the ruthenium complex.

\section{Ratiometric sensing measurements}

For ratiometric sensing studies, $1 \mathrm{mg}$ of $\mathbf{S 1}$ was suspended in $3 \mathrm{~mL}$ of the acetonitrile and the emission spectra, upon excitation at $341 \mathrm{~nm}$, registered. Suspensions of $\mathbf{S 1}$ alone showed the typical broad structured pyrene monomer emission in the 370-450 nm range. Addition of increasing quantities of TNT and Tetryl, to $\mathbf{S 1}$ suspensions, induced a gradual quenching of the pyrene monomer emission together with the appearance of a new fluorescence centred at $625 \mathrm{~nm}$ (due to the ruthenium complex released upon gate opening). Figure SI-8 showed the emission changes observed for acetonitrile $\mathbf{S 1}$ suspensions upon addition of increasing quantities of TNT (nearly the same response was obtained upon addition of Tetryl). 


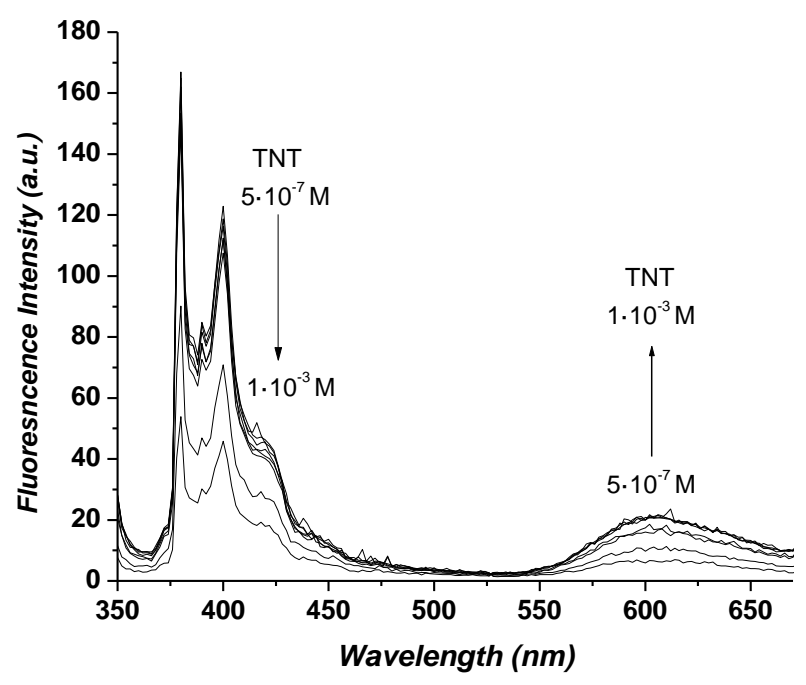

Figure SI-8. Emission changes of $\mathbf{S 1}$ acetonitrile suspensions (at $25^{\circ} \mathrm{C}$ ) upon addition of increasing quantities of TNT (excitation at $341 \mathrm{~nm}$ ).

\section{Limits of detection studies}

The limits of detection using S1 for TNT and Tetryl were determined using $4 \mathrm{mg}$ of solid S1, which were suspended in $10 \mathrm{~mL}$ of the different solutions containing increasing concentrations of the corresponding explosive (at $25^{\circ} \mathrm{C}$ ). Different aliquots $(2 \mathrm{~mL})$ were taken up and filtered after 10 minutes. The delivery of the $\left[\mathrm{Ru}(\mathrm{bipy})_{3}\right]^{2+}$ complex from the pore voids to the solution was easily monitored by the emission band at $625 \mathrm{~nm}$ (see Figure SI-9). 


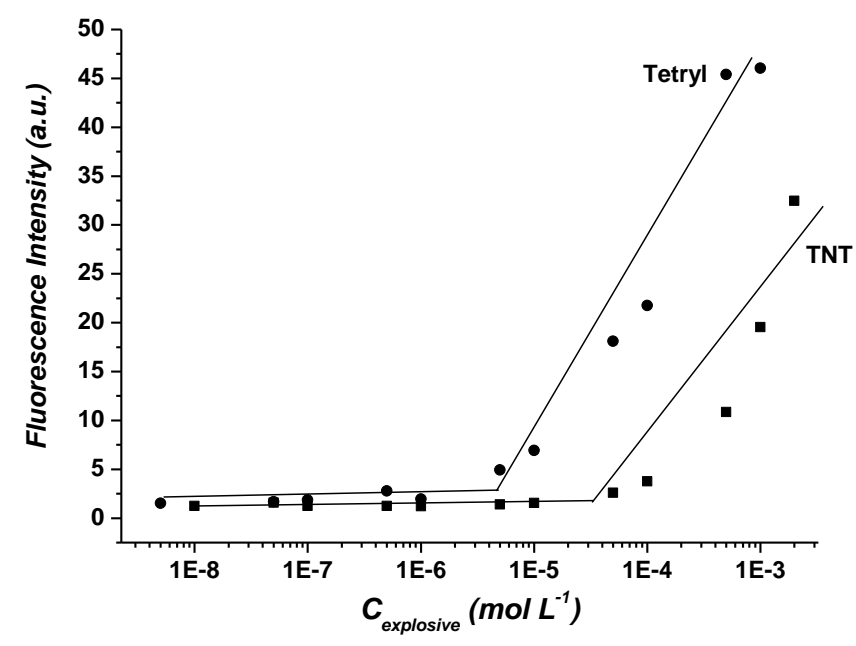

Figure SI-9. Calibration curves obtained from the acetonitrile suspensions of $\mathbf{S 1}$ (at $25^{\circ} \mathrm{C}$ ) upon addition of increasing quantities of TNT and Tetryl (excitation at $451 \mathrm{~nm}$, emission at $625 \mathrm{~nm}$ ).

The fluorimetric titrations, shown in Figure SI-9, allowed us to determine the limits of detection for Tetryl (1.4 ppm) and TNT (11.4 ppm).

The detection limits for Tetryl and TNT using solid $\mathbf{S 1}$ were also determined by monitoring the nitroaromatic-induced pyrene quenching. In particular, $4 \mathrm{mg}$ of solid $\mathbf{S 1}$ were suspended in $10 \mathrm{~mL}$ of the different solutions containing increasing concentrations of the corresponding explosive. Different aliquots $(2 \mathrm{~mL})$ were taken up after 10 minutes. The quenching delivery of the appended pyrene was easily monitored by the monomer emission bands in the 370-440 $\mathrm{nm}$ range (see Figures $\mathrm{SI}-10$ and $\mathrm{SI}-11$ ). The fluorimetric titrations allowed us to determine the limits of detection for Tetryl (8.6 ppm) and TNT (9.1 ppm). 


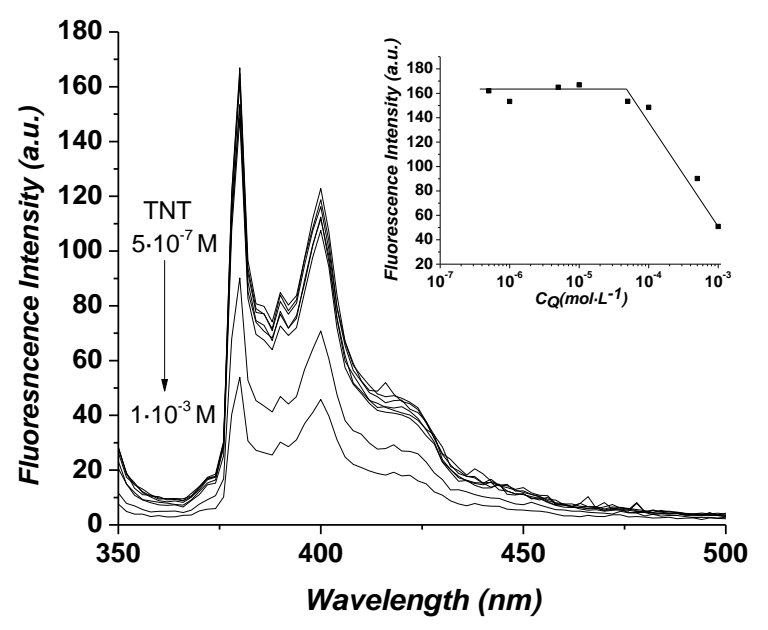

Figure SI-10. Quenching of the grafted pyrene upon addition of increasing quantities of TNT to acetonitrile suspensions of $\mathbf{S 1}\left(\right.$ at $\left.25^{\circ} \mathrm{C}\right)$. The inset shows the calibration curves obtained from the acetonitrile suspensions of $\mathbf{S 1}$ upon addition of increasing quantities of TNT (excitation at $341 \mathrm{~nm}$, emission at $380 \mathrm{~nm}$ ).

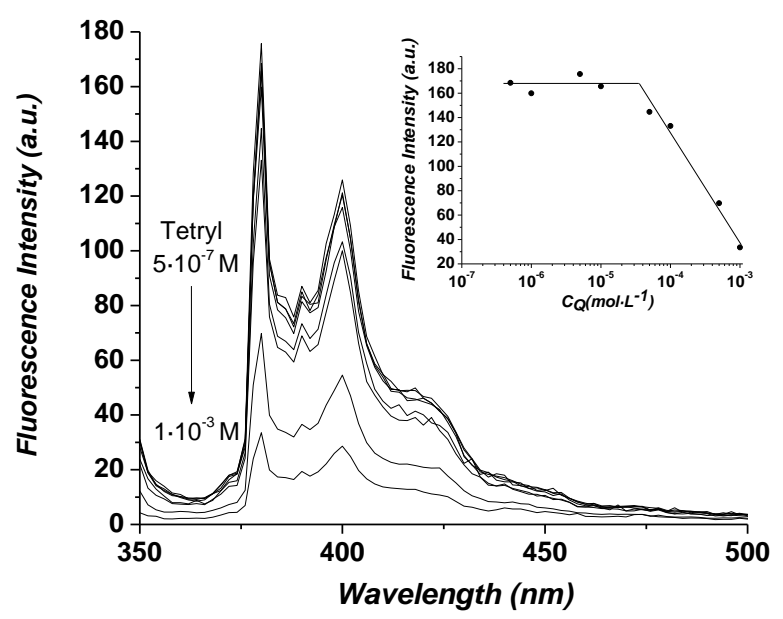

Figure SI-11. Quenching of the grafted pyrene upon addition of increasing quantities of Tetryl to acetonitrile suspensions of $\mathbf{S 1}\left(\right.$ at $25^{\circ} \mathrm{C}$ ). The inset shows the calibration curves obtained from the acetonitrile suspensions of $\mathbf{S 1}$ upon addition of increasing quantities of Tetryl (excitation at $341 \mathrm{~nm}$, emission at $380 \mathrm{~nm}$ ). 


\section{Gating mechanism}

The experimental evidences, no pyrene excimer emission in acetonitrile and in water was observed, pointed to an alternative mechanism rather than to a simple pyrene-pyrene interaction. At this respect, the high quantity of pyrene grafted in the outer of the pores $\left(0.104 \mathrm{mmol} / \mathrm{g} \mathrm{SiO}_{2}\right)$ pointed toward the formation of a relatively dense monolayer around the pores that inhibited the release of the entrapped ruthenium complex. Bearing in mind an external surface area of $29 \mathrm{~m}^{2}$ $\mathrm{g}^{-1}$ (for the solid with the pores loaded with ruthenium complex and the azide moiety grafted in the outer surface) and applying the equation (1):

$$
\beta_{A}=\alpha_{A} \cdot 10^{-3} \cdot S^{-1} \cdot 10^{-18} \cdot N_{A}
$$

where $\alpha_{A}$ is the mmol of pyrene derivative/g solid in $\mathbf{S 1}, S$ is the external surface area and $N_{A}$ is the Avogadro's number, an average distance between pyrene molecules of $7.8 \AA$ was estimated. With an average pore diameter of $2.29 \mathrm{~nm}$ and an $a_{0}$ cell parameter of $3.64 \mathrm{~nm}$ we can estimate that each pore was surrounded by 10 pyrene molecules. This leads to the formation of a dense pyrene network around the pore outlets that inhibit cargo release. Also the molecule that acts as gate is composed by a pyrene fluorophore (electron donor character) and by a 1,2,3-triazole heterocycle (electron acceptor character). As a consequence, a charge-transfer process, in the pyrene-triazole molecule, is active leading to the generation of a strong dipole moment (of $3.2 \mathrm{D}$ estimated through quantum mechanical calculations at the semi-empirical level using Hyperchem 6.0 software). Bearing in mind this fact, strong dipole-dipole interactions between the gating molecules would be active in S1 and most likely accounted for the inhibition of the cargo release observed. The nitroaromatic explosives (Tetryl and TNT) added could give charge-transfer interactions, with the grafted pyrene subunits inhibiting the dipole-dipole interaction and therefore inducing a reduction of the steric crowding around the pore outlets and the disruption of the 
dipole-dipole forces. As a consequence a release of the entrapped ruthenium complex was observed.

Moreover, in order to discard a possible nitroaromatic-induced displacement of the ruthenium complex due to the diffusion of nitroaromatics into the pores several experiences were carried out. At this respect, the chromogenic response in the presence of Tetryl and TNT of a hybrid solid that contains the ruthenium complex, in the inner of the pores, and azide moieties, in the external surface, has been tested. For that, $4 \mathrm{mg}$ of solid were suspended in acetonitrile $(10 \mathrm{~mL})$ or in acetonitrile containing Tetryl or TNT $\left(10 \mathrm{~mL}, 2.0 \times 10^{-3} \mathrm{~mol} \mathrm{dm}^{-3}\right)$. The suspensions were stirred for 10 minutes and then filtered. Then, the absorption or the emission band of the ruthenium complex released was measured. The same absorbance (see Figure SI-12) and emission intensity for the solid alone or solid in the presence of Tetryl and TNT was obtained indicating that there are no displacement of ruthenium complex by the nitroaromatic explosives.

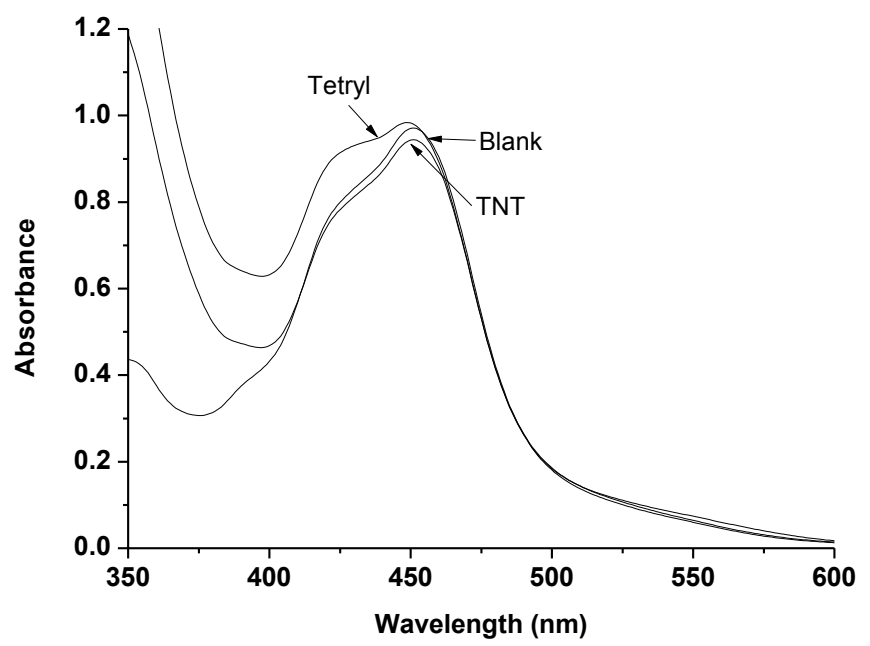

Figure SI-12. Absorbance of acetonitrile suspensions of a solid that contains the ruthenium complex (in the inner of the pores) and azide moieties (in the external surface) in the absence and in the presence of Tetryl and TNT $\left(2.0 \times 10^{-3} \mathrm{~mol} \mathrm{dm}^{-3}\right)$. 

5.4 Tetrathiafulvalene-capped hybrid materials for the optical detection of explosives. 



\title{
Tetrathiafulvalene-capped hybrid materials for the optical detection of explosives
}

\author{
Yolanda Salinas, ${ }^{\dagger \ddagger \S}$ Ramón Martínez-Máñez, ${ }^{+\neq \S}$ \\ Jan O. Jeppesen, *II Lars H. Petersen, ${ }^{I I}$ Félix Sancenón, ${ }^{\neq \neq \S}$ \\ María Dolores Marcos, ${ }^{\dagger \neq \S}$ Juan Soto, ${ }^{\dagger \neq}$ Carmen Guillem ${ }^{\perp}$ \\ and Pedro Amorós ${ }^{\perp}$
}

+ Instituto de Reconocimiento Molecular y Desarrollo Tecnológico, Centro Mixto Universidad Politécnica de Valencia - Universitat de Valencia, E-46022, Valencia, Spain.

${ }^{\ddagger}$ Departamento de Química. Universidad Politécnica de Valencia. Camino de Vera $s / n$. E-46022, Valencia, Spain.

${ }^{\S}$ CIBER de Bioingeniería, Biomateriales y Nanomedicina (CIBER-BBN).

"Department of Physics, Chemistry and Pharmacy, University of Southern Denmark, Campusvej 55, 5230 Odense M, Denmark.

${ }^{\perp}$ Institut de Ciència dels Materials (ICMUV), Universitat de Valencia, P.O. Box 2085, E-46071, Valencia, Spain.

Received: $14^{\text {th }}$ December 2012

First published on the web: $4^{\text {th }}$ February 2013

ACS Applied Materials and Interfaces, 2013, 5, 1538-1543 (Reproduced with permission of American Chemical Society) 



\section{Abstract}

Mesoporous silica microparticles capped with TTF moieties and containing a ruthenium dye in the pores were used for the turn-on optical detection of the nitroaromatic explosives Tetryl and TNT via a selective pore uncapping and release of the entrapped dye.

Keywords: Controlled release, mesoporous solids, molecular gates, nitroaromatic explosives, tetrathiafulvalene, chemosensors.

Among sulfur-containing heterocycles, tetrathiafulvalene (TTF) and its derivatives have been intensively studied in materials science during the past two decades. $^{1-8}$ Moreover, the utility of TTF derivatives as building blocks in macrocyclic and supramolecular chemistry has revealed that the TTF moiety is useful beyond the field of materials chemistry and it has been incorporated into a number of exotic molecules, such as catenanes, cyclophanes, dendrimers, polymers, and rotaxanes etc. ${ }^{9,10}$ The huge potential of TTF and its derivatives was first established by the discovery of their conductive behavior. ${ }^{11,12}$ Since then, other properties of the TTF unit, such as its electroactive and strong $\pi$-donor nature have proven advantageous. As a result, a number of redox responsive ligands and sensors which incorporate the TTF unit into their framework have been reported. ${ }^{13}$

Current international public awareness on terrorist attacks using explosives has resulted in an increasing interest in the development of quick and reliable methods to detect these chemicals. ${ }^{14}$ Furthermore, explosives are used in landmines and large quantities of explosives have been dumped in the environment. In the midst of the different chemical explosives, nitroaromatics are perhaps among the most commonly used. Current procedures employed for the detection of nitroaromatic explosives are in many cases based on complex instrumental analysis. ${ }^{15-17}$ Recently, as an alternative to these classical analytical 
protocols, the design of optical probes has freshly emerged. ${ }^{18}$ In these systems, the interaction of explosive molecules with the probe (alone or attached in a polymeric matrix) induced color changes or quenching of the fluorophore emission. Jeppesen and co-workers has used TTF to prepare colorimetric sensors for nitroaromatic explosives, in the shape of TTF-calix[4]pyrroles. ${ }^{19-21}$ In these systems, the strong interaction between the electron-deficient nitroaromatics and the electron-rich TTF subunits are responsible for the observed color modulation.

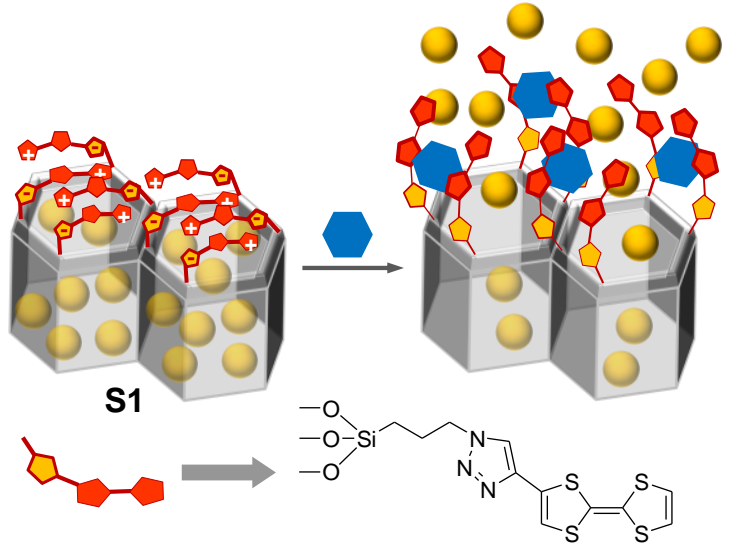

$\rightarrow$ Nitroaromatic explosive
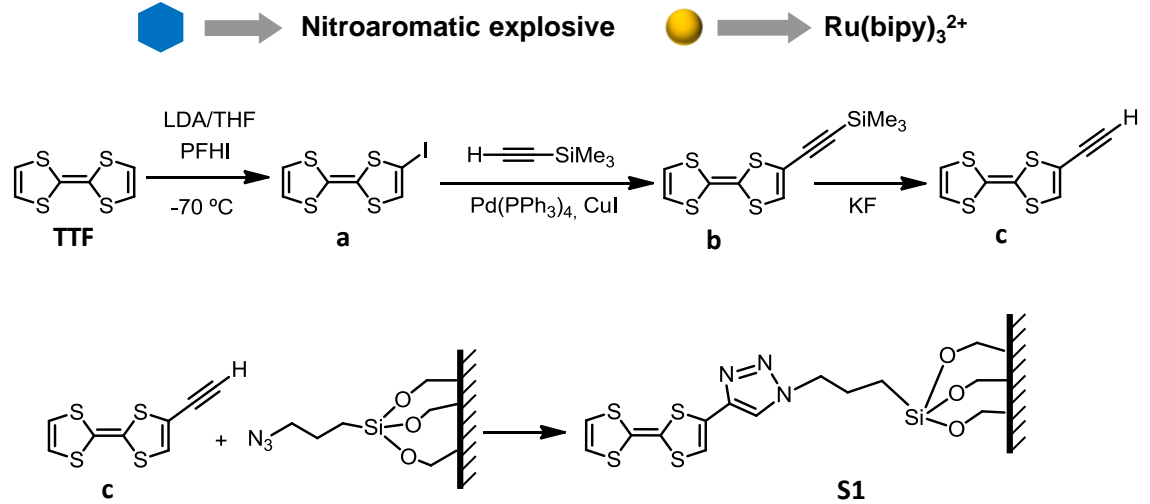

Scheme 1. Schematic representation (top) of the sensing mechanism of the solid $\mathbf{S 1}$ in the presence of explosives, synthesis (middle) of TTF derivative $c$, and synthesis (bottom) of the $\mathbf{S 1}$ material.

Very recently, the development of nanoscopic hybrid materials equipped with "molecular gates" showing the ability of releasing target entrapped guests upon 
application of an external trigger has attracted great attention and has been extensively explored during the past years. ${ }^{22,23}$ These nano-devices are composed by two subunits, namely, a suitable support and certain capping entities grafted on the surface of the scaffold. ${ }^{24}$ The support is used as a suitable reservoir in which certain chemicals could be stored whereas the molecules attached on the outer surface act as a "gate" and could control the release of the entrapped molecules at will. Both components have been carefully selected and arranged in order to achieve a wide range of required functionalities using diverse chemistries. These capped materials have been fundamentally used as controlled drug delivery nano-platforms. ${ }^{25-28}$ In contrast their use in sensing applications are less common. ${ }^{29-31}$

Bearing in mind these independent research fields and as a continuation of our work in the design of new explosive probes ${ }^{32}$ and new applications using capped mesoporous materials, we report herein the synthesis and sensing behavior of a gated solid functionalized with TTF subunits for the turn-on chromo-fluorogenic detection of nitroaromatic explosives. An illustration of the signaling protocol is shown in Scheme 1. In our approach, a suitable inorganic mesoporous support has been selected and their pores loaded with a dye. Subsequently, a TTF derivative that can act as a molecular cap was grafted on the outer surface. The presence of a dense network of TTF units around the pores was expected to inhibit the delivery of the dye. The signaling paradigm relies on the strong electron accepting character of the nitroaromatic derivatives and the formation of TTF-nitroaromatic complexes, ${ }^{33-36}$ which result in the rupture of TTF-TTF interactions, e.g., the gate is unlocked followed by delivery of the dye.

As inorganic support, mesoporous MCM-41 silica microparticles were chosen on account of their unique properties such as large load capacity and well-known functionalization procedures. ${ }^{37-39}$ The MCM-41 mesoporous scaffold was prepared by using tetraethyl orthosilicate (TEOS) as inorganic precursor and hexadecyltrimethylammonium bromide (CTAB) as a porogen species. ${ }^{40}$ The surfactant was 
removed by calcination and the final MCM-41 support was obtained. The inorganic material was then loaded with $\left[\mathrm{Ru}(\mathrm{bipy})_{3}\right]^{2+}$ as a suitable fluorophore and the outer surface was functionalized with 3-(azidopropyl)triethoxisylane groups. In the second step (Scheme 1), the TTF derivative $\mathbf{c}$ was attached to solid S1 by a copper (I)-catalyzed Huisgen azide/alkyne 1,3-dipolar cycloaddition "click" reaction. ${ }^{41}$ This led to the formation of a 1,2,3-triazole heterocycle and yielded the final hybrid material $\mathbf{S 1}$. The resulting solid was filtered, intensively washed with water and with organic solvents before being dried overnight at $36^{\circ} \mathrm{C}$. Water washings were carried out in order to eliminate possible traces of copper in the surface of S1. SEM analysis using Energy Dispersive X-ray spectroscopy (EDX, 20 $\mathrm{kV}$ ) carried out on the S1 material did not show any characteristic signal for copper indicating that residual copper is not present in the final isolated S1 material. EDX also clearly indicated the presence of sulphur atoms (due to the grafted TTF moieties) in $\mathbf{S 1 .}$

The TTF derivative c was synthesized (Scheme 1) following a three-step procedure ${ }^{42,43}$ from TTF (see Supporting Information for experimental details). In the first step, 2-iodo-TTF (compound a) was prepared by lithiation of TTF with lithium diisopropylamide (LDA) in THF at $-70^{\circ} \mathrm{C}$ following reaction of the lithiated TTF derivative with perfluorohexyl iodide (PFHI). Subsequently, compound a was reacted with trimethylsilylacetylene in a mixture of THF and diisopropylamine and with catalytic amounts of $\mathrm{Cul}$ and $\mathrm{Pd}\left(\mathrm{PPh}_{3}\right)_{4}$ to afford 2-trimethylsilylethynyl-TTF (compound b). Finally, the conversion to the corresponding ethynylated-TTF derivative (compound $\mathbf{c}$ ) was carried out by treatment of compound $\mathbf{b}$ with KF. ${ }^{44}$ Moreover, In order to corroborate the negligible effect of the click reaction in the electrochemical features of TTF a model compound $\mathbf{2}$ was synthesized (see Supporting Information). Solution oxidation potentials obtained from the cyclic voltammograms (CVs) of TTF and $\mathbf{2}$ are summarized in Table S3. CV of compound 2 and TTF showed two reversible one-electron redox waves as expected (see Figure SI-12 and Table S3). 
The starting MCM-41 materials and final sensing solid S1 were characterized by a variety of different techniques. The presence of the MCM-41 support was confirmed (Figure 1 ) by X-ray diffraction (XRD) and transmission electron microscopy (TEM) techniques. Figure 1a shows the powder X-ray pattern of MCM41 as-synthesized, MCM-41 calcined, and the $\mathbf{S 1}$ material. The powder XRD of siliceous MCM-41 as-synthesized shows four low-angle peaks typical of an hexagonal-ordered array which can be indexed as (100), (110), (200), and (210) Bragg reflections. A shift of the (100) peak and a remarkable broadening of the (110) and (200) reflections in the XRD of the MCM-41 calcined sample was observed, whereas $\mathbf{S 1}$ only shows the characteristic (100) reflection. The presence of this peak in $\mathbf{S 1}$ indicates that the mesoporous structure was preserved throughout the filling process with the dye and the anchoring of the TTF derivative. Figure $1 \mathrm{~b}$ and $1 \mathrm{c}$ show TEM images of the micrometric MCM-41 solid support and of the final hybrid material S1, showing the typical porosity associated with this type of inorganic support. The $\mathrm{N}_{2}$ adsorption-desorption isotherms of calcined MCM-41 showed a typical type IV-curve with a specific surface of $1036.2 \mathrm{~m} \mathrm{~g}^{2}$, and a pore volume of $0.45 \mathrm{~cm}^{3} \mathrm{~g}^{-1}$ (see Figure SI-5). From the XRD, porosimetry, and TEM studies, the $a_{0}$ cell parameter $(3.65 \mathrm{~nm})$, the pore diameter $(2.25 \mathrm{~nm})$ and the wall thickness $(1.40 \mathrm{~nm})$ were obtained. Additionally, the $\mathrm{N}_{2}$ adsorption-desorption isotherm of $\mathbf{S} \mathbf{1}$ was typical of mesoporous systems with partially filled mesopores, ${ }^{45}$ and a decrease in the $\mathrm{N}_{2}$ volume adsorbed and surface area $\left(816.2 \mathrm{~m}^{2} \mathrm{~g}^{-1}\right)$ was observed. The organic content in S1 was determined by thermogravimetric analyses (see Figure SI-6); S1 contained $0.044 \mathrm{mmol}$ of the ruthenium complex $/ \mathrm{g} \mathrm{SiO}_{2}$ and $0.290 \mathrm{mmol}$ of the TTF derivative/g $\mathrm{SiO}_{2} .{ }^{29} \mathrm{Si}$ and ${ }^{13} \mathrm{C}$ MAS NMR studies on $\mathbf{S 1}$ were also carried out confirming the functionalization of the solid with TTF groups (see Figure SI-7, Table S2 in the Supporting Information). 


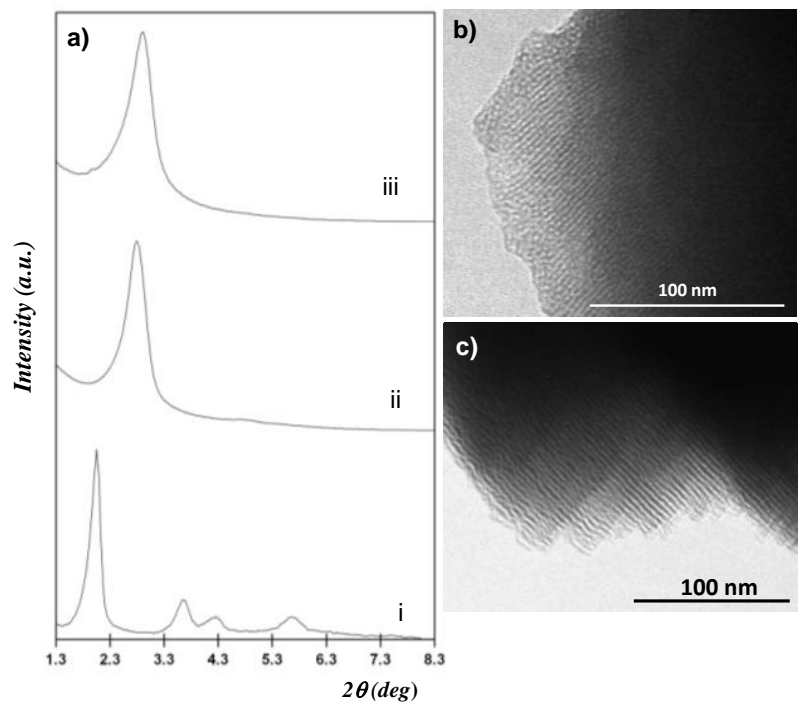

Figure 1. a) X-ray patterns of (i) MCM-41 as-synthesized, (ii) MCM-41 calcined, and (iii) solid S1. b) TEM image of MCM-41 calcined. c) TEM image of solid S1.

In order to prove the proposed sensing mechanism (Scheme 1), the interaction of $\mathbf{S 1}$ with nitroaromatics was studied through the delivery of the ruthenium complex. Release studies were carried out in acetonitrile where a tight pore closure was observed (vide infra) and both, the ruthenium dye and the selected nitroaromatics were soluble. In a preliminary assay, it was demonstrated that acetonitrile solutions of $\mathbf{S 1}$ in the absence of nitrated explosives showed "zero release". The capping molecule is composed by an electron donating TTF subunit, and a triazole heterocycle, that have electron accepting character. Consequently, the grafted molecular gate have a permanent dipole moment of $1.78 \mathrm{D}$ (estimated by molecular calculations with Hyperchem 8.0 software) and dipole-dipole interactions between gating TTF molecules in the dense network around the pore outlets seems likely to inhibit dye delivery (Scheme 1, left top). In further studies delivery assays in the presence of nitroaromatics were carried out. In a typical assay, $4 \mathrm{mg}$ of $\mathbf{S 1}$ was suspended in $10 \mathrm{~mL}$ of acetonitrile containing the selected explosives and after a certain time the solution was filtered. Delivery of the dye to the bulk solution was easily detected by monitoring the metal-to-ligand-charge- 
transfer $(\mathrm{MLCT})$ transition band of the $\left[\mathrm{Ru}(\text { bipy })_{3}\right]^{2+}$ complex centred at $453 \mathrm{~nm}$ or its luminescence at $615 \mathrm{~nm} .^{46-47}$

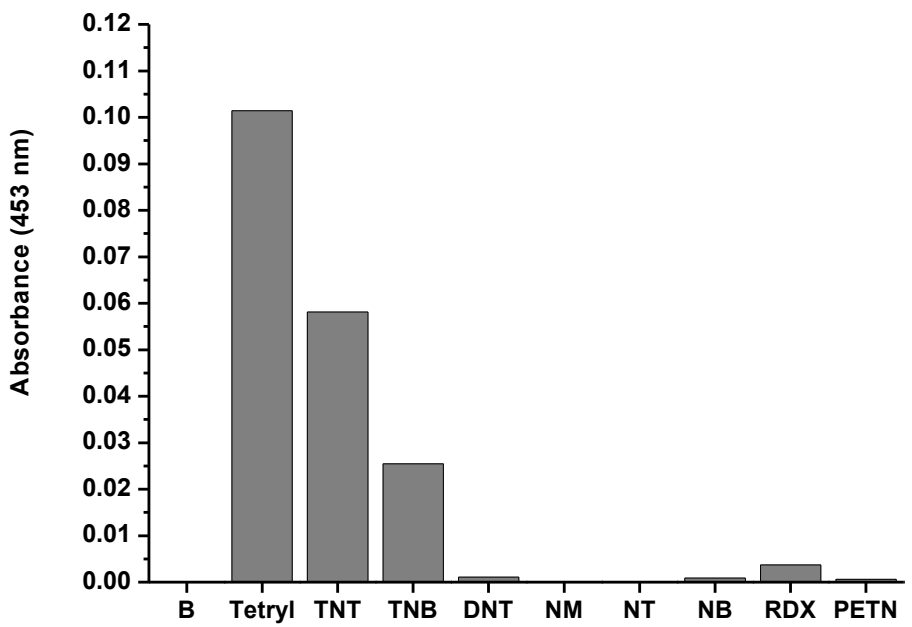

Figure 2. Absorbance intensity at $453 \mathrm{~nm}$ (ruthenium complex band) of acetonitrile suspensions of $\mathbf{S 1}$ in the presence of different nitroaromatics $\left(2 \times 10^{-3} \mathrm{~mol} \mathrm{~L}^{-1}\right)$ and non-aromatic nitrated compounds after 150 min of addition.

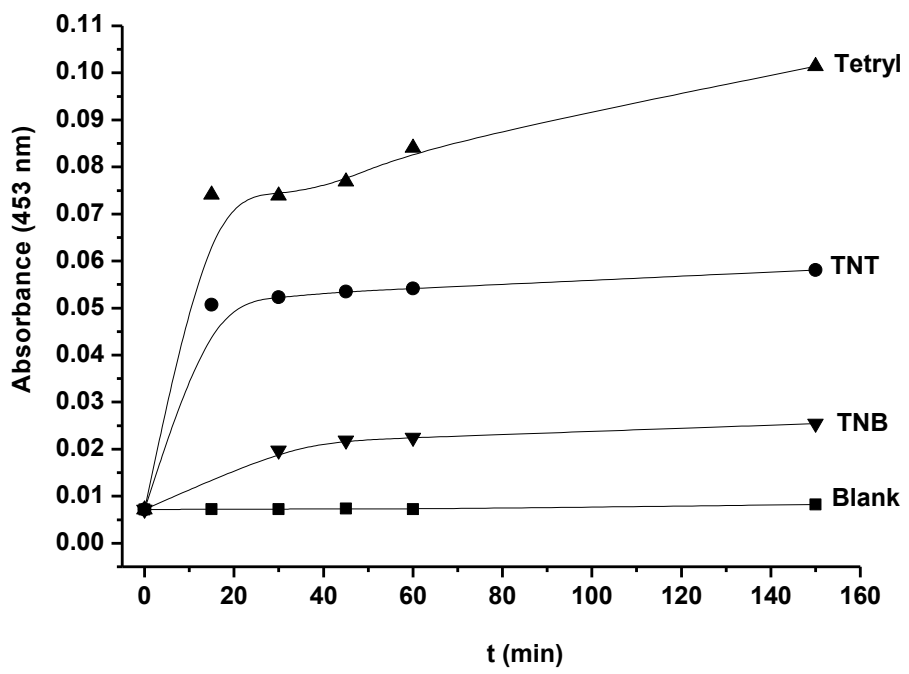

Figure 3. Kinetics of the release of the $\left[\mathrm{Ru}(\text { bipy })_{3}\right]^{2+}$ dye from the solid $\mathbf{S 1}$ in the absence (blank) and the presence of the nitroaromatic explosives Tetryl, TNT, and TNB $\left(2.0 \times 10^{-3} \mathrm{~mol} \mathrm{~L}^{-1}\right)$ in acetonitrile obtained using the $\left[R u(b i p y)_{3}\right]^{2+}$ absorbance at $\lambda=453 \mathrm{~nm}$ as probe. 
Following this protocol, the chromo-fluorogenic response of $\mathbf{S 1}$ to 2,4,6trinitrophenylmethylnitramine (Tetryl), 2,4,6-trinitrotoluene (TNT), 1,3,5trinitrobenzene (TNB), 2,4-dinitrotoluene (2,4-DNT), N-methylaniline (NM), 2nitrotoluene (NT), nitrobenzene (NB), hexahydro-1,3,5-trinitro-1,3,5-triazine (RDX) and pentaerythritol tetranitrate (PETN) was studied. As could be interfered from Figure 2, dye delivery from $\mathbf{S 1}$ was only observed for Tetryl, TNT, and in a lesser extent for TNB. ${ }^{48}$ Additionally, Figure 3 shows the kinetics of the release of the ruthenium dye from $\mathbf{S 1}$ in the presence of Tetryl, TNT, and TNB. In all cases dye delivery was observed within ca. 20 minutes. This observation can most likely be accounted for by the formation of TTF-nitroaromatic complexes, which results in the rupture of the dipole-dipole interactions between the grafted TTF molecules allowing the gate to open. ${ }^{33-36}$ This hypothesis is supported by the fact that for a certain concentration, the amount of dye delivered from $\mathbf{S 1}$ follow the order Tetryl > TNT > TNB which is also the order of the electron accepting character of these nitro derivatives, an observation which strongly suggest that it is their interaction with the electron donating TTF units which are responsible for the uncapping process. In addition, ${ }^{13} \mathrm{C}$ NMR spectroscopic investigations carried out on the solid S1 in the presence of Tetryl (see materials characterization in Supporting Information) supported the proposed opening mechanism.

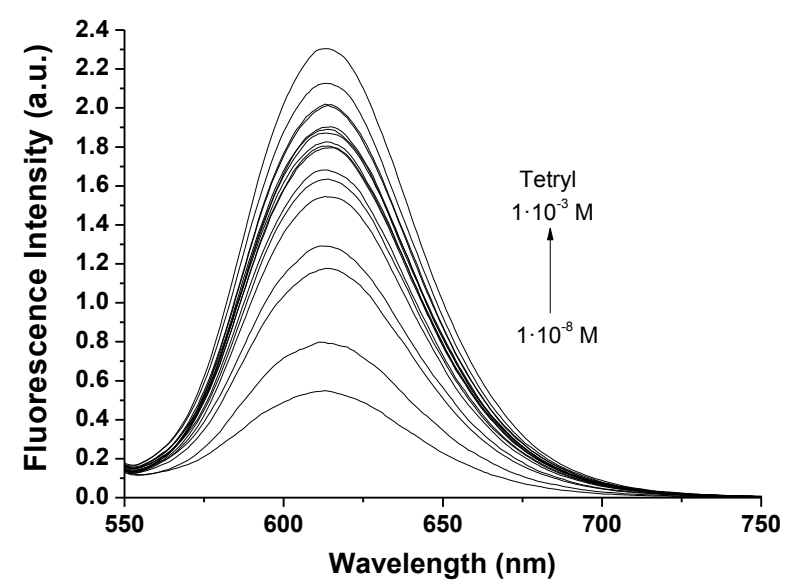

Figure 4. Changes in the emission band of the ruthenium complex released from acetonitrile suspensions of $\mathbf{S 1}$ upon addition of increasing quantities of Tetryl $\left(\lambda_{e x}=453 \mathrm{~nm}\right)$ after $60 \mathrm{~min}$. 
Further studies were carried out and titration curves in the presence of Tetryl and TNT were obtained (see limits of detection studies in Supporting Information). In particular, the controlled release of $\left[\mathrm{Ru}(\mathrm{bipy})_{3}\right]^{2+}$ from the inner of the pores of S1 in the presence of increasing quantities of TNT and Tetryl was studied though the absorbance (at $453 \mathrm{~nm}$ ) or emission (at $615 \mathrm{~nm}$ ) of the complex. In these experiments, an increase in the absorbance (see Figure SI-9 for TNT in the Supporting Information) or in the intensity of the luminescence emission band (see Figure 4 for Tetryl) of the $\left[\mathrm{Ru}(\mathrm{bipy})_{3}\right]^{2+}$ dye in the solution was found to be proportional to the concentration of the explosive, which is in agreement with the above-described assisted uncapping protocol. A simple UV-visible titration (by plotting the absorbance or the emission of the released complex versus nitroaromatic explosive concentration) allowed us to calculate limits of detection (LOD) of $28 \mu \mathrm{M}(8 \mathrm{ppm})$ and $66 \mu \mathrm{M}(15 \mathrm{ppm})$ for Tetryl and TNT, respectively. By means of fluorescence measurements LOD of $3.5 \mu \mathrm{M}(1 \mathrm{ppm})$ and $26 \mu \mathrm{M}(6 \mathrm{ppm})$ were found for Tetryl and TNT, respectively (see Figure SI-8 and SI-10 in Supporting Information). For the sake of comparison Table S4 (see Supporting Information) list some sensing characteristics of recently reported colorimetric probes for the detection of nitroaromatic explosives using supramolecular-based concepts.

The limits of detection measured for $\mathbf{S 1}$ are in the range reported for related TTF-calix[4]pyrroles (ca. $3 \mathrm{ppm}$ ). ${ }^{21}$ Subtle differences in LOD and selectivity for nitroaromatic explosives of $\mathbf{S 1}$ and these reported TTF-calix[4]pyrrol derivatives are most likely due to the different sensing mechanism in both systems; i.e. whereas in the later the explosive interacts directly with the TTF-calix[4]pyrrol cavity yielding colour changes, for $\mathbf{S 1}$ the nitroaromatic explosive interacts with the grafted TTF opening the pores and allowing the release of the entrapped ruthenium complex. An additional advantage of our system, when compared with others supramolecular-based probes for TNT detection, is that in our case a turnon of the emission is observed. Besides, despite the relatively high limit of detection obtained, in the ppm range, another difference of our hybrid material is 
its modular character. In particular, the possible use of different fluorophores as cargo and the possible functionalisation of the external surface of mesoporous materials with other gating electron-deficient groups (to tune or enhance selectivity) makes this approach versatile for the future development of materials with appropriate sensing properties.

Finally, the possible use of solid $\mathbf{S 1}$ for explosive detection in soil samples was tested. In particular we used soil samples spiked with a known amount of Tetryl (97 $\mu \mathrm{M}, 27.81 \mathrm{ppm}$ ) and applied the standard addition method in order to overcome the matrix effect. The spiked soil samples were extracted with acetonitrile and then increasing volumes of a standard Tetryl solution were added (see soil extraction procedures in the Supporting Information). Figure 5 depicts the absorbance of the ruthenium complex release as a function of Tetryl concentration. By using this curve a concentration of $88 \mu \mathrm{M}(25.15 \mathrm{ppm})$ of Tetryl was measured ( $88 \%$ of recovery).

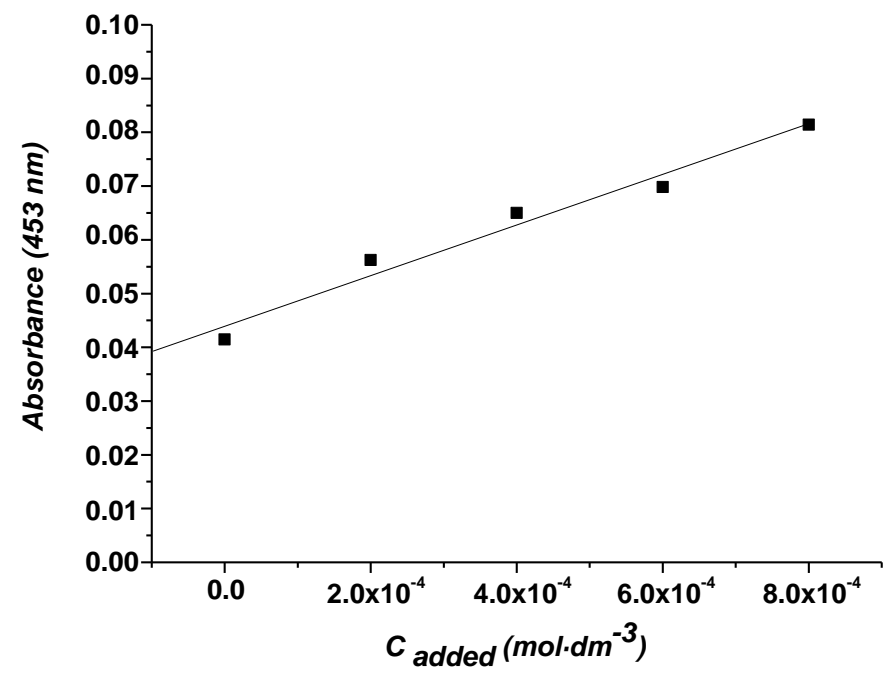

Figure 5. Absorbance measured at $453 \mathrm{~nm}$ (ruthenium complex band released from S1) in acetonitrile soil extracts in the presence of increasing quantities of Tetryl.

In summary, we have reported the synthesis of new nanoscopic silica mesoporous supports capped with an electron donating TTF derivative for the 
easy turn-on optical sensing of nitroaromatic explosives. The presence of Tetryl, TNT, and in a lesser extent TNB in acetonitrile suspensions of the hybrid material induced pore opening with the subsequent release of an entrapped dye. This allows the detection of Tetryl and TNT in a new protocol that uses a standard MCM-41 material functionalized with TTF $\pi$-donor units and a dye. It is advisable to note that this paradigm relies on a different poorly-explored approach and therefore it displays new possibilities of modulation that cannot be obtained in simple molecular-based receptors. Moreover, the preparation of the sensing material is synthetically undemanding and allows a large number of binding (TTFlike donors) and signaling units (dyes) to be probed. By using this simple procedure, color or emission changes allows the selective detection of Tetryl and TNT at the ppm level. Finally, the hybrid material was used for the detection of Tetryl in soil samples with good results. To the best of our knowledge, this represents one of the very few examples showing a turn-on of color or luminescence in the presence of nitroaromatic explosives, ${ }^{32}$ and the first example using TTF as a molecular gate. Further functionalization of the external surface of mesoporous materials with other electron-donating TTF derivatives (containing different linking units and number of sulphur atoms) to enhance and tune the selectivity are currently being pursued.

\section{Acknowledgment}

Financial support from the Spanish Government (project MAT2012-38429-C0401) and the Generalitat Valencia (project PROMETEO/2009/016) is gratefully acknowledged. Y.S. is grateful to the Spanish Ministry of Science and Innovation for her grant. J.O.J. gratefully acknowledges financial support provided by the Villum Foundation and the Danish Natural Science Research Council (\#11-106744).

\section{References}

1. Adam, M.; Müllen, K. Adv. Mater. 1994, 6, 439-459. 
2. Jørgensen, T.; Hansen, T. K.; Becher, J. Chem. Soc. Rev. 1994, 23, 41-51.

3. Bryce, M. R. J. Mater. Chem. 1995, 5, 1481-1496.

4. Garin, J. Adv. Heterocycl. Chem. 1995, 62, 249-304.

5. Schukat, G.; Fanghänel, E. Sulfur Rep. 1996, 18, 1-294.

6. Bryce, M. R. J. Mater. Chem. 2000, 10, 589-598.

7. Nielsen, M. B.; Lomholt, C.; Becher, J. Chem. Soc. Rev. 2000, 29, 153-164.

8. Segura, J. L.; Martín, N. Angew. Chem. Int. Ed. 2001, 40, 1372-1409.

9. Jeppesen, J. O.; Becher, J. Eur. J. Org. Chem. 2003, 3245-3266.

10. Jeppesen, J. O.; Nielsen, M. B.; Becher, J. Chem. Rev. 2004, 104, 5115-5132.

11. Wudl, F.; Wobschal, D.; Hufnagel, E. J. J. Am. Chem. Soc. 1972, 94, 670-672.

12. Ferraris, J.; Walatka, V.; Perlstein, J.; Cowan, D. O. J. Am. Chem. Soc. 1973, 95, 948-949.

13. Canevet, D.; Sallé, M.; Zhang, G.; Zhang, D.; Zhub, D. Chem. Commun. 2009, 2245-2269.

14. Singh, S. J. Haz. Mat. 2007, 144, 15-28.

15. Smith, R. G.; D'Souza, N.; Nicklin, S. Analyst 2008, 133, 571-584.

16. Schulte-Ladbeck, R.; Vogel, M.; Karst, U. Anal. Bioanal. Chem. 2006, 386, 559-565.

17. Moore, D. S. Rev. Sci. Inst. 2004, 75, 2499-2512.

18. Salinas, Y.; Martínez-Máñez, R.; Marcos, M. D.; Sancenón, F.; Costero, A. M.; Parra, M.; Gil, S. Chem. Soc. Rev. 2012, 41, 1261-1296.

19. Kim, D. S.; Lynch, V. M.; Nielsen, K. A.; Johnsen, C.; Jeppesen, J. O.; Sessler, J. L. Anal. Bioanal. Chem. 2009, 395, 393-400.

20. Nielsen, K. A.; Cho, W. -S.; Jeppesen, J. O.; Lynch, V. M.; Becher, J.; Sessler, J. L. J. Am. Chem. Soc. 2004, 126, 16296-16297.

21. Su Park, J.; Le Derf, F.; Bejger, C. M.; Lynch, V. M.; Sessler, J. L.; Nielsen, K. A.; Johnsen, C.; Jeppesen, J. O. Chem.-Eur. J. 2010, 16, 848-854.

22. Saha, S.; Leung, K. C. -F.; Nguyen, T. D.; Stoddart, J. F.; Zink, J. I. Adv. Func. Mater. 2007, 17, 685-693.

23. Trewyn, B. G.; Slowing, I. I.; Giri, S.; Chen, H. -T.; Lin, V. S. -Y. Acc. Chem. Res. 2007, 40, 846853.

24. Aznar, E.; Martínez-Máñez, R.; Sancenón, F. Expert Opin. Drug Deliv. 2009, 6, 643-655.

25. Agostini, A.; Mondragón, L.; Coll, C.; Aznar, E.; Marcos, M. D.; Martínez-Máñez, R.; Sancenón, F.; Soto, J.; Pérez-Payá, E.; Amorós, P. Chem. Open 2012, 1, 17-20.

26. Coll, C.; Mondragón, L.; Martínez-Máñez, R.; Sancenón, F.; Marcos, M. D.; Soto, J.; Amorós, P.; Pérez-Payá, E. Angew. Chem. Int. Ed. 2011, 50, 2138-2140.

27. Climent, E.; Martínez-Máñez, R.; Sancenón, F.; Marcos, M. D.; Soto, J.; Maquieira, A.; Amorós, P. Angew. Chem. Int. Ed. 2010, 49, 7281-7283.

28. Bernardos, A.; Aznar, E.; Marcos, M. D.; Martínez-Máñez, R.; Sancenón, F.; Soto, J.; Barat, J. M.; Amorós, P. Angew. Chem. Int. Ed. 2009, 48, 5884-5887. 
29. Casasús, R.; Aznar, E.; Marcos, M. D.; Martínez-Máñez, R.; Sancenón, F.; Soto, J.; Amorós, P. Angew. Chem. Int. Ed. 2006, 45, 6661-6664.

30. Climent, E.; Bernardos, A.; Martínez-Máñez, R.; Maquieira, A.; Marcos, M. D.; Pastor-Navarro, N.; Puchades, P.; Sancenón, F.; Soto, J.; Amorós, P. J. Am. Chem. Soc. 2009, 131, 14075-14080.

31. Candel, I.; Bernardos, A.; Climent, E.; Marcos, M. D.; Martínez-Máñez, R.; Sancenón, F.; Soto, J.; Costero, A. M.; Gil, S.; Parra, M. Chem. Commun. 2011, 47, 8313-8315.

32. Salinas Y.; Climent, E.; Martínez-Máñez, R.; Sancenón, F.; Marcos, M. D.; Soto, J.; Costero, A. M.; Gil, S.; Parra, M.; Pérez de Diego, A. Chem. Commun. 2011, 47, 11885-11887.

33. Jeppesen, J. O.; Nielsen, M. B.; Becher, J. Chem. Rev. 2004, 104, 5115-5131.

34. Fourmigue M., Boubekeur, K.; Batail, P.; Renouard, J.; Jacob, G. New J. Chem. 1998, 22, 845850.

35. Kong, H.; Jung, B. J.; Sinha J.; Katz, H. E. Chem. Mater. 2012, 24, 2621-2623.

36. Frere P.; Skabara, P. J. Chem. Soc. Rev. 2005, 34, 69-98.

37. Beck, J. S.; Vartuli, J. C.; Roth, W. J.; Leonowicz, M. E.; Kresge, C. T.; Schmitt, K. D.; Chu, C. T. W.; Olson, D. H.; Sheppard, E. W.; McCullen, S. B.; Hoggins, J. B.; Schlenker, J. L. J. Am. Chem. Soc. 1992, 114, 10834-10843.

38. Wright, A. P.; Davis, M. E. Chem. Rev. 2002, 102, 3589-3614.

39. Kickelbick, G. Angew. Chem. Int. Ed. 2004, 43, 3102-3104.

40. Cabrera, S.; El Haskouri, J.; Guillem, C.; Latorre, J.; Beltrán, A.; Beltrán, D.; Marcos, M. D.; Amorós, P. Solid State Sci. 2000, 2, 405-420.

41. Kolb, H. C.; Finn, M. G.; Sharpless, K. B. Angew. Chem. Int. Ed. 2001, 40, 2004-2021.

42. Green, D. C. J. Org. Chem. 1979, 44, 1476-1479.

43. Wang, C.; Ellern, A.; Khodorkovsky, V.; Becker, J. Y.; Bernstein, J. J. Chem. Soc., Chem. Commun. 1994, 2115-2116.

44. Goze, C.; Liu, S. -X.; Leiggener, C.; Sanguinet, L.; Levillain, E.; Hauser, A.; Decurtins, S. Tetrahedron 2008, 64, 1345-1350.

45. Casasús, R.; Climent, E.; Marcos, M. D.; Martínez-Máñez, R.; Sancenón, F.; Soto, J.; Amorós, P.; Cano, J.; Ruiz, E. J. Am. Chem. Soc. 2006, 130, 1903-1917.

46. Felix, F.; Ferguson, J.; Guedel, H. U.; Ludi, A. J. Am. Chem. Soc. 1980, 102, 4096-4102.

47. Lytle, F. E.; Hercules, D. M. J. Am. Chem. Soc. 1969, 91, 253-257.

Addition of benzoquinone $\left(2.0 \times 10^{-3} \mathrm{~mol} \mathrm{dm}^{-3}\right)$ to acetonitrile suspensions of solid $\mathbf{S 1}$ (4 $\mathrm{mg}$ in $10 \mathrm{~mL}$ ) induced pore opening with the subsequent release of the entrapped ruthenium complex. The release of the complex was observed by emission measurements ( $\lambda_{\text {em }}=615 \mathrm{~nm}$, $\lambda_{\text {exc }}=453 \mathrm{~nm}$ ) but not by UV-visible because the yellow color of the benzoquinone solution masked the $\left[\mathrm{Ru}(\text { bipy })_{3}\right]^{2+} \mathrm{MLCT}$ band at $453 \mathrm{~nm}$. This pore opening is due to the formation of strong charge-transfer complexes between the electron donor TTF subunits and the electron acceptor benzoquinone molecules. This suggested that as it happens in other molecular-based probes planar electron-acceptor molecules (such as benzoquinone) are potential interferents. 



\title{
SUPPORTING INFORMATION
}

\section{Tetrathiafulvalene-capped hybrid materials for the optical detection of explosives}

\author{
Yolanda Salinas, Ramón Martínez-Máñez, ${ }^{*}$ Jan O. Jeppesen,* \\ Lars H. Petersen, Félix Sancenón, María Dolores Marcos, Juan Soto,
} Carmen Guillem and Pedro Amorós

\section{Chemicals}

The chemicals tetraethylorthosilicate (TEOS) (98\%), $n$ cetyltrimethylammonium bromide (CTAB) ( $\geq 99 \%)$, sodium hydroxide $(\geq 98 \%)$, triethanolamine $\left(\mathrm{TEAH}_{3}\right) \quad(\geq 99 \%)$, tris(2,2'-bipyridyl)dichlororuthenium(II) hexahydrate $\left(\left[\mathrm{Ru}(\text { bipy })_{3}\right] \mathrm{Cl}_{2} \cdot 6 \mathrm{H}_{2} \mathrm{O}\right)(100 \%), 2,4$-dinitrotoluene (2,4-DNT), 1,3,5trinitrobenzene (TNB), N-methylaniline (NM) (98\%), 2-nitrotoluene (NT), nitrobenzene (NB) (99\%), tetrathiafulvalene (TTF), perfluorohexyl iodide (PFHI), lithium diisopropylamide (LDA), potassium fluoride (KF), ethynyltrimethylsilane, tetrakis(palladium)trifenilfosfine $\left(\mathrm{Pd}\left(\mathrm{PPh}_{3}\right)_{4}\right)$, and tetrahydrofurane (THF) were provided by Sigma-Aldrich and used as received. The $3 \%$ solution in acetonitrile of the nitroaromatic explosives 2,4,6-trinitrophenylmethylnitramine (Tetryl), 2,4,6trinitrotoluene (TNT), hexahydro-1,3,5-trinitro-1,3,5-triazine (RDX), pentaerythritol tetranitrate (PETN), and 3-(azidopropyl)triethoxysilane were purchased from SelectLab Chemicals. L-Ascorbic sodium salt (99\%), potassium carbonate, sodium sulfate, and copper (II) sulfate pentahydrate $\left(\mathrm{CuSO}_{4} \cdot 5 \mathrm{H}_{2} \mathrm{O}\right)$ were acquired from Scharlab (Barcelona, Spain). Diisopropylamine (i- $\left.\mathrm{Pr}_{2} \mathrm{NH}\right)$ was acquired from Fluka. Analytical-grade solvents were purchased from Scharlab (Barcelona, Spain). All reagents were used as received except THF which was distilled from sodium/benzophenone before being used. 


\section{General Techniques}

Powder X-Ray diffraction, TG analysis, and $\mathrm{N}_{2}$ adsorption-desorption techniques were used to characterize the prepared materials. X-Ray measurements were carried out using a Philips D8 Advance diffractometer using $\mathrm{CuK}_{\alpha}$ radiation. Thermo-gravimetric analyses were carried out on a TGA/SDTA 851e Mettler Toledo balance, using an oxidant atmosphere (air, $80 \mathrm{~mL} / \mathrm{min}$ ) with a heating programme consisting of a heating ramp of $10^{\circ} \mathrm{C}$ per minute from $293 \mathrm{~K}$ to $1273 \mathrm{~K}$ and an isothermal heating step at this temperature for 30 minutes. $\mathrm{N}_{2}$ adsorption-desorption isotherms were recorded with a Micromeritics ASAP2010 automated sorption analyzer. Samples were degassed at $120{ }^{\circ} \mathrm{C}$ in vacuum overnight. Specific surface areas were calculated from the adsorption data in the low pressures range using the Brunauer-Emmett-Teller (BET) model. ${ }^{\mathrm{S} 1}$ Pore size was determined following the Barret-Joyner-Halenda (BJH) method. ${ }^{\text {S2 }}$ TEM images were obtained with a $100 \mathrm{kV}$ Philips CM10 microscope. UV-visible spectroscopy was carried out on a Lambda 35 UV/Vis Spectrometer (Perkin Elmer Instruments). Fluorescence spectroscopy was carried out with a Jasco Spectrofluorometer FP8500. 1D and 2D NMR spectra were recorded on a Bruker AVANCE III $400 \mathrm{MHz}$ Spectrometer, where ${ }^{1} \mathrm{H}$ NMR spectra were recorded at $400 \mathrm{MHz}$ at $298 \mathrm{~K}$, while ${ }^{13} \mathrm{C}$ NMR spectra were recorded at $100 \mathrm{MHz}$ at $298 \mathrm{~K}$. The NMR samples were dissolved in deuterated solvents purchased from Cambridge Isotope Labs or Sigma-Aldrich, and TMS or the residual solvent were used as internal standard. ${ }^{29} \mathrm{Si}$ and ${ }^{13} \mathrm{C}$ MAS NMR spectra were recorder on a Bruker WB AVANCE III $400 \mathrm{MHz}$ Spectrometer operating at 79.5 and $128.3 \mathrm{MHz}$, respectively, and using a magic angle spinning speed of $10 \mathrm{kHz}$. Electron impact ionization mass spectrometry (MS-EI) was performed on a Thermo Finnigan MAT SSQ710 single stage quadropole instrument. Matrix-assisted laser-desorption/ionization mass spectrometry was performed on a Bruker Autoflex III Smartbeam mass spectrometer, using a 2,5-dihydroxybenzoic acid (DHB) matrix. The quantum chemical calculations, at the semi-empirical level, in order to estimate the dipole moment of the grafted TTF derivative (product c), were carried out with the 
HyperChem 6.03 software (HyperChem 6.03 Molecular Modeling System, Hypercube Inc., Gainesville, Florida, USA, 2000).

\section{Synthesis of the mesoporous silica support (MCM-41)}

The molar ratio of the reagents in the mother liquor was fixed to 7.0 $\mathrm{TEAH}_{3}: 2.0$ TEOS: 0.52 CTAB: $0.50 \mathrm{NaOH}: 8.89 \mathrm{H}_{2} \mathrm{O}$. In a typical synthesis leading to the MCM41 pure silica, CTAB (4.67 g) was added at $118{ }^{\circ} \mathrm{C}$ to a $\mathrm{TEAH}_{3}$ solution (25.76 g) containing $\mathrm{NaOH}(0.012 \mathrm{~mol})$ and a silatrane derivative (e.g., $0.049 \mathrm{~mol}, 11 \mathrm{~mL}$ of TEOS was added at $70{ }^{\circ} \mathrm{C}$ to $\mathrm{TEAH}_{3}$, e.g., in the form of $\operatorname{Si}(\mathrm{TEA})\left(\mathrm{TEAH} \mathrm{H}_{2}\right)$, where TEA was the fully deprotonated ligand). Then deionized water $(80 \mathrm{~mL})$ was added with vigorous stirring at $70{ }^{\circ} \mathrm{C}$. After some minutes, a white suspension was obtained. This mixture was aged at room temperature overnight. The resulting powder was collected by filtration and washed with water until $\mathrm{pH} 6-7$. Finally the solid was dried at $70{ }^{\circ} \mathrm{C}$ (MCM-41 as-synthesized). To prepare the final porous material (MCM-41), the as-synthesized solid was calcined at $550{ }^{\circ} \mathrm{C}$ for $5 \mathrm{~h}$ to remove the template.

\section{Synthesis of product a}

A solution of LDA $(1.58 \mathrm{~mL}, 1.00 \mathrm{mmol})$ in THF $(10 \mathrm{~mL})$ was added to a solution of TTF $(0.204 \mathrm{~g}, 1.00 \mathrm{mmol})$ in THF $(30 \mathrm{~mL})$ at $-70^{\circ} \mathrm{C}$ under argon over a period of $15 \mathrm{~min}$. Near the end of the addition, a yellow precipitate was formed, whereafter the resulting slurry was stirred for $15 \mathrm{~min}$ at $-70{ }^{\circ} \mathrm{C}$ to allow the formation of tetrathiafulvalenyllithium. ${ }^{\mathrm{S3}}$ Subsequently, PFHI $(0.324 \mathrm{~mL}, 1.49 \mathrm{mmol}$,) was added to the slurry of tetrathiafulvalenyllithium and the reaction mixture was stirred for $1 \mathrm{~h}$ at $-70^{\circ} \mathrm{C}$ and then for $1 \mathrm{~h}$ at room temperature until an orange precipitate was formed. The reaction mixture was quenched with water and diethyl ether. Purification by silica gel column chromatography [petroleum ether/toluene 4:1 as eluent] and then recrystallization from petroleum ether gave the product (265.6 $\mathrm{mg}, 80 \%)$ as red-orange needles. M.p. $68-69{ }^{\circ} \mathrm{C}^{\mathrm{S} 4}{ }^{1} \mathrm{H} \mathrm{NMR}\left(400 \mathrm{MHz}^{\mathrm{C}} \mathrm{CDCl}_{3}\right): \delta$ 
$6.33(\mathrm{~s}, 2 \mathrm{H}, \mathrm{S}-\mathrm{CH}=\mathrm{CH}-\mathrm{S}), 6.42(\mathrm{~s}, 1 \mathrm{H},(\mathrm{CH})-\mathrm{C}-\mathrm{I}) ;{ }^{13} \mathrm{C} \mathrm{NMR}\left(100 \mathrm{MHz}, \mathrm{CDCl}_{3}\right): \delta 63.7$, 110.1, 111.1, 112.9, 119.1, 124.3. HRMS-El $\mathrm{m} / \mathrm{z}$ : calcd for $\mathrm{C}_{6} \mathrm{H}_{3} \mathrm{IS}_{4}{ }^{+}$329.8157; found: 329.6431.
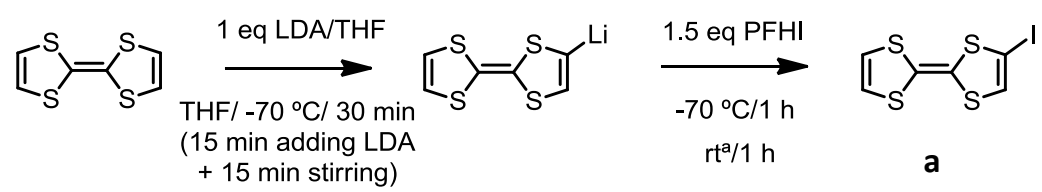

Figure SI-1. Synthesis of compound $\boldsymbol{a}$.

\section{Synthesis of product $b$}

A solution of 2-iodotetrathiafulvalene (155 $\mathrm{mg}, 0.47 \mathrm{mmol})$, trimethylsilylacetylene (98.77 $\mu \mathrm{L}, 0.71 \mathrm{mmol}), \mathrm{Pd}\left(\mathrm{PPh}_{3}\right)_{4}(32.17 \mathrm{mg}, 0.21 \mathrm{mmol})$, and an excess of $i-\mathrm{Pr}_{2} \mathrm{NH}(5 \mathrm{~mL}, 35.37 \mathrm{mmol})$ in THF $(20 \mathrm{~mL})$ was purged with argon before Cul $(8.95 \mathrm{mg}, 0.047 \mathrm{mmol}$ ) was added, whereafter the reaction mixture was heated under argon at $70{ }^{\circ} \mathrm{C}$ for $16 \mathrm{~h} .{ }^{55}$ After complete consumption of the starting material, the solvent was removed under vacuum. The crude product was purified by column chromatography on a column packed with silica gel [cyclohexane/dichloromethane 3:1 as eluent]. The pure product was obtained by recrystallization [cyclohexane/dichloromethane 1:1] affording the product (99.5 mg, 71\%) as a dark brown oil. ${ }^{1} \mathrm{H}$ NMR $\left(400 \mathrm{MHz}, \mathrm{CDCl}_{3}\right): \delta 0.18(\mathrm{~s}, 9 \mathrm{H}, \mathrm{Si}-$ $\left.\left(\mathrm{CH}_{3}\right)_{3}, 6.28(\mathrm{~s}, 2 \mathrm{H}, \mathrm{S}-\mathrm{CH}=\mathrm{CH}-\mathrm{S}), 6.48(\mathrm{~s}, 1 \mathrm{H}, \mathrm{CH}=\mathrm{C}-\mathrm{C} \equiv \mathrm{C}-\mathrm{SiMe})_{3}\right) ;{ }^{13} \mathrm{C}$ NMR (100 $\left.\mathrm{MHz}, \mathrm{CDCl}_{3}\right) ; \delta 2.33,95.5,100.2,108.5,113.5,116.4,119.1,126.0,128.6$. HRMSEl $\mathrm{m} / \mathrm{z}$ : calcd for $\mathrm{C}_{11} \mathrm{H}_{12} \mathrm{~S}_{4} \mathrm{Si}^{+}$299.9586; found: 300.1048 .

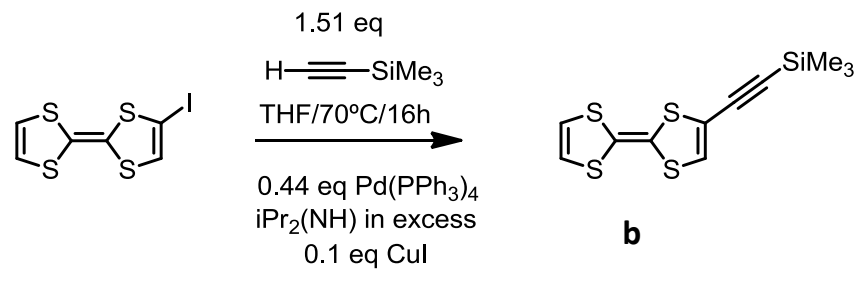

Figure SI-2. Synthesis of compound $\boldsymbol{b}$. 


\section{Synthesis of product c}

KF (96 mg, $1.65 \mathrm{mmol}$ ) was added to a stirred solution of 2trimethylsilyltetrathiafulvalene $(99.5 \mathrm{mg}, 0.33 \mathrm{mmol})$ in THF/MeOH $(50 \mathrm{ml}, 1: 1$ $\mathrm{v} / \mathrm{v}$ ) at room temperature. ${ }^{\mathrm{S3}}$ After complete consumption of the starting material $(16 \mathrm{~h})$, the reaction mixture was concentrated and extracted with water: $\mathrm{CH}_{2} \mathrm{Cl}_{2}$ twice, dried with $\mathrm{MgSO}_{4}$, and concentrated again under vacuum to yield 2ethynyltetrathiafulvalene $(39.8 \mathrm{mg}, 53 \%)$ as dark brown solid. M.p. $43-45^{\circ} \mathrm{C}^{\mathrm{S6}{ }^{1} \mathrm{H}}$ NMR (400 MHz, $\mathrm{CDCl}_{3}$ ): $\delta 3.23(\mathrm{~s}, 1 \mathrm{H}, \mathrm{C} \equiv \mathrm{CH}$ ), 6.32 (s, 2H, S-CH=CH-S), 6.58 (s, $1 \mathrm{H}, \mathrm{CH}=\mathrm{C}-\mathrm{C} \equiv \mathrm{C}-\mathrm{H}) ;{ }^{13} \mathrm{C}$ NMR $\left(100 \mathrm{MHz} \mathrm{CDCl}_{3}\right): \delta 74.9,81.8,107.7,114.9,118.8$, 119.1, 126.7. HRMS-El $\mathrm{m} / \mathrm{z}$ : calcd for $\mathrm{C}_{8} \mathrm{H}_{4} \mathrm{~S}_{4}{ }^{+} 227.9190$; found: 228.0353 .

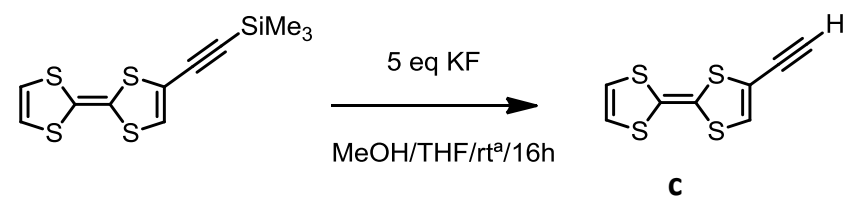

Figure SI-3. Synthesis of compound .

\section{Synthesis of solid S1}

In a typical synthesis, template-free MCM-41 $(1 \mathrm{~g})$ and $\left[\mathrm{Ru}(\text { bipy })_{3}\right] \mathrm{Cl}_{2} \cdot 6 \mathrm{H}_{2} \mathrm{O}(0.6$ $\mathrm{g}, 0.8 \mathrm{mmol})$ were suspended in acetonitrile $(40 \mathrm{~mL})$ in a round-bottomed flask. To remove the adsorbed water, $10 \mathrm{~mL}$ of acetonitrile were distilled off using a DeanStark set-up. Then, the mixture was stirred for $24 \mathrm{~h}$ at room temperature for the purpose of achieving maximum loading in the pores of the MCM-41 scaffolding. Afterwards an excess of 3-(azidopropyl)triethoxysilane $(0.49 \mathrm{~mL}, 2 \mathrm{mmol}$ ) was added, and the suspension was stirred for $5.5 \mathrm{~h}$. Finally, the orange-yellow solid was filtered off. In a second step, anhydrous DMF $(50 \mathrm{~mL})$ was purged with $\mathrm{N}_{2}$ for $1 \mathrm{~h}$. TTF derivative c (121.1 $\mathrm{mg}, 0.531 \mathrm{mmol})$ was placed in an empty flask and, using a needle, the $\mathrm{N}_{2}$ purged DMF $(10 \mathrm{~mL})$ was transferred into the flask containing c. The same procedure was used for an ascorbic acid (56.3 $\mathrm{mg}, 0.32$ mmol) and $\mathrm{CuSO}_{4} \bullet 5 \mathrm{H}_{2} \mathrm{O}(39.9 \mathrm{mg}, 0.16 \mathrm{mmol})$ mixture. Finally, the initial loaded 
solid was suspended in DMF-water $1: 2 \mathrm{v} / \mathrm{v}$ containing $\left[\mathrm{Ru}(\mathrm{bipy})_{3}\right] \mathrm{Cl}_{2} \cdot 6 \mathrm{H}_{2} \mathrm{O}(0.6 \mathrm{~g}$, $0.8 \mathrm{mmol}$ ). Afterwards, the ascorbic acid/ $\mathrm{CuSO}_{4} \bullet 5 \mathrm{H}_{2} \mathrm{O}$ solution in anhydrous DMF was added simultaneously by a needle. Then, the same operation was carried out with the DMF solution containing the TTF derivative $\mathbf{c}$. The final crude reaction mixture was stirred at room temperature for 5 days. The resulting microparticles were filtered off and washed with $\mathrm{CH}_{2} \mathrm{Cl}_{2}(100 \mathrm{~mL}), \mathrm{H}_{2} \mathrm{O}(100 \mathrm{~mL})$, acetonitrile (100 $\mathrm{mL})$, THF (100 mL), and dried at $35{ }^{\circ} \mathrm{C}$ for $12 \mathrm{~h}$. A green-brown solid (S1) was obtained $(871.5 \mathrm{mg})$. The scheme of the $\mathbf{S 1}$ synthesis is shown figure SI-4.

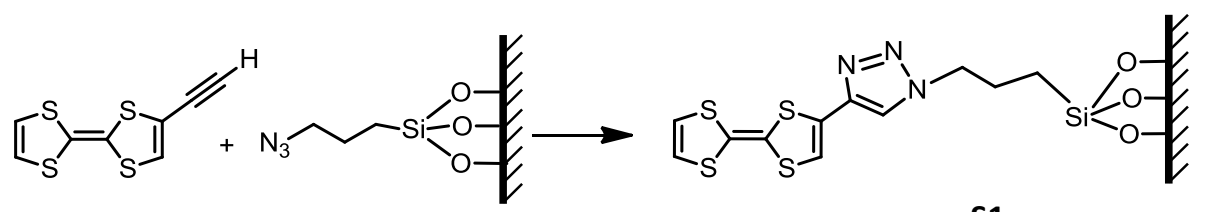

S1

Figure SI-4. Synthesis of S1.

\section{Materials Characterization}

MCM-41 as-synthesized, calcined MCM-41, and S1 materials were characterized by standard techniques. Figure 1 in the manuscript shows the powder X-ray patterns of the solid MCM-41 as-synthesized (without calcination), calcined MCM-41 and S1. The powder XRD of siliceous MCM-41 as-synthesized shows four low-angle reflections that are typical of the hexagonal-ordered array which can be indexed as (100), (110), (200), and (210) Bragg peaks. A significant shift of the (100) reflection and a broadening of the (110) and (200) peaks in the powder XRD of the MCM-41 calcined sample are clearly seen. This scenario corresponds to an approximate cell contraction of approximately 6-8 $\AA$ during the calcination step. Despite this clear partial order loss, the fact that the overlapped (100) and (200) reflections are observed indicates that a certain relative mesopore symmetry is preserved after calcination. Figure 1 in the manuscript also shows the curve that corresponds to S1. For this solid, reflections (110) and (200) were lost, most probably relating to a reduced contrast because of the pore voids filling with the ruthenium complex. Nevertheless, the clear presence of the (100) peak in this 
pattern suggests that the loading process with the $\left[\mathrm{Ru}(\text { bipy })_{3}\right]^{2+}$ complex, and the additional functionalization with 3-(azidopropyl)triethoxysilane and TTF derivative c, have not substantially modified the mesoporous MCM-41 support.

The presence of the mesoporous structure in the final functionalized solid S1 was also confirmed by TEM analysis, in which the typical channels of the MCM-41 matrix were visualized as alternate black and white stripes (see Figure 1 in the manuscript for solid S1). TEM and SEM studied also shows that the prepared S1 was obtained as microparticles.

The $\mathrm{N}_{2}$ adsorption-desorption isotherms of the microparticulated MCM-41 calcined material shows an adsorption step at intermediate $P / P_{0}$ value $(0.1-0.3)$ typical of this solids (see Figure SI-5). This step can be related to the nitrogen condensation inside the mesopores by capillarity. The absence of a hysteresis loop in this interval and the narrow distribution suggest the existence of uniform cylindrical mesopores with pore volume of $0.45 \mathrm{~cm}^{3} \mathrm{~g}^{-1}$ calculated by using the $\mathrm{BJH}$ model on the adsorption branch of the isotherm. The application of the BET model resulted in a value for the total specific surface of $1036.2 \mathrm{~m}^{2} \mathrm{~g}^{-1}$. From the $\mathrm{XRD}$, porosimetry, and TEM studies, the $a_{0}$ cell parameter $(3.65 \mathrm{~nm})$, the pore diameter $(2.25 \mathrm{~nm})$, and the wall thickness $(1.40 \mathrm{~nm})$ were calculated.

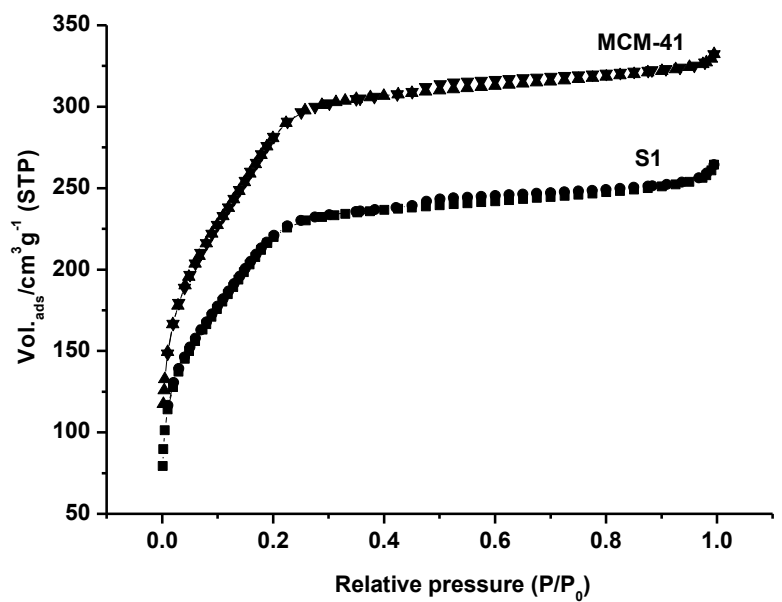

Figure SI-5. Nitrogen adsorption-desorption isotherms for MCM-41 mesoporous material and $\mathbf{S 1 .}$ 
The $\mathrm{N}_{2}$ adsorption-desorption isotherm of $\mathbf{S} \mathbf{1}$ is typical of mesoporous systems with partially filled mesopores (see Figure $\mathrm{SI}-5$ ), and a decrease in the $\mathrm{N}_{2}$ volume adsorbed and surface area $\left(816.2 \mathrm{~m}^{2} \mathrm{~g}^{-1}\right)$ is observed. BET specific surface values, pore volumes, and pore sizes calculated from the $\mathrm{N}_{2}$ adsorption-desorption isotherms for MCM-41 and $\mathbf{S 1}$ are listed in Table S1.

Table S1. BET specific surface values, pore volumes and pore sizes calculated from the $\mathrm{N}_{2}$ adsorption-desorption isotherms for selected materials.

\begin{tabular}{c|ccc}
\hline & $\begin{array}{c}\text { SBET } \\
\left(\mathrm{m}^{2} \mathrm{~g}^{-1}\right)\end{array}$ & $\begin{array}{c}\text { Pore Volume } \\
\left(\mathrm{cm}^{3} \mathrm{~g}^{-1}\right)\end{array}$ & $\begin{array}{c}\text { Pore size }^{\text {a }} \\
(\mathrm{nm})\end{array}$ \\
\hline MCM-41 & 1036.2 & 0.45 & 2.25 \\
S1 & 816.2 & 0.37 & 2.27 \\
\hline \multicolumn{4}{r}{${ }^{a}$ Volume $(V)$ and diameter $(D)$ of mesopore. }
\end{tabular}

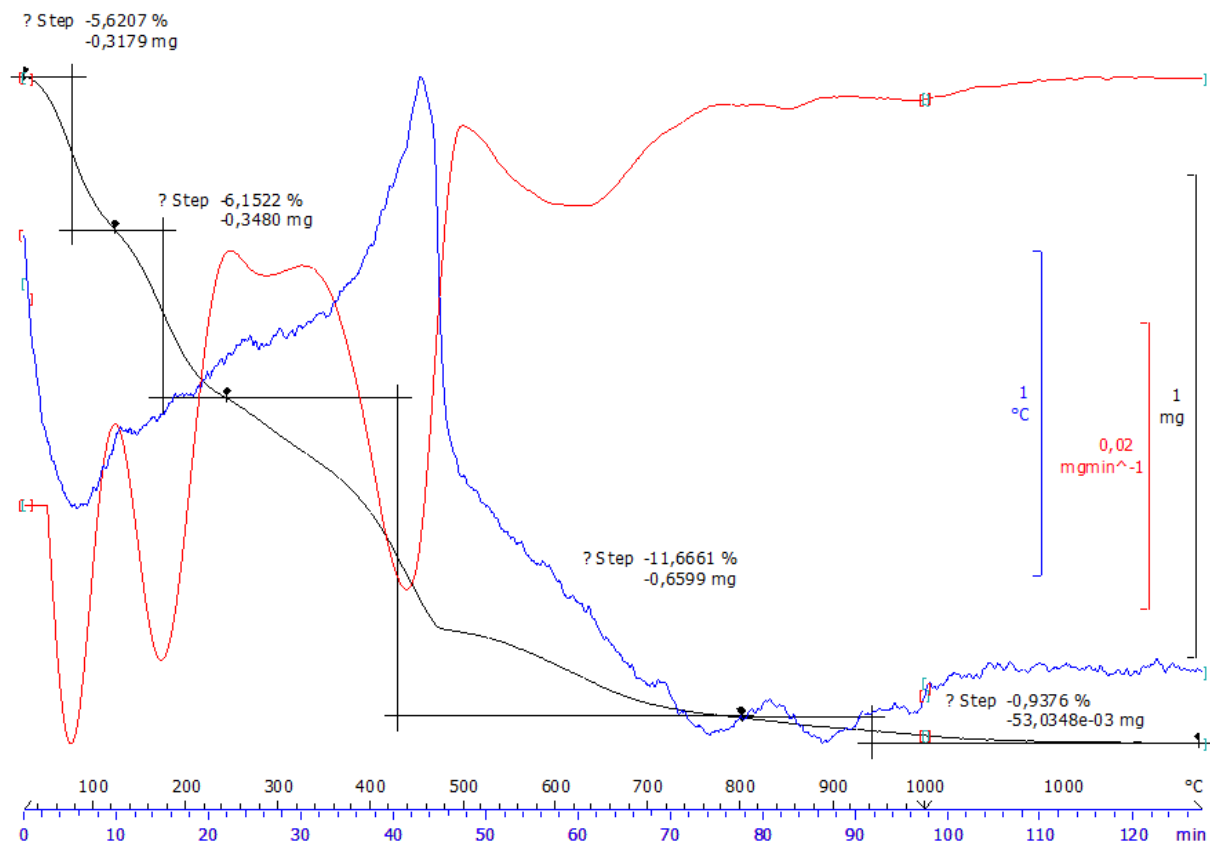

Figure SI-6. Thermogravimetric curve of solid S1.

The content of the $\left[\mathrm{Ru}(\mathrm{bipy})_{3}\right]^{2+}$ complex and the TTF derivative in the prepared solid $\mathbf{S 1}$ was determined by thermogravimetric analysis, and amount to 
$0.044 \mathrm{mmol} / \mathrm{g} \mathrm{SiO}_{2}$ and $0.290 \mathrm{mmol} / \mathrm{g} \mathrm{SiO}_{2}$, respectively. The heating ramp used to perform the thermogravimetric analyses consisted in a heating of $10{ }^{\circ} \mathrm{C}$ per minute, from $20^{\circ} \mathrm{C}$ to $1000{ }^{\circ} \mathrm{C}$, and an isothermal step at this temperature for 30 minutes. Examination of the thermogravimetric curve and its first derivative (see Figure SI-6) shows four weight loss steps: a first weight loss of $11.77 \%$ corresponding to solvents elimination $\left(T<210^{\circ} \mathrm{C}\right)$; a second weight loss of $11.66 \%$ due to the decomposition of the organic groups anchored on the siliceous surface and to the decomposition of the ruthenium complex $\left(210^{\circ} \mathrm{C}<T<800^{\circ} \mathrm{C}\right)$ finally, a weight loss of $0.93 \%$ owing to the condensation of the silanols on the siliceous surface $\left(T>800{ }^{\circ} \mathrm{C}\right)$. SEM analysis using Energy Dispersive $\mathrm{X}$-ray spectroscopy (EDX, $20 \mathrm{kV}$ ) carried out on S1 showed the presence of sulphur atoms in the final material with a ratio $\mathrm{mol} \mathrm{Si} / \mathrm{mol} \mathrm{S}$ of 17.9 .

In short, although the functionalization degree achieved seems to be apparently low (it can be estimated that the amount of TTF-containing silanes is approximately $2 \%$, relative to the total amount of $\mathrm{Si}$ ), this results provide enough evidence that the new system can act as a gate-like assembly, at least, for a certain proportion of mesopores (sufficient to deliver, after interaction with selected explosives, a quantity of dye molecules adequate for sensing purposes). This value fits very well with estimations realized from ${ }^{29} \mathrm{Si}$ NMR spectroscopic measurements carried out on the parent MCM-41 silica and S1 solids (see Figure $\mathrm{SI}-7)$. The organic functionalization on the silica surface is confirmed by the clear decrease (8\%) in the amount of $Q^{3}$ (silanol) sites (Table S2). Hence, assuming that for each 3-(azidopropyl)triethoxysilane are required three silanol groups to guarantee a complete anchoring, we can roughly estimate a proportion of $2.7 \%$ modified Si sites/total Si atoms (very similar to the value determined using TGA). 


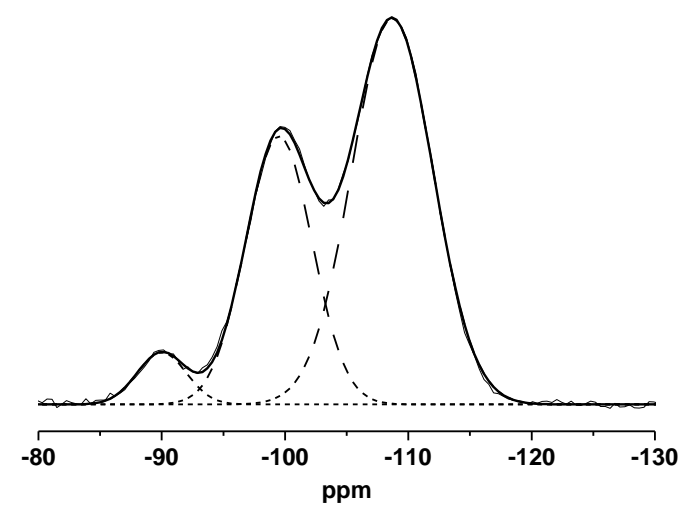

Figure SI-7. ${ }^{29}$ Si NMR spectrum of solid S1 showing the $Q^{2}, Q^{3}$, and $Q^{4}$ sites.

Table S2. ${ }^{29}$ Si NMR spectroscopic data.

\begin{tabular}{c|ccc}
\hline & $\mathbf{Q}^{2}$ & $\mathbf{Q}^{3}$ & $\mathbf{Q}^{4}$ \\
& $(\%)$ & $(\%)$ & $(\%)$ \\
\hline MCM-41 & 7 & 42 & 51 \\
S1 & 6 & 34 & 60 \\
\hline
\end{tabular}

We expect that the TTF-containing organic groups result anchored preferentially on the external silica surface due to: (1) the existence of dye molecules included in the mesopores during the functionalization (blocking, at least partially, the pore entrances), (2) the relatively low proportion of organic silane used in the preparative procedure, and (3) the medium size of the organic moiety. Then, in order to determine the density of TTF derivatives we need the value of the external MCM-41 surface. For this purpose, we used the surfactantcontaining mesostructured MCM-41 material. Hence, by applying the BET model on the $\mathrm{N}_{2}$ adsorption isotherm of this last sample, a surface of $77 \mathrm{~m}^{2} / \mathrm{g}$ has been estimated. This leads to an average density of organic silanes on the external silica surface of 1.7 groups $/ \mathrm{nm}^{2} .{ }^{\mathrm{S} 7}$ This value is consistent with a usual density of silanol groups (ca. $5 \mathrm{Si}-\mathrm{OH} / \mathrm{nm}^{2}$ ) on silica surfaces.

Also ${ }^{13} \mathrm{C}$ MAS NMR spectra of the different solids were measured. At this respect, the solid charged with the $\left[\mathrm{Ru}(\text { bipy })_{3}\right]^{2+}$ complex and with the 3azidopropyl moieties grafted in the outer surface showed two well defined zones 
in their ${ }^{13} \mathrm{C}$ spectra. The first in the $20-60$ ppm interval in which appeared the carbons of the propyl chain that linked the azido moiety to the inorganic scaffold, whereas the other signals were located between 120 and $160 \mathrm{ppm}$ and are due to the bipyridine moieties of the entrapped complex. ${ }^{13} \mathrm{C}$ MAS NMR spectra of final solid S1 showed the same two well defined zones with the carbons of the propyl chain located in the 20-60 ppm interval, whereas the aromatic carbons appeared in the 120-170 ppm range. The formation of the 1,2,3-triazole ring, through the click reaction, and the appended TTF induced the appearance of new carbon signals at $122.2,122.9,129.4,137.4,155.7,161.6$, and 162.8 .

In order to test the mechanism of the gate opening in the presence of nitroaromatic explosives ${ }^{13} \mathrm{C}$ MAS NMR measurements were carried out. At this respect, solid $\mathbf{S 1}$ was suspended in acetonitrile and then, an excess of Tetryl was added to the suspension that was stirred during 24 hours in order to achieve the maximum delivery of the $\left[\mathrm{Ru}(\mathrm{bipy})_{3}\right]^{2+}$ complex. Then, the solid was filtered, washed with acetonitrile $(10 \mathrm{~mL})$ and dried. The most remarkable feature of the

${ }^{13} \mathrm{C}$ spectra of this solid is the broadening and the shits (0.1-0.2 ppm to lower fields) of the TTF signals ascribed to the formation of charge-transfer complexes with Tetryl. The formation of these complexes induced pore opening (with the subsequent dye release) due to the inhibition of dipole-dipole interactions, between the grafted TTF-triazole subunits, that are active in solid $\mathbf{S 1}$.

\section{Dye release studies in the presence of explosives and possible interferents}

The procedure used is analogous to that described above. Briefly, $4 \mathrm{mg}$ of $\mathbf{S 1}$ were suspended in $10 \mathrm{~mL}$ of acetonitrile solution $\left(2.0 \times 10^{-3} \mathrm{~mol} \mathrm{~L}^{-1}\right)$ of the following compounds: 2,4-DNT, TNT, Tetryl, hexahydro-1,3,5-trinitro-1,3,5-triazine (RDX), pentaerythritol tetranitrate (PETN), trinitrobenzene (TNB), $N$-methylaniline $(\mathrm{NM})$, 2-nitrotoluene (NT) and nitrobenzene (NB). Different aliquots $(2 \mathrm{~mL})$ were separated and filtered after 60 minutes. The delivery of the dye from the pore voids to the solution was monitored by the maximum wavelength band of the $\left[\mathrm{Ru}(\text { bipy })_{3}\right]^{2+}$ complex centred at $453 \mathrm{~nm}$. The results are observed in Figure 2 in 
the manuscript. Of all the nitroaromatic derivatives tested, only Tetryl, TNT, and TNB were able to uncap the pores with the subsequent release of the ruthenium complex.

\section{Kinetics of dye release in the presence of TNB, TNT and Tetryl}

To confirm the fact that the observed response of solid S1 arises from the interaction between the anchored TTF and nitroaromatic explosives TNB, TNT, and Tetryl, the absorbance at $453 \mathrm{~nm}$ in the presence of selected guests was used as probe. For this purpose, $4 \mathrm{mg}$ of $\mathbf{S 1}$ was suspended in $10 \mathrm{~mL}$ of the acetonitrile solutions of TNB, TNT, and Tetryl $\left(2.0 \times 10^{-3} \mathrm{~mol} \mathrm{~L}^{-1}\right)$. Uncapping and subsequent delivery of the dye to the acetonitrile solution was easily detected, after filtering $1.5 \mathrm{~mL}$ of the suspension, via monitorization of the metal-to-ligand charge transfer transition band of the $\left[\mathrm{Ru}(\text { bipy })_{3}\right]^{2+}$ dye at $453 \mathrm{~nm}$. As seen in Figure 3 in the manuscript, only the more electron deficient compounds TNT, TNB, and Tetryl were able to open the gate with subsequent dye delivery.

\section{Dye release and limits of detection studies}

The limits of detection using $\mathbf{S 1}$ for TNT and Tetryl (i.e., the most strong electron deficient compounds) were determined using $4 \mathrm{mg}$ of solid S1, which were suspended in $10 \mathrm{~mL}$ of different solutions containing increasing concentrations of the corresponding explosive. Different aliquots $(1.5 \mathrm{~mL})$ were taken up and filtered after 60 minutes. The delivery of the $\left[\mathrm{Ru}(\mathrm{bipy})_{3}\right]^{2+}$ complex from the pore voids to the solution was easily monitored using the absorbance band at $453 \mathrm{~nm}$ (see Figure SI-8 and SI-9) and by emission measurements at 615 $\mathrm{nm}$ (see Figure $\mathrm{SI}-10$ ). 

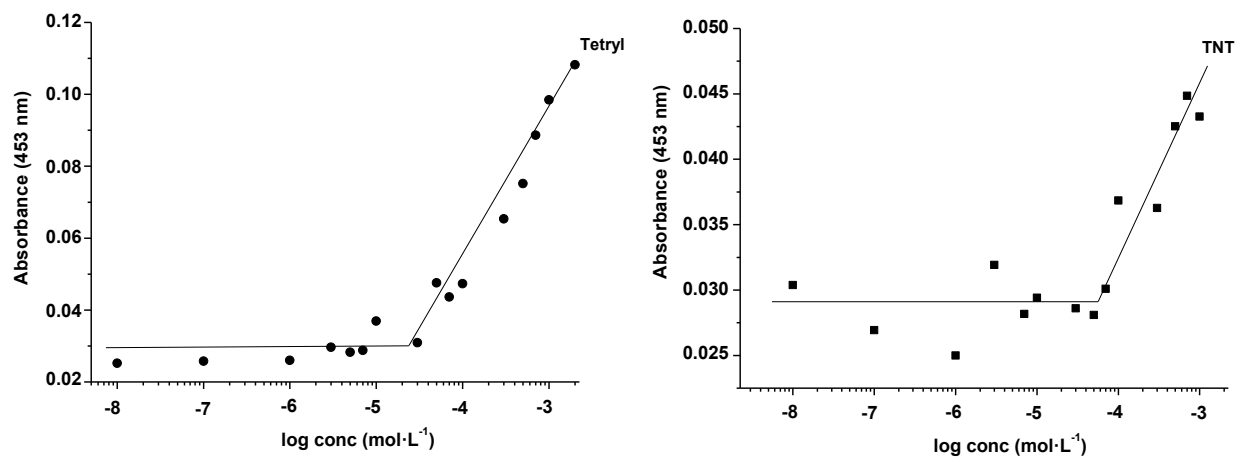

Figure SI-8. Calibration curves obtained from the acetonitrile suspensions of $\mathbf{S 1}$ upon addition of increasing quantities of TNT and Tetryl (maximum absorbance of dye at $453 \mathrm{~nm}$ ) after $60 \mathrm{~min}$.

The absorbance titrations, shown in Figure $\mathrm{SI}-8$, allowed us to determine the limits of detection for Tetryl $\left(2.8 \times 10^{-5} \mathrm{~mol} \mathrm{dm}^{-3}, 8 \mathrm{ppm}\right)$ and TNT $\left(6.6 \times 10^{-5} \mathrm{~mol}\right.$ $\left.\mathrm{dm}^{-3}, 15 \mathrm{ppm}\right)$. By using fluorescence spectroscopy an improvement in the limits of detection for Tetryl $\left(3.5 \times 10^{-6} \mathrm{~mol} \mathrm{dm}^{-3}, 1 \mathrm{ppm}\right)$ and TNT $\left(2.6 \times 10^{-5} \mathrm{~mol} \mathrm{dm}^{-3}, 6\right.$ ppm) was obtained.

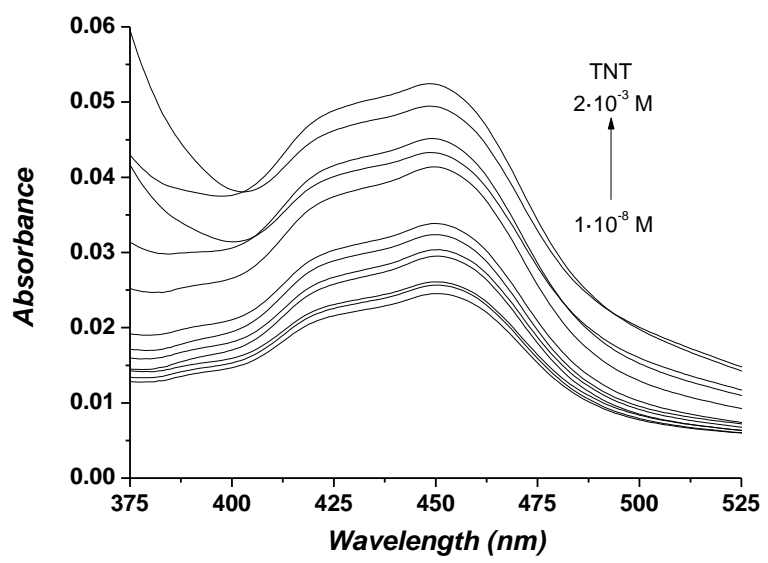

Figure SI-9. Changes in the absorption band of the $\left[R u(\text { bipy })_{3}\right]^{2+}$ complex released from acetonitrile suspensions of $\boldsymbol{S} 1$ upon addition of increasing quantities of TNT after $60 \mathrm{~min}$. 


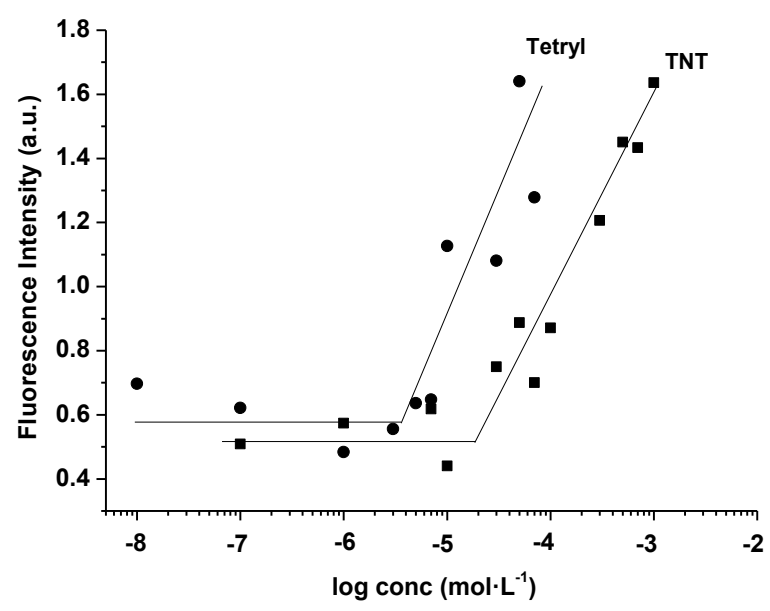

Figure SI-10. Calibration curves obtained from the acetonitrile suspensions of S1 upon addition of increasing quantities of TNT and Tetryl $\left(\lambda_{e x}=453 \mathrm{~nm}, \lambda_{e m}=615 \mathrm{~nm}\right)$ after $60 \mathrm{~min}$.

\section{Electrochemistry}

In order to corroborate the negligible effect of the click reaction in the electrochemical features of TTF a model compound $\mathbf{2}$ was synthesized. The experimental conditions used in the reaction (see Figure SI-11) were identical to those in the Figure SI-4 (synthesis of S1). Solution oxidation potentials obtained from the cyclic voltammograms (CVs) of TTF and $\mathbf{2}$ are summarized in Table S3. CV of compound $\mathbf{2}$ and TTF showed two reversible one-electron redox waves as expected (see Figure SI-12).<smiles>CC(C)Cc1ccc(OCCCCCN)cc1</smiles>

Figure SI-11. Synthesis of compound 2. 


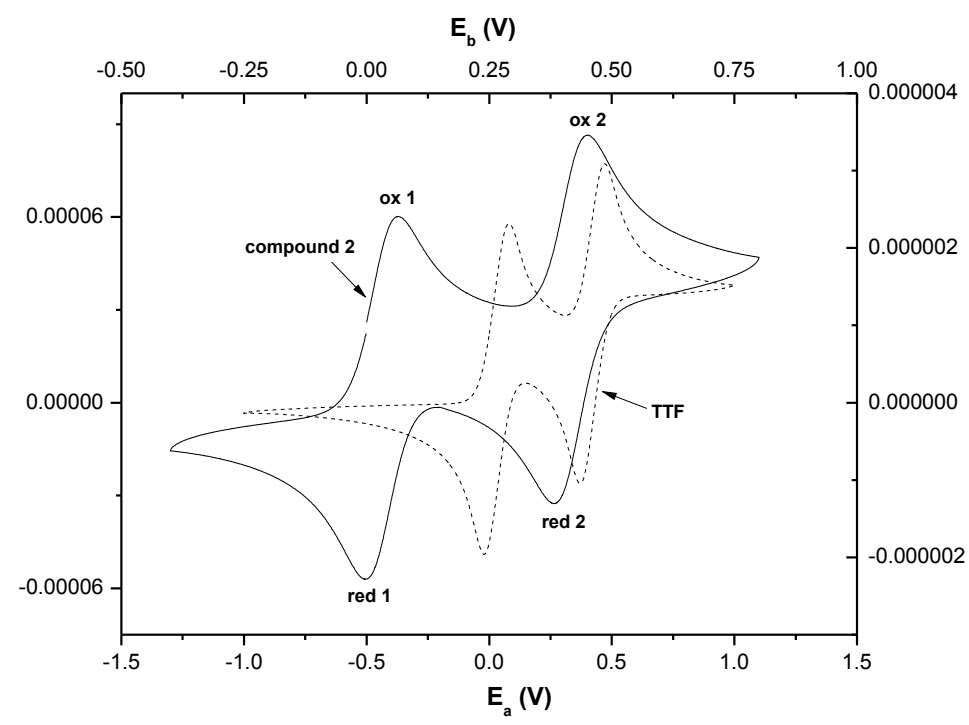

Figure SI-12. Cyclic Voltammograms. $E_{a}$ is the oxidation potential of TTF and $E_{b}$ is the oxidation potential of compound 2.

Table S3. Oxidation Potentials $E^{1 / 2}{ }^{1}$ and $E^{1 / 2}$ of TTF derivatives in MeCN Determined by Cyclic Voltammetry ${ }^{a}$

\begin{tabular}{cccc} 
& $E^{1} 2^{1}(\mathrm{~V})$ & $E^{1} 2^{2}(\mathrm{~V})$ & $\Delta E_{\mathrm{p}}(\mathrm{V})$ \\
\hline TTF & +0.29 & +0.48 & +0.19 \\
Compound 2 & +0.06 & +0.44 & +0.38 \\
\hline
\end{tabular}

${ }^{a}$ Conditions: Working and counter electrodes were made of $\mathrm{Pt}$, and the reference electrode was $\mathrm{Ag} / \mathrm{AgNO}_{3}$. The concentration of the examined compounds was $10^{-3} \mathrm{M}$ and $0.10 \mathrm{M} n-\mathrm{Bu}_{4} \mathrm{NPF}_{6}$ was added as supporting electrolyte. CVs were obtained with a sweep rate of $100 \mathrm{mV} \mathrm{s}^{-1}$. The half-wave potentials $\left(E_{1 / 2}\right)$, reported were obtained from an average of the cathodic and anodic cyclic voltammetric peaks.

\section{Soil extraction measurements}

$10 \mathrm{~g}$ of finely grinded homogeneous soil sample was doped with a known concentration of Tetryl solution ( $10 \mathrm{~mL}$ of concentration $\left.1.0 \times 10^{-4} \mathrm{~mol} \mathrm{dm}^{-3}\right)$. This dopant was extracted with acetonitrile solution $(3 \times 15 \mathrm{~mL})$. Then the extract obtained was dried in a rotary evaporator until the solvent was eliminated. The 
crude extract was dissolved in $10 \mathrm{~mL}$ of acetonitrile. Five different samples ( $2 \mathrm{~mL}$ of crude extract) were prepared with the addition of increasing volumes of acetonitrile standard Tetryl solution $(0,1,2,3$, and $4 \mathrm{ml}$ with concentration of 2.0 $\times 10^{-4} \mathrm{~mol} \mathrm{dm}^{-3}$ ) and the final volume of each sample was adjusted to $10 \mathrm{~mL}$ by adding different volumes of acetonitrile. Finally, $10 \mathrm{~mL}$ of each sample solution was added to $4 \mathrm{mg}$ of $\mathbf{S 1}$ and the mixture was stirred for 60 minutes before the absorbance at $453 \mathrm{~nm}$ was measured. Linear regression analysis was performed and the slope and y-intercept of the calibration curve are used to calculate the concentration of Tetryl in the sample (see Figure SI-13).

From the linear regression: $A=m \cdot C_{\text {added }}+b$, an $m$ value of 46.78 and $a b$ value of 0.0441 were obtained with a $R^{2}$ value of 0.9629 . Applying the equation $C_{\text {unknow }}=$ $\left(b-A_{0}\right) / m$ we could obtained the unknown Tetryl concentration in the soil. The Tetryl concentration was found to be $8.76 \times 10^{-5} \mathrm{~mol} \mathrm{dm}^{-3}(25.15 \mathrm{ppm})$ with a $12 \%$ error when compared with doped Tetryl concentration $\left(1.0 \times 10^{-4} \mathrm{~mol} \mathrm{dm}^{-3}, 28.71\right.$ ppm). Therefore, $\mathbf{S 1}$ was efficiently used to determine trace amount of Tetryl from contaminated soils.

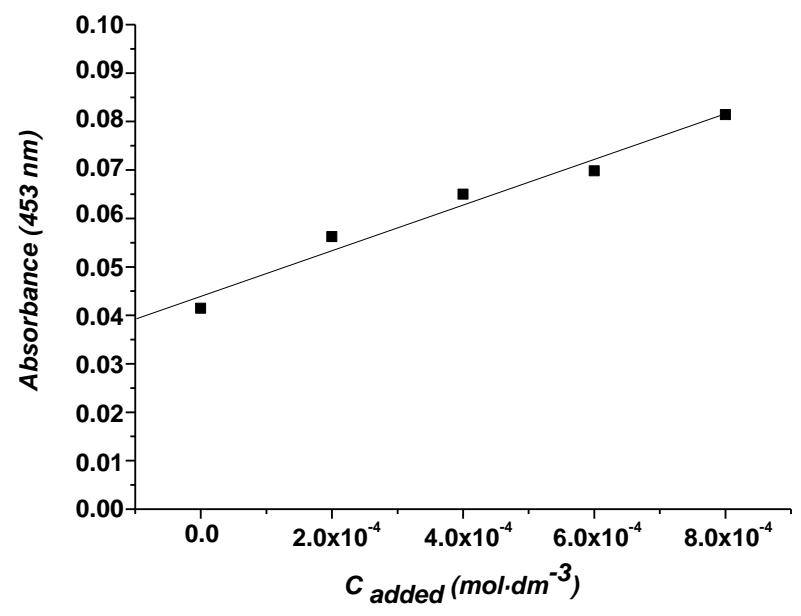

Figure SI-13. Absorbance of the ruthenium complex (453 nm) released from solid S1 suspended in acetonitrile soil extracts and doped with increasing Tetryl concentrations (standard addition method). 


\section{Colorimetric detection of nitroaromatic explosives applying supramolecular concepts}

Table S4 summarizes published colorimetric methods for detection of nitroaromatic explosives using supramolecular concepts. For comparative purposes, the characteristics of the sensing material S1 is also included. However, polymeric materials are not included on account of their intrinsic amplification features. Table S4 includes the method, the working environment, the detection limits, the time of the measurement, and the interfering species. It transpires that the sensing features of $\mathbf{S 1}$ are similar to those presented by molecular receptors bearing TTF subunits synthesized by Jeppesen and co-workers.

Table S4. Published colorimetric methods for detection of nitroaromatic explosives using supramolecular concepts

\begin{tabular}{|c|c|c|c|c|c|c|}
\hline System & $\begin{array}{l}\text { Detection } \\
\text { in phase }\end{array}$ & $\begin{array}{l}\text { Analyte } \\
\text { detected }\end{array}$ & Interferents & $\begin{array}{c}\text { Assay time } \\
\text { /sec }\end{array}$ & LOD /ppb & Ref. \\
\hline $\begin{array}{c}\text { Gated material loaded } \\
\text { with dye }\end{array}$ & Solution & $\begin{array}{c}\text { Tetryl, } \\
\text { TNT }\end{array}$ & $T N B$ & 600 & $\begin{array}{c}8000 \\
15000 \\
\end{array}$ & $\begin{array}{l}\text { This } \\
\text { paper }\end{array}$ \\
\hline $\begin{array}{c}\text { Calix[4]pyrrole } \\
\text { derivatives bearing } \\
\text { four TTF }\end{array}$ & Solution & $\begin{array}{l}\text { PA } \\
\text { TNB } \\
\text { TNT }\end{array}$ & $\begin{array}{l}\text { Tetrafluoro- } p \text { - } \\
\text { benzoquinone } \\
\text { Tetrachloro- } p \text { - } \\
\text { benzoquinone }\end{array}$ & n. $r$. & $\begin{array}{c}600-2700 \\
300-1500 \\
3000- \\
15000\end{array}$ & $\bar{i}$ \\
\hline $\begin{array}{c}\text { Cysteamine- } \\
\text { functionalized gold } \\
\text { nanoparticles }\end{array}$ & Solution & TNT & No interference & n. r. & 0.0003 & ii \\
\hline $\begin{array}{c}\text { Bis-tetrathiafulvalene- } \\
\text { calix[4]tiophene[2] } \\
\text { pyrrole derivative }\end{array}$ & Solution & $\begin{array}{l}\text { TNB } \\
\text { PA } \\
\text { TNT }\end{array}$ & n. $r$. & n. r. & n. r. & iii \\
\hline $\begin{array}{l}\text { Reaction between } \\
\text { cymantrene and } \\
\text { nitroaromatics }\end{array}$ & Solid & $\begin{array}{l}\text { 2,4-DNT } \\
1,3-\mathrm{DNB}\end{array}$ & n. $r$. & $60-90$ & 0.0003 & iv \\
\hline $\begin{array}{c}\text { Polymer films } \\
\text { containing dyes } \\
\text { functionalized with } \\
\text { thiophenes }\end{array}$ & Gas & $2,4-\mathrm{DNT}$ & n. r. & 3600 & ppb level & $\mathrm{v}$ \\
\hline $\begin{array}{l}\text { Complexes of } \\
\text { explosives with } \\
\text { electron donor } \\
\text { molecules. Array }\end{array}$ & Solution & $\begin{array}{l}\text { TNT } \\
\text { RDX }\end{array}$ & n. $r$. & n. $r$. & n. r. & vi \\
\hline
\end{tabular}




\begin{tabular}{|c|c|c|c|c|c|c|}
\hline System & $\begin{array}{c}\text { Detection } \\
\text { in phase }\end{array}$ & $\begin{array}{c}\text { Analyte } \\
\text { detected }\end{array}$ & Interferents & $\begin{array}{c}\text { Assay time } \\
\text { /sec }\end{array}$ & LOD /ppb & Ref. \\
\hline $\begin{array}{c}\text { Reaction of } \\
\text { tetramethylammonium } \\
\text { hydroxide with } \\
\text { explosives }\end{array}$ & solution & $\begin{array}{c}\text { TNT } \\
2,4-\text { DNT }\end{array}$ & n. r. & n. r. & $\begin{array}{c}1 \text { microg } \\
2 \text { microg }\end{array}$ & vii \\
\hline $\begin{array}{c}\text { Chemical modification } \\
\text { of TNT to yield an azo } \\
\text { dye-SERS }\end{array}$ & solution & TNT & n. r. & n. r. & 0.0003 & viii \\
\hline $\begin{array}{c}\text { Microchip capillary } \\
\text { electrophoresis (CE) } \\
\text { coupled with solid } \\
\text { phase extraction (SPE) } \\
\text { and deprotonation }\end{array}$ & solution & $\begin{array}{c}\text { TNT } \\
\text { Tetryl } \\
\text { TNB }\end{array}$ & n. r. & 30 & $0.19-0.34$ & ix \\
\hline $\begin{array}{c}\text { 1-buty-3- } \\
\text { methylimidazolium } \\
\text { hexafluorophosphate } \\
\text { monolayer into an } \\
\text { indium tin oxide- } \\
\text { printed electrode }\end{array}$ & gas & $\begin{array}{c}\text { PA } \\
\text { TNT }\end{array}$ & No interference & 600 & 1 & $\mathrm{x}$ \\
\hline
\end{tabular}

\section{References}

S1. a) S. Brunauer, P. H. Emmett, E. Teller, J. Am. Chem. Soc., 1938, 60, 309-311; b) E. P. Barrett, L.G. Joyner, P. P. Halenda, J. Am. Chem. Soc., 1951, 73, 373-375; c) M. Kruck, M. Jaroniec, Chem. Mater., 2001, 13, 3169-3183.

S2. a) E. P. Barrett, L.G. Joyner, P. P. Halenda, J. Am. Chem. Soc., 1951, 73, 373-375; b) M. Kruck, M. Jaroniec, Chem. Mater., 2001, 13, 3169-3183.

S3. D. C. Green, J. Org. Chem., 1979, 44, 1476-1479.

S4. C. Wang, A. Ellern, V. Khodorkovsky, J. Berstein, J. Y. Becker, J. Chem. Soc. Chem. Commun., 1994, 9893-9894.

S5. C. Goze, S.-X. Liu, C. Leiggener, L. Sanguinet, E. Levillain, A. Hauser, S. Decurtins, Tetrahedron, 2008, 64, 1345-1350.

S6. T. Otsubo, K. Kochi, A. Bitoh, F. Ogura, Chem. Lett., 1994, 2047-2050.

S7. a) I. Candel, E. Aznar, L. Mondragón, C. de la Torre, R. Martínez-Máñez, F. Sancenón, M. D. Marcos, P. Amorós, C. Gullem, E. Pérez-Payá, A. Costero, S. Gil, M. Parra, Nanoscale, 2012, 4, 7237-7245; b) C. Sanfeliu, R. Martínez-Máñez, F. Sancenón, J. Soto, V. Puchol, P. Amorós, M. D. Marcos, J. Mater. Chem., 2012, 22, 25362-25372. 
i. a) K. A. Nielsen, W. -S. Cho, J. O. Jeppesen, V. M. Lynch, J. Becher, J. L. Sessler, J. Am. Chem. Soc., 2004, 126, 16296-16297; b) J. S. Park, F. Le Derf, C. M. Bejger, V. M. Lynch, J. L. Sessler, K. A. Nielsen, C. Johnsen, J. O. Jeppesen, Chem. Eur. J., 2010, 16, 848-854.

ii. Y. Jiang, H. Zhao, N. Zhu, Y. Lin, P. Yu, L. Mao, Angew. Chem. Int. Ed., 2008, 47, 8601-8604; Angew. Chem., 2008, 120, 8729-8732.

iii. D. S. Kim, V. M. Lynch, K. A. Nielsen, C. Johnsen, J. O. Jeppesen, J. L. Sessler, Anal. Bioanal. Chem., 2009, 395, 393-400.

iv. L. M. Dorozhkin, V. A. Nefedov, A. G. Sabelnikov, V. G. Sevastjanov, Sens. Actuators, B, 2004, 99, 568-570.

v. A. Chen, H. Sun, A. Pyayt, X. Zhang, J. Luo, A. Jen, P. A. Sullivan, S. Elangoyan, L. R. Dalton, R. Dinu, D. Jin, D. Huang, J. Phys. Chem. C, 2008, 112, 8072-8078.

vi. A. Ponnu, N. Y. Edwards, E. V. Anslyn, New J. Chem., 2008, 32, 848-855.

vii. S. A. H. Amas, H. J. Yallop, Analyst, 1966, 91, 336-337.

viii. C. J. McHugh, R. Keir, D. Graham, W. E. Smith, Chem. Commun., 2002, 580-581.

ix. Q. Lua, G. E. Collins, M. Smith, J. Wang, Anal. Chim. Acta, 2002, 469, 253-260.

x. E. S. Forzani, D. Lu, M. J. Leright, A. Díaz Aguilar, F. Tsow, R. A. Iglesias, Q. Zhang, J. Lu, J. Li, N. Tao, J. Am. Chem. Soc., 2009, 131, 1390-1391. 

5.5 Chromo-fluorogenic detection of nitroaromatic explosives using silica mesoporous supports gated with tetrathiafulvalene derivatives. 



\title{
Chromo-fluorogenic detection of nitroaromatic explosives using silica mesoporous supports gated with tetrathiafulvalene derivatives
}

\author{
Yolanda Salinas, ${ }^{[a, b]}$ Marta V. Solano, ${ }^{[c]}$ Rebecca E. \\ Sørensen, ${ }^{[c]}$ Karina R. Larsen, ${ }^{[c]}$ Jan O. Jeppesen, ${ }^{*[c]}$ Ramón \\ Martínez-Máñez, ${ }^{*[a, b]}$ Félix Sancenón, ${ }^{[a, b]}$ M. Dolores \\ Marcos, ${ }^{[a, b]}$ Pedro Amorós ${ }^{[d]}$ and Carmen Guillem ${ }^{[d]}$
}

${ }^{a}$ Centro de Reconocimiento Molecular y Desarrollo Tecnológico, Centro Mixto Universidad Politécnica de Valencia - Universitat de Valencia, E-46022, Valencia, Spain. Departamento de Química. Universidad Politécnica de Valencia. Camino de Vera s/n. E-46022, Valencia, Spain.

${ }^{b}$ CIBER de Bioingeniería, Biomateriales y Nanomedicina (CIBER-BBN).

${ }^{c}$ Department of Physics, Chemistry, and Pharmacy, University of Southern Denmark Campusvej 55, 5230 Odense M, Denmark.

${ }^{d}$ Institut de Ciència dels Materials (ICMUV), Universitat de Valencia, P.O. Box 2085, E-46071, Valencia, Spain.

Chemistry A European Journal, 2013, submitted (Reproduced with permission of Wiley-VCH Verlag GmbH \& Co. KGaA, Weinheim) 



\section{Abstract}

Three new hybrid gated mesoporous materials $\left(\mathbf{S N}_{\mathbf{3}} \mathbf{- 1}, \mathbf{S N H}_{\mathbf{2}}-\mathbf{2}\right.$, and $\mathbf{S N}_{\mathbf{3}} \mathbf{- 3}$ ) loaded with the dye $\left[\mathrm{Ru}(\mathrm{bipy})_{3}\right]^{2+}$ and capped with different tetrathiafulvalene (TTF) derivatives (having different sizes and shapes and bearing different number of sulfur atoms) have been prepared. The materials $\mathbf{S N}_{\mathbf{3}} \mathbf{- 1}$ and $\mathbf{S N}_{\mathbf{3}} \mathbf{- 3}$ are functionalized on their external surface with the TTF derivatives $\mathbf{1}$ and $\mathbf{3}$, respectively, by employing the click chemistry reaction, whereas $\mathbf{S N H}_{\mathbf{2}} \mathbf{- 2}$ incorporate the TTF derivative $\mathbf{2}$ which is anchored to the solid via an amidation reaction. The final gated materials were characterized by standard techniques. Acetonitrile suspensions of these solids show "zero release" most likely because of the formation of dense TTFs networks around the pore outlets. The delivery of the entrapped $\left[\mathrm{Ru}(\text { bipy) }]_{3}\right]^{2+}$ dye from $\mathbf{S N}_{\mathbf{3}} \mathbf{- 1}, \mathbf{S N H}_{\mathbf{2}} \mathbf{- 2}$, and $\mathbf{S N}_{\mathbf{3}} \mathbf{- 3}$ was studied in the presence of selected explosives (Tetryl, TNT, TNB, DNT, RDX, PETN, PA and TATP). $\mathbf{S N H}_{\mathbf{2}} \mathbf{- 2}$ shows a fairly selective response to Tetryl whereas for $\mathbf{S N}_{\mathbf{3}} \mathbf{- 1}$ and $\mathbf{S N}_{\mathbf{3}} \mathbf{- 3}$ dye delivery was found to occur with Tetryl, TNT, and TNB. The uncapping process, in the three materials, can be ascribed to the formation of chargetransfer interactions between the electron donating TTF units and the electron accepting nitroaromatic explosives. Finally, solids $\mathbf{S N H}_{\mathbf{2}} \mathbf{- 2}$ and $\mathbf{S N}_{\mathbf{3}} \mathbf{- 1}$ were tested for Tetryl detection in soil with good results, pointing toward a possible use of these or similar hybrid capped materials as probes for the chromo-fluorogenic selective detection of nitroaromatic explosives.

Keywords: Gated materials - nitroaromatic explosives · optical detection . tetrathiafulvalene.

\section{Introduction}

The indiscriminate use of explosives in terrorist attacks in the last few years has increased the attention of the design of new probes for the reliable and 
accurate detection of these lethal chemicals. In this field, and taking into account the widespread use of explosive formulations, the analysis of explosives is of relevant interest in forensic research, landmine detection, and in the study of environmental problems associated with their residues. ${ }^{[1]}$

Explosive compounds, depending on their chemical nature, are classified into four classes namely (i) nitroaromatics and nitroalkanes, (ii) nitramines, (iii) nitrate esters, and (iv) peroxides. ${ }^{[2]}$ Of all these classes, nitroaromatics are perhaps the most used in criminal acts, in landmines, and in cluster bombs. Nitroaromatic explosives are molecules composed of a benzene ring fucntionalized with several nitro groups. Nitroaromatic explosives are electron deficient in nature on account of the presence of electron-withdrawing nitro moieties which lower the energy of the empty $\pi^{*}$ orbital thereby making them good electron acceptors. ${ }^{[3]}$

Standard methodologies for detection and quantification of explosives involve, among others, the use of trained canine teams, ${ }^{[4]}$ gas chromatography coupled with mass spectrometry, ${ }^{[5]}$ gas chromatography-electron capture detection, ${ }^{[6]}$ surface-enhanced Raman spectroscopy, ${ }^{[7]}$ mass spectrometry, ${ }^{[8]} \mathrm{X}$-ray imaging, ${ }^{[9]}$ thermal neutron analysis, ${ }^{[10]}$ electrochemical procedures, ${ }^{[11]}$ and ion mobility spectroscopy (IMS). ${ }^{[12]}$ The above mentioned methods offer several advantages but some of them also present drawbacks related to lack of portability (for "in situ" detection), susceptibility of false positives owing to environmental contaminants and false-negative readings on account of interfering compounds. In this context, the use of chromo-fluorogenic chemosensors based on supramolecular approaches has been explored for explosives detection. ${ }^{[13]}$ In these molecular probes, the interaction with the explosive induced changes in colour or in fluorescence that are easily measurable. Based on this simple concept certain chemosensors for optical detection of explosives using different functionalized dye molecules have been reported. ${ }^{[14]}$ Most of these probes try to take advantage of the electron-deficient character of nitroaromatic explosives allowing them to form $\pi$-stacking charge-transfer complexes with electron 
donating molecules. ${ }^{[15]}$ However, one common drawback in these probes is that fluorescence quenching usually is observed because of the presence of electron transfer processes taking place between the corresponding excited fluorophore and the nitroaromatic explosive. However, probes which exhibit a turn-on response rather than a turn-off behavior are preferred, but to the best of our knowledge, only a few examples on probes with a turn-on response for nitroaromatic explosives have been reported in the literature. ${ }^{[16]}$

Polycyclic aromatic hydrocarbons have been extensively used as electron-rich molecules in the development of fluorogenic probes for detection of nitroaromatic explosives. ${ }^{[17]}$ Other electron-rich molecules that deserve attention are tetrathiafulvalenes (TTF). The huge potential of TTF derivatives was first established by the discovery of their conductive behavior. ${ }^{[18]}$ Since then, other properties of the TTF unit, such as its electro-active character and its strong $\pi$ donating nature have also been exploited. ${ }^{[19]}$ Because of the later property, TTF moieties have recently been included in calixarenes and other supramolecular frameworks in order to prepare chemosensors for nitroaromatic explosives. ${ }^{[20]}$

From another point of view, the blending of supramolecular concepts and inorganic materials has recently resulted in the preparation of gated materials. ${ }^{[21]}$ These are systems in which the delivery of an entrapped cargo can be controlled on-command by means of the use of selected external stimuli which controls the state of the gate (open or closed). ${ }^{[22]}$ These gated materials usually contain two components; i) a switchable gate-like ensemble and ii) a suitable inorganic support which acts as nanocontainer and on which the gate-like system is grafted. Mesoporous silica materials with different pore sizes and morphologies have been selected and used as inorganic scaffolds in the preparation of gated ensembles. These supports show a large surface area (up to $1200 \mathrm{~m}^{2} \mathrm{~g}^{-1}$ ), a large load capacity, are chemical inert, and are easy to functionalize through the use of the well-known alkoxysilane chemistries. ${ }^{[23]}$ In relation to the gate-like ensemble, several molecular, supramolecular, and nanoscopic systems have been used. 
Moreover, opening of the gate and cargo deliver has been accomplished using several physical, ${ }^{[24]}$ chemical, $^{[25]}$ and bio-chemical ${ }^{[26]}$ triggers. Although most of these reported gated materials have been designed for drug delivery applications, some recent examples dealing with the use of capped mesoporous particles for sensing have also been reported. ${ }^{[27]}$ The underlying concept here is that interaction of a target analyte with the gated-ensemble triggers the delivery of the cargo (a dye), resulting in a chromo-fluorogenic signal. ${ }^{[28]}$ This novel approach is highly modular and displays potential for the development of novel signaling systems via the selection of different inorganic porous supports, diverse guestselective gate-like ensembles, and a wide range of dyes and fluorophores. In addition, this approach separates the recognition protocol (binding site-analyte interaction) from the signaling event making sensing independent of the stoichiometry of the host-guest complex and sometimes displaying features of signal amplification. ${ }^{[29]}$

Bearing in mind these independent concepts and following our interest in the preparation of new probes for detection of explosives ${ }^{[16]}$ and in the design of new applications for capped mesoporous materials, ${ }^{\left[{ }^{[0]}\right.}$ we report herein the synthesis and signaling behavior toward nitroaromatic explosives of three gated mesoporous supports decorated on the external surface with three different $\pi$ electron-donating TTF derivatives (Scheme 1) and loaded with a dye (e.g., $\left.\left[\mathrm{Ru}(\text { bipy })_{3}\right]^{2+}\right)$. The prepared nano-probes are designed to show "zero" delivery because of the formation of a dense network of TTF units around the pores. The signaling paradigm (Scheme 1) rely on the interaction between electron-deficient nitroaromatic explosives with the strong $\pi$-electron-donating TTF moieties which result in the rupture of TTF-TTF interactions followed by the delivery of the entrapped dye. Finally, it is demonstrated that this approach leads to relatively simple hybrid probes for nitroaromatic explosives capable of showing a turn-on response in contrast with the widely turn-off observed behavior shown by probes based on single molecules or in fluorophore-containing polymers. 


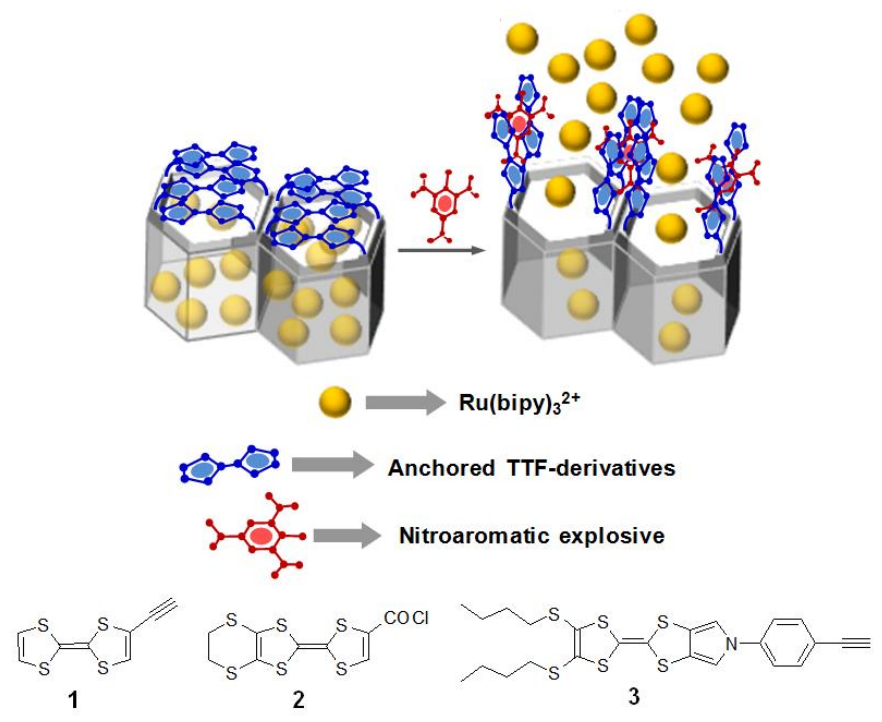

Scheme 1. Schematic representation (top) of the sensory hybrid mesoporous materials and the uncapping mechanism in the presence of nitroaromatic explosives. The structures (bottom) of the TTF-derivatives (1, 2, and 3) used for surface functionalization are also shown.

\section{Results and Discussion}

\section{The gated material}

The prepared hybrid solids are schematically illustrated in Scheme 1. The MCM-41 mesoporous support was prepared, via well-known procedures, from tetraethyl orthosilicate (TEOS) as inorganic precursor and $n$ cetyltrimethylammonium bromide (CTAB) as a porogen species. ${ }^{[31]}$ The surfactant was removed by calcination to obtain the final MCM-41 starting material. The solid was then loaded with $\left[\mathrm{Ru}(\mathrm{bipy})_{3}\right]^{2+}$, as suitable fluorophore, and the outer surface functionalized with 3-(azidopropyl)triethoxisylane (giving $\mathbf{S N}_{\mathbf{3}}$, for the further preparation of the sensing materials $\mathbf{S N}_{\mathbf{3}} \mathbf{- 1}$ and $\mathbf{S N}_{\mathbf{3}}-\mathbf{3}$ ) or with 3(aminopropyl)triethoxisylane groups (giving $\mathbf{S N H}_{2}$, for the preparation of the sensing support $\mathbf{S N H}_{2}-2$ ). Following this grafting procedure, the silane groups are preferentially attached to the external surface rather than to the inside of the mesopores, which contain the $\left[\mathrm{Ru}(\mathrm{bipy})_{3}\right]^{2+}$ dye. In the second step (Scheme 2), 
the TTF derivatives $\mathbf{1}$ or $\mathbf{3}$ both containing an alkyne moiety were attached to outer surface of solid $\mathbf{S N}_{\mathbf{3}}$ by a copper(I)-catalyzed Huisgen azide/alkyne 1,3dipolar cycloaddition "click" reaction. ${ }^{[32]}$ This led to the formation of a 1,2,3triazole heterocycle and yielded the final hybrid materials $\mathbf{S N}_{\mathbf{3}}-\mathbf{1}$ and $\mathbf{S N}_{\mathbf{3}}-\mathbf{3}$, respectively. The resulting solids were filtered, intensively washed with water and with organic solvents before being dried overnight at $36^{\circ} \mathrm{C}$. Water washings were carried out in order to eliminate possible traces of copper in the surface of the final solids. For the preparation of $\mathbf{S N H}_{\mathbf{2}} \mathbf{- 2}$, the solid $\mathbf{S} \mathbf{N H}_{\mathbf{2}}$ was reacted (Scheme 2) with the acyl chloride derivative $\mathbf{2}$ in acetonitrile/ $\mathrm{K}_{2} \mathrm{CO}_{3}$ in order to attach the TTF derivative through an amide linkage. After completion of the reaction, the final sensing material was filtered and intensively washed before being dried overnight at $36^{\circ} \mathrm{C}$.

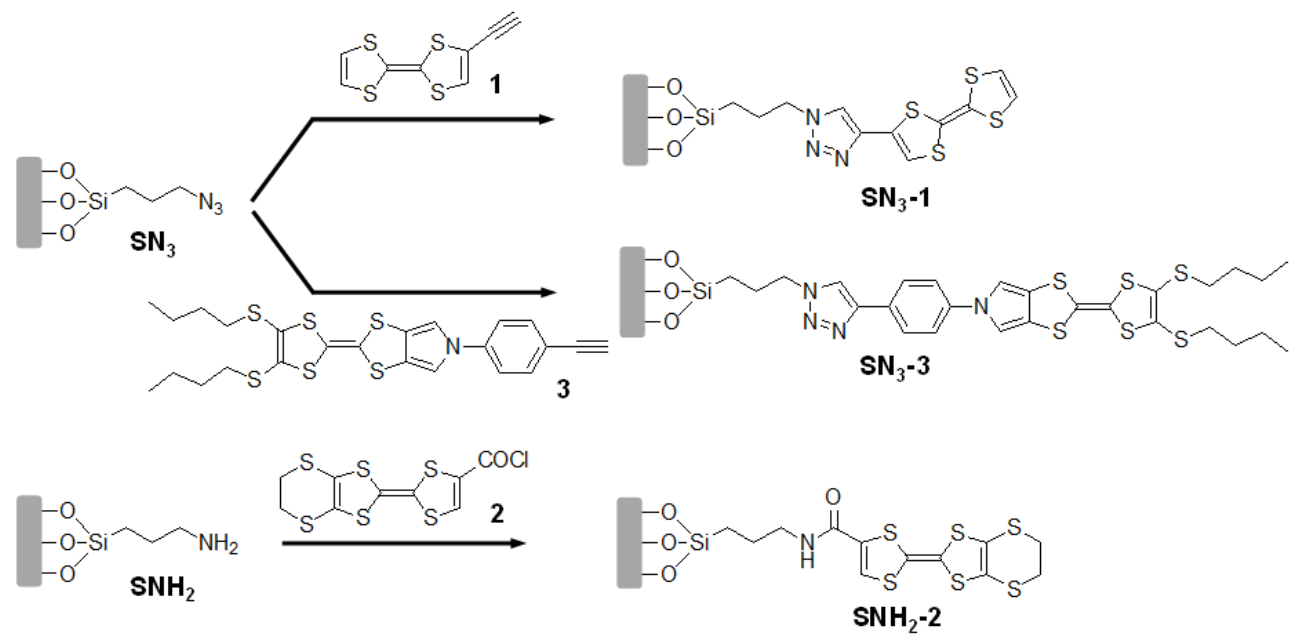

Scheme 2. . Synthetic route for the preparation of solids $\mathrm{SN}_{3}-\mathbf{1}, \mathrm{SNH}_{2}-\mathbf{2}$ and $\mathrm{SN}_{3}-\mathbf{3}$. 


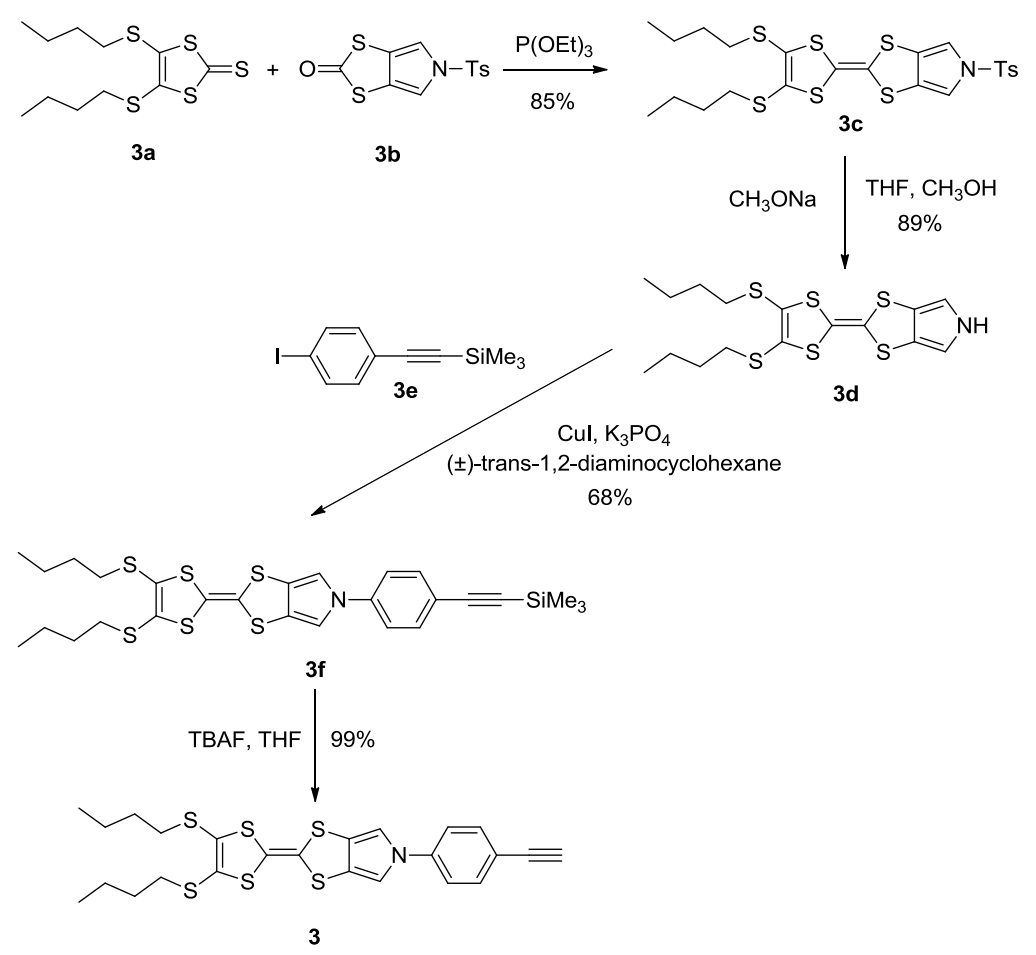

Scheme 3. Synthetic route for the preparation of compound 3

The TTF derivatives $\mathbf{1}^{[33]}$ and $\mathbf{2}^{[34]}$ were prepared following literature procedures, whereas the novel TTF derivative $\mathbf{3}$ was synthesized via a four step procedure as depicted in Scheme 3. Its synthesis involves in a first step a crosscoupling of 4,5-bis(butylthio)-1,3-dithiole-2-thione (3a) $)^{[35]}$ with $N$-tosyl-(1,3)dithiolo[4,5-c]pyrrole-2-on $(\mathbf{3 b})^{[36]}$ in refluxing triethyl phosphite yielding the TTF derivative $\mathbf{3 c}$ in $85 \%$ yield. The tosyl protecting group in $\mathbf{3 c}$ was removed by treatment with sodium methoxide in THF-methanol giving ( $89 \%$ yield) compound 3d. The third step was a microwave-assisted coupling between $\mathbf{3 d}$ and (4iodophenylethylyl)trimethylsilane (3e) catalyzed by $\mathrm{Cul}$ that afforded the TTFderivative $3 f$ in $68 \%$ yield. Finally, the alkynyl-TTF derivative $\mathbf{3}$ was obtained in almost quantitative yield by deprotection ${ }^{[37]}$ of the TMS group using tetra- $n$ butylammonium fluoride (TBAF). 


\section{Materials characterization}

The starting MCM-41 material and final sensing solid $\mathbf{S N}_{\mathbf{3}} \mathbf{- 1}, \mathbf{S N H}_{\mathbf{2}} \mathbf{- 2}$, and $\mathbf{S N}_{\mathbf{3}} \mathbf{- 3}$ were characterized by conventional solid state procedures. The mesoporous structure of the MCM-41 material was confirmed by powder X-ray diffraction (PXRD) and transmission electron microscopy (TEM) techniques. Figure 1 shows the PXRD pattern of the MCM-41 as-synthesized, MCM-41 calcined, and that of the final supports $\mathbf{S N}_{\mathbf{3}} \mathbf{- 1}, \mathbf{S N H}_{\mathbf{2}} \mathbf{- 2}$, and $\mathbf{S N}_{\mathbf{3}} \mathbf{- 3}$. The PXRD of siliceous MCM-41 assynthesized shows four low-angle reflexions typical of an hexagonal-ordered array which can be indexed as (100), (110), (200), and (210) Bragg peaks. A shift of the (100) reflexion and a remarkable broadening of the (110) and (200) peaks in the PXRD of the MCM-41 calcined was observed. This corresponds to an approximate cell contraction of ca. 6-8 Å during the calcination step. Despite this partial order loss, the fact that the overlapped (100), (110) and (200) reflections observed indicates that the mesopore symmetry is preserved after calcination. The PXRD of the final capped solids $\left(\mathbf{S N}_{\mathbf{3}} \mathbf{- 1}, \mathbf{S N H}_{\mathbf{2}} \mathbf{- 2}\right.$, and $\left.\mathbf{S N}_{\mathbf{3}} \mathbf{- 3}\right)$ only displayed the (100) reflection. For these solids, peaks (110) and (200) were lost, most probably relating to a reduced contrast because of the pore voids filling with the ruthenium complex. Nevertheless, the clear presence of the (100) peak in this pattern indicate that the loading and functionalization process did not substantially modify the mesoporous structure of the final supports.

The presence of the mesoporous structure in the final functionalized solids was also confirmed by TEM analysis, in which the typical channels of the MCM-41 matrix are seen (Figure 2) as black and white stripes. TEM images also show that the final solids were obtained as microparticles. SEM analysis using Energy Dispersive X-ray spectroscopy (EDX, $20 \mathrm{kV}$ ) did not show any characteristic signal for $\mathrm{Cu}$, indicating that no residual copper from the click reaction is present in the final isolated $\mathbf{S N}_{\mathbf{3}} \mathbf{- 1}$ and $\mathbf{S N}_{\mathbf{3}} \mathbf{- 3}$ materials. Moreover EDX also clearly indicated the presence of sulphur atoms (due to grafted TTF moieties) in $\mathbf{S N}_{\mathbf{3}}-\mathbf{1}, \mathbf{S N}_{\mathbf{3}}-\mathbf{3}$, and $\mathrm{SNH}_{2}$-2. 


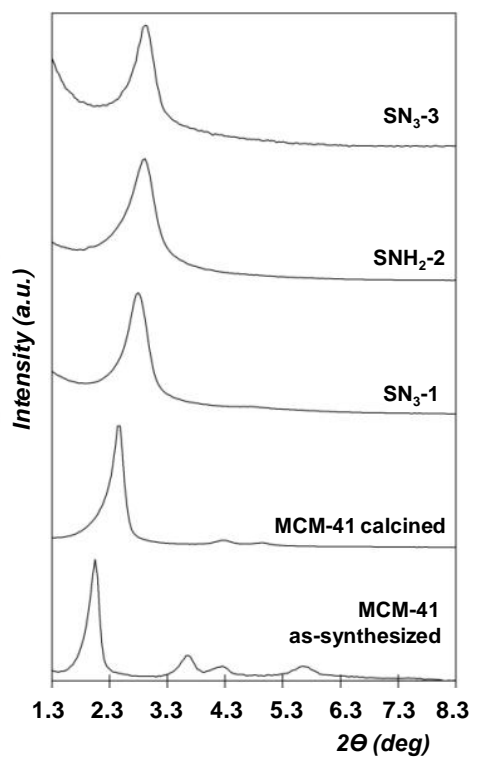

Figure 1. Small-angle PXRD patterns of as-synthesized MCM-41, MCM-41 calcined and the final solids $\mathrm{SN}_{3}-1, \mathrm{SNH}_{2}-2$ and $\mathrm{SN}_{3}-3$.

The $\mathrm{N}_{2}$ adsorption-desorption studies of the MCM-41 calcined, $\mathbf{S N}_{\mathbf{3}} \mathbf{- 1}, \mathbf{S N H}_{\mathbf{2}} \mathbf{- 2}$, and $\mathbf{S N}_{\mathbf{3}} \mathbf{- 3}$ materials were also carried out. As an example, Figure 3 shows the nitrogen adsorption-desorption isotherms obtained for MCM-41 calcined and $\mathbf{S N H}_{\mathbf{2}} \mathbf{- 2}$. The MCM-41 calcined showed a typical curve for this mesoporous support, consisting of an adsorption step at an intermediate $P / P_{0}$ value (0.1-0.3). These isotherms could be classified as type IV, characteristic of mesoporous materials in which the observed step deals with nitrogen condensation inside the mesopores. Pore size distributions (PSD) of these samples, was calculated by employing the Barret-Joyner-Halenda (BJH) method. ${ }^{[38]}$ The pore-diameter estimated from the respective TEM image analysis were in agreement with these values. The narrow BJH pore distribution and the absence of a hysteresis loop in this interval suggest the existence of uniform cylindrical mesopores (pore diameter of $2.25 \mathrm{~nm}$ and pore volume of $0.45 \mathrm{~cm}^{3} \mathrm{~g}^{-1}$ calculated by using the $\mathrm{BJH}$ model on the adsorption branch of the isotherm). Application of the BrunauerEmmett-Teller (BET) model ${ }^{[39]}$ resulted in a value of $1036.2 \mathrm{~m}^{2} \mathrm{~g}^{-1}$ for the total 
specific surface. From the PXRD, porosimetry, and TEM studies, the $a_{0}$ cell parameter $(3.65 \mathrm{~nm})$ and the wall thickness $(1.4 \mathrm{~nm})$ were obtained.
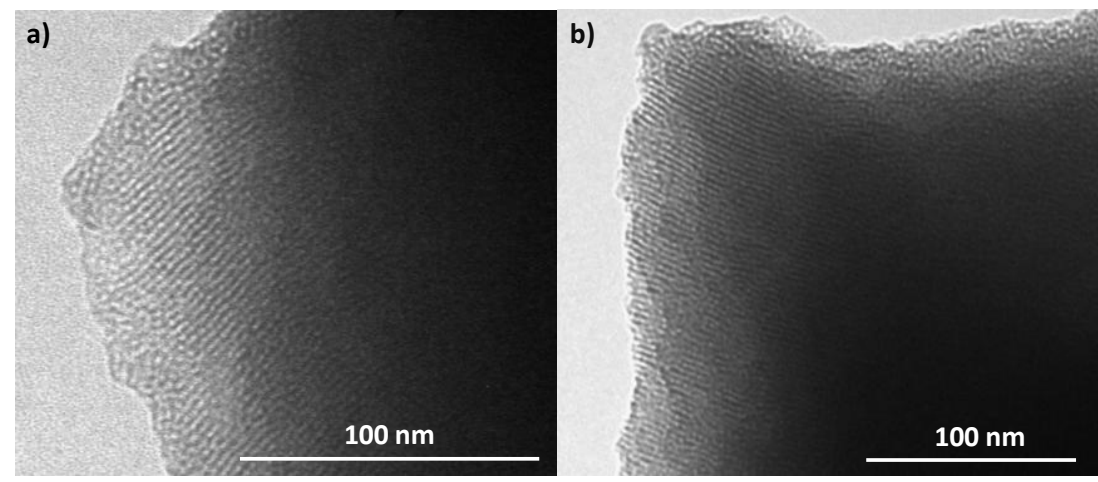

Figure 2. The TEM image of MCM-41 calcined (a), and final solid $\mathbf{S N H} \mathbf{H}_{\mathbf{2}} \mathbf{- 2}$ (b) showing the typical porosity of the MCM-41 matrix.

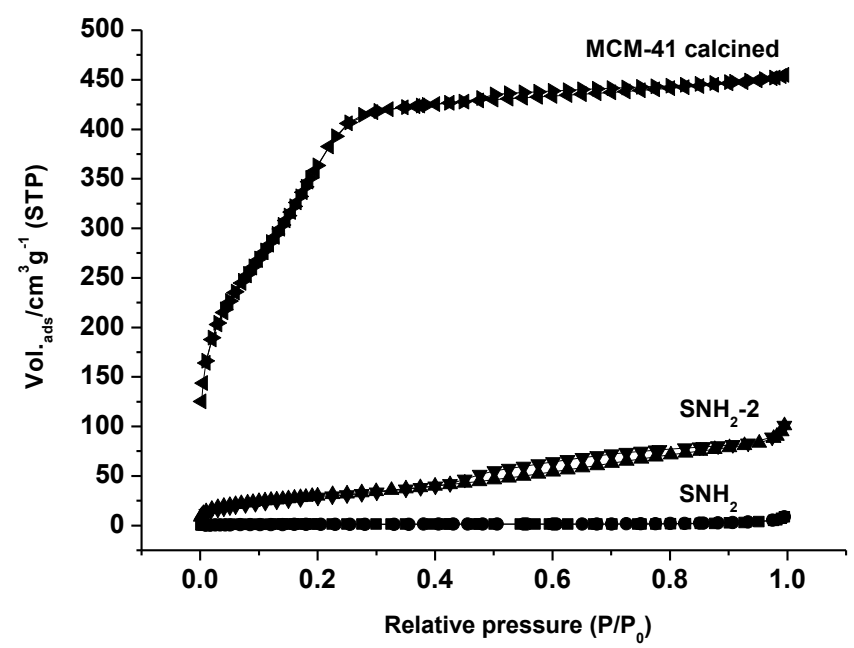

Figure 3. Nitrogen adsorption-desorption isotherms for MCM-41 calcined, $\mathbf{S N H}_{\mathbf{2}}$ and $\mathbf{S N H}_{\mathbf{2}}-\mathbf{2}$.

The $\mathrm{N}_{2}$ adsorption-desorption isotherms of solids $\mathbf{S N}_{\mathbf{3}}, \mathbf{S N H}_{\mathbf{2}}, \mathbf{S N}_{\mathbf{3}} \mathbf{- 1}, \mathbf{S N H}_{\mathbf{2}} \mathbf{- 2}$, and $\mathbf{S N}_{3}-\mathbf{3}$ are typical of mesoporous systems with partially filled mesopores and a decrease in the $\mathrm{N}_{2}$ volume adsorbed and specific surface area (see Table 1) is 
observed. This is especially pronounced for the solids $\mathbf{S N}_{\mathbf{3}}, \mathbf{S N H}_{\mathbf{2}}, \mathbf{S N H}_{\mathbf{2}}-\mathbf{2}$, and $\mathbf{S N}_{\mathbf{3}}-$ 3, whereas for solid $\mathbf{S N}_{\mathbf{3}}-\mathbf{1}$ a relatively high specific surface was being observed. This reduction in the BET surface when compared with that of the MCM-41 starting material is attributed to the loading of the pores with the ruthenium(II) complex and to the functionalization of the surface silanols with bulky TTF moieties. ${ }^{[40]}$

Table 1. BET-specific surface values, pore volumes and pore sizes calculated from the $\mathrm{N}_{2}$ adsorption-desorption isotherms.

\begin{tabular}{lccc}
\hline Sample & $\begin{array}{c}\mathrm{S}_{\mathrm{BET}} \\
{\left[\mathrm{m}^{2} \mathrm{~g}^{-1}\right]}\end{array}$ & $\begin{array}{c}\text { BJH Pore } \\
{[\mathrm{nm}]}\end{array}$ & $\begin{array}{c}\text { Total Pore Volume } \\
{[\mathrm{bm}]} \\
{\left[\mathrm{cm}^{3} \mathrm{~g}^{-1}\right]}\end{array}$ \\
\hline MCM-41 & 1036.2 & 2.25 & 0.45 \\
SN $_{\mathbf{3}}$ & 77.9 & $<2$ & 0.03 \\
SNH $_{\mathbf{2}}$ & 50.2 & $<2$ & 0.01 \\
SN $_{\mathbf{3}}-\mathbf{1}$ & 816.2 & 2.27 & 0.37 \\
SN $_{\mathbf{3}}-\mathbf{3}$ & 558.0 & 2.61 & 0.27 \\
SNH $_{\mathbf{2}}-\mathbf{2}$ & 111.4 & $<2$ & 0.15 \\
\hline
\end{tabular}

\footnotetext{
${ }^{[a]}$ Pore volumes and pore sizes were associated with only intraparticle mesopores.

${ }^{[b]}$ Pore size estimated by the BJH model applied to the adsorption branch of the isotherm.
}

The content of the $\left[\mathrm{Ru}(\text { bipy })_{3}\right]^{2+}$ complex and the TTF derivative in the solids was determined by thermogravimetric analysis, EDX, and elemental analysis (see Table 2). The thermogravimetric curve for $\mathbf{S N}_{\mathbf{3}} \mathbf{- 1}, \mathbf{S N H}_{\mathbf{2}} \mathbf{- 2}$, and $\mathbf{S N}_{\mathbf{3}} \mathbf{- 3}$ materials show three weight loss steps $\left(T<210^{\circ} \mathrm{C}, 210^{\circ} \mathrm{C}<T<800^{\circ} \mathrm{C}, T>800^{\circ} \mathrm{C}\right)$ related with solvent elimination (11.77\%, 8.23\%, and $15.49 \%$ for $\mathbf{S N}_{\mathbf{3}} \mathbf{- 1}, \mathbf{S N H}_{\mathbf{2}} \mathbf{- 2}$, and $\mathbf{S N}_{\mathbf{3}} \mathbf{-}$ 3, respectively), decomposition of grafted organic groups and of ruthenium complex (11.66\%, 31.06\%, and $12.13 \%$ for $\mathbf{S N}_{\mathbf{3}} \mathbf{- 1}, \mathbf{S N H}_{\mathbf{2}} \mathbf{- 2}$, and $\mathbf{S N}_{\mathbf{3}} \mathbf{- 3}$, respectively) and, finally, condensation of silanols on the siliceous surface $(0.93 \%, 1.18 \%$, and $1.17 \%$ for $\mathbf{S N}_{3}-\mathbf{1}, \mathbf{S N H}_{2}-\mathbf{2}$, and $\mathbf{S N}_{3}-\mathbf{3}$, respectively).

The specific surface areas of the final solids is clearly correlated to the dye contents in the porous network as it transpires from the data collected in Tables 1 
and 2. For instance solid $\mathbf{S N}_{\mathbf{3}}-\mathbf{1}$ displays a higher specific surface $\left(816.2 \mathrm{~m}^{2} \mathrm{~g}^{-1}\right)$, when compared with $\mathbf{S N H}_{2} \mathbf{- 2}$ (specific surface $111.4 \mathrm{~m}^{2} \mathrm{~g}^{-1}$ ) which correlates well with the lower ruthenium (II) content found for the former.

Table 2. Content ( $\alpha$ ) of anchored molecules and dye in $\mathrm{mmol} \mathrm{g}^{-1}$ of $\mathrm{SiO}_{2}$.

\begin{tabular}{ccccc}
\hline & $\begin{array}{c}\alpha_{\text {amine }} \\
(\mathrm{mmol} / \mathrm{g}\end{array}$ & $\begin{array}{c}\alpha_{\text {azide }} \\
(\mathrm{mmol} / \mathrm{g}\end{array}$ & $\begin{array}{c}\alpha_{\text {dye }} \\
(\mathrm{mmol} \mathrm{g}\end{array}$ & $\begin{array}{c}\alpha_{\text {TTF }} \\
(\mathrm{mmol} / \mathrm{g}\end{array}$ \\
Solid & $\left.\mathrm{SiO}_{2}\right)$ & $\left.\mathrm{SiO}_{2}\right)$ & $\left.\mathrm{SiO}_{2}\right)$ & $\left.\mathrm{SiO}_{2}\right)$ \\
\hline $\mathbf{S N}_{\mathbf{3}}$ & - & 0.65 & 0.53 & - \\
$\mathbf{S N}_{\mathbf{3}}-\mathbf{1}$ & - & & 0.04 & 0.29 \\
$\mathbf{S N}_{\mathbf{3}}-\mathbf{3}$ & - & & 0.14 & 0.10 \\
$\mathbf{S N H}_{\mathbf{2}}$ & 0.73 & - & 0.55 & - \\
$\mathbf{S N H}_{\mathbf{2}}-\mathbf{2}$ & & - & 0.52 & 0.42 \\
\hline
\end{tabular}

In addition, the data in Table 2 also indicate that functionalization with the TTF derivatives on the azide- and amine-functionalized solids $\mathbf{S N}_{\mathbf{3}}$ and $\mathbf{S N H}_{\mathbf{2}}$ was not complete. It can be calculated that ca. 44 and $15 \%$ of anchored azides in $\mathbf{S N}_{\mathbf{3}}$ were functionalized with the TTF derivatives $\mathbf{1}$ and $\mathbf{3}$, in solids $\mathbf{S N}_{\mathbf{3}}-\mathbf{1}$ and $\mathbf{S N}_{\mathbf{3}}-\mathbf{3}$, respectively. Moreover ca. $57 \%$ of the anchored amines in $\mathbf{S} \mathbf{N H}_{\mathbf{2}}$ reacted with the TTF derivative 2 .

A ${ }^{29}$ Si NMR spectroscopic study carried out on the solids $\mathbf{S N H}_{\mathbf{2}}$ and $\mathbf{S N H}_{\mathbf{2}} \mathbf{- 2}$ as well as the starting MCM-41 material confirms the anchoring of the organosilane groups (see Figure 4 and Table 3). A relative decrease in the amount of $Q^{2}+Q^{3}$ (silanol) sites towards $Q^{4}$ (fully condensed) sites in $\mathbf{S N H}_{\mathbf{2}}$ can be observed when compared with the MCM-41 material. This variation is in accordance with the apparition of the $\mathrm{T}^{1}, \mathrm{~T}^{2}$, and $\mathrm{T}^{3}$ peaks corresponding to the anchored silane groups. However, taking into account that each 3-(aminopropyl)triethoxysilane can be anchored through three, two, or at least one silanol groups to guarantee a certain anchoring effect, we can roughly estimate that the decrease of the silanol groups seems somehow lower than incorporation of organosilane groups. Hence, a 
certain condensation among incorporated organosilanes cannot be excluded additionally to their simultaneous anchoring to the silica surface. Whether the condensation of silanes takes place, these species will be located preferably at the mesopore entrances. Finally, after the second preparative step leading to $\mathbf{S N H}_{\mathbf{2}} \mathbf{- 2}$, an appreciable hydroxylation of the silica surface occurs affecting both $Q$ and $T$ sites. Hence, while $\mathrm{T}^{3}$ and $\mathrm{T}^{2}$ sites are preserved in a large extent, the preparative conditions appear to favor the leaching of $\mathrm{T}^{1}$-type organosilane groups.
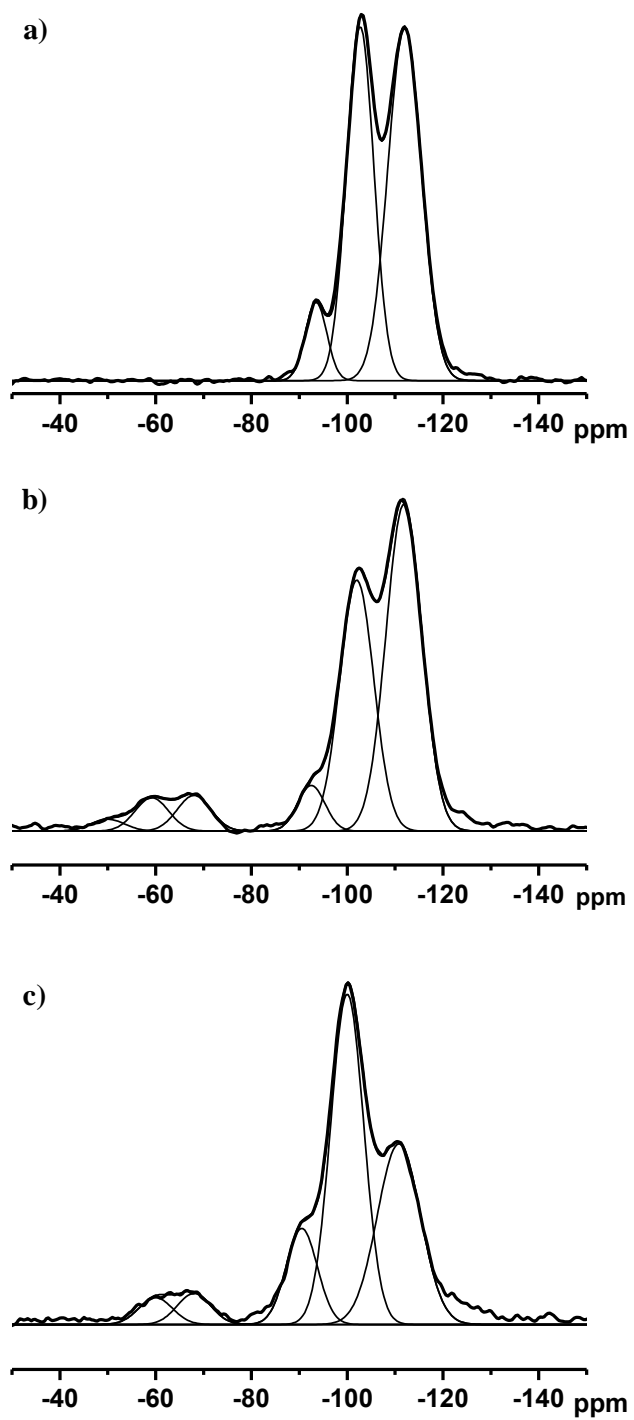

Figure 4. ${ }^{29}$ Si NMR spectra (400 MHz) recorded at $298 \mathrm{~K}$ for solids a) MCM-41, b) $\mathbf{S N H}_{\mathbf{2}}$ and c) $\mathbf{S N H}_{\mathbf{2}}-\mathbf{2}$. 
Table 3. ${ }^{29}$ Si NMR spectroscopic solids MCM-41, $\mathbf{S N H}_{\mathbf{2}}$ and $\mathrm{SNH}_{\mathbf{2}} \mathbf{- 2}$.

\begin{tabular}{c|cccccc}
\hline & $\begin{array}{c}\mathrm{Q}^{2} \\
(\%)\end{array}$ & $\begin{array}{c}\mathrm{Q}^{3} \\
(\%)\end{array}$ & $\begin{array}{c}\mathrm{Q}^{4} \\
(\%)\end{array}$ & $\begin{array}{c}\mathrm{T}^{1} \\
(\%)\end{array}$ & $\begin{array}{c}\mathrm{T}^{2} \\
(\%)\end{array}$ & $\begin{array}{c}\mathrm{T}^{3} \\
(\%)\end{array}$ \\
\hline MCM-41 & 7.3 & 41.7 & 51 & - & - & - \\
$\mathbf{S N H}_{2}$ & 5.2 & 35.2 & 48.5 & 1.6 & 4.6 & 4.9 \\
SNH $_{2}-2$ & 12.7 & 46.2 & 32.9 & - & 3.8 & 4.4 \\
\hline
\end{tabular}

\section{Dye release studies in the presence of explosives}

In order to test the proposed sensing mechanism (Scheme 1), the interaction of $\mathbf{S N}_{\mathbf{3}}-\mathbf{1}, \mathbf{S N H}_{\mathbf{2}}-\mathbf{2}$, and $\mathbf{S N}_{\mathbf{3}}-\mathbf{3}$ with selected explosives was studied through the delivery of the ruthenium complex entrapped in the porous network of the inorganic supports. Release studies were carried out in acetonitrile solutions where a tight pore closure was observed and where both the ruthenium dye and the studied explosives were clearly soluble. The following molecules were selected for this study: 2,4-dinitrotoluene (2,4-DNT), 2,4,6-trinitrotoluene (TNT), 2,4,6-trinitrophenylmethylnitramine (Tetryl), trinitrobenzene (TNB), hexahydro1,3,5-trinitro-1,3,5-triazine (RDX), pentaerythritol tetranitrate (PETN), picric acid (PA), triacetone triperoxide (TATP), N-methylaniline (NM), 2-nitrotoluene (NT) and nitrobenzene (NB).

In a typical assay, $4 \mathrm{mg}$ of the corresponding solid $\left(\mathbf{S N}_{\mathbf{3}}-\mathbf{1}, \mathbf{S N H}_{\mathbf{2}}-\mathbf{2}\right.$, or $\left.\mathbf{S N}_{\mathbf{3}} \mathbf{- 3}\right)$ was suspended in $10 \mathrm{~mL}$ of acetonitrile in the presence of 2,4-DNT, TNT, Tetryl, TNB, RDX, PETN, PA, TATP, NM, NT, or NB $\left(2.0 \times 10^{-3} \mathrm{~mol} \mathrm{~L}^{-1}\right)$ at $25^{\circ} \mathrm{C}$. Delivery of the dye to the bulk solution was easily detected by monitoring the $d-\pi$ metal-toligand charge transfer (MLCT) transition band of the $\left[\mathrm{Ru}(\text { bipy })_{3}\right]^{2+}$ complex at 453 $\mathrm{nm}$, or via its luminescence at $615 \mathrm{~nm}\left(\lambda_{\mathrm{ex}}=453 \mathrm{~nm}\right) .{ }^{[41]}$ As an illustrative example, Figure 5 shows the release kinetics of the ruthenium dye from $\mathbf{S N}_{\mathbf{3}}-\mathbf{3}$ in the presence of selected explosives. As it can be seen, solid $\mathbf{S N}_{\mathbf{3}} \mathbf{- 3}$ is tightly capped in solution and shows a negligible release of the entrapped $\left[R u(b i p y)_{3}\right]^{2+}$ complex. The presence of Tetryl, TNT, or TNB induces the opening of the pores and the 
subsequent release of the dye. After ca. $60 \mathrm{~min}$, the delivery reaches a plateau. In contrast, DNT, RDX, PETN, PA, TATP, NM, NT, and NB were unable to induce the release of the ruthenium complex (data not shown) when added to solutions of probe $\mathbf{S N}_{\mathbf{3}}-\mathbf{3}$ (see Figure 6).

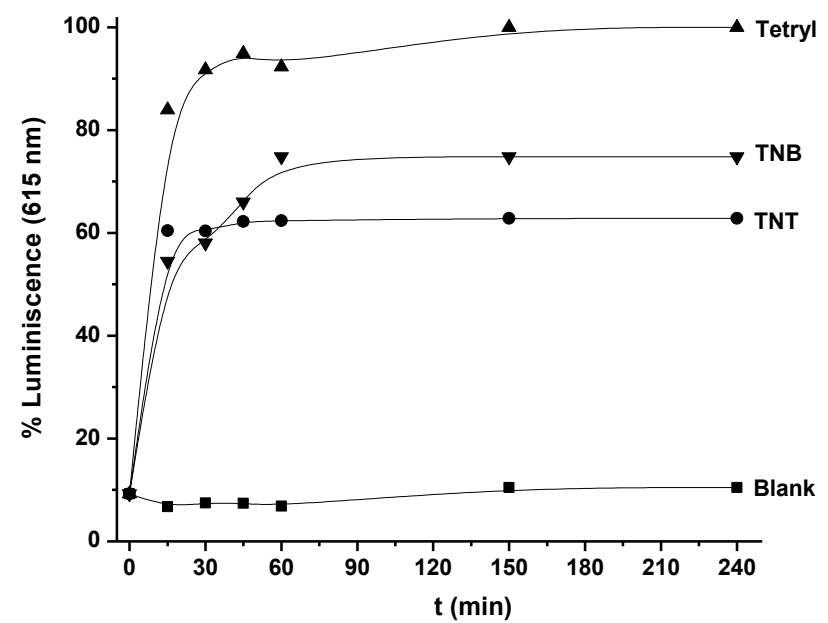

Figure 5. Kinetics of the release of the $\left[\mathrm{Ru}(\text { bipy })_{3}\right]^{2+}$ dye from solid $\mathrm{SN}_{3}-\mathbf{3}$ in the absence (blank) and the presence of the nitroaromatic explosives Tetryl, TNT, and TNB $\left(2.0 \times 10^{-3} \mathrm{~mol} \mathrm{~L}^{-1}\right)$ in acetonitrile.

Delivery studies were carried out using solids $\mathbf{S N}_{\mathbf{3}}-\mathbf{- 1}, \mathbf{S N H}_{\mathbf{2}}-\mathbf{2}$ with similar overall results; i.e., a tight capping of the pores in the solid alone and delivery of the dye in the presence of certain explosives. As a summary of the delivery behavior, Figure 6 shows the relative release of ruthenium complex from acetonitrile suspensions of solids $\mathbf{S N}_{\mathbf{3}} \mathbf{- 1}, \mathbf{S N H}_{\mathbf{2}}-\mathbf{2}$, and $\mathbf{S N}_{\mathbf{3}}-\mathbf{3}$ after ca. 60 min upon addition of different species. As it could be seen Tetryl, TNT, and TNB were able to induce, to some extent, the opening of the "molecular gate" for the three solids with subsequent dye release and turn-on of the emission, whereas other substances tested were unable to induce payload release. The less selective material is $\mathbf{S N}_{\mathbf{3}} \mathbf{- 3}$ for which Tetryl, TNT, and TNB induced nearly the same behavior. On the other hand, solid $\mathbf{S N H} \mathbf{2}-\mathbf{2}$ shows a fairly selective response to Tetryl. The studies show that changes in the nature of the appended TTF derivative (different size and number of sulfur atoms) are finally reflected in subtle differences in the response of the three sensing materials. 

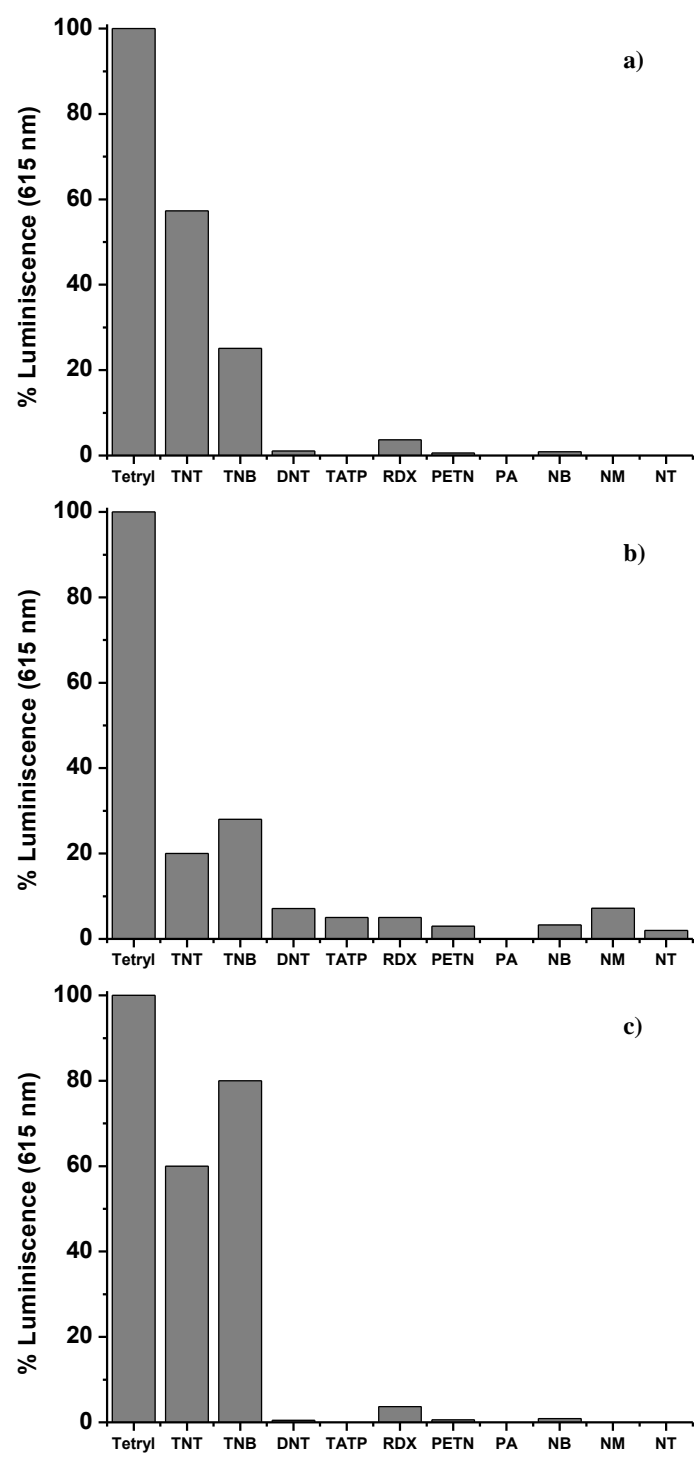

Figure 6. Release of ruthenium complex from acetonitrile suspensions of solids a) $\mathbf{S N}_{3}-\mathbf{1}$, b) $\mathbf{S N H}_{2}-\mathbf{2}$ and c) $\mathbf{S N}_{\mathbf{3}}-\mathbf{3}$ in the presence of different explosives $\left(2 \times 10^{-3} \mathrm{~mol} \mathrm{~L}^{-1}\right)$. The emission at $615 \mathrm{~nm}$ (excitation at $453 \mathrm{~nm}$ ) was measured 60 min after addition of the explosive.

From the studies above it was demonstrated that acetonitrile solutions of $\mathbf{S N}_{\mathbf{3}}$ 1, $\mathbf{S N H}_{2}-\mathbf{2}$, and $\mathbf{S N}_{\mathbf{3}}-\mathbf{3}$ are firmly capped. This behavior is attributed to the formation of dense TTF networks through $\pi$-stacked face-to-face and S $\cdots S$ 
interactions, around the pores, which inhibited cargo release. Moreover, semiempirical molecular calculations using HyperChem software show that the anchored TTF derivatives have significant dipole moments of ca. 1.8, 3.9, and 6.4 D for 1, 2, and 3, respectively. Therefore, it is likely that the strong dipole-dipole interactions between anchored molecules around the pore outlets will take place and therefore inhibit dye delivery.

In addition, when certain nitoraromatic explosives are added to solutions of the sensing solids, a clear cargo delivery is observed. This behavior can most likely be accounted for by the formation of TTF-nitroaromatic complexes, which results in the rupture of the TTF-TTF interactions (including $\pi$-stacking and dipole interactions) allowing the gate to open. Moreover, this behavior is only observed for molecules displaying a large electron accepting character, i.e., Tetryl, TNT, and TNB, an observation which suggests that it is their interaction with the electron donating TTF units which are responsible for the uncapping process. Furthermore, ${ }^{13}$ C MAS NMR spectroscopic investigations carried out on the solids $\mathbf{S N}_{\mathbf{3}}$ and $\mathbf{S N}_{\mathbf{3}} \mathbf{- 1}$ in the presence of Tetryl supported the proposed opening mechanism. Solid $\mathbf{S N}_{\mathbf{3}}$ showed two well defined zones in their ${ }^{13} \mathrm{C}$ spectrum; one in the $20-60 \mathrm{ppm}$ region in which the resonances of the carbons of the propyl chain linking the azido moiety and the the inorganic scaffold appears, and another in the 120-160 ppm region in which signals of the bipyridine moieties of the entrapped dye appear. $A$ ${ }^{13}$ C MAS NMR spectrum of the final solid $\mathbf{S N}_{\mathbf{3}} \mathbf{- 1}$ showed the same two well defined zones with the carbons of the propyl chain located in the 20-60 ppm region, whereas the aromatic carbons appeared in the 120-170 ppm region. The formation of the 1,2,3-triazole ring (due to the click reaction) with a concomitant immobilization of the TTF moiety result in the appearance of new carbon signals resonating at $122.2,122.9,129.4,137.4,155.7,161.6$, and 162.8 ppm. In a further experiment, the solid $\mathbf{S N}_{\mathbf{3}} \mathbf{- 1}$ was suspended in acetonitrile and an excess of Tetryl was added to the suspension which was stirred for 24 hours in order to achieve the maximum interaction TTF-Tetryl and delivery of the $\left[\mathrm{Ru}(\text { bipy })_{3}\right]^{2+}$ complex. The most remarkable feature of the ${ }^{13} \mathrm{C}$ MAS NMR spectrum recorded of this solid was 
the broadening and a small shits (0.1-0.2 ppm to lower fields) of the TTF signals (120-170 ppm) which is tentatively attributed to the formation of TTF-Tetryl charge-transfer complexes.

To complete the characterization of the sensing behavior of the hybrid solids $\mathbf{S N}_{\mathbf{3}}-\mathbf{1}, \mathbf{S N H}_{2}-\mathbf{2}$, and $\mathbf{S N}_{\mathbf{3}}-\mathbf{3}$ the limits of detection (LODs) in the presence of TNT, $\mathrm{TNB}$, and Tetryl were determined from the corresponding calibration curves using fluorescence as the detection method (see Table 5). As an example, Figure 7 shows the calibration curve obtained for $\mathbf{S N H}_{\mathbf{2}} \mathbf{- 2}$ upon addition of increasing quantities of TNB. LODs for TNT, TNB, and Tetryl were found to be in the 1-10 ppm range.

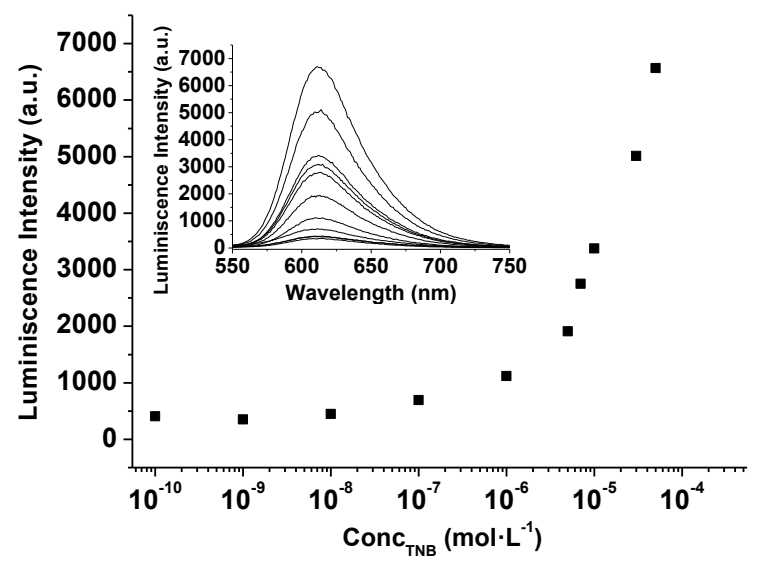

Figure 7. Calibration curves obtained from acetonitrile suspensions of $\mathbf{S N H}_{2}-\mathbf{2}$ upon addition of increasing quantities of TNB $\left(\lambda_{e x}=453 \mathrm{~nm}, \lambda_{e m}=615 \mathrm{~nm}\right) 60 \mathrm{~min}$ after adittion of TNB. The inset shows the turn-on emission spectra of the $\left[\mathrm{Ru}(\text { bipy })_{3}\right]^{2+}$ dye released from $\mathbf{S N H}_{2}-\mathbf{2}$ upon addition of increasing quantities of TNB.

These values are similar to those found for molecular-based probes ${ }^{[20]}$ but are higher than those obtained with gold nanoparticles, ${ }^{[42]}$ organic polymers, ${ }^{[43]}$ and tin oxide printed electrodes. ${ }^{[44]}$ As a remarkable difference solids $\mathbf{S N}_{\mathbf{3}} \mathbf{- 1}, \mathbf{S N H}_{\mathbf{2}} \mathbf{- 2}$, and $\mathbf{S N}_{\mathbf{3}}-\mathbf{3}$ display a turn-on response to nitroaromatic explosives in contrast with the quite common turn-off behavior usually found with other sensing systems. 
Table 5. Limits of detection (in ppm) for Tetryl, TNT and TNB using solids $\mathrm{SN}_{3}-1, \mathrm{SNH}_{2}-2$ and $\mathrm{SN}_{3}-3$.

\begin{tabular}{cccc}
\hline Solid & Tetryl & TNT & TNB \\
\hline $\mathbf{S N}_{3}-\mathbf{1}$ & 1 & 6 & 10 \\
$\mathbf{S N H}_{2}-\mathbf{2}$ & 1 & 2 & 2 \\
$\mathbf{S N}_{3}-\mathbf{3}$ & 2 & 7 & 6 \\
\hline
\end{tabular}

\section{Tetryl detection in soils}

After assessing the selective response of solids $\mathbf{S N}_{\mathbf{3}} \mathbf{- 1}, \mathbf{S N H}_{\mathbf{2}} \mathbf{- 2}$, and $\mathbf{S N}_{\mathbf{3}} \mathbf{- 3}$ toward nitroaromatic explosives in solution, we focused our interest to the possible use of these materials for detection in soil samples. For this purpose we selected solids $\mathbf{S N}_{\mathbf{3}} \mathbf{- 1}$ and $\mathbf{S N H}_{\mathbf{2}} \mathbf{- 2}$ as sensing systems and Tetryl as a representative explosive. In a typical experiment, $10 \mathrm{~g}$ of a finely grinded homogeneous soil sample was doped with a known concentration of Tetryl $(10 \mathrm{~mL}$ of a Tetryl solution of concentration $1.0 \times 10^{-4} \mathrm{~mol} \mathrm{dm}^{-3}$ in acetonitrile). The prepared Tetrylspiked soil sample was extracted with acetonitrile $(3 \times 15 \mathrm{~mL})$. Then the obtained extract was concentrated and the resulting extract was dissolved in $10 \mathrm{~mL}$ of acetonitrile. Five different samples ( $2 \mathrm{~mL}$ of crude extract each) were prepared with the addition of increasing volumes of acetonitrile standard Tetryl solution and the final volume of each sample was adjusted to $10 \mathrm{~mL}$ by adding different volumes of acetonitrile. Finally, to $10 \mathrm{~mL}$ of each sample solution $4 \mathrm{mg}$ of $\mathbf{S N}_{\mathbf{3}}-\mathbf{1}$ or $\mathbf{S N H}_{2}-\mathbf{2}$ was added and the mixture stirred for 60 minutes. The mixture was then filtered and the absorbance at $453 \mathrm{~nm}$ was measured. The well-known standard addition method was followed to calculate the Tetryl concentration. Linear regression analysis was performed and the slope and y-intercept of the calibration curve were used to calculate the concentration of Tetryl in the sample. From the linear regression: $\mathrm{A}=m \cdot C_{\text {added }}+b, a b$ value of 0.0441 and an $m$ value of 46.78 were obtained with a $\mathrm{R}^{2}$ of 0.96 for solid $\mathbf{S N}_{3}-\mathbf{1}$. For $\mathbf{S N H}_{2}-\mathbf{2}$, values of 0.1279 , 59.11, and 0.91 for $b, m$, and $\mathrm{R}^{2}$, respectively, were obtained. A Tetryl concentration of $25.2 \mu \mathrm{g}$ Tetryl g ${ }^{-1}$ soil using $\mathbf{S N}_{\mathbf{3}} \mathbf{- 1}$ and $27.4 \mu \mathrm{g}$ Tetryl $\mathrm{g}^{-1}$ soil using 
$\mathbf{S N H}_{\mathbf{2}}-\mathbf{2}$ were obtained. These values are in good agreement with the doped Tetryl concentration (28.7 $\mu \mathrm{g}$ Tetryl g ${ }^{-1}$ soil).

\section{Conclusions}

We have reported herein the preparation of three new silica mesoporous supports capped with different electron donating TTF moieties $\left(\mathbf{S N}_{\mathbf{3}} \mathbf{- 1}, \mathbf{S N H}_{\mathbf{2}} \mathbf{-} \mathbf{-}\right.$, and $\mathbf{S N}_{\mathbf{3}}-\mathbf{3}$ ) for the easy chromo-fluorogenic sensing of nitroaromatic explosives. These materials consists of a mesoporous MCM-41-like structure loaded with the $\left[\mathrm{Ru}(\text { bipy })_{3}\right]^{2+}$ complex and capped with the TTF derivatives $\mathbf{1}, \mathbf{2}$, and $\mathbf{3}$. The capping TTF units (1 and 3 ) used for the preparation of the $\mathbf{S N}_{3}-\mathbf{1}$ and $\mathbf{S N}_{3}-\mathbf{3}$ sensory materials were grafted through a click chemistry reaction, whereas $\mathbf{S N H}_{2}-\mathbf{2}$ was functionalized through an amidation reaction with TTF derivative $\mathbf{2}$. The three novel materials showed "zero release" when suspended in acetonitrile solutions. Subtle differences in the chemical structure of the TTF capping moieties resulted in a different response of the solids. The explosives Tetryl, TNT, and TNB are able to induce, to some extent, dye release from $\mathbf{S N}_{\mathbf{3}} \mathbf{- 1}$ and $\mathbf{S N}_{\mathbf{3}} \mathbf{- 3}$, whereas solid $\mathbf{S N H}_{\mathbf{2}}$ 2 shows a fairly selective response to Tetryl. As a remarkable result a turn-on response is observed. All other substances tested were unable to induce payload release. Moreover, color or emission measurement reveals that detection of Tetryl, TNB, and TNT at the ppm level can be achieved. Finally, $\mathbf{S N}_{\mathbf{3}} \mathbf{- 1}$ and $\mathbf{S N H}_{\mathbf{2}} \mathbf{- 2}$ were used for the chromogenic detection of Tetryl in soil samples with good results. This paradigm displays further possibilities of modulation. For instance, the support, the $\pi$-donor units, and the dye can easily be changed without the use of complex chemistries in order to tune selectivity and the optical properties of the signaling dye.

\section{Experimental Section}

Caution! Highly explosives should be used with extreme caution and handled only in small quantities. 


\section{General methods}

Powder X-ray diffraction, $\mathrm{TG}$ analysis, and $\mathrm{N}_{2}$ adsorption-desorption techniques were used to characterize the prepared materials. X-ray measurements were carried out using a Philips D8 Advance diffractometer using CuKa radiation. Thermo-gravimetric analyses were carried out on a TGA/SDTA 851e Mettler Toledo balance, using an oxidant atmosphere (air, $80 \mathrm{~mL} / \mathrm{min}$ ) with a heating programme consisting of a heating ramp of $10{ }^{\circ} \mathrm{C}$ per minute from $293 \mathrm{~K}$ to $1273 \mathrm{~K}$ and an isothermal heating step at this temperature for 30 minutes. $\mathrm{N}_{2}$ adsorptiondesorption isotherms were recorded with a Micromeritics ASAP2010 automated sorption analyzer. Samples were degassed at $393 \mathrm{~K}$ in vacuum overnight. Specific surface areas were calculated from the adsorption data in the low pressures range using the Brunauer-Emmett-Teller (BET) model. Pore size was determined following the Barret-Joyner-Halenda (BJH) method. TEM images were obtained with a $100 \mathrm{kV}$ Philips CM10 microscope. UV-visible spectroscopy was carried out on a Lambda 35 UV/Vis Spectrometer (Perkin Elmer Instruments) at $298 \mathrm{~K}$. Fluorescence spectroscopy studies were carried out at $298 \mathrm{~K}$ with a Jasco Spectrofluorometer FP-8500 and with a Felix 32 Analysis, version 1.2 (Build 56) PTI (Photon Technology International). 1D and 2D NMR spectra were obtained on a Bruker AVANCE III $400 \mathrm{MHz}$ Spectrometer, where ${ }^{1} \mathrm{H}$ NMR spectra were recorded at $400 \mathrm{MHz}$ at $298 \mathrm{~K}$, while ${ }^{13} \mathrm{C} \mathrm{NMR}$ spectra were recorded at $100 \mathrm{MHz}$ at $298 \mathrm{~K}$. The NMR samples were dissolved in deuterated solvents purchased from Cambridge Isotope Labs or Sigma-Aldrich, and TMS or the residual solvent were used as internal standard. ${ }^{29} \mathrm{Si}$ and ${ }^{13} \mathrm{C}$ MAS NMR spectra were recorder on a Bruker WB AVANCE III $400 \mathrm{MHz}$ Spectrometer operating at 79.5 and $128.3 \mathrm{MHz}$, respectively, and using a magic angle spinning speed of $10 \mathrm{kHz}$. Electron impact ionization mass spectrometry (MS-EI) was performed on a Thermo Finnigan MAT SSQ710 single stage quadropole instrument. Matrix-assisted laserdesorption/ionization mass spectrometry was performed on a Bruker Autoflex III Smartbeam mass spectrometer, utilizing a 2,5-dihydroxybenzoic acid (DHB) matrix. The quantum chemical calculations, at the semi-empirical level, in order to 
estimate the dipole moment of the grafted TTF derivative (product 1, $\mathbf{2}$ and 3), were carried out with the HyperChem 6.03 software (HyperChem 6.03 Molecular Modeling System, Hypercube Inc., Gainesville, Florida, USA, 2000).

\section{Chemicals}

The chemicals tetraethylorthosilicate (TEOS) (98\%), $n$-cetyltrimethylammonium bromide (CTAB) ( $\geq 99 \%)$, sodium hydroxide $(\geq 98 \%)$, triethanolamine $\left(\mathrm{TEAH}_{3}\right) \quad(\geq 99 \%)$, tris(2,2'-bipyridyl)dichlororuthenium(II) hexahydrate $\left(\left[\mathrm{Ru}(\mathrm{bipy})_{3}\right] \mathrm{Cl}_{2} \cdot 6 \mathrm{H}_{2} \mathrm{O}\right)(100 \%), 2,4$-dinitrotoluene $(2,4-\mathrm{DNT}), \mathrm{N}$ methylaniline (NM) (98\%), 2-nitrotoluene (NT), nitrobenzene (NB) (99\%), picric acid (PA), tetrathiafulvalene (TTF), perfluorohexyl iodide (PFHI), lithium diisopropylamide (LDA), potassium fluoride (KF), ethynyltrimethylsilane, tetrakis(palladium)triphenylphosphine $\left(\mathrm{Pd}\left(\mathrm{PPh}_{3}\right)_{4}\right)$, mercury (II) acetate, acetic acid, celite $545, \mathrm{CH}_{2} \mathrm{Cl}_{2}, \mathrm{NaHCO}_{3}, \mathrm{MgSO}_{4}$, triethyl phosphate, toluene, diethyl ether, petroleum ether, $\mathrm{LiBr}$, dimethyl sulfoxide (DMSO), $\mathrm{MeOH}$, sodium methoxide, Cul, $\mathrm{K}_{3} \mathrm{PO}_{4}, \mathrm{LiOH} \cdot \mathrm{H}_{2} \mathrm{O}$, oxalyl chloride, tetra- $n$-butylammonium fluoride, ( \pm -trans-1,2-diaminocyclohexane, pyridine, 3(aminopropyl)triethoxysilane, and tetrahydrofurane (THF) were provided by Sigma-Aldrich. The $3 \%$ solution in acetonitrile of the nitroaromatic explosives 2,4,6-trinitrophenylmethylnitramine (Tetryl), 2,4,6-trinitrotoluene (TNT), 1,3,5trinitrobenzene (TNB), hexahydro-1,3,5-trinitro-1,3,5-triazine (RDX), pentaerythritol tetranitrate (PETN), and 3-(azidopropyl)triethoxysilane were purchased from Selectlab Chemicals. Triacetone triperoxide (TATP), ${ }^{[4]} 4,5-$ bis(butylthio)-1,3-dithiole-2-thione ${ }^{[35]} \quad$ (3a), and $N$-tosyl-(1,3)-dithiolo[4,5c]pyrrole-2-one ${ }^{[36]}(\mathbf{3 b})$ were synthesized according to literature procedures. LAscorbic sodium salt (99\%), potassium carbonate, sodium sulfate, and copper (II) sulfate pentahydrate $\left(\mathrm{CuSO}_{4} \cdot 5 \mathrm{H}_{2} \mathrm{O}\right)$ were acquired from Scharlab (Barcelona, Spain). Diisopropylamine $\left(i-\mathrm{Pr}_{2} \mathrm{NH}\right)$ was acquired from Fluka. Analytical-grade solvents were purchased from Scharlab (Barcelona, Spain). All reagents were used 
as received except THF which was distilled from sodium/benzophenone before being used.

\section{Mesoporous MCM-41 microparticles}

The molar ratio of the reagents in the mother liquor was fixed to $7.0 \mathrm{TEAH}_{3}: 2.0$ TEOS: 0:52 CTAB: $0.50 \mathrm{NaOH}: 8.89 \mathrm{H}_{2} \mathrm{O}$. The mesoporous MCM-41 support was first synthesized using the so-called "atrane route" in which $4.68 \mathrm{~g}$ of CTAB was added at $118{ }^{\circ} \mathrm{C}$ to a solution of $\operatorname{TEAH}_{3}(25.79 \mathrm{~g})$ containing $0.049 \mathrm{~mol}$ of a silatrane derivative (11 mL of TEOS). Next, $80 \mathrm{~mL}$ of water was slowly added with vigorous stirring at $70{ }^{\circ} \mathrm{C}$. After a few minutes, a white suspension was formed. This mixture was aged at room temperature overnight. The resulting powder was collected by filtration and washed with water and ethanol until pH 6-7. Finally, the white solid was dried at $70{ }^{\circ} \mathrm{C}$ (MCM-41 as-synthesized). To prepare the final porous material, the as-synthesized solid was calcined at $550{ }^{\circ} \mathrm{C}$ using oxidant atmosphere for $5 \mathrm{~h}$ in order to remove the template phase (MCM-41).

\section{Solid $\mathrm{SN}_{3}-1$}

In a typical synthesis, template-free MCM-41 $(1 \mathrm{~g})$ and $\left[\mathrm{Ru}(\text { bipy })_{3}\right] \mathrm{Cl}_{2} \cdot 6 \mathrm{H}_{2} \mathrm{O}(0.6$ $\mathrm{g}, 0.8 \mathrm{mmol})$ were suspended in acetonitrile $(40 \mathrm{~mL})$ in a round-bottomed flask. To remove the adsorbed water, $10 \mathrm{~mL}$ of acetonitrile were distilled off using a DeanStark set-up. Then, the mixture was stirred for $24 \mathrm{~h}$ at room temperature for the purpose of achieving maximum loading in the pores of the MCM-41 scaffold. Afterwards an excess of 3-(azidopropyl)triethoxysilane $(0.49 \mathrm{~mL}, 2 \mathrm{mmol}$ ) was added to the reaction mixture, and the suspension was stirred for $5.5 \mathrm{~h}$. Finally, the orange-yellow solid was collected by filtration affording $\mathbf{S N}_{3}$ as solid. Subsequently, anhydrous DMF (50 mL) was purged with $\mathrm{N}_{2}$ for $1 \mathrm{~h}$ and the TTF derivative 1 (121.1 mg, $0.531 \mathrm{mmol}$ ) was placed in an empty flask. Using a needle, the $\mathrm{N}_{2}$ purged DMF (10 mL) was transferred into the flask containing 1. A similar procedure was used for a mixture of ascorbic acid $(56.3 \mathrm{mg}, 0.32 \mathrm{mmol}$ ) and 
$\mathrm{CuSO}_{4} \bullet 5 \mathrm{H}_{2} \mathrm{O}(39.9 \mathrm{mg}, 0.16 \mathrm{mmol})$. Thereafter, the solid $\mathbf{S N}_{3}$ was suspended in DMF-water $1: 2 \mathrm{v} / \mathrm{v}$ containing $\left[\mathrm{Ru}(\text { bipy })_{3}\right] \mathrm{Cl}_{2} \cdot 6 \mathrm{H}_{2} \mathrm{O}(0.6 \mathrm{~g}, 0.8 \mathrm{mmol})$. Afterwards, the ascorbic acid/CuSO ${ }_{4} \bullet 5 \mathrm{H}_{2} \mathrm{O}$ solution in anhydrous DMF was added simultaneously to the reaction mixture using a needle. Finally, a similar operation was carried out with the DMF solution containing the TTF derivative 1 . After the additions were completed, the reaction mixture was stirred at room temperature for 5 days, whereafter the resulting microparticles were collected by filtration, washed with $\mathrm{CH}_{2} \mathrm{Cl}_{2}(100 \mathrm{~mL})$, water $(100 \mathrm{~mL})$, acetonitrile $(100 \mathrm{~mL})$, THF $(100 \mathrm{~mL})$, and dried at $35^{\circ} \mathrm{C}$ for $12 \mathrm{~h}$ obtaining $\mathbf{S N}_{\mathbf{3}} \mathbf{- 1}(872 \mathrm{mg})$ as a green-brown solid .

\section{Solid $\mathrm{SNH}_{2}-\mathbf{2}$}

In a typical synthesis, template-free MCM-41 $(1 \mathrm{~g})$ and $\left[\mathrm{Ru}(\text { bipy })_{3}\right] \mathrm{Cl}_{2} \cdot 6 \mathrm{H}_{2} \mathrm{O}(0.6$ $\mathrm{g}, 0.8 \mathrm{mmol})$ were suspended in acetonitrile $(40 \mathrm{~mL})$ in a round-bottomed flask. To remove the adsorbed water, $10 \mathrm{~mL}$ of acetonitrile were distilled off using a DeanStark set-up. Then, the mixture was stirred for $24 \mathrm{~h}$ at room temperature for the purpose of achieving maximum loading in the pores of the MCM-41 scaffold. Afterwards, an excess of 3-(aminopropyl)triethoxysilane $(0.47 \mathrm{~mL}, 2 \mathrm{mmol}$ ) was added, and the suspension was stirred for $5.5 \mathrm{~h}$. The resulting orange-yellow solid was collected by filtration providing $\mathbf{S N H}_{\mathbf{2}}$ as a solid. Subsequently, $1 \mathrm{~g}$ of $\mathbf{S N H}_{\mathbf{2}}$, was suspended in acetonitrile $(40 \mathrm{~mL}$ ) and compound 2 (378.3 $\mathrm{mg}, 1.06 \mathrm{mmol}$ ), the ruthenium dye $(600 \mathrm{mg}, 0.8 \mathrm{mmol})$, and $\mathrm{K}_{2} \mathrm{CO}_{3}(2 \mathrm{~g}, 14.5 \mathrm{mmol})$ were added to the reaction mixture. The resulting suspension was heated under reflux for $16 \mathrm{~h}$ under an inert atmosphere of argon. Finally, the solid $\mathbf{S N H}_{\mathbf{2}}$ was collected by filtration, intensively washed with water and thereafter with a mixture of acetonitrile and water $(100 \mathrm{~mL}$ of acetonitrile and $100 \mathrm{~mL}$ of miliQ water per 100 mg of final solid, stirring during 24 hours) before being dried overnight at $36{ }^{\circ} \mathrm{C}$ to a afford $\mathbf{S N H}_{\mathbf{2}}-\mathbf{2}$ (1.98 g) as a brown solid. 


\section{5-Tosyl-2-(4,5-bis(butylthio)-1,3-dithiol-2-ylidene)-[1,3]dithiolo[4,5-c]pyrrole} (3c)

The thione 3a $(4.00 \mathrm{~g}, 13.5 \mathrm{mmol})$ and the ketone $\mathbf{3 b}(3.36 \mathrm{~g}, 10.79 \mathrm{mmol})$ were dissolved in freshly distilled triethyl phosphite $(60 \mathrm{~mL})$ and degassed under an Argon atmosphere for $15 \mathrm{~min}$. The reaction mixture was quickly heated to $130^{\circ} \mathrm{C}$. After $16 \mathrm{~min}$ at $130{ }^{\circ} \mathrm{C}$ another portion of the thione $3 \mathrm{a}(4.00 \mathrm{~g}, 13.59$ mmol) was added and the reaction mixture was stirred at $130{ }^{\circ} \mathrm{C}$ for $1.2 \mathrm{~h}$, then cooled to room temperature. Cold methanol $(75 \mathrm{~mL})$ was added and the resulting orange solid was collected by filtration. The filtrated was left in the freezer overnight to producing a second crop of the product which was collected by filtration. The combined solids were washed with small portions of methanol $(5 \times$ $15 \mathrm{~mL})$ and dried in vacuo before being purified by flash chromatography $\left(\mathrm{SiO}_{2}\right.$, $\mathrm{CH}_{2} \mathrm{Cl}_{2}$ : petroelum ether, $1: 1$ as eluent). The yellow band $\left(R_{\mathrm{f}}=0.29\right.$, $\mathrm{CH}_{2} \mathrm{Cl}_{2}$ :petroleum ether, $\left.1: 1\right)$ was collected and concentrated to give the title compound $3 \mathrm{c}(5.25 \mathrm{~g}, 85 \%)$ as yellow crystals. ${ }^{[46]}{ }^{1} \mathrm{H} \mathrm{NMR}\left(500 \mathrm{MHz},\left(\mathrm{CD}_{3}\right)_{2} \mathrm{SO}\right): \delta=$ $0.86(\mathrm{t}, J=7.3 \mathrm{~Hz}, 6 \mathrm{H}), 1.31-1.43(\mathrm{~m}, 4 \mathrm{H}), 1.47-1.57(\mathrm{~m}, 4 \mathrm{H}), 2.38(\mathrm{~s}, 3 \mathrm{H}), 2.84(\mathrm{t}$, $J=7.3 \mathrm{~Hz}, 4 \mathrm{H}), 6.94(\mathrm{~s}, 2 \mathrm{H}), 7.30(\mathrm{~d}, J=8.6 \mathrm{~Hz}, 2 \mathrm{H}), 7.73(\mathrm{~d}, J=8.6 \mathrm{~Hz}, 2 \mathrm{H})$;

${ }^{13} \mathrm{C}$ NMR $\left(125 \mathrm{MHz},\left(\mathrm{CD}_{3}\right)_{2} \mathrm{SO}\right): \delta=13.5,20.9,21.1,31.3,35.1,112.4,112.7,117.4$, 125.9, 126.7, 126.8, 130.4, 134.5, 145.8; MS (MALDI) $\mathrm{m} / \mathrm{z}$ : calcd for $\mathrm{C}_{23} \mathrm{H}_{27} \mathrm{NO}_{2} \mathrm{~S}_{7}^{+}$ 573.01; found: 572.98 .

\section{2-(4,5-Bis(butylthio)-1,3-dithiol-2-ylidene)-[1,3]dithiolo[4,5-c]pyrrole (3d)}

Compound 3c $(4.46 \mathrm{~g}, 7.77 \mathrm{mmol})$ dissolved in a mixture of anhydrous THF $(250 \mathrm{~mL})$ and methanol $(100 \mathrm{~mL})$ was degassed under an Argon atmosphere for 60 min. Sodium methoxide ( $25 \% \mathrm{w} / \mathrm{w}$ in $\mathrm{MeOH}, 4.323 \mathrm{~g}, 80.03 \mathrm{mmol}$ ) was added in one portion and the reaction mixture was heated under reflux for $30 \mathrm{~min}$. After being cooled to room temperature, water $(400 \mathrm{~mL})$ was added to the reaction mixture, which was subsequently extracted with $\mathrm{CH}_{2} \mathrm{Cl}_{2}(2 \times 200 \mathrm{~mL})$. The combined organic phases were dried $\left(\mathrm{MgSO}_{4}\right)$ and concentrated to give a yellow 
oil which was purified by flash chromatography $\left(\mathrm{SiO}_{2}, \mathrm{CH}_{2} \mathrm{Cl}_{2}\right.$ :cyclohexane, 2:1 gradient elution). The broad yellow band was collected and concentrated to afford the title compound $3 \mathbf{d}(2.90 \mathrm{~g}, 89 \%)$ as a yellow powder. ${ }^{[46]}{ }^{1} \mathrm{H}$ NMR (500 $\left.\mathrm{MHz},\left(\mathrm{CD}_{3}\right)_{2} \mathrm{SO}\right): \delta=0.87(\mathrm{t}, J=7.3 \mathrm{~Hz}, 6 \mathrm{H}), 1.35-1.42(\mathrm{~m}, 4 \mathrm{H}), 1.49-1.59(\mathrm{~m}, 4 \mathrm{H})$, $2.85(\mathrm{t}, J=7.3 \mathrm{~Hz}, 4 \mathrm{H}), 6.81(\mathrm{~s}, 2 \mathrm{H}), 11.14$ (br s, $1 \mathrm{H}) ;{ }^{13} \mathrm{C} \mathrm{NMR}(125 \mathrm{MHz}$, $\left.\left(\mathrm{CD}_{3}\right)_{2} \mathrm{SO}\right): \delta=13.5,20.9,31.31,35.0,107.4,110.8,117.1,121.7,126.7$; MS (MALDI) $\mathrm{m} / \mathrm{z}$ : calcd for $\mathrm{C}_{16} \mathrm{H}_{21} \mathrm{NS}_{6}{ }^{+} 419.00$; found: 418.98 .

\section{2-(4,5-Bis(butylthio)-1,3-dithiol-2-ylidene)-5-(4-((trimethylsilyl)ethynyl)phenyl)- $[1,3]$ dithiolo[4,5-c]pyrrole (3f)}

Compound 3d (1.05 g, $2.502 \mathrm{mmol})$, Cul (0.93 g, $4.878 \mathrm{mmol}), \mathrm{K}_{3} \mathrm{PO}_{4}(1.78 \mathrm{~g}$, $8.388 \mathrm{mmol}$ ), and (4-iodophenylethylyl)trimethylsilane (3e) (3.60 g, $12.0 \mathrm{mmol})$ were dissolved in freshly distilled THF $(50 \mathrm{~mL})$ and degassed under an Argon atmosphere for $20 \mathrm{~min}$, whereafter ( \pm )-trans-1,2-diaminocyclohexane (1.06 g, 1.2 $\mathrm{mL}, 9.33 \mathrm{mmol}$ ) was added in one portion. The reaction was heated at $115{ }^{\circ} \mathrm{C}$ in the microwave for $3 \mathrm{~h}$ before it was allowed to reach room temperature and then extracted with $\mathrm{CH}_{2} \mathrm{Cl}_{2}(100 \mathrm{~mL})$. The organic phase was washed with an aqueous solution of $\mathrm{NaOH}(5 \%$ in $100 \mathrm{~mL} \mathrm{H}$ O) $(3 \times 20 \mathrm{~mL})$, water $(3 \times 150 \mathrm{~mL})$, and dried $\left(\mathrm{MgSO}_{4}\right)$. Concentration gave a yellow residue which was purified by column chromatography $\left(\mathrm{SiO}_{2}, \mathrm{CH}_{2} \mathrm{Cl}_{2}\right.$ :petroleum ether 1:3, gradient elution). The yellow band $\left(R_{\mathrm{f}}=0.74, \mathrm{CH}_{2} \mathrm{Cl}_{2}\right.$ :petroleum ether, $\left.1: 1\right)$ was collected and concentrated to provide the title compound $\mathbf{3 f}(0.99 \mathrm{~g}, 68 \%)$ as yellow crystals. M.p $=116.0-118.0$ ${ }^{\circ} \mathrm{C} ;{ }^{1} \mathrm{H}$ NMR $\left(500 \mathrm{MHz}, \mathrm{CD}_{2} \mathrm{Cl}_{2}\right): \delta=0.25(\mathrm{~s}, 9 \mathrm{H}), 0.92(\mathrm{t}, J=7.3 \mathrm{~Hz}, 6 \mathrm{H}), 1.40-1.48$ $(\mathrm{m}, 4 \mathrm{H}), 1.59-1.65(\mathrm{~m}, 4 \mathrm{H}), 2.84(\mathrm{t}, J=7.3 \mathrm{~Hz}, 4 \mathrm{H}), 6.94(\mathrm{~s}, 2 \mathrm{H}), 7.28(\mathrm{~d}, J=8.8$ $\mathrm{Hz}, 2 \mathrm{H}), 7.50(\mathrm{~d}, J=8.8 \mathrm{~Hz}, 2 \mathrm{H}) ;{ }^{13} \mathrm{C}$ NMR $\left(125 \mathrm{MHz}, \mathrm{CD}_{2} \mathrm{Cl}_{2}\right): \delta=0.1,13.9,22.2$, 32.4, 36.5, 95.6, 104.4, 111.2, 119.9, 121.2, 123.3, 128.2, 133.9, 140.3 (2 signals are missing/overlapping); HRMS-EI $\mathrm{m} / \mathrm{z}$ : calcd for $\mathrm{C}_{27} \mathrm{H}_{33} \mathrm{NS}_{6} \mathrm{Si}^{+}$591.0701; found: 591.1000; elemental analysis (\%) calcd for $\mathrm{C}_{27} \mathrm{H}_{33} \mathrm{NS}_{6}$ (592.0): $\mathrm{C} 54.78, \mathrm{H} 5.62, \mathrm{~N}$ : 2.37; found: C 54.97, H 5.80, N 2.38. 


\section{2-(4,5-Bis(butylthio)-1,3-dithiol-2-ylidene)-5-(4-ethynylphenyl)-[1,3]dithiolo[4,5- c]pyrrole (3)}

Compound $3 \mathrm{f}(0.30 \mathrm{~g}, 0.5 \mathrm{mmol})$ was dissolved in anhydrous THF $(10 \mathrm{~mL})$ whereafter tetra- $n$-butylammonium fluoride $(0.26 \mathrm{~g}, 1 \mathrm{mmol})$ was added in one portion. The reaction mixture was stirred for $20 \mathrm{~min}$ at room temperature before water $(75 \mathrm{~mL})$ was added and then extracted with $\mathrm{CH}_{2} \mathrm{Cl}_{2}(2 \times 75 \mathrm{~mL})$. The combined organic phases were dried $\left(\mathrm{MgSO}_{4}\right)$ and concentrated to afford the title compound $3(0.25 \mathrm{~g}, 99 \%)$ as an analytical pure orange solid. M.p. $=165.8-137.2$ ${ }^{\circ} \mathrm{C} ;{ }^{1} \mathrm{H}$ NMR $\left(500 \mathrm{MHz},\left(\mathrm{CD}_{3}\right)_{2} \mathrm{SO}\right): \delta=0.88(\mathrm{t}, J=7.3 \mathrm{~Hz}, 6 \mathrm{H}), 1.37-1.43(\mathrm{~m}, 4 \mathrm{H})$, 1.52-1.58 (m, $4 \mathrm{H}), 2.87(\mathrm{t}, J=7.3 \mathrm{~Hz}, 4 \mathrm{H}), 4.23(\mathrm{~s}, 1 \mathrm{H}), 7.53(\mathrm{~s}, 2 \mathrm{H}), 7.55(\mathrm{~s}, 4 \mathrm{H})$;

${ }^{13} \mathrm{C}$ NMR $\left(125 \mathrm{MHz},\left(\mathrm{CD}_{3}\right)_{2} \mathrm{SO}\right): \delta=13.3,20.8,31.1,34.9,81.1,82.7,109.6,111.3$, $118.5,121.4,126.6,133.1,139.2$ (2 signals are missing/overlapping); HRMS-EI $\mathrm{m} / \mathrm{z}$ : calcd for $\mathrm{C}_{24} \mathrm{H}_{25} \mathrm{NS}_{6}{ }^{+} 519.0306$; found: 518.9600 ; elemental analysis calcd (\%) for $\mathrm{C}_{24} \mathrm{H}_{25} \mathrm{NS}_{6}$ (519.9): C 55.45, H 4.85, N 2.69; found: C 55.38, H 4.89, N 2.80.

\section{Solid $\mathrm{SN}_{3}-3$}

In a typical synthesis, template-free MCM-41 $(1 \mathrm{~g})$ and $\left[\mathrm{Ru}(\text { bipy })_{3}\right] \mathrm{Cl}_{2} \cdot 6 \mathrm{H}_{2} \mathrm{O}(0.6$ $\mathrm{g}, 0.8 \mathrm{mmol}$ ) were suspended in acetonitrile $(40 \mathrm{~mL})$ in a round-bottomed flask. To remove the adsorbed water, $10 \mathrm{~mL}$ of acetonitrile were distilled off using a DeanStark set-up. Then, the mixture was stirred for $24 \mathrm{~h}$ at room temperature for the purpose of achieving maximum loading in the pores of the MCM-41 scaffold. Afterwards, an excess of 3-(azidopropyl)triethoxysilane $(1.20 \mathrm{~mL}, 5 \mathrm{mmol}$ ) was added, and the suspension was stirred for $5.5 \mathrm{~h}$. The resulting orange-yellow solid was collected by filtration and washed with $\mathrm{CH}_{2} \mathrm{Cl}_{2}(50 \mathrm{~mL})$ to afford $\mathbf{S N}_{3}$ as a solid. Subsequently a mixture of $\mathbf{S N}_{3}(0.5 \mathrm{~g})$ and compound 3 (303.2 $\mathrm{mg}, 0.98 \mathrm{mmol}$ ) were suspended in 50:50 v/v DMF-water $(40 \mathrm{~mL})$ in the presence of an excess of the ruthenium (II) dye $(0.3 \mathrm{~g}, 0.4 \mathrm{mmol}$ ) (in order to avoid the delivery of the dye from the pores to the bulk solution during the synthesis of this solid). Finally, a solution of $\mathrm{CuSO}_{4} \cdot 5 \mathrm{H}_{2} \mathrm{O}(1.248 \mathrm{mg}, 0.005 \mathrm{mmol})$ and sodium ascorbate $(9.905 \mathrm{mg}$, 
$0.05 \mathrm{mmol}$ ) was added and the reaction mixture was stirred at room temperature for 5 days. The microparticles were collected by filtration and intensively washed with water and thereafter with acetonitrile $(100 \mathrm{~mL}$ of acetonitrile per $100 \mathrm{mg}$ of final solid, stirring during 24 hours) before being dried at $36^{\circ} \mathrm{C}$ for $12 \mathrm{~h}$ to afford $(0.55 \mathrm{~g}) \mathrm{SN}_{3}-3$ as a yellow solid.

\section{Acknowledgements}

Financial support from the Spanish Government (project MAT2012-38429-C0401) and the Generalitat Valencia (project PROMETEO/2009/016) is gratefully acknowledged. J. O. Jeppesen gratefully acknowledges financial support provided by the EC FP7 ITN "FUNMOLS" Project No. 212942), the Villum Foundation, and the Danish Natural Science Research Council (\#11-106744). Y. Salinas thanks the Spanish Ministry of Science and Innovation for her grant. We also thank Stephen Boyer, School of Human Sciences, Science Centre, from the London Metropolitan University, for carrying out the Elemental Analyses.

\section{References}

1. S. Singh, J. Haz. Mat. 2007, 144, 15-28; b) R. Schulte-Ladbeck, M. Vogel, U. Karst, Anal. Bioanal. Chem., 2006, 386, 559-565.;c) R. G. Smith, N. D’Souza, S. Nicklin, Analyst, 2008, 133, 571-584.

2. J. P. Agrawal, R. D. Hodgson, Organic Chemistry of Explosives, John Wiley \& Sons, Chicheter, 2007.

3. K. -S. Focsaneanu, J. C. Scaiano, Photochem. Photobiol. Sci., 2005, 4, 817-821.

4. K. G. Furton, L. J. Myers, Talanta, 2001, 54, 487-500.

5. K. Hakansson, R. V. Coorey, R. A. Zubarev, V. L. Talrose, P. Hakansson, J. Mass Spectrom., 2000, 35, 337-346.

6. M. E. Walsh, Talanta, 2001, 54, 427-438.

7. J. M. Sylvia, J. A. Janni, J. D. Klein, K. M. Spencer, Anal. Chem. 2000, 72, 5834-5840.

8. a) J. Yinon, Mass Spectrom. Rev. 1982, 1, 257-307; b) J. C. Mathurin, T. Faye, A. Brunot, J. C. Tabet, Anal. Chem. 2000, 72, 5055-5062.

9. S. F. Hallowell, Talanta, 2001, 54, 447-458.

10. C. Vourvopoulos, P. C. Womble, Talanta, 2001, 54, 459-468.

11. E. S. Forzani, D. Lu, M. J. Leright, A. D. Aguilar, F. Tsow, R. A. Iglesias, Q. Zhang, J. Lu, J. Li, N. Tao, J. Am. Chem. Soc., 2009, 131, 1390-1391. 
12. E. Wallis, T. M. Griffin, N. Popkie, Jr., M. A. Eagan, R. F. McAtee, D. Vrazel, J. McKinly, Proc. SPIE-Int. Soc.Opt. Eng., 2005, 5795, 54-64.

13. Y. Salinas, R. Martínez-Máñez, M.D. Marcos, F. Sancenón, A. M. Costero, M. Parra, S.Gil Chem. Soc. Rev., 2012, 41, 1261-1296.

14. M. E. Germain, M. J. Knapp, Chem. Soc. Rev. 2009, 38, 2543-2555.

15. a) H. Kong, B. J. Jung, J. Sinha, H. E. Katz, Chem. Mater., 2012, 24, 2621-2623; b) P. Frere, P. J. Skabara, Chem. Soc. Rev., 2005, 34, 69-98.

16. a) Y. Salinas, E. Climent, R. Martínez-Máñez, F. Sancenón, M. D. Marcos, J. Soto, A. M. Costero, S. Gil, M. Parra, A. Pérez de Diego Chem. Commun. 2011, 47, 11885-11887; b) Y. Salinas, A. Agostini, E. Pérez-Esteve, R. Martínez-Máñez, F. Sancenón, M. D. Marcos, J. Soto, A. M. Costero, S. Gil, M. Parra, P. Amorós, J. Mater. Chem. A, 2013, 1, 3561-3564; c) Y. Salinas, R. Martínez-Máñez, J. O. Jeppesen, L. H. Petersen, F. Sancenón, M. D. Marcos, J. Soto, C. Guillem, P. Amorós, ACS Appl. Mater. Interfaces, 2013, 5, 1538-1543.

17. See for example: a) A. D. Hughes, I. C. Glenn, A. D. Patrick, A. Ellington, E. V. Anslyn, Chem. Eur. J. 2008, 14, 1822-1827; b) Y. H. Lee, H. Liu, J. Y. Lee, S. H. Kim, S. K. Kim, J. L. Sessler, Y. Kim, J. S. Kim, Chem. Eur. J., 2010, 13, 5895-5901; c) C. Vijayakumar, G. Tobin, W. Schmitt, M. Kima, M. Takeuchi, Chem. Commun. 2010, 46, 874-876; d) G. V. Zyryanov, M. A. Palacios, P. Anzembacher Jr., Org. Lett. 2008, 10, 3681-3684.

18. a) J. O. Jeppesen, M. B. Nielsen, J. Becher, Chem. Rev. 2004, 104, 5115-5132; b) F. Wudl, D. Wobschal, E. J. Hufnagel, J. Am. Chem. Soc. 1972, 94, 670-672; c) J. Ferraris, V. Walatka, J. Perlstein, D. O. Cowan, J. Am. Chem. Soc. 1973, 95, 948-949.

19. a) M. Adam, K. Müllen, Adv. Mater. 1994, 6, 439-459; b) T. Jørgensen, T. K. Hansen, J. Becher, Chem. Soc. Rev. 1994, 23, 41-51; c) M. R. Bryce, J. Mater. Chem. 1995, 5, 1481-1496; d) J. Garin, Adv. Heterocycl. Chem. 1995, 62, 249-304. e) G. Schukat, E. Fanghänel, Sulfur Rep. 1996, 18, 1-294; f) M. R. Bryce, J. Mater. Chem. 2000, 10, 589-598; g) M. B. Nielsen, C. Lomholt, J. Becher, Chem. Soc. Rev. 2000, 29, 153-164; h) J. L. Segura, N. Martín, Angew. Chem. Int. Ed. 2001, 40, 1372-1409.

20. a) D. S. Kim, V. M. Lynch, K. A. Nielsen, C. Johnsen, J. O. Jeppesen, J. L. Sessler, Anal. Bioanal. Chem. 2009, 395, 393-400; b) K. A. Nielsen, W.-S. Cho, J. O. Jeppesen, V. M. Lynch, J. Becher, J. L. Sessler, J. Am. Chem. Soc. 2004, 126, 16296-16297; c) J. Su Park, F. Le Derf, C. M. Bejger, V. M. Lynch, J. L. Sessler, K. A. Nielsen, C. Johnsen, J. O. Jeppesen, Chem.-Eur. J. 2010, 16, 848-854.

21. a) A. B. Descalzo, R. Martínez-Máñez, F. Sancenón, K. Hoffmann, K. Rurack, Angew. Chem. Int. Ed., 2006, 45, 5924-5948; b) K. Ariga, A. Vinu, J. P. Hill, T. Mori, Coord. Chem. Rev., 2007, 251, 2562-2591.

22. See for example: a) E. Aznar, R. Martínez-Máñez, F.Sancenón, Expert Opin. Drug. Deliv. 2009, 6, 643-655; b) B. G. Trewyn, I. I. Slowing, S. Giri, H. T. Chen, V. S. -Y. Lin, Acc. Chem. Res. 2007, 40, 846-853; c) S. Saha, K. C. -F. Leung, T. D. Nguyen, J. F. Stoddart, J. I. Zink, Adv. Func. Mater. 2007, 17, 685-693; d) R. Klajn, J. F. Stoddart, B. A. Grzybowski, Chem. Soc. Rev. 2010, $39,2203-2237$.

23. a) J. S. Beck, J. C. Vartuli, W. J. Roth, M. E. Leonowicz, C. T. Kresge, K. D. Schmitt, C. T. -W. Chu, D. H. Olson, E. W. Sheppard, S. B. McCullen, J. B. Hoggins, J. L. Schlenker, J. Am. Chem. Soc. 1992, 114, 10834-10843; b) A. P. Wright, M. E. Davis, Chem. Rev. 2002, 102, 3589-3614; 
c) G. Kickelbick, Angew. Chem. Int. Ed. 2004, 43, 3102-3104; d) K. Ariga, A. Vinu, Y. Yamauchi, Q. Ji, J. P. Hill, Bull. Chem. Soc. Japan 2012, 85, 1-32.

24. See for example: a) N. K. Mal, M. Fujiwara, Y. Tanaka, Nature 2003, 421, 350-353; b) E. Aznar, L. Mondragón, J. V. Ros-Lis, F. Sancenón, M. D. Marcos, R. Martínez-Máñez, J. Soto, E. PérezPayá, P. Amorós, Angew. Chem. Int. Ed. 2011, 50, 11172-11175; c) C. Chen, J. Geng, F. Pu, X. Yang, J. Ren, X. Qu, Angew. Chem. Int. Ed. 2011, 50, 882-886; d) E. Ruíz-Hernández, A. Baeza, M. Valler-Regí, ACS Nano 2011, 5, 1259-1266.

25. See for example: a) E. Climent, M. D. Marcos, R. Martínez-Máñez, F. Sancenón, J. Soto, K. Rurack, P. Amorós, Angew. Chem. Int. Ed. 2009, 48, 8519-8522; b) H. Meng, M. Xue, T. Xia, Y. -L. Zhao, F. Tamanoi, J. F. Stoddart, J. I. Zink, A. E. Nel, J. Am. Chem. Soc. 2010, 132, 1269012697; c) A. Schlossbauer, C. Dohmen, D. Schaffert, E, Wagner, T. Bein, Angew. Chem. Int. Ed. 2011, 50, 6828-6830; d) M. Chen, C. Huang, C. He, W. Zhu, Y. Xu, Y. Lu, Chem. Commun. 2012, 48, 9522-9524; e) R. Hernandez, H. -R. Tseng, J. W. Wong, J. F. Stoddart, J. I. Zink, J. Am. Chem. Soc. 2004, 126, 3370-3371.

26. See for example: a) E. Climent, A. Bernardos, R. Martínez-Máñez, A. Maquieira, M. D. Marcos, N. Pastor-Navarro, R. Puchades, F. Sancenón, J. Soto, P. Amorós, J. Am. Chem. Soc. 2009, 131, 14075-14080; b) A. Schlossbauer, J. Kecht, T. Bein, Angew. Chem. Int. Ed. 2009, 48, 30923095; c) C. Park, H. Kim, S. Kim, C. Kim, J. Am. Chem. Soc. 2009, 131, 16614-16615; d) P. D. Thornton, A. Heise, J. Am. Chem. Soc. 2010, 132, 2024-2028; e) A. Agostini, L- Mondragón, C. Coll, E. Aznar, M. D. Marcos, R. Martínez-Máñez, F. Sancenón, J. Soto, E. Pérez-Payá, PAmorós, Chem. Open 2012, 1, 17-20.

27. a) R. Casasús, E. Aznar, M. D. Marcos, R. Martínez-Mañez, F. Sancenón, J. Soto, P. Amorós, Angew. Chem. Int. Ed. 2006, 45, 6661-6664; b) C. Coll, R. Casasús, E. Aznar, M. D. Marcos, R. Martínez-Máñez, F. Sancenón, J. Soto, P. Amorós, Chem. Commun. 2007, 1957-1959; c) E. Aznar, C. Coll, M.D. Marcos, R. Martínez-Máñez, F. Sancenón, J. Soto, P. Amorós, J. Cano, E. Ruíz, Chem. Eur. J. 2009, 15, 6877-6888; d) E. Climent, R. Martínez-Máñez, F. Sancenón, M. D. Marcos, J. Soto, A. Maquieira, P. Amorós, Angew. Chem. Int. Ed. 2010, 49, 7281-7283; e) E. Climent, R. Martínez-Máñez, A. Maquieira, F. Sancenón, M. D. Marcos, E. M. Brun, J. Soto, P. Amorós, Chem. Open 2012, 1, 251-259; f) M. Oroval, E. Climent, C. Coll, R. Eritja, A. Aviñó, M. D. Marcos, F. Sancenón, R. Martínez-Máñez, P. Amorós, Chem. Commun. 2013, 49, $5480-$ 5482; g) E. Climent, D. Gröninger, M. Hecht, M. A. Walter, R. Martínez-Máñez, M. G. Weller, F. Sancenón, P. Amorós, K. Rurack, Chem. Eur. J. 2013, 19, 4117-4122; h) E. Climent, L. Mondragón, R. Martínez-Máñez, F. Sancenón, M. D. Marcos, J. R. Murguía, P. Amorós, K. Rurack, E. Pérez-Payá, Angew. Chem. Int. Ed. 2013, DOI: 10.1002/anie.201302954.

28. a) R. Martínez-Máñez, F. Sancenón, M. Hencht, M. Biyical, K. Rurack, Anal. Bioanal. Chem. 2011, 399, 55-74; b) M. Biyical, M. Hecht, R. Martínez-Máñez, K. Rurack, F. Sancenón, Supramol. Chem. 2012, 3669-3698.

29. E. Climent, M. D. Marcos, R. Martínez-Máñez, F. Sancenón, J. Soto, K. Rurack, P. Amorós, Angew. Chem. Int. Ed. 2009, 48, 8519-8522.

30. C. Coll, A. Bernardos, R. Martínez-Máñez, F. Sancenón, Acc. Chem. Res. 2013, 46, 339-349.

31. S. Cabrera, J. El Haskouri, C. Guillem, J. Latorre, A. Beltrán, D. Beltrán, M. D. Marcos, P. Amorós, Solid State Sci. 2000, 2, 405-420.

32. H. C. Kolb, M. G. Finn, K. B. Sharpless, Angew. Chem. Int. Ed. 2001, 40, 2004-2021. 
33. a) C. Goze, S. -X. Liu, C. Leiggener, L. Sanguinet, E. Levillain, A. Hauser, S. Decurtins, Tetrahedron 2008, 64, 1345-1350; b) T. Otsubo, Y. Koichi, A. Bitoh, F. Oruga, Chem. Lett. 1994, 2047-2050.

34. a) K. Heuze, M. Foumigue, P. Batail, J. Mater. Chem. 1999, 9, 2373-2379; b) P. Blanchard, M. Sallé, G. Duguay, M. Jubault, A. Gorgues, Tetrahedron Lett. 1992, 33, 2685-2688.

35. a) N. Le Narvor, N. Robertson, E. Wallace, J. D. Kilburn, A. E. Underhill, N. P. Bartlett, M. Webster, Dalton Trans. 1996, 823-828; b) T. Chen, C. Wang, Z. Cong, B. Ying, K. Imafuku, Heterocycles, 2004, 65, 187-193.

36. a) J. O. Jeppesen, K. Takimiya, N. Thorup, J. Becher, Synthesis, 1999, 803-810; b) J. O. Jeppesen, K. Takimiya, F. Jensen, T. Brimert, K. Nielsen, N. Thorup, J. Becher, J. Org. Chem. 2000, 65, 5794-5805.

37. C. Cai, A. Vasella, Helv. Chim. Acta 1995, 78, 732-757.

38. E. P. Barret, L. G. Joyner, P. P. Halenda, J. Am. Chem. Soc. 1951, 73, 373-380.

39. S. Brunauer, P. H. Emmet, E. Teller, J. Am. Chem. Soc. 1938, 60, 309-319.

40. R. Casasús, E. Climent, M. D. Marcos, R. Martínez-Mañez, F. Sancenón, J. Soto, P. Amorós, J. Cano, E. Ruiz, J. Am. Chem. Soc, 2008, 130, 1903-1917.

41. a) F. Felix, J. Ferguson, H. U. Gudel, A. Ludi, J. Am. Chem. Soc. 1980, 102, 4096-4102; b) F. E. Lytle, D. M. Hercules, J. Am. Chem. Soc. 1969, 91, 253-257.

42. Y. Jiang, H. Zhao, N. Zhu, Y. Lin, P. Yu, L. Mao, Angew. Chem. Int. Ed. 2008, 47, 8601-8604.

43. S. W. Thomas III, G. D. Joly, T. M. Swager, Chem. Rev. 2007, 107, 1339-1386.

44. E. S. Forzani, D. Lu, M. J. Leright, A. Díaz Aguilar, F. Tsow, R. A. Iglesias, Q. Zhang, J. Lu, J. Li, N. Tao, J. Am. Chem. Soc. 2009, 131, 1390-1391.

45. D. F. Laine, C. W. Roske, I. F. Cheng, Anal. Chim. Acta, 2008, 608, 56-60.

46. Takase, M.; Yoshida, N.; Nishinaga, T.; lyoda, M. Org. Lett., 2011, 13, 3896 -3899. 

6. Conclusions and perspectives 



\section{Conclusions and perspectives}

The widespread use of explosive formulation in industry and in military subjects makes their reliable and accurate detection an issue of international concern. The detection of explosives is crucial for homeland security, environmental cleaning, forensic research and land mine detection. Also, the recent rise in global terrorism has required that methods followed to detect explosives should be both sensitive and low-cost. Taking into account these facts, the present $\mathrm{PhD}$ thesis is devoted to the exploration of new approaches for the preparation of hybrid organic-inorganic sensory materials for the selective and sensitive optical detection of nitroaromatic explosives.

The first chapter of this PhD thesis is devoted to the introduction of supramolecular chemistry and material science concepts that are the basis for the preparation of these new hybrid sensors prepared.

In order to acquire a nearly complete knowledge of the advances published in the field of chromo-fluorogenic sensors for detection of explosives an exhaustive bibliographical search has been carried out. The results of this search are reflected in chapter 2 of this PhD thesis. The search comprises examples published from 1947 until the start of 2011 . Nearly $70 \%$ of the papers dealing with the optical detection of explosives are based in the use of fluorescence as an output signal. The fluorogenic explosive sensors should be classified in three main groups' namely (i) molecule-base fluorescent sensors, (ii) fluorescent polymers and (iii) hybrid materials. One of the most serious drawbacks of the fluorescent sensors for explosives published deals with their "on-off" behavior. All of them used electron rich fluorophores (alone or covalently linked with polymeric or siliceous supports) as electron rich moieties that coordinated with the electron withdrawing explosives (yielding charge-transfer complexes). These coordination 
processes leads to a marked quenching of the flurophore. From an analytical point of view an "off-on" emission behavior is of interest in order to prepare highly sensitive sensory materials. This relatively new fascinating approach has result in the preparation of the hybrid organic-inorganic materials able to detect nitroaromatic explosives that are presented in this PhD thesis.

The hybrid organic-inorganic sensors prepared in the present PhD make use of ion channel (chapter 3), biomimetic cavities (chapter 4) and gated materials (chapter 5) approaches. In several of the prepared solids an "off-on" chromofluorogenic behavior has been achieved.

- The ion channel sensor described used silica nanoparticles, as inorganic support, that were functionalized with thiols (as reactive subunits) and polyamines (as binding sites). The chromo-fluorogenic response arises from the access of a blue squaraine dye to the thiol moieties on the surface. In the absence of Tetryl, the squaraine is able to react with the thiols (grafted in the surface) with a subsequent color change from blue to colorless (an also with a loss of its emission). In the presence of Tetryl the thiol-squaraine reaction is inhibited due to the formation of amineexplosive charge-transfer complexes. This inhibition allows the visual detection of Tetryl in solution.

- Hybrid materials with biomimetic cavities were prepared by the grafting of selected fluorophores (pyrene, dansyl and fluorescein) into the pores of an MCM-41 mesoporous support and then by hydrophobation of the inner surface. These hydrophobic materials are able to extract Tetryl and picric acid into their biomimetic cavities with the subsequent emission quenching of the grafted fluorophore. One important feature of these materials is their reusability that is an important issue for new low-cost practical sensory systems for measurements in real samples. 
- Pyrene and tetrathiafulvalenes have also been used for the development of a hybrid gated material able to detect nitroaromatic explosives by means of fluorescence measurements. At this respect, mesoporous MCM41 silica was selected as inorganic scaffold. The pores of the inorganic support were loaded with a fluorescent Ru(II) complex and the outer surface functionalized with a pyrene or tetrathiafulvalene derivatives. The formation of a dense self-assembled monolayer (of pyrene or tetrathiafulvalenes) around the pore outlets inhibits dye delivery. Addition of nitroaromatic explosives disrupts the self-assembled monolayer (through $\pi-\pi$ interactions of the explosives with the grafted pyrene and tetrathiafulvalene) allowing the delivery of the $\mathrm{Ru}(\mathrm{II})$ complex. The presence of nitroaromatic explosives is signaled by the appearance of the luminescence of the Ru(II) complex released ("turn on" fluorogenic detection). The prepared hybrid materials were also used for trace explosive detection in soil samples.

The new hybrid organic-inorganic sensory materials presented in this $\mathrm{PhD}$ thesis are a clear alternative to the typical molecular-based explosive sensors. However, the sensing performances of the polymer-based sensors are still better, particularly in terms of sensitivity. Nevertheless, one of the great advantages of hybrid materials is their intrinsic modular character that allows modifications, in order to tune the final sensing features, without complicated synthetic pathways. At this respect, future directions in order to prepare more selective and sensitive materials involved:

- For the ion channel based sensors an accurate detection of the binding site (the use of stronger electron donor molecules) would modulate the selectivity toward the more electron withdrawing explosive molecules.

- Dealing with hybrid materials equipped with biomimetic cavities, the sensitivity would be enhanced by changing the grafted fluorophore 
(selecting those with higher quantum yields) or by functionalization the inner of the pores by more than one fluorescent molecule.

- For the gated hybrid materials lower limits of detection would be achieved by selecting fluorophores (that would be entrapped in the inner of the porous network of the inorganic scaffold) with higher quantum yields.

- The use of antigen-antibody interactions for the capping/uncapping protocol would yield hybrid sensory materials with enhanced performances (in terms of sensitivity and selectivity). At this respect, polyclonal antibodies for selected nitroaromatic explosives would be prepared and used as caps in the preparation of sensory gated materials. The pores of the MCM-41 scaffold would be loaded with a selected dye and the outer surface functionalized with a hapten derivative. Then the pores would be capped upon addition of the antibody. In the presence of the target antigen (the nitroaromatic explosive) the pores would be opened (displacement of the antibody due to their preferential coordination with the antigen) with the subsequent release of the entrapped dye. This paradigm has been recently used for the chromofluorogenic detection of TATP and would be envisioned its application to the detection of nitroaromatic explosives. 
Gracias al Ministerio de Ciencia e Innovación por concederme una beca de Formación del Profesorado Universitario (FPU) 